\title{
EL TIEMPO DE VIAJE COMO VARIABLE CRÍTICA PARA LA PLANIFICACIÓN DEL TRANSPORTE PÚBLICO MASIVO Y EL DESARROLLO URBANO.
}

\section{PROSPECTIVAS PARA EL GRAN LA PLATA}

\author{
Tesis doctoral presentada por \\ CRISTIAN COLA \\ ante la \\ Facultad de Arquitectura y Urbanismo de la \\ Universidad Nacional de La Plata \\ para acceder al grado académico de \\ DOCTOR EN ARQUITECTURA Y URBANISMO
}

Dirección de tesis:

Director: Jorge Karol

Co Directora: Irene Martini

Asesora: Laura Aón

La Plata, Argentina

Febrero, 2019 


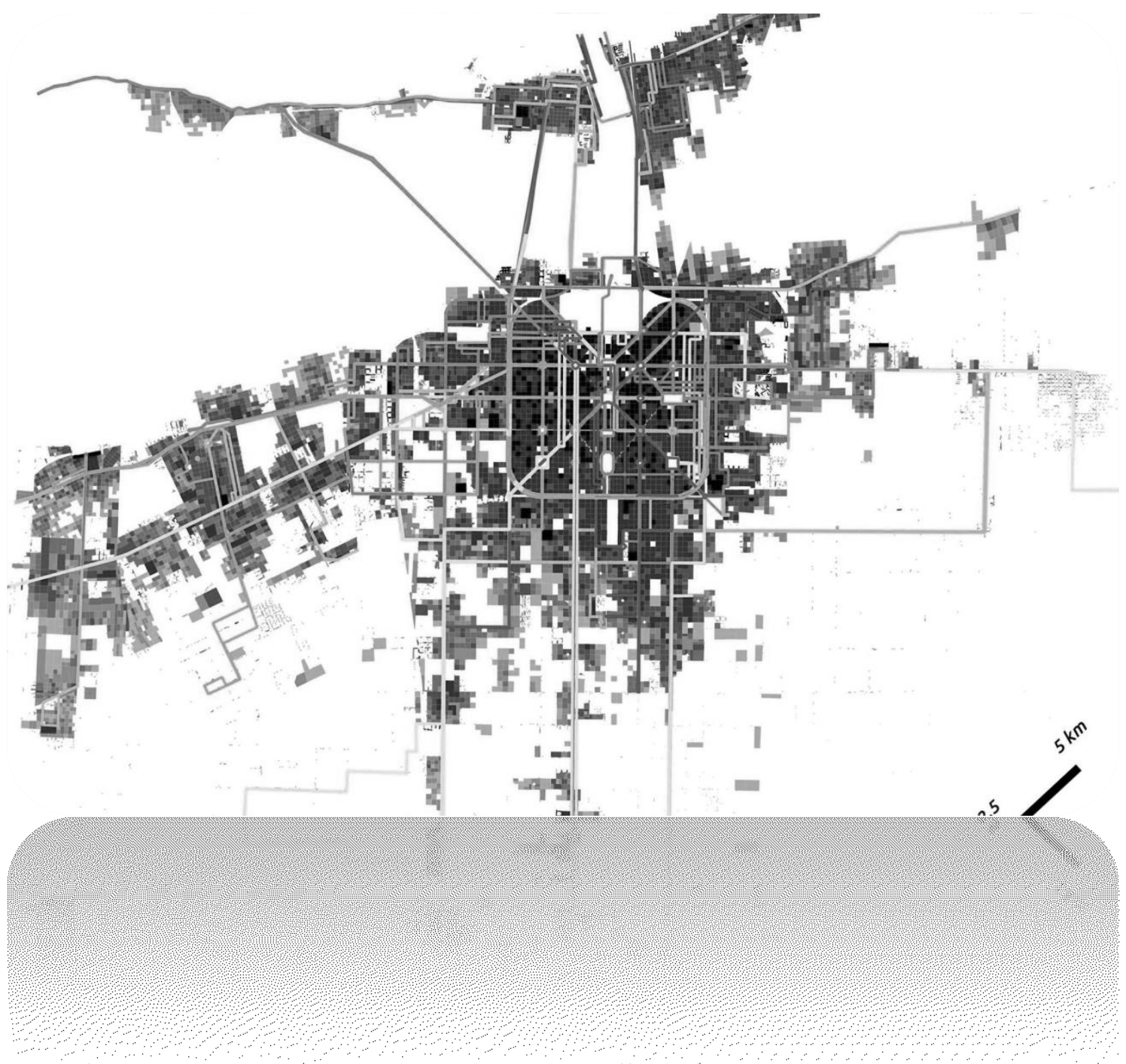

EL TIEMPO DE VIAJE COMO VARIABLE CRÍTICA PARA LA PLANIFICACIÓN DEL TRANSPORTE PÚBLICO MASIVO Y EL DESARROLLO URBANO. PROSPECTIVAS PARA EL GRAN LA PLATA 
A mi familia, por el apoyo incondicional. A mi madre Irma, a mi hermana María Sol y mi hermano Rodrigo.

A Mariana, por su cariño y por construir juntos nuevos desafíos.

A los estudiantes y trabajadores que luchan/ron, y al esfuerzo de mi padre, a quienes les debo mi tránsito por la educación pública.

A mis compañeros del PTS, por emprender desinteresadamente el camino por un mundo donde seamos socialmente iguales, humanamente diferentes y totalmente libres (R.L.).

A mis compañeros del IIPAC por hacer del instituto un lugar ameno de trabajo. En particular a mis compañeras del GII Julieta L., Nadia y Luciana por hacer un equipo/topadora. A Laura quien me abrió las puertas del IIPAC, junto con Julieta F., por el empuje a contracorriente por formar equipos de investigación en un sistema científico basado en el desarrollo individual. Sin ese trabajo conjunto, y su aporte, habría sido imposible esta investigación.

A Irene por la predisposición a solucionar cada obstáculo que se (le) presente, a Jorge por sus correcciones minuciosas y exhaustivas. Con sus distintos criterios ayudaron a que esta tesis sea infinitamente mejor.

A Judith del INENCO por recibirme y al equipo del CIDMEJu. 
A la memoria de mi padre Juan Carlos 
AGRADECIMIENTOS

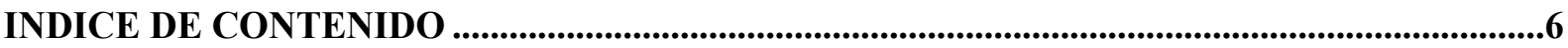

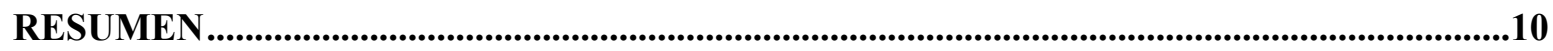

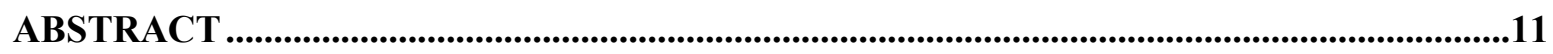

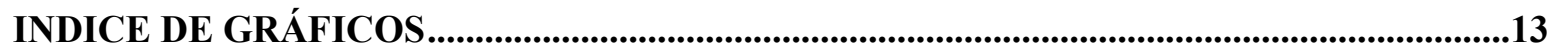

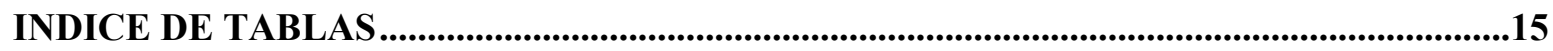

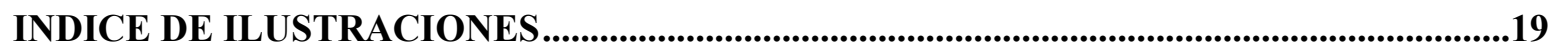

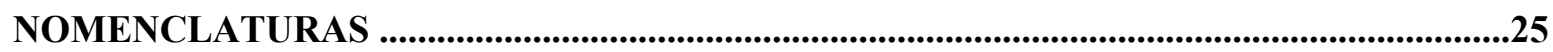

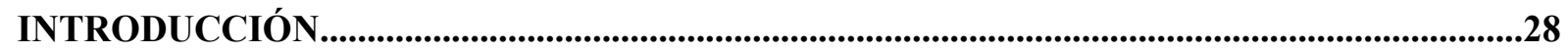

CAPITULO I: ESTADO DEL ARTE, MARCO TEÓRICO Y OBJETIVOS DEL TRABAJO..32

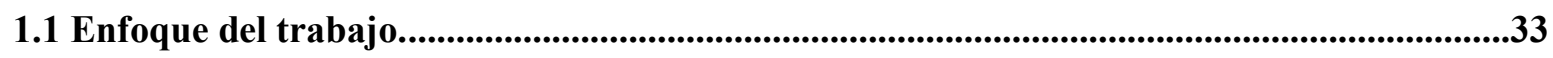

1.2.1. Estado del arte: Planificación integrada y tiempos de viaje..................................................36

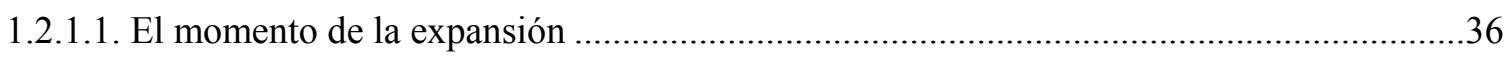

1.2.1.2. El momento de la modernización desarrollista y Estado de Bienestar (Welfare State) ....38

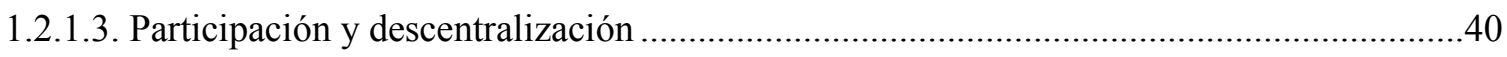

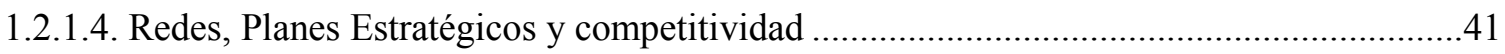

1.2.2. Debate sobre la planificación integrada de uso de suelo y transporte..................................42

1.2.2.1. Planificación integrada en el ámbito Europeo.................................................................46

1.2.2.2. Situación de la planificación integrada en América Latina y Argentina.............................48

1.2.2.3. El caso de estudio: la Micro Región del Gran La Plata........................................................54

1.2.3. La variable "tiempo" en la movilidad ........................................................................................56

1.3. Marco teórico.......................................................................................................................................60

1.3.1. La teoría general de sistemas en la ciudad y transporte. .....................................................60

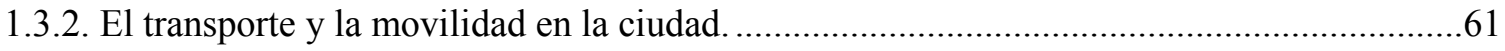

1.4. Fundamentación, hipótesis y objetivos del trabajo ..................................................................63 


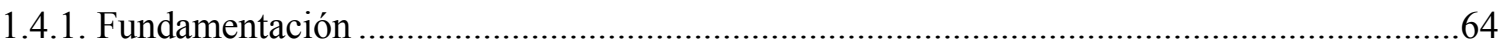

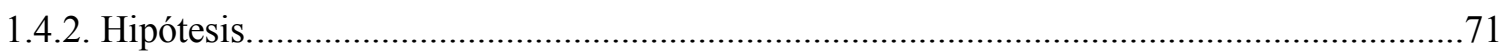

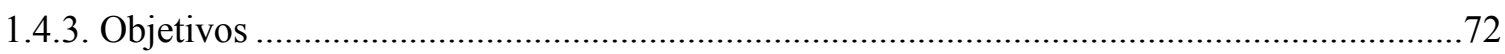

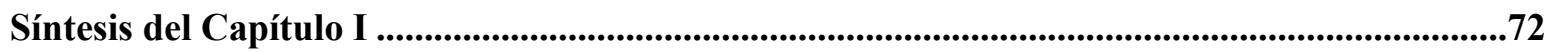

CAPITULO II: METODOLOGIA PARA LA CONSTRUCCION Y ENSAYO DE ESCENARIOS INTEGRADOS DE TRANSPORTE PÚBLICO MASIVO Y USO Y

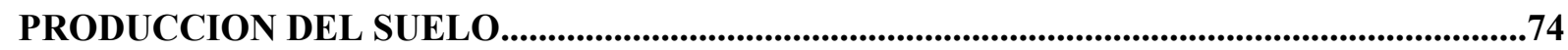

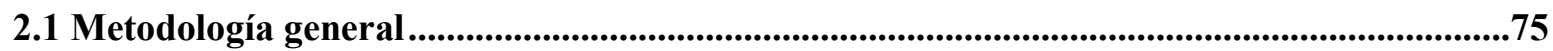

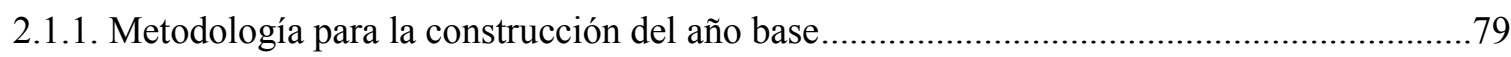

2.1.2. Metodología para la construcción del Escenario Tendencial ...............................................96

2.1.3. Metodología para la construcción de los Escenarios Alternativos ........................................99

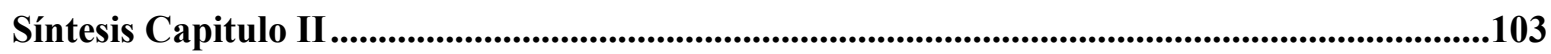

CAPITULO III: DESARROLLO URBANO Y TRANSPORTE PÚBLICO EN EL GRAN LA

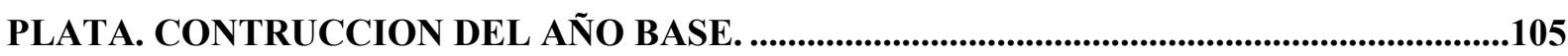

3.1. Descripción histórica del desarrollo urbano-territorial de la ciudad de La Plata..............106

3.1.1. Fundación y proceso de configuración urbana de la ciudad................................................106

3.1.2. La planificación normativa y el transporte en La Plata ......................................................111

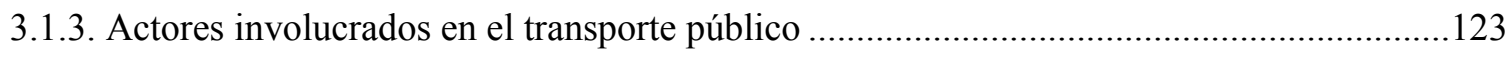

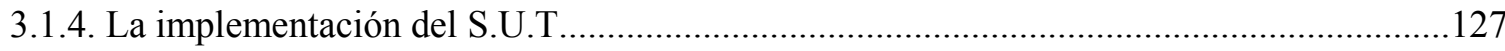

3.2. Análisis de las problemáticas de planificación y gestión.........................................................132

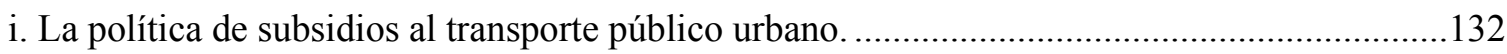

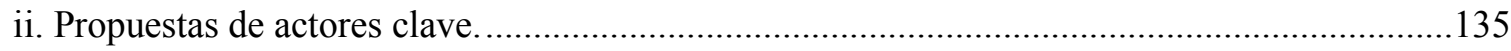

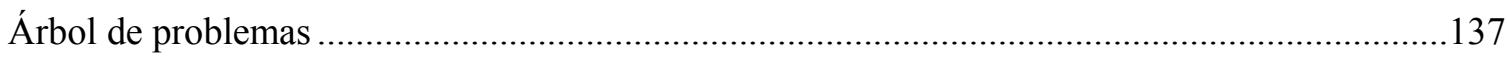

3.3. Construcción del año base de desarrollo urbano y transporte público del Gran La Plata.

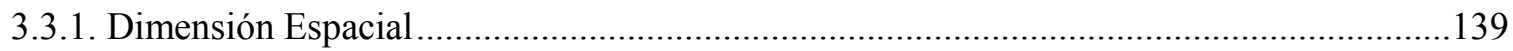

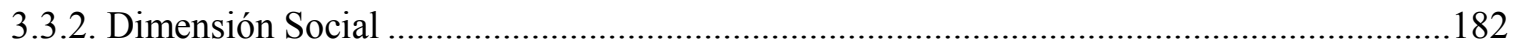

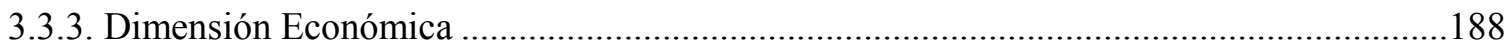

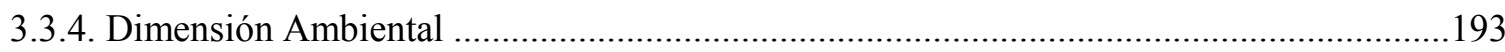




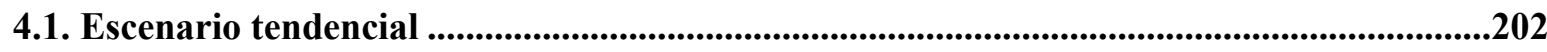

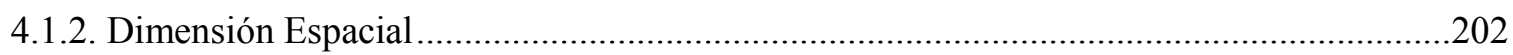

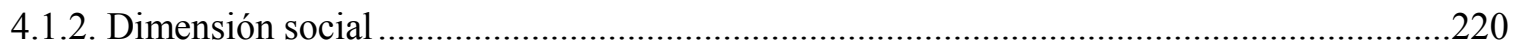

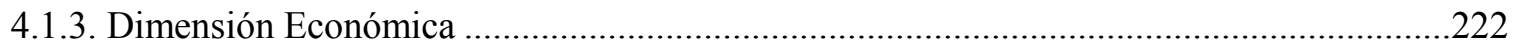

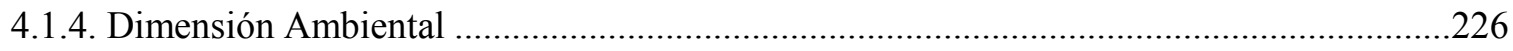

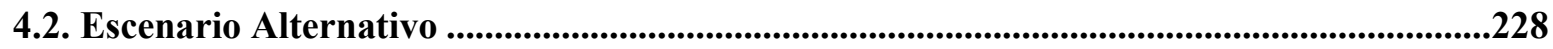

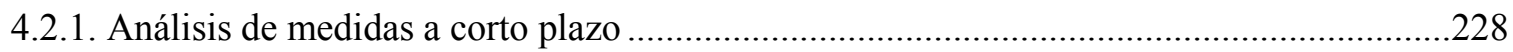

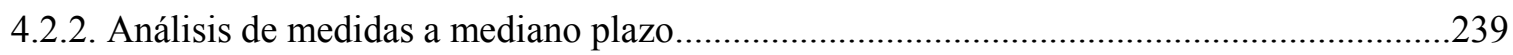

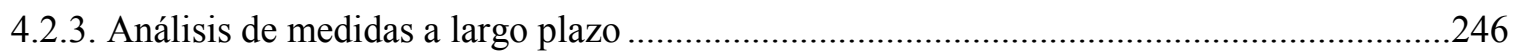

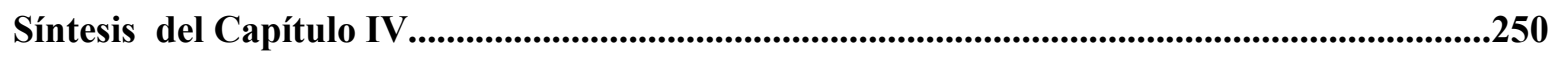

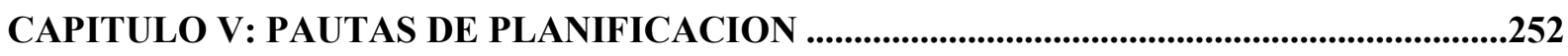

5.1. Pautas para la planificación integrada de los usos del suelo y transporte público.............253

5.2. Ideas para un modelo de gestión más eficiente .................................................................255

5.3. Pautas para el Financiamiento del Transporte Público de La Plata ..................................256

Síntesis del Capítulo V ...................................................................................................................259

CAPITULO VI: REFLEXIONES SOBRE EL TRABAJO REALIZADO ................................260

6.1. Resultados alcanzados.......................................................................................................................261

6.2. Dificultades y límitaciones del trabajo ....................................................................................263

6.3. Nuevos interrogantes para futuras investigaciones...............................................................264

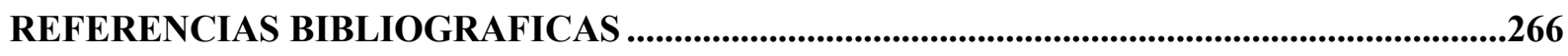

ANEXOS

A.1. Entrevista a ex director de transporte.........................................................................................275

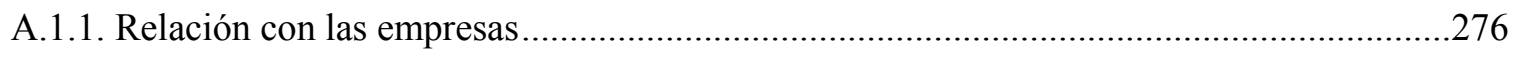

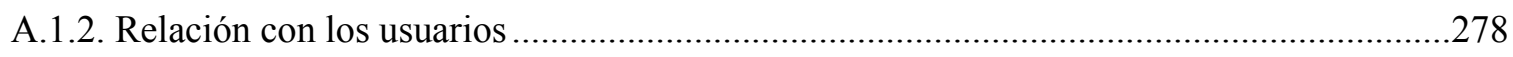

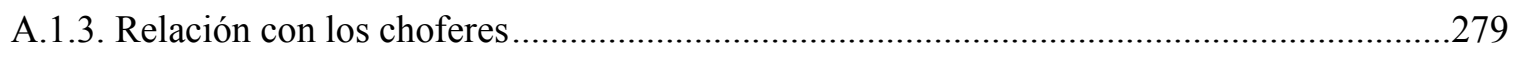




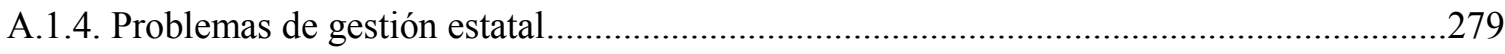

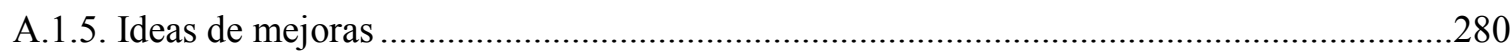

A.1.6. Transcripción entrevista a Ex Director de Transporte de La Plata ....................................281

A.2. Talleres con Choferes de líneas de Transporte...................................................................317

A.2.1. Problemáticas de transporte detectada por los choferes ................................................... 317

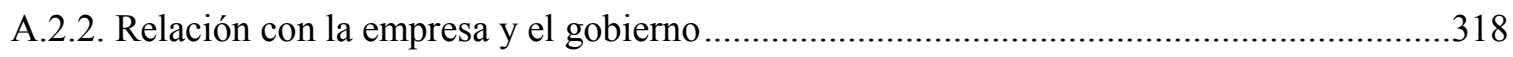

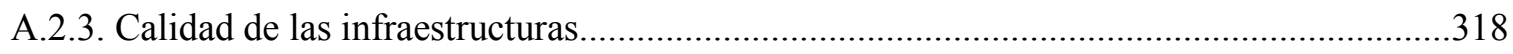

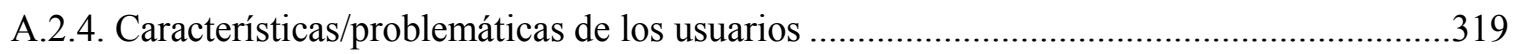

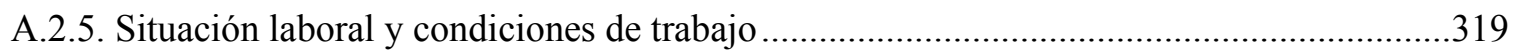

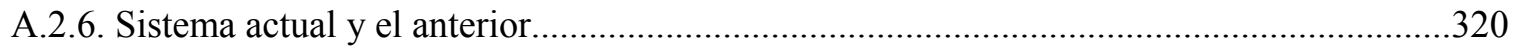

A.2.7. Matriz Síntesis Talleres con Choferes de líneas de Transporte.........................................320

A.3. Tablas de cálculo consumo energético y emisiones de CO2.................................................326

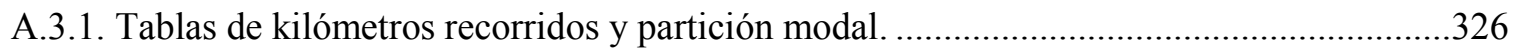

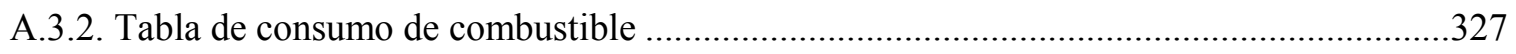

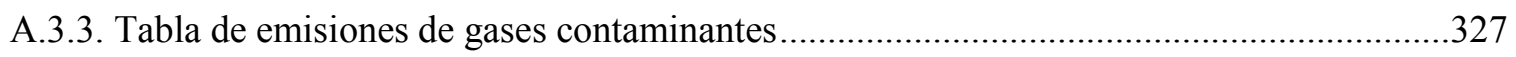

A.3.4. Síntesis consumo de combustible y emisiones de gases contaminantes según modos

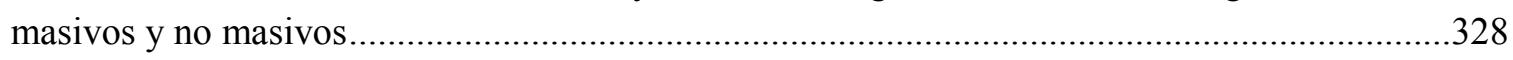

A.4. Planos de conectividad por delegación ....................................................................329 


\section{RESUMEN}

EL TIEMPO DE VIAJE COMO VARIABLE CRÍTICA PARA LA PLANIFICACIÓN DEL TRANSPORTE PÚBLICO MASIVO Y EL DESARROLLO URBANO. PROSPECTIVAS PARA EL GRAN LA PLATA

La presente tesis doctoral aborda el tiempo de viaje como variable crítica para la planificación del transporte público y el desarrollo urbano para el Gran La Plata en 2013-2014, con prospectivas para el año 2030. Mediante la construcción de escenarios analítico-empíricos se busca generar pautas de planificación de la movilidad urbana desde criterios que integren la planificación de los usos de suelo y la del transporte. Se le otorga centralidad en el análisis al tiempo de viaje en transporte público por estar vinculado con problemáticas importantes que hacen al tema en cuestión, entre ellas la congestión vehicular, el incremento de las distancias de viaje, la adecuación de las infraestructuras, las distancias a la red de transporte público y sus frecuencias, la cobertura territorial del sistema y la accesibilidad de la población.

Para ello se realiza un análisis histórico del desarrollo urbano territorial del caso de estudio, focalizando en 2013-2014 con cuatro dimensiones: espacial, en el cual se aborda la ocupación del suelo y la movilidad; social donde se analiza la cobertura del transporte público para los sectores de mayor dependencia del servicio; la económica que se estudia los costos de la expansión urbana y se comparan con índices salariales del INDEC; y finalmente la ambiental donde se evalúa al sistema de transporte desde el consumo de energía y emisiones contaminantes. Para la construcción de los datos correspondientes a dichas dimensiones se utilizan datos censales y de diversas fuentes estadísticas, así como una novedosa encuesta web, complementada con muestras en polos atractores de viaje. También se estudian las lógicas moldeadas históricamente y las particularidades de algunos de los actores involucrados en el transporte público del periodo de estudio, con una entrevista al director de transporte y talleres participativos con choferes.

Seguidamente se proyecta una evolución tendencial del sistema y se construyen escenarios alternativos que contienen propuestas de reducción de tiempos de viaje en transporte público en tres periodos de aplicación y alcance. A corto plazo con medidas que incrementen la velocidad operativa el sistema. A mediano plazo a partir de una política de suelo activa con el objetivo de orientar el crecimiento urbano densificando sobre corredores de transporte público que permitan incrementar el uso de este sistema por sobre el automóvil. Y a largo plazo, que consiste en la reducción de modos motorizados a partir de la descentralización de actividades de servicio, como centros de salud, educación y compras/trámites. A partir de estas 
propuestas, se evalúan pautas de gestión que involucren a los actores intervinientes que permitan acercarse al modelo deseado.

La construcción y ensayo de escenarios integrados de transporte público masivo y usos y producción del suelo planteado en el presente trabajo permitieron generar argumentos sobre la implementación de las diversas medidas de mejoramiento y, a la vez, generar un insumo de utilidad para la planificación. Asimismo, se ha podido corroborar que la metodología propuesta y el esquema de abordaje lograron, ante un objeto de estudio complejo, responder satisfactoriamente a los objetivos planteados al inicio del mismo.

\section{ABSTRACT}

\section{TRAVEL DURATION AS A CRITICAL VARIABLE FOR INTEGRATING MASSIVE PUBLIC TRANSPORTATION AND URBAN DEVELOPMENT PLANNING. PROJECTIONS FOR GREATER LA PLATA}

This doctoral thesis considers travel duration as a critical variable for integrating the planning of both public transportation and urban development for Greater La Plata in 2013-2014, including also linear projections and alternative scenarios towards 2030. means of these analytical-empirical scenarios, this thesis aims to generate planning guidelines for urban mobility by means of integrating land uses and transportation planning. The analysis of travel duration in public transportation is a key issue because of its connections to the understanding of vehicular congestions, increase of travel distances, adequacy of infrastructures, distances to the public transport corridors and networks, transport frequencies, territorial coverage of transport systems and differential social accessibility.

To this end, a historical analysis of the territorial urban development of Greater La Plata is carried out, focusing on four dimensions: spatial, addressing land occupation and mobility; social, analyzing the coverage of public transport for social groups with higher dependence on the service; economic, studying urban expansion costs and its comparison with wage indexes and, finally, environmental, evaluating energy consumption and GHG emissions produced by transport system. Besides population, households and housing censuses and other various official data sources, the thesis also makes the most of a new web survey, complemented with travelers' samples extracted at travel attraction nodes. We also study historical rationalities 
and distinctive singularities of some key actors involved in public transportation during the analyzed period, by interviewing a former Transportation Director and conducting participatory workshops with bus drivers.

Subsequently, a system's linear evolution is projected and alternative scenarios are constructed, developing proposals for reducing travel durations in public transport, in three application scopes and ranges: measures that increase the operating speed of the system are proposed for the short term; active land use and urban growth orientation policies by densifying public transport corridors in order to increase the use of this system over the automobile, in the medium term; finally, reducing the need to use motorized mobility modes through an active decentralization of service activities - such as health centers, education and regular purchases - in the long term. Based on these proposals, management guidelines are evaluated that involve the intervening actors and foster progressive approximations towards the desired model.

The construction and testing of these scenarios that integrate massive public transportation and land use and production patterns enabled us to elaborate arguments concerning the actual implementation of the various improvement measures and, at the same time, generating useful input for urban planning. We could also confirm that the proposed methodological approach to this highly complex system achieved a satisfactory response in terms of the initial objectives. 


\section{INDICE DE GRÁFICOS}

GRÁFICO 1. DISTRIBUCIÓN DE PORCENTAJES DE ÁREA URBANA, CANTIDAD DE POBLACIÓN Y DE VIVIENDAS CUBIERTAS SEGÚN TIEMPOS DE VIAJE A LOS DISTINTOS NAP DE SALUD, EDUCACIÓN, RECREACIÓN Y SEGURIDAD. FUENTE:

ESCOBAR GARCÍA, D., CADENA, C. Y SALAS, A. (2015).

GRÁFICO 2. SUBSIDIO ACUMULADO POR EMPRESA DE TRANSPORTE DEL GRAN LA PLATA EN 2.013. FUENTE:

ELABORACIÓN PROPIA, EN BASE A DATOS DEL MINISTERIO DEL INTERIOR Y TRANSPORTE.

GRÁFICO 3. POBLACIÓN POR DELEGACIÓN MUNICIPAL 2013. FUENTE: ELABORACIÓN PROPIA EN BASE A DATOS DE INDEC.

GRÁFICO 4. VIVIENDAS POR DELEGACIÓN 2013. FUENTE: ELABORACIÓN PROPIA EN BASE A DATOS INDEC. 143

GRÁFICO 5. CRECIMIENTO POBLACIONAL 201-2014. FUENTE: ELABORACIÓN PROPIA EN BASE A CENSO 2001, 2010. PROYECCIÓN 2014, INDEC.

GRÁFICO 6. PORCENTAJE DE CRECIMIENTO HABITACIONAL 2001-2013. FUENTE: ELABORACIÓN PROPIA, EN BASE A DATOS DE INDEC.

GRÁFICO 7. PATENTAMIENTOS ANUALES - LA PLATA. FUENTE: ELABORACIÓN PROPIA EN BASE DATOS DE ASOCIACIÓN DE Concesionarios de AUtomotores de La RePÚbliCa ARGENTINa Regional La PLATA. 148

GRÁFICO 8. CANTIDAD DE RAMALES POR LÍNEA DEL GRAN LA PLATA. FUENTE: ELABORACIÓN PROPIA, EN BASE A DATOS DE LAS ÁREAS DE TRANSPORTE DE LA PROVINCIA DE BUENOS AIRES Y MUNICIPALIDAD DE LA PLATA ... 152

GRÁFICO 9. PARTICIÓN DE CANTIDAD DE RAMALES POR JURISDICCIÓN. FUENTE: ELABORACIÓN PROPIA, EN BASE A DATOS DE LAS ÁREAS DE TRANSPORTE DE LA PROVINCIA DE BUENOS AIRES Y MUNICIPALIDAD DE LA PLATA ... 152

GRÁFICO 10. KILÓMETROS RECORRIDOS POR LÍNEA GRAN LA PLATA. FUENTE: ELABORACIÓN PROPIA, EN BASE A DATOS DE LAS ÁREAS DE TRANSPORTE DE LA PROVINCIA DE BUENOS AIRES Y MUNICIPALIDAD DE LA PLATA ... 154

GRÁFICO 11. PASAJEROS TRANSPORTADOS POR LINNEA. FUENTE: ELABORACIÓN PROPIA, EN BASE A DATOS DE LAS ÁREAS DE TRANSPORTE DE LA PROVINCIA DE BUENOS AIRES Y MUNICIPALIDAD DE LA PLATA......

GRÁFICO 12. PASAJEROS POR KILÓMETRO RECORRIDO POR LINNEA GRAN LA PLATA. FUENTE: ELABORACIÓN PROPIA, EN BASE A DATOS DE LAS ÁREAS DE TRANSPORTE DE LA PROVINCIA DE BUENOS AIRES Y MUNICIPALIDAD DE LA PLATA 156

GRÁFICO 13. PARTICIÓN MODAL POR MODOS DE TRANSPORTE GRAN LA PLATA 2013. FUENTE: ELABORACIÓN PROPIA, EN BASE A ENCUESTA DE MOVILIDAD DEL GRAN LA PLATA - GII IIPAC FAU.

GRÁFICO 14. VIAJES AL CASCO POR ZONA. FUENTE: ELABORACIÓN PROPIA, EN BASE A ENCUESTA DE MOVILIDAD DEL GRAN LA PLATA - GII IIPAC FAU.

GRÁFICO 15. PARTICIÓN MODAL POR DELEGACIÓN 2013-2014. FUENTE: ELABORACIÓN PROPIA, EN BASE A ENCUESTA DE MOVILIDAD DEL GRAN LA PLATA - GII IIPAC FAU.

GRÁFICO 16. CONSUMO DE COMBUSTIBLE EN TEP SEGÚN MODO DE TRANSPORTE GRAN LA PLATA 2013. FUENTE: ELABORACIÓN PROPIA, EN BASE A ENCUESTA DE MOVILIDAD URBANA DEL GRAN LA PLATA GII IIPAC FAU $U N L P$.

GRÁFICO 17. EFICIENCIA DE CONSUMO DE COMBUSTIBLE EN TEP A NIVEL DE HOGAR. FUENTES: ENCUESTA DE MOVILIDAD URBANA PARA LA MICRO REGIÓN DEL GRAN LA PLATA 1993/2003 Y OTROS. (AON, GIGLIO, COLA, 2016). 
GRÁFICO 18. POBLACIÓN POR DELEGACIÓN MUNICIPAL 2014-2030. FUENTE: ELABORACIÓN PROPIA, EN BASE A DATOS INTERCENSALES 2001-2010 DE INDEC.

GRÁFICO 19. VIVIENDAS POR DELEGACIÓN MUNICIPAL 2.014-2.030. FUENTE: ELABORACIÓN PROPIA, EN BASE A DATOS DE INTERCENSALES 2001-2010 DE INDEC......

GRÁFICO 20. PROYECCIÓN PARQUE AUTOMOTOR 1993- 2030. FUENTE: ELABORACIÓN PROPIA, EN BASE A DATOS ASOCIACIÓN DE CONCESIONARIOS DE AUTOMOTORES DE LA REPÚBLICA ARGENTINA.

GRÁFICO 21. PROYECCIÓN TASA DE MOTORIZACIÓN 1993 - 2030. FUENTE: ELABORACIÓN PROPIA, EN BASE A DATOS ASOCIACIÓN DE CONCESIONARIOS DE AUTOMOTORES DE LA REPÚBLICA ARGENTINA.

GRÁFICO 22. PROYECCIÓN TASA DE GENERACIÓN DE VIAJE 1993 - 2030. FUENTE: ELABORACIÓN PROPIA, EN BASE A DATOS ENCUESTA OD 1993, AÓN, MORO, RAVELLA (2003) Y ENCUESTA DE MOVILIDAD DEL GRAN LA PLATA GII IIPAC FAU UNLP.

GRÁFICO 23. POBLACIÓN CON NBI POR DELEGACIÓN NO CUBIERTA POR EL TRANSPORTE PÚBLICO, PROYECCIÓN 2030. FUENTE: ELABORACIÓN PROPIA, EN BASE A DATOS DE INDEC......

GRÁFICO 24. CONSUMO DE COMBUSTIBLE EN TEP POR MODO CON PROYECCIÓN A 2030. FUENTE: ELABORACIÓN PROPIA, EN BASE A EXPERIMENTACIÓN NUMÉRICA DE POLÍTICAS Y ESTRATEGIAS DE DESARROLLO SUSTENTABLE. FONCYT-PICT 2011-2013.

GRÁFICO 25. PROYECCIÓN 2030 DE CONSUMO EN TEP POR ZONA. FUENTE: ELABORACIÓN PROPIA, EN BASE A EXPERIMENTACIÓN NUMÉRICA DE POLÍTICAS Y ESTRATEGIAS DE DESARROLLO SUSTENTABLE. FONCYT-PICT 2011-2013.

GRÁFICO 26. PARTICIÓN DE TIEMPOS UTILIZADOS EN EL TRASLADO. FUENTE: ELABORACIÓN PROPIA

GRÁFICO 27. TIEMPO DE DESPLAZAMIENTO DESAGREGADO ACTUAL Y TIEMPO DE DESPLAZAMIENTO EN ESCENARIO ALTERNATIVO POR ÁREA: SINCRONIZACIÓN DE SEMÁFOROS. FUENTE: ELABORACIÓN PROPIA.

GRÁFICO 28. TIEMPO DE DESPLAZAMIENTO DESAGREGADO ACTUAL Y TIEMPO DE DESPLAZAMIENTO EN ESCENARIO ALTERNATIVO POR ZONA: REORGANIZACIÓN DE PARADAS. FUENTE: ELABORACIÓN PROPIA.

GRÁFICO 29. TIEMPO Y VELOCIDAD ENTRE REGISTRO Y MODIFICADO ESCENARIO ALTERNATIVO CARRIL EXCLUSIVO POR ZONA. FUENTE: ELABORACIÓN PROPIA.

GRÁFICO 30. SÍNTESIS TIEMPO DE VIAJE Y REDUCCIÓN DE TIEMPO POR PROPUESTA. FUENTE: ELABORACIÓN PROPIA.

GRÁFICO 31. POBLACIÓN SOBRE EL CORREDOR POR DELEGACIÓN 2014-2030. FUENTE: ELABORACIÓN PROPIA, EN BASE A DATOS DE INDEC......

GRÁFICO 32. PORCENTAJES DE DESTINOS DE VIAJES INTERNOS Y EXTERNOS DE CADA DELEGACIÓN DEL CORREDOR AV. 7. FUENTE: ELABORACIÓN PROPIA, EN BASE A LA ENCUESTA DE MOVILIDAD DEL GRAN LA PLATA GII IIPAC FAU.

GRÁFICO 32. MOTIVOS DE VIAJE EXTERNO POR DELEGACIÓN DEL CORREDOR AV. 7. FUENTE: ELABORACIÓN PROPIA, EN BASE A LA ENCUESTA DE MOVILIDAD DEL GRAN LA PLATA GII IIPAC FAU. 
TABLA 1. NIVEL DE URBANIZACIÓN DE GRANDES REGIONES DEL MUNDO (\%). FUENTE: LATTES, 2000. 34

TABLA 2. LONGITUD, PASAJEROS BENEFICIADOS Y REDUCCIÓN DE TIEMPO DE VIAJE DE LA RED DE METROBUS CABA. FUENTE: ELABORACIÓN PROPIA EN BASE A INFORMACIÓN DISPONIBLE EN LA WEB OFICIAL DEL GOBIERNO DE LA CIUDAD AUTÓNOMA DE BUENOS AIRES WWW.BUENOSAIRES. GOB.AR/MOVILIDA.

TABLA 3. CONSUMO POR KILÓMETRO POR MODO Y TIPO DE COMBUSTIBLE 2013. FUENTE: ELABORACIÓN PROPIA. .... 94

TABLA 4. FACTORES DE CONVERSIÓN COMBUSTIBLES A TEP. FUENTE: ELABORACIÓN PROPIA. 95

TABLA 5. EMISIONES CONTAMINANTES POR MODO DE TRANSPORTE. FUENTE: ELABORACIÓN PROPIA EN BASE MATRIZ APORTADA POR AÓN (2003)....

TABLA 6. COMPARATIVO DE SUPERFICIES PARA LAS TRES NORMATIVAS DE USO DE SUELO DE LA PLATA. FUENTE: ELABORACIÓN PROPIA, EN BASE A INFORMACIÓN DIFUNDIDA POR LA MUNICIPALIDAD DE LA PLATA.

TABLA 7. ANÁLISIS DE MOVILIDAD SEGÚN DENSIDADES MÁXIMAS PERMITIDAS POR C10 EN CASCO FUNDACIONAL. FUENTE: ELABORACIÓN PROPIA EN BASE A PLANOS DIFUNDIDOS POR EL MUNICIPIO DE LA PLATA.

TABLA 8. ANÁLISIS DE MOVILIDAD SEGÚN DENSIDADES MÁXIMAS EN CORREDORES C00. FUENTE: ELABORACIÓN PROPIA EN BASE A PLANOS DEL COO APORTADOS POR EL MUNICIPIO DE LA PLATA Y PROYECCIÓN ENCUESTA OD (AÓN, 2003).

TABLA 9. SUBSIDIO ACUMULADO POR EMPRESA DE TRANSPORTE DEL GRAN LA PLATA EN 2.013. FUENTE: ELABORACIÓN PROPIA, EN BASE A DATOS DEL MINISTERIO DEL INTERIOR Y TRANSPORTE.

TABLA 10. MATRIZ DE RELACIONES CONFLICTIVAS ENTRE ACTORES DEL TRANSPORTE PÚBLICO DEL GRAN LA PLATA. FUENTE: ELABORACIÓN PROPIA.

TABLA 11. TOTAL DE POBLACIÓN CENSO 2010 Y PROYECCIÓN INDEC. FUENTE: ELABORACIÓN PROPIA EN BASE A DATOS DEL INDEC.

TABLA 12. POBLACIÓN 2013 Y PORCENTAJE QUE REPRESENTA CADA CIUDAD EN EL GRAN LA PLATA. FUENTE: ELABORACIÓN PROPIA CON DATOS CENSO 2010 E INDEC.

TABLA 13. POBLACIÓN POR DELEGACIÓN MUNICIPAL 2013. FUENTE: ELABORACIÓN PROPIA EN BASE A DATOS DE INDEC.

TABLA 14. PERSONAS POR VIVIENDA POR DELEGACIÓN. FUENTE: ELABORACIÓN PROPIA EN BASE A DATOS DE INDEC.

TABLA 15. PATENTAMIENTOS ANUALES 2.005- 2.013. FUENTE: ELABORACIÓN PROPIA EN BASE DATOS DE ASOCIACIÓN

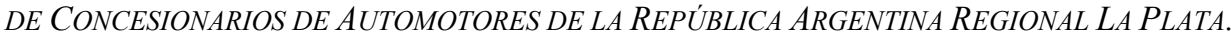

TABLA 16. LÍNEAS Y RAMALES POR JURISDICCIÓN GRAN LA PLATA 2013/2014. FUENTE: ELABORACIÓN PROPIA, EN BASE A DATOS DE LAS ÁREAS DE TRANSPORTE DE LA PROVINCIA DE BUENOS AIRES Y MUNICIPALIDAD DE LA PLATA

TABLA 17. REPARTO MODAL ENCUESTAS MOVILIDAD GRAN LA PLATA 2013. FUENTE: ELABORACIÓN PROPIA, EN BASE A ENCUESTA DE MOVILIDAD DEL GRAN LA PLATA - GII IIPAC FAU.

TABLA 19. PARTICIÓN MODAL POR ZONA. FUENTE: ELABORACIÓN PROPIA, EN BASE A ENCUESTA DE MOVILIDAD DEL GRAN LA PLATA - GII IIPAC FAU. 
TABLA 20. PORCENTAJES DE VIAJES AL CASCO URBANO POR DELEGACIÓN 2013. FUENTE: ELABORACIÓN PROPIA, EN BASE A ENCUESTA DE MOVILIDAD DEL GRAN LA PLATA - GII IIPAC FAU.

TABLA 21. PARTICIÓN MODAL POR DELEGACIÓN. FUENTE: ELABORACIÓN PROPIA, EN BASE A ENCUESTA DE MOVILIDAD DEL GRAN LA PLATA - GII IIPAC FAU.

TABLA 22. CANTIDAD DE VIAJES Y TASA DE GENERACIÓN DE VIAJE POR DELEGACIÓN. FUENTE: ELABORACIÓN PROPIA, EN BASE A ENCUESTA DE MOVILIDAD DEL GRAN LA PLATA - GII IIPAC FAU. 166

TABLA 23. PORCENTAJE DE VIAJES DE CADA DELEGACIÓN HACIA EL RESTO DE LAS DELEGACIONES. FUENTE: ELABORACIÓN PROPIA, EN BASE A ENCUESTA DE MOVILIDAD DEL GRAN LA PLATA - GII IIPAC FAU.

TABLA 24. PERSONAS, TASA DE GENERACIÓN DE VIAJES Y VIAJES DE LA COBERTURA DE RAMALES CON FRECUENCIAS MENORES A 10 MINUTOS POR TIEMPO DE TRASLADO POR DELEGACIONES CUBIERTAS. FUENTE: ELABORACIÓN PROPIA, EN BASE A DATOS DE ENCUESTA DE MOVILIDAD DEL GRAN LA PLATA.

TABLA 25. PERSONAS, TASA DE GENERACIÓN DE VIAJES Y VIAJES DE LA COBERTURA DE RAMALES CON FRECUENCIAS MENORES A 30 MINUTOS POR TIEMPO DE TRASLADO POR DELEGACIONES CUBIERTAS. FUENTE: ELABORACIÓN PROPIA, EN BASE A INDEC Y ENCUESTAS DE MOVILIDAD DEL GRAN LA PLATA GII IIPAC-FAU.

TABLA 26. PERSONAS, TASA DE GENERACIÓN DE VIAJES Y VIAJES DE LA COBERTURA DE RAMALES CON FRECUENCIAS DE 30 A 60 MINUTOS POR TIEMPO DE TRASLADO POR DELEGACIONES CUBIERTAS. FUENTE: ELABORACIÓN PROPIA, EN BASE A ENCUESTA DE MOVILIDAD DEL GRAN LA PLATA.

TABLA 27. PERSONAS, TASA DE GENERACIÓN DE VIAJES Y VIAJES DE LA COBERTURA DE RAMALES CON FRECUENCIAS MAYORES A 60 MINUTOS POR TIEMPO DE TRASLADO POR DELEGACIONES CUBIERTAS. FUENTE: ELABORACIÓN PROPIA, EN BASE A DATOS DE ENCUESTA DE MOVILIDAD DEL GRAN LA PLATA.

TABLA 28. POBLACIÓN CON NBI POR DELEGACIÓN. FUENTE: ELABORACIÓN PROPIA, EN BASE A DATOS DEL INDEC.

TABLA 29. POBLACIÓN CON NBI CUBIERTA POR TRANSPORTE PÚBLICO Y TIEMPOS DE VIAJE. FUENTE: ELABORACIÓN PROPIA, EN BASE A DATOS DE INDEC Y ÁREAS DE TRANSPORTE PBA Y MUNICIPALIDAD DE LA PLATA.

TABLA 30. COSTOS DE VIAJE MENSUALES POR USUARIO. FUENTE: ELABORACIÓN PROPIA. 189

TABLA 31. CANASTA BÁSICA ALIMENTARIA, CANASTA BÁSICA TOTAL Y SALARIO MÍNIMO COMPARADO CON EL COSTO DE TRANSPORTE EN AUTO Y COLECTIVO, POR DELEGACIÓN 2013. FUENTE: ELABORACIÓN PROPIA, EN BASE A DATOS DEL INDEC.

TABLA 32. VIAJES, CONSUMO DE COMBUSTIBLE Y EMISIONES DE CO2 GLP 2013. FUENTE: ELABORACIÓN PROPIA, EN BASE A ENCUESTA MOVILIDAD DEL GRAN LA PLATA Y NUMEX (2013).

TABLA 33. CONSUMO DE COMBUSTIBLE Y KILÓMETROS RECORRIDOS DIARIOS POR MODO DE TRANSPORTE GRAN LA PLATA AÑO 2013. FUENTE: ELABORACIÓN PROPIA, EN BASE A ENCUESTA DE MOVILIDAD URBANA DEL GRAN LA PLATA GII IIPAC FAU UNLP

TABLA 34. PARTICIÓN MODAL, CONSUMO TEP, EMISIONES CO2 DIARIOS POR ÁREA PARA GLP. FUENTE: ELABORACIÓN PROPIA EN BASE A LA ENCUESTA DE MOVILIDAD URBANA 1993-2013. (AON, GIGLIO, COLA, 2016). 196

TABLA 35. PROYECCIÓN VARIACIÓN POBLACIONAL 2014-2030. FUENTE: ELABORACIÓN PROPIA, EN BASE A PROYECCIÓN POBLACIONAL INDEC. 202

TABLA 36. PROYECCIÓN VARIACIÓN POBLACIONAL 2014-2030 POR DELEGACIÓN MUNICIPAL. FUENTE: ELABORACIÓN PROPIA, EN BASE A PROYECCIÓN POBLACIONAL INTERCENSAL 2001-2010, INDEC. 203 
TABLA 37. REPARTO MODAL PROYECCIÓN AL AÑO 2030. FUENTE: ELABORACIÓN PROPIA, EN BASE A ENCUESTA DE MOVILIDAD DEL GRAN LA PLATA GII IIPAC FAU UNLP.

TABLA 38. VIAJES Y POR DELEGACIÓN, PROYECCIÓN 2030. FUENTE: ELABORACIÓN PROPIA, EN BASE A ENCUESTA DE MOVILIDAD DEL GRAN LA PLATA GII IIPAC FAU UNLP.

TABLA 39. TASA DE GENERACIÓN DE VIAJE EN COLECTIVO (TGVC), TASA DE GENERACIÓN DE VIAJE EN AUTO (TGVA) Y TASA DE GENERACIÓN DE VIAJE (TGV) POR DELEGACIÓN EN 2013 Y PROYECCIÓN 2030. FUENTE: ELABORACIÓN PROPIA, EN BASE A ENCUESTA DE MOVILIDAD DEL GRAN LA PLATA GII IIPAC FAU UNLP....210

TABLA 40. PASAJEROS POR COCHE 2013-2030. FUENTE: ELABORACIÓN PROPIA, EN BASE A ENCUESTA DE MOVILIDAD DEL GRAN LA PLATA GII IIPAC FAU UNLP.

TABLA 41. INCREMENTO DE TIEMPO VIAJE LÍNEAS SUR Y 520. FUENTE: ELABORACIÓN PROPIA, EN BASE A DATOS APORTADOS POR LA DIRECCIÓN DE TRANSPORTE DEL MUNICIPIO DE LA PLATA.

TABLA 42. VELOCIDAD DE DESPLAZAMIENTO, TIEMPO DE ESPERA Y DE VIAJE DE LOS RAMALES 273 BG, 273 D PARA EL AÑO 2017 Y 2030. FUENTE: ELABORACIÓN PROPIA.

TABLA 43. VELOCIDAD DE DESPLAZAMIENTO, TIEMPO DE ESPERA Y DE VIAJE DE LOS RAMALES ESTE 14 PARA EL AÑO 2017 Y 2030. FUENTE: ELABORACIÓN PROPIA.

TABLA 44. POBLACIÓN CON NBI POR DELEGACIÓN NO CUBIERTA POR EL TRANSPORTE PÚBLICO, PROYECCIÓN 2030. FUENTE: ELABORACIÓN PROPIA, EN BASE A DATOS DE INDEC

TABLA 45. COSTOS DE VIAJE AL CASCO URBANO POR DELEGACIÓN. FUENTE: ELABORACIÓN PROPIA, SE UTILIZARON DATOS DE ENCUESTA DE MOVILIDAD DEL GRAN LA PLATA GII IIPAC FAU UNLP.

TABLA 46. EMISIONES SEGÚN MODOS MASIVOS/NO MASIVOS DEL GRAN LA PLATA, PROYECCIÓN 2030. FUENTE: ELABORACIÓN PROPIA, EN BASE A EXPERIMENTACIÓN NUMÉRICA DE POLÍTICAS Y ESTRATEGIAS DE DESARROLLO SUSTENTABLE. FONCYT-PICT 2011-2013.

TABLA 47. CONSUMO EN TEP Y PORCENTAJE POR MODO DE TRANSPORTE DEL GRAN LA PLATA. FUENTE: ELABORACIÓN PROPIA, EN BASE A EXPERIMENTACIÓN NUMÉRICA DE POLÍTICAS Y ESTRATEGIAS DE DESARROLLO SUSTENTABLE. FONCYT-PICT 2011-2013.

TABLA 48. PROYECCIÓN 2030 DE CONSUMO EN TEP Y EMISIONES DE CO2 POR ZONA. FUENTE: ELABORACIÓN PROPIA, EN BASE A EXPERIMENTACIÓN NUMÉRICA DE POLÍTICAS Y ESTRATEGIAS DE DESARROLLO SUSTENTABLE. FONCYTPICT 2011-2013.

TABLA 49. TIEMPO UTILIZADO POR SEMÁFOROS Y PARADAS DE COLECTIVO POR ZONA DEL CORREDOR. FUENTE: ELABORACIÓN PROPIA.

TABLA 50. TIEMPO DE TRASLADO DESAGREGADO Y TIEMPO DESAGREGADO OPTIMIZADO (EN MINUTOS) A PARTIR DE LA SINCRONIZACIÓN DE SEMÁFOROS PARA EL CORREDOR AV. 7. FUENTE: ELABORACIÓN PROPIA.

TABLA 51. TIEMPO UTILIZADO EN EL TRASLADO POR ÁREA DEL CORREDOR AV. 7 CON LA PROPUESTA DE REORGANIZACIÓN DE PARADAS. FUENTE: ELABORACIÓN PROPIA

TABLA 52. TIEMPOS DE TRASLADO Y VELOCIDADES OPERATIVAS DE TRANSPORTE PÚBLICO CORREDOR AV. 7 ESTE. FUENTE: ELABORACIÓN PROPIA....

TABLA 53. TIEMPO Y VELOCIDAD ENTRE REGISTROS Y MODIFICACIONES SEGÚN ESCENARIO ALTERNATIVO DE CARRIL EXCLUSIVO. FUENTE: ELABORACIÓN PROPIA. 
TABLA 55. PROPUESTA DE DENSIFICACIÓN DEL CORREDOR AV. 7. FUENTE: ELABORACIÓN PROPIA, EN BASE A DATOS DE INDEC.

TABLA 56. POBLACIÓN 2014, 2030 E INCREMENTO DEL PERÍODO. FUENTE: ELABORACIÓN PROPIA, EN BASE A DATOS DE INDEC.

TABLA 57. VIAJES EN COLECTIVO Y NO MASIVOS POR DELEGACIÓN A PARTIR DE LA DENSIFICACIÓN DEL CORREDOR AV. 7. FUENTE: ELABORACIÓN PROPIA, EN BASE A LA ENCUESTA DE MOVILIDAD DEL GRAN LA PLATA GII IIPAC FAU.

TABLA 58. PORCENTAJE MOTIVOS DE VIAJE POR DELEGACIÓN DEL CORREDOR AV. 7. FUENTE: ELABORACIÓN PROPIA, EN BASE A LA ENCUESTA DE MOVILIDAD DEL GRAN LA PLATA GII IIPAC FAU. 248

TABLA 59. PORCENTAJES DE ACTIVIDADES AL CASCO URBANO QUE SE EVITARÍAN CON LA DESCENTRALIZACIÓN DE ACTIVIDADES DE SERVICIO, VIAJES TOTALES Y AUTOS MENOS CON DESTINO AL CASCO URBANO. FUENTE: ELABORACIÓN PROPIA, EN BASE A LA ENCUESTA DE MOVILIDAD DEL GRAN LA PLATA GII IIPAC FAU. 


\section{INDICE DE ILUSTRACIONES}

ILUSTRACIÓN 1. MAPA RED DE METROBUS CIUDAD AUTÓNOMA DE BUENOS AIRES. FUENTE: PÁGINA OFICIAL DEL GOBIERNO DE LA CIUDAD. WWW.BUENOSAIRES.GOB.AR/MOVILIDAD/METROBUS/SERVICIOS-DEL-METROBUS..... 53

ILUSTRACIÓN 2. ESQUEMA DE ELEMENTOS QUE CONFORMAN LA VARIABLE TIEMPO DE VIAJE. FUENTE: ELABORACIÓN PROPIA.

ILUSTRACIÓN 3. ESQUEMA DE CONSTRUCCIÓN DE ESCENARIOS. FUENTE: ELABORACIÓN PROPIA.

ILUSTRACIÓN 4. ESQUEMA DE ESTRUCTURA DE ÁRBOL DE PROBLEMAS. FUENTE: ELABORACIÓN PROPIA EN BASE A ÁRBOL DE PROBLEMAS DESARROLLADO POR ITEM CIUDAD.

ILUSTRACIÓN 5. ESQUEMA DE COBERTURA DE TRANSPORTE PÚBLICO (TP) UTILIZADA. FUENTE: ELABORACIÓN PROPIA.

ILUSTRACIÓN 6. PASOS PARA LA AGREGACIÓN DE DATOS CENSALES EN DISTINTAS ESCALAS A LOS RADIOS. FUENTE: ELABORACIÓN PROPIA.

ILUSTRACIÓN 7. ESQUEMA DE LA ELECCIÓN DE LA RUTA MÁS DIRECTA ENTRE ÁREAS GENERADORAS Y ÁREA ATRACTORA. FUENTE: ELABORACIÓN PROPIA.

ILUSTRACIÓN 8. ESQUEMA ÁREA DE COBERTURA DE TP Y ÁREA A DENSIFICAR. FUENTE: ELABORACIÓN PROPIA. 102

ILUSTRACIÓN 9. PROPUESTA DE VÍNCULOS DE LA MICRO-REGIÓN (GRAN LA PLATA) Y ZONIFICACIÓN DE USOS. PROYECTO 1883-93. Fuente: El TRANSPORTE EN LA PLATA. (1996). MUNICIPALIDAD DE LA PLATA.

ILUSTRACIÓN 10. RED DE TRANVÍAS ELÉCTRICOS HASTA 1930. FUENTE: EL TRANSPORTE EN LA PLATA. (1996). MUNICIPALIDAD DE LA PLATA.

ILUSTRACIÓN 11. RED DE AUTOTRANSPORTE HASTA 1940. FUENTE: ETLP (1996). MUNICIPALIDAD DE LA PLATA. . 109

ILUSTRACIÓN 12. DENSIDADES NORMATIVAS: UTILIZANDO LAS DENSIDADES DE LA ÚLTIMA NORMATIVA SOBRE LA OCUPACIÓN PROPUESTAS POR TODOS LOS CÓDIGOS URBANOS DE LA PLATA. FUENTE: ELABORACIÓN PROPIA, EN base a DATOS DE LA DiRECCIÓN DE OBRAS PARTICULARES MUNICIPIO DE LA PLATA, WEB MUNICIPALIDAD DE LA PLATA (WWW.LAPLATA.GOB.AR).

ILUSTRACIÓN 13. ZONAS DE TRANSPORTE SELECCIONADAS. FUENTE: ELABORACIÓN PROPIA.

ILUSTRACIÓN 14. ZONAS DEL GRAN LA PLATA. FUENTE: ELABORACIÓN PROPIA, EN BASE A DATOS DE AON, MORO, RAVELLA (2004).

ILUSTRACIÓN 15. ÁRBOL DE PROBLEMAS. FUENTE: ELABORACIÓN PROPIA.

ILUSTRACIÓN 16. DENSIDAD POBLACIONAL - CENSO 2001 Y 2010, NUEVAS DENSIDADES PERIFÉRICAS. FUENTE: ELABORACIÓN PROPIA EN BASE A DATOS CENSO 2001 Y 2010, INDEC.

ILUSTRACIÓN 17. DENSIDAD POBLACIONAL 2013 MANZANAS MENORES A 10 HA. FUENTE: ELABORACIÓN PROPIA EN BASE A DATOS CENSALES Y UBICACIÓN DE MEDIDORES DE CONSUMO ELÉCTRICO.

ILUSTRACIÓN 18. DENSIDAD HABITACIONAL 2013 MANZANAS MENORES A 10 HA. FUENTE: ELABORACIÓN PROPIA EN BASE A DATOS CENSALES Y UBICACIÓN DE MEDIDORES DE CONSUMO ELÉCTRICO.

ILUSTRACIÓN 20. PORCENTAJE DE CRECIMIENTO POBLACIONAL PERIODO 2001 - 2013 POR DELEGACIÓN. FUENTE: ELABORACIÓN PROPIA EN BASE A DATOS DE INDEC. 
ILUSTRACIÓN 21. PORCENTAJE DE CRECIMIENTO POBLACIONAL 2001-2014. FUENTE: ELABORACIÓN PROPIA, EN BASE A DATOS DE INDEC.

ILUSTRACIÓN 22. RED VIAL DEL GRAN LA PLATA 2013. FUENTE: ELABORACIÓN PROPIA. SHAPE DE REDES MARÍA JULIETA LÓPEZ (2015).

ILUSTRACIÓN 23. TRENES ACTIVOS EN GRAN LA PLATA 2013. FUENTE: ELABORACIÓN PROPIA, EN BASE A DATOS DEL GOBIERNO DE PBA Y UNLP.

ILUSTRACIÓN 24. LÍNEAS DE TRANSPORTE PÚBLICO DEL GRAN LA PLATA 2013/2014. FUENTE: ELABORACIÓN PROPIA, EN BASE A DATOS DE LAS ÁREAS DE TRANSPORTE DE LA PROVINCIA DE BUENOS AIRES Y MUNICIPALIDAD DE LA PLATA

ILUSTRACIÓN 25. VIAJES DIARIOS TOTALES POR ZONA EN 2013.FUENTE: ELABORACIÓN PROPIA, EN BASE A ENCUESTA DE MOVILIDAD DEL GRAN LA PLATA - GII IIPAC FAU.

ILUSTRACIÓN 26. VIAJES DIARIOS EN COLECTIVO POR ZONA EN 2013. FUENTE: ELABORACIÓN PROPIA, EN BASE A ENCUESTA DE MOVILIDAD DEL GRAN LA PLATA - GII IIPAC FAU.

ILUSTRACIÓN 27. VIAJES DIARIOS EN AUTOMÓVIL POR ZONA EN 2013.FUENTE: ELABORACIÓN PROPIA, EN BASE A ENCUESTA DE MOVILIDAD DEL GRAN LA PLATA - GII IIPAC FAU.

ILUSTRACIÓN 28. VIAJES DIARIOS NO MOTORIZADOS POR ZONA EN 2013. FUENTE: ELABORACIÓN PROPIA, EN BASE A ENCUESTA DE MOVILIDAD DEL GRAN LA PLATA - GII IIPAC FAU.

ILUSTRACIÓN 29. PORCENTAJE DE MODOS MASIVOS POR DELEGACIÓN Y RED DE TRANSPORTE PÚBLICO. FUENTE: ELABORACIÓN PROPIA EN BASE A ENCUESTA DE MOVILIDAD DEL GRAN LA PLATA 2013/2014.

ILUSTRACIÓN 30. PORCENTAJE DE MODOS NO MASIVOS POR DELEGACIÓN Y RED VIAL. FUENTE: ELABORACIÓN PROPIA CON DATOS DE ENCUESTA DE MOVILIDAD DEL GRAN LA PLATA 2013 Y VÍAS DE LÓPEZ, 2016.

ILUSTRACIÓN 31. PORCENTAJE DE VIAJES EN MODOS NO MOTORIZADOS POR DELEGACIÓN. FUENTE: ELABORACIÓN PROPIA EN BASE A ENCUESTA DE MOVILIDAD DEL GRAN LA PLATA 2013/2014.

ILUSTRACIÓN 32. VIAJES DIARIOS TOTALES POR DELEGACIÓN. FUENTE: ELABORACIÓN PROPIA, EN BASE A ENCUESTA DE MOVILIDAD DEL GRAN LA PLATA - GII IIPAC FAU.

ILUSTRACIÓN 33. VIAJES DIARIOS EN AUTO POR DELEGACIÓN. FUENTE: ELABORACIÓN PROPIA, EN BASE A ENCUESTA DE MOVILIDAD DEL GRAN LA PLATA - GII IIPAC FAU.

ILUSTRACIÓN 34. VIAJES DIARIOS EN TRANSPORTE PÚBLICO POR DELEGACIÓN. FUENTE: ELABORACIÓN PROPIA, EN BASE A ENCUESTA DE MOVILIDAD DEL GRAN LA PLATA - GII IIPAC FAU.

ILUSTRACIÓN 35. VIAJES DIARIOS A PIE Y BICICLETA POR DELEGACIÓN. FUENTE: ELABORACIÓN PROPIA, EN BASE A ENCUESTA DE MOVILIDAD DEL GRAN LA PLATA - GII IIPAC FAU.

ILUSTRACIÓN 36. TASA DE GENERACIÓN DE VIAJE POR DELEGACIÓN. FUENTE: ELABORACIÓN PROPIA, EN BASE A ENCUESTA DE MOVILIDAD DEL GRAN LA PLATA - GII IIPAC FAU.

ILUSTRACIÓN 37. TASA DE GENERACIÓN DE VIAJE EN AUTO POR DELEGACIÓN. FUENTE: ELABORACIÓN PROPIA, EN BASE A ENCUESTA DE MOVILIDAD DEL GRAN LA PLATA - GII IIPAC FAU.

ILUSTRACIÓN 38. TASA DE GENERACIÓN DE VIAJE EN COLECTIVO POR DELEGACIÓN. FUENTE: ELABORACIÓN PROPIA, EN BASE A ENCUESTA DE MOVILIDAD DEL GRAN LA PLATA - GII IIPAC FAU. 
ILUSTRACIÓN 39. TASA DE GENERACIÓN DE VIAJE A PIE Y BICICLETA POR DELEGACIÓN. FUENTE: ELABORACIÓN PROPIA, EN BASE A ENCUESTA DE MOVILIDAD DEL GRAN LA PLATA - GII IIPAC FAU.

ILUSTRACIÓN 40. PORCENTAJE DE VIAJES DE CADA DELEGACIÓN AL CASCO URBANO. FUENTE: ELABORACIÓN PROPIA, EN BASE A ENCUESTA DE MOVILIDAD DEL GRAN LA PLATA - GII IIPAC FAU.

ILUSTRACIÓN 41. COBERTURA DE TP CON MÁS DE 20 SERVICIOS DIARIOS. FUENTE: ELABORACIÓN PROPIA, EN BASE A dATOS DE ÁREAS DE TRANSPORTE DE LA PROVINCIA DE BUENOS AIRES Y MUNICIPALIDAD DE LA PLATA.

ILUSTRACIÓN 42. COBERTURA DE TP CON MÁS 13 SERVICIOS DIARIOS. FUENTE: ELABORACIÓN PROPIA, EN BASE A DATOS DE ÁREAS DE TRANSPORTE DE LA PROVINCIA DE BUENOS AIRES Y MUNICIPALIDAD DE LA PLATA......... 175

ILUSTRACIÓN 43. COBERTURA DE TP CON 13 A 8 SERVICIOS DIARIOS. FUENTE: ELABORACIÓN PROPIA, EN BASE A DATOS DE ÁREAS DE TRANSPORTE DE LA PROVINCIA DE BUENOS AIRES Y MUNICIPALIDAD DE LA PLATA......... 175

ILUSTRACIÓN 44. COBERTURA TP 1 A 7 SERVICIOS DIARIOS. FUENTE: ELABORACIÓN PROPIA, EN BASE A DATOS DE ÁREAS DE TRANSPORTE DE LA PROVINCIA DE BUENOS AIRES Y MUNICIPALIDAD DE LA PLATA.

ILUSTRACIÓN 45. FRECUENCIAS Y TIEMPO DE VIAJE DE RAMALES CON MÁS DE 20 SERVICIOS POR DÍA. FUENTE: ELABORACIÓN PROPIA, EN BASE A DATOS DE ÁREAS DE TRANSPORTE DE LA PROVINCIA DE BUENOS AIRES Y MUNICIPALIDAD DE LA PLATA.

ILUSTRACIÓN 46. FRECUENCIAS Y TIEMPO DE VIAJE DE RAMALES CON MÁS DE 13 SERVICIOS POR DÍA. FUENTE: ELABORACIÓN PROPIA, EN BASE A DATOS DE ÁREAS DE TRANSPORTE DE LA PROVINCIA DE BUENOS AIRES Y MUNICIPALIDAD DE LA PLATA.

ILUSTRACIÓN 47. FRECUENCIAS Y TIEMPO DE VIAJE DE RAMALES ENTRE 8 Y 13 SERVICIOS POR DÍA. FUENTE: ELABORACIÓN PROPIA, EN BASE A DATOS DE ÁREAS DE TRANSPORTE DE LA PROVINCIA DE BUENOS AIRES Y MUNICIPALIDAD DE LA PLATA.

ILUSTRACIÓN 48. FRECUENCIAS Y TIEMPO DE VIAJE DE RAMALES ENTRE 8 Y 13 SERVICIOS POR DÍA. FUENTE: ELABORACIÓN PROPIA, EN BASE A DATOS DE ÁREAS DE TRANSPORTE DE LA PROVINCIA DE BUENOS AIRES Y MUNICIPALIDAD DE LA PLATA.

ILUSTRACión 49. Población CON NBI GRAN LA Plata. Fuente: ELABORACIÓN PROPIA EN BASE AL CENSO 2.010, INDEC

ILUSTRACIÓN 50. POBLACIÓN CON NBI CUBIERTA POR TRANSPORTE PÚBLICO CON MÁS DE 20 SERVICIOS DIARIOS. FUENTE: ELABORACIÓN PROPIA, EN BASE A DATOS DE INDEC Y ÁREAS DE TRANSPORTE PBA Y MUNICIPALIDAD DE LA PLATA.

ILUSTRACIÓN 51. POBLACIÓN CON NBI CUBIERTA POR TRANSPORTE PÚBLICO CON MÁS DE 13 SERVICIOS DIARIOS. FUENTE: ELABORACIÓN PROPIA, EN BASE A DATOS DE INDEC Y ÁREAS DE TRANSPORTE PBA Y MUNICIPALIDAD DE LA PLATA.

ILUSTRACIÓN 52. POBLACIÓN CON NBI CUBIERTA POR TRANSPORTE PÚBLICO CON ENTRE 13 A 8 SERVICIOS DIARIOS. FUENTE: ELABORACIÓN PROPIA, EN BASE A DATOS DE INDEC Y ÁREAS DE TRANSPORTE PBA Y MUNICIPALIDAD DE LA PLATA.

ILUSTRACIÓN 53. POBLACIÓN CON NBI CUBIERTA POR TRANSPORTE PÚBLICO CON ENTRE 1 A 7 SERVICIOS DIARIOS. FUENTE: ELABORACIÓN PROPIA, EN BASE A DATOS DE INDEC Y ÁREAS DE TRANSPORTE PBA Y MUNICIPALIDAD DE LA PLATA.

ILUSTRACIÓN 54. COBERTURA DE TRANSPORTE PÚBLICO A VILLAS, ASENTAMIENTOS PRECARIOS Y BARRIOS DEGRADADOS 2013. FUENTE: ELABORACIÓN PROPIA. DATOS DEL REGISTRO PÚBLICO PROVINCIAL DE VILLAS Y 
ASENTAMIENTOS PRECARIOS (RPPVAP) CREADO EN EL MARCO DE LA LEY 14449. GOBIERNO DE LA PROVINCIA DE BUENOS AIRES.

ILUSTRACIÓN 55. PRECIO DE SUELO EN DÓLARES 2013 Y VÍAS JERARQUIZADAS DEL GLP. FUENTE: ELABORACIÓN PROPIA, EN BASE A COLA, C., BARBERO, D., MARTINI, I., AÓN, L. (2017).

ILUSTRACIÓN 56. PRECIO DEL SUELO EN DÓLARES 2013 Y FRECUENCIAS DE TP GLP. FUENTE: ELABORACIÓN PROPIA, EN BASE A COLA, C., BARBERO, D., MARTINI, I., AÓN, L. (2017).

ILUSTRACIÓN 57. CRECIMIENTO POBLACIONAL 2014-2030 POR DELEGACIÓN MUNICIPAL DEL GRAN LA PLATA. FUENTE: ELABORACIÓN PROPIA, EN BASE A DATOS INTERCENSALES 2001-2010 DE INDEC.

ILUSTRACIÓN 58. CRECIMIENTO VIVIENDAS 2014-2030 POR DELEGACIÓN DEL GRAN LA PLATA. FUENTE: ELABORACIÓN PROPIA, EN BASE A DATOS INTERCENSALES 2001-2010 DE INDEC.

ILUSTRACIÓN 59. DENSIDAD POBLACIONAL GRAN LA PLATA 2013. FUENTE: ELABORACIÓN PROPIA, EN BASE A DATOS INTERCENSALES 2001-2010 DE INDEC.

ILUSTRACIÓN 60. DENSIDAD POBLACIONAL GRAN LA PLATA PROYECCIÓN 2030. FUENTE: ELABORACIÓN PROPIA, EN BASE A DATOS INTERCENSALES 2001-2010 DE INDEC.

ILUSTRACIÓN 61. RECORRIDOS DE LÍNEAS SUR Y 520. FUENTE: ELABORACIÓN PROPIA, EN BASE A DATOS APORTADOS POR DIRECCIÓN DE TRANSPORTE DEL MUNICIPIO DE LA PLATA.

ILUSTRACIÓN 62. VELOCIDAD DEL TRANSPORTE PÚBLICO EN CORREDORES ZONA NORTE 2017. FUENTE: ELABORACIÓN PROPIA.

ILUSTRACIÓN 63. VELOCIDAD DE TRANSPORTE PÚBLICO EN CORREDORES ZONA NORTE PROYECCIÓN 2030. FUENTE: ELABORACIÓN PROPIA.

ILUSTRACIÓN 64. VELOCIDAD RAMAL ESTE 14 POR TRAMO DE 5 MINUTOS EN 2017. FUENTE: ELABORACIÓN PROPIA.

ILUSTRACIÓN 65. VELOCIDAD RAMAL ESTE 14 POR TRAMO DE 5 MINUTOS PROYECCIÓN A 2030. FUENTE:

ELABORACIÓN PROPIA.

ILUSTRACIÓN 66. TIEMPO DE TRASLADO EN TRANSPORTE PÚBLICO POR DELEGACIÓN EN 2013. FUENTE: ELABORACIÓN PROPIA.

ILUSTRACIÓN 67. TIEMPO DE TRASLADO EN TRANSPORTE PÚBLICO POR DELEGACIÓN PROYECCIÓN 2030. FUENTE: ELABORACIÓN PROPIA.

ILUSTRACIÓN 68. TIEMPO DE VIAJE EN TRANSPORTE PÚBLICO SEGÚN FRECUENCIAS Y TIEMPO DE TRASLADO DE ZONAS CUBIERTAS EN 2013. FUENTE: ELABORACIÓN PROPIA

ILUSTRACIÓN 69. TIEMPO DE VIAJE EN TRANSPORTE PÚBLICO SEGÚN FRECUENCIAS Y TIEMPO DE TRASLADO DE ZONAS CUBIERTAS PROYECCIÓN 2030. FUENTE: ELABORACIÓN PROPIA.

ILUSTRACIÓN 70. CANTIDAD DE PERSONAS NO CUBIERTAS POR TP CON NBI. FUENTE: ELABORACIÓN PROPIA, EN BASE A DATOS DE INDEC. 221

ILUSTRACIÓN 71. COSTO POR VIAJE EN AUTO AL CASCO 2013. FUENTE: ELABORACIÓN PROPIA. 223

ILUSTRACIÓN 72. COSTO POR VIAJE EN TRANSPORTE PÚBLICO AL CASCO 2013. FUENTE: ELABORACIÓN PROPIA. ..... 223 
ILUSTRACIÓN 73. COSTO POR DELEGACIÓN DE VIAJES AL CASCO URBANO EN AUTO Y COLECTIVO EN 2013. FUENTE: ELABORACIÓN PROPIA

ILUSTRACIÓN 74. ILUSTRACIÓN 6. COSTO POR DELEGACIÓN DE VIAJES AL CASCO URBANO EN AUTO Y COLECTIVO PROYECCIÓN 2030. FUENTE: ELABORACIÓN PROPIA.

ILUSTRACIÓN 77. CORREDOR AV. 7: UBICACIÓN DE PARADAS, VELOCIDAD DE TP POR TRAMO Y VIAJES EN TP PRODUCIDOS. FUENTE: ELABORACIÓN PROPIA, SE UTILIZARON DATOS DE DENSIDAD OBTENIDOS DEL INDEC. 229

ILUSTRACIÓN 78. ÁREAS DEL CORREDOR AV. 7. FUENTE: ELABORACIÓN PROPIA. 230

ILUSTRACIÓN 80. METROBUS SUR, C.A.B.A.. FUENTE: HTTPS://WWW.CEXT.ES/POSTS/CIUDADANIA/MOVERSE-PORBUENOS-AIRES-SERA-MAS-CARO-A-PARTIR-DE-FEBRERO/ (ACCEDIDO 31-10-2018).

ILUSTRACIÓN 81. PROPUESTA CONJUNTA, CARRIL EXCLUSIVO Y DISTRIBUCIÓN DE PARADAS CADA 300 METROS. FUENTE: ELABORACIÓN PROPIA.

ILUSTRACIÓN 82. ZONIFICACIÓN COU DEL CORREDOR. FUENTE: ELABORACIÓN PROPIA, EN BASE AL COU DE 2010.

ILUSTRACIÓN 83. DENSIDADES MÁXIMAS PERMITIDAS POR EL COU LA PLATA. FUENTE: ELABORACIÓN PROPIA, EN BASE AL COU DE 2010

ILUSTRACIÓN 84. DENSIDAD DE HABITANTES POR HECTÁREA 2014. FUENTE: ELABORACIÓN PROPIA, EN BASE A DATOS DE INDEC.

ILUSTRACIÓN 85. PROPUESTA DE DENSIFICACIÓN DEL CORREDOR AV. 7. FUENTE: ELABORACIÓN PROPIA, LOS CURSOS DE AGUA PROVIENEN DE INFORMACIÓN HISTÓRICA CONSTRUIDA POR EL IIPAC FAU UNLP. 243

ILUSTRACIÓN 86. APROXIMACIÓN DE IMPLEMENTACIÓN DE PROPUESTA DE DENSIFICACIÓN DEL CORREDOR AV. 7. FUENTE: ELABORACIÓN PROPIA, EN BASE A DATOS DE INDEC, Y ARCHIVO HISTÓRICO IIPAC FAU.

ILUSTRACIÓN 88. USOS ATRACTORES DE VIAJE EN EL CORREDOR AV. 7. FUENTE: ELABORACIÓN PROPIA, EN BASE A INFORMACIÓN DIFUNDIDA POR EL MUNICIPIO DE LA PLATA (DATOS ABIERTOS.).....

ILUSTRACIÓN 89. EJEMPLO: TRAMO DE CARRIL EXCLUSIVO POSIBLE DE CONSTRUIR EN 2013, FINANCIABLE CON UN MONTO EQUIVALENTE A LA GANANCIA DE LAS EMPRESAS DE TRANSPORTE DURANTE UN AÑO. FUENTE: ELABORACIÓN PROPIA

ILUSTRACIÓN 90. VIAJES A LUGARES EXTERNOS AL GLP POR DELEGACIÓN MUNICIPAL. FUENTE: ELABORACIÓN PROPIA, EN BASE A DATOS DE LA ENCUESTA DE MOVILIDAD DEL GRAN LA PLATA GII- IIPAC FAU UNLP.

ILUSTRACIÓN 91. VIAJES A VILLA ELVIRA POR DELEGACIÓN MUNICIPAL. FUENTE: ELABORACIÓN PROPIA, EN BASE A DATOS DE LA ENCUESTA DE MOVILIDAD DEL GRAN LA PLATA GII- IIPAC FAU UNLP

ILUSTRACIÓN 92. VIAJES A VILLA ELISA POR DELEGACIÓN MUNICIPAL. FUENTE: ELABORACIÓN PROPIA, EN BASE A DATOS DE LA ENCUESTA DE MOVILIDAD DEL GRAN LA PLATA GII- IIPAC FAU UNL.P.... 330

ILUSTRACIÓN 93. VIAJES A TOLOSA POR DELEGACIÓN MUNICIPAL. FUENTE: ELABORACIÓN PROPIA, EN BASE A DATOS dE LA ENCUESTA DE MoVILIDAD DEL GRAN LA PLATA GII- IIPAC FAU UNLP .330

ILUSTRACIÓN 94. VIAJES A SAN CARLOS POR DELEGACIÓN MUNICIPAL. FUENTE: ELABORACIÓN PROPIA, EN BASE A DATOS DE LA ENCUESTA DE MOVILIDAD DEL GRAN LA PLATA GII- IIPAC FAU UNLP.....

ILUSTRACIÓN 95. VIAJES A RINGUELET POR DELEGACIÓN MUNICIPAL. FUENTE: ELABORACIÓN PROPIA, EN BASE A DATOS DE LA ENCUESTA DE MOVILIDAD DEL GRAN LA PLATA GII- IIPAC FAU UNLP 
ILUSTRACIÓN 96. VIAJES A OLMOS POR DELEGACIÓN MUNICIPAL. FUENTE: ELABORACIÓN PROPIA, EN BASE A DATOS DE LA ENCUESTA DE MOVILIDAD DEL GRAN LA PLATA GII- IIPAC FAU UNLP.

ILUSTRACIÓN 97. VIAJES A MELCHOR ROMERO POR DELEGACIÓN. FUENTE: ELABORACIÓN PROPIA, EN BASE A DATOS DE LA ENCUESTA DE MOVILIDAD DEL GRAN LA PLATA GII- IIPAC FAU UNLP

ILUSTRACIÓN 98. VIAJES A LOS HORNOS POR DELEGACIÓN MUNICIPAL. FUENTE: ELABORACIÓN PROPIA, EN BASE A DATOS DE LA ENCUESTA DE MOVILIDAD DEL GRAN LA PLATA GII- IIPAC FAU UNLP.

ILUSTRACIÓN 99. VIAJES A HERNÁNDEZ POR DELEGACIÓN MUNICIPAL. FUENTE: ELABORACIÓN PROPIA, EN BASE A DATOS DE LA ENCUESTA DE MOVILIDAD DEL GRAN LA PLATA GII- IIPAC FAU UNLP. 333

ILUSTRACIÓN 100. VIAJES A GORINA POR DELEGACIÓN MUNICIPAL. FUENTE: ELABORACIÓN PROPIA, EN BASE A DATOS DE LA ENCUESTA DE MOVILIDAD DEL GRAN LA PLATA GII- IIPAC FAU UNLP.

ILUSTRACIÓN 101. VIAJES A GONNET POR DELEGACIÓN MUNICIPAL. FUENTE: ELABORACIÓN PROPIA, EN BASE A DATOS DE LA ENCUESTA DE MOVILIDAD DEL GRAN LA PLATA GII- IIPAC FAU UNLP

ILUSTRACIÓN 102. VIAJES A ETCHEVERRY POR DELEGACIÓN MUNICIPAL. FUENTE: ELABORACIÓN PROPIA, EN BASE A DATOS DE LA ENCUESTA DE MOVILIDAD DEL GRAN LA PLATA GII- IIPAC FAU UNLP.

ILUSTRACIÓN 103. VIAJES A EL PELIGRO POR DELEGACIÓN MUNICIPAL. FUENTE: ELABORACIÓN PROPIA, EN BASE A DATOS DE LA ENCUESTA DE MOVILIDAD DEL GRAN LA PLATA GII- IIPAC FAU UNLP

ILUSTRACIÓN 104. VIAJES A CITY BELL POR DELEGACIÓN MUNICIPAL. FUENTE: ELABORACIÓN PROPIA, EN BASE A DATOS DE LA ENCUESTA DE MOVILIDAD DEL GRAN LA PLATA GII- IIPAC FAU UNLP. 336

ILUSTRACIÓN 105. VIAJES A ARANA POR DELEGACIÓN MUNICIPAL. FUENTE: ELABORACIÓN PROPIA, EN BASE A DATOS DE LA ENCUESTA DE MOVILIDAD DEL GRAN LA PLATA GII- IIPAC FAU UNLP. 336

ILUSTRACIÓN 106. VIAJES A ABASTO POR DELEGACIÓN MUNICIPAL. FUENTE: ELABORACIÓN PROPIA, EN BASE A DATOS DE LA ENCUESTA DE MOVILIDAD DEL GRAN LA PLATA GII- IIPAC FAU UNLP.

ILUSTRACIÓN 107. VIAJES A ALTOS DE SAN LORENZO POR DELEGACIÓN MUNICIPAL. FUENTE: ELABORACIÓN PROPIA, EN BASE A DATOS DE LA ENCUESTA DE MOVILIDAD DEL GRAN LA PLATA GII- IIPAC FAU UNLP..... 337 


\section{NOMENCLATURAS}

AEPS - Asignación por Embarazo para Protección Social

AGTP - Administración General del Transporte de Pasajeros

AMBA - Área Metropolitana de Buenos Aires

AUH - Asignación Universal por Hijo

BID - Banco Interamericano de Desarrollo

BRT - Bus Rapid Transit

C00 - Código de Ordenamiento Urbano de 2000

C10 - Código de Ordenamiento Urbano de 2010

C78 - Código de Ordenamiento Urbano de 1978

CABA - Ciudad Autónoma de Buenos Aires

CAF - Corporación Andina de Fomento, Banco de desarrollo de América Latina

CBA - Canasta Básica Alimentaria

CBT - Canasta Básica Total

CEPAL - Comisión Económica Para América Latina y el Caribe

CNRT - Comisión Nacional de Regulación del Transporte

CO2 - Dióxido de carbono

COU - Código de Ordenamiento Urbano La Plata

COUT - Consejo de Ordenamiento Urbano Territorial

CTP - Consorcio de Transporte de Pasajeros

DF - Distrito Federal de México

EE.UU - Estados Unidos de América

EMR - Ente de Movilidad de Rosario

EOD - Encuesta de origen y destino

ETR - Ente de Transporte de Rosario

FOS - Factor de Ocupación del Suelo

FOT - Factor de Ocupación Total 
GBA - Gran Buenos Aires

GII - Grupo Movilidad, Ambiente y Territorio del IIPAC

GNC - Gas Natural Comprimido

GTZ - Agencia de Cooperación Técnica Alemana ( Deutsche Gesellschaft für Technische Zusammenarbeit)

IIPAC - Instituto de Investigaciones y Políticas del Ambiente Construido

INDEC - Instituto Nacional de Estadísticas y Censos de la República Argentina

IPK - Índice Pasajero Kilometro

ITDP - Instituto para la Política de Transporte y Desarrollo (Institute for Transportation an Development Policy)

LEAP - Sistema de Planificación de Alternativas Energéticas de Largo Plazo

NAP - Nodos de Actividad Primaria

NBI - Necesidades Básicas Insatisfechas

PAX - Pasajeros de transporte público

PBG - Producto Bruto Geográfico

PROCREAR - Programa de Crédito Argentino

PTUMA - Programa de Transporte Urbano para Áreas Metropolitanas

RMBA - Región Metropolitana de Buenos Aires

RMV - Transportes Públicos Regionales de Alemania

SIG - Sistema de Representación Geográfica

SISTAU - Sistema Integral de Subsidios al Transporte Automotor Urbano

SM - Salario Mínimo

STPAP - Sistema de Transporte Público Automotor de Pasajeros

SUBE - Sistema Único de Boleto Electrónico

SUT - Sistema Urbano de Transporte

SUTR - Sistema Único de Transporte Regional

TEP - Toneladas equivalente de petróleo 
TGV - Tasa de Generación de Viaje

TGVA - Tasa de Generación de Viaje en Auto

TGVC - Tasa de Generación de Viaje en Colectivo

TOD - Transit Orientes Development

TP - Transporte público

TSC - Tarjeta Sin Contacto

UE - Unión Europea

UITP - Asociación Internacional de Transporte Público

UN - Naciones Unidas (United Nations)

UTA - Unión Tranviarios Automotor

UTE - Unión Transitoria de Empresas 


\section{INTRODUCCIÓN}

La presente tesis doctoral aborda el tiempo de viaje como variable crítica para la planificación del transporte público y el desarrollo urbano, con prospectivas para el Gran La Plata. El trabajo se realiza en base a la construcción de escenarios analítico-empíricos para la generación de pautas de planificación de la movilidad urbana. Dichas pautas se plantean desde los criterios de planificación integrada de usos de suelo y transporte, tan desarrollados teóricamente pero con menos suerte en su aplicación. En este marco, el presente trabajo de tesis se propone otorgarle centralidad al análisis del tiempo de viaje en transporte público por estar compuesto por problemáticas críticas que hacen al tema en cuestión. Entre ellas la congestión vehicular, el incremento de las distancias de viaje, la adecuación de la infraestructura de movilidad, la distancia a la red de transporte público y sus frecuencias.

Se parte de la hipótesis de que la integración de las políticas de desarrollo urbano y movilidad que incorporen al tiempo de viaje como variable de ajuste a partir de escenarios alternativos de transporte público masivo y usos de suelo, permiten generar pautas de planificación orientadas a equilibrar la actual situación de sobre oferta en áreas centrales y déficit en áreas periféricas del caso de estudio. De esta hipótesis principal se desprende el objetivo general de la tesis que consiste en elaborar pautas de planificación mediante la construcción y ensayo de escenarios de transporte público de pasajeros del Gran La Plata focalizando en el tiempo de viaje como variable critica que permite integrar la movilidad y el desarrollo urbano.

A partir de este objetivo se estructuran los capítulos de este trabajo. En el primer capítulo se presenta el estado del arte referido a la planificación integrada de los usos del suelo y la movilidad urbana. Comienza con un repaso de la historia de la planificación del transporte y el modo en que se ha considerado la variable "tiempo de traslado" en diferentes periodos históricos desde finales del siglo XIX a la actualidad. Asimismo, se identifican diferentes posturas sobre la planificación integrada, tomando para ello casos paradigmáticos internacionales, latinoamericanos y argentinos. Es en ese marco donde se aborda la problemática de la movilidad, los usos del suelo y la planificación del transporte, y se discute el valor asignado a la variable "tiempo de viaje" en la movilidad. 
A continuación, se desarrolla el marco teórico del trabajo a partir de entender la ciudad como un sistema abierto y complejo en el que el transporte y la movilidad son complementarios entre sí, y a su vez parte de un mismo sistema interdependiente con los usos del suelo. Es decir, se tenga en cuenta o no, las características que adquiera la movilidad dependen de la planificación y/o asignación de localizaciones espaciales determinadas a distintos tipos de actividades (sociales, económicas, productivas, recreativas, institucionales, de gestión, etc), a sus densidades y capacidad atractora de viajes, y viceversa. Finalmente se desarrollan los fundamentos de la investigación y se problematiza el caso de estudio, para el que se desprenden (y aplican) las hipótesis y los objetivos del trabajo.

En el segundo capítulo se describe la metodología para la construcción y ensayo de escenarios integrados de transporte público masivo y uso del suelo. Se comienza con el desarrollo de la metodología para la construcción del año base el cual resulta un componente fundamental para la posterior elaboración del escenario tendencial y el alternativo. En el año base se focaliza el estudio o reflexión de los métodos utilizados para el relevamiento de la información, la explicitación de los procedimientos, las variables y supuestos adoptados, entre otros aspectos operativos que luego serán utilizados en el resto de los escenarios. En este sentido, para la construcción del año base, se utilizan distintos métodos e instrumentos de recolección de la información, fuentes y técnicas apropiadas para su procesamiento, las cuales se utilizan para la posterior construcción del escenario tendencial y los alternativos. Dicho año base está anclado temporalmente en el periodo 2013-2014, años en los cuales el Grupo 2 de Movilidad Ambiente y Territorio del IIPAC-CONICET-UNLP realizó una novedosa encuesta de movilidad con base en la web en base a centros atractores urbanos que permite obtener datos actualizados de transporte para el Gran La Plata.

En una primera aproximación, las variables a analizar para la construcción del año base se fundamentan en entender al transporte público masivo como uno de los principales modos de transporte utilizados para dar respuesta a la necesidad de movilizarse de la población que ocupa un territorio determinado. A su vez se considera al tiempo de viaje como una variable critica para generar pautas de planificación que sirvan como guías para las políticas de movilidad. En ese sentido se tendrán en cuenta: las densidades poblacionales y habitacionales de ocupación del suelo, las particiones modales, indicadores de accesibilidad urbana para el transporte público, tiempos de espera y traslado en transporte público

A su vez, se tiene en cuenta para la construcción de los escenarios la valorización y producción del suelo a partir de la cercanía al transporte público y los costos operativos, como 
así también el ajuste de densidades de población y vivienda como pauta para el trazado de infraestructura e inversiones en periferias, para garantizar la sustentabilidad económica y la calidad de los servicios de transporte público masivo. Asimismo se analizan variables propias del transporte masivo como son el diseño de los recorridos, los kilómetros de desplazamiento, la velocidad operativa de las unidades, tiempos de viaje, los pasajeros transportados, la cantidad de servicios diarios, frecuencias por cada franja horaria y tiempos de recorrido real y legal.

El escenario tendencial, es aquel en el que se mantienen los modos y propensiones de evolución de las variables de las variables con su tendencia propia e individual. Para este caso se plantea un escenario tendencial a medio plazo, con proyección 20132030 con la intención de que coincida con el plan estratégico que plantea el Municipio de La Plata para el mismo año, con los Objetivos de Desarrollo Sostenible (2016-2030) de la ONU, permitiendo a los lectores comparar los distintos análisis de la situación futura.

Por último, en el escenario alternativo, se plantea la incorporación de las diferentes medidas propuestas atendiendo a los aspectos críticos de tiempo de viaje detectados en el "año base", ensayando medidas de mejoramiento de transporte público masivo y uso del suelo. En este caso, también se plantea un análisis al año 2030 que permita comparar alternativas desde la planificación integrada del crecimiento urbano y la movilidad en uno de los corredores principales de transporte de la ciudad. Así, los resultados obtenidos a partir de la implementación de la metodología para la construcción de escenarios contribuyen a generar pautas e insumos que colaboren con la planificación integral de transporte público y uso del suelo.

En el tercer capítulo se plantea la construcción del "año base" a partir del análisis del caso de estudio propuesto. Para ello, se analiza el proceso histórico de conformación del Gran La Plata y el rol que desempeña en ese marco el sistema de transporte público colectivo de la región, para llegar al sistema actual, el Sistema Urbano de Transporte de La Plata. Se prestará especial atención al proceso de implementación de dicho sistema en mayo del 2002 y el rol jugado por distintos actores ya que junto con la política de subsidios al transporte urbano colectivo iniciada ese año, son fundamentales para comprender la complejidad de conflictos que limitan la introducción de mejoras sustanciales del sistema.

Luego de la descripción histórica del desarrollo urbano-territorial de la ciudad de La Plata se analizan distintas dimensiones que hacen a la problemática del transporte local con especial atención en los tiempos de viaje: una dimensión espacial que contempla datos de población, 
ocupación del territorio y movilidad; una social donde se analizan las características sociales en relación al $\mathrm{NBI}^{1}$ de la población cubierta por transporte publico según tiempos de viaje por delegación del Gran La Plata; otra económica que aborda los costos de la expansión urbana en términos de movilidad y un estudio de la incidencia de la cobertura espacial de la red de transporte público sobre los precios del suelo según zona de transporte $^{2}$; y por último un análisis algunas de las problemáticas de planificación y gestión, a través de un estudio del funcionamiento de los subsidios y de entrevistas a algunos actores involucrados en el funcionamiento efectivo del sistema.

En el cuarto capítulo se plantea el ejemplo de aplicación de la construcción de los escenarios tendencial y alternativo, tomando como horizonte temporal el año 2030. Para ello, se utiliza la metodología desarrollada en el Capítulo II. Asimismo, la simulación de ambos escenarios son consecuencia del "año base", construido en el Capítulo III, donde se utilizó a la ciudad de La Plata como caso de estudio.

Finalmente en el quinto capítulo se exponen algunas pautas de planificación de la movilidad focalizando en las políticas de transporte público y desarrollo urbano que se desprenden de las problemáticas analizadas en el escenario base y en los escenarios alternativos. En ese marco las pautas propuestas se pueden agrupar en: a) pautas para la mejora del sistema de transporte público de pasajeros; b) pautas para políticas de uso de suelo con criterios de movilidad; c) ideas de un modelo de gestión del transporte público más eficiente; y por último d) algunas pautas para el financiamiento del transporte público de La Plata.

El último capítulo, el sexto, presenta los resultados alcanzados a partir de los objetivos del plan de trabajo y la hipótesis propuesta. Asimismo se analizan las dificultades y límites del trabajo realizado y se proponen nuevos interrogantes para futuras investigaciones.

\footnotetext{
${ }^{1}$ Necesidades Básicas Insatisfechas según CENSO nacional de población, hogares y viviendas 2010.

${ }^{2}$ Agrupamiento de radios censales según cercanía y comportamientos de movilidad por corredores.
} 


\section{CAPITULO I: ESTADO DEL ARTE, MARCO TEÓRICO Y OBJETIVOS DEL}

TRABAJO

\section{Resumen}

En este capítulo se presenta el estado del arte referido a la planificación integrada de los usos del suelo y la movilidad urbana, repasando la historia de la planificación del transporte y el modo en que se ha considerado la variable "tiempo de viaje" en diferentes periodos históricos, desde finales del siglo XIX a la actualidad. Asimismo, se identifican diferentes posturas sobre la planificación integrada, tomando para ello casos paradigmáticos internacionales, latinoamericanos y argentinos. Es en ese marco donde se aborda la problemática de la movilidad, los usos del suelo y la planificación del transporte, y se discute el valor asignado a la variable "tiempo" en la movilidad.

A continuación, se desarrolla el marco teórico del trabajo a partir de entender la ciudad como un sistema abierto y complejo en el que el transporte y la movilidad son complementarios entre sí, y a su vez parte de un mismo sistema interdependiente con los usos del suelo. Finalmente se desarrollan los fundamentos de la investigación y se problematiza el caso de estudio, para el que se desprenden (y aplican) las hipótesis y los objetivos del trabajo. 


\subsection{Enfoque del trabajo.}

La humanidad está atravesando un muy importante proceso de crecimiento poblacional y, en particular, de urbanización. Según las Naciones Unidas (U.N., 2015) la población mundial crece a razón de 80 millones de habitantes al año. La población urbana del planeta pasó a ser mayoría en 2008 y, apenas siete años después, en 2015, esa proporción alcanzó el 54,85\%. Para ese mismo año la población mundial ascendió a 7300 millones y se espera que para 2050 la población sea de 9700 millones, con el 66\% viviendo en ciudades. Es decir que para 2050, la cantidad de personas viviendo en ciudades será equivalente al $87,7 \%$ de la población mundial de 2015.

Según Davis, M (2007), esta situación extraordinaria en términos históricos pone las capacidades físicas, territoriales, de planificación y de gestión de cada una de las ciudades en el centro del problema. También estarán a prueba las tradiciones de planificación urbana y los modos en que cada ciudad ha conjugado a lo largo de los años las modalidades de crecimiento urbano con las necesidades de desplazamiento de sus habitantes entre sus distintas actividades (residencia, trabajo, estudio, etc.).

En ese marco es que se considera fundamental afrontar esta problemática a partir de la profundización de distintas políticas de mejoramiento orientadas a integrar la planificación de los usos del suelo y la movilidad urbana. En este sentido, existen experiencias relevantes de países europeos como Alemania, Francia u Holanda cuyos planes urbanos integrales y normativas nacionales específicas, tienen en cuenta dicha problemática, como se registran en GTZ, Planificación del Uso del Suelo y Transporte Urbano (2006).

En la mayoría de las ciudades latinoamericanas, tanto las dinámicas de urbanización como el estado de la planificación son distintos a los casos antes mencionados. Entre las diferencias más importantes se puede mencionar la profundización de los procesos no planificados de urbanización. Dicho proceso alcanzó para el año 2000 el segundo lugar en el ranking de regiones con mayor tasa de urbanización, muy cerca de América del Norte, superando a Europa y Oceanía (Tabla 1). Estos grandes y muy rápidos aumentos de población en contextos urbanos de baja capacidad de planificación y gestión urbana, están típicamente asociados con un descenso en el nivel de la calidad de vida en las ciudades latinoamericanas. 
Tabla 1. Nivel de urbanización de grandes regiones del mundo (\%). Fuente: Lattes, 2000.

\begin{tabular}{|lccccc|}
\hline \multicolumn{1}{|c}{ Regiones } & 1925 & 1950 & 1975 & 2000 & 2025 \\
\hline Total mundial & 20,5 & 29,7 & 37,9 & 47,0 & 58,0 \\
\hline Regiones más desarrolladas & 40,1 & 54,9 & 70,0 & 76,0 & 82,3 \\
Regiones menos desarrolladas & 9,3 & 17,8 & 26,8 & 39,9 & 53,5 \\
\hline África & 8,0 & 14,7 & 25,2 & 37,9 & 51,8 \\
América Latina & 25,0 & 41,4 & 61,2 & 75,3 & 82,2 \\
América del Norte & 53,8 & 63,9 & 73,8 & 77,2 & 83,3 \\
Asia & 9,5 & 17,4 & 24,7 & 36,7 & 50,6 \\
Europa & 37,9 & 52,4 & 67,3 & 74,8 & 81,3 \\
Oceanía & 48,5 & 61,6 & 71,8 & 70,2 & 73,3 \\
\hline
\end{tabular}

En efecto, la ausencia de pautas y prácticas eficientes de planificación y previsión generan patrones desiguales y discontinuos de ocupación territorial, de ubicación de viviendas, de puestos de trabajo, de equipamientos de salud, educación y de oferta de comercios y servicios. Esta situación induce modalidades críticas de movilidad de mercancías y personas, tanto para ciclistas y peatones cuya operatividad se vuelve difícil y riesgosa por falta de planificación e inversión en infraestructuras acordes, como para los usuarios de automóviles y de transporte masivo de pasajeros, que deben adecuarse a las deficiencias de oferta y a la mala calidad de los servicios que, en algunas ciudades, se combinan también con altas tarifas.

Completan el panorama crítico el uso asimétrico del espacio para la movilidad, debido a que el uso creciente del automóvil particular por parte de los sectores de población de ingresos altos y medios, compite y restringe la circulación de los vehículos de transporte colectivo, cómo se registra en un informe de la CAF (2001). Esta situación deteriora la calidad de vida urbana en nuestras ciudades. Por un lado, demanda un mayor uso del tiempo de vida para la movilidad cotidiana y por otro, produce un incremento de la contaminación del aire debido a la extensión de los recorridos de viajes en las periferias, el mayor uso del automóvil y la intensificación de la congestión en áreas centrales. Esta relación conflictiva también incrementa la accidentalidad, además de lo mencionado sobre la pérdida de espacio para los peatones y el deterioro del espacio público, devaluando cada vez más el rol que cumple en la ciudad como estructurador de la vida propiamente urbana. Este escenario deriva, en parte, de la combinación entre el avance de los sectores económicos concentrados, las prácticas mercantiles de los desarrolladores inmobiliarios y los efectos del operar competitivo de los empresarios de transporte colectivo, ya que estos últimos tienden a sobre ofertar los recorridos más rentables de la ciudad mientras desabastecen a las periferias poco densas, produciendo 
una convergencia crítica de difícil solución en los marcos actuales, según Aón, Cola y Giglio (2016), caracterizado además en general por limitaciones y debilidades de la planificación territorial o su orientación explicita en apoyo de aquellos avances y prácticas.

Sin embargo, en algunas ciudades argentinas se han desplegado algunas buenas prácticas de planificación urbana. Por ejemplo, durante la vigencia de políticas neoliberales en los años '90, la reducción de la capacidad estatal de intervención y regulación y la descentralización operativa provocaron que en Rosario se fortaleciera la capacidad de planificación urbana desde los organismos de gobierno local. Esta planificación se basó en planes de re funcionalización y conservación de áreas con valor histórico arquitectónico y sistemas de transporte público colectivo y no motorizado en áreas centrales, aunque se vio limitada por las dificultades para resolver la gran fragmentación socio espacial marcada por una importante extensión de periferias urbanas empobrecidas. Estas dificultades de la planificación de Rosario podrían generalizarse para muchas de las ciudades latinoamericanas que presentan realidades muy distintas entre sus centros y sus periferias. Asimismo, dichas dificultades impactan en la movilidad y dificultan la simple necesidad de trasladarse para poder acceder a los establecimientos educativos, de salud o a los lugares de trabajo.

En este sentido, en función de lo expuesto, se reconoce que las políticas y las intervenciones referidas a la movilidad, de transporte y de usos del suelo se interdefinen, como menciona Garcia, R (2006). Es decir que la alternativa de abordar la solución a las problemáticas del desarrollo urbano sólo con medidas de transporte o de suelo por separado no logrará cambiar esta configuración en la ocupación del territorio. Consecuentemente, se constituirán medidas sesgadas y paliativas de corto plazo y de escasa o nula articulación.

Para abordar aspectos de esta interdefinición entre movilidad, transporte y uso de suelo, en este trabajo se profundizará en el análisis de la variable 'tiempo de viaje en transporte público' ya que permiten conjugar varias de las problemáticas mencionadas, como son la extensión espacial de la ciudad que incrementa distancias y los tiempos de desplazamiento afectados por el aumento del parque automotor circulante que produce mayor congestión en áreas centrales. También se vincula con otro tema no mencionado hasta aquí, como es la conflictiva relación entre los tiempos de recorrido de cada ramal de transporte público establecidos por contrato y los tiempos reales de desplazamiento: estas discrepancias (ligadas a los subsidios al transporte público aportados por el Estado Nacional) afectan la calidad de los servicios y las condiciones de trabajo de los choferes. 
Para aportar a la resolución de estas problemáticas, el presente trabajo apunta a elaborar pautas de planificación urbana que orienten el crecimiento de nuestras ciudades articulando las políticas de desarrollo, producción y ocupación del suelo con la planificación de la movilidad y el desarrollo de medidas de transporte público, a través de la construcción y ensayo de escenarios alternativos de crecimiento urbano, focalizando sobre la región del Gran La Plata como caso de estudio.

\subsubsection{Estado del arte: Planificación integrada y tiempos de viaje.}

Los problemas de las ciudades vinculados al transporte y al desarrollo urbano han planteado a los planificadores distintas maneras de estudiar e intervenir la ciudad. Para comprender la situación actual se presenta una síntesis de las distintas etapas de la planificación urbana a lo largo de la historia moderna. Asimismo se analizará la variable 'tiempo de viaje en transporte público' a partir de estudios o intervenciones que se expresan en cada etapa identificada, según los criterios históricos y periodización propuestos en Novick (2004).

\subsubsection{El momento de la expansión}

Luego de la Gran Depresión de 1873 que duró hasta 1879 y que es conocida como la primera crisis sistémica del capitalismo, en el marco de la segunda revolución industrial ${ }^{3}$ se produjo $^{2}$ un salto en la concentración de capital y trabajo en las ciudades. Esta situación indujo un crecimiento urbano de gran magnitud a ritmos acelerados en Europa y Estados Unidos, con una ciudad no preparada que se expandía sobre el territorio y que también necesitaba expandirse hacia adentro, es decir, de integrarse como sociedad a partir de estar compuesta mayoritariamente de migrantes que venían del campo o pueblos rurales. En ese marco, los grandes problemas del periodo fueron la pobreza urbana, la falta de infraestructuras, las epidemias, la ciudad en construcción, migraciones y emigraciones, la generalización de una economía monetaria y la aparición de nuevos problemas de control y de gestión administrativa, como menciona Novick, A (2004).

Las contradicciones entre capital-trabajo y campo-ciudad desarrolladas por Marx y Engels $(1848,1873,1884)$ ayudaron a entender las dicotomías motoras de los cambios sociales y urbanos. Desde el punto de vista del Estado y de distintas disciplinas, las grandes epidemias y

3. Con innovaciones técnicas como el gas, el petróleo y la electricidad, nuevos materiales y sistemas de transporte (avión y automóvil) y comunicación (teléfono y radio) 
los movimientos sociales que expresaban estas problemáticas fueron vistos como constitutivos de "la cuestión urbana", ya que no se encontraban en las condiciones de vida rural características de la época anterior, como describe Hall, P (1996). Por tal motivo a fin del siglo XIX, se pensaba que interviniendo en los problemas de la ciudad y que modificando el ambiente se podía modificar las condiciones de riesgo que la sociedad enfrentaba con la trasposición entre dos localizaciones (campo/ciudad) que, en rigor, expresaba la contradicción entre dos modos de producción. Con este criterio se dan las primeras modificaciones sanitaristas y urbanísticas en las ciudades industriales inglesas presentadas en 1885, así como propuestas como la ciudad lineal del madrileño Soria, A (1895).

Paralelamente, el crecimiento de la industria creó una visión de control estatal desde la racionalidad y para ello fue incorporando un conjunto de ciencias y técnicas que intentaron controlar las acciones del Estado, como menciona Novick, A (2004). Acompañando los muchos cambios que se dan en el campo de las ideas y las relaciones entre la sociedad y sus espacios, es que surgen nuevos instrumentos para "intervenir (normas, reglamentos) y controlar" (estadísticas, cartografía) en base al registro y conocimiento de lo que sucedía en la realidad. La utilización de estas herramientas impulsó la aparición en las oficinas públicas o privadas y las universidades de los nuevos especialistas de la ciudad como los trabajadores sociales, los ingenieros vinculados a la expansión del ferrocarril y la explotación de minas, y los higienistas. Como expertos con métodos científicos, todos ellos van a ir conformando organismos tecnocráticos de intervención pública, cumpliendo un rol de mediadores entre la sociedad y el Estado, que comienzan a reemplazar la filantropía y el patronazgo de las clases pudientes en relación a las clases trabajadoras y los vulnerados por la transición.

Al no existir grandes extensiones urbanas consolidadas ni medios de transporte urbanos económicamente accesibles para los nuevos sectores obreros, el automóvil era un bien de lujo y el tren era un transporte interurbano. Así, el problema del tiempo de viaje para el funcionamiento de la ciudad estaba vinculado con la economía productiva, y específicamente al transporte de carga.

En ese marco los primeros estudios de transporte y usos del suelo fueron la base de la elaboración de la teoría de la localización de actividades por Von Thünen, J. H. (1820) quien desarrolla el primer modelo que intenta explicar (desde una perspectiva económica del territorio) las implicancias, de las nuevas relaciones económicas que establece el capitalismo a partir de separar el lugar de la producción del lugar del consumo. Se apoya sobre estudios 
económicos previos y desarrolla los aspectos territoriales a partir de un modelo aplicado a un espacio isótropo.

Von Thünen, J. H. (1820) aplica su modelo a una escala productiva estudiando el costo en recursos y en tiempo que generan las transformaciones territoriales del capitalismo en desarrollo, donde la producción agrícola se encuentra en las periferias y el mercado de consumo en el centro, en la ciudad. La variable tiempo estudiada por Von Thünen, J. H. (1820) en el transporte está asociada al traslado de mercancías; por ende, su estudio se enfoca en los costos diferenciales de traslado de la producción según la localización.

Por otro lado, Weber, A (1909) estudió la importancia de la localización para la ubicación de la industria, donde las variables de reducción de costos radicaban en la localización de la industria balanceando el costo de traslado de las mercancías y el precio de la mano de obra. Más tarde, la Teoría de la Ecología Humana elaborada por Park y Burgess (1925) para Chicago proporcionó los primeros conocimientos sobre la organización espacial de las estructuras sociales urbanas. Por su parte Christaller (1933) y Losch $(1940,1957)$ con su teoría de los lugares centrales desarrolla un modelo sobre la optimización de la distribución espacial de las actividades económicas, comerciales y servicios vinculados geométricamente por una red de conectividad que crea regiones al que, desde otro ángulo, Losch $(1940,1957)$ aporta elementos sustanciales que vinculan deductivamente el funcionamiento de oferta y demanda en los mercados de bienes y servicios con la forma y la estructura territorial

\subsubsection{El momento de la modernización desarrollista y Estado de Bienestar (Welfare State)}

Esta etapa va desde el periodo de entreguerras hasta el fin de la etapa de crecimiento (boom) posterior a la segunda guerra mundial. Es un ciclo de confianza en el que el crecimiento puede ser planificado, ordenado y en el que la intervención del Estado es imprescindible para intentar contrarrestar ciclos económicos adversos, generando consumo y empleo (New Deal). Los principales problemas pasan por cómo se tiene que dar la expansión de la economía, el empleo y la intervención del Estado, se cree que la clave es pensarlos desde una lógica de gran escala, no solo referido a lo urbano sino también a lo económico y territorial. El resultado de este paradigma van a ser las grandes intervenciones, planes y programas y las 
nuevas instituciones multilaterales ${ }^{4}$ que van a tener como premisa que la planificación y criterios de racionalidad administrativa podían resolver el conjunto de las problemáticas del momento.

En ese marco, las dos teorías más utilizadas por los Estados en países desarrollados son la teoría política del desarrollo y la teoría política keynesiana mientras que en América Latina se discute cómo lograr una industrialización no dependiente y cuáles son las políticas que se tienen que instrumentar a partir de los planes de desarrollo, como se ve en Prebisch, R. (1949). En ambas situaciones se ve la necesidad de construir Estados nacionales de mayor envergadura y capacidad de incidencia en la orientación del crecimiento, cuestión que generó distintos debates acerca de las áreas del Estado que debían impulsar la planificación, si dentro del poder legislativo o ejecutivo y con qué organigramas. En esta etapa, surge desde las áreas de planeamiento una preocupación por establecer los límites de la ciudad y es la primera vez donde se plantea la necesidad de hacer diagnósticos y propuestas para las áreas metropolitanas

Estas nuevas visiones van a expresarse en cambios en el discurso y términos de la planificación. La pobreza para los higienistas se va a transformar en falta de orden a la cual hay que contraponer organización, regulación y sensatez administrativa expresadas en el Plan Regulador: pasar del discurso técnico con las estadísticas, a una sobrevaloración del Plan para ordenar lo espacial pero también lo social.

En este marco, en 1960 el Ministro de Transporte de Gran Bretaña nombró en el área de transporte urbano al arquitecto, ingeniero civil y planificador Buchanan, C. (1963) para que hiciese el primer estudio de desarrollo a largo plazo del tránsito motorizado en las áreas urbanas, y del efecto que el mismo podría llegar a tener sobre las ciudades de esa región. A partir de algunos estudios de ciudades y planes, dicho estudio, conocido como Traffic in Towns (Trafico en las Ciudades), problematiza el creciente uso del auto y las complicaciones que genera la creciente congestión generalizada. En el análisis considera el tiempo de viaje de los usuarios del automóvil en términos de costo producido por la congestión, a diferencia de los estudios del periodo anterior que focalizaban en el costo de traslado de carga en relación a las distancias que debían cubrir para cumplir con el ciclo de reproducción del capital. En su estudio habla de accesibilidad refiriéndose a la "facilidad de acceso", del cual menciona dos

\footnotetext{
${ }^{4}$. Por ejemplo el Fondo Monetario Internacional (FMI), Organización de las Naciones Unidas (ONU), Banco Mundial (BM) y Comisión Económica para América Latina y el Caribe (CEPAL).
} 
condiciones básicas: el poder trasladarse de un lado a otro de la ciudad con seguridad, velocidad, de modo directo y en condiciones agradables; y por otro lado poder estacionar sin dificultades en las inmediaciones.

En el caso latinoamericano, es destacable en este periodo el Plan Maestro de Curitiba (1965) a cargo del arquitecto y urbanista Jaime Lerner, que pasó de una estructura radial del Plan Agache de 1943, a una lineal con ejes estructurantes que orientan el crecimiento de la ciudad sobre la base de tres pilares: el uso del suelo, el sistema vial y el transporte público. En este plan, la accesibilidad se interpreta en términos espaciales y a pesar de ser un ejemplo de avanzada (por ley la distancia a una red de transporte público no puede ser mayor a los 500 metros) con varias líneas de escala y jerarquía diferenciada, el tiempo de viaje no parece ser una variable jerarquizada y la articulación entre una muy buena cobertura y el tiempo de viaje no es la más óptima. Por ejemplo, al día de hoy los tiempos de espera promedio de transporte público en Curitiba son de 17 minutos y mayores a 20 minutos para el 33\% de los usuarios. La mayoría de los pasajeros hace un trasbordo por día y el 23\% hace más de un trasbordo por día para un viaje, según datos de Moovit (2018)

\subsubsection{Participación y descentralización}

Este es el periodo del fin del crecimiento de postguerra expresada en la denominada crisis del petróleo, cuando comienzan a implementarse políticas estatales y privadas de desregulación y descentralización. Desde distintas ópticas, esta crisis puso en cuestión la gran teoría de la modernización y del desarrollo y planteó los límites de la actividad del planeamiento en el capitalismo.

Algunas de las críticas provinieron desde las ciencias ambientales, cuestionando que esta forma de planificar no contemplaba el cuidado del medio ambiente y el uso racional de los recursos naturales. También se cuestionó el rol centralizado que usualmente asumen los organismos públicos de planificación y se implantaron los primeros desarrollos en modelos y tecnologías de gestión. Otros cuestionamientos se dieron desde la antropología que problematizó la dimensión cultural de las ciudades, como plantea Geertz, C (1973), a partir de las distintas representaciones de la población sobre los productos y servicios urbanos, articulando la gran crítica a los conjuntos habitaciones de gran escala (objeto de problemas, generadores de revueltas sociales, de falta de integración, etc). 
Desde estas miradas, el planeamiento y la arquitectura sólo aportaban soluciones tecnocráticas que no se adaptaban a la multiplicidad de formas de habitar de cada lugar, como plantea Jacobs, J (1961). Este cuestionamiento se transformó en reivindicación para movimientos sociales y junto con otras cuestiones - tales como la desfinanciación del Estado para el hábitat social - impulsaron procesos de creciente participación y autoconstrucción popular.

En este sentido, desde el marxismo tomaron fuerza las críticas a la ciudad capitalista, argumentando que la planificación aparenta ser neutral pero en realidad es la expresión de la alianza que existe entre el Estado y el capital para resolver los ciclos de auge y crisis del capitalismo. También desde la CEPAL a partir de la Teoría de la Dependencia se diferencian, según Cardoso, F.H., Faletto, E. (1977), desarrollos estructurales desiguales y dependientes económicamente entre países centrales y periféricos. En este marco el técnico cambia su ubicación en la sociedad: deja la neutralidad sin volver al higienismo academicista, y se transforma en un mediador y revolucionario que critica las bases propias del sistema que generan las problemáticas urbanas.

En Europa, el cuestionamiento académico al modelo de planificación de la modernidad también significó en los años 60 y 70 el desarrollo de la "escuela francesa" de sociología urbana, integrada entre otros por Lefebvre, H., Castells, M. y Topalov, Ch, y en planificación el auge del proyecto urbano a partir de la recuperación de los centros históricos, una mediación entre el plan de urbanismo y el proyecto de arquitectura. Esto se fundamenta en que su impacto va a ir más allá que su propia entidad ayudando a reactivar sectores de ciudad. El argumento de los impulsores radica en la imposibilidad real de los planes para operar en el conjunto, a diferencia de los proyectos urbanos que son más acotados en recursos y extensión.

\subsubsection{Redes, Planes Estratégicos y competitividad}

Finalmente, en una última etapa, la descentralización presupuestaria e institucional y las políticas desregulatorias pegan un nuevo salto. Es el momento de los planes estratégicos con el caso emblemático del plan de Barcelona para los Juegos olímpicos de 1992. La lógica del plan estratégico que viene del mundo empresarial instala la idea de competencia entre ciudades para el desarrollo en un mundo globalizado con mayor peso del capital en las administraciones estatales. La vivienda toma relevancia y se instalan los grandes proyectos urbanos en áreas centrales mientras que las problemáticas de la periferia quedan en un segundo plano. 
En Argentina es un periodo de alto crecimiento de barrios privados en áreas periféricas de las grandes ciudades, sobre todo de la ciudad de Buenos Aires. El caso emblemático es el barrio Nordelta $^{5}$ por ser uno de los más grandes del país y por las múltiples denuncias de ambientalistas, académicos y vecinos por las constantes inundaciones que se producen a raíz de la modificación del territorio que se aplicaron en este tipo de emprendimientos inmobiliarios. Según la Federación Argentina de Clubes de Campo ${ }^{6}$ en 2011 existían 700 barrios privados en el país con 300.000 habitantes y para 2014 la cantidad de urbanizaciones ascendía a 1.000, de las cuales 800 se situaban en la Provincia de Buenos Aires. Como contracara de esta situación, se han multiplicado exponencialmente las villas miserias, asentamientos y barrios precarios en las periferias; en 2016 la cantidad de familias viviendo en estas condiciones ascendía a 788.425, según datos de TECHO (2016).

Este desarrollo abrupto de las periferias con predominancia residencial ha aumentado las distancias de viaje, ha incrementado los índices de congestión y dificultado la racionalización del transporte público ineficiente. Es decir, estas características contradictorias de la ocupación de la periferia han vuelto más crítica aun la problemática de la movilidad y del transporte de personas y en particular a los tiempos de viaje, una variable muy importante para el desarrollo de la vida cotidiana tanto de sectores de ingresos medios y altos como para los más empobrecidos. Las respuestas desde la planificación se han limitado a la construcción de infraestructura de tipo autopistas y, en algunas pocas ciudades, la implementación de carriles exclusivos de transporte público.

\subsubsection{Debate sobre la planificación integrada de uso de suelo y transporte.}

La planificación integrada de transporte y usos del suelo es un tema muy discutido en ámbitos académicos y de gestión a nivel internacional desde hace varias décadas, pero así como en relación al concepto de movilidad, existen distintos interpretaciones o aplicaciones según el contexto social, histórico, económico, político de la ciudad y del país.

5. Situado en el municipio de Tigre al norte de la Área Metropolitana de Buenos Aires (AMBA) que funciona desde el año 2000 cuando se vendió la primer vivienda.

6. Red de Countries, Barrios privados, Clubes de Chacras, Clubes de Campo. Centro de acopio de información y experiencia, jurisprudencia. Asesoramiento jurídico, gremial, tributario. Promoción y defensa de los intereses de los Conjuntos inmobiliarios en todo el país. 
Según Gakemheimer ${ }^{7}$ (2006) en la actualidad existe un mayor acuerdo en la necesidad de la planificación para facilitar la movilidad con mayores divergencias en torno al uso del suelo, sobre todo a partir del debate abierto en 1997 en la revista Journal of the American Planning Association entre Reid Edwing ${ }^{8}$ por un lado y Peter Gordon ${ }^{9}$ junto a Harry Richardson ${ }^{10}$ por otro.

Ewing (1997), Cervero ${ }^{11}(2001)$, Rueda ${ }^{12}$ (1997) y otros plantean limitar forzosamente la expansión del desarrollo urbano y planificar el diseño y el alcance de los usos del suelo, con el fin de acortar los trayectos y promover modelos de transporte responsables desde un punto de vista social, el uso racional del espacio urbano, con medidas como la peatonalización, reducción de tráfico rodado, ciclismo, servicios de transporte público, estacionamiento regulado, etc.

Por otro lado, existen posturas aludiendo a que la expansión urbana no hace aumentar significativamente los costos de transporte o de las infraestructuras, ni tampoco provoca un aumento sustancial de los niveles de contaminación o de consumo de combustible. Asimismo, argumentan que la expansión urbana se rige por ventajas de índole económica y de estilo de vida, y que no está limitada a medios prácticos. Dicha argumentación se basa en una visión específica de la economía urbana y una generalización de patrones urbanos más que en la composición de los usos de suelo de la ciudad. Plantean que se puede reducir el impacto ambiental generado por el mayor consumo energético y emisiones de gases contaminantes producidos por un aumento en las distancias de viaje y en el uso del automóvil, mediante mejoras tecnológicas y por restricciones del uso de vehículos mediante un control de costos de combustibles. Esta posición es defendida por autores como Gordon y Richardson (1989), así como también Liffmann, Huntsinger, y Forero (2000) y Sanderson (2013).

Es importante mencionar que este debate se ha propiciado sobre todo en Estados Unidos, donde las tasas de motorización son muy altas, no se percibe falta de terrenos para cultivo ya que la industria tiene mucho peso en la economía y donde la planificación del transporte no

\footnotetext{
7. Ralph Gakemheimer, Departamento de Estudios Urbanos y Planificación, Massachusetts Institute of Technology.

${ }^{8}$. Reid Ewing, Department of City and Metropolitan Planning University of Utah, Estados Unidos de América. Departamento de la ciudad y metropolitano de panificación. Universidad de Utah, EE.UU.

9 . Peter Gordon, University of Southern California, Los Angeles, Estados Unidos de América.

${ }^{10}$. Harry Richardson, University of Southern California, Los Angeles, Estados Unidos de América.

11. Robert Cervero, Institute of Urban and Regional Development, University of California, Berkeley, Estados Unidos de América.

12. Salvador Rueda, Director de la Agencia de Ecología Urbana, Universidad de Cataluya, Estado Español.
} 
sigue criterios políticos, y por lo tanto (se argumenta) durará en el tiempo, como plantea Gakenheimer, R, (2006).

A pesar de que el debate continúa abierto, la postura que impulsa la necesidad de planificar el crecimiento de las ciudades de manera controlada, en función de criterios de movilidad racional y sostenible (argumentadas desde las problemáticas generadas vinculadas al calentamiento global, la contaminación ambiental y la congestión) fue ganando peso en la academia y ocasionalmente en algunos planes producidos por oficinas técnicas de gestión urbana de países europeos como Alemania o Francia. Esta tendencia plantea la necesidad de planificar el uso de suelo con el fin de reducir los tiempos de transporte, acortar trayectos y promover el uso del transporte público mientras éste se planifica y se crean las infraestructuras necesarias.

Pero el desacople con la implementación de estas ideas se debe al peso que tienen en el territorio ( $\mathrm{y}$ en su planificación y/u ocupación) los sectores inmobiliarios y empresas vinculadas al transporte (por ejemplo la industria automotriz y de explotación de servicios). Por otro lado, el rol del Estado suele aparecer como garante de estas lógicas que tienden a querer maximizar la rentabilidad empresarial por sobre los derechos urbanos de la población, permitiendo a los agentes del mercado que determinen los puntos de demanda de transporte y organizan las políticas de servicios de transporte con el objetivo de facilitarlo, mientras continua la dependencia sobre todo de la tecnología del automóvil. Además, en países de fuerte dependencia económica externa, como son los latinoamericanos, los criterios de financiación de los organismos internacionales de crédito para proyectos de incidencia directa territorial tienden a reforzar el rol que los Estados están cumpliendo en esa dirección.

En este sentido, desde Traffic in Towns elaborado por Buchanan, C (1963) en adelante, existen estudios que demuestran que la ampliación de la infraestructura vial como principal política de movilidad y transporte es una medida que mejora algunos índices de congestión y tiempo de viaje de manera circunstancial, pero profundiza el problema en un largo plazo. Si el aumento de las vías desacoplado de una planificación consciente de la ocupación del suelo que limite al mercado inmobiliario, se produce un rápido crecimiento urbano de tipo disperso, monofuncional, de muy baja densidad y con servicios públicos deficientes, entre ellos el de transporte, , lo que incrementa las distancias y los tiempos de viaje, alienta un mayor uso del automóvil particular y ocasiona un nuevo ciclo de saturación de las vías de comunicación. Es 
decir, un desarrollo de baja densidad y áreas de grandes vías aumentan la duración del viaje y llevan a una mayor participación de viajes en automóvil, como sugiere Petersen, R (2006).

Además, según Petersen, R (2006) al ser el espacio urbano un espacio limitado, desde el punto de vista físico y normativo, el aumento del espacio viario compite con espacios públicos dedicados a las actividades que dotan a la ciudad su valor de uso singular, tales como espacios colectivos de recreación, relajación, distracción e interacción, espacios verdes que además aportan a proveer condiciones de vida saludable al limpiar el aire contaminante, absorber ruidos, ayudar a regular la humedad y temperatura. En ese marco, la planificación integrada de los usos del suelo y transporte con criterios de movilidad sustentable están orientadas a mantener un equilibrio entre el crecimiento histórico de las urbes y ambientes urbanos vivibles en armonía con la naturaleza.

Es por ello que resulta preocupante el aumento en el uso del automóvil y la ampliación constante de infraestructura vial para transporte ya que es cada vez mayor la porción utilizada de suelo urbano en general y de los espacios colectivos en particular. Las ciudades con altas tasas de motorización utilizan para las vías una proporción mayor del espacio urbano. Así por ejemplo en EE.UU., en algunas ciudades japonesas y europeas los porcentajes promedios oscilan entre el 15\% y el 25\%. A su vez, como menciona Petersen, R (2006) se puede observar que si bien las sociedades con altos índices de motorización han dedicado mayores proporciones de espacio para el automóvil, la densidad de población ha descendido.

Como plantea Miralles- Guasch, C (2010), el problema de la forma de la ciudad y la densidad para lograr una ciudad más sostenible desde el punto de vista económico, ambiental pero también desde la búsqueda de la democratización de los sistemas de transporte y la visión de la movilidad como un derecho y no un privilegio, fue estudiado por primera vez por Newman y Kenworthy (1989). Estos autores además estudiaron que tanto la centralidad, la densidad, la presencia de infraestructura viaria y la facilidad para estacionar, eran los factores determinantes para el uso del automóvil. Precisamente siete años después R. Cervero (2002) demuestra que la distancia de viaje entre la vivienda y el trabajo es importante a nivel consumo, y que, por lo tanto, las áreas monofuncionales hacían aumentar el número de desplazamientos largos. También Cervero (2002) plantea a partir de un estudio en varias ciudades de Estados Unidos que la distancia a infraestructuras de transporte también tiene un efecto modificador de la movilidad. Según su relevamiento las personas que vivían a más de 900 metros de una estación de tren, usaban ese medio de transporte un 50\% menos que los 
que tenían su vivienda a 150 metros. Según Haedicar y Curtis (1998) una situación similar se da en personas que utilizan más el automóvil si residen cerca de una autopista o vía jerarquizada.

Por todo lo mencionado, la planificación de los usos del suelo es muy importante para alentar la utilización de determinados modos de transporte por sobre otros, pero tanto MirallesGuasch (2010) como Petersen (2006) plantean que la planificación de usos de suelo, densidad y forma no son suficientes para comprender los desplazamientos. Según Kitamura (1997) y Stead (2001) citados por Petersen (2006) la estructura social económica también tiene un peso importante. En base a sus estudios afirman que representa un 50\% de la variación de la movilidad. Teniendo en cuenta esto hay varios autores como Hanson (1982), Naess (1993) y Cervero (1996) que coinciden en que mientras mayores son los ingresos de una familia más se usa el automóvil. Pero por otro lado Petersen (2006) en su informe menciona la existencia de ejemplos en Singapur, Hong Kong y ejemplos europeos como Zurich en Suiza donde el transporte público puede ganar alta aceptación en ciudades con altos ingresos. Es claro que la “densidad de población” desarrollado por Newman y Kenworthy (1989) y UITP (Asociación Internacional de Transporte Público) no es el único elemento a tener en cuenta para orientar el transporte urbano al transporte público, sino que otros aspectos de la forma urbana son importantes, como la mixtura de usos, anchos de calles y de veredas, espacios colectivos agradables y otras cuestiones propias del diseño y la planificación urbana, tales como las subcentralidades. Las estructuras urbanas de este tipo limitan el espacio para el automóvil y dan más lugar al uso del transporte público, la bicicleta y la caminata (Petersen, 2006).

En función de lo expuesto es que resulta fundamental analizar distintos casos de aplicación de la planificación integrada de uso de suelo y transporte tanto en el contexto europeo como latinoamericano y argentino enfatizando en el caso de estudio, la Micro Región del Gran La Plata.

\subsubsection{Planificación integrada en el ámbito Europeo.}

Europa es sin dudas, la región con más desarrollo en términos de planificación de la movilidad con una perspectiva integrada de usos de suelo y transporte. Desde lo normativo, existen ejemplos más desarrollados los cuales se sitúan en Alemania, Francia y Holanda donde existen normativas nacionales que promueven la planificación integrada. 
En Holanda, según Petersen, R. (2006), se reglamentó que las ciudades con más de 100.000 habitantes deben realizar planes de uso de suelo que partan de criterios de movilidad, distribuyendo el área urbana en tres categorías $\mathrm{ABC}$ :

A) Localizaciones en las que se pueda acceder a transportes públicos locales, regionales y nacionales, donde el uso del automóvil para ir al trabajo deberá estar entre el 10\% y 20\% de la población. Estas áreas son restringidas para oficinas con muchos empleados o visitantes

B) Localizaciones que pueden acceder tanto por medio del transporte público local, regional como también a automóviles. En estas áreas la proporción de ir al trabajo en automóvil no debe superar el 35\% de los viajes, y se planifica para instituciones u oficinas donde el personal dependa del auto particular para desarrollar su tarea y

C) Áreas de fácil acceso de automóvil pero con menos transporte público, hogares donde las actividades principales son las industriales.

Por su parte, Francia posee desde 1982 una normativa que fomenta el desarrollo del transporte público por sobre el privado, también para ciudades mayores a los 100.000 habitantes. Los primeros planes fueron en Nantes y Grenoble con el principal objetivo de acompañar el desarrollo del tranvía en un momento en que la dinámica de la ciudad se desarrollaba en función del automóvil. Pero los últimos PDU (Planes de Desplazamiento Urbano) como el desarrollado en Estrasburgo, Nantes o Montpellier, han avanzado en incorporar la planificación del crecimiento de la ciudad en cortas distancias, con politicas de gestión del estacionamiento, como así también de incentivo de la caminata y el uso de bicicleta, con criterios de mejoramiento de la salud mediante el ejercicio corporal y de reducción del consumo energético, como se ve en Merle, N. (2013).

En Alemania el área administrativa de Transportes Públicos Regionales (RMV) viene impulsando en los últimos 20 años cambios de normativa en distintas ciudades alemanas a favor de la densificación de áreas próximas a los polos principales de transporte público. En Frankfurt por ejemplo, la RMV adoptó desde 1996 un esquema para el desarrollo de las estaciones de ferrocarril como centros de intercambio con la densificación de sus inmediaciones.

Más allá de estas buenas normativas y planes de movilidad, un estudio reciente de la Comisión Europea de Transporte y Movilidad (Transport White Paper, 2013) plantea los 
objetivos de movilidad sostenible para el área de la Unión Europea, en el que reconoce que las ciudades con más de 100 mil habitantes están lejos de tener un sistema de transporte competitivo en relación al uso del automóvil, eficientes en recursos, definidos por niveles de congestión, accidentes, ruidos y emisiones de CO2. Para alcanzar este objetivo, el documento plantea que las ciudades deberán implementar un número de medidas de usos de suelo, comportamiento de transporte e infraestructura de transporte aceptando que cada ciudad es única, que no existe un único paquete de medidas óptimo que pueda lograrlo y que la solución objetiva es la implementación de enfoques integrados de movilidad urbana. A modo de balance, el informe plantea que las ciudades europeas están avanzando en la integración de la movilidad urbana, que el desarrollo ha sido positivo en los últimos 10 años pero que pocas o casi ninguna de las ciudades implementó un plan de integración de movilidad urbana “perfecto". Algunas ciudades específicas muestran una planificación del transporte urbano en un nivel avanzado, aunque planificadores de transporte y también varios investigadores, plantean la falta de coordinación como un desafío singular.

\subsubsection{Situación de la planificación integrada en América Latina y Argentina.}

En los países periféricos las perspectivas marcadas por altos índices de pobreza, crecimiento histórico de la población urbana, crecimiento de las manchas urbanas en baja densidad e infraestructura urbana deficiente, son distintas a la de los países centrales. Según Figueroa, O (2005) esta situación se da más fuertemente desde los años ' 80 y sobre todo en los '90 con las políticas económicas basadas en una mayor concentración de riquezas de los sectores de mayores ingresos, de privatizaciones de los principales resortes de las economías, de flexibilización laboral y recortes presupuestarios de los Estados, todo lo cual ha llevado en América Latina a una crisis (entre otros ) de los sistemas de transporte público.

Pero a partir del crecimiento económico a nivel global de principios de este siglo, el incremento de las demandas sociales y la crisis del neoliberalismo en la región desde el año 2000, llevó a los organismos internacionales de crédito a fomentar el endeudamiento para obras de infraestructura relacionadas al $\mathrm{BRT}^{13}$. A nivel del sector transporte se expresó en la implementación de reestructuraciones de los sistemas de transporte con el llamado "boom" de los BRT en América Latina, como plantean Zamora, U., Campos, H., y Calderon, J. (2013). Estas reestructuraciones fueron importantes con respecto a las políticas anteriores donde el

13. En ingles "Bus Rapid Transit”, o Autobús de Transito Rápido. 
presupuesto vinculado a áreas de transporte y movilidad se utilizó casi exclusivamente para la construcción de infraestructura para el automóvil particular. Pero por otro lado, estas políticas estuvieron desligadas de una planificación del crecimiento de la ciudad en general y sus políticas de usos de suelo, las cuales, en la mayoría de los países de América Latina continuaron las lógicas neoliberales.

Este auge de los BRT en la región se inicia desde finales de los '90 principios de '00 a partir de una recuperación del Plan Maestro de Curitiba Brasil de finales de los '60, aunque con una gran debilidad en la planificación conjunta con la de los usos del suelo. En 1995 se construye el primer ramal de BRT en Quito y luego existe una seguidilla de implementaciones del sistema en otros países de la región. Por ejemplo, en 2003 se impulsa el "Transmilenio" de Bogotá y el "Interligado" de Sao Paulo, en 2005 en México DF, en 2006 en las ciudades de Pereira y Guayaquil, luego se implementa el sistema en Guatemala en 2007, en Lima en 2009 y en 2011 si introduce el Metrobus en la ciudad de Buenos Aires. Estos son algunas de las 54 ciudades que poseen el sistema en América Latina, que a su vez concentran el $60 \%$ de los pasajeros que a nivel global se trasladan en los sistemas BRT (Global BRT Data, 2018).

Desde el punto de vista de la intervención urbana Estatal en áreas de transporte, lo que sigue primando en América Latina es la construcción de infraestructuras, vías jerarquizadas para el transporte automotor en general y los BRT a nivel transporte público. Pero desde el punto de vista académico las visiones sobre la problemática están más divididas. Por un lado, las áreas vinculadas a la ingeniería se enfocan en el estudio del funcionamiento de esas infraestructuras en función de la movilidad de las ciudades desde una mirada afianzada en los datos cuantitativos de la oferta, de la demanda y niveles socioeconómicos característicos de la realidad latinoamericana. Por otro lado, Scholl et al. (2016) analizan la accesibilidad (posibilidad de acceso, tiempo de viaje, distancia y costos) y asequibilidad (costo en función de los ingresos del hogar) a partir de comparar los efectos de los sistemas BRT de Lima y Cali sobre los sectores más pobres de esas ciudades. Los autores llegaron a la conclusión de que la cercanía a la red y el tiempo de viaje pero sobre todo la tarifa son determinantes en la aceptación y la usabilidad del sistema. En el caso de Lima donde no existe boleto combinado y la red se encuentra a mayor distancia de los barrios más pobres, el uso del BRT se da mayoritariamente entre los sectores medios y medios bajos, a diferencia de Cali donde la utilización de los más empobrecidos es mayor, existe boleto combinado y la cercanía a la red es mejor. De todas formas, según los autores, la utilización del sistema por parte de los 
sectores más pobres es solo para viajes muy necesarios y de mucha distancia (trabajo o educación).

También desde la academia es interesante el estudio de accesibilidad territorial de Escobar García, D., Cadena, C. y Salas, A. (2015) para el caso de Manizales, Colombia, que analizan el tiempo de viaje desde distintas áreas de la ciudad a los distintos Nodos de Actividad Primaria (NAP) que brindan las principales necesidades de la comunidad: salud, educación, recreación, seguridad y que fueron definidos por el Plan de Ordenamiento Territorial local.

Gráfico 1. Distribución de porcentajes de área urbana, cantidad de población y de viviendas cubiertas según tiempos de viaje a los distintos NAP de salud, educación, recreación y seguridad. Fuente: Escobar García, D., Cadena, C. y Salas, A. (2015).
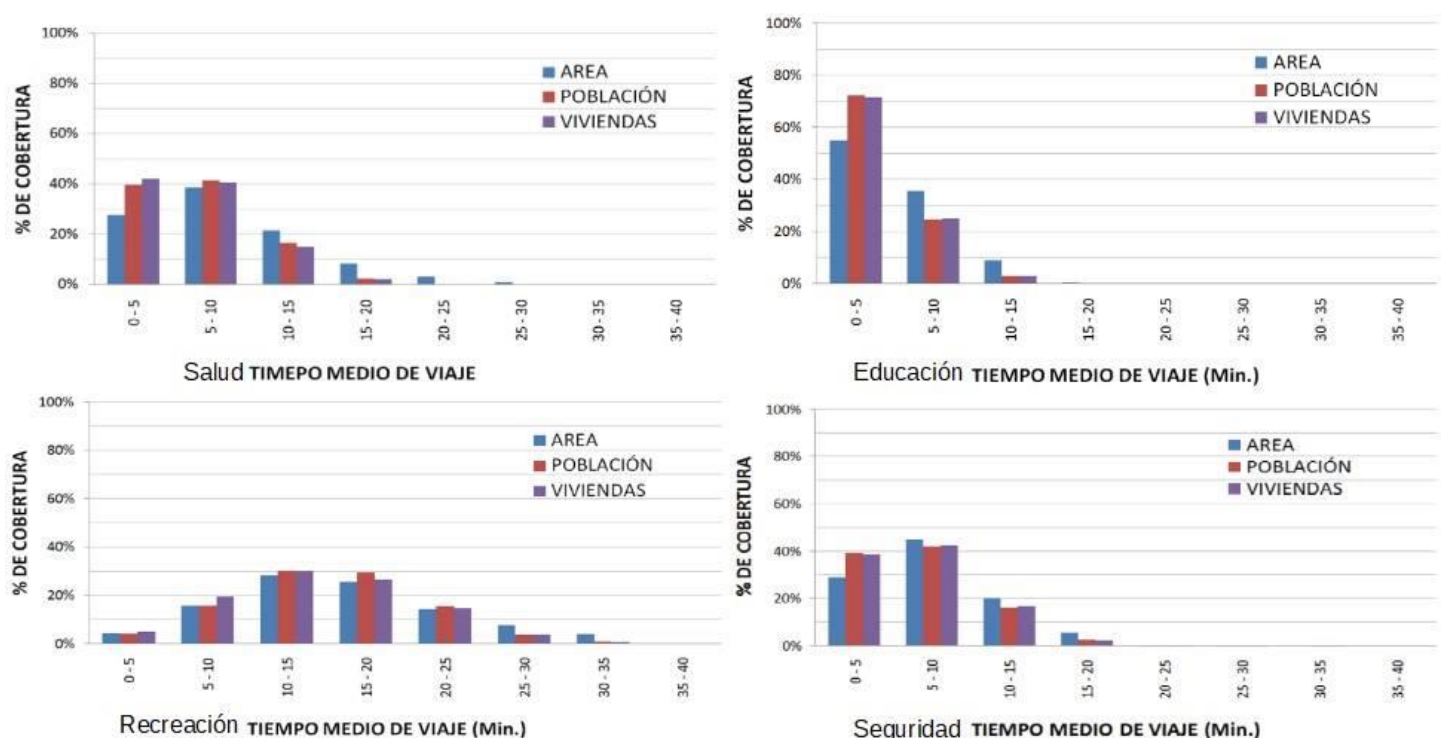

En el Gráfico 1 se puede observar la distribución de tiempo de viaje a los distintos tipos de NAP en Manizales, donde los nodos de educación muestran una mayor accesibilidad en tiempos de viaje, luego los correspondientes a salud, seguridad y por ultimo recreación. Este análisis permite dimensionar, a partir de la variable tiempo de viaje, los niveles de descentralización de actividades de servicio de una ciudad que permitan planificar el crecimiento de la ciudad, identificando la necesidad de nuevos NAP, limitando la expansión urbana de baja densidad y utilizando herramientas de planificación que permitan densificar en las zonas de mayor acceso a los NAP.

Martín Hansz Riva (2016) retoma la metodología de Graham Currie,(2010) quien estudia áreas urbanas con desventajas en transporte de diferentes ciudades de Australia, y asocia ese 
concepto con características sociales de diversos grupos de la población, tales como la edad, acceso a transporte privado, ingresos, capacidades físicas, desempleo, nivel de estudios y distancia de residencias al centro de la ciudad. Esta metodología es replicada primeramente en Latinoamérica por Jaramillo, J., Lizarraga, C. y Grindlay, A. (2012) para Santiago de Chile, pero incorpora, como otra característica a tener en cuenta, la capacidad de pago de las personas. A partir de ello, Hansz Riva, M. (2016) construye una serie de indicadores tomando a Montevideo como caso de estudio

Por otro lado, los estudios vinculados a las ciencias sociales, que poseen en América Latina una fuerte tradición vinculada a comprender y problematizar la pobreza, la exclusión y la desigualdad, han desarrollado en los últimos años algunas investigaciones que integran esta tradición con la movilidad a partir del estudio de casos con grupos sociales reducidos y sobre todo desde la metodología cualitativa.

Un ejemplo es la investigación realizada por Gutiérrez, A. (2009) sobre la movilidad por salud, en particular a los viajes que realizan un grupo de 34 embarazadas adolescentes de bajos recursos residentes en los partidos de Pilar y General Rodríguez ubicados en la Provincia de Buenos Aires. Otro es el realizado por Avellaneda, P. y Lazo, A. (2011) que investigan la relación entre transporte público y exclusión social a través de entrevistas en los barrios populares Juan Pablo II en el municipio de San Juan de Lurigancho en Lima y en el sector El Castillo en la comuna de La Pintana en Santiago de Chile. Estos aportes novedosos son importantes para la comprensión más precisa de los problemas en la vida cotidiana que genera las complicaciones de movilidad para los sectores más excluidos.

Desde lo académico es interesante la reciente publicación del libro "Manual sobre metodologías de estudio aplicables a la planificación y gestión del transporte y la movilidad" compilado por Gutiérrez, A. (2017) donde se pone en relación a nueve metodologías para la construcción de información de transporte y movilidad, tanto cuantitativas como cualitativas. Esta publicación es de gran relevancia ya que tanto en el país, como en la región, la información que permita hacer diagnósticos para poder planificar es muy escasa a pesar que desde la academia se han llevado adelante metodologías originales y diversas.

En Argentina la intervención estatal en las áreas de transporte público tiene mayor tradición de planificación en la ciudad de Rosario. Desde el año 2011, esta ciudad impulsa el Plan Integral de Movilidad que asume un cambio de paradigma. Entre los cambios más 
importantes se podrían citar el cambio del Ente de Transporte de Rosario (ETR) por Ente de Movilidad de Rosario (EMR) con mayores injerencias que solo el transporte público y una mayor articulación con las áreas de planeamiento urbano del municipio. Si bien no se ha logrado aún una planificación altamente integrada, se lograron avances con respecto al resto de las ciudades del país. De esta manera actualmente la ciudad cuenta con carriles exclusivos, tarifa por tiempo y no por viaje, boleto combinado, tecnología aplicada al transporte público y la construcción de indicadores a partir de la información que provee la base de datos de la Tarjeta Sin Contacto (TSC).

Por otro lado, a nivel nacional una de las políticas estatales que más modificaron al transporte público fue la implementación de la tarjeta $\mathrm{SUBE}^{14}$ que funciona en varias provincias del país y que plantea la posibilidad de ser utilizada como una herramienta que facilite el trasbordo y la integración con distintas ciudades, además de ser una fuente de información que, en caso de ser procesada, podría ser muy útil para construir indicadores que permitan ser herramientas para la planificación del transporte público urbano en todo el país.

En Buenos Aires, la extensión del sistema BRT en los últimos años, quedó acotada (como el Metro Bus de Buenos Aires) a la implementación de carriles exclusivos en los corredores urbanos más congestionados de las ciudades (ver Ilustración 1). Los resultados desde el punto de vista de lo urbano fueron sobre todo la mejora de los tiempos de viaje del transporte público colectivo y un impacto urbano positivo desde el punto de vista de la movilidad.

14. Sistema Único de Boleto Electrónico, comenzó a funcionar en 2011 en el AMBA y se extendió a toda la Provincia de Buenos Aires, Catamarca, Chaco, Chubut, Corrientes, Entre Ríos, Formosa, Jujuy, La Pampa, Misiones, Neuquén, Rio Negro, San Juan, San Luis, Santa Cruz, Santa Fe y Tierra del Fuego. 


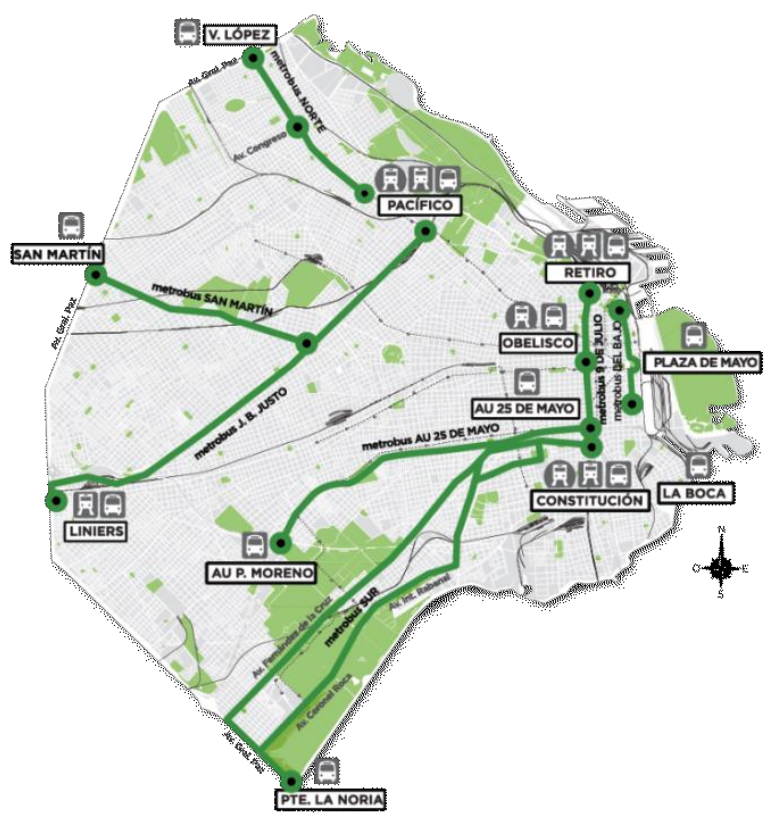

Ilustración 1. Mapa red de Metrobus Ciudad Autónoma de Buenos Aires. Fuente: Página oficial del gobierno de la ciudad. www.buenosaires.gob.ar/movilidad/metrobus/servicios-del-metrobus.

Tabla 2. Longitud, pasajeros beneficiados y reducción de tiempo de viaje de la red de

Metrobus $\boldsymbol{C A B A}$. Fuente: Elaboración propia en base a información disponible en la web oficial del gobierno de la Ciudad Autónoma de Buenos Aires www.buenosaires.gob.ar/movilida.

\begin{tabular}{|c|c|c|c|}
\hline Metrobus & Longitud (Km) & $\begin{array}{c}\text { Pasajeros } \\
\text { beneficiados }\end{array}$ & $\begin{array}{c}\text { Reducción de } \\
\text { TV (\%) }\end{array}$ \\
\hline Juan B Justo & 12 & 150000 & 40 \\
\hline 9 de Julio & 3 & 255000 & 50 \\
\hline Sur & 23 & 250000 & 20 \\
\hline AU 25 de mayo & 7,5 & 120000 & 50 \\
\hline Norte 2 & 2,8 & 250000 & 35 \\
\hline Norte & 5 & 200000 & 32 \\
\hline San Martin & 5,8 & 70000 & 20 \\
\hline Bajo & 2,9 & 300000 & 45 \\
\hline
\end{tabular}

Como lo muestra la Tabla 2, la reducción en tiempos de viaje, según corredor fue entre el $20 \%$ y el $50 \%$. Al no existir una política de usos de suelo que proponga densificar en torno a dichos corredores a partir de instrumentos de recuperación de plusvalía de los propietarios de mayores recursos que se vieron beneficiados de la intervención, se perdió una oportunidad para propiciar soluciones movilidad de un mayor alcancen temporal. Por un lado de iniciar un proceso de planificación integrada de usos de suelo y transporte, o la de crear un fondo especial para el financiamiento de dicha planificación. Por el contrario se aprovechó el costo relativamente bajo de estas infraestructuras, financiado por organismos internacionales de 
crédito, y se permitió que el mercado inmobiliario a través de la valorización del suelo, captase toda la rentabilidad de la intervención.

Justamente, la buena aceptación de estas infraestructuras desde los usuarios y los distintos gobiernos municipales que ayudaron a que se replicara de forma creciente en muchas ciudades de la región, radica en que significan un cambio importante inmediatamente desde su implementación. Sin embargo, según algunos autores como Ventura I Teixidor, Nunes da Silva, Castro García (2016) sistemas como el Metrobus no son buenos para demandas superiores a los 15.000 viajeros/hora/sentido ya que los sistemas de control de pago y acceso limitan la capacidad de gestionar ágilmente los flujos de entrada y salida. La infraestructura actúa como barrera entre zonas de la estructura urbana y dificulta el acceso de los usuarios y la adaptabilidad a personas de movilidad reducida. Es decir que su potencialidad decae en la medida que la ciudad crezca o se incremente la cantidad de viajes.

En base a los límites expuestos de la adaptación del BRT en América Latina en los últimos años, se puede decir que si no hay una planificación del sistema de transporteen conjunto con el desarrollo urbano que permita mantener (o aumentar evolutivamente) la demanda de viajes a determinadas zonas atractoras de viaje, es una solución cortoplacista que puede ser muy crítica en el mediano y largo plazo si se tienen en cuenta los altos índices de crecimiento de la urbanización del territorio de manera dispersa, monocéntrica, y también de población urbana que viene registrando América Latina.

\subsubsection{El caso de estudio: la Micro Región del Gran La Plata}

En este marco, el caso de estudio propuesto, la micro región del Gran La Plata, compuesta por los municipios de La Plata, Berisso y Ensenada, refleja algunas de las tendencias generales de las ciudades latinoamericanas a pesar de tener la particularidad de que su ciudad cabecera se planificó antes de su fundación.

A lo largo del siglo XX la ciudad ha evolucionado sin una planificación integral, transitando los cambios político-económicos más agudos del periodo, sin prácticas sostenidas de planificación. Su desarrollo económico y territorial se vio condicionado desde sus inicios por la actividad productiva de la región a partir de corredores de crecimiento. En primer lugar los que la conectan con la ciudad de Buenos Aires, y en segundo lugar por los que se vinculan 
con áreas de perfiles más productivos en las primeras décadas de la fundación desde la ciudad en 1882 .

Desde ese año hasta mediados del siglo XX, el avance en la ocupación territorial fue dando cuenta de estas tracciones de la capital del país, desarrollándose patrones diferenciados de ocupación sobre los ejes noroeste y sudoeste. Sin embargo en 1948, con la promulgación de la ley de propiedad horizontal, se intensificó el uso del suelo residencial en el casco fundacional, con incidencia en ciertos sectores de las periferias. En ese momento el Estado tomó control de las concesiones de tranvía mientras que entró en escena el transporte colectivo automotor como emprendimiento privado, para satisfacer una demanda local de viajes que acompañó al crecimiento urbano a lo largo de la segunda mitad del siglo XX y comenzó a desplazar al sistema de tranvías compitiendo por recorridos, hasta eliminarlo completamente en 1966, como desarrollan Aón, L., Giglio, M.L. y Cola, C. (2016).

De esta manera se inicia la gestión privada del transporte público en la ciudad a la vez que, hacia fines de los años '80, comienza a intensificarse la ocupación del territorio y el uso del automóvil. A partir de entonces, empieza a ser más notoria la problemática urbana producida por la desarticulación entre las políticas de uso del suelo, el proceso de ocupación del territorio y la planificación y gestión de la movilidad de las personas y las cosas

El resultado crítico de estas operaciones particionadas y desarticuladas comenzó tempranamente a afectar a los valores funcionales y estéticos fundacionales. A principios de la década del '60, el municipio dio cuenta de la pérdida de rumbo de la ciudad planificada, convocando al grupo URBIS para definir un Plan Regulador para la micro región que ya en ese momento incluía a Berisso y Ensenada. El plan se desarrolló con todas las componentes de integralidad de ocupación territorial y movilidad para la ciudad y para la región, aunque finalmente no se llevó adelante. Su único legado fue la creación de la oficina de planeamiento urbano del municipio de La Plata. Desde entonces, el único instrumento de planificación con que han contado los partidos de La Plata, Berisso y Ensenada es la normativa de usos de suelo y, en el caso de La Plata, el Código de Ordenamiento Urbano ${ }^{15}$ basado solo en densidades y alturas máximas por zona.

${ }^{15}$. COU. Normativa de usos de suelo del Partido de La Plata que contempla zonificaciones, densidades, alturas permitidas y jerarquización de vías. 
Actualmente, en el caso de las áreas centrales se observa una creciente pérdida de su patrimonio histórico arquitectónico, un marcado deterioro del espacio público y del ambiente urbano por la presencia del automóvil como modo de transporte principal y un despliegue de torres en pequeños lotes urbanos que reducen significativamente la luz del sol directa y aumentan la contaminación del aire, provocando además un brusco recambio poblacional y de prácticas urbanas tradicionales de vecindad.

En la periferia el proceso se reconoce en su dispersión y fragmentación, sin una planificación integral del Estado, con vacíos y vacancias, cavas, arroyos, tramas de calles irregulares y agrupamientos de viviendas de distintas calidades con bajos niveles de consolidación, que se desarrollan como grandes barrios dormitorio, sin equipamientos ni centralidades, sin espacio

público y en ocasiones sin servicios urbanos, sin infraestructuras de circulación adecuadas y sin transporte público.

\subsubsection{La variable "tiempo" en la movilidad}

Como se planteó en los apartados anteriores, el tiempo de viaje en el transporte es un factor importante para la movilidad a lo largo de la historia, se haya tenido en cuenta o no para pensar políticas de planificación urbana. En efecto el "tiempo de viaje" es una expresión física, tecnológica, económica y social de los muy diversos modos posibles (históricamente determinados), para gestionar y resolver la fricción que las distancias territoriales introducen en la conexión y el relacionamiento entre las personas y entre sus actividades. En general, las principales propuestas en esta dirección en tiempos recientes han consistido en la amplificación de la infraestructura existente y la incorporación de desarrollos tecnológicos e innovaciones tecnológicas a los modos de transporte para incrementar la velocidad y así reducir los tiempos de desplazamiento. También como se mencionó, el nivel socio económico de los habitantes tiende a ser un factor determinante para acceder a las posibilidades de reducir la duración de los traslados.

Desde otra perspectiva, Teresa Torns (2004) afirma que deberían - desde el Estado desarrollarse estudios de cuantificación de los tiempos de viaje para mejorar la calidad de vida de las personas. La escasez de tiempo es una constante tanto en los países centrales como periféricos, y está asociado al tiempo de trabajo necesario para el sustento de la economía del hogar. Como resultado de las políticas de flexibilización, a los sectores medios bajos y bajos de la población la jornada laboral de ocho horas no resulta suficiente para obtener los ingresos 
necesarios para tener una buena calidad de vida, y muchas veces para lograrlo, realizan horas extras o encaran otros trabajos y/o impulsan la participación de más miembros del hogar en el mercado de trabajo. Si bien, en términos económicos, el tiempo de los sectores de mayores ingresos "vale" más por ser mejor pago, tienden a tener mayor tiempo para el ocio y recursos para poder desprenderse del trabajo doméstico, y optar entre distintos modos de transporte según su conveniencia. En los hogares de menores ingresos el tiempo para el trabajo doméstico y actividades recreativas o descanso es más reducido, y las opciones de modo de transporte también. Estas situaciones intervienen, junto con muchos otras, en la complejidad de la movilidad de la ciudad.

Según Miralles-Guasch, C (2011) el tiempo de la movilidad está compuesto por dos aspectos: i. espacial y ii. temporal.

El aspecto espacial se conoce como el uso de la ciudad y se vincula a lo que ya se mencionó sobre la utilización del tiempo para acceder a las distintas actividades localizadas en el territorio, como el trabajo, lugares de compra, instituciones educativas o de salud. Este aspecto está relacionado tanto a las áreas de planificación de los usos del suelo y ordenamiento del territorio, como también a la construcción de infraestructuras viales y de la gestión del transporte que determinan los tiempos de desplazamiento.

En cambio el aspecto temporal, si bien es complementario al espacial, tiene en cuenta la utilización del tiempo de desplazamiento como parte del conjunto de las actividades cotidianas y se lo analiza como parte del uso social del tiempo. Desde ésta óptica, el tiempo de la movilidad tiene que valorarse desde una perspectiva global de los tiempos desde la realidad cotidiana de la población de la ciudad, en competencia o complementariedad, del conjunto de las actividades que consumen tiempo.

Desde el aspecto espacial del tiempo de viaje y las dinámicas de desplazamiento y proximidad (medida en tiempo entre punto de origen a punto de destino) Miralles-Guasch, C., Cebollada, A. y Requena, R. (2010) realizan un análisis en Barcelona donde la densidad bruta de habitantes es de $22.000 \mathrm{hab} / \mathrm{km} 2$, con un $16 \%$ de la superficie urbana ocupada por servicios (el pequeño comercio domina la estructura comercial), equipamientos sanitarios y educativos, distribuidos en todos los barrios. Plantean que esa estructura urbana es lo que le permite que el $32 \%$ de los desplazamientos se realicen en menos de 10 minutos, y que el $47 \%$ de los viajes se puedan hacer a pie, lo que a su vez, beneficia al comercio de proximidad, diversifica las posibilidades de desplazamiento y resultan más productivos. 
Cabe destacar que la realidad socioeconómica es un factor importante en las decisiones de movilidad. Según el estudio de Miralles-Guasch, C., Cebollada, A. y Requena, R. (2010) los mayores índices de proximidad en Barcelona se encontraron tanto en las zonas más ricas como en algunas más pobres. Las diferencias se basaron en los modos utilizados, ya que en los barrios ricos, a pesar de tener viajes menores a 10 minutos, alrededor del $76 \%$ de la población lo hace a pie, mientras que en los barrios más pobres este porcentaje es superior. Estos índices son atípicos en comparación con el resto de las ciudades y se debe fundamentalmente a una muy fuerte tradición histórica de planificación integrada, sobre todo del tipo espacial.

En Argentina, las encuestas de origen y destino impulsadas por PTUMA (2009) ${ }^{16}$ incorporan un relevamiento sobre la distribución horaria del viaje donde también registran la variable el tiempo de viaje. Por ejemplo, la encuesta realizada en Rosario en 2008 demostró un promedio de viaje de 22,7 minutos y una distancia media de 4,6 $\mathrm{km}$ donde se pudo evidenciar una diferencia importante en tiempo de viaje por nivel socio económico ya que los sectores de ingresos altos tienden a realizar viajes más cortos y de menor duración que los de menores ingresos; incluso, a la misma distancia, los habitantes de estratos bajos tardan más tiempo en llegar a destino. La encuesta también muestra que la población que realiza viajes por trabajo que vive en las periferias tarda 90 minutos para ir y volver a su lugar de residencia.

Por otro lado, en Salta la encuesta demostró que en esa ciudad la dispersión urbana y la monocentralidad inciden en el tiempo de viaje mucho más que el nivel socio económico, ya que tanto el quintil más alto como el más bajo tienen un promedio de viaje de 25 minutos, mientras que los viajes dentro del centro tienen un promedio de 15 minutos, dentro del partido 29 minutos y hacia las zonas conurbanas 40 minutos. Otro factor importante para el tiempo de viaje en esta ciudad es el modo de transporte utilizado. Por ejemplo desde el conurbano de Salta al centro el tiempo de viaje en transporte público relevado por la encuesta es de 41 minutos, mientras que en taxi es 15 minutos y en auto particular 25 minutos.

El mismo estudio para la Región Metropolitana de Buenos Aires, segmenta los viajes por etapas. Muestra que el $89 \%$ realiza su viaje en 1 etapa y demora 30 minutos, mientras que los que lo realizan en más de una etapa tardan 90 minutos promedio por viaje. Para el caso de los 
que tienen mayores distancias y utilizan transporte publico deben realizar su viaje en un número mayor de etapas llegan a tardar 144 minutos. Estos datos dejan en evidencia que la intermodalidad es un déficit de la planificación del transporte desde la perspectiva del tiempo de viaje en el RMBA. Sin dudas estos estudios son una buena base para mejorar las políticas de movilidad, transporte y desarrollo urbano para cada ciudad relevada, sin embargo no han sido el caso. Desde el aspecto temporal de la movilidad se conocen pocas experiencias de intervención Estatal, como la iniciativa plasmada en proyecto de ley en Italia de los años '90 conocida como "Ley del Tiempo" destinada a regular el tiempo de los municipios de más de 30000 habitantes, los horarios de los servicios municipales, de las escuelas, de los transportes, de los comercios y de las empresas con el fin de reducir al máximo posible el uso de tiempo innecesario en la vida cotidiana, como son los tiempos de espera en la administración y el utilizado en la movilidad.

Por el contrario, desde el aspecto espacial del tiempo en la movilidad se puede mencionar el sistema de indicadores que impulsa desde el 2014 de manera anual el Departamento de Estadísticas de Accesibilidad del Reino Unido. En este caso la buena o mala accesibilidad de la población se mide según la cercanía al valor promedio de tiempo que se tarda en auto, transporte público, bicicleta o a pie, en acceder desde determinadas áreas de residencia a ocho tipos de actividades que consideran clave: centros de empleo (chicos, medianos y grandes), escuelas primarias, secundarias, otras instituciones educativas, salas sanitarias, hospitales, lugares de compra de alimentos y el centro de la ciudad. Además de manera más reciente han desarrollado indicadores de conectividad utilizando también la variable tiempo de viaje a grandes nodos de conexión como aeropuertos, estaciones de tren y rutas nacionales o regionales. Estos indicadores podrían ser insumos eficaces para planificar la forma de crecimiento de la ciudad entre los usos del suelo y las actividades de manera integrada con la planificación de la movilidad urbana.

En otra realidad muy distinta, en Portland ${ }^{17}$ con la intención de favorecer el comercio de menor escala, barrial, el municipio impulsa desde hace unos años el concepto de "barrio 20 minutos" donde el trabajo, las escuelas, los centros comerciales, restaurantes, parques y entretenimientos están a menos de 20 minutos de caminata desde las viviendas. Si bien solo el $11 \%$ de los barrios de Portland cumple con este concepto, el municipio plantea que en su ciudad se utiliza un $20 \%$ menos el auto que en otras ciudades de EE.UU. de tamaño similar y

17. Ciudad en el noroeste del Estado de Oregon, Estados Unidos de América. 
plantea que por este motivo los habitantes se ahorran 850 millones de dólares, se reduce el congestionamiento y el impacto ambiental. El programa tiene un plan de expansión hacia el conjunto de la ciudad hacia el año 2030. Iniciativas similares se están desarrollando actualmente en las ciudades de Sydney y Melbourne, en Australia.

\subsection{Marco teórico}

El marco teórico de este trabajo de investigación parte de considerar al territorio como un sistema complejo, en el que sus elementos y subsistemas se interdefinen (García, 2006), y son modelados a través de la relación y los conflictos entre intereses sociales contrapuestos, emergentes de la relación cultura - naturaleza, y considerando asimismo al sistema de transporte como una configuración compleja de la relación socio-territorial emergente, condicionada por las características del medio y la participación de los actores políticos, económicos y sociales que configuran el territorio y cada uno de los subsistemas que lo componen.

Las contribuciones más tempranas de Ludwing Von Bertalanffy a su monumental "Teoría General de los Sistemas" se inicia en 1940 y fueron desarrolladas durante esa década. El "Significado de la teoría general de los sistemas" es de 1956 y la primera edición unificada de todos los principales componentes de la Teoría (editorial Penguin, UK) se remonta a 1968. La primera edición en español de la Teoría salío por Fondo de Cultura Económica en 1976. Ver Von Bertalanffy, L. (1976).

\subsubsection{La teoría general de sistemas en la ciudad y transporte.}

El primer modelo matemático de representación de las ciudades como un sistema complejo (Urban Dynamics) fue elaborado por Jay Forrester y publicado (MIT Press) en 1969 y demuestra que los principales aspectos críticos del funcionamiento de las ciudades son generados por fuerzas y condicionamientos internos y no pueden ser solucionados atacando sus síntomas externos. En relación a la teoría general de sistemas en la ciudad y el transporte, Karol y Fernández (2008) ayudan a comprender las características formales por la cual se considera a la ciudad como un sistema abierto ${ }^{18}$.

18. Según los autores la teoría general de sistemas tiene como uno de sus objetivos identificar estructuras en distintos niveles de la realidad que permitan encontrar leyes generales que puedan aplicarse para comprender su 
Pero la ciudad, además de ser un sistema abierto es también un sistema complejo. García, R. (2006) afirma que en las problemáticas complejas están involucrados el medio físicobiológico, la producción, la tecnología, la organización social y económica, cuyos procesos e interrelaciones constituyen un sistema que funciona como una totalidad organizada e interdependiente. Es decir que es necesaria una visión interdisciplinaria para poder abordar la problemática de este tipo de sistemas. Lejos de ser la suma de perspectivas disciplinarias sobre cada una de las componentes del sistema, lo interdisciplinario radica en la metodología necesaria para el estudio de un sistema complejo. En el presente trabajo esta mirada sistémica se canaliza a partir de las distintas dimensiones cuya vinculación se investiga a través de las diversas metodologías cualitativas y cuantitativas utilizadas para el análisis de cada una de sus variables.

En ese marco, las componentes y variables de los sistemas y sub-sistemas sociales, económicos-culturales y ambientales-urbanos claramente incluyen a las componentes y variables del transporte como son las infraestructuras, el parque automotor, el sistema de organización urbano espacial para la circulación y funcionamiento de los diferentes modos de transporte. Estos componentes y variables mencionadas se abordarán aquí desde una mirada específica que los considera instrumentos de la movilidad urbana, en la que se combinan necesidades y deseos de desplazamiento, prácticas y experiencias de los habitantes del sistema urbano y de los diversos patrones de movilidad de los hogares en torno a las diversas localizaciones territoriales de los polos atractores y generadores de viajes.

\subsubsection{El transporte y la movilidad en la ciudad.}

comportamiento y dinámica. El segundo objetivo es poder definir los mismos conceptos y términos para describir los rasgos principales de sistemas reales muy diferentes entre sí. La ciudad se puede considerar un ejemplo de sistema real, ya que este tipo de sistemas son entidades materiales conformadas por partes o componentes organizados y que interactúan entre sí de tal manera que las propiedades que tiene el conjunto del sistema no puede deducirse completamente con el solo hecho de conocerse las propiedades de las partes o componentes de ese sistema. Teniendo en cuenta esto, esta teoría analiza la dinámica de los sistemas que además se despliegan a través de procesos históricos, no pueden ser comprendidos sin conocer y tener en cuenta su particular trayectoria en el tiempo, que se vinculan directamente con poder comprender como y porqué se relacionan y cuáles son sus cadenas causales (Karol, Fernández, 2008).

Es decir que esta teoría pone especial énfasis en la comprensión de la naturaleza de las relaciones entre las partes o componentes de un sistema. Esta aproximación al conocimiento permite trascender el abordaje analítico disciplinario, construyendo abordajes transdisciplinarios que busquen identificar las propiedades comunes a sistemas presentes en todos los niveles de la realidad.

Los autores plantean que para poder analizar la dinámica de los sistemas reales es necesaria la comprensión clara de sus límites, salidas y entradas, y que pueden darse tres tipos de sistemas reales: aislados, cerrados y abiertos. Dichos sistemas se definen según su nivel de interacción con su entorno, siendo los abiertos los que poseen mayor interacción, de energía, información y materia en términos comparables. Indudablemente, las ciudades son ejemplos de sistemas (urbanos) de alto orden de complejidad. 
Ahora bien, en el sistema capitalista la ciudad cumple un rol importante en la valorización del capital. Según Gutiérrez, A. (2005) "el proceso de valorización en el capitalismo tiene ciertas particularidades que definen su forma de producir espacio" y cita a Ciccolella, P (1993) para afirmar que la producción capitalista se caracteriza por tres necesidades estructurales a) la expansión, en términos económicos (diversificación) y territoriales (nuevos mercados, ampliar fronteras), b) el incremento de la tasa de ganancia y c) la concentración de los medios de producción y del capital. Como conclusión la autora plantea que "la valorización del capital y del espacio en el capitalismo puede resumirse en la dinámica de dos movimientos opuestoscomplementarios: expansión y concentración.”

Fernández Duran (1980, citado por Gutierrez, A. 2005) plantea que la estructura urbana de las ciudades está determinada por la división (económica y social) del espacio y también por la forma de producción del espacio urbano (promoción inmobiliaria, intervención estatal, etc.). Estos procesos se dan gracias a que en el capitalismo el suelo es un tipo especial de mercancía, como expuso Marx, C. (1867) regido por un valor de uso y de cambio expresado en el precio o renta del suelo que está determinado por la localización y accesibilidad generada por el sistema de transporte. En este marco el transporte público como servicio cumple el rol de mejorar la accesibilidad entre distintas áreas de la ciudad o inter ciudades, pero a su vez es parte de la valorización del suelo de esas áreas.

Justamente el concepto de movilidad, que contiene al de accesibilidad, lo desarrolla primeramente la Escuela de Sociología Urbana francesa que desde una perspectiva marxista aborda el estudio de las desigualdades sociales a nivel espacial y al transporte con un rol importante en la segregación socio espacial, como plantea Gutierrez, A. (2005).

La definición de movilidad que se abordará en este trabajo es la desarrollada por Gutierrez A. (2009) que la entiende como "una práctica social de viaje que conjuga deseos y necesidades de desplazamiento (que en conjunto pueden definirse como requerimientos de movilidad) y capacidad de satisfacerlos. De su interacción resultan las condiciones de accesibilidad de grupos sociales, sea de sí mismos o de sus bienes. Según la autora, esa práctica de viaje se realiza en el territorio e implica una frecuencia de realización con un patrón de desplazamiento en un contexto social, espacial y temporalmente determinado

Este concepto difiere al de solo transporte que hacer hincapié en el modo utilizado para realizar el viaje. En ese sentido los estudios focalizados sólo en el transporte abordan la 
problemática del viaje realizado, en tanto la movilidad estudia la necesidad (y la viabilidad) de desplazamientos de distintos grupos sociales en el territorio, se realice o no el viaje. En ese marco Gutiérrez, A. (2009) considera tres universos de análisis para la movilidad según la relación del individuo con el viaje en el contexto social en que se desarrolla: los pensados, es decir la "movilidad concebida", los reales o "movilidad realizada", y por último los posibles denominados "movilidad posible".

La "movilidad concebida" es de difícil abordaje desde la planificación del transporte, pero es muy útil para comprenderla subjetividad y cultura de las personas que inciden en la toma de decisiones de movilidad. Tener esto en cuenta puede ser de gran ayuda para pensar propuestas que mejoren la movilidad. En esta escala, podría decirse que tradicionalmente desde la planificación del transporte se aborda el problema de la movilidad realizada, desde la oferta de transporte. Desde las concepciones de la planificación integrada de usos del suelo y movilidad se intenta orientar el crecimiento urbano pensando también en la posibilidad de desplazamiento de los grupos sociales en el territorio, es decir pensando en orientar la demanda de transporte. Los estudios de caso o intervenciones de este tipo también utilizan el término de accesibilidad y utilizan la distancia a los modos o el tiempo de desplazamiento de determinadas áreas urbanas, aunque muchas veces no son los determinantes en un contexto social complejo. Según Cervero, R. (2013), existen estudios que demuestran que la cercanía a determinado modo de transporte fomenta o dificulta su utilización

Para finalizar podemos decir que, en las teorías originales clásicas del transporte se abordaron condicionantes sociales y económicas de la movilidad, de las personas y hogares, acorde a su organización, estructura familiar y localización residencial, desde los primeros estudios realizados hasta hoy. Sin embargo es justo señalar que muchos otros estudios cuantitativos y espaciales de transporte, las han omitido total o parcialmente, focalizando en los efectos espaciales de congestión que los patrones de movilidad producen en las ciudades.

En ese marco, la mirada sistémica de la ciudad que propone esta tesis permite comprender la relación interdependiente entre los usos del suelo y la movilidad, de la cual el transporte es instrumento, y en ese marco la necesidad de una planificación integrada entre ambos. Además esta perspectiva permite el análisis de la movilidad en diversas dimensiones complementarias, de las cuales la variable tiempo de viaje es parte..

\subsection{Fundamentación, hipótesis y objetivos del trabajo}




\subsubsection{Fundamentación}

La relación entre políticas de producción/ocupación del suelo, de movilidad y de transporte resulta clave para la planificación del desarrollo urbano de las ciudades medias y grandes si consideramos dos aspectos importantes. Por un lado los patrones generales de uso del suelo y las actividades que se desarrollan en el territorio (junto con las tasas de generación de viaje) definen en gran medida el volumen de pasajeros transportados. Por otro lado, la exigencia sobre las infraestructuras de transporte el tamaño del volumen de la demanda, va a variar según el tipo de actividad localizada y la intensidad del uso del suelo en cuestión. Ambos aspectos claves para la planificación urbana desde una perspectiva que integra usos de suelo y transporte, lo son para formular escenarios de crecimiento de mediano y largo plazo que tiendan a resolver una de las problemáticas que atraviesan nuestras ciudades históricamente y que se agudizan en la medida que pasan los años, que se expresa en la forma del crecimiento por expansión en la periferia y por densificación en las áreas centrales urbanas.

A pesar de que la planificación integrada de uso de suelo y transporte es un concepto desarrollado incipientemente desde Von Thunen (1820) y más acabado a la actualidad, su implementación efectiva en la gestión urbana es muy acotada..

Desde el año 2003, en contexto de la Unión Europea, se está comenzando a introducir un concepto operativo de planificación de transporte hacia uno de planificación más amplio a partir de integrar profesionales con perfiles diversos (Portal UE citado en Aón, Cola, Giglio, 2014). Estas nuevas orientaciones en áreas de planificación de transporte llevan a una ampliación y diversificación de los equipos técnicos tradicionales formados casi exclusivamente por ingenieros de transporte. En este marco, la tradición proyectual orientada a mejorar la oferta de transporte se comienza a desplazar hacia una práctica de planificacióngestión de la demanda de movilidad, lo que implica la formación de técnicos en movilidad de nuevo tipo. Estas modificaciones en las áreas tradicionalmente de transporte, también implicarían una reestructuración de las áreas de planeamiento y gestión en general, como plantean Aón, L., Cola, C. y Giglio, M.L. (2014).

En cuanto a las Políticas de Transporte en particular, varios países europeos como Dinamarca, Finlandia y Alemania, están desarrollando aplicaciones financieras para redistribuir recursos que antes se utilizaban para proyectos de infraestructura con la intención de direccionarlos para financiar estudios que generen pautas de gestión, disuasión y orientación de la demanda 
de la movilidad, con la intención de consolidar estos enfoques y puntos de vista con proyecciones al largo plazo. Ejemplo de esto trata el informe del Portal UE Transporte y Usos de Suelo (2003) que da cuenta de algunos casos europeos en los que, en vez de subvencionar proyectos de construcción o mejoras de infraestructuras para la circulación de automóviles financiados mediante impuestos a las empresas, se solicita a éstas que inviertan y subvencionen los sistemas de transporte público.

Desde lo técnico, en nuestra región y en nuestro país, no se han encarado cambios como los reseñados: todavía el enfoque sigue estando centrado sobre la infraestructura de transporte, por lo que los equipos técnicos se conforman bajo esos criterios. A pesar de que el sistema de transporte público esté fuertemente subsidiado, no se expresa en lo concreto un interés por parte del Estado por mejorar los procesos de gestión-planificación en todas las escalas territoriales. En nuestro país, de la misma manera que la planificación y gestión del suelo, el transporte público esta signado por un fuerte protagonismo del sector privado, con un Estado a veces colaborador, otras veces sin interés de control, con visiones del territorio anclados en criterios económico-sociales neoliberales. En el caso del partido de La Plata, la sola planificación de cada una de estas dos grandes dimensiones territoriales pone en juego intereses privados históricamente arraigados en lo territorial y político, cuya evolución y desplazamiento no han variado significativamente a lo largo de su historia de planificación. En cambio, es la fortaleza del Estado Planificador de los tiempos de la fundación lo que efectivamente se ha transformado a medida que avanzó el siglo XX y hasta nuestros días, habiendo crecido el protagonismo de los sectores privados frente a los sectores públicos, como herencia del Estado neoliberal que cobro fuerza a partir de la última dictadura cívico militar, en contextos de progresivo crecimiento de la presión sobre el suelo y de la ciudad y del predominio de los intereses y posibilidades de los sectores inmobiliarios, que hoy dominan la escena del desarrollo urbano.

A pesar de que ésta problemática es abordada en los ámbitos académicos desde los años '80 donde se relata, explica y ejemplifica las articulaciones entre transporte y uso de suelo en ciudades, se puede observar que casi de manera generalizada en el ámbito técnico político de los gobiernos de nuestro país y de nuestras ciudades, el transporte y la movilidad continúan calificando como "políticas sectoriales” en el ámbito de la gestión pública territorial, y cuando se planifica, se lo hace de manera aislada de las políticas de suelo. Las barreras que impiden su integración constituyen un problema que esta enraizado en la estructuración político institucional de los gobiernos, especialmente los municipales que tienen la responsabilidad de 
la planificación territorial. Este problema es muy evidente en el caso de la ciudad de La Plata, en el que actualmente operan por separado las áreas de planeamiento, de transporte, de tránsito y de ambiente, con el agravante de desarrollar la normativa última ${ }^{19}(\mathrm{C} 10)$ de usos de suelo, no solamente desvinculada de todo estudio territorial y de transporte sino además por fuera de la oficina de planeamiento de la municipalidad local.

El problema de desacople entre usos de suelo y transporte sin embargo, claramente excede al tema de los organigramas de gobierno municipal, dado que su integración para la mejora de la movilidad urbana, requeriría del desarrollo de estudios complejos para el diseño de instrumentos normativos articulados con dimensiones estructurales, como lo son la forma urbana y la gestión de las distancias a través de políticas e instrumentos de transporte público, subsidios, infraestructuras de circulación, demandas de movilidad y tendencias y alternativas de futuros crecimientos urbanos. La complejidad de tal abordaje requiere de información y de formación de recursos humanos para llevarla a cabo. En este sentido se observa un particular vacío en el ámbito municipal y provincial expresado en una escases generalizada de personal técnico, de dispositivos de construcción de información y de desarrollo y aplicación de instrumentos de planificación, de presupuesto, tanto en el ámbito de planeamiento como en el de transporte.

Esta omisión, podría pasar algo más inadvertida en ciudades pequeñas y/o de tradición ordenada, sin embargo en casos como La Plata, ciudad media de alta complejidad, y con los valores de población y automóviles de la actualidad, la falta de equipos técnicos en número necesario para tal objetivo y formados para abordar el estudio conjunto de las dinámicas territoriales y proponer cambios acordes a los resultados, resulta de una gravedad creciente día a día.

En función de lo expuesto, la tesis evalúa el modo y el grado en que la variable tiempo de viaje puede contribuir a la mejora de la planificación y la gestión de la movilidad, partiendo de considerarlo efecto de distancias entre actividades (con su incidencia en el consumo energético y por ende en la racionalidad económica), velocidades de los modos de transporte, frecuencias del transporte público, características de la infraestructura, niveles de congestión y por ende parque automotor y particiones modales, y a su vez consecuencia de parte de las decisiones de movilidad de la población. El tiempo que una persona tarda en llegar de un

\footnotetext{
${ }^{19}$. Código de Ordenamiento Urbano del Municipio de La Plata, modificado en 2010.
} 
punto a otro de la ciudad, de una actividad a otra, cobra gran importancia cuando determina los niveles de acceso a determinadas actividades y sobre todo cuando esas actividades son considerados derechos adquiridos como son el trabajo, la salud, educación, una vivienda o descanso. En ese marco, estudiar el tiempo de viaje en el transporte masivo entendido como un servicio público es de una relevancia aún mayor. De esta manera lo perciben los usuarios del sistema de transporte público de La Plata, donde los reclamos por las malas frecuencias ocupan el primer lugar en cantidad de quejas recibidas al municipio.

El tiempo de viaje en transporte público considera el tiempo empleado hasta llegar a la parada de colectivo, la espera, la duración del trayecto del recorrido que el pasajero realiza en la unidad y el tiempo que tarda desde la parada de colectivo donde descendió hasta el lugar de destino. De todos los momentos que componen el tiempo de viaje en transporte público, el eje central de las quejas de los usuarios radica sobre todo en el momento de la espera al servicio en la parada.

Ahora bien, se evidencio que las malas frecuencias del transporte público tienen como trasfondo la imposibilidad de los choferes de cumplir con la duración del recorrido que exigen los permisos de explotación del servicio por diversos motivos externos a su desempeño como conductor $^{20}$. Más allá del conflicto legal que genera que no se respeten los permisos de explotación del servicio entre el municipio y las empresas concesionarias, la complejidad de la problemática tiene raíces en la deficiente planificación de la movilidad y en las complicaciones para orientar las transformaciones urbanas marcadas por la necesidad del crecimiento. Son estas las dimensiones que motivaron la inquietud de este trabajo y son las que se intentarán desarrollar.

Esta dificultad para lograr el cumplimiento de los tiempos de recorrido pactados en las normativas en un contexto urbano de menores distancias de viaje y congestión, lejos de ser un aspecto más entre otros como la antigüedad o características de los coches en los contratos de concesión del servicio, es el desencadenante de muchos de los problemas que atraviesa el transporte público de la región. Uno de ellos es la imprevisibilidad del servicio por la variabilidad de los tiempos de espera en las paradas y también la duración del viaje en transporte público. Sobre todo la extensión de los tiempos del viaje, ya que generan impuntualidad del servicio y dificultades a los usuarios para llegar a destino, especialmente

\footnotetext{
20. Situación reconocida luego de instancias metodológicas cualitativas a través de talleres participativos con los choferes de todas las líneas de transporte colectivo de la región.
} 
para los pasajeros que deben cumplir horarios estrictos para llegar al trabajo, a alguna institución educativa o de salud. Es decir que esta situación le demanda al usuario más tiempo para movilizarse que -cuando el objetivo del pasajero no radica en el disfrute del viaje sino en llegar a destino- repercute negativamente en la posibilidad de realizar otras actividades de la vida diaria, ya sean productivas o reproductivas.

Otro de los problemas que se genera a partir de la extensión del tiempo de espera, es una mayor concentración de pasajeros en las paradas y hacinamiento en las unidades. Esta saturación del servicio se expresa en incomodidad de los pasajeros, con mayor riesgo de accidentes para menores de edad o personas con movilidad corporal reducida por tener que viajar varios minutos parados con la unidad en movimiento.

En este marco de compleja solución, las empresas prestadoras del servicio trasladan a los conductores la presión por cumplir el tiempo de viaje legal para evitar acumular posibles sanciones del Estado por el incumplimiento de frecuencias. Esta situación implica que los choferes tengan que utilizar el tiempo de descanso que poseen entre servicios como variable de ajuste. En algunas ocasiones es la misma empresa la que reduce el descanso de los choferes para poder cumplir el tiempo del recorrido y las frecuencias, o también extiende la jornada laboral de los choferes para poder completar los servicios. Ante esta situación los choferes adoptan estrategias propias para tratar de evitar la extensión de su jornada laboral, la disminución del tiempo de descanso entre servicios reglamentados y las dificultades de manejo que ocasiona conducir un colectivo que supera ampliamente su nivel de ocupación de pasajeros sentados y parados.

Éstas medidas que adoptan para poder sobrellevar las presiones cotidianas muchas veces entran en conflicto directo con los usuarios y las normas de tránsito. Por ejemplo, los mismos choferes reconocen que no paran en todas las paradas que les corresponde o que se adelantan algunos minutos a la salida del servicio desde la terminal produciendo modificaciones en la frecuencia del servicio; o tratan de aumentar la velocidad de la unidad lo máximo posible para recuperar tiempo, incrementando las probabilidades de cometer o provocar accidentes viales ( a veces incluso violando leyes de transito básicas, como pasar semáforos en rojo) o mayores dificultades para los pasajeros para subir, bajar o mantener el equilibrio en los colectivos.

Esta situación empuja a los usuarios a buscar modos alternativos al transporte público que garanticen mayor grado de previsibilidad, puntualidad, seguridad y comodidad. Dichos modos 
suelen ser los no masivos, sobre todo el automóvil particular que registra un aumento importante en su tasa de motorización (los patentamientos de automóvies nuevos tienen su registro máximo en la Provincia de Buenos Aires en 2013). Es decir que la tendencia de la población que puede elegir entre usar el transporte masivo o el no masivo, se inclina por el segundo. Además de los problemas que ocasiona en la movilidad urbana la utilización del automóvil - ya desarrollados en innumerables trabajos desde perspectivas diversas - plantea una situación particularmente crítica para la población que no tiene otra alternativa que movilizarse en transporte público y padecer las problemáticas que lo atraviesan.

Por otro lado, a pesar de los aspectos negativos del sistema ya mencionados, la cantidad de viajes en transporte público sigue creciendo e incluso ha avanzado en proporción al auto en relación a las años '90, es decir que la magnitud del problema se incrementa en el sentido de afectar directamente a una porción más grande de la población.

Como se puede evidenciar, es una problemática con múltiples repercusiones y las condiciones $\mathrm{y}$ determinantes se pueden encontrar en diversas dimensiones y en varios niveles. Uno de ellos corresponde a los aspectos económicos que hacen al financiamiento del sistema de transporte, a su racionalidad económica, pero al tratarse de un servicio público que el Estado administra (ya sea entregando la concesión a privados, con empresas estatales o mixtas) lo que sucede en el ámbito técnico-político, en las oficinas de planeamiento urbano y de transporte, es de una importancia aún mayor.

El municipio de La Plata, a pesar de ser una ciudad planificada aun antes de su fundación, posee una histórica orientación política de poco control al sector privado concentrado que interviene en el territorio. Tal es así que el transporte público colectivo surge como iniciativa privada en el año 1934, y comienza a competir con los recorridos más rentables del tranvía que, siendo una tecnología novedosa en ese entonces, había posicionado a la ciudad como de avanzada en América Latina en materia de transporte público. Con el paso del tiempo en el año 1966 el sistema de transporte público automotor reemplazó completamente al tranvía y pasó a ser el único transporte masivo de la ciudad.

Pero la competencia por los recorridos más rentables no cesó. Esta situación llevó a una crisis del sistema en las áreas con menor demanda de pasajeros de las periferias a fines de los 90 . En el año 2000 el municipio propuso una reestructuración del sistema dividiendo las áreas de cobertura de la ciudad y le entregó a cada empresa un área con el objetivo de reducir la 
competencia entre las mismas. Con mucha resistencia de empresarios y del gremio, el plan de la dirección de transporte no logró implementarse en su totalidad. A su vez el área municipal de Transporte fue reduciendo progresivamente su presupuesto y personal técnico. Más allá de esta reestructuración que ocasiono muchos problemas en su implementación, existe históricamente una carencia de equipos técnicos, planes de desarrollo urbano y movilidad, un déficit importante en la planificación del transporte público en general y muy alejado de dimensionar la importancia de la componente tiempo en particular.

Una situación similar sucede con el área de planeamiento urbano conformada en los años 90 y que como criterio general se ha apoyado en el desarrollo inmobiliario en el casco y las periferias, sin una planificación integrada del crecimiento, lo que dio como resultado una ciudad monocéntrica, dispersa y mayormente homogénea en el uso residencial en las periferias.

Como se mencionó, las características del modelo de financiación del transporte público marcaron aspectos importantes de los problemas del sistema. Históricamente el financiamiento provino de los ingresos generados para las empresas en función de la cantidad de pasajeros transportados (ya sea por la venta de boletos y por subsidios) donde las problemáticas a resolver estaban marcadas por la alta competencia de las empresas por los recorridos más rentables. En la actualidad el subsidio estatal tiene un peso importante en el funcionamiento de sistema de transporte por sobre el ingreso por boleto vendido. Las compensaciones no son más por pasajero transportado y, aunque existen subsidios a la demanda (jubilados, escolares y discapacidad), el índice que se utiliza para el monto subsidiado es el kilómetro recorrido por empresa en base a un kilometraje estático acordado entre municipio y empresas según cantidad de unidades funcionando y pasajeros transportados al momento de la implementación del nuevo sistema de reparto de subsidios.

En este caso la racionalidad empresarial de maximización de ganancias se asienta de manera especulativa sobre los subsidios recibidos por kilómetro recorrido, que se expresa en la cantidad de unidades funcionando y el tiempo de recorrido legal, que en la mayoría de los casos está congelado desde la implementación subsidios por kilómetro al actual sistema de transporte reestructurado en el 2000. Esta situación tiene como efecto que no se cumplan aspectos de los contratos de concesión del servicio referidos a la cantidad de unidades funcionando y la cantidad de unidades necesarias para cumplir las frecuencias pautadas, ya 
que al incorporar más unidades crecerían la cantidad de kilómetros recorridos de la empresa por los cuales no recibiría subsidio.

Como se mencionó, existen deficiencias normativas de parte del Estado nacional y municipal para mejorar la reglamentación de la gestión y financiamiento del transporte público que se expresa en la desactualización del sistema de asignación de subsidios en relación a las transformaciones urbanas que experimentó la ciudad, concretamente en el tiempo legal estipulado para cada recorrido basado en el tiempo por vuelta necesario de hace 20 años atrás.

Esas transformaciones urbanas no tenidas en cuenta en las normativas y que inciden en la imposibilidad de que se cumplan los tiempos de recorrido tienen que ver con un aumento de la congestión vehicular en las áreas centrales de la ciudad producto de un aumento del uso del automóvil desde la periferia al centro pero también de las distancias de viaje promedio, es decir con el aumento de las distancias entre las actividades cotidianas y la residencia.

Como se mencionó anteriormente, el desarrollo urbano del Gran La Plata monocéntrico y disperso en las periferias está orientado por los instrumentos de planificación municipal que facilitan la libre expansión del mercado inmobiliario especulativo. La única herramienta utilizada es el código de ordenamiento urbano (COU) que incentiva la proliferación de torres en el micro centro, y al mismo tiempo a través de ordenanzas se favorece la construcción de urbanizaciones residenciales alejadas.

Es por ello que resulta fundamental y necesario la formulación de pautas de planificación integrada de uso de suelo y transporte que hagan foco en la problemática derivada de los tiempos asociados al transporte público, ya que es una variable sensible a la confluencia de los aspectos negativos del incremento del parque automotor, las tasas de generación de viajes por hogar, el desarrollo de crecimiento monocéntrico y disperso en las periferias, la gestión empresarial, municipal y la política del Estado nacional a través del subsidio, la calidad del viaje y tiempos de espera y las condiciones de trabajo de los choferes.

En función de la problemática enunciada, se postulan la siguiente hipótesis de trabajo para orientar el presente trabajo de tesis:

\subsubsection{Hipótesis.}


La integración de las políticas de desarrollo urbano y movilidad incorporando al tiempo de viaje como variable de ajuste, permitirá a partir de escenarios alternativos del sistema de transporte público masivo y usos de suelo, generar pautas de planificación orientadas a equilibrar la actual situación de sobre oferta en áreas centrales y déficit en áreas periféricas.

Finalmente, la hipótesis planteada requiere su verificación y o corroboración a partir del cumplimiento de los siguientes objetivos generales y específicos.

\subsubsection{Objetivos}

\section{Objetivo General}

Elaborar pautas de planificación mediante la construcción y ensayo de escenarios de transporte público de pasajeros del Gran La Plata focalizando en el tiempo de viaje como variable critica que permite integrar la movilidad y el desarrollo urbano.

\section{Objetivos específicos}

1- Analizar los aspectos de la variable "tiempo de viaje en transporte público" que la vuelve critica en la relación transporte masivo - crecimiento urbano a partir del análisis de las tendencias que configuran la ciudad fragmentada en general y el Gran La Plata en particular.

2- Caracterizar las lógicas política, económica y social que motorizan las dinámicas de crecimiento y ocupación del suelo, relacionadas a la movilidad, su efecto en el transporte público y el tiempo de viaje.

3- Formular y evaluar escenarios alternativos de mediano plazo de transporte público y desarrollo urbano, tomando tiempos de viaje en transporte público como variable principal.

4- Generar pautas espaciales, temporales y económicas para la planificación integrada del transporte público de pasajeros del Gran La Plata.

\section{Síntesis del Capítulo I}


En este primer capítulo se plantearon los principales debates alrededor de la planificación integrada de uso de suelo y transporte, focalizando en la variable "tiempo de viaje en transporte público”. Además se recorrieron algunos ejemplos europeos, de América Latina y Argentina. También se abordó el marco teórico sobre el transporte público en la ciudad entendida como sistema complejo, dentro del cual el tiempo es un factor importante muy poco estudiado como instrumento de análisis de los sistemas urbanos y como variable destacada para generar propuestas que mejoren la relación entre la movilidad y el desarrollo urbano. En ese marco se problematizó el transporte público del Gran La Plata abordando tanto los problemas espaciales, sociales como también los de gestión municipal y empresarial. Por último, se plantearon las hipótesis y objetivos del trabajo. En función de lo expuesto, el siguiente capítulo plantea la metodología desarrollada para la construcción y ensayo de escenarios integrados de transporte público masivo, uso y producción de suelo. 


\section{CAPITULO II: METODOLOGIA PARA LA CONSTRUCCION Y ENSAYO DE ESCENARIOS INTEGRADOS DE TRANSPORTE PÚBLICO MASIVO Y USO Y PRODUCCION DEL SUELO}

\section{Resumen}

En el presente capítulo se describe la metodología para la construcción y ensayo de escenarios que integran transporte público masivo y usos del suelo. Se comienza con el desarrollo de la metodología para la construcción del año base el cual resulta un componente fundamental para la posterior elaboración de los escenarios tendencial y alternativos.

La construcción del año base se realiza a partir de una descripción del desarrollo urbanoterritorial y su relación con los usos del suelo y el transporte público del área de estudio, y de un análisis de las problemáticas de planificación y gestión, y de las dimensiones involucradas. Para esta tesis se plantea un año base anclado temporalmente en el período 2013-2014, años en los cuales el Grupo 2 de Movilidad, Ambiente y Terriotorio del IIPAC-CONICET-UNLP condujo una novedosa encuesta de movilidad con base en la web en centros atractores urbanos que permitió obtener datos actualizados de movilidad para el Gran La Plata.

Para la construcción del escenario tendencial, se plantea un escenario a mediano plazo, con proyección al 2030 que coincide con el horizonte temporal del plan estratégico que plantea el Municipio de La Plata y que permitirá comparar el análisis de la situación futura.

Por último, se plantea la metodología para la construcción del escenario alternativo, incorporando diferentes medidas atendiendo a los aspectos críticos detectados en el año base interviniendo en cada una de las variables. En este caso, también se plantea un análisis al año 2030 que permita comparar propuestas desde la planificación integrada del crecimiento urbano y la movilidad de la población. 


\subsection{Metodología general}

La metodología a aplicar parte de un abordaje dialéctico entre teoría - empírea, considerando al territorio como un sistema complejo, donde los elementos y subsistemas se interdefinen, como plantea García, R (2006), y a su vez se considera al sistema de transporte público como un servicio social, que es parte de una configuración compleja de la relación socio-territorial emergente. Dicha relación se encuentra condicionada por las características del medio y la participación de los actores políticos, económicos y sociales que configuran el territorio y cada uno de los subsistemas que lo componen.

Es decir, que para abordar la problemática del transporte público es necesario comprender su interrelación con otros subsistemas que conforman el territorio a estudiar. Como son las características del tejido urbano, la jerarquía de las vías de comunicación y los modos de transporte utilizados, la estructura social espacializada, la dinámica del mercado inmobiliario, los recursos económicos que se utilizan para desplazarse o las características del medio natural. En ese marco se optó por definir las dimensiones que permiten analizar elementos de los subsistemas que se vinculan directamente con el funcionamiento de la movilidad en general y del transporte público en particular, y por ende las más adecuadas para el análisis de las problemáticas que hacen al objeto de estudio.

Estas dimensiones son, por un lado la espacial, donde se analiza la ocupación del territorio por la población y las viviendas, y las características de la movilidad en términos espaciales y de comportamiento de la población. Estas variables son de suma importancia ya que inciden en la capacidad de las infraestructuras destinadas a la movilidad, a distancias y tiempos de viaje de la población, así como también en la cantidad de viajes y proporción de uso de los distintos modos de transporte disponibles.

Se considera también significativa la consideración de una dimensión social donde se analiza la capacidad del sistema de transporte de cubrir los sectores sociales más vulnerables del caso de estudio, lo que permite caracterizar al sistema de transporte como un servicio público socialmente importante para sectores que dependen de este modo de transporte para poder desplazarse.

A su vez se desarrolla una dimensión económica que tiene por objeto comprender la racionalidad económica de la movilidad en el caso de estudio, importante para mejorar criterios de utilización de recursos para la planificación de la movilidad. Este aspecto se lleva adelante a través de un análisis comparativo de costos por viaje de los modos motorizados 
más utilizados en el caso de estudio, el auto particular y transporte público. A su vez para caracterizar críticamente dichos costos, se los compara con algunos índices de salario construido por organismos oficiales para el periodo de estudio.

Por último para conocer el impacto de la movilidad sobre el medio ambiente se propone una dimensión ambiental donde se analizan los efectos del transporte en términos de consumo de combustible y de emisiones contaminantes para el caso de estudio.

Complementariamente se analizan asimismo los roles y las diversas modalidades de participación/intervención de siete actores principales involucrados en la problemática: el estado municipal con las políticas de transporte y uso del suelo desde los organismos locales; el estado provincial que administra parte de las concesiones de los recorridos de transporte público; las empresas de transporte que detentan la concesión del servicio; los choferes de los colectivos, las empresas inmobiliarias; los usuarios de transporte público y, finalmente, la población general, sus patrones modales y su capacidad de producir viajes.

Para abordar el objeto de estudio desde este enfoque y teniendo en cuenta la escasez de información a una escala que permita distinguir la heterogeneidad territorial del caso de estudio, se utiliza la triangulación metodológica. Por un lado se utiliza para complementar los resultados generados a través de técnicas cualitativas y cuantitativas para la observación y registro del medio y los actores que conforman los fenómenos urbanos que dan cuenta de la problemática de movilidad asociada al transporte público y el desarrollo urbano. Por otro lado, se utiliza la triangulación de datos para la contrastación de información aportada por las distintas fuentes primarias o secundarias y a su vez en distintas escalas de agregación territorial, como los radios censales, las zonas de transporte, las delegaciones municipales, las grandes áreas o los municipios en su totalidad.

En cuanto a la variable tiempo de viaje en transporte, se plantea analizarla a partir de los problemas vinculados con la forma de crecimiento por densificación en áreas centrales y disperso en la periferia producen, individualmente y combinadas, la extensión de los tiempos de viaje. En las áreas centrales, la tendencia al incremento de la congestión vehicular se expresa en disminución de la velocidad de desplazamiento que incide en los tiempos de viaje en general. Y a su turno, el crecimiento disperso incrementa las distancias de viaje producto de la expansión urbana residencial de baja densidad, lo que aumenta los tiempos de viaje.

A su vez, la incorporación de la variable tiempo de viaje en el análisis de cobertura de transporte público permite una mejor caracterización de dicha cobertura. En los análisis 
clásicos de cobertura de transporte público ${ }^{21}$ sólo se considera la distancia entre los lugares donde se generan los viajes y la red o refugios del transporte público pero dejan de lado el tiempo como una variable que hace a la calidad de la movilidad. Por el contrario, incorporando criterios de accesibilidad por tiempo y proximidad desarrollados en el capítulo anterior, se puede complementar la técnica clásica con la totalidad del tiempo de viaje necesario para llegar al destino deseado desde los respectivos orígenes.

Es así que al incorporar esta variable confluyen en el análisis no solo la distancia a la red, sino la distancia al destino, el nivel de congestión que reduce la velocidad de modo de transporte motorizado. En el caso del transporte público las frecuencias que afectan a los usuarios, son una parte fundamental de la composición del tiempo de viaje. A su vez las frecuencias son resultado de la cantidad de servicios circulando que provee la empresa prestadora del servicio y que la gestión municipal se encarga de controlar, es por ello que confluyen en la variable tiempo problemáticas que abordan cotidianamente las empresas, los organismos estatales y los usuarios.

Otro elemento que compone el tiempo de viaje en transporte público es su velocidad operativa, donde su variabilidad está sujeta a la congestión vehicular, la cantidad de pasajeros y la calidad de la infraestructura. Ver Ilustración 2.

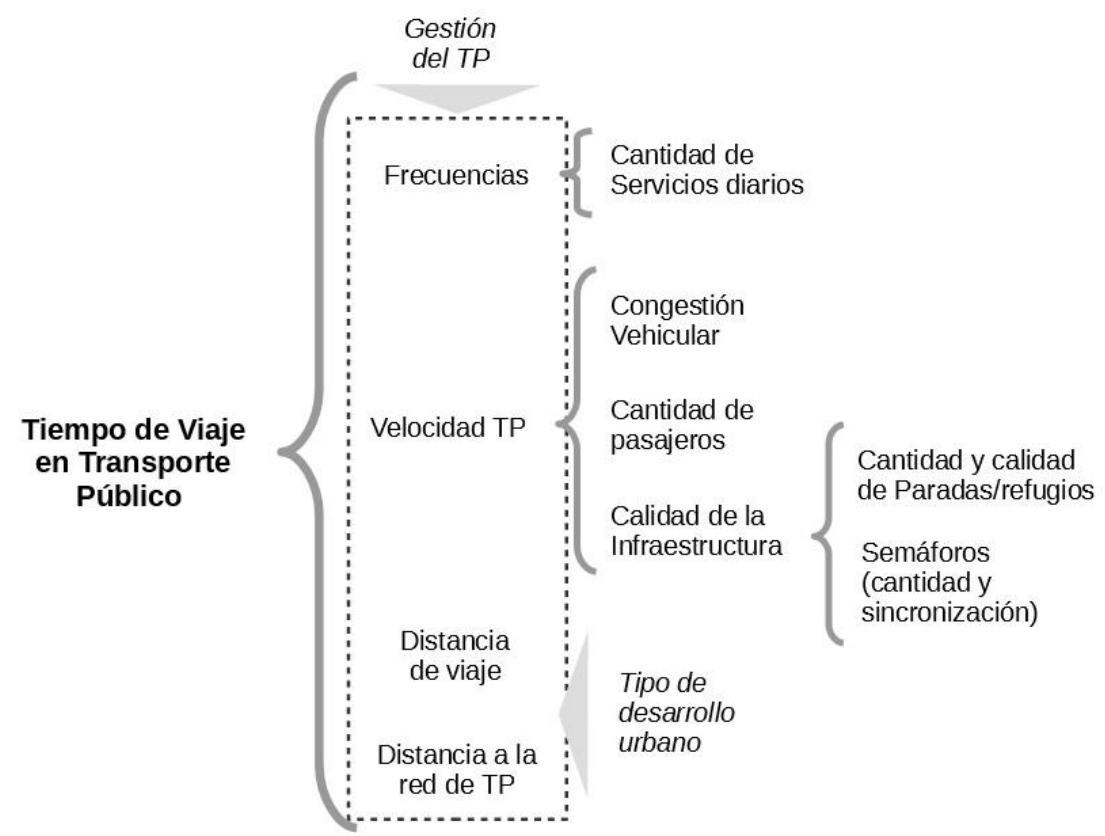

Ilustración 2. Esquema de elementos que conforman la variable tiempo de viaje. Fuente: Elaboración propia.

${ }^{21}$ ITDP, DOT, etc. 
Para la aplicación de este análisis se propone un recorte espacial en el Gran La Plata, que comprende a las ciudades de La Plata, Berisso y Ensenada, y un área testigo sobre un corredor del Gran La Plata para la construcción de los escenarios alternativos. El recorte temporal corresponde al último periodo intercensal (2001-2010) con extensión a los cambios urbanos hasta el bienio 2013-2014. El abordaje del caso considera como referencias los trabajos previos del equipo de investigación como base de análisis histórico, de proyecciones y escenarios futuros sobre la situación del transporte en áreas en procesos de cambios de densidad poblacional y habitacional, ya sea en áreas centrales como periféricas

Para cumplir con el objetivo de elaborar pautas de planificación integrada entre transporte público y desarrollo urbano este trabajo se estructura a través de la construcción de escenarios futuros de las dimensiones propuestas. Según Cely B. A. (1999), la premisa principal de los escenarios se basa en que el futuro no sucede ciegamente, sino que depender de la acción de los actores involucrados. Parte del principio lógico e indispensable que el futuro del territorio aún no existe y se puede concebir como un realizar múltiple que depende de la planificación y de la política. Por esta razón, los escenarios se consideran en este trabajo como una herramienta fundamental de planificación, que además de tratar de prever las tendencias que marcarán el futuro, permite orientar acciones que conduzcan la realización de los mismos.

Para ello se consideran tres instancias fundamentales: analizar el fenómeno en estudio, desde el punto de vista retrospectivo y actual, aspecto que se aborda principalmente en la construcción del año base; en segundo lugar analizar la influencia de los grupos sociales que son gestores del desarrollo del fenómeno así como de los factores de cambio; y por ultimo presentar los resultados finales en forma de escenarios. En ese marco se propone la realización de un año base, el escenario tendencial y escenarios alternativos (ver Ilustración 3) que se desarrollan en los puntos 2.1.1., 2.1.2., 2.1.3. 


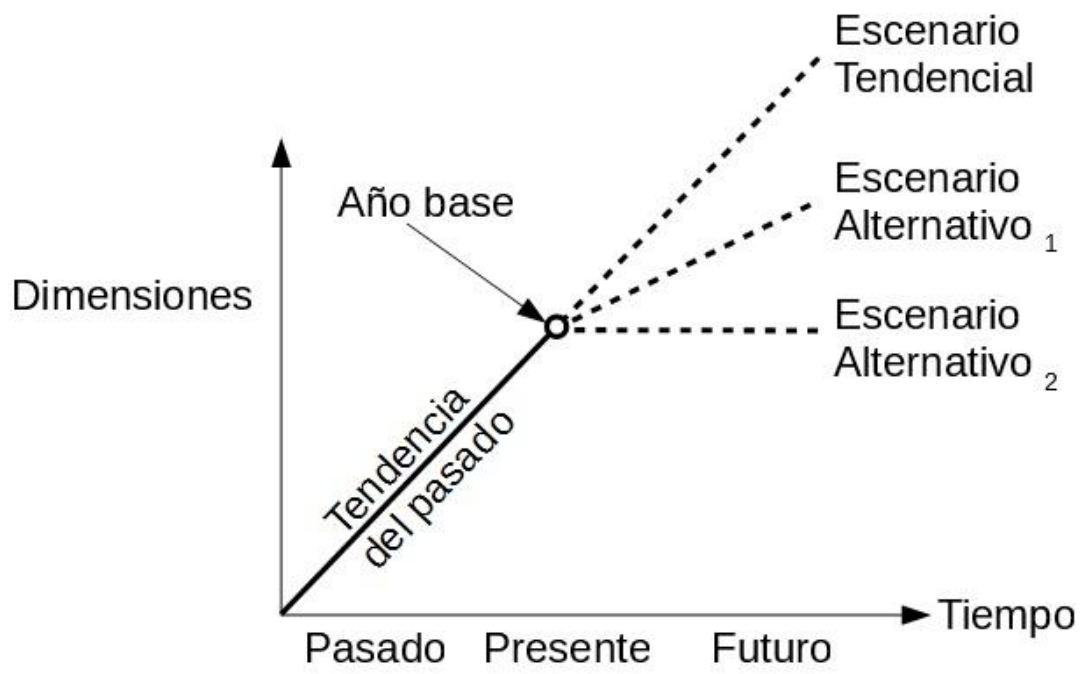

Ilustración 3. Esquema de construcción de escenarios. Fuente: Elaboración propia.

\subsubsection{Metodología para la construcción del año base}

El desarrollo de la metodología para la construcción del año base se refiere al estudio o reflexión de los métodos utilizados, la explicitación de los procedimientos, las variables y supuestos adoptados. En este sentido, se utilizan distintos métodos de recolección de la información, fuentes y técnicas apropiadas para el procesamiento de la información y posterior construcción de los escenarios tendencial y alternativos.

En una primera aproximación, las variables a seleccionar y analizar para la construcción del año base se fundamenta en entender al transporte público masivo como uno de los modos de transporte que satisface la necesidad de movilizarse de la población que ocupa un territorio, y su vez al tiempo de viaje como una variable importante para generar pautas de planificación que sean guías para las políticas de movilidad. Allí se identifican las densidades poblacionales y habitacionales de ocupación del suelo, las particiones modales, tiempos de viaje, características socioeconómicas de la población cubierta y no cubierta por transporte público y costos de desplazamiento. También se considerara la valorización y producción de suelo a partir de la cercanía al transporte público, los costos operativos del transporte público, así como en el ajuste de densidades como pauta de trazado de infraestructura e inversiones en periferias, para garantizar la sustentabilidad económica y la calidad de los servicios de transporte público masivo. Además se plantea relevar variables propias de la planificación de la movilidad urbana y territorial como son el diseño de los recorridos de transporte público, los kilómetros de desplazamiento, la velocidad operativa de las unidades, tiempos de viaje, los 
pasajeros transportados, la cantidad de servicios diarios, frecuencias por cada franja horaria y tiempos de recorrido real y legal. De esta manera, se plantea la construcción del año base a partir de:

\section{i) Descripción histórica del desarrollo urbano-territorial del caso de estudio}

ii) Análisis de las problemáticas de planificación y gestión

iii) Construcción del año base de desarrollo urbano y transporte público

\section{i. Descripción histórica del desarrollo urbano-territorial del caso de estudio.}

En este punto se plantea analizar el proceso de configuración urbana del área de estudio, haciendo hincapié en la importancia de la relación entre los usos del suelo y la movilidad. Se parte de un marco histórico territorial del área de estudio y a su vez sus transformaciones normativas de uso del suelo y del sistema de transporte público. Asimismo se plantea analizar los distintos actores involucrados en el sistema de transporte, tanto empresariales, estatales como gremiales y sus problemáticas.

\section{ii. Análisis de las problemáticas de planificación y gestión}

En este apartado se analiza la política de subsidios al transporte público urbano que emprendió el Estado Nacional a partir de 2002. A su vez, se realiza el análisis de las informaciones provistas los actores clave a los cuales se pudo acceder, como son el director de transporte del Partido de La Plata en 2013 y los choferes de las líneas de transporte público del Gran La Plata, con el objetivo de conocer su perspectiva de las problemáticas del transporte público.

Para la política de subsidios se realiza un estudio crítico de la bibliografía sobre el tema. Los datos de subsidios para el caso de estudio que se utilizan se obtuvieron de la página web oficial del máximo organismo estatal que los regula ${ }^{22}$. Para el análisis de posiciones, comportamientos y orientaciones políticas de los actores se utilizan métodos cualitativos. En

\footnotetext{
${ }^{22}$ Ministerio del Interior y Transporte:

https://servicios.transporte.gob.ar/subsidios/colectivos.php?idProv=1\&idMuni=\&idEmpr=
} 
primera instancia para el caso del Director de Transporte de la Municipalidad de La Plata se realiza una entrevista semiestructurada ${ }^{23}$, donde los ejes de consulta son los siguientes.

a) Las problemáticas en el transcurso de su gestión relacionadas a lo urbanos general y de transporte del Gran La Plata en particular.

b) Problemas que observa de gestión urbana en general y de transporte en particular por parte del Estado Municipal.

c) La relación con los empresarios a cargo de las concesiones de los servicios.

d) La relación con los choferes y el gremio.

e) El vínculo con los usuarios y las principales demandas registradas.

f) Medidas implementadas y propuestas que no pudo implementar durante su gestión. Características de los obstáculos de gestión.

Para abordar la perspectiva de los choferes se optó por la realización de talleres participativos de los que participaron 45 choferes de las distintas líneas de transporte del Gran La Plata en 5 talleres distintos. Los grupos se trataron de dividir por líneas que compartan zonas de cobertura y de diferente antigüedad laboral para tener la perspectiva de los trabajadores nuevos y de los que atravesaron distintas transformaciones, tanto del sistema de transporte como de la movilidad y lo urbano en general.

La preparación, organización y funcionamiento de los talleres estuvo a cargo del GII-IIPAC bajo la dirección de Mg. Laura Aón, directora a su vez del Observatorio de Movilidad del Gran La Plata. Los grupos se conformaron de la siguiente manera.

a) Línea 273. De jurisdicción provincial. Zona norte del Gran La Plata. Cantidad de choferes participantes: 11 .

b) Líneas 214 y 202. Jurisdicción provincial. Delegaciones que recorren: Los Hornos, Casco Urbano y Berisso. Cantidad de choferes participantes: 11.

c) Líneas 307 y Sur. Jurisdicción provincial y municipal respectivamente. Delegaciones que recorren: Los Hornos, Altos San Lorenzo, Casco Urbano y Ensenada.

d) Líneas Norte, Este y 520. Jurisdicción Municipal. Zona norte y este del Gran La Plata. Cantidad de choferes participantes: 12 .

\footnotetext{
${ }^{23}$ En anexos se puede acceder a la desgravación de la entrevista.
} 
e) Línea Oeste. Jurisdicción Municipal. Recorre la zona oeste del Gran La Plata. Cantidad de choferes participantes: 6 .

En cada taller se entregó a los choferes participantes una hoja con preguntas guía ${ }^{24}$ cuyos ejes son los siguientes.

a) Las problemáticas de transporte que observan.

b) La demanda de viajes según recorridos urbanos de transporte público.

c) La demanda de viajes según los barrios.

d) Principales atractores de viaje de transporte público.

e) Tiempo de viaje.

f) Perspectiva histórica del transporte público.

A su vez, para cada taller se utiliza un plano base de la estructura de vías de comunicación por donde circulan cada una de las líneas para que sirva de apoyo grafico de los aportes de los participantes.

Por último se realiza un árbol de problemas como recurso técnico-metodológico para problematizar las relaciones entre el problema central (tronco), sus condiciones determinantes (raíz) y efectos (copa) a partir del estudio de los resultados analizados en los apartados anteriores del año base. En la delimitación y explicación del problema existe siempre un conjunto de valores que influyen sobre su demarcación y jerarquización, dándole una estructura semejante al árbol, y donde la ubicación de las diferentes situaciones se le atribuye un status lógico diferente, respecto de una circunstancia a la que se le asigna el lugar del problema central. En este caso las primeras situaciones relacionadas con el problema central son las problemáticas primarias consideradas en los escenarios. Ver Ilustración 4.

\footnotetext{
${ }^{24}$ En anexo se adjunta el formulario base.
} 


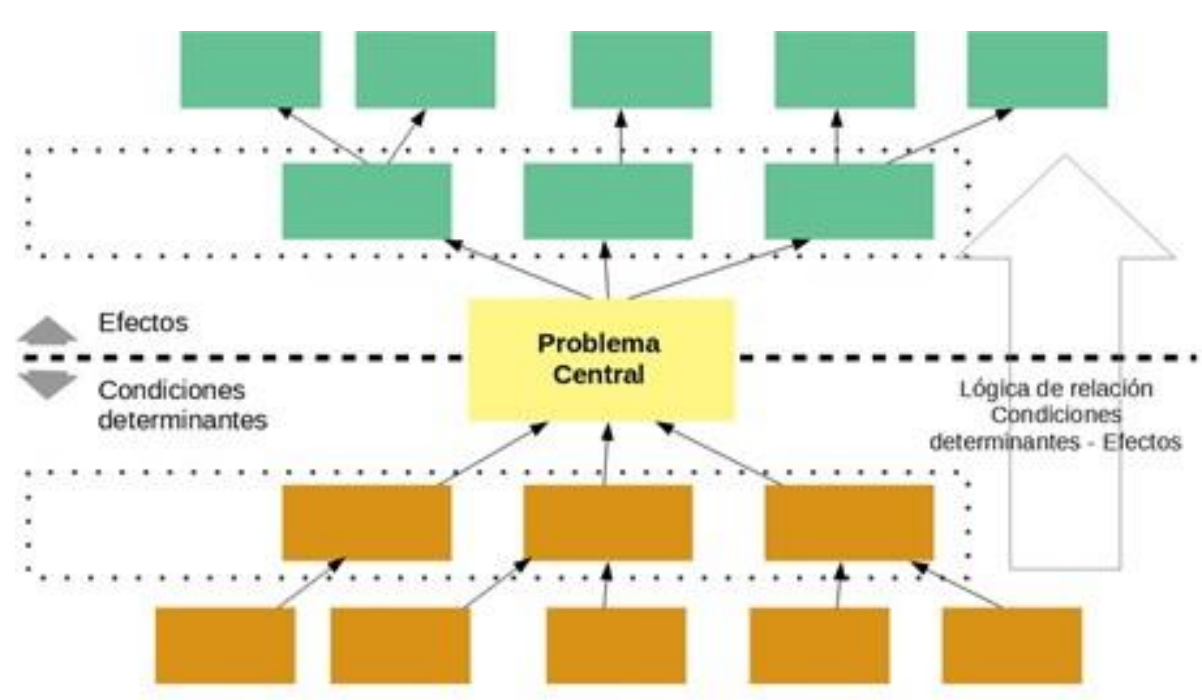

Ilustración 4. Esquema de estructura de árbol de problemas. Fuente: Elaboración propia en base a Árbol de Problemas desarrollado por ITEM Ciudad.

Los criterios para la enunciación del problema central $\operatorname{son}^{25}$

a) Constituir el núcleo del entramado problemático que se está analizando, pero no se debe confundir con las causas que lo generan, ni con las consecuencias que desencadena.

b) Se define como una carencia o déficit.

c) Se presenta como un estado negativo.

d) Es una situación real, está ocurriendo.

e) Se localiza en una población determinada y en un recorte territorial bien definido.

Para la formulación de causas y consecuencias se utilizan los siguientes criterios.

a) Identificar las causas, es decir las razones por las cuales el Problema Central ocurre, que siempre son varias y diversas.

b) Ubicar las condiciones determinantes inmediatas en el primer nivel por debajo del Problema Central, y proceder así en niveles sucesivos (es decir, las condiciones de las condiciones) hasta agotarlas, es decir llegar a las condiciones más alejadas del problema central.

c) Establecer las interrelaciones de las causas.

d) Identificar los efectos, es decir las consecuencias que provoca el Problema Central, que siempre son varias y diversas.

\footnotetext{
${ }^{25}$ La metodología abordada para la construcción del árbol de problemas es la desarrollada por el Equipo Técnico ITEM Ciudad para el curso Planificación y Gestión Urbano-Territorial en Municipios. La Plata, Junio de 2.017.
} 
e) Colocar los efectos más inmediatos en el primer nivel por encima del Problema Central y proceder así en niveles sucesivos (es decir, efectos de los efectos) hasta agotarlos, es decir llegar a las consecuencias últimas

f) Analizar las interrelaciones de los efectos.

\section{iii. Construcción del año base de desarrollo urbano y transporte}

El año base sintetiza el comportamiento de las principales dimensiones a analizar en determinado momento, en este caso en 2013-2014, siendo: a. Dimensión espacial, b. Dimensión social, c. Dimensión económica y d. Dimensión ambiental.

\subsubsection{Dimensión Espacial}

En esta dimensión se analizaran por un lado la ocupación del territorio y por otro, aspectos espaciales de la movilidad y transporte

\section{Ocupación del territorio}

En este apartado se realiza un estudio socio-espacial de localización de población y vivienda del área de estudio para reconocer los diversos niveles de concentración que permitirán identificar la diversidad de ocupación territorial y analizar las respectivas demandas de movilidad. Para ello se cuenta con datos globales correspondientes al Censo de 2001 y al del 2010 por cada uno de las jurisdicciones que conforman el caso de estudio, georreferenciados por radios censales provistos por el propio INDEC utilizando el software QGIS 2.14.9- Essen.

\section{Movilidad y transporte público}

Para el estudio de la movilidad y del transporte público se analizan datos "duros" que permitirán conocer cómo es la movilidad en el caso de estudio y sobre que infraestructura funciona. Para ello, por un lado se analizan datos de fuentes secundarias como son los valores del parque automotor que a través de la tasa de motorización permite dimensionar la cantidad de automóviles particulares del caso de estudio, como así también la tendencia en el uso del auto a partir de la periodización anual. A continuación se expresa la fórmula utilizada para el cálculo de la Tasa de Motorización: 


$$
T M=a / h
$$

\section{TM: Tasa de Motorización}

$a$ : Cantidad de Autos

$h$ : Cantidad de habitantes

A su vez se analizan las características del soporte físico de la movilidad, es decir la infraestructura de transporte disponible que permite evaluar la capacidad del caso de estudio en este aspecto. Para tal fin, se detallan algunas características de la red de vías de trenes de las entidades que administran los ramales y de las vías de comunicación automotor que permitan distinguir que zonas poseen infraestructuras de comunicación de este tipo. Con este mismo criterio, aunque con más detalle, se analizan datos de las líneas de transporte público automotor como son sus ramales, qué jurisdicción recorren, cómo son sus recorridos y frecuencias, cuántos sus pasajeros transportados y kilómetros recorridos. A partir de esta información se busca comprender la lógica general de funcionamiento del sistema en las distintas zonas del caso de estudio. Seguidamente, este análisis se complementa con datos de comportamiento de la población en relación a la movilidad a partir de la Encuesta de Movilidad del Gran Plata realizada por el GII IIPAC, FAU -UNLP, desarrollada en Aón, L (2017).

La metodología propuesta para el análisis de la movilidad se estructura sobre el concepto de generación de viajes e involucra el binomio producción - atracción de viajes. En este tipo de concepto vienen focalizando los estudios clásicos cuantitativos para diseñar los métodos de recolección de datos en los habituales lugares de generación de viajes, es decir en los hogares y sus residencias.

El planteo conceptual de la generación de viajes, enfoca el análisis en la unidad-hogar, asumiendo que la generación de viajes de pasajeros es una función de los atributos sociales, económicos e inclusos culturales, de los hogares donde se definen las actividades que los miembros del hogar desarrollan. En este marco se establecen los conceptos de producción de viajes y atracción de viajes como componentes de la generación, donde la producción constituye una lectura analítica de los viajes en relación al uso residencial, mientras que la atracción es una lectura analítica de esos mismos viajes, pero desde la perspectiva de usos noresidenciales, donde las personas realizan sus actividades.

A partir de este concepto, se desarrolla la metodología de relevamiento de datos de movilidad con un criterio distinto a las técnicas tradicionales que realizan las muestras en los lugares donde se genera el viaje. En este caso lo novedoso de la encuesta es que se llevó adelante en los lugares de atracción de viajes. Las razones para la utilización de una herramienta de este 
tipo radican en que se puede llegar a resultados aceptables de patrones de movilidad para ciudades de tamaño intermedio casi al instante de terminado el relevamiento y cargado de información al sistema web, gracias a las ventajas de la plataforma utilizada que genera informes automáticos ${ }^{26}$. Por otro lado, posee la ventaja de realizarse con pocos recursos humanos y económicos en comparación con las tradicionales encuestas de origen y destino $(\mathrm{EOD})^{27}$.

La encuesta utilizada cuenta con una muestra de 983 encuestas web y 1.129 en centros atractores, recabando datos aproximadamente de 7.500 personas, ya que además de los encuestados se hicieron preguntas sobre el comportamiento de movilidad del resto del hogar. Este universo encuestado representa aproximadamente el 1\% de la población del área de estudio y aporta información referida a 1) Practicas de viaje (comportamientos de movilidad), 2) Variabilidad y regularidad de esas prácticas, 3) Problemas asociados al uso de cada modo de transporte, 4) Producción y atracción de viajes por zona, 5) Localización de los orígenes y destinos de viaje, 6) Tasas de generación de viajes, tasas de motorización, según modo y motivo, por personas y hogares, de acuerdo al tipo y tamaño, como plantea Aón, L. (2017).

Al ser una encuesta sin administrador/encuestador en el caso de las encuestas web, y con asistencia en el caso de las realizadas en los centros atractores, para una adecuada recolección de datos es necesario desarrollar diferentes estrategias. Por un lado de comunicación, complementando las preguntas del formulario con frases introductorias y cuidando la extensión del conjunto del cuestionario para ayudar a la comprensión y a su completamiento. A su vez es necesario facilitar al encuestado la manera de responder consignas complejas como por ejemplo el itinerario, horarios y tiempos viajes. Para ello se utilizaron distintas matrices con opciones de selección de motivos de viaje, franjas horarias, costos de los viajes y modos de transporte elegidos. Por último, según Aón, L. (2017), es necesaria la verificación de la consistencia de los datos aportados por el encuestado a través de realizar preguntas cuyas respuestas puedan ser corroboradas a partir de otras respuestas del formulario.

De esta encuesta desarrollada por el GII para UN proyecto de investigación, ${ }^{28}$, en esta tesis se utiliza información referida a las particiones modales, tasas de generación de viaje, tiempos de viaje y destinos de viaje por barrio/delegación del caso de estudio. La base de datos de esta

\footnotetext{
${ }^{26}$ Plataforma virtual E-Encuesta.com del proveedor de aplicaciones web Webtools S.L. con sede central en Madrid, España. Link de acceso: www.e-encuesta.com.

${ }^{27}$ Mientras la encuesta web requiere US\$50 cada tres meses de uso y el trabajo de 10 personas, la encuesta OD, para la realización en Argentina, demandó la necesidad de un préstamo del Banco Mundial y la disponibilidad de listadores, encuestadores, supervisores, coordinadores y editores.

${ }^{28}$ Proyecto PPID U002 denominado Transformaciones de la movilidad y de la accesibilidad urbanas en procesos de localización y relocalización residencial del Gran La Plata entre 2003 y 2013, formulado y dirigido por Laura Aón y realizado por GII IIPAC FAU UNLP entre el 2012 y 2014.
} 
encuesta referida a las variables mencionadas, aportaron la información de movilidad necesaria para la construcción del modelo urbano territorial que integra usos de suelo y movilidad a partir del cruce de información referido a ambos aspectos con de la utilización de herramientas del software QGIS Essen de georreferenciación de datos espaciales.

Para poder realizar los análisis de cobertura en las distintas dimensiones propuestas es necesario tener información georreferenciada a una escala compatible con el radio de cobertura de transporte público propuesto. Dicha cobertura se realiza con un criterio de una distancia de 400 metros a algún ramal de la red del sistema, equivalente a un tiempo de traslado promedio máximo de 5 minutos de caminata. Ver Ilustración 5.

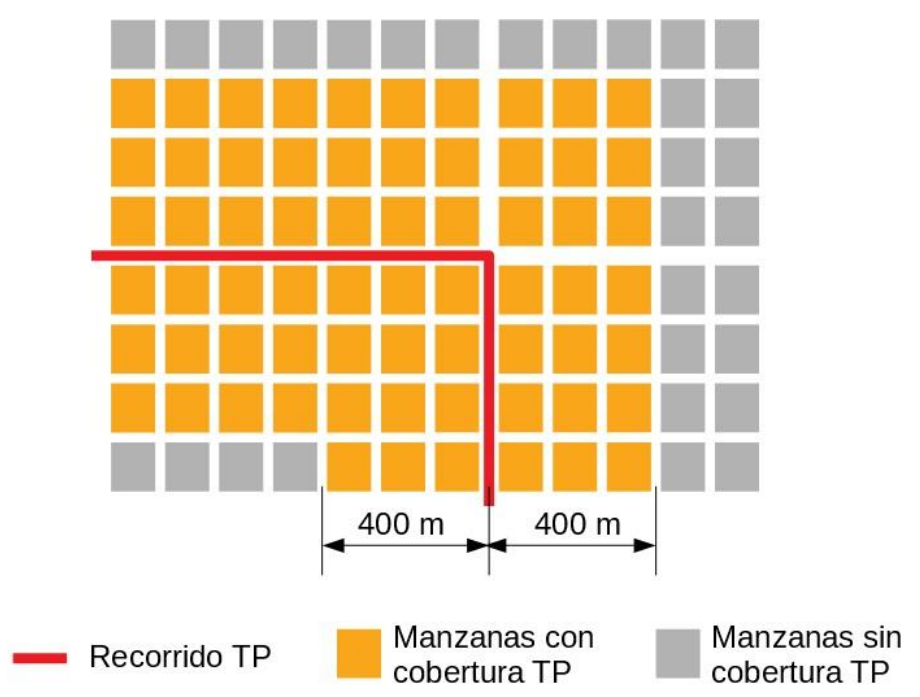

Ilustración 5. Esquema de cobertura de Transporte Público (TP) utilizada. Fuente: Elaboración propia.

Pero poder realizar el análisis mencionado es necesario poder contar con información censal a una escala menor a los radios censales, que para la región varían su superficie entre 1,3 ha y $9.352,4$ ha. Para ello se opta por construir un plano con datos de vivienda y población por manzanas menores a 16 hectáreas por ser la superficie más grande que se podría cubrir si la red de transporte público circundaría la manzana ${ }^{29}$. En el caso de que la manzana supere esa superficie, se considera a la residencia de manera independiente de la misma. Una vez tenido el valor de vivienda por manzana menor a 16 ha y la ubicación de la residencia individual para parcelas de mayor superficie se puede hacer la disminución de la escala del radio censal

\footnotetext{
${ }^{29}$ Esto es así por ser 16 ha el resultado de la superficie de una manzana o parcela de $400 \mathrm{~m}$ de lado, equivalente a la distancia de cobertura a la red adoptada.
} 
de los datos poblacionales. Como primer paso se calcula la cantidad de personas por vivienda en cada radio censal, seguidamente se utiliza ese índice para obtener la cantidad de personas por manzana. Esta estimación por manzanas menores a 16ha permite la agregación de datos según la escala necesaria para cada análisis que se necesite, ya sea manzanas, área cubierta por transporte público, barrio/delegación o gran zona.

Un esquema del procedimiento de cálculo se muestra en la Ilustración 6: en la figura A) los radios censales ( $r$ ) abarcan manzanas y parcelas ( $\mathrm{m}$ ), en la figura B) se muestra el traspaso de atributos de los radios ( $\mathrm{r}$ ) a las manzanas y parcelas ( $\mathrm{m}$ ). En la figura C) se muestra la agregación de esos atributos en zonas más grandes ( $\mathrm{z}$ ) y en la D) en áreas menores ( d ).

A)

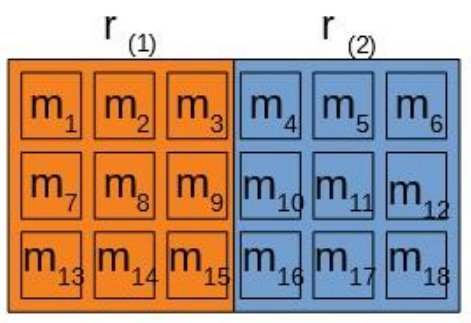

C)

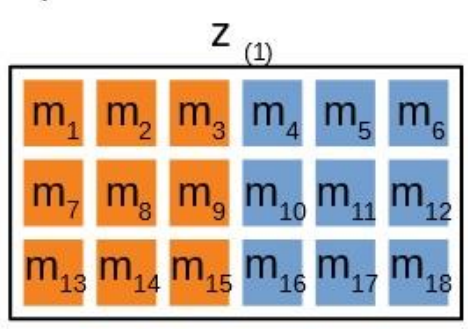

B)

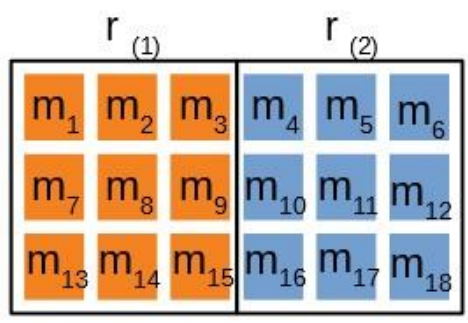

D)

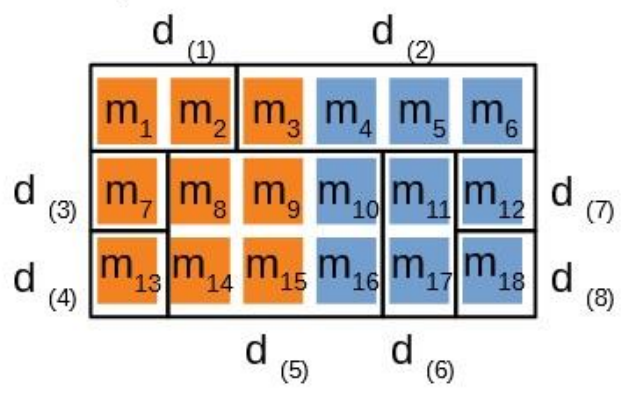

Ilustración 6. Pasos para la agregación de datos censales en distintas escalas a los radios. Fuente: Elaboración propia.

Como se menciona en el punto 2.1. Metodología general, se propone sumar la variable tiempo de viaje al análisis de cobertura espacial detallado con anterioridad. Como los destinos de viaje de una persona son infinitos, las distancias y tiempos de viaje también lo son. Por esta razón se adopta el criterio de analizar solo los tiempos de los viajes en transporte público cuyo destino sea el área central del caso de estudio, ya que es el destino que atrae la mayor cantidad viajes.

Para ello, el tiempo de viaje en transporte público a nivel global se obtiene a partir de los resultados de las encuestas de movilidad. A su vez, éste resultado es revisado y ajustado con 
datos de tiempo de desplazamiento obtenidos a partir de la velocidad operativa promedio del transporte público ${ }^{30}$ y el tiempo de espera estimado en la mitad de las frecuencias promedio de un día de los distintos ramales del sistema ${ }^{31}$. Es decir, el tiempo de viaje se calcula por ramal y de la siguiente manera ${ }^{32}$ :

\section{Tiempo de viaje $=$ Tiempo de traslado + tiempo de espera}

A su vez el tiempo de espera se calcula de la siguiente manera:

Tiempo de espera $=$ frecuencia promedio $/ 2$

\subsubsection{Dimensión Social}

Esta dimensión busca analizar la capacidad de cobertura del sistema de transporte a los sectores sociales más propensos a depender del mismo por su bajo costo en comparación con otros modos motorizados. Entendiendo al transporte público como un Servicio Público cuya función social debería ser garantizar la posibilidad de acceso del conjunto de la población a centros de salud, educación y trabajo desde su lugar de residencia, se analizan las características sociales de la población utilizando niveles de pobreza a partir del indicador de Necesidades Básicas Insatisfechas $(\mathrm{NBI})^{33}$. La utilización de este índice radica en ser la metodología más extendida a nivel de América Latina para la medición de la pobreza ${ }^{34}$, es

\footnotetext{
${ }^{30}$ Estimada en $18 \mathrm{~km} / \mathrm{h}$ para el caso de estudio. Esta información es obtenida a partir de datos aportados por el Municipio de La Plata en su página web oficial, y declaraciones juradas de las empresas de transporte provinciales de 2015 aportadas por el área de transporte del Gobierno de la Provincia de Buenos Aires.

${ }^{31}$ Se estima en la mitad de la frecuencia del ramal ya que el promedio de tiempo de espera por ejemplo de un ramal con una frecuencia de 10 minutos va desde 1 minuto a 10 minutos según el momento en que el pasajero llegue a la parada de micros, en este caso el promedio seria 5 minutos, es decir la mitad de 10 minutos.

${ }^{32}$ No se incorporan en este cálculo los tiempos de caminata a las paradas/refugios de origen, tampoco desde las paradas/refugios destino porque su variabilidad dentro del área de cobertura no representa diferencias cualitativas.

${ }^{33}$ Las necesidades Básicas Insatisfechas (NBI) fueron definidas según la metodología utilizada en "La pobreza en la Argentina (Serie Estudios INDEC. N 1, Buenos Aires, 1984). Los hogares con NBI son los hogares que presentan alguna de estas condiciones: Vivienda, hogares en una vivienda de tipo inconveniente (pieza de inquilinato, vivienda precaria u otro tipo, lo que excluye casa, departamento y rancho; Condiciones sanitarias, hogares que no tuvieran ningún tipo de retrete; Hacinamiento, hogares que tuvieran más de tres personas por cuarto; Asistencia escolar, hogares que tuvieran algún niño en edad escolar (6 a 12 años) que no asistiera a la escuela; Capacidad de subsistencia, hogares que tuvieran cuatro o más personas por miembro ocupado y, además, cuyo jefe no haya completado tercer grado de escolaridad primaria.

${ }^{34}$ Feres J., Mancero X. 2001. El método de las necesidades básicas insatisfechas (NBI) y sus aplicaciones en América Latina. División de Estadísticas y Proyecciones Económicas, CEPAL.
} 
decir que los resultados obtenidos en este trabajo pueden ser comparados con otros casos latinoamericanos. Y, por otro lado, no menos importante, que es el único índice disponible por radio censal para el caso de estudio que da cuenta de sectores económicamente vulnerables y que su periodización censal permite estimar proyecciones.

Es por ello que se utiliza este indicador del censo 2010, pero se proyectará la cantidad de población con NBI a 2013 según la tendencia de crecimiento de éste índice entre los censos 2001 a 2010. A su vez, por medio del software QGIS, se analiza la población cubierta y no cubierta con y sin NBI, según el nivel de acceso determinado por las frecuencias y tiempo promedio de traslado en transporte público.

Como complemento a este análisis, se realiza este mismo procedimiento para evaluar el nivel de cobertura de transporte público para villas y asentamientos del caso de estudio. Este complemento se realiza para identificar puntualmente los sectores de mayor vulnerabilidad socio-económica del caso de estudio. Para ellos se utilizan datos del Registro Público Provincial de Villas y Asentamientos Precarios (RPPVAP) creado en el marco de la Ley 14449, siendo la herramienta única y centralizada de relevamiento y captación de datos para la implementación del "régimen de integración socio-urbana de villas y asentamientos precarios" (artículo 28). Es una herramienta de actualización periódica y de construcción progresiva, que integra información social, catastral, dominial, urbana y de antecedentes de intervenciones pública en cada uno de los barrios inscriptos.

Los datos utilizados son los difundidos por dicho organismo para el periodo comprendido desde mediados de 2014 hasta fines de 2015. A su vez, la identificación de la tipología de los barrios a incorporar en el Registro surge del artículo 27 de la Ley 14.449, que comprende villas, asentamientos precarios y otros ${ }^{35}$.

\footnotetext{
${ }^{35}$ Las definiciones textuales de la Ley 14.449 son las siguientes: Villas: Urbanizaciones o auto-urbanizaciones informales producto de ocupaciones de tierra urbana vacante o de la afectación de tierras fiscales por el Estado para asentar a las familias provisoriamente, cuyas características son tramas irregulares (no son barrios amanzanados sino organizados en intrincados pasillos), viviendas construidas con materiales precarios, alta densidad poblacional, escaso o nulo espacio verde e infraestructura autoprovista.

Asentamientos Precarios: Barrios informales (en términos dominiales) con trazados urbanos que tienden a ser regulares y planificados, y que generalmente (aunque no de modo excluyente) cumplen algunas de las siguientes características: son decididos y organizados colectivamente, los ocupantes buscan legitimarse como propietarios, las viviendas tienen algún grado de firmeza y su ubicación puede encontrarse en tierras degradadas.

Otros: La complejidad de la realidad urbana-habitacional, exigió abrir una tercera categoría que se denominó "Otro" con el objetivo de incluir una serie de barrios con situaciones particulares que conforman parte de la misma problemática. En esta tipología los casos más típicos incluidos son: (i) mixtura entre villa/asentamiento para dar cuenta de aquellos casos que presentan una combinación de tramas urbanas asociados a los diferentes momentos históricos de formación y del proceso de expansión del barrio; (ii) villa o asentamiento urbanizado (en forma parcial o completa) utilizada en aquellos barrios con intervención del Estado en programas de urbanización integrales que hayan modificado en forma concluyente sus niveles de consolidación e integración socio-urbana; (iii) asentamiento histórico consolidado o semiconsolidado hace referencia a asentamientos que
} 


\subsubsection{Dimensión Económica}

Esta dimensión tiene como objetivo poder comprender los costos económicos de la movilidad en el caso estudio para los usuarios de automóvil particular y colectivo. Este análisis se considera importante para dar cuenta del impacto que significa la movilidad en la economía de los hogares del caso de estudio, como consecuencia de las actuales políticas de transporte y de desarrollo urbano.

Para ello se analizan los costos para los usuarios como resultado del tipo de expansión urbana actual. Este cálculo se realiza a partir de las distancias medias de viaje y el consumo de combustible por kilómetro según modo de transporte utilizado. Para el cálculo de las distancias medias de viaje de modos de transporte no masivos se adoptó el criterio de utilizar las distancias desde el centro geométrico del área generadora de viajes (en este caso barrios/delegaciones), al centro geométrico del área de mayor demande viajes a través de la ruta más directa. Ver Ilustración 7.

por su nivel de consolidación en los materiales constructivos y el grado de presencia de servicios no se diferencia sustantivamente de los barrios lindantes, a pesar de lo cual persisten irregularidad en la titularidad del dominio; (iv) loteo "clandestino" o loteo "pirata" se vincula con situaciones de irregularidad dominial asociada al mercado de compra-venta informal dirigidos a sectores populares, donde un actor "intermediario" (sin ser el titular del dominio) promueve el loteo.

Dichas operaciones pueden estar o no vinculadas con la venta de "derecho posesorio" o la posterior reivindicación de los mismos; (a) conjunto habitacional "tomado" se utiliza para hacer referencia a conjuntos de vivienda construidos por el Estado, que sin contar con el final de obra fueron ocupados de forma precaria por hogares que sufren situaciones de déficit habitacional; (b) situaciones de informalidad dispersa, esta denominación es utilizada para designar zonas que presentan irregularidad dominiales en algunos lotes pero no en la totalidad del barrio, donde frecuentemente se combinan tomas de tierra individual (o atomizada) con mercados de cesión de "derecho posesorio". Son situaciones frecuentemente asociadas a la ocupación progresiva de loteos remanentes subdivididos con anterioridad a la sanción de la ley 8912/77. 


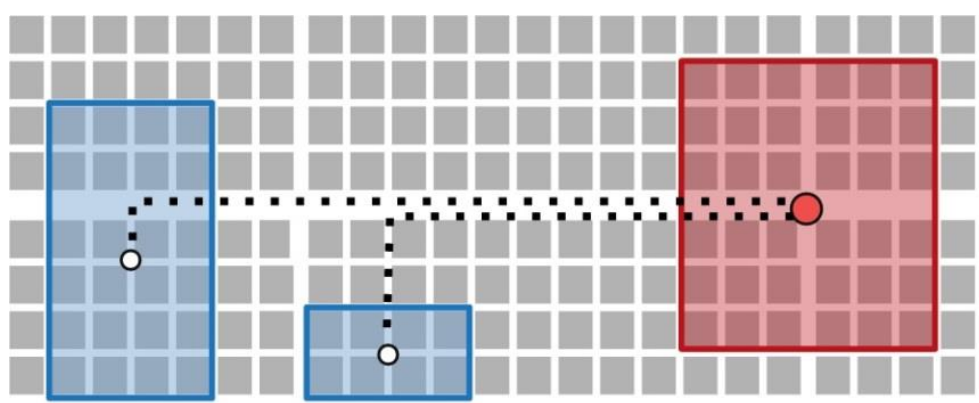

Área central atractora

Centro de gravedad área central

Áreas generadoras

(barrios/delegaciones)

Centro de gravedad

área generadoras

(barrios/delegaciones)

Ilustración 7. Esquema de la elección de la ruta más directa entre áreas generadoras y área atractora. Fuente: Elaboración propia.

A partir de esa distancia se calcula el precio del viaje a través de la relación costo de combustible por kilómetro recorrido de un auto. De la siguiente manera:

$$
\$ \mathrm{v}=\mathrm{D} * \$ / \mathrm{km}
$$

\$v: Costo del viaje $\quad$ D: Distancia ruta más directa $(\mathrm{km}) \quad \$ / \mathrm{km}$ : Precio por kilómetro

En el caso de transporte público se utilizó el mismo criterio para la elección del destino del viaje, es decir desde las áreas generadoras de viajes (barrios/delegaciones municipales) al área central, con la diferencia que el costo de usuario no se traduce en kilómetros recorridos sino que se da partir del pago del boleto. El precio del boleto a su vez lo define el esquema tarifario oficial según las secciones basadas en distancias en kilómetros del recorrido por cada ramal que el usuario realiza.

Una vez obtenidos los resultado de costos por viaje, se calcula el costo diario utilizando la tasa de generación de viaje por día de cada área ${ }^{36}$. Finalmente se realiza la suma de costos acumulados en un mes de la siguiente manera:

$$
\$ \mathrm{~m}_{1}=\$ \mathrm{v}_{1} * \mathrm{TGV}_{1} * 30
$$

$\$ \mathrm{~m}_{1}$ : Costo mensual de viaje

$\mathrm{TGV}_{1}$ : Tasa de Generación de Viaje

\footnotetext{
${ }^{36}$ Cálculo realizado en la Dimensión Espacial de este capítulo.
} 
Esta agregación de costos permite hacer una comparación con el valor de la Canasta Básica Alimentaria (CBA), la Canasta Básica Total (CBT) y su relación con el Salario Mínimo (SM) estipulados por el INDEC. Esta comparación tiene por objetivo conocer la proporción de costos de la movilidad en relación a los ingresos básicos y mínimos de la población, lo que permitirá aproximarse a la estimación de los costos de la movilidad para los sectores de ingresos más bajos.

Paralelamente se incorpora un análisis sobre el grado de impacto de la red de transporte público en el precio del suelo con el objetivo de evaluar el grado de su valorización a partir de la cercanía de los inmuebles a este servicio. De darse esta situación, permitiría considerar la posibilidad de recuperación de plusvalía urbana a partir del transporte público.

Para ello, se utilizó un plano de precios del suelo actualizado a 2013 por Cola, C., Barbero, D., Martini, I. y Aón, L. (2017) y se superpuso una capa shape de recorridos de transporte público para comparar los precios de suelo obtenidos con el diseño y frecuencias de la red.

\subsubsection{Dimensión Ambiental}

La dimensión ambiental del año base analiza cómo el modelo de transporte y desarrollo urbano actual impactan en el medio ambiente en terminos de consumo de combustible no renovable y emisiones de contaminantes. Estas dos variables cobran importancia en el marco de los debates entorno a la insuficiencia energética nacional por la dependencia del combustible fosil, y por otro lado las emisiones de $\mathrm{CO}_{2}$ que impactan en el calentamiento global produciendo catastrofes ecológicas y sociales.

Para la construccion de esta dimension se analiza el consumo de combustible y emisiones de contaminantes de $\mathrm{CO}_{2}$ producidos por la movilidad del caso de estudio. Para ello se utilizarán como base tablas de calculo de consumo energetico y emisiones contaminantes desarrolladas por el GII-IIPAC para el año 2003 para el Proyecto NUMEX (2013) ${ }^{37}$.

Dichas tablas toman como base principal la partición modal de movilidad ${ }^{38}$ de la ciudad, cantidad de viajes realizados, la particion de combustibles utilizados por los distintos modos

\footnotetext{
${ }^{37}$ Experimentación numérica de políticas y estrategias de desarrollo sustentable. FONCyT-PICT 2011-2013.

${ }^{38}$ Porcentaje de modos utilizados.
} 
de transporte, (en este caso nafta, gas oil y $\mathrm{GNC}^{39}$ ) y los kilometros promedio por viaje y por modo de transporte privado. Para los modos de transporte público se calculó según los kilómetros diarios recorridos por unidad.

Las particiones modales y cantidad de viajes realizados globales y por gran zona se obtienen a partir de la encuesta de movilidad utilizada para este trabajo ${ }^{40}$ y desarrollada en el punto 2.1.1. La distancia de viaje para los modos privados como el automovil particular, motos y la categoria otros, se utilizaron los calculados para el punto 2.1.1.

La cantidad de unidades de los modos de transporte públicos se obtuvo por consulta y procesamiento de datos de distintas fuentes secundarias. En cuanto a la cantidad de Remisses y Taxis se obtuvo a traves de articulos peridisticos basados en declaraciones del Presidente de la Unión de Propietarios de Autos Taxi de La Plata y representantes del municipio de La Plata. La distancia recorrida promedio por día del transporte público masivo y la cantidad de unidades se obtuvieron de los datos brindados por la Dirección de Transporte de La Plata y el area de Transporte del Gobierno de la Provincia de Buenos Aires.

Para la equivalencia entre litros de combustible consumido por kilómetro recorrido se utilizaron indicadores de la siguiente tabla.

Tabla 3. Consumo por kilómetro por modo y tipo de combustible 2013. Fuente: Elaboración propia.

\begin{tabular}{|c|c|c|c|}
\hline \multirow{2}{*}{ Vehículo } & $\begin{array}{c}\text { Tipo } \\
\text { combustible }\end{array}$ & $\begin{array}{c}\text { Valor promedio } \\
\text { de consumo } \\
\text { L/100km(1) }\end{array}$ & $\begin{array}{c}\text { Valor promedio de } \\
\text { consumo } \\
\text { incrementado (2)(3) }\end{array}$ \\
\hline \multirow{3}{*}{ Autos } & Nafta & 7,07 & 9,54 \\
\cline { 2 - 4 } & Diesel Oil & 5,38 & 7,26 \\
\cline { 2 - 4 } & GNC & 6,37 & 8,6 \\
\hline \multirow{3}{*}{ Camionetas } & Nafta & 6,25 & 8,44 \\
\cline { 2 - 4 } & Diesel Oil & 6,03 & 8,14 \\
\cline { 2 - 4 } & GNC & 7,45 & 10,06 \\
\hline Buses & Gas Oil & 37,5 & 50,63 \\
\hline Pesados & Gas Oil & 31,5 & 42,53 \\
\hline Motos & Nafta & 1,4 & 3 \\
\hline Tren (1) & Gas Oil & 0,805 & 1,09 \\
\hline
\end{tabular}

(1) El consumo de trenes esta expresado en litros ton $/ 100 \mathrm{~km}$

\footnotetext{
${ }^{39}$ Siglas de Gas Natural Comprimido.

${ }^{40}$ Encuesta de Movilidad del Gran La Plata, desarrollada por GII miembros del IIPAC FAU - CONICET, UNLP.
} 
(2) Con un litro de GNC se pueden recorrer $38,18 \mathrm{~km}$

(3) Incremento consumo Urbano (35\%)

Para la conversión de volumen de combustible a $\mathrm{TEP}^{41}$ y para su equivalencia en $\mathrm{TJ}^{42}$ se utilizaron los siguientes valores.

Tabla 4. Factores de conversión combustibles a TEP. Fuente: Elaboración propia.

\begin{tabular}{|c|c|c|}
\hline \multicolumn{3}{|c|}{ Factores de conversión } \\
\hline Combustible & Unidades & TEP \\
\hline Nafta & $1 \mathrm{~m}^{3}$ & 0,7607 \\
\hline Diesel Oil & $1 \mathrm{~m}^{3}$ & 0,88 \\
\hline GNC & $1000 \mathrm{~m}^{3}$ & 0,829 \\
\hline Gas Oil & $1 \mathrm{~m}^{3}$ & 0,8619 \\
\hline
\end{tabular}

$$
1 T E P=0,041868 T J
$$

Para el resultado de las emisiones contaminantes producto de la combustión de los TJ calculados se utilizaran valores construidos por la Fundación Bariloche utilizados en las tablas del software LEAP $^{43}$. Los valores para cada gas emitido son los siguientes.

Tabla 5. Emisiones contaminantes por modo de transporte. Fuente: Elaboración propia en base matriz aportada por Aón (2003)

\begin{tabular}{|c|c|c|c|c|c|c|c|}
\hline \multicolumn{7}{|c|}{ Tablas Leap (Valores de la Fundacion Bariloche) - En Kg/TJ Consumido } \\
\hline Vehículo & Combustible & CO2 & CO & CH4 & COVDM & Nox & N2O \\
\hline \multirow{3}{*}{$\begin{array}{c}\text { Autos y } \\
\text { Motos }\end{array}$} & Nafta & 68.607 & 13.000 & 30 & 1.500 & 600 & 1 \\
\cline { 2 - 8 } & Diesel & 73.326 & 300 & 2 & 70 & 300 & 4 \\
\cline { 2 - 8 } & GNC & 55.539 & 720 & 630 & 90 & 380 & - \\
\hline \multirow{3}{*}{ Camionetas } & Nafta & 68.607 & 8.300 & 20 & 1.400 & 700 & 1 \\
\cline { 2 - 9 } & Diesel & 73.326 & 400 & 1 & 100 & 400 & 4 \\
\cline { 2 - 8 } & GNC & 55.539 & 720 & 630 & 90 & 380 & - \\
\hline Buses & Diesel & 73.326 & 900 & 6 & 200 & 1.000 & 3 \\
\hline Pesados & Diesel & 73.326 & 900 & 6 & 200 & 1.000 & 3 \\
\hline Tren & Diesel & 73.326 & 610 & 6 & 130 & 1.800 & 2 \\
\hline
\end{tabular}

${ }^{41}$ TEP: Unidad de energía. Tonelada Equivalente a Petróleo.

${ }^{42}$ TJ: Unidad de energía. Terajoule.

${ }^{43}$ Software LEAP: Sistema de Planificación de Alternativas Energéticas de Largo Plazo. 
Una vez definido el año base, el siguiente paso consiste en la construcción del escenario tendencial.

\subsubsection{Metodología para la construcción del Escenario Tendencial}

El primer escenario a analizar es el tendencial, es decir un escenario en el que se proyecta a futuro las tendencias actuales para cada variable analizada en el año base con el objetivo de poder visibilizar la criticidad de los distintos indicadores del año base en un contexto sin modificaciones que contrarresten dichas tendencias. Este escenario es al año 2030 para el cual el municipio de La Plata fijó sus objetivos con el Plan Estratégico LP.30 desarrollado por la Secretaria de Planeamiento Urbano y Desarrollo Económico. Para la construcción de dech escenario, así como para la construcción del año base, se analizan las dimensiones espacial, social, económica y ambiental al año 2030.

\subsubsection{Dimensión Espacial 2030}

La dimensión espacial proyectada a 2.030 comprende tres variables.

a) Población y ocupación del territorio.

b) Movilidad.

En cuanto a la población y ocupación del territorio, se proyecta la cantidad de población, viviendas, tasa de crecimiento poblacional y habitacional por delegación a partir de la tendencia de crecimiento intercensal para los años 2001-2010 y proyección poblacional del INDEC a 2013 y 2014. Para el resto de las proyecciones se utiliza la tendencia lineal a partir de como mínimo dos valores del mismo índice registrados en distintos años, de la siguiente manera:

\begin{tabular}{|c|c|}
\hline AÑO & VALOR \\
\hline $\mathrm{A} 1$ & $\mathrm{~B} 1$ \\
\hline $\mathrm{A} 2$ & $\mathrm{~B} 2$ \\
\hline $\mathrm{A} 3$ & $\mathrm{X}$ \\
\hline
\end{tabular}


Donde la ecuación es:

$$
X=\frac{B 2-B I}{A 2-A 1} *(A 3-A 2)+B 2
$$

$\mathrm{X}$ : valor de la proyección

A2 : año del ultimo valor disponible
A1 : año del primer valor disponible

B1 : valor del primer año disponible

B2 : valor del último año disponible

En cuanto a la movilidad, se proyecta el incremento del parque automotor siguiendo las tendencias de patentamientos anuales desde 2005 a 2013, años de los cuales se dispone información. Para la proyección a 2030 de la Tasa de Generación de Viaje (cantidad de viajes diarios por persona) se estimará a partir de los valores del indicador producidos en 1993 por la Encuesta Origen Destino realizada por la Municipalidad de La Plata en ese año, la proyectada por el GII IIPAC para el año 2003 y la Encuesta de Movilidad del Gran La Plata también realizada por el GII IIPAC entre los años 2013 y 2014.

Para la construcción de este escenario se mantiene el reparto modal del año base y, se calculan las tasas de generación de viaje por modo de transporte colectivo, no masivo y no motorizado con la proyección de los datos de cantidad de viajes a partir de la misma ecuación utilizada anteriormente. Con la información de cantidad de pasajeros, de coches, la cantidad de servicios y cantidad de servicios por coche con destino al Casco Urbano, se calculan la cantidad de pasajeros por coche y por servicio con destino al Casco Urbano, lo que permite aproximar en nivel de ocupación del colectivo y la cantidad de coches aproximados necesarios para evitar el hacinamiento en las unidades.

La proyección del tiempo de viaje en transporte público a 2030 se realiza sobre la base de un recorte del sistema de transporte. Para ello se utilizan datos aportados por el Director de Transporte y Transito en 2013 sobre la variación del tiempo que tarda un coche de los distintos ramales en completar una vuelta de su recorrido en 2012 y 2015.

A partir de esa variación en el tiempo de recorrido se calcula la disminución del tiempo de recorrido y la disminución de velocidad por año. Esta variación anual permite proyectar el tiempo de recorrido y la velocidad a 2030. La velocidad de estos ramales proyectados a 2030 
se utiliza en primer lugar para estimar tiempos de traslado por delegación al Casco Urbano para 2030 para poder cruzar esta información con los aportados por la encuesta de movilidad.

En segundo lugar, esta información obtenida sirve para proyectar una estimación de reducción de velocidad a 2030 de tres ramales del sistema de transporte del cual se relevó en campo la velocidad del coche en segmentos de 5 minutos en hora pico. Dichos ramales se seleccionaron en función de hacer recorridos sobre corredores de transporte de jerarquía en la región, que poseen mucha congestión de tránsito por recibir las mayores demandas de pasajeros y por otro lado por circular por zonas de densidad muy variable.

Por último, la proyección del tiempo de desplazamiento y velocidad a 2030, se generalizan al conjunto de los ramales del sistema para estimar la variación de las frecuencias en transporte público si no se incorporan ni restan unidades a los recorridos.

\subsubsection{Dimensión Social 2030}

En la dimensión social se analizan las características socioeconómicas de la población cubierta y no cubierta por transporte público utilizando los porcentajes de NBI construido a partir de datos censales del año 2010 a la proyección poblacional para el año 2030. Es decir se estima la población con NBI en 2030 aplicando los mismos porcentajes de NBI del censo 2010 a la población proyectada por el INDEC a $2030^{44}$. Los porcentajes de población cubierto y no cubierta por transporte público son los construidos en el año base.

\subsubsection{Dimensión Económica 2030}

En esta apartado se analizan los costos de traslado globales y por delegación municipal del caso de estudio utilizando precios de combustibles y tarifas de transporte público de 2013 para la población y tasa de generación de viaje proyectada a 2030. A su vez se comparan esos costos mensualizados con la Canasta Básica Alimentaria, la Canasta Básica Total y Salario Mínimo establecido en 2013. La utilización de tarifas y valores de CBA, CBT y SM con valores de 2013 proviene de la imposibilidad de hacer proyecciones a 2030 debido a la inestabilidad de los valores tarifarios y de la inflación de los precios.

\subsubsection{Dimensión Ambiental 2030}

\footnotetext{
${ }^{44}$ Esta proyección de NBI responde al la dificultad de predecir reducciones o incrementos de niveles de pobreza por los cambios cotidianos de los índices económicos.
} 
Para la proyección de las variables comprendidas en la dimensión ambiental se utilizan las mismas matrices de datos vinculados construidos para el año base, pero se modifican los valores de entrada de incremento de población y la modificación de la tasa de generación de viaje calculada en la Dimensión Espacial 2030. Se mantienen las mismas particiones modales, kilómetros recorridos de transporte público y distancia promedio de viaje en los modos privados.

\subsubsection{Metodología para la construcción de los Escenarios Alternativos}

Por último, en los escenarios alternativos, se plantea la incorporación de las diferentes medidas atendiendo a los aspectos críticos detectados en el año base, interviniendo en cada una de estas variables ensayando medidas que mejoren la relación entre el transporte público masivo y uso del suelo a corto, mediano y largo plazo. En este caso, también se plantea un análisis al año 2030 que permita comparar propuestas desde la planificación integrada del crecimiento urbano y la movilidad en uno de los corredores de transporte de la ciudad.

Las propuestas de optimización intentarán reducir tiempos de viaje, y a través de esta variable mejorar resultados obtenidos de las distintas dimensiones analizadas en el año base y en el escenario tendencial para el análisis de la movilidad en general del modelo construido para el Gran La Plata. Este conjunto de propuestas son tres según tiempos necesarios para su implementación y también según el alcance en términos de tiempo de la mejora:

- Corto plazo.

- Mediano plazo.

- Largo plazo.

\subsubsection{Metodología para medidas a corto plazo}

El corto plazo se estima en un tiempo menor a 5 años donde se analizan posibles propuestas para reducir el tiempo de viaje en transporte público a través de medidas que permitan aumentar la velocidad de circulación de las unidades. Las medidas a analizar en este escenario son: 
- Sincronización de semáforos

- Distribución de paradas cada 300 metros

- Implementación de carril exclusivo para transporte público

Las modificaciones producidas a partir de estas medidas se modelan en un corredor de transporte público que pueda expresar la diversidad territorial del caso de estudio que permita generalizar algunos resultados. Es así que la elección del corredor depende de varios factores: por un lado, que sea un corredor de jerarquía urbana que tenga un alcance desde el área central de la ciudad hasta los límites del partido, es decir que abarque una porción importante del territorio; por otro lado, que atraviese distintas densidades poblacionales y a su vez que recorra áreas de distintos niveles socioeconómicos; y por último, que se disponga de la suficiente información que permita realizar los análisis propuestos.

La sincronización de semáforos permitiría reducir tiempos de recorrido de los coches. El cálculo del tiempo utilizado por semáforo se estimará teniendo en cuenta por un lado el tiempo de frenado, el tiempo de espera en el semáforo promedio y tiempo de puesta en marcha nuevamente.

Mediante trabajo de campo se propone una estimación del porcentaje de semáforos en luz rojo que obligan al colectivo a detenerse y de esta manera poder calcular la reducción de tiempo de viaje que esta medida aportaría. ${ }^{45}$

Para la distribución de paradas se plantea realizar un relevamiento para conocer la cantidad y su actual distancia entre ellas. A su vez se propone redefinir la cantidad de paradas en el marco de una distancia de 300 metros y se calcula la reducción en tiempo de viaje a partir de la implementación de esta alternativa

Por un lado se estimará la reducción en tiempo de recorrido utilizando el tiempo de frenado y puesta en marcha dispuesta en la propuesta de sincronización de semáforos, y por otro, mediante trabajo de campo, se buscará estimar un tiempo para que el pasajero suba el coche y abone con tarjeta magnética ${ }^{46}$.

\footnotetext{
${ }^{45}$ Realizando un viaje de ida y vuelta en el ramal Este 14 desde el centro del Casco Urbano hasta el final del recorrido en la periferia, se pudo corroborar que de 29 semáforos existentes en corredor el colectivo se detuvo en 22 , es decir en un $80 \%$ aproximadamente. Se estimó que la sincronización de semáforos permitiría reducir ese porcentaje por lo menos a $50 \%$ y se realizaron los cálculos para esa disminución.

${ }^{46}$ Tiempo aproximado en 3 segundos.
} 
Por último, se analizará la reducción de tiempo de recorrido por la implementación de carril exclusivo así como el posible incremento en la cantidad de pasajeros transportados a partir de su implementación.

El carril exclusivo para transporte público permite aumentar la velocidad operativa mínimo de $25 \mathrm{~km} / \mathrm{h}$. Es así que como primer paso se identifican los tramos del recorrido en los cuales el transporte público tiene velocidades menores a ese valor y luego se calcula el impacto en el tiempo de recorrido al incrementar las velocidades de eso tramos.

Por otro lado para aproximar el incremento en la cantidad de pasajeros producto de su implementación, se procederá a hacer una analogía con estudios realizados por Cervero, $\mathrm{R}$ (2014) para los sistemas TOD ${ }^{47}$, en particular los desarrollados en la ciudad de San Francisco. Según sus trabajos la distancia a menos de 800 y 600 metros a una red de infraestructura de transporte público de $\mathrm{BRT}^{48}$ incrementa su utilización entre un $24 \%$ a un $33 \%$. Teniendo en cuenta este dato se entiende que la infraestructura propuesta en este escenario difiere de los BRT, en parte porque los BRT tienen una mayor distancia entre paradas, también por la posibilidad de pago de la tarifa en los refugios y la utilización de coches de gran capacidad, se evalúa para el caso de aplicación utilizar una menor distancia a la red que las mencionadas.

Dentro de la propuesta de carril exclusivo, se agrega una estimación de costo teniendo como ejemplo análogo el MetroBus Sur de CABA y de Rosario ya que en ambos ejemplos el sistema atraviesa áreas urbanas con distintas densidades poblacionales. Asimismo, se plantea un análisis de reducción de tiempos de traslado en el caso de realizar las tres propuestas conjuntas. Además, en esta propuesta se evalúa la incorporación de un rondín en zonas de muy baja densidad, con un análisis de costos y subsidios para un coche de menor tamaño y menor consumo de combustible. También se analiza la posibilidad de que circule con frecuencias más espaciadas que el carril exclusivo pero que no supere los 25 minutos, ya que a pesar que la demanda es menor es necesario mantener una buena frecuencia para garantizar una buena accesibilidad.

\subsubsection{Metodología para mediadas a mediano plazo}

Para el mediano plazo la propuesta es proyectar la densificación en el corredor propuesto para mejorar la racionalidad del transporte público, incorporando carriles exclusivos y evaluando la necesidad de modificar el diseño del sistema.

\footnotetext{
${ }^{47}$ Transit Oriented Development.

${ }^{48}$ Por su sigla en inglés, Bus Rapid Transist.
} 
En primer lugar se reconoce la densidad permitida por la normativa de uso de suelo (C10) y se compara con la densidad real, lo que permite dilucidar si existe una correlación entre lo permitido por la normativa y lo que finalmente sucede. A partir de esta confrontación de información se busca sacar conclusiones sobre las herramientas de planificación necesarias para densificar sobre el corredor seleccionado.

Luego se calcula el crecimiento poblacional a 2030 en cantidad de habitantes nuevos en la zona de cobertura de transporte público del corredor y se construye el escenario suponiendo que ese incremento se diera en el radio de cobertura de 120 metros del corredor. Es decir se trabaja sobre la suposición de que con medidas de planificación apropiadas, todo el crecimiento poblacional a 2030 del corredor, podría desviarse a 120 metros del carril exclusivo. A su vez se aplica una partición modal de $28 \%$ más de viajes favorable al transporte público (ver Ilustración 8), y a partir de allí se calcula el impacto en menor cantidad de viajes en autos, y en cantidad de coches menos utilizando la relación "parque automotor-cantidad de viajes en auto" de 2013.

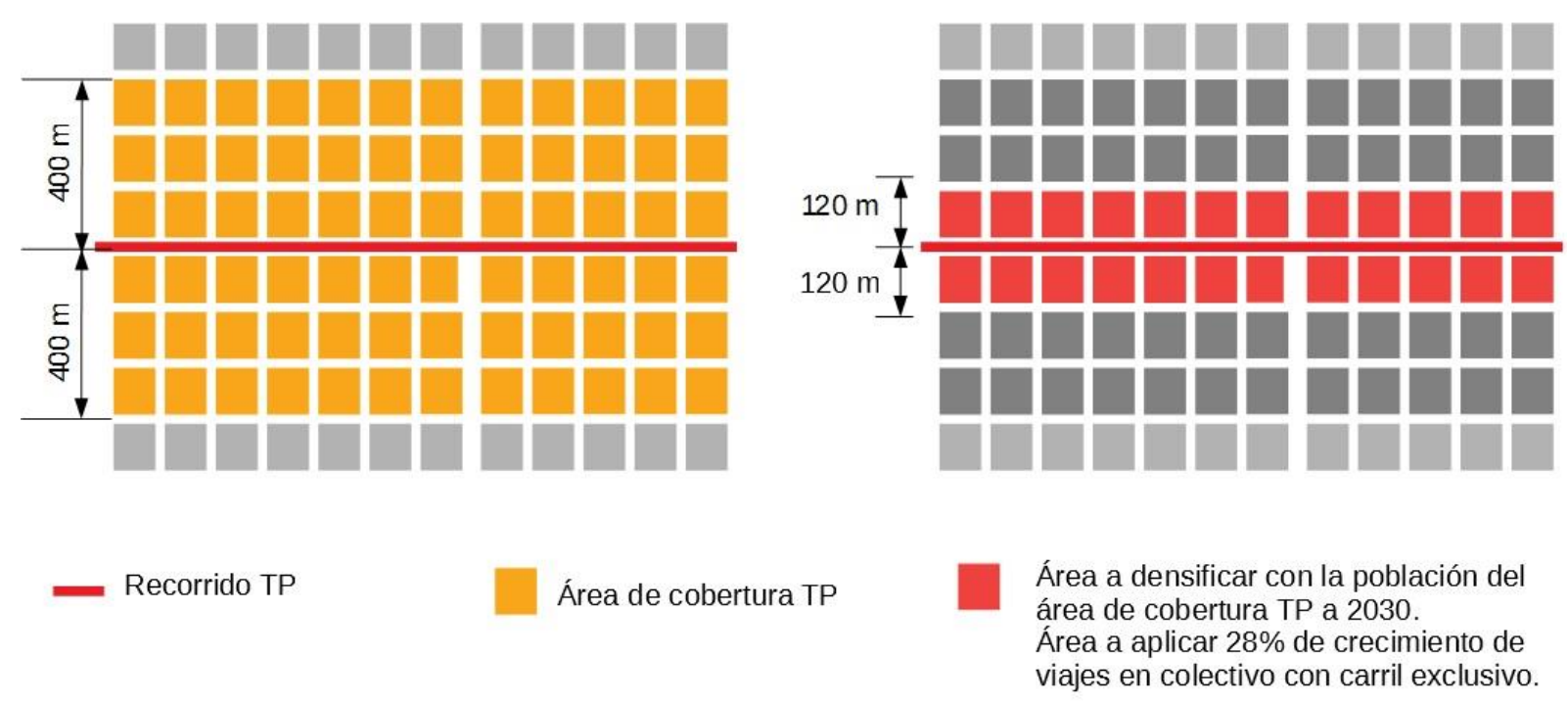

Ilustración 8. Esquema área de cobertura de TP y área a densificar. Fuente: Elaboración propia.

\subsubsection{Metodología para medidas a largo plazo}

En el largo plazo se trata de analizar la posible reducción de la producción de viajes a otras delegaciones a partir de la descentralización de actividades para reducir tiempos de viaje disminuyendo congestión, achicando distancias entre origen y destino, favoreciendo los viajes no motorizados. 
Para ello se considera como área testigo la analizada en los escenarios a corto y mediano plazo $^{49}$ y se utilizan los datos provenientes de la Encuesta de Movilidad realizada por el G2 del IIPAC en 2013.

Para cada delegación del corredor seleccionado se analiza los viajes que podrían descentralizarse según su destino. Entre ellas las actividades que tienen por función dar servicios a la comunidad, como son los servicios de salud, educación obligatoria (primaria y secundaria) y compras/tramites. Quedan afuera de este criterio los viajes por trabajo y educación universitaria.

En ese marco se analizan la cantidad de viajes a la principal área atractora de viajes ${ }^{50}$ que podrían evitarse, reduciendo tiempos de viajes y modos de transporte motorizados si los servicios mencionados se realizaran en las propias delegaciones. Para esto es necesario identificar en cada delegación establecimientos destinados a dar respuesta a las actividades atractoras que, bajo el criterio utilizado, pueden descentralizarse, como son Hospitales, Salas Sanitarias, escuelas primarias y secundarias, delegaciones municipales y cajeros automáticos.

\section{Síntesis Capitulo II}

En este capítulo se desarrolló la metodología para la construcción y ensayo de escenarios integrados de transporte público masivo y uso y producción del suelo.

Asimismo, se desarrollaron las distintas variables utilizadas para dichos escenarios, donde confluyen la revisión bibliográfica, análisis de antecedentes, la construcción de información cuantitativa y cualitativa, con encuestas, entrevistas y talleres participativos. Para dicho análisis se utilizaron diversas técnicas que ayudaron a crear nuevos datos y sintetizar otros, como el software QGIS-Essen, o el árbol de problemas.

Así, los resultados obtenidos a partir de la implementación de la metodología desarrollada en este capítulo para la construcción del año base y de los escenarios tendencial y alternativos contribuirán a generar conclusiones e insumos que aporten a la planificación integrada de transporte público y uso del suelo, lo que se desarrollarán en los capítulos 3 y 4 de la presente tesis.

\footnotetext{
${ }^{49}$ Es decir un segmento del corredor de Av. 7 hacia la zona sur del partido de La Plata y su radio de cobertura de transporte público que contempla sectores de Villa Elvira, Arana (más exactamente el barrio Sicardi) y el Casco Urbano.

${ }^{50}$ Para el caso de estudio, el Casco Urbano.
} 


\section{CAPITULO III: DESARROLLO URBANO Y TRANSPORTE PÚBLICO EN EL GRAN LA PLATA. CONTRUCCION DEL AÑO BASE.}

\section{Resumen}

En este capítulo se plantea la construcción del año base para el Gran La Plata, el cual sintetiza el comportamiento de las principales variables a analizar en un determinado año, en este caso el 2013/2014. Éste se utiliza como año inicial en la simulación de escenarios y se construye a partir de información sintetizada en una base de datos que contiene variables/indicadores relacionados a la dimension espacial, social, económico y ambiental. Se comienza con el desarrollo del proceso histórico de conformación del Gran La Plata y en ese marco el sistema de transporte público colectivo de la región, hasta llegar al sistema actual, el SUT ${ }^{51}$. Se presta especial atención al proceso de implementación de dicho sistema en 2002 y el rol jugado por los distintos actores, ya que junto con la política de subsidios al transporte urbano colectivo iniciada ese año, son fundamentales para comprender la complejidad del conflicto que limita mejoras sustanciales del sistema.

Luego de la descripción histórica del desarrollo urbano-territorial de la ciudad de La Plata se analizan distintas dimensiones que hacen a la problemática del transporte local con especial atención en los tiempos de viaje. Las dimensiones analizadas son: una dimensión espacial que contempla datos de población, ocupación del territorio y movilidad; una social donde se analizan las características sociales en relación al NBI ${ }^{52}$ de la población cubierta por transporte publico según tiempos de viaje por delegación municipal del Gran La Plata; otra económica que aborda los costos de la expansión urbana en términos de movilidad y un estudio de la incidencia de la red de transporte público en los precios del suelo por zona de transporte ${ }^{53}$; y una ambiental que analiza el consumo energético y las emisiones de $\mathrm{CO} 2$ de la movilidad motorizada del caso de estudio. Finalmente se plantea un análisis de las problemáticas de planificación y gestión, a través de un estudio del funcionamiento de los subsidios y de la lógica de algunos los actores clave.

\footnotetext{
${ }^{51}$ SUT.: Sistema Urbano de Transporte.

${ }^{52}$ Necesidades Básicas Insatisfechas según CENSO nacional de población, hogares y viviendas 2010.

${ }^{53}$ Agrupamiento de radios censales según cercanía y comportamientos de movilidad por corredores.
} 


\subsubsection{Fundación y proceso de configuración urbana de la ciudad.}

La ciudad de La Plata fue proyectada en 1882 como capital de la Provincia de Buenos Aires con motivo de la ley de federalización de la ciudad de Buenos Aires impulsada por el presidente de ese entonces Nicolás Avellaneda. El territorio elegido para la nueva ciudad fue el entonces partido de Ensenada ubicado a $60 \mathrm{~km}$ de la Capital Federal.

En ese marco Dardo Rocha, gobernador en ese entonces, encarga al ingeniero Pedro Benoit el diseño de la ciudad de La Plata con ideas estéticas y paisajistas del urbanismo Barroco Europeo del siglo XVII, el higienismo ambiental y funcional del XIX y moderna tecnología para la época como el telégrafo o los tranvías. La planificación urbana en el partido de La Plata desde el tiempo de la Fundación ha atravesado diversos procesos territoriales que influyeron en la configuración actual de los usos del suelo y del transporte. Procesos dominados por las lógicas privadas de la ciudad rentable, ya sea para el mercado inmobiliario o los negocios vinculados del transporte de pasajeros, con un Estado con distintos grados de funcionalidad y colaboración. En sus primeros años y hasta los '40, fue acompañando las políticas urbanas orientadas en afianzar la ocupación y apropiación del nuevo territorio, y se fue desarrollando de manera radial, con las áreas centrales de intercambio y la ubicación de los edificios públicos, como puntos centrales.

A lo largo de los años, la ciudad no entró en contradicción con el modelo fundacional desde el punto de vista que se mantuvo su área central, aunque la ocupación dominante prevista no se concretó. La idea original planteaba el desarrollo de la ciudad sobre el eje Norte-Sur por la vinculación del puerto de La Plata con el interior de la Provincia de Buenos Aires para facilitar la exportación agropecuaria. Pero este planteo perdió fuerza por circunstancias político económicas y cobró impulso el desarrollo de la ciudad en sentido Este-Oeste hacia la periferia Norte, sobre los corredores de vinculación con la Ciudad de Buenos Aires.

La ocupación territorial más importante estuvo ligada al Camino Centenario hacia Buenos Aires (1910) y el Camino General Belgrano hacia Avellaneda (1916) complementados más tarde por el completamiento del último tramo de la Autopista Buenos Aires-La Plata, en el año 1999. La infraestructura vial del cuadrado fundacional de la ciudad, integrado al entorno preexistente, se organizó en una traza ortogonal en damero de orden jerarquizado que fue estructurante del sistema de transporte de pasajeros. Con el paso del tiempo, la red del casco se extendió por fuera del mismo hacia las periferias. 
Según un documento realizado por el Municipio en 1996 ETLP (1996) desde su construcción la ciudad y el territorio platense fueron pensados como un proceso integrado de planeamiento, donde el transporte estaba incorporado como un servicio inseparable de su desarrollo. Su plan director establecía los usos de suelo, los grandes equipamientos y el trazado vial jerarquizado (ver Ilustración 9).

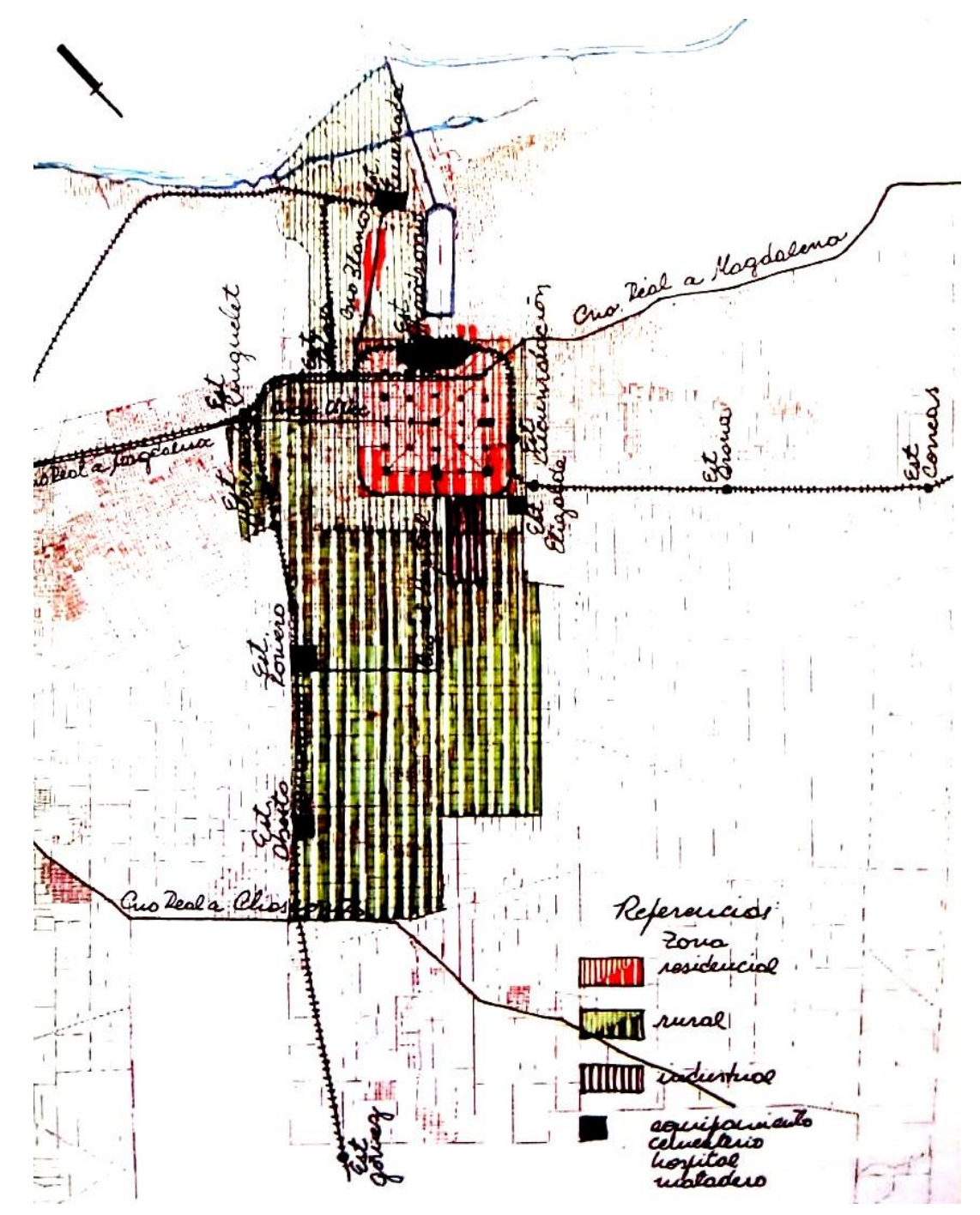

Ilustración 9. Propuesta de vínculos de la micro-región (Gran La Plata) y zonificación de usos. Proyecto 1883-93. Fuente: El Transporte en La Plata. (1996). Municipalidad de La Plata.

Ejemplo de eso son el Camino Real a la Magdalena que cedió su traza a la avenida 1 entre 526 y 72, el Camino Blanco a Ensenada que mantuvo la conexión entre la ciudad "vieja" y la "nueva". Estas infraestructuras resultaron fundamentales para el transporte de carne (saladeros y luego frigoríficos), producción de gran relevancia para el desarrollo inicial regional. Otro ejemplo es el corredor ferroviario que vinculaba la ciudad con lo que hoy conocemos como Brandsen, que daba servicio al Hospital de Melchor Romero y al Matadero Regional de Abasto con directa conexión al puerto. Con el tiempo el incremento de actividad del Hospital 
y el Matadero demandaron el sistema de Tranvía Decauville, tirado por caballos, que intercambiaba pasajeros con el casco y que luego fue reemplazado en 1901 por el Tranway Municipal a vapor ${ }^{54}$. En el sector Norte del partido se encontraba la Estancia Grande vinculada a la producción agrícola y ganadera con vínculo comercial hacia el puerto pero que dadas sus características paisajísticas comienza a transformarse en zona urbana, proceso que se da a partir de la construcción de casas de fin de semana que van consolidando el área y que se incrementa con la instalación de la estación Villa Elisa en 1888.

En 1910 comienza a funcionar el tranvía eléctrico con la concesión de explotación a dos empresas privadas, una nacional y otra de capitales ingleses. Los recorridos de tranvía cubrían principalmente las áreas urbanas de La Plata y reforzaron el vínculo con Berisso y Ensenada a la par que se extendían los servicios de agua, cloacas, alumbrado público y pavimentos, los que articulaban un claro plan de consolidación urbana (ver Ilustración 10).

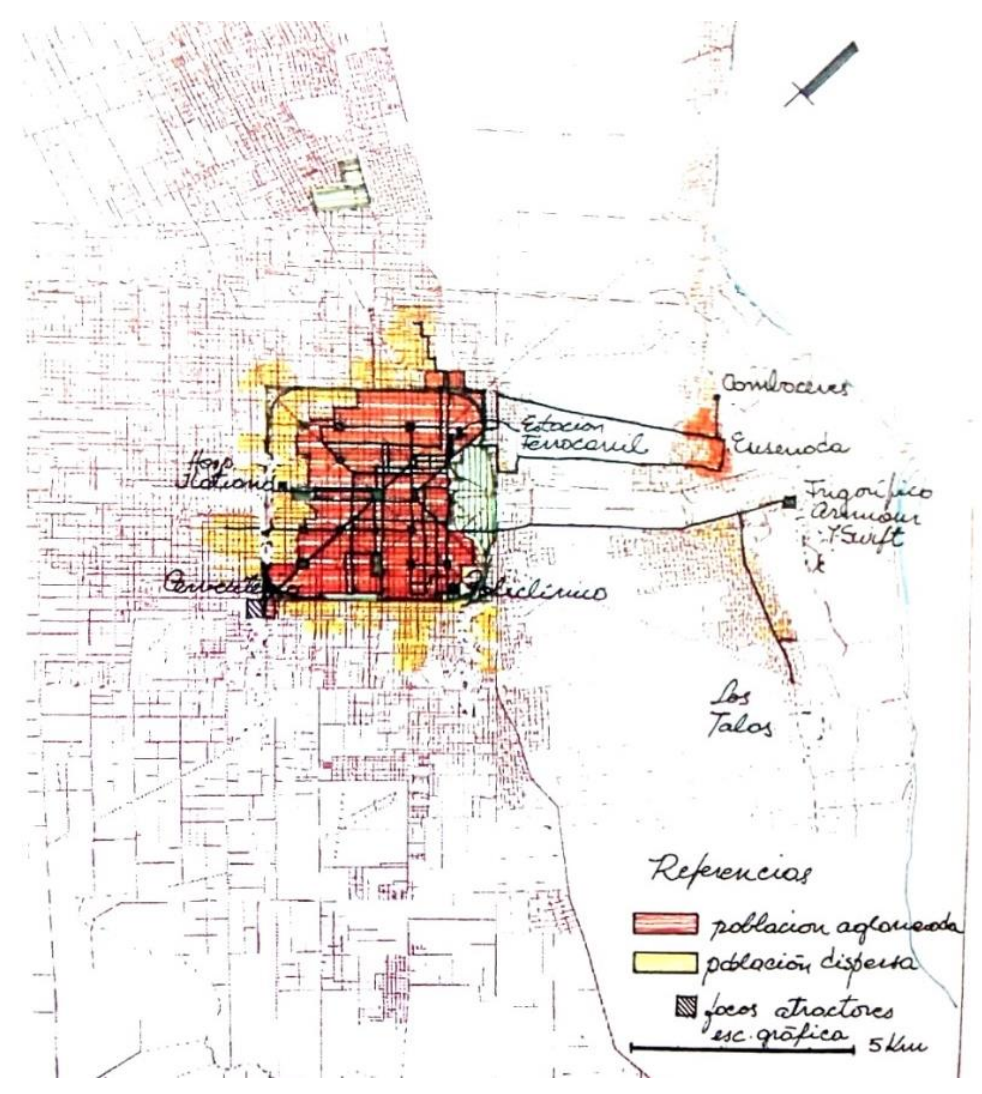

Ilustración 10. Red de tranvías eléctricos hasta 1930. Fuente: El Transporte en La Plata. (1996). Municipalidad de La Plata.

En 1934 el municipio comenzó a otorgar las primeras concesiones para la explotación de recorridos de líneas de autotransporte público de pasajeros que en tan solo 6 años llegaron a

${ }^{54}$ Conocido popularmente como La Clementina y entre 1932-1948 por una especie de autoriel mezcla de microbús con rodado ferroviario 
ser $20^{55}$. Estas líneas competían con los puntos de atracción que ya cubría el tranvía y produjeron una desigual calidad de cobertura según sector de la ciudad.

Por ejemplo en las zonas céntricas del casco se produce una superposición de líneas sobre determinados corredores que producen congestión, contaminación y dificultad para el cumplimiento de los tiempos de viaje, mientras que en las periferias la dispersión de la ocupación (ver Ilustración 11) junto con la escasa infraestructura vial genera recorridos largos en tiempo y distancia, con pocas frecuencias y caros, como se plantea en ETLP (1996). Es posible que haya sido para contrarrestar esta situación que, en un primer momento, el municipio impulsó y explotó por su cuenta líneas llamadas "de fomento" que llegaron a Olmos, Abasto, Etcheverry, Las Quintas y La Cumbre, como afirman Segovia, M., Vallejos, V.H., Ciafardo, R. y Lagos, S. (2003).

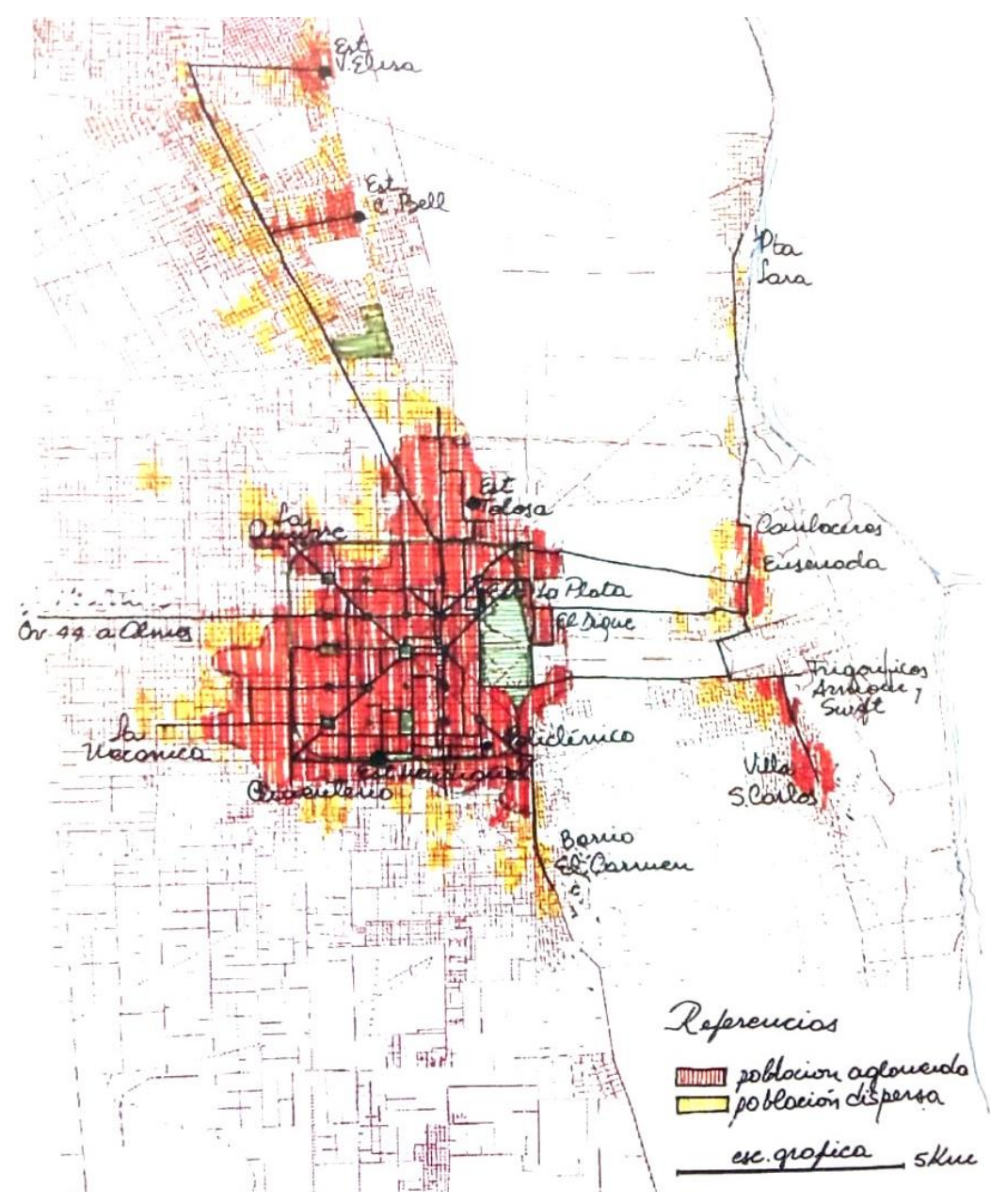

Ilustración 11. Red de autotransporte hasta 1940. Fuente: ETLP (1996). Municipalidad de La Plata. En el año 1936 la legislación provincial con le ley 4.375 permitió la instalación de los servicios intercomunales propuestos por el gobierno provincial con el acuerdo de los

\footnotetext{
${ }^{55}$ Dichas líneas vinculaban el centro de la ciudad con Berisso, Ensenada, Los Hornos, Tolosa, City Bell, Villa Elisa y otros puntos del Partido
} 
municipios con la salvedad de que no entraran en superposición con los recorridos locales. Existe documentación ${ }^{56}$ que plantea que en la década del '40 comienza un fuerte proceso de dispersión urbana en las periferias rurales ${ }^{57}$ y cuyas raíces provienen del impacto migratorio, la falta de normativa reguladora de subdivisión del suelo que impidiera el loteo especulativo y la facilidad de pago de lotes a largo plazo para la población de bajos recursos que buscaba instalarse en la ciudad. Los nuevos loteos carecían de servicios y el sistema de transporte más fácil de poner en funcionamiento en poco tiempo fue el transporte público colectivo, que poseía pocas frecuencias, eran incomodos y caros por tener que adaptarse a la gran dispersión residencial, como se menciona en ETLP, 1996).

En 1948 se establece la ley de propiedad horizontal que favoreció la densificación en el casco y periferias, y en el marco de la estatización durante esa década de los servicios de ferrocarriles, telefónicas, gas y aerolíneas, el municipio finaliza las concesiones de las líneas de tranvía y crea la Administración General del Transporte de Pasajeros (AGTP) que se encarga de gestionar el sistema estatal y privado. Además de tomar el control de las líneas de tranvía, el municipio elimina el autoriel, crea nuevas líneas de colectivo para cubrir zonas alejadas, e impulsa en 1955 el trolebús. En 1959 se promueve la creación de cooperativas de transporte a las cuales se les concede la explotación de las líneas.

Un año más tarde anuncia la creación del Consorcio de Transporte de Pasajeros (CTP) que es un antecedente importante de organismo de coordinación regional conjunta entre el municipio de La Plata y la Provincia de Buenos Aires, aunque fuera solo para administrar el sistema eléctrico de tranvías y trolebuses que perdía cada vez más terreno con el sistema automotor (Segovia, et al. 2003). Finalmente en 1966 el sistema de tranvía y trolebuses deja de funcionar y se termina de consolidar el autotransporte público de pasajeros como único modo de transporte publico estrictamente urbano, ya que también continuó el ramal Roca desde la estación Constitución, en la ciudad de Buenos Aires, hasta la estación de av. 1 y av. 44, en La Plata.

A 70 años de su fundación ya era evidente que el modelo de ciudad planificada integralmente, articulando el desarrollo económico territorial junto al de la movilidad que existió en su origen como proyecto político-económico de la llamada "generación de '80", se había terminado. Ante esta situación a finales de los años '50, el municipio de La Plata impulsa, junto con el municipio de Ensenada, el Plan Regulador Conjunto que encomiendan al grupo de arquitectos Urbis. En dicho plan se planteaba que en ambos partidos existían problemas de

56 "El transporte en La Plata", Municipalidad de La Plata, 1996.

57 Algunas de las zonas de la periferia con problemas de inundación 
dispersión urbana, especulación indiscriminada de la tierra urbana y rural, áreas pobladas sin servicios básicos y complementarios que, además, eran muy costosos, junto con una creciente conflictividad de usos entre las actividades instaladas y el crecimiento urbano (ETLP, 1996).

Según Aón, L., Moro, S. y Ravella, O. (2004) el plan diseñado por el grupo Urbis en 1962 "fue un intento de reordenamiento físico y de desarrollo económico y regional, que retomó la concepción primigenia, conjugando las ideas de la carta de Atenas y el urbanismo de la época. Sus objetivos se centraron en reforzar la función de capitalidad de La Plata, promover el desarrollo y la industria, exaltar el rol universitario de la ciudad y crear un centro regional de recreación y esparcimiento en el partido de Ensenada."

Las principales acciones que planteaba el documento eran definir grandes áreas, racionalizar y conformar una red circulatoria, establecer límite al crecimiento en función del trazado urbano existente, obtener la organicidad morfológica entre las funciones y las localizaciones, respetar la ciudad existente, concebir el centro como direccional, enfatizando la localización de la universidad y, promoviendo con localizaciones parciales, la condición de centro universitario. También dicho documento se proponía definir zonas destinadas a la industria, a parques industriales y concretar dentro de las áreas rurales y semirurales, sus parcelamientos y dimensiones por tipo de explotación. A su vez establecía para Ensenada la función de sede regional de esparcimiento.

En dicho plan, los principales planteos que involucran a la movilidad fueron la zonificación de usos, el control de la subdivisión de la tierra urbana y rural, la ratificación de la estructura circulatoria fundacional y las nuevas prolongaciones a continuación del casco, jerarquización de las vías del sistema urbano y regional, y por último, la propuesta de un Centro Intermodal de Transferencia ubicado en el bosque. A pesar de estas ideas, el Plan Regulador Conjunto nunca se puso en marcha como tal, y a pesar de los posibles límites de la propuesta, los problemas detectados en ese entonces también pueden reconocerse actualmente en las problemáticas territoriales que padece la región y que esperan solución.

\subsubsection{La planificación normativa y el transporte en La Plata}

Posteriormente a la no-implementación del Plan Urbis, el único tipo de instrumento de planificación territorial con que ha contado el Partido de la Plata y su Micro Región ha sido casi exclusivamente normativo, sobre todo de zonificación. Desde mediados del siglo XX, a partir de la creación de la ley que reguló la copropiedad del suelo, se inició un proceso de densificación del espacio construido en las áreas urbanas centrales que se ha intensificado en los últimos once años. Sin embargo el crecimiento del espacio construido de las áreas urbanas 
centrales no ha sido acompañado en todo el periodo por el crecimiento poblacional, que comenzó a tener un saldo negativo desde 1970 y hasta 2001. En este periodo se registró una disminución de población de aproximadamente un $16 \%$ en el centro, mientras la región registró un crecimiento del 12,5\% de habitantes. Ver Ilustración 12.

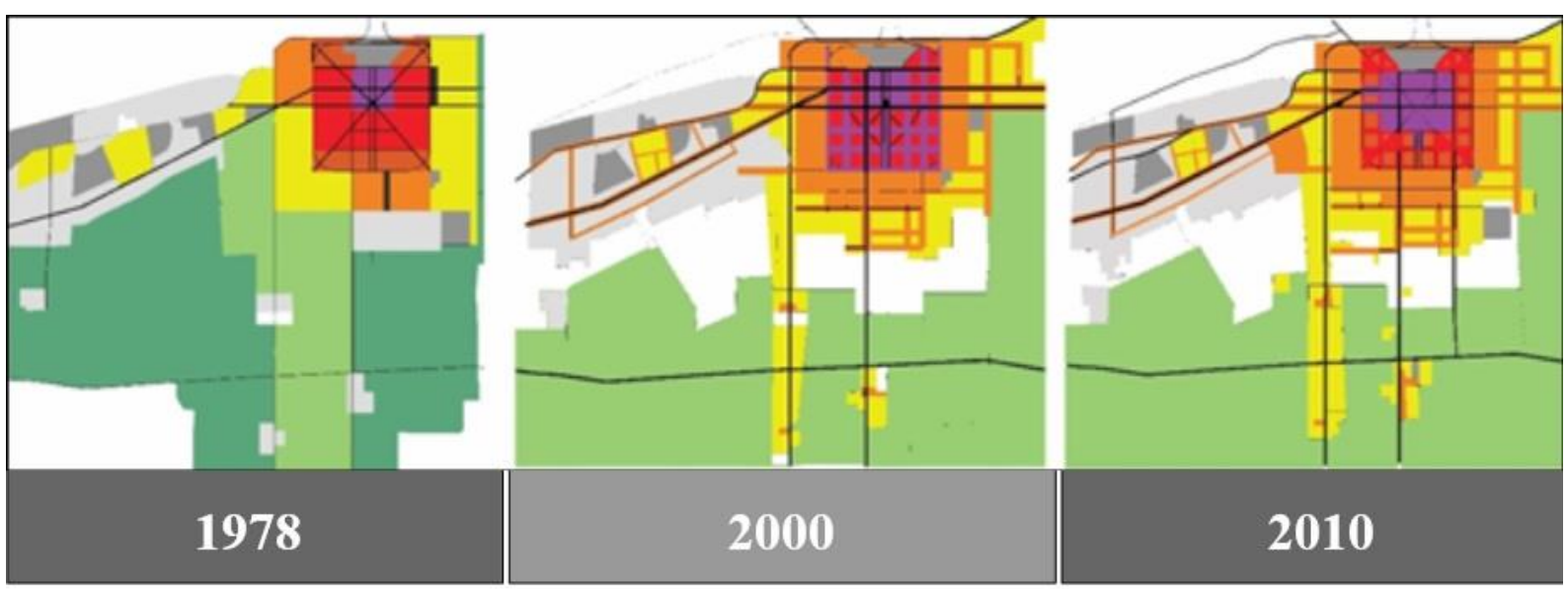

Ilustración 12. Densidades normativas: utilizando las densidades de la última normativa sobre la ocupación propuestas por todos los códigos urbanos de La Plata. Fuente: Elaboración propia, en base a datos de la Dirección de Obras Particulares Municipio de La Plata, web Municipalidad de La Plata (www.laplata.gob.ar).

Este periodo normativo se compone de tres etapas: la etapa inicial comienza con la aprobación y reglamentación de la normativa local que se desarrolló como respuesta del municipio a la demanda provincial que imponía la ley decreto 8912/77; la segunda etapa se inicia a partir del nuevo milenio, con la aprobación de la segunda normativa del partido y primera producida por un gobierno democrático; y finalmente, la tercera etapa, la más breve y actualmente vigente, se inicia a partir de abril de 2010 con la aprobación de la normativa de la gestión política que se desarrolla en el corte temporal propuesto en este trabajo.

Estos tres instrumentos presentan características diferenciadas en sus propósitos, nivel de definiciones y calidades como instrumento técnico. Cada instrumento expresa el posicionamiento político de cada gobierno en lo específico territorial, también al perfil y a las capacidades técnicas de los equipos participantes en su formulación.

\section{Las primeras normativas de uso de suelo}

La Normativa de zonificación según uso $\mathrm{N}^{\circ}$ 4495/78 (en adelante C78) fue aprobada por decreto Provincial en julio de 1978 en el marco de la adecuación a las prescripciones de la Ley $\mathrm{N}^{\circ}$ 8912/77. En ese momento la población total del Partido de La Plata ascendía aproximadamente a un total de 459.054 personas, según datos del censo 1980. 
La C78 comprendía un área urbana bruta de 10.8702,00 ha (ver Tabla 6) diferenciados en 44 tipos de uso distintos: Este instrumento propone 15 valores de densidad distintos que varían entre 80 y 2000 hab/ha y no establece alturas máximas o cantidad de unidades funcionales permitidas. A su vez, considera a las vías jerarquizadas o avenidas solo como límites divisorios de la zonificación y no como corredores de uso. Intenta reconocer los procesos urbanos particulares de cada sector de la ciudad, tanto en el casco como en la periferia, pero con una visión inconexa y fragmentaria de yuxtaposición de zonas que no respondían a ningún criterio vinculado a la movilidad urbana.

Tabla 6. Comparativo de superficies para las tres normativas de uso de suelo de La Plata. Fuente: Elaboración propia, en base a información difundida por la Municipalidad de La Plata.

\begin{tabular}{|c|c|c|c|c|}
\hline \multirow{2}{*}{ Normativa } & \multicolumn{4}{|c|}{ Superficie En Hectáreas } \\
\cline { 2 - 5 } & Urbana & Periurbana & Complementaria & Total \\
\hline $4495 / 78$ & 1716,00 & 9154,00 & ------ & 10870,00 \\
& & & & \\
\hline $9231 / 00$ & 1716,00 & 16936,00 & 1189,60 & 19841,60 \\
\hline $10703 / 10$ & 1716,00 & 17042,80 & 1306,00 & 20064,80 \\
\hline
\end{tabular}

En relación a transporte la normativa define zonas de uso específico para transporte, conceptualiza los "espacios circulatorios", plantea la obligatoriedad de establecer conexión vial con los ensanches urbanos futuros y/o barrios integrales de viviendas y ratifica la necesidad de establecer stándares y tecnologías para la estructuración vial del Partido. Además en el marco de la gestación de la normativa, la Dirección de Tránsito, Pavimentación, Catastro y Planeamiento crea la Comisión de Tránsito y Estacionamiento con la intención de ejecutar acciones en relación a la movilidad vehicular.

Al mismo tiempo se implementan medidas restrictivas y de incompatibilidad de ciertos usos en el área central vinculados al estacionamiento, el transporte, la circulación y entre 19841991 desde la Dirección de Planeamiento se elaboran proyectos de ordenanzas que ratifican la jerarquización vial destinada al transporte de pasajeros, carga y usos de suelo vinculados a actividades que requieren vinculación directa con las vías con la nueva figura de "corredor". Además en 1988 se crea la Dirección de Transporte dependiente de la Subsecretaria de Planeamiento Urbano y Regional.

Por otro lado, la Normativa de Ordenamiento Territorial y Uso de Suelo No 9231 (en adelante C00) fue sancionada en diciembre del año 2000, para una población de aproximadamente 
663.943 habitantes (censo 2001). Comprendía un área bruta urbana de 19.841,6 ha (ver Tabla б) y una densidad poblacional entre 80 y 2.000 hab/ha. Este instrumento diferencia, entre 42 tipos de usos distintos, de los cuales 14 refieren a corredores y sub-centros que admiten mayores densidades útiles para promover la movilidad masiva.

A su vez, propone 8 valores de densidad distintos, establece una cantidad máxima de unidades funcionales por parcela y limitaciones de alturas desde 3 hasta 10 niveles en las áreas centrales y premios por retiros en corredores del microcentro de hasta un $70 \%$ de FOT y densidad. La C00 es una normativa que comienza a dar cuenta de la relación entre usos y movilidad a través de la diferenciación por avenidas en el casco urbano, y de la incorporación de la categoría de sub-centros y zonas complementarias, que dan cuenta de un modelo de ciudad en expansión, y zonas inundables en las periferias. Aunque, por otro lado, aplica una zonificación que es casi simétrica al eje fundacional.

La normativa 10703/10 (en adelante C10) de Uso del Suelo para la ciudad de La Plata fue aprobada en 2010, para una población de 799.523 habitantes, según los datos censales de ese mismo año. Comprende un área urbana bruta de 20.064,80 ha (ver Tabla 6). Diferencia 78 tipos de uso distintos: 23 urbanos (8 en zonas centrales, 9 residenciales, 3 para el eje fundacional,1 de promoción y 2 de articulación), 3 para áreas complementarias (reserva urbana, corredor de servicios e industrial mixta), 18 zonas especiales (9 de preservación patrimonial, 1 de recuperación territorial, 6 de usos específicos, 1 de esparcimiento y 1 de arroyos y bañados) y 5 zonas rurales (sub-centros de servicios rurales, industrial exclusiva, zona de clubes de campo, rural intensiva y rural extensiva) sin distinguir entre ellas a ningún corredor urbano, haciendo de esta manera, caso omiso de la dinámica de movilidad real tanto como de la que potencialmente generará la nueva propuesta de crecimiento poblacional que prevé este instrumento (ver Tabla 7). El mismo propone 11 densidades distintas entre $60 \mathrm{y}$ $2.000 \mathrm{hab} / \mathrm{ha}$ concentrado los mayores valores en el micro centro de la ciudad, y estableciendo límites de alturas de hasta 12 niveles, con premios por cocheras y equipamiento en edificios hasta un máximo total de 14 niveles. C10 es una normativa que pone énfasis en la centralidad única del micro centro de la ciudad, con una visión espacialista, que deriva en aplicar en los corredores una zonificación solo para las parcelas frentistas y fortalecer la simetría al eje fundacional. 
Tabla 7. Análisis de movilidad según densidades máximas permitidas por C10 en casco fundacional. Fuente: Elaboración propia en base a planos difundidos por el Municipio de La Plata.

\begin{tabular}{|l|l|l|}
\hline $\begin{array}{l}\text { Zonas Urbanas } \\
\text { del COU en el } \\
\text { Casco }\end{array}$ & $\begin{array}{l}\text { Población } \\
\text { Máxima } \\
\text { Permitida }\end{array}$ & $\begin{array}{l}\text { Demanda de } \\
\text { Viajes estimada } \\
(1,51 \mathrm{v} / \mathrm{d})\end{array}$ \\
\hline U/C1a & 39000 & 58890 \\
\hline U/C2b & 54000 & 81540 \\
\hline U/C3 & 123000 & 185730 \\
\hline U/R 1 & 140000 & 211400 \\
\hline TOTAL & 356000 & 537560 \\
\hline
\end{tabular}

La C78 establecía una superficie urbana legal total de 10.870 ha, centrada en el casco urbano, primer y segundo anillo periférico, y el área que conforman los caminos Centenario y Belgrano. También contemplaba como zonas residenciales sobre los corredores de Av. 520 y Av. 44 Melchor Romero, Abasto, Lisandro Olmos, y Arturo Seguí alrededor de la vieja estación de trenes.

En el año 2000, la C00 aumenta la superficie urbana del Partido de La Plata a 1189,6 ha, con un crecimiento hacia el Noroeste, a partir de corredor de Camino Belgrano y Av. 520 y al Sureste a partir de los corredores Av. 7, Av. 13 y Ruta $n^{\circ} 11$. También crecen los barrios dispersos sobre los corredores y se les permite un uso comercial sobre éstos. Además, la C00 incorpora el tipo Reserva Urbana con áreas importantes que llegan a 3024 ha. La C10, aprobada 10 años después, plantea un crecimiento de las zonas urbanas principalmente en forma dispersa en suelo RU, y también en forma de corredor sobre las avenidas 44, 60 y 66 hasta Ruta n³6. Además se amplía el centro de Lisandro Olmos en un 40\%.

De esta manera el área legal urbana de la ciudad pasó desde considerar de forma compacta el área del casco urbano de la ciudad y los caminos como zonas baja densidad en el C78, al C00 que proponía una ciudad que mantiene la centralidad en el casco pero considera las distintas escalas de los corredores y subcentros, y establece reservas de crecimiento en expansión, hasta llegar al C10 que fortalece los corredores hacia el Oeste, pero es disperso en la creación de las nuevas áreas urbanas en general. 
La planificación de los usos del suelo orientada por el C00 fue elaborada en el marco de un trabajo de investigación del área de planificación del municipio de La Plata cuyo objetivo primario fue "incorporar al análisis territorial el estudio de aspectos sociales, económicos, físico construidos y fisico naturales", una categorización de componentes territoriales que adoptan para la construcción del modelo explicativo de los procesos territoriales que abordan. Las variables utilizadas para la identificación de lógicas de ocupación incluyeron el marco legal, el nivel de ingreso, las características físicas (naturales y construidas) y la dinámica temporal, excluyendo de manera implícita la dinámica espacial que da cuenta de los patrones de movilidad pero reconociendo el concepto de accesibilidad y el valor de los corredores según sus jerarquías de transporte, para la definición de indicadores de densidad (ver Tabla $8)$.

Tabla 8. Análisis de movilidad según densidades máximas en corredores C00. Fuente: Elaboración propia en base a planos del C00 aportados por el Municipio de La Plata y proyección Encuesta OD (Aón, 2003).

\begin{tabular}{|l|l|l|}
\hline $\begin{array}{l}\text { Corredores } \\
\text { zonificados }\end{array}$ & $\begin{array}{l}\text { Población max. } \\
\text { Permitida }\end{array}$ & $\begin{array}{l}\text { Demanda de Viajes } \\
\text { estimada }(1,51 \mathrm{v} / \mathrm{d})\end{array}$ \\
\hline AV. 7 & 142.200 & 214.722 \\
\hline AV. 13 & 44.500 & 67.195 \\
\hline AV. 44 & 99.600 & 150.396 \\
\hline AV. 60 & 92.736 & 140.031 \\
\hline AV. 66 & 69.000 & 104.190 \\
\hline AV. 90 & 39.600 & 59.796 \\
\hline TOTALES & 487.636 & 736.330 \\
\hline
\end{tabular}

Este instrumento producido a lo largo de una década de estudios y discusiones técnico políticas en el marco del COUT $^{58}$, aplica medidas tales como la inclusión a usos urbanos de suelos decapitados, a la vez que se restringe el uso urbano en áreas ya ocupadas, detectadas como anegables. La normativa establece además el abastecimiento de infraestructuras de

58 El COUT o Consejo de Ordenamiento Urbano Territorial fue un espacio de trabajo creado para la formulación de un proceso de planificación territorial del Partido de La Plata con participación representada de universidades, colegios profesionales, cámaras empresarias y entidades de gobierno, el cual funcionó desde mediados de la década de los años 90 hasta el cambio de gestión municipal efectivizado en diciembre del año 2007. 
servicios en áreas de expansión urbana y propone, aunque de manera no-especifica, la ampliación de la oferta de espacios verdes. Esta lógica de respuesta a problemas urbanoterritoriales emergentes no contempla en qué medida las transformaciones en los usos pueden producir disfuncionalidades en los sistemas de transporte en general, y particularmente en el de transporte público con su posibilidad material de sustentabilidad económica. Por otro lado, sí considera la accesibilidad a la ciudad como un factor de planificación y los corredores urbanos, como concentradores de densidades poblacionales, estableciendo una jerarquización de vías y densidades.

En este sentido la C00 generó un potencial para la planificación y promoción de una oferta de transporte público masivo que absorbiera una mayor demanda de viajes generados en áreas centrales o del primer anillo de desborde. Sin embargo este potencial no fue aprovechado para la planificación del sistema de recorridos de transporte público, implementada dos años más tarde. En efecto, el plan de transporte público fue desarrollado, al igual que la normativa en cuestión, a lo largo de la década de los años '90, mediante una fuerte inversión del Estado municipal en estudios de campo y relevamientos. Ambos estudios se desarrollaron en oficinas contiguas pero sin interrelación alguna, sin conocimiento ni aprovechamiento de las ventajas y oportunidades que un instrumento podría proveerle al otro. De esta manera el sistema de transporte público ignoró el sistema de corredores urbanos como oportunidad de diseñar un sistema de recorridos racionalizados, e impuso un esquema de distribución de áreas urbanas dividiendo la ciudad en cuatro zonas iguales, independientes de los corredores, según cuatro puntos cardinales con el solo propósito de evitar conflictos al interior del sector empresario.

La formulación de la C00 ofreció otra potencialidad para la planificación de la movilidad que tampoco fue tomada en cuenta para la planificación del transporte público, que fue el reconocimiento de áreas de centralidad urbana, asimilables a áreas atractoras de viajes. A éstas áreas la $\mathrm{C} 00$ aplica restricciones asociadas a aspectos morfológicos y corrección de usos permitidos y densidades. Sin embargo no se aprovechan estos aspectos en la formulación del plan de transporte, como tampoco se consideran ni establecen desde la propia normativa restricciones espaciales para un mejoramiento de la infraestructura de circulación de masivos y no motorizados.

En el Casco Urbano la C00 aumentó la potencial densificación poblacional en un 82\% respecto de la situación anterior, estableciendo un límite máximo total de población para la totalidad del partido de 1.428.120. Esta cantidad de población supone un total de viajes diarios promedio anual de 2.156.461, de los cuales el $80 \%$ se concentra en áreas centrales, mientras que si se analizaran en función de los corredores el porcentaje sería un 55,73 \%. 
Si se consideran los premios que establecía esta normativa en el centro del Casco Urbano para las manzanas del eje fundacional y las ubicadas sobre las avenidas comprendidas entre 1, 14, 43 y 61, el máximo de población a que apuntaba era de 275.400 que implicaban un total de viajes diarios de 415.854. Estos máximos valores de viajes diarios constituirían un $37 \%$ del total de viajes potenciales para la micro región que podrían ser resueltos articulando esta propuesta con una oferta de transporte público masivo en corredores, carriles exclusivos con coches biarticulados y paradas a nivel, frecuencias de diez minutos con capacidades de 270 pasajeros. Esta propuesta podría haber sido una respuesta integradora entre uso de suelo y transporte público que habría mejorado la movilidad en la ciudad.

En la periferia, esta ordenanza establece en el primer anillo periférico una densidad de 300 hab/ha y 3 niveles de altura pero a las manzanas sobre los corredores se les permite un FOT mayor $(1,2$ contra 0,8$)$. A su vez, se transforman a suelo urbano 7782 ha y 1189 ha a zonas complementarias, de las cuales $59 \%$ correspondían en la normativa anterior a zonas rurales extensivas y $41 \%$ a intensivas. Estas nuevas áreas urbanas que incorpora la normativa poseen una distancia media máxima al centro urbano de la ciudad de 8 kilómetros, donde las densidades de población son muy bajas, de 150 o 60 hab/ha, ya que la mayoría de los terrenos que se pasaron a suelo urbano corresponden a una legalización de localizaciones residenciales que se fueron asentando de hecho.

La C00 constituye un instrumento de superior calidad a su predecesora C78 desde el punto de vista de la integración uso de suelo - transporte y como instrumento de planificación territorial en general. Aunque por otro lado, el plan de transporte carece de una racionalidad acorde a las infinitas posibilidades del diseño urbano de la estructura física de la ciudad y del buen acompañamiento normativo de la C00. El desacople aparece de la mano del diseño institucional, operativo y en parte también a las capacidades técnicas de los recursos humanos involucrados, que pudiendo acceder mutuamente a la conformación de los respectivos planes de suelo y transporte, decidieron trabajar de manera autónoma y desarticulada.

\section{El nuevo sistema de transporte y la actual normativa de usos de suelo}

La reestructuración en el sistema de transporte público automotor de pasajeros, propuesta por la Dirección de Transporte de la Municipalidad de La Plata, implementada en junio del año 2002, implicó un importante cambio respecto del sistema de recorridos anterior, y también en la forma de gestión institucional. La propuesta implicó un avance importante en la racionalización económica del sistema (que significó una reducción del 33\% en los kilómetros recorridos diarios) pero por otro lado, quedó sujeta a la puja de intereses del sector empresario 
por una distribución equitativa de los recorridos urbanos más rentables. El resultado fue una virtual zonificación de la ciudad particionada según la cantidad de empresas, convergiendo todas en el área central de la ciudad. El planteo de partida promovió una concentración de servicios y congestión urbana en el centro de la ciudad, lo que se materializó en una intensificación de las malas condiciones de vida urbano-ambientales del área central de La Plata.

El criterio de división de la planta urbana de la ciudad en cuatro partes tuvo el claro propósito de evitar lo más posible la superposición de líneas y servicios comunales, pero nunca pudo evitar la superposición con las líneas de transporte público provinciales. Este fue uno de los déficits de la propuesta, y derivó del hecho de no contar con una entidad administrativa común entre los municipios y la provincia. El esquema de división comunal dejó antiguos servicios inconexos que fueron cubriendo las líneas provinciales, en un rápido proceso de adaptación al cambio. También existieron dificultades en comunicación a la comunidad de los cambios producidos en el sistema de transporte, y en generar consenso con el sector empresario sobre la propuesta. Este sector se opuso a la modificación del sistema reclamando una presunta pérdida de puestos de trabajos y kilómetros recorridos. En ese marco, y sumada a la crisis económica nacional de 2001, se produjo también una notable pérdida de pasajeros del modo masivo y una absorción de esa demanda hacia el modo remisse, cuya tarifa (en esos años) competía cómodamente con la del transporte público. Según Aón, L. Giglio, M.N. y Cola, C. (2017) esta convergencia de fenómenos incrementó el uso de automóviles en la ciudad, y con ello crecieron los niveles de contaminación, congestión y protagonismo del automóvil en el espacio urbano.

A principios del milenio, el proceso de densificación del espacio construido crecía de manera lenta mientras decrecía la población del centro. Con la recuperación de la crisis económica del 2001, particularmente a partir de mediados del año 2003, comenzó un crecimiento sostenido de la construcción de viviendas sostenido, especialmente en el centro de la ciudad, en la medida en que los grupos inmobiliarios y los ahorristas, encontraron una mayor seguridad financiera en los inmuebles que en la banca local, que había capturado sus ahorros a fines de 2001. Según datos del INDEC, el crecimiento de población en el casco urbano para 2010 fue de 4,95\%. De acuerdo con datos del censo nacional de población, hogares y viviendas 2010, en 9 años se incorporaron en La Plata 21.551 casas y 14.417 departamentos. Esto representa un incremento del $17,6 \%$ y $37,9 \%$ respectivamente. Es decir, se construyeron 1.602 departamentos por año, una tasa de crecimiento superior a la Capital Federal. (4,4 \% en casas y $9,68 \%$ en departamentos). El crecimiento de superficie construida sigue siendo 
proporcionalmente mayor al crecimiento de habitantes en el área central, aunque se registra un incremento poblacional de 8.218 nuevos habitantes en áreas centrales, situación que no sucedía desde los años '70, como desarrollan Aón, L. Giglio, M.N. y Cola, C. (2017).

La adquisición de inmuebles como "bienes de cambio" y no como "bienes de uso" y la proporción elevada de inmuebles vacíos (19\%) presiona sobre el precio de los inmuebles y alquileres a la vez que produce incertidumbre acerca de quiénes serán los nuevos habitantes del área central. Al respecto, las hipótesis que maneja el mercado inmobiliario local incluyen a parejas para su primera vivienda y estudiantes. De esta manera el casco urbano se densifica desde 2003 predominantemente con emprendimientos de propiedad horizontal y con tipología en torre, siguiendo inicialmente la lógica de la $\mathrm{C} 00$ y posteriormente adaptándose a las densidades incrementadas de la C10. Las torres han venido ocupando algunos lotes vacantes y más frecuentemente a reemplazar viviendas unifamiliares antiguas e incluso nuevas, sobre los corredores principales y en torno a las plazas de la ciudad. Según Freaza, N. y Aón, L (2013), dadas las características del trazado urbano de la ciudad de La Plata, con plazas y avenidas cada seis cuadras, el cambio fisonómico tiene un fuerte impacto visual, ambiental, poblacional y cultural para la totalidad de las áreas centrales urbanas.

Este escenario de densificación del espacio construido y de población no sólo implica un crecimiento de la cantidad de automóviles, sino que además crece la actividad del transporte producido en las áreas centrales. A esta situación se suma el patrón de movilidad propio del centro, que es zona atractora del $80 \%$ de los viajes totales que se producen en toda la micro región. En el caso del casco urbano, la cantidad total de viajes producidos alcanza en la actualidad al $25 \%$ del total de viajes. De esta manera más de 1.000 .000 de desplazamientos diarios se producen en una superficie urbana de aproximadamente 3.000 hectáreas incluidas en el casco fundacional de la ciudad, y de los cuales 340.000 corresponden a los residentes que tenía el casco fundacional hasta 2001, fecha en la que el índice de motorización era de un automóvil cada cuatro habitantes.

La C10 ha sido muy cuestionada por facilitar estas tendencias urbanas en el área central. Las alturas permitidas dentro del microcentro de la ciudad aumentan hasta 14 niveles con premios y a su vez se amplían las áreas más permisivas en un 400\%, también se incrementa un 200\% el área para construir hasta 12 niveles (con posibilidad de mayores incrementos bajo la figura de los premios) en algunas zonas donde C00 permitía 6 niveles. En áreas residenciales del casco entre circunvalación y Av. 1, Av. 38, Av. 19 y Av. 66. donde antes se construía edificios de un máximo de 4 niveles se redujo a 3. En este sentido, la C10 fomenta la 
densificación habitacional y poblacional en las áreas centrales. En una de las áreas más densificadas del casco fundacional, la zona de transporte $21^{59}$ (ver Ilustración 13) hubo un crecimiento de $39 \%$ de viviendas (aproximadamente $25,3 \%$ deshabitado) y un aumento del $20 \%$ de población respecto del año 2001. En esta área en la que se estima una cantidad de autos de 3.736 con una cantidad de estacionamientos de 386 , la oferta de transporte público es relativamente alta en lo cuantitativo y de baja calidad en frecuencias, teniendo hasta 50 min en "horas valle" con un $60 \%$ de los ramales con frecuencias menores a los 30 minutos y cerca del 30\% con frecuencias menores a 15 minutos, como plantean Aón, L. Giglio, M.N. y Cola, C. (2017).

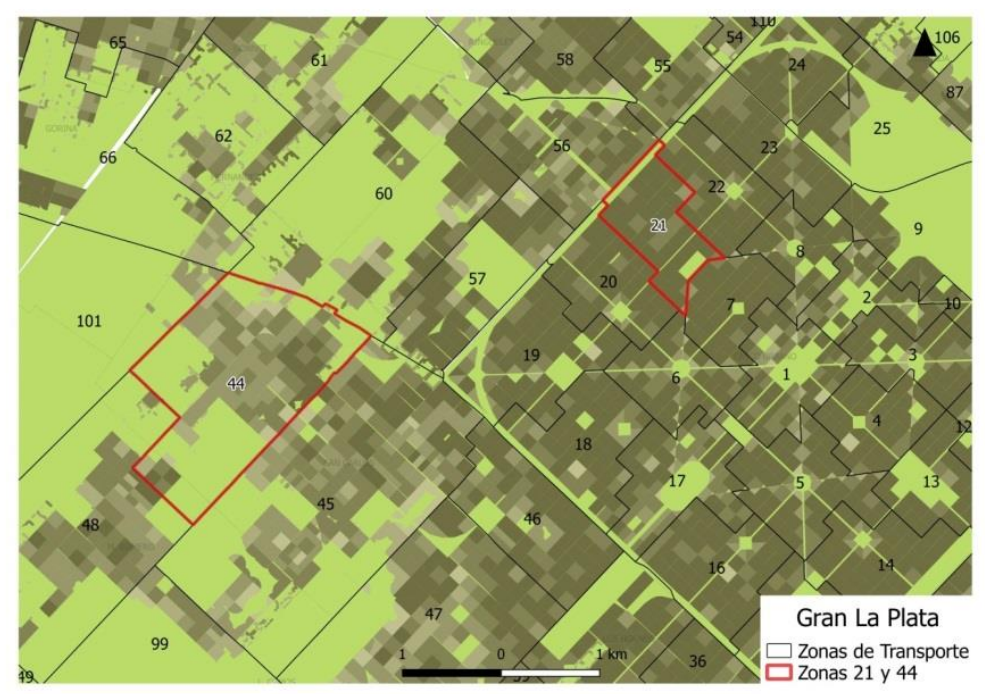

Ilustración 13. Zonas de transporte seleccionadas. Fuente: Elaboración propia.

Como política de suelo y desde el punto de vista de la planificación de la oferta de transporte masivo y de los patrones de movilidad de los habitantes, también en su propuesta de extensión periférica, el instrumento profundiza las tendencias negativas que repercuten en la movilidad. El aumento de la superficie de zonas para residencia en la periferia fue de 223 ha en sectores puntualmente localizados cuya configuración inconexa evidencia la falta de previsión planificada del crecimiento urbano. En este sentido, es destacable que casi la mitad de esa nueva área urbana periférica propuesta (104 ha) eran terrenos de actividad rural intensiva mientras que el resto de la nueva área urbana periférica había sido prevista por la normativa precedente como área de reserva urbana. En este sentido se verifica una tendencia de expansión rápida y heterogénea en la ocupación del suelo en el último anillo periférico

59 La zonificación para estudios de transporte de La micro región del Gran La Plata se compone de zonas y macrozonas de transporte, que agrupan radios censales según tamaño de población de las áreas y cantidad y tipo de corredores urbanos que las definen. Realizada por la UI6B IDEHAB FAU UNLP 1987. 
urbano, que no fue contemplada como problema en este nuevo instrumento. Todo esto incide en la fragmentación periférica que constituye una de las principales barreras políticoeconómicas para planificar una oferta de transporte masivo sustentable en lo económico y social, es decir, que lo acepten las empresas y que esté al alcance económico del conjunto social.

Un caso testigo periférico es la zona de transporte $44^{60}$ (ver Ilustración 13 ) que registró en el periodo (2001-2010) un crecimiento habitacional aproximado de un $117 \%$ y poblacional de $105 \%$, en algunos sectores de asentamientos precarios con densidades habitacionales superiores a las que contempla de normativa (asentamiento Las Quintas con 325 hs/ha situado en UR3 con $150 \mathrm{~h} /$ ha propuesto) o loteos residenciales aprobados en áreas CIM solo apto para industrias inocuas. El comportamiento del SUT en las áreas periféricas es escaso en cuanto a la oferta de destinos de los recorridos, bajas frecuencias y escaso en horario nocturno. El caso testigo evidenció que todos los recorridos que por allí pasan se dirigen al microcentro de la ciudad, donde el $90 \%$ de los ramales tienen una frecuencia mayor a los 15 minutos, y el 60\% mayor a 30 minutos, para una zona de transporte que posee casi el doble de población que el área testigo central, como desarrollan Aón, L., Cola, C., y Giglio, M.L.(2014).

Esta situación de conjunto describe la preponderancia del sector privado sobre el público, tanto en materia de crecimiento habitacional como de movilidad y transporte. La normativa C10 incrementa la rentabilidad del suelo con mayores alturas y densidades en el micro centro permitiendo a las inmobiliarias mayor rentabilidad absoluta y relativa. El mismo gobierno municipal también argumentó que gracias a esa baja y el aumento permitido a las zonas de uso contiguas hasta 6 niveles, la rentabilidad está favorecida por el uso de ascensor, es obligatorio a partir del $4^{\circ}$ nivel. Con esa misma lógica pero fuera de las zonas urbanas se permite la creación de clubes de campo en ambas manos de la Ruta Provincial n ${ }^{\circ} 2$ con el objetivo de "promover el desarrollo de esa actividad que, en los últimos tiempos, aprovecharon distritos vecinos como Brandsen y Berazategui” (E1 Día, 7/2009). En el sentido de una ciudad dispersa en la periferia, la normativa también permite la realización de Loteos Sociales, a los cuales podrán acceder cooperativas, asociaciones, colegios o cualquier institución que tenga personería jurídica, con posibilidad de realizar loteos inferiores al mínimo permitido por la normativa en terrenos periféricos o adyacentes urbanos. Además en los últimos la mayor demanda de lotes años a partir de los créditos PROCREAR fortaleció la dispersión de la ciudad. En ese proceso el municipio tuvo un rol de facilitador, modificando la normativa para que se pudieran llevar adelante estos proyectos que ejercieron una presión al

60 Correspondiente a la zonificación antes mencionada. 
aumento del precio del suelo, aun cuando en muchos casos con contaban con servicios básicos completos.

La falta de planificación integrada se verifica una vez más en las prácticas de planificación local en la materia específica del transporte. Al respecto, las medidas de la gestión municipal dirigidas a mejorar el transporte público colectivo automotor en los últimos 5 años, estuvieron signadas por acuerdos no cumplidos por parte de las empresas prestadoras del servicio, lo que, en la mayoría de los casos, se combinó con una actitud pasiva en la mayoría de los casos por parte del Municipio. En mayo de 2011 se impulsan la recuperación de recorridos tradicionales preexistentes al SUT (las antiguas líneas 500) en formato semirrápido. También se modifican los recorridos y ramales que forman parte del SUT. Debido a estos cambios con poca difusión, en septiembre de 2011 la justicia solicita más indicaciones en las paradas de colectivos con el objetivo de presionar tanto al municipio como a las empresas a brindar la información necesaria sobre recorridos y horarios a los usuarios. Los cambios introducidos por el municipio desde 2008 tratan de responder de forma puntual y pragmática a la problemática, encontrándose en ocasiones en contradicción algunas de las medidas implementadas.

En este contexto cabe recordar que al comienzo de la gestión municipal (a finales de 2007) más de la mitad de los reclamos de la comunidad sobre los servicios municipales correspondían a reclamos sobre un sistema de transporte público, que el flamante intendente se había comprometido a solucionar en su campaña. Sin embargo, la oposición constante de las empresas a invertir y su propensión a evitar medidas que fueran en el sentido de un mayor control por parte del Estado, así como la baja inversión del municipio en estudios y planificación de la movilidad urbana, constituyeron barreras para la mejora del sistema.

\subsubsection{Actores involucrados en el transporte público}

\section{Los empresarios, la rentabilidad por sobre el servicio}

El autotransporte público de pasajeros en La Plata comienza como una iniciativa privada en los años '30 a partir de la asociación de 2 o más dueños de colectivos que le solicitaban al municipio la explotación de los recorridos. Varios trabajos como ETLP (1996); Aón, L., Moro, S., y Ravella, O. (2004); Segovia, et al. (2003); y Frediani, J., Elizalde, M.E. (2003) plantean que este origen del sistema de transporte colectivo marcó la fuerte lógica de maximización de la rentabilidad de los empresarios de transporte en desmedro de brindar un buen servicio. Desde el comienzo, los recorridos propuestos por las empresas fueron los que demandaban mayor cantidad de viajes, es decir los viajes desde las áreas consolidadas de la 
ciudad hacia el centro. Sin estudios previos la municipalidad fue aprobando a lo largo de los años los recorridos de distintas empresas que se superponían entre sí, que en los primeros 30 años de su aparición llegaron a ser 50 líneas, mientras se encargaba de administrar las líneas de fomento que cubrían las periferias. La superposición y competencia de recorridos exacerbada fue desproporcionada para la demanda y la rentabilidad empresarial (se basada en el alto precio de la tarifa) llegó a ser la más cara del país en términos relativos, transfiriendo a los usuarios la irracionalidad del sistema. Pero esta situación tuvo su techo y el sistema de transporte colectivo entró en declinación. En el año 1991, el comienzo de la privatización del Ferrocarril Roca y la recesión económica fueron cruciales en una baja importante de los viajes en transporte público colectivo en la micro región.

Los despidos masivos de los años '90 como producto de las privatizaciones empujaron a las familias desocupadas a tener que buscar sustento económico en la actividad privada, algunas ellas ligadas al transporte automotor. Muchos de ellos utilizaron las indemnizaciones para comprar autos (de precios relativamente baratos por la paridad del peso/dólar y promovidos por el "plan canje") y aprovecharon los altos costos de las tarifas de colectivo y la mala cobertura para volcarse al transporte público no masivo como taxis y remisses. Esta modalidad se fue incrementando, mientras que el volumen de pasajeros transportados por el transporte público disminuyó en un 35\% entre 1993 y 1997. En forma paralela, también incidió en este panorama el crecimiento del parque automotor de un auto cada 5 personas en 1993 a un auto cada 3,5 personas en el año 1999.

A raíz de esta situación varias empresas transportistas quebraron o fueron absorbidas por otras, que para mantenerse, también realizaron ajustes disminuyendo la cantidad de coches, choferes y frecuencias, y eliminando servicios nocturnos, entre otras acciones.

\section{El Estado, entre la regulación provincial y municipal del transporte}

El transporte público de pasajeros que funciona en el Gran La Plata se rige por disposiciones legales de la provincia de Buenos Aires que, según el recorrido de los ramales, determinan cuales corresponden a ser regulados por la provincia y cuales por los municipios.

Desde lo normativo el decreto ley vigente es el 16.378/57 que, a pesar de ser más acotado que la ley 5808 precedente, nunca se aplicó plenamente y fue sufriendo modificaciones. Según Segovia et al. (2003) la derogación de la ley 5808 y su reemplazo por el Decreto/Ley 16.378 constituyeron un hito en el devenir del transporte en la provincia, que se reflejó en la ciudad de La Plata. Los autores plantean que se anularon las concepciones sociales y se mantuvieron las medidas prácticas y administrativas en la mera organización y fiscalización de los 
servicios. También se mantuvo la facultad de la Dirección Provincial de Transporte para crear planes integrales de reorganización regional y otras figuras legales que permitían planificar coordinadamente el transporte público cuando dos o más ciudades que conformaran una región lo desearen.

A pesar de ello, se fueron anulando y derogando facultades progresivas, como por ejemplo, la consulta a las sociedades vecinales ante algún cambio en el sistema o la facultad del Estado para imprimir los boletos y solicitar la presentación periódica de los libros de contabilidad de las empresas para una mejor fiscalización y control, la aplicación del producto del pago del impuesto a los Ingresos Brutos por parte de las empresas a la integración de un fondo para caminos de fomento rural, la prerrogativa del municipio a ejecutar la caducidad del contrato ante el incumplimiento de las empresas a las directivas estatales, la entrega de información inexacta, o el incumplimiento grave o repetido de la normativa, lo que facultaba al municipio a optar entre la expropiación o la fijación de nuevas bases para otras concesiones.

A partir de 1959, las líneas que unían a La Plata, Berisso y Ensenada pasaron a jurisdicción provincial quedando cinco líneas municipales y cinco provinciales que se fueron modificando hasta las transformaciones más importantes del sistema desde esta época que fue la implementación del SUT. Esta "provincialización” de las líneas municipales obstruyó la posibilidad de una planificación del transporte a nivel regional. Según la encuesta Origen Destino realizada en $1993^{61}$, el vínculo entre La Plata y Berisso significaban 13.000 viajes diarios y la ligazón con Ensenada otros 8.000. Las modificaciones realizadas no contemplaron los roles que cumplía cada una de las líneas en el territorio, la ubicación de las terminales o la superposición de áreas y recorridos.

Segovia (et al. 2003) plantean acertadamente que otro grave error fue no contemplar las necesidades propias de los nuevos municipios que no poseían servicios locales, como son Berisso y Ensenada, y que poseían 16.000 y 9.600 viajes internos respectivamente. Tampoco se tuvieron en cuenta los antecedentes históricos de distintas modalidades, ya sea decauville o tranvía que unían barrios de Berisso y Ensenada con el frigorífico. Esta situación llegó al límite a fines de los años ' 80 con la obstrucción por parte de la autoridad provincial y las empresas del área, a que Berisso obtuviera una línea propia que conectase el barrio El Carmen con el centro de la ciudad.

Otro mal manejo y connivencia entre el gobierno provincial y las empresas ocurrió en los años ' 70 con el traspaso de la línea 503 (la actual 273) a la esfera provincial. Este traspaso fue

\footnotetext{
${ }^{61}$ Encuesta Origen Destino del Gran La Plata. Municipalidad De La Plata y IDEHAB. 1993.
} 
justificado a partir de la extensión de un ramal que llegaba hasta Gutiérrez (zona Sur de Berazategui), pero el $90 \%$ de cuyos recorridos no salían de La Plata. Para las empresas, la ventaja buscada obedecía a que las líneas provinciales poseen un régimen económico ventajoso con respecto a las municipales.

\section{El gremio}

El sindicato mayoritario de los trabajadores agremiados del sistema de transporte público del Gran La Plata es la Unión Tranviarios Automotor (U.T.A.) fundada en 1919. Al poco tiempo, en 1925, fue uno de los primeros sindicatos organizados por rama de industria en la Argentina. Por el rol que el transporte de pasajeros juega en la economía siempre se lo consideró como uno de los sindicatos estratégicos del movimiento obrero del país.

La influencia alcanzada por los grandes gremios en los años 30 llevó a que sus dirigentes se separasen cada vez más de las bases acelerando el proceso de burocratización y logrando importantes beneficios para sus propios intereses sectoriales. La figura paternalista de los caudillos sindicales que deciden a espaldas de los obreros, reemplazó al histórico método de democracia directa de viejos sindicatos anarquistas. Perón, desde la Secretaría de Trabajo y Previsión (1943 a 1945) reguló las relaciones entre el capital y el trabajo y medió en los asuntos gremiales. Entendió que si quería gobernar necesitaba a los dirigentes y a sus sindicatos como aliados estratégicos para contener, cuando fuere sea necesario, la lucha de reclamos.

El gobierno peronista, además de impulsar masivamente la sindicalización de los trabajadores, le brindó un lugar central a las direcciones de los sindicatos. Esto la llevó a pegar un salto de calidad, recibiendo importantes beneficios económicos del Estado. Las centrales sindicales se subordinaron plenamente al gobierno y actuaron bajo su órbita. Con una serie de concesiones que permitieron mejorar las condiciones de los trabajadores, los sindicatos se convirtieron en un grupo de apoyo político directo al régimen y al gobierno, reforzando el proceso de burocratización y estatización de las organizaciones obreras. Según Rojo, A., Luzuriaga, J., Moretti, W. y Lotito, D. (2016), la Ley de Asociaciones Profesionales fue clave para consolidar esta relación: le permitía al Estado controlar la actividad sindical, reglamentar las huelgas y determinar qué gremios estaban autorizados a negociar con las patronales.

Las reformas del Estado a partir de la Ley 23.696 sancionada en el gobierno de Carlos Menem en 1989 le abrieron paso a la administración de los servicios de transporte de pasajeros a 
grandes grupos empresarios, como por ejemplo el Grupo Plaza ex empresa de los hermanos Cirigliano. En toda la década del '90 las líneas pequeñas que no podían cumplir con los nuevos requisitos comenzaron a caer. Muchas fueron absorbidas por nuevos compradores donde además se permitía la participación de las direcciones sindicales en los directorios de las empresas privatizadas o concesionadas. A su vez los trabajadores asistieron a la disminución de la cantidad y calidad de los servicios, a retiros voluntarios, jubilaciones y despidos de trabajadores.

Según Segovia, et al. (2003) "la novedad de los años noventa fue la participación de las direcciones de los gremios en el desguace de las empresas enajenadas. "Pero era dato viejo que los poderosos sindicatos, surgidos durante el peronismo y conniventes con las dictaduras, habian conformado una casta de privilegiados burócratas que medraron con el rol jerárquico prestado por su condición de líderes, negociando los derechos de sus representados desde 1955” (Budeisky, 1974:33). La diferencia en los años noventa consistió en la cobertura legal del doble rol de patrón más gremialista y abarcó desde las empresas estratégicas hasta las de transporte en ciudades intermedias".

A partir de ese análisis y de su visión sobre el rol que cumplieron las conducciones gremiales en la implementación del SUT, los autores Segovia, et al. (2003) dejan abierta la posibilidad de que los representantes sindicales tuvieran injerencia, directa o indirecta, en la gestión de algunas operadoras locales. Denuncias similares de complicidad entre las empresas y las conducciones gremiales salieron a la luz en los medios de comunicación en 2016 a raíz de un conflicto por despidos en la empresa Expreso que administra las líneas Este y 520 de trabajadores que se proponían ser delegados gremiales no alineados con la dirección del sindicato. Este planteo es de suma importancia porque permitiría comprender el porqué de la mala calidad del servicio asociada al estrés por los ritmos y condiciones de trabajo de los choferes. En este sentido es posible pensar que mejoras en las condiciones laborales de los conductores podría mejorar algunas problemáticas del sistema de transporte en su conjunto.

\subsubsection{La implementación del S.U.T.}

\section{Las dificultades para un sistema de transporte regional}

La Dirección de Transporte de La Plata se creó en el año 1987 con el objetivo de buscar alternativas al sistema de transporte que evidenciaba una situación problemática por lo descripto en los apartados anteriores, pero sobre todo por el reclamo de la comunidad por su 
elevado costo de la tarifa, uno de los más altos del país en ese momento. La intención del estado municipal era preparar la nueva concesión del servicio que vencía a finales de los años siguientes y donde la renovación se otorgaba por 10 años más. Los cambios realizados por la Dirección de Transporte de La Plata se coordinaron con la homónima provincial y se implementaron en 1991. Estos se realizaron en base a la primera etapa de un estudio de un equipo multidisciplinario de la Universidad Nacional de La Plata bajo la dirección de la arquitecta Olga Ravella (actual Profesora Consulta de la FAU UNLP). De todas formas, los cambios fueron parciales y no terminaron de responder al conjunto de las problemáticas planteadas, por lo cual se propuso generar una nueva propuesta para el siguiente vencimiento de las concesiones con mayores relevamientos, estudios y evaluaciones.

En ese marco se realiza en el año 1993 una encuesta de origen- destino de viaje, que con una muestra de 9.000 hogares pasó a ser la herramienta fundamental básica que tomó la Dirección de Transporte para el rediseño del sistema de transporte. Ya con la información de la encuesta procesada y analizada, se impulsaron (a partir de 1996) una serie de reuniones de debate y mesas de trabajo a las que invitó a instituciones políticas, académicas y técnicas. Entre ellas a representantes de los tres municipios que componen el Gran La Plata, la Dirección Provincial de Transporte, a la Universidad Nacional de La Plata, a Vialidad provincial y al Comité de Seguridad y Tránsito. Según plantean Segovia et al., (2003), autores que fueron parte del equipo técnico de la Dirección de Transporte de La Plata de ese entonces, la participación política fue la gran ausente, contando sólo un concejal platense, y donde las problemáticas tratadas fueron la gestión del transporte, el diseño del sistema, la cobertura espacial, la tecnología utilizada, la accesibilidad y conectividad, y por último la tarifa. En la última reunión, de la cual participaron técnicos del municipio, empresarios y el gremio, se presentaron las propuestas y síntesis de las reuniones previas, en la cual se consensuaron los siguientes puntos:

- "El sistema de transporte público de pasajeros para el área, por comprender a los tres municipios, es una unidad integral y debe ser tratado como tal.

- Las autoridades nacionales, provinciales y municipales con políticas coordinadas integralmente deben planificar e implementar el servicio público de pasajeros.

- La accesibilidad económica del servicio de transporte se hace factible con la concepción de un sistema que contemple las modalidades de movimiento de la población, donde se elimine aquellos factores que lo hacen irracional. 
- El diseño superador del sistema de transporte debe evitar la competencia empresarial e incluir el modo ferroviario para un aprovechamiento integral de la infraestructura regional.". Segovia et al. (2003)

Según los mismos autores el límite de la propuesta radicaba en no contemplar al sistema de transporte como parte de un desarrollo urbano integral junto con las políticas de suelo, de lo cual responsabilizan al poco interés en que esto sucediera en los marcos generales del Estado Nacional y Provincial que inciden en facilitar esa integración.

A partir de esos cuatro puntos comunes la Dirección de Transporte de La Plata desarrolló algunos criterios básicos para el diseño del sistema, los cuales se mencionan a continuación:

- "Organizar al territorio en seis zonas de transporte, operada cada una de ellas por una empresa; cuatro zonas, Norte, Sur, Este y Oeste del partido de La Plata, y las correspondientes a los partidos de Berisso y Ensenada respectivamente, de servicios intercomunales, que convergen todas en el área central de La Plata.

- Reivindicar el carácter comunal de los viajes cuyo origen y destino se encuentran en territorio municipal. Esta figura legal es aplicada por la provincia de Buenos Aires, para justificar líneas de su jurisdicción en concesiones nacionales. De esta forma la Municipalidad de La Plata recupera su injerencia en Los Hornos, City Bell, Villa Elisa, etc. donde había perdido el manejo del transporte por el accionar incoherente de la Provincia.

- Liderar el rol conductor de la problemática de transporte por defección del resto. Para ello presentó a debate una propuesta concreta de alcance regional, fundada en gestiones y estudios especificos, que no fueron asumidos por los otros municipios, ni por la Dirección Provincial de Transporte. Dicha propuesta no fue refutada con otra, evidenciándose el desinterés por resolver los acuciantes conflictos comunes, que congestionan el espacio público y producen deseconomías sociales.

- Llevar a cabo las gestiones ante la dirección Provincial de Transporte, que dispone de herramientas necesarias dadas por ley, para coordinar politicas en áreas complejas, como la región de La Plata, donde la superposición de jurisdicciones genera un sistema inapropiado de transporte público, desarticulado y socialmente injusto. Sin embargo aquélla hace caso omiso del conflicto y deserta de su responsabilidad.”. Segovia, et al. (2003). 
Además, a modo de balance los autores plantean que el usuario "fue el gran olvidado" en el proceso de planificación y solo fueron consultados una vez decididas las medidas a implementar, lo que además generó muchos problemas de aceptación en la abrupta implementación del nuevo sistema, donde las instancias de participación comunal fueron "un artilugio político suplente de una verdadera instancia participativa”, como así también resultaron un fracaso las Audiencias Públicas programadas por motivos similares. Por otro lado plantean que el plan regional no tuvo el respaldo necesario de los actores para poder llevarse adelante En ese marco la perspectiva de la Dirección de Transporte de La plata era impulsar el SUTR (Sistema Único de Transporte Regional) con la suposición que el resto de los actores se acoplaría, cuestión que no sucedió. En Segovia et al. (2003) hacen principal hincapié en los obstáculos que impuso la autoridad provincial y los actores políticos del cual responsabilizan de "despreciar el plan regional sin estudiarlo, discutirlo ni confrontarlo, desperdiciar diez años de labor de más de treinta trabajadores empleados en su formación, despilfarrar dinero público invertido para tal fin y desoír antiguas necesidades sociales incumplidas".

\section{El plan alternativo, el S.U.T.}

A raíz de las dificultades para la implementación del SUTR, la crisis que atravesaba el sistema de transporte público que perdía usuarios año a año y formaba parte de los reclamos más sentidos de la población, el Municipio platense toma la decisión de continuar con el plan pero ajustándolo al área local, y en 1998 se inicia el proceso licitatorio. Esta situación generó una reacción negativa por parte del gobierno provincial que interpuso medidas judiciales porque veía afectadas a sus operadoras. Finalmente cesaron las medidas judiciales pero decidieron unilateralmente un aumento de las tarifas y la implementación de nuevos ramales provinciales que entraban en directa competencia con el municipio (Segovia, et al.2003).

La nueva alternativa, el Sistema Urbano de Transporte (SUT) contemplaba la división del partido en cuatro zonas de transporte (ver Ilustración 14), la definición de algunos corredores por donde se sintetizó el diseño de los recorridos y se propuso un área de convergencia en el área central de la ciudad delimitada por las avenidas 1 a 13 y 44 a 60 con la intención de ajustar la oferta de viajes a la demanda real terminando con la sobreoferta en el centro, reduciendo tiempos de viaje y costos. Los tipos de recorridos (troncales, circulares, periféricos, interzonales y de fomento) se definieron a partir un análisis de flujos de demanda en los orígenes del viaje obtenido en la encuesta de origen y destino del '93, declaraciones juradas de las empresas y mediciones de flujos parciales. 


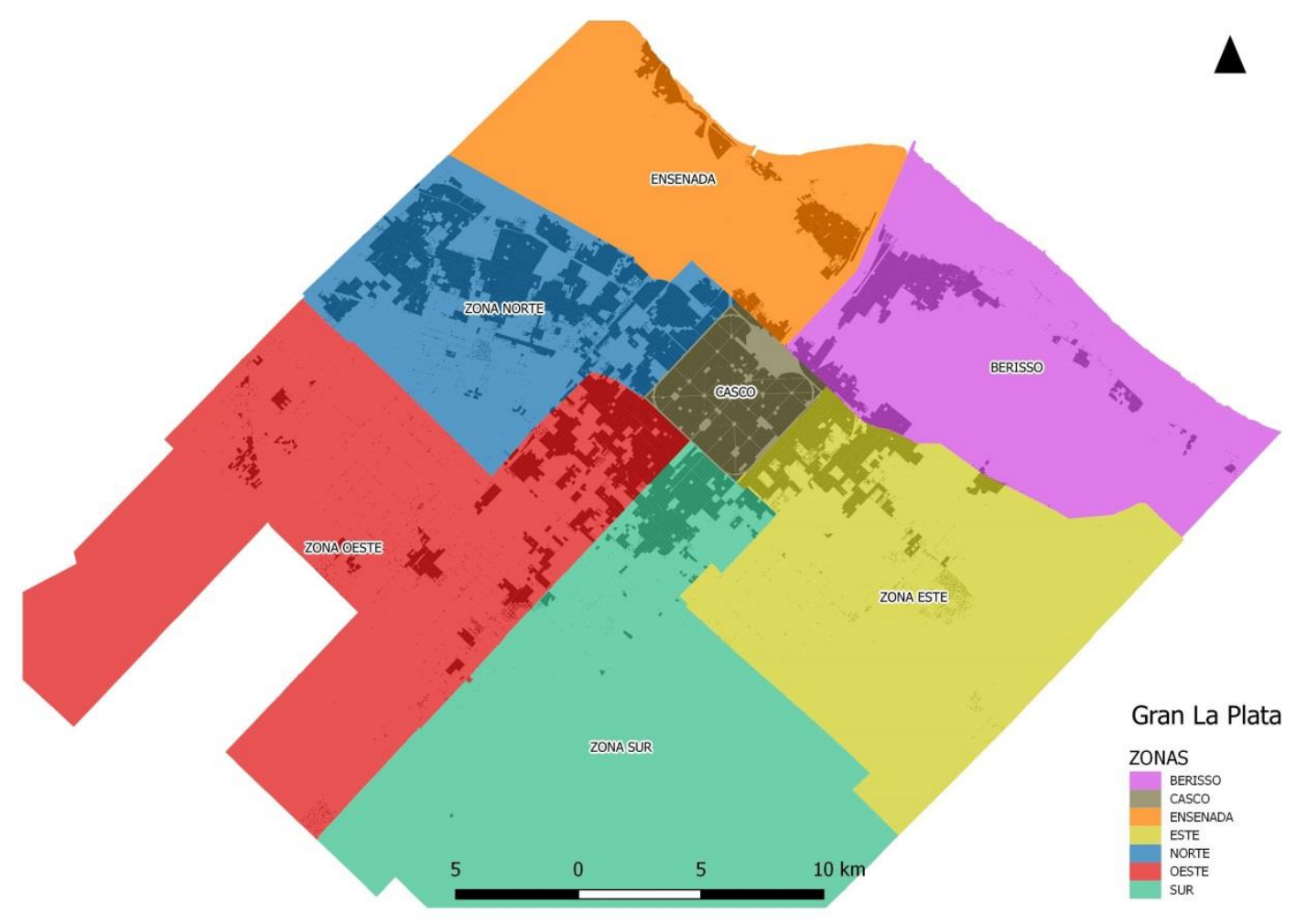

Ilustración 14. Zonas del Gran La Plata. Fuente: Elaboración propia, en base a datos de Aon, Moro, Ravella (2004).

Por otro lado, la propuesta original del SUT establecía la posibilidad de realizar transbordos para posibilitar combinaciones y completar viajes en el caso en que el punto de origen y el de destino no estuvieran cubiertos de forma directa. También se pensó en una línea céntrica formada por minibuses y denominada Circuito Centro para las conexiones internas del área central, la tarifa plana y boleto único en el caso de combinaciones y completamiento de viajes. A su vez la idea original planteaba la construcción de una sala de monitoreo con información a tiempo real, buses adaptados para los distintos tipos de recorridos, demandas horarias y temporarias, la incorporación de servicios diferenciados, ejecutivos y puerta a puerta.

\section{El segundo fracaso del sistema de transporte}

La implementación de la nueva propuesta de sistema de transporte público para la región sufre un nuevo fracaso, y los planes teóricos vuelven a frustrarse tras la imposibilidad del S.U.T.R.

Según Aón, et al. (2003) la puesta en marcha del sistema fue caótica, con poca información a los usuarios, las empresas modificaron los recorridos acordados, así como las paradas, los seccionados, las frecuencias y combinaciones. Tampoco implementaron las nuevas terminales 
que había ofertado, el boleto combinado ni el Circuito Centro o la tecnología necesaria para el seguimiento de las unidades en tiempo real. Para completar el fracaso, las empresas provinciales incorporaron recorridos nuevos que entraron en conflicto con el sistema municipal.

A partir de las características y lógicas moldeadas históricamente de los distintos actores involucrados en la problemática de movilidad y desarrollo urbano del caso del Gran La Plata, a continuación se analizan las problemáticas de planificación y gestión que involucran al periodo de estudio.

\subsection{Análisis de las problemáticas de planificación y gestión}

En cuanto al análisis de las problemáticas de planificación y gestión del transporte público, se analiza a continuación: i. La política de subsidios al transporte público urbano que emprendió el Estado Nacional a partir de 2002 y ii. Las propuestas en relación a la movilidad y al transporte público de los actores clave, como son el director de transporte del Partido de La Plata en 2013 y los choferes de las líneas de transporte público del Gran La Plata ${ }^{62}$. Por último se plantea un árbol de problemas que sintetiza las principales problemáticas, según las diversas posiciones e interpretaciones de los actores.

\section{i. La política de subsidios al transporte público urbano.}

La década de 1990 fue uno de los momentos de la historia del país en los que se fomentó la utilización del desplazamiento automotor con autopistas nuevas y ampliación de las existentes, mientras se desfinanciaba, para su privatización, el sistema de transporte ferroviario. Posteriormente, la crisis del 2001 incluyó una crisis fiscal y la devaluación del peso argentinao, lo que incremento los costos de bienes y servicios de las empresas y una depreciación de los salarios de la población.

Según Fernández, C.A. (2015), esta situación, sumado al alto nivel del precio de las materias primas a nivel internacional, benefició directamente a los propietarios de bienes sujetos al comercio exterior, generando fuertes ingresos de divisas para el país, y a partir de impuestos o retenciones, crecientes ingresos fiscales. Esta masa de ingresos para el Tesoro Nacional, sumada a la situación social y política crítica, motivó al Gobierno Nacional a implementar una política de contención social, uno de cuyos aspectos fue el control del precio de las tarifas de

\footnotetext{
${ }^{62}$ Un análisis más detallado de las entrevistas y talleres se pueden ver en los Anexos A.1. y A.2.
} 
transporte público automotor vía subsidios para mantener la relación con los niveles salariales golpeados por la devaluación. Según Sánchez, J. (2011), esta operatoria ya venía funcionando para el sistema ferroviario de superficie y subterráneo como parte de la concesión de los servicios.

Los mecanismos de subsidio utilizados fueron, por un lado, dinero directamente transferido a los operadores y por otro un precio diferencial de combustible en aproximadamente un tercio y un cuarto del precio de mercado, como plantea Fernández, C.A. (2015). En sus orígenes las variables utilizadas para la distribución de los subsidios fueron a) recaudación, b) pasajeros transportados y c) kilómetros recorridos por empresa, relevadas en base a declaraciones juradas de las empresas prestatarias ante las autoridades de las direcciones provinciales de transporte.

En el año 2006 se creó un nuevo régimen de compensaciones mensuales complementario al sistema existente (SISTAU) con fondos del Tesoro Nacional, destinado a los incrementos de costos incurridos por las empresas de servicios de transporte público de pasajeros automotor de carácter urbano y suburbano del AMBA. El objetivo de estas compensaciones era cubrir costos por desajustes en salarios, renovación de la flota, formación y capacitación del personal, para que las empresas prestadoras puedan garantizar la continuidad de los contratos licitatorios.

Más tarde, en el año 2011, el Estado deja de subsidiar a las empresas con precios diferenciales del gasoil y comienza a subsidiar todo en dinero. Además, crea un programa de renovación del parque automotor para la adquisición de unidades cero kilómetros o usadas menores a siete años de antigüedad, con bonificaciones sobre las tasas de interés del Banco Nación. En el año 2013 se amplía la cantidad de Grupos Tarifarios: Distrito Federal, Suburbanas Grupo I, Suburbanas Grupo II, las de jurisdicción provincial y las líneas de jurisdicción Municipal, variable según la ubicación de sus cabeceras y las jurisdicciones por las que circulan sus recorridos. Además, se incorporan nuevas compensaciones tarifarias asociada a la demanda (como atributo social) $^{63}$, por recorrido superior a los $12 \mathrm{~km}$ y por uso global de la tarjeta SUBE. (Fernandez, 2015).

\footnotetext{
${ }^{63}$ Por atributo social se entiende a los subsidios directamente otorgado a los usuarios registrados y su aplicación es automática en su tarjeta SUBE personal. En este grupo se encuentran alumnos preescolares y primarioscon un boleto de 0,10; estudiantes secundarios y terciarios que ronda en una reducción aproximada del $50 \%$ de la tarifa, exención de la tarifa para personas con capacidades especiales y por ultimo lo que se denomina Grupos de Afinidad o Atributos Sociales, categoría que incluye a jubilados y pensionados, beneficiarios de AUH, de AEPS, del programa Jefes de Hogar, personal de trabajo doméstico, Veteranos de Malvinas y beneficiarios del plan Progresar, todos los cuales tienen derecho a una tarifa con un descuento del $40 \%$.
} 
En el caso de los subsidios a las empresas prestadoras, la CNRT es la encargada de informar a la Secretaria de Transporte de la Nación las necesidades de gasoil del sistema, el listado de empresas beneficiarias y el volumen asignado a cada uno de ellas. Para ello se encarga de penalizar a los vehículos sin seguro o revisión técnica, también establece un valor máximo de kilómetros por unidad y por mes, si se superar ese valor la empresa es penalizada en un $10 \%$ de los subsidios otorgados por kilometraje promedio por mes y por unidad. A su vez, como menciona Fernandez, C.A. (2015), en caso de incurrir en alguna de estas penalizaciones, se retienen las Compensaciones Tarifarias. La penalización por kilometraje sobrepasado es muy importante para esta investigación, ya que es allí donde se concentran varias de las problemáticas referidas a las frecuencias, hacinamiento de coches y al estrés de los choferes que influyen en el tiempo y comodidad del viaje en transporte público, como se verá más adelante.

Tanto el subsidio a la oferta como a la demanda ha aumentado significativamente desde 2002 a la actualidad. En ese año representaba solo el 7\% de los ingresos de las empresas de transporte público automotor, mientras que en 2010 ya alcanzaban el 77\%. Esto representa una variación de subsidio por pasajero que pasó de $\$ 30$ a \$939. Asimismo, como plantean Castro, L., Szenkman, P. (2012), los subsidios al transporte alcanzaron \$17.000 millones en 2011, lo que representó el 1\% del PBI y al 30\% del gasto total en subsidios del Estado nacional donde el 70\% se destina al transporte urbano e interurbano de pasajeros. En 2013, el $72,2 \%$ de los subsidios al transporte automotor fueron destinados a la compensación de las empresas y el 27,8 a los usuarios, como desarrolla Fernández, C.A. (2015).

En el Gran La Plata, el acumulado de subsidios para el año 2013 fue de \$190.648.162,56. Si se proyecta la proporción de ingresos de las empresas, el Estado nacional cubriría el $81 \%$ de los ingresos para el funcionamiento de las mismas, es decir que el 19\% serían los ingresos provenientes de los pasajes vendidos. Según las declaraciones juradas de las empresas, el gasto de gerenciamiento equivaldría al 12\%. Ver Tabla 9 y Gráfico 2.

Tabla 9. Subsidio acumulado por empresa de transporte del Gran La Plata en 2.013. Fuente: Elaboración propia, en base a datos del Ministerio del Interior y Transporte.

\begin{tabular}{|c|c|}
\hline Empresa Prestadora & Acumulado 2013 \\
\hline Línea 7 & $65.717 .465,49$ \\
\hline 9 de Julio & $77.414 .970,27$ \\
\hline La Unión & $10.324 .803,33$ \\
\hline Unión Platense & $37.190 .923,47$ \\
\hline TOTAL & $190.648 .162,56$ \\
\hline
\end{tabular}




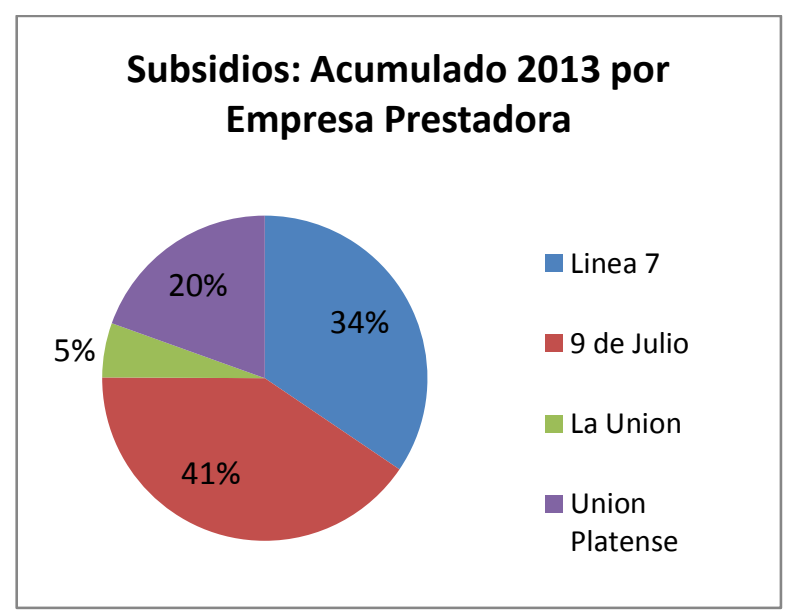

Gráfico 2. Subsidio acumulado por empresa de transporte del Gran La Plata en 2.013.

Fuente: Elaboración propia, en base a datos del Ministerio del Interior y Transporte.

En ese año la empresa que más subsidios recibió en la región fue la empresa 9 de Julio, que en ese momento administraba las líneas Oeste, Norte y las provinciales 215 y 225. Con $\$ 65.717 .465,49$ de subsidios acumulados en 2013, se ubicaba la empresa Línea 7 que administraba la línea Este, Sur y la provincial 307; a continuación la Unión Platense que poseía la concesión centralmente de las líneas 273 y 214 y finalmente la Unión de la línea 202.

Desde 2002 a la actualidad, los subsidios pasaron a ser un factor decisivo para el funcionamiento de los sistemas de transporte urbano de pasajeros y el Gran La Plata no está exento de eso. Comparado con el presupuesto del municipio de La Plata, los subsidios equivalen aproximadamente al $8 \% \mathrm{y}$, como ya se analizó, representan aproximadamente el $81 \%$ de los ingresos totales de las empresas. Esta situación produce que los indicadores que permiten mantener esos subsidios, ampliarlos, o reducirlos, estén sujetos a una tensión constante que, en este caso, se refiere a los kilómetros recorridos mensuales que se trasladan a los tiempos de recorrido y de viaje, lo que genera fricciones constantes entre los actores involucrados.

\section{ii. Propuestas de actores clave.}

En el marco de un taller realizado en la Sede de UTA $^{64}$ La Plata en el año 2017 y de una entrevista realizada al director de transporte del partido de La Plata en el año 2013 surgieron

\footnotetext{
${ }^{64}$ Unión Tranviarios Automotor, gremio de choferes y personal del transporte colectivo.
} 
propuestas de modificación al actual sistema de transporte las cuales se detallan a continuación: :

a) Reorganizar las paradas en el centro, mínimo cada 200 metros o 300. También sacar las paradas en las plazas.

b) Sincronizar los semáforos.

c) Implementar los carriles exclusivos en Av. 7 desde 32 a Plaza Rocha en ambas direcciones.

d) Tomar medidas para disminuir el acceso del auto particular al centro, como por ejemplo: centros de disuasión en las periferias vinculados al sistema de transporte, estacionamiento medido, mayor control desde la oficina de tránsito municipal, campañas de concientización al conductor de auto particular; liberar de estacionamiento las paradas de colectivo.

e) Incorporar más unidades para que mejoren las frecuencias

f) Rediseñar algunos tramos de los recorridos por infraestructura vial inadecuada y por congestión.

g) Sumar información del servicio en las paradas. Mejorar la infraestructura de paradas en ruta.

h) Reducción de la jornada laboral a 6 horas.

i) Que los servicios de recolección de residuos, mantenimiento del arbolado, bacheo se realicen en horarios nocturnos para no dificultar el tránsito.

j) Que se normalicen recorridos de contingencia ante cortes.

A continuación, (ver Tabla 10. Matriz de relaciones conflictivas entre actores del transporte público del Gran La Plata. Fuente: Elaboración propia. se presenta una matriz de las relaciones conflictivas entre usuarios, choferes, Estado y empresas. En las filas se plantean las problemáticas desde el punto de vista de los actores, en las columnas los actores con los que existe conflicto. 
Tabla 10. Matriz de relaciones conflictivas entre actores del transporte público del Gran La

Plata. Fuente: Elaboración propia.

\begin{tabular}{|c|c|c|c|c|}
\hline Actores & Usuarios & Choferes & Estado & Empresas \\
\hline Usuarios & $\begin{array}{l}\text { Tensiones cuando el } \\
\text { micro circula con } \\
\text { ocupación máxima, } \\
\text { entre el pasajero abordo } \\
\text { y el que quiere subir. }\end{array}$ & $\begin{array}{c}\text { Cuando los } \\
\text { colectivos no paran, } \\
\text { cuando hay } \\
\text { hacinamiento de } \\
\text { coches y maniobras } \\
\text { bruscas. }\end{array}$ & $\begin{array}{l}\text { Tensiones por la falta de } \\
\text { información sobre } \\
\text { recorridos, malas } \\
\text { frecuencias, } \\
\text { hacinamiento en las } \\
\text { unidades }\end{array}$ & $\begin{array}{l}\text { Los reclamos a las } \\
\text { empresas por lo general } \\
\text { son a través de la } \\
\text { dirección de transporte } \\
\text { cuando existen } \\
\text { irregularidades en } \\
\text { frecuencias y recorridos. }\end{array}$ \\
\hline Choferes & $\begin{array}{l}\text { Cuando los usuarios } \\
\text { consultan repetidamente } \\
\text { sobre recorridos, por no } \\
\text { poseer información en } \\
\text { paradas. }\end{array}$ & $\begin{array}{l}\text { En ocasiones, } \\
\text { competencia por } \\
\text { levantar menos } \\
\text { pasajeros para ir } \\
\text { más tranquilo y } \\
\text { poder cumplir con } \\
\text { el tiempo de } \\
\text { recorrido }\end{array}$ & $\begin{array}{l}\text { Aducen que no son } \\
\text { escuchadas sus } \\
\text { problemáticas }\end{array}$ & $\begin{array}{l}\text { Tensiones por malas } \\
\text { condiciones laborales, } \\
\text { jornadas extendidas, } \\
\text { presión por cumplir } \\
\text { horarios de recorrido } \\
\text { desactualizados. }\end{array}$ \\
\hline Estado & $\begin{array}{l}\text { Con cuestionamientos } \\
\text { exagerados, según el } \\
\text { municipio, de los } \\
\text { usuarios en relación a la } \\
\text { mala calidad del servicio }\end{array}$ & $\begin{array}{l}\text { Conflictos por el no } \\
\text { cumplimiento de } \\
\text { normas de tránsito, } \\
\text { accidentes viales. }\end{array}$ & $\begin{array}{l}\text { Problemáticas de gestión: } \\
\text { poco presupuesto para } \\
\text { infraestructura y áreas } \\
\text { técnicas de transporte. } \\
\text { Dificultades para una } \\
\text { gestión común del } \\
\text { sistema de transporte con } \\
\text { la provincia. }\end{array}$ & $\begin{array}{l}\text { Tensiones por el no } \\
\text { cumplimiento de } \\
\text { horarios y frecuencias } \\
\text { acordadas. }\end{array}$ \\
\hline Empresas & Sin información & $\begin{array}{c}\text { Tensión por } \\
\text { incumplimientos de } \\
\text { horarios, accidentes } \\
\text { y reclamos por } \\
\text { condiciones } \\
\text { laborales }\end{array}$ & $\begin{array}{l}\text { Reclamo de aumento de } \\
\text { subsidios o del precio de } \\
\text { las tarifas. }\end{array}$ & $\begin{array}{l}\text { Competencia por } \\
\text { recorridos y horarios más } \\
\text { rentables. Las empresas } \\
\text { que reciben mayor } \\
\text { subsidio fueron } \\
\text { comprando al resto de las } \\
\text { empresas, aumentando } \\
\text { los rasgos monopólicos } \\
\text { de los recorridos. }\end{array}$ \\
\hline
\end{tabular}

\section{Árbol de problemas}

A continuación, se presenta un árbol de problemas construido a partir de las problemáticas vinculado a los actores desarrollado en el punto 3.4. En el mismo se desarrollan las determinantes y efectos de la problemática central resumida en las "dificultades vinculadas al tiempo de viaje que impiden lograr un transporte público de calidad en el Gran La Plata”. Ver Ilustración 15. 


\section{Municipal}

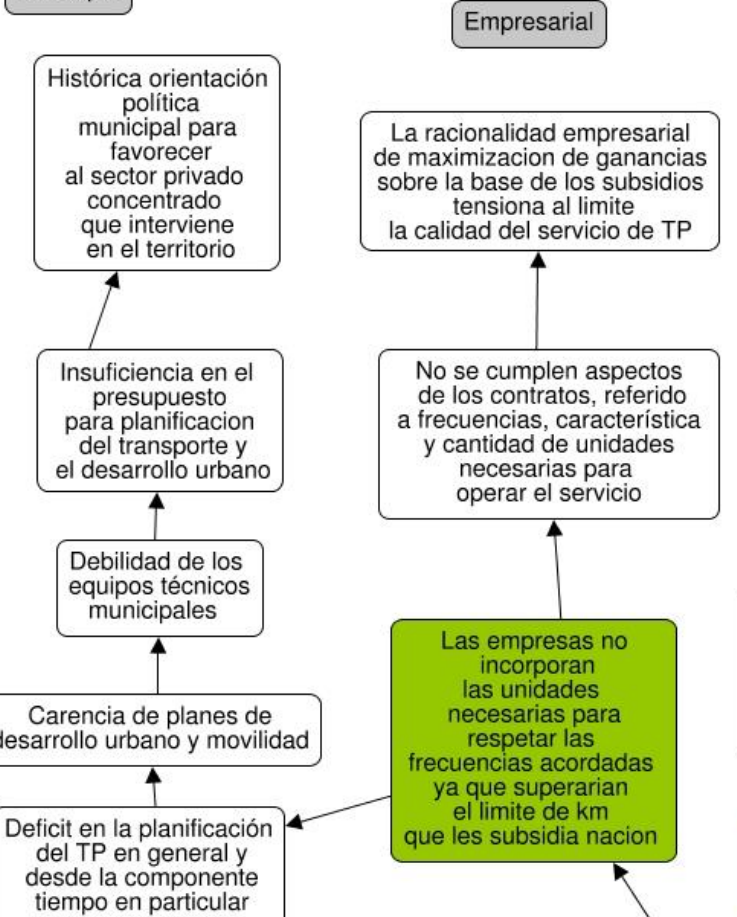

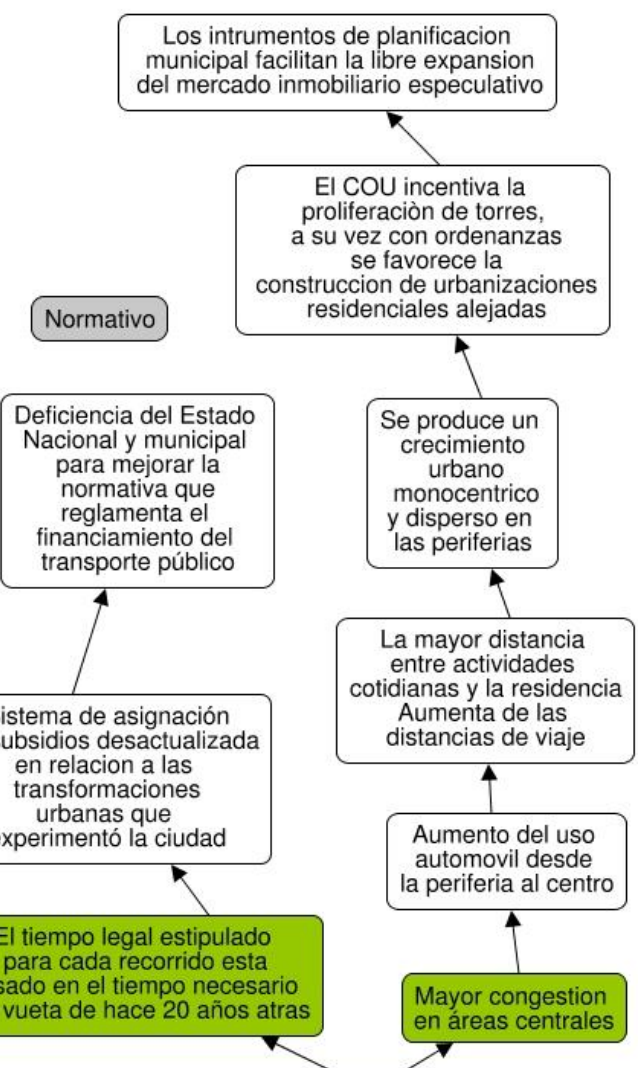

DIFICULTADES VINCULADAS AL "TIEMPO DE VIAJE" QUE IMPIDEN LOGRAR UN TRANSPORTE PÚBLICO DE CALIDAD EN EL GRAN LA PLATA

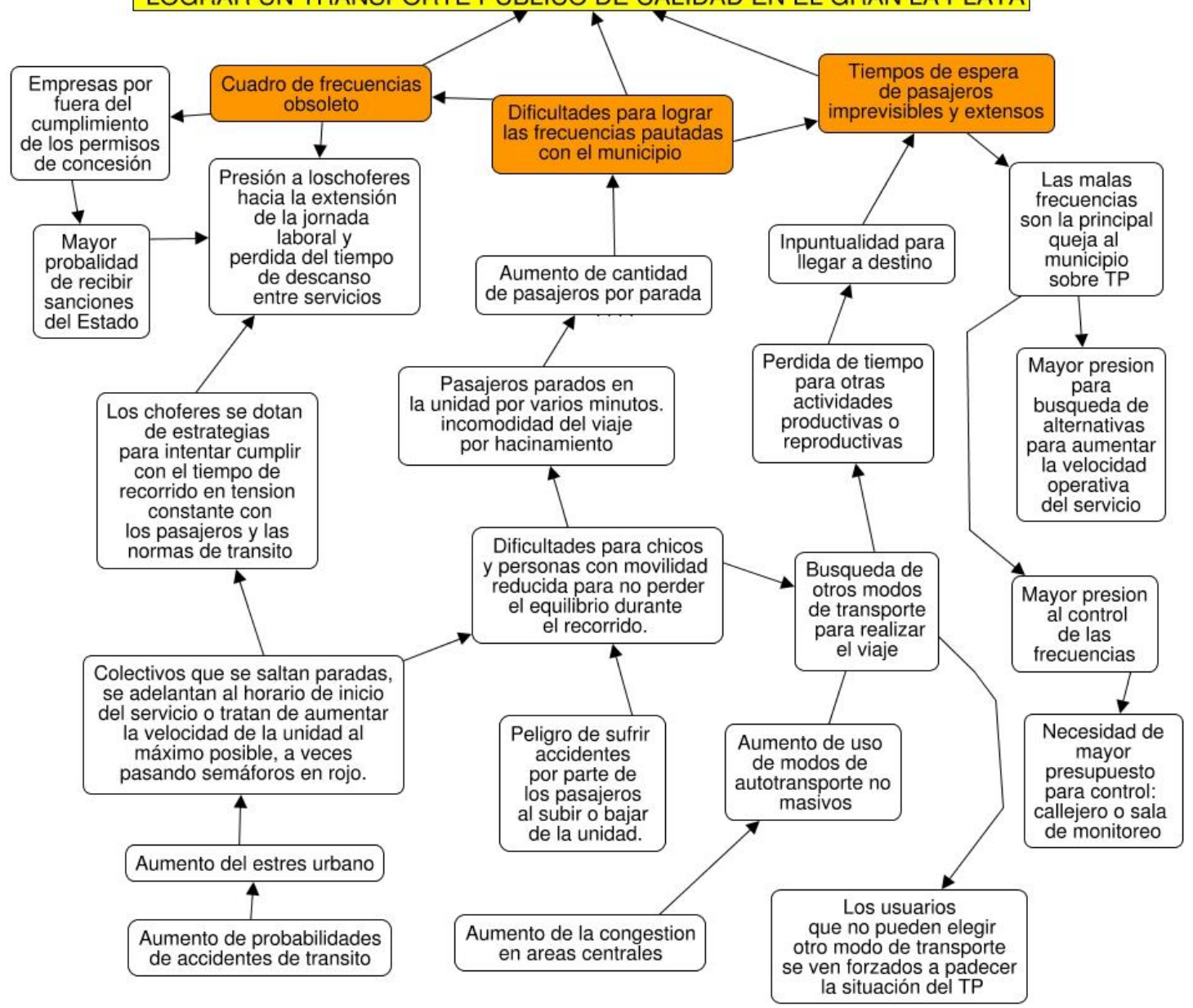

Ilustración 15. Arbol de problemas. Fuente: Elaboración propia. 
A partir de las características y lógicas de distintos actores involucrados en la problemática de movilidad y desarrollo urbano del caso del Gran La Plata, a continuación de desarrollan las dimensiones y variables que analizan a esta problemática desde distintos ángulos

\subsection{Construcción del año base de desarrollo urbano y transporte público del Gran La} Plata.

Para la construcción del año base del transporte público del Gran La Plata se utilizaron dimensiones desarrolladas en el capítulo II de este trabajo de tesis, las mismas son: Dimensión Espacial; Dimensión Social; Dimensión Económica y Dimensión Ambiental. A continuación se desarrollan cada una de ellas.

\subsubsection{Dimensión Espacial}

En la dimensión espacial se analiza, por un lado los datos poblacionales y ocupación del territorio por zona y delegación, y por otro lado la situación de la movilidad en general y el transporte público en particular.

\section{i. Población y ocupación del territorio}

El Gran La Plata poseía una población de 805.768 habitantes en $2010^{65}$, con una proyección elaborada por el INDEC para el año 2013 de 826.246 habitantes, el 5,07\% del total de la población de la Provincia de Buenos Aires. Está compuesto por los Partidos de La Plata, Berisso y Ensenada, donde La Plata posee con 676.195 habitantes el 81,8\% de la población del aglomerado, Berisso con 91.466 el 11,1\% y Ensenada que cuenta con 58.585 habitantes representa el 7,1\% de la población. En este sentido es clara la jerarquía en términos de cantidad de población que tiene el Partido de La Plata con respecto a Berisso y Ensenada. Ver Tabla 11 .

65 Fuente: INDEC, Censo Nacional de Población, Hogares y Vivienda, 2010. 
Tabla 11. Total de Población censo 2010 y proyección INDEC. Fuente: Elaboración propia en base a datos del INDEC.

\begin{tabular}{|c|c|c|c|c|c|c|}
\hline Distrito & $\mathbf{2 0 1 0}$ & $\mathbf{2 0 1 1}$ & $\mathbf{2 0 1 2}$ & 2013 & $\mathbf{2 0 1 4}$ & $\mathbf{2 0 1 5}$ \\
\hline Total PBA & 15.716 .942 & 15.909 .607 & 16.100 .618 & 16.289 .599 & 16.476 .149 & 16.659 .931 \\
\hline La Plata & 659.575 & 664.746 & 670.477 & 676.195 & 681.831 & 687.378 \\
\hline Berisso & 89.070 & 89.877 & 90.675 & 91.466 & 92.246 & 93.015 \\
\hline Ensenada & 57.123 & 57.615 & 58.103 & 58.585 & 59.062 & 59.532 \\
\hline Total GLP & 805.768 & 812.238 & 819.255 & 826.246 & 833.139 & 839.925 \\
\hline
\end{tabular}

La Plata es la segunda ciudad de la provincia en cantidad de habitantes pero se encuentra en la posición $25^{\circ}$ de la ciudades con mayor densidad poblacional, en una ubicación similar entre si se encuentran Berisso y Ensenada. Esto tiene que ver por la importante extensión de superficie productiva de La Plata y la extensión de zonas inundables con características de bañados que caracterizan tanto a Berisso y Ensenada. Ver Tabla 12.

Tabla 12. Población 2013 y porcentaje que representa cada ciudad en el Gran La Plata. Fuente: Elaboración Propia con datos Censo 2010 e INDEC.

\begin{tabular}{|c|c|}
\hline Partido & \% de GLP \\
\hline La Plata & 81,84 \\
\hline Berisso & 11,07 \\
\hline Ensenada & 7,09 \\
\hline Total GLP & 100,00 \\
\hline
\end{tabular}

En el periodo de 2001-2010 los datos censales evidencian mayores incrementos de la densidad en los radios censales de zonas periféricas del Oeste y Suroeste. Ver Ilustración 16.

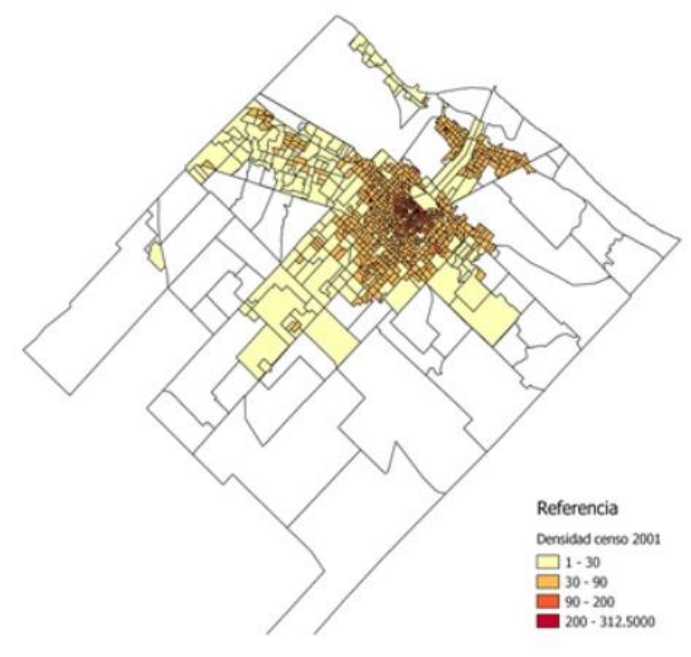

2001

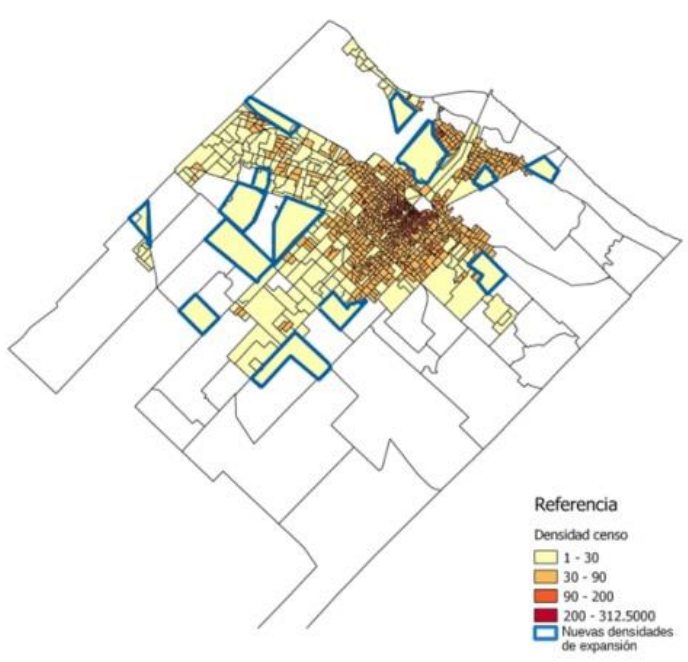

2010

Ilustración 16. Densidad Poblacional - censo 2001 y 2010, nuevas densidades periféricas. Fuente: Elaboración propia en base a datos censo 2001 y 2010, INDEC. 
Con una mayor precisión en la Ilustración 17, la densidad poblacional por manzanas menores a 10 hectáreas se puede observar el peso poblacional de las distintas áreas de la ciudad del Gran La Plata en el territorio complementando los datos de la Tabla 13, el Gráfico 3 y Tabla 13.

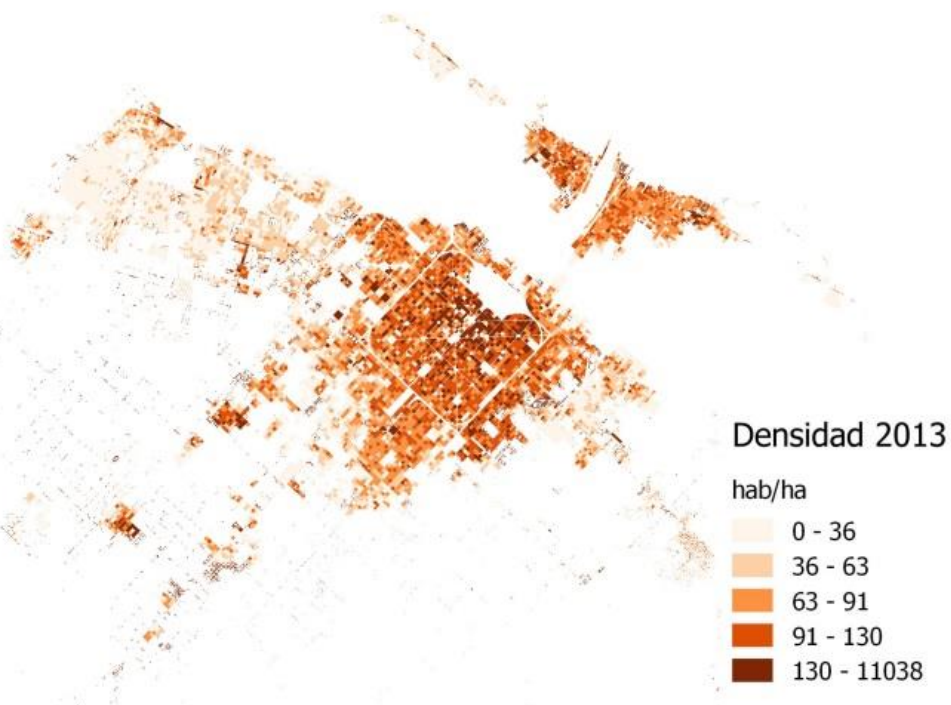

Ilustración 17. Densidad poblacional 2013 manzanas menores a 10 Ha. Fuente: Elaboración propia en base a datos censales y ubicación de medidores de consumo eléctrico.

Gráfico 3. Población por Delegación Municipal 2013. Fuente: Elaboración propia en base a datos de INDEC.

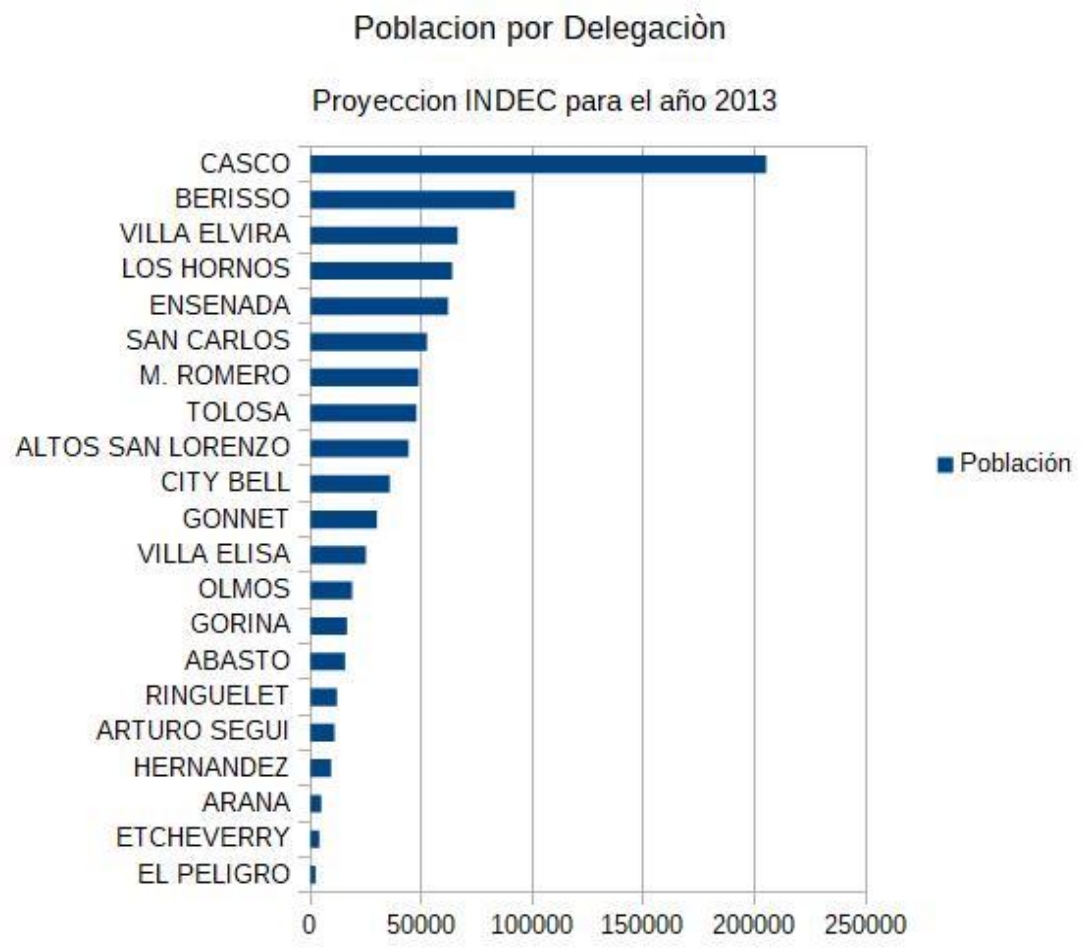


Tabla 13. Población por Delegación Municipal 2013. Fuente: Elaboración propia en base a datos de INDEC.

\begin{tabular}{|c|c|}
\hline DELEGACION & Población \\
\hline $\mathrm{CASCO}$ & 205262 \\
\hline LOS HORNOS & 63800 \\
\hline VILLA ELVIRA & 66332 \\
\hline SAN CARLOS & 52405 \\
\hline TOLOSA & 47733 \\
\hline GONNET & 29903 \\
\hline ALTOS SAN LORENZO & 44255 \\
\hline CITY BELL & 35706 \\
\hline M. ROMERO & 48686 \\
\hline VILLA ELISA & 24971 \\
\hline RINGUELET & 11923 \\
\hline OLMOS & 18757 \\
\hline ARTURO SEGUI & 10882 \\
\hline GORINA & 16451 \\
\hline ABASTO & 15579 \\
\hline HERNANDEZ & 9249 \\
\hline ARANA & 4897 \\
\hline ETCHEVERRY & 3929 \\
\hline EL PELIGRO & 2312 \\
\hline
\end{tabular}

Por otro lado, la Ilustración 18 también permite observar que el gradiente de densidad habitacional visualiza una mayor concentración de viviendas en el casco, mientras que densidad poblacional sin perder la centralidad del casco, muestra varias áreas de concentración secundarias. Esta situación se debe a que en muchas de las delegaciones periféricas hay menos viviendas por manzanas pero mayor cantidad de personas por vivienda, como por ejemplo Gorina (promedio de 5 personas por vivienda) o Melchor Romero (promedio de 4,5 personas por vivienda). Ver Ilustración 18, Gráfico 4 y Tabla 14. 


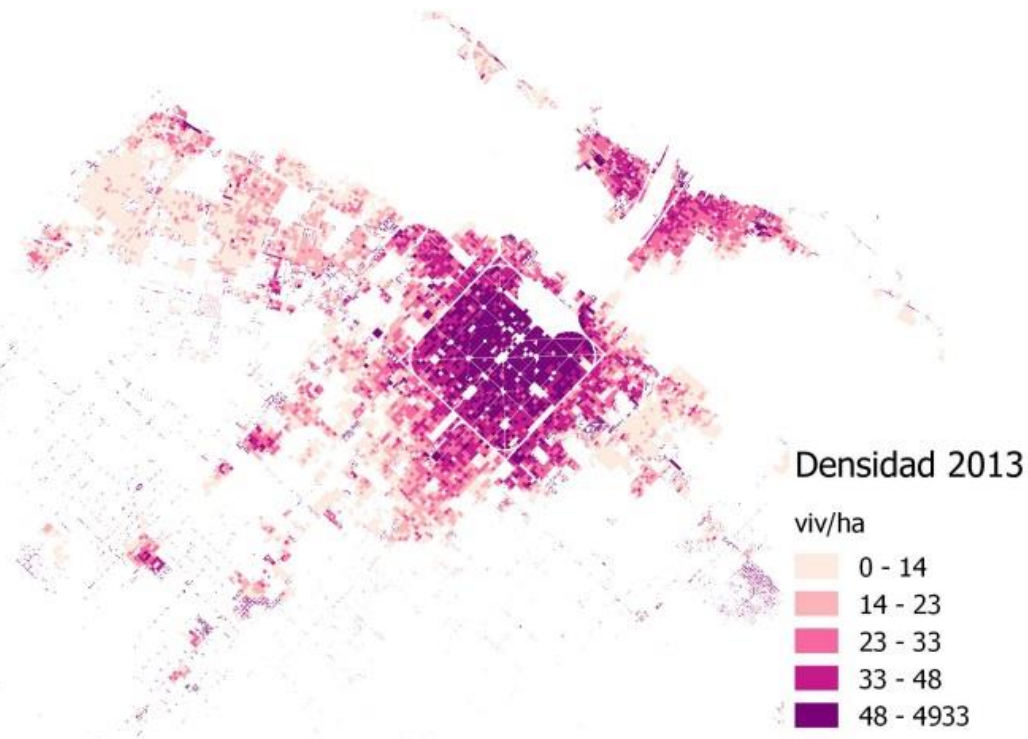

Ilustración 18. Densidad habitacional 2013 manzanas menores a 10 Ha. Fuente: Elaboración propia en base a datos censales y ubicación de medidores de consumo eléctrico.

Gráfico 4. Viviendas por delegación 2013. Fuente: Elaboración propia en base a datos INDEC.

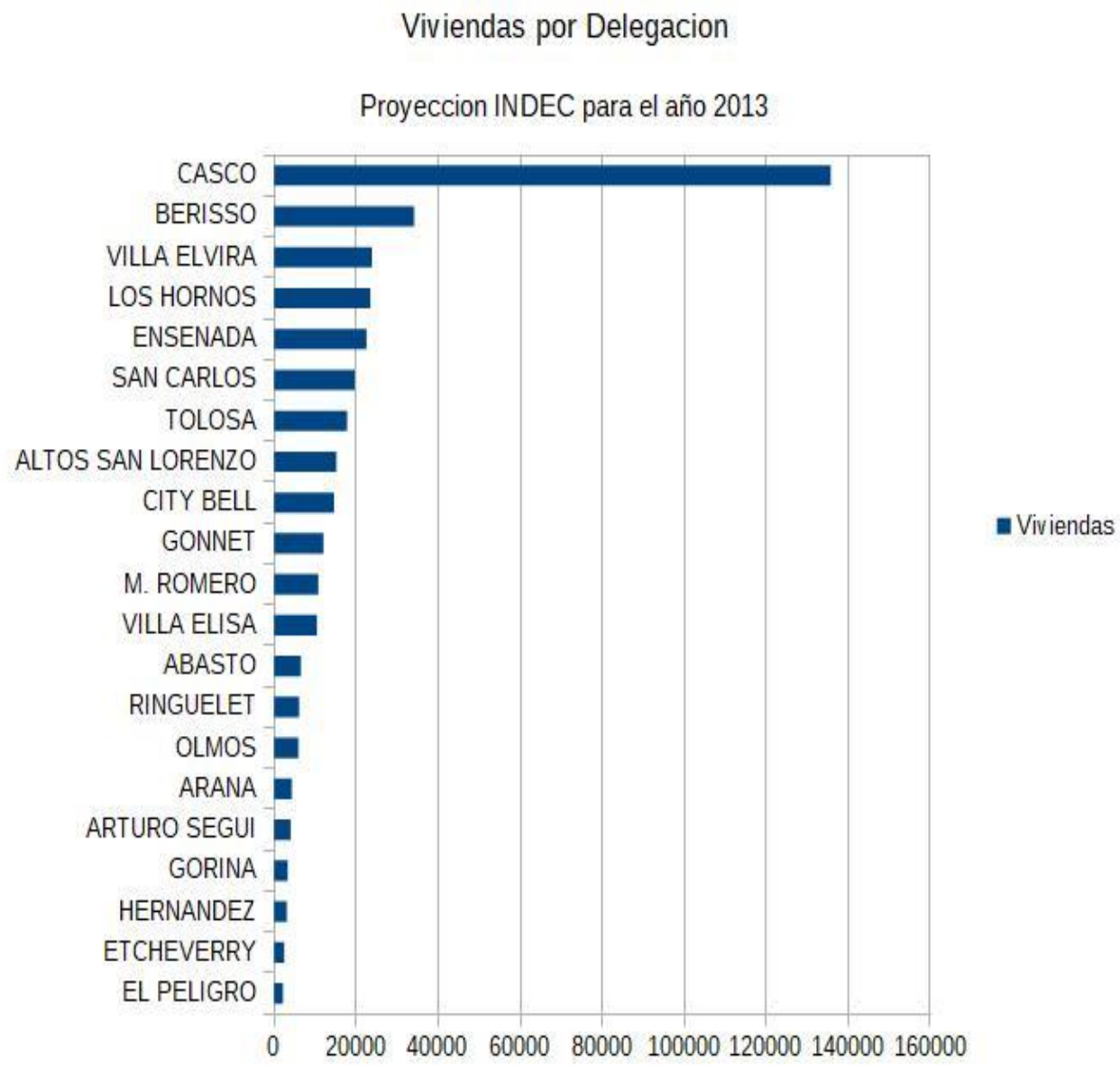


Tabla 14. Personas por vivienda por delegación. Fuente: Elaboración propia en base a datos de INDEC.

\begin{tabular}{|c|c|}
\hline DELEGACIÓN & $\begin{array}{c}\text { Promedio de } \\
\text { personas } \\
\text { por vivienda }\end{array}$ \\
\hline GORINA & 5 \\
\hline M. ROMERO & 4,5 \\
\hline OLMOS & 3,2 \\
\hline HERNANDEZ & 3 \\
\hline ALTOS SAN LORENZO & 2,9 \\
\hline VILLA ELVIRA & 2,8 \\
\hline ENSENADA & 2,8 \\
\hline LOS HORNOS & 2,7 \\
\hline BERISSO & 2,7 \\
\hline ARTURO SEGUI & 2,7 \\
\hline TOLOSA & 2,7 \\
\hline SAN CARLOS & 2,7 \\
\hline GONNET & 2,5 \\
\hline CITY BELL & 2,4 \\
\hline ABASTO & 2,4 \\
\hline VILLA ELISA & 2,4 \\
\hline RINGUELET & 2 \\
\hline ETCHEVERRY & 1,6 \\
\hline CASCO URBANO & 1,5 \\
\hline ARANA & 1,1 \\
\hline EL PELIGRO & 1,1 \\
\hline & \\
\hline & \\
\hline
\end{tabular}

En este marco, los porcentajes mostrados en la Ilustración 1920, Ilustración 20, Gráfico 5 y Gráfico 6 expresan el crecimiento poblacional y habitacional por delegación entre 2001 y 2013, lo que permite visualizar la variabilidad de crecimiento según las distintas zonas del Gran La Plata. 


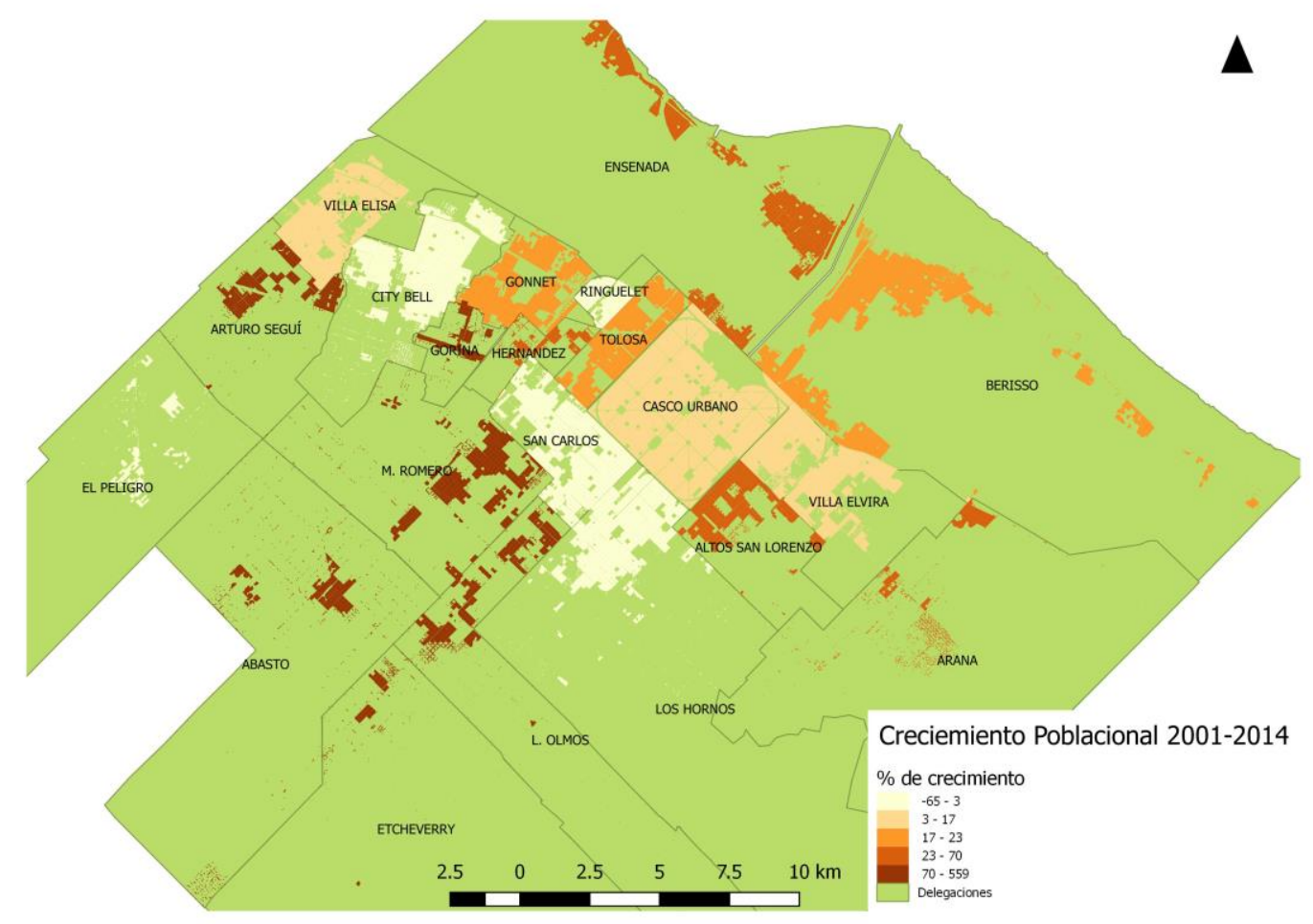

Ilustración 19. Porcentaje de Crecimiento Poblacional periodo 2001 - 2013 por delegación. Fuente: Elaboración propia en base a datos de INDEC.

Gráfico 5. Crecimiento poblacional 201-2014. Fuente: Elaboración propia en base a Censo 2001, 2010. Proyección 2014, INDEC.

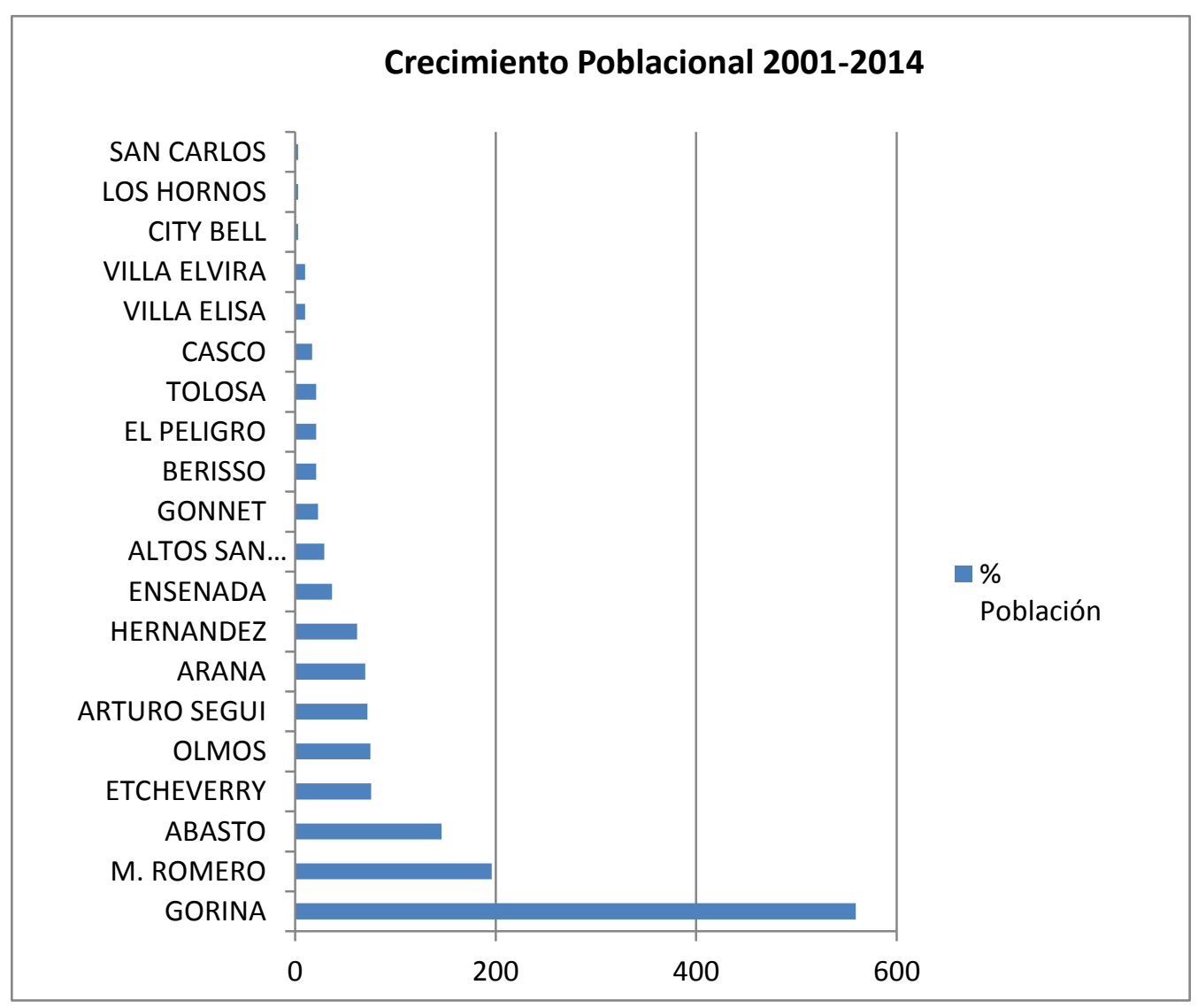




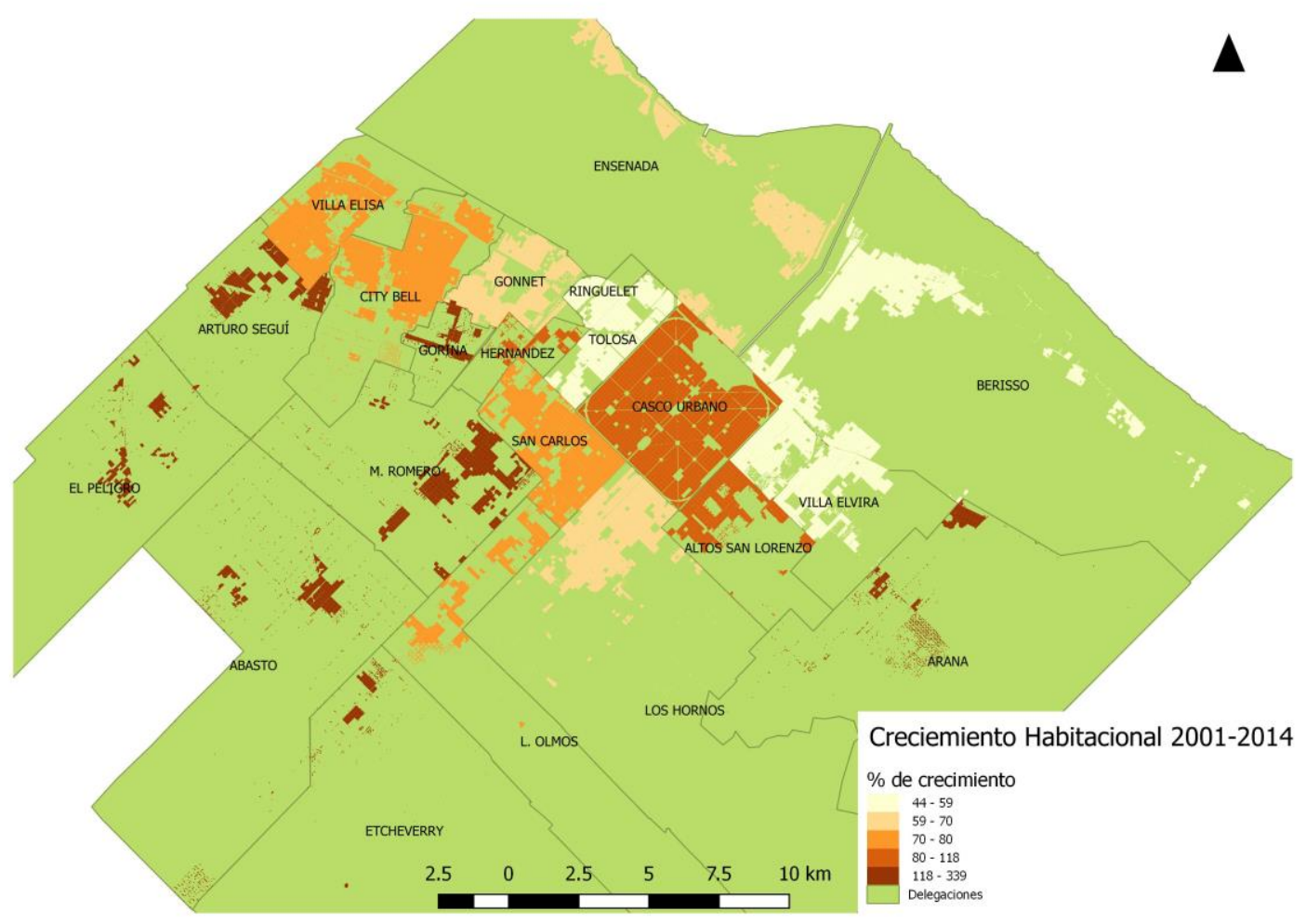

Ilustración 20. Porcentaje de Crecimiento Poblacional 2001-2014. Fuente: Elaboración propia, en base a datos de INDEC.

Gráfico 6. Porcentaje de Crecimiento Habitacional 2001-2013.

Fuente: Elaboración propia, en base a datos de INDEC.

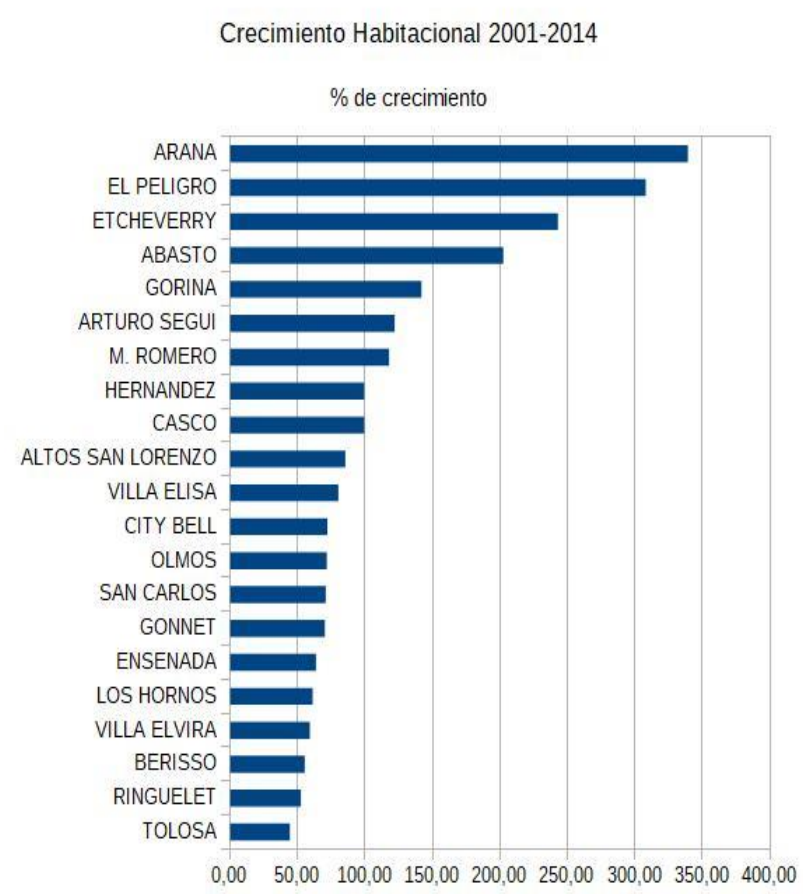


Como se puede observar, el mayor crecimiento poblacional en el periodo 2001 a 2014 se da en la zona Oeste del Gran La Plata, en localidades como Melchor Romero, Abasto, Olmos o Etcheverry. Además, delegaciones de desborde de las áreas más consolidadas de la zona Norte del partido de La Plata, como son Gorina y Arturo Segui, también muestran un importante crecimiento en ese periodo.

Por otro lado, el crecimiento habitacional del periodo 2001-2014 es encabezado por la localidad de Arana con más del 300\% de nuevas viviendas, seguido por El Peligro, Etcheverry, Abasto, Gorina y Arturo Segui. Salvo Gorina, el resto de las delegaciones son limítrofes con partidos que no forman parte del Gran La Plata y tienen tradicionalmente un marcado perfil rural y poca población.

Esta situación da cuenta de que el mayor ritmo de crecimiento tanto poblacional como habitacional del aglomerado se da por expansión y en las áreas del partido más alejadas del casco urbano. En el caso del caso urbano, el porcentaje de crecimiento poblacional se ubica en el décimo cuarto lugar, mientras que se encuentra octavo en el habitacional a pesar de ser la delegación más consolidada en cuanto a servicios y concentración de actividades. Es decir, que el crecimiento habitacional se da por densificación del área central del Gran La Plata y como se puede observar en los planos de densidad, en sus zonas más céntricas.

En función de lo expuesto, para completar el análisis de la Dimensión Espacial se plantea profundizar en los aspectos relacionados a la movilidad y al transporte público masivo,

\section{ii. Movilidad y transporte público.}

El partido de La Plata en 2013 con 290.791 vehículos era el municipio de la provincia de Buenos Aires con más automóviles registrados, un 6,6\% del total provincial. En ese año, la cantidad de vehículos patentados fue de 24.299, mientras que Berisso patentó 1.223 y Ensenada 864, lo que da un total de 26.386 nuevos vehículos registrados para el Gran La Plata. Si se compara con el crecimiento poblacional, en 2013 el incremento en cantidad de personas de la micro región fue de 6.991 nuevos habitantes, lo que equivale a decir que ese año se registraron 3,77 autos nuevos por cada nueva persona en el Gran La Plata.

Este fuerte crecimiento del parque automotor modificó rápidamente la tasa de motorización de la región alcanzando un total de 2,8 habitantes por vehículo en el año 2013 siendo a nivel nacional un promedio de 3,3 habitantes por vehículo. Ver Gráfico 7 y Tabla 15. 
Gráfico 7. Patentamientos anuales - La Plata. Fuente: Elaboración propia en base datos de Asociación de Concesionarios de Automotores de la República Argentina Regional La Plata.

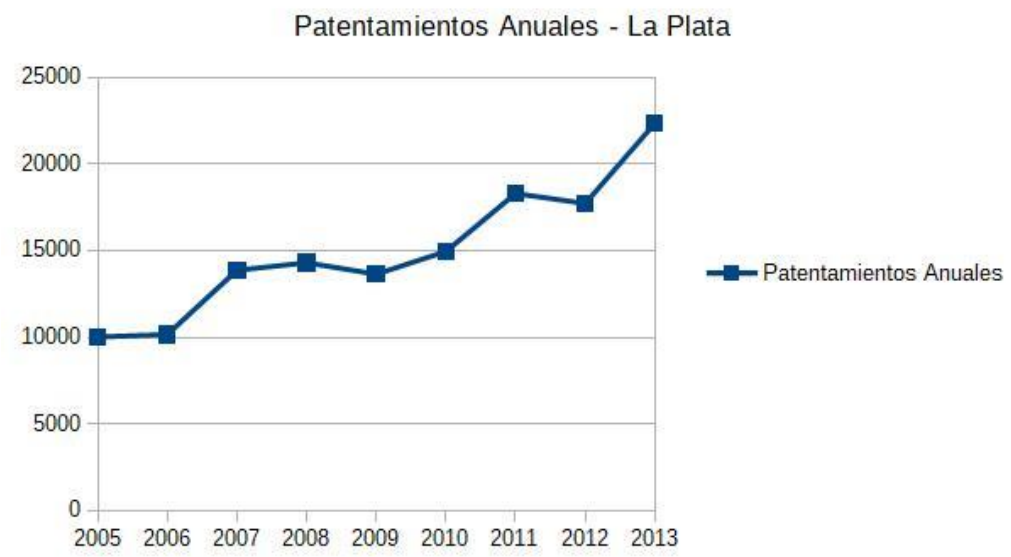

Tabla 15. Patentamientos anuales 2.005- 2.013. Fuente: Elaboración propia en base datos de Asociación de Concesionarios de Automotores de la República Argentina Regional La Plata.

\begin{tabular}{|c|c|}
\hline La Plata & $\begin{array}{c}\text { Patentamientos } \\
\text { Anuales }\end{array}$ \\
\hline 2005 & 10.020 \\
\hline 2006 & 10.169 \\
\hline 2007 & 13.873 \\
\hline 2008 & 14.301 \\
\hline 2009 & 13.642 \\
\hline 2010 & 14.959 \\
\hline 2011 & 18.299 \\
\hline 2012 & 17.723 \\
\hline 2013 & 24.299 \\
\hline
\end{tabular}

En el proceso de transformación de la ciudad en ese contexto, la red de infraestructura vial de la región ha sido desarticulada como elemento estructurante físico-espacial de la ciudad y sustento material para la movilidad integral de la población. El aumento de la congestión, el transito y accidentes vehiculares producto de un aumento del uso del automóvil y del parque automotor se dio en un contexto de crecimiento acelerado de las periferias, y donde las políticas estatales, como plantea López, M.J. (2015), fueron de completamiento de la red dando como resultado una ciudad donde los corredores principales y los medios de transporte motorizados cobraron mucha importancia para la movilidad de la región. Ver Ilustración 21. 


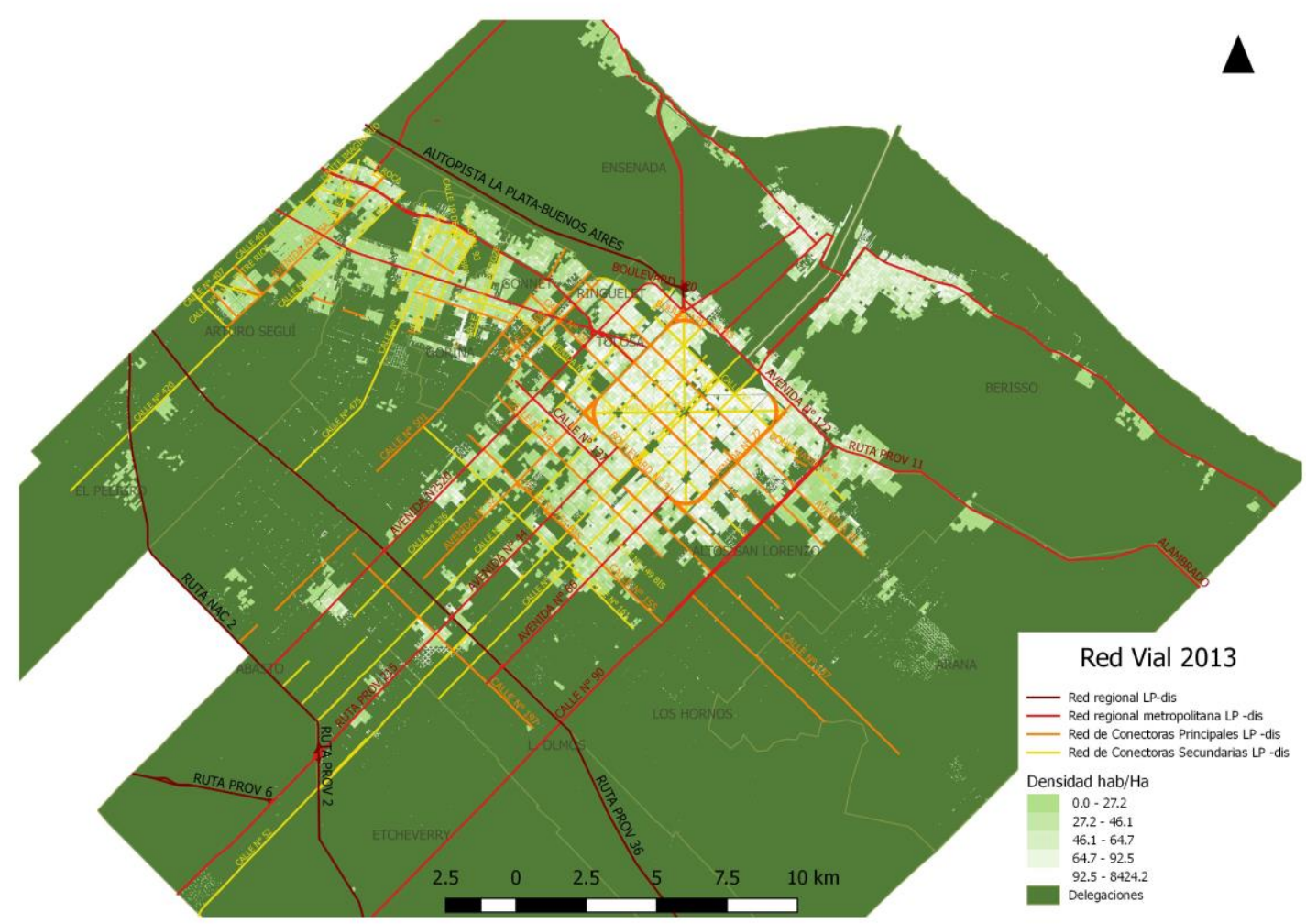

Ilustración 21. Red Vial del Gran La Plata 2013. Fuente: Elaboración propia. Shape de redes María Julieta López (2015).

Como consecuencia de este crecimiento poblacional y sin ningún tipo de planificación de la movilidad (situación que se acentúa en las periferias), la cantidad de taxis y remisses, aumentó a fines de los años '90 contando en 2013 con una flota de 1700 y 1500 vehículos respectivamente. Desde el punto de vista del transporte público masivo, el Gran La Plata cuenta con un tren de pasajeros interurbano, el Ferrocarril Roca de La Plata a Constitución (CABA), que a su vez posee estaciones en las delegaciones del partido de La Plata de la zona Norte, como son Villa Elisa, City Bell, Gonnet, Ringuelet, Tolosa y el casco de La Plata. Además en Abril de 2013 comenzó a funcionar el tren universitario que conecta la estación de trenes del casco con las facultades de Arquitectura y Urbanismo, Informática, Medicina, Periodismo y termina en el Hospital Interzonal General de Adultos. General San Martín. Ver Ilustración 22. 


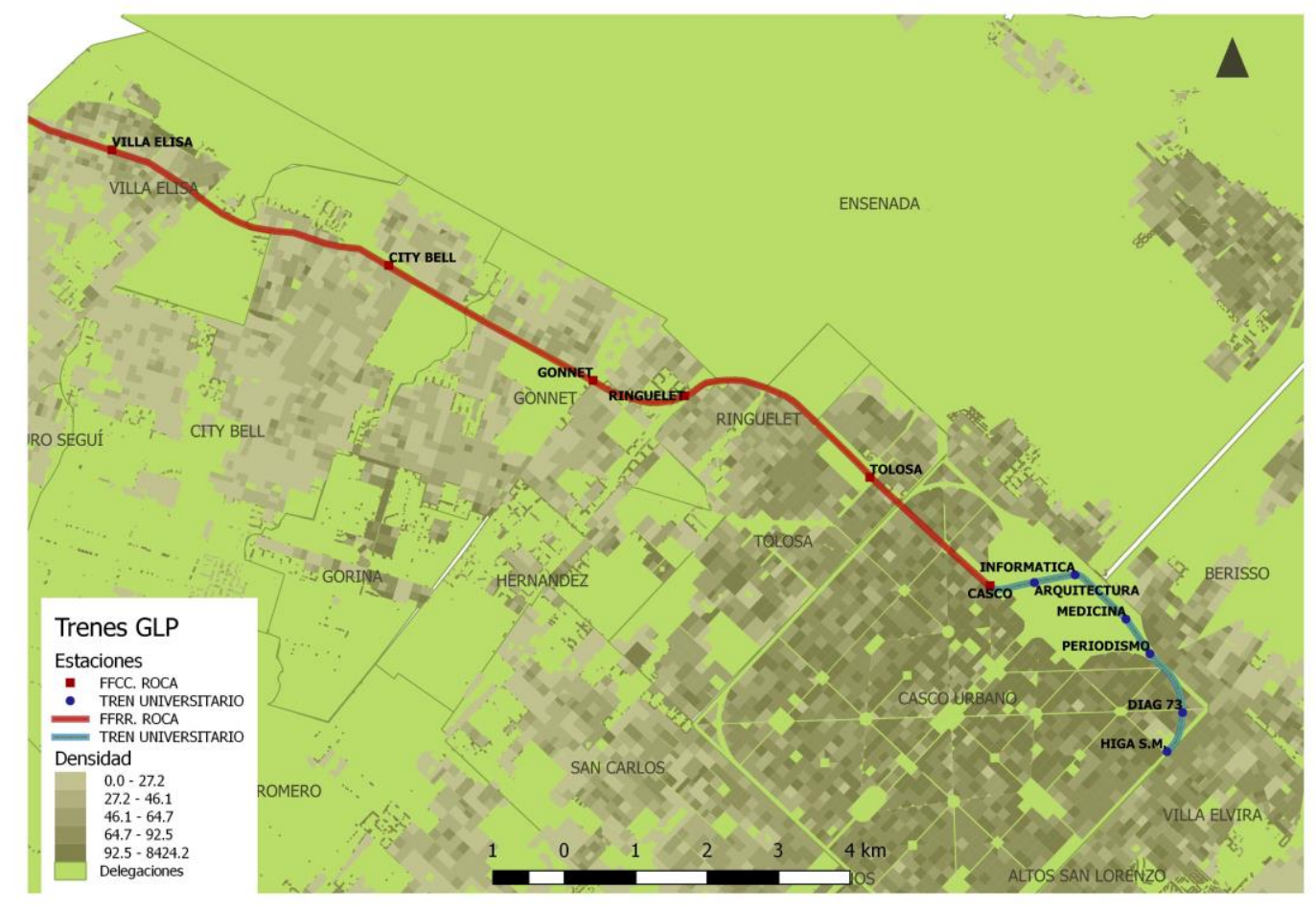

Ilustración 22. Trenes activos en Gran La Plata 2013. Fuente: Elaboración propia, en base a datos del Gobierno de PBA y UNLP.

De todas formas, el uso del tren para viajes dentro del Gran La Plata es muy reducido, siendo el transporte público colectivo el principal medio de movilidad masivo con el que cuenta la micro región. Está constituido por 9 líneas municipales, 8 provinciales y una línea concesionada por la universidad, el "rondín" universitario que fue inaugurado en febrero de 2014.

A continuación (Tabla 16) se detallan los recorridos por línea, ramal y jurisdicción a cargo (Gráfico 8, Gráfico 9): 
Tabla 16. Líneas y ramales por jurisdicción Gran La Plata 2013/2014. Fuente: Elaboración propia, en base a datos de las áreas de Transporte de la Provincia de Buenos Aires y Municipalidad de La Plata

\begin{tabular}{|c|c|}
\hline \multicolumn{2}{|c|}{ PROVINCIAL } \\
\hline LINEA & RAMAL \\
\hline \multirow{5}{*}{202} & $202 \_\mathrm{AB}$ \\
\hline & $202 C D$ \\
\hline & 202_EF \\
\hline & $202 \mathrm{I}$ \\
\hline & $202 \mathrm{~J}$ \\
\hline \multirow{3}{*}{214} & $214 \_\mathrm{A}$ \\
\hline & 214_B \\
\hline & 214_D \\
\hline \multirow{2}{*}{215} & $215 \mathrm{R} 2$ \\
\hline & $215 \mathrm{R} 3$ \\
\hline 225 & 225 \\
\hline \multirow{12}{*}{273} & $273 \_\mathrm{A}$ \\
\hline & 273_B1 \\
\hline & 273 BC \\
\hline & $273 \_\mathrm{BG}$ \\
\hline & 273 C \\
\hline & $273 \_D$ \\
\hline & $273 \_\mathrm{F}$ \\
\hline & $273 \_\mathrm{G}$ \\
\hline & $273 \_\mathrm{H}$ \\
\hline & $273 \mathrm{I}$ \\
\hline & 273_R4 \\
\hline & 273_RT \\
\hline \multirow{7}{*}{275} & $275 \_5 \mathrm{M}$ \\
\hline & 275_DI \\
\hline & $275 \_\mathrm{EN}$ \\
\hline & $275 \mathrm{MO}$ \\
\hline & $275 \_\mathrm{PL}$ \\
\hline & $275 \_\mathrm{PR}$ \\
\hline & $275 \_\mathrm{UO}$ \\
\hline \multirow{7}{*}{307} & 307_A \\
\hline & 307_B \\
\hline & $307 \mathrm{C}$ \\
\hline & $307 \_\mathrm{D}$ \\
\hline & $307 \_\mathrm{E}$ \\
\hline & $307 \mathrm{~F}$ \\
\hline & 307 G \\
\hline
\end{tabular}

\begin{tabular}{|c|c|}
\hline \multicolumn{2}{|c|}{ MUNICIPAL } \\
\hline LINEA & RAMAL \\
\hline \multirow{4}{*}{506} & $506 \quad 18$ \\
\hline & 50640 \\
\hline & $506 \quad 41$ \\
\hline & 50680 \\
\hline 508 & 508 \\
\hline 518 & 518 \\
\hline \multirow{3}{*}{520} & 5201 \\
\hline & $520 \_2$ \\
\hline & 5203 \\
\hline 561 & 561 \\
\hline \multirow{11}{*}{ ESTE } & E 10 \\
\hline & E 11 \\
\hline & E 12 \\
\hline & E 13 \\
\hline & E 14 \\
\hline & E 15 \\
\hline & E 16 \\
\hline & E 45 \\
\hline & E 46 \\
\hline & E 61 \\
\hline & E 80 \\
\hline \multirow{8}{*}{ NORTE } & N_10 \\
\hline & N 11 \\
\hline & $\mathrm{N} 12$ \\
\hline & N 13 \\
\hline & N 15 \\
\hline & N 16 \\
\hline & N 17 \\
\hline & N 18 \\
\hline \multirow{19}{*}{ OESTE } & $\mathrm{O}-10$ \\
\hline & O 11 \\
\hline & O_14 \\
\hline & O 15 \\
\hline & O_16 \\
\hline & O 17 \\
\hline & O_18 \\
\hline & O 19 \\
\hline & O_22 \\
\hline & O 23 \\
\hline & O 24 \\
\hline & O 26 \\
\hline & O 27 \\
\hline & 061 \\
\hline & O 62 \\
\hline & O 65 \\
\hline & O 83 \\
\hline & O 84 \\
\hline & O 86 \\
\hline \multirow{3}{*}{ SUR } & S 10 \\
\hline & S 19 \\
\hline & S 21 \\
\hline
\end{tabular}

\begin{tabular}{|c|c|}
\hline \multicolumn{2}{|c|}{ UNIVERSITARIO } \\
\hline LINEA & RAMAL \\
\hline Universitario & Rondín \\
\hline
\end{tabular}


Gráfico 8. Cantidad de ramales por línea del Gran La Plata. Fuente: Elaboración propia, en base a datos de las áreas de Transporte de la Provincia de Buenos Aires y Municipalidad de La Plata

Cantidad de ramales por linea del Gran La Plata

2013/2014

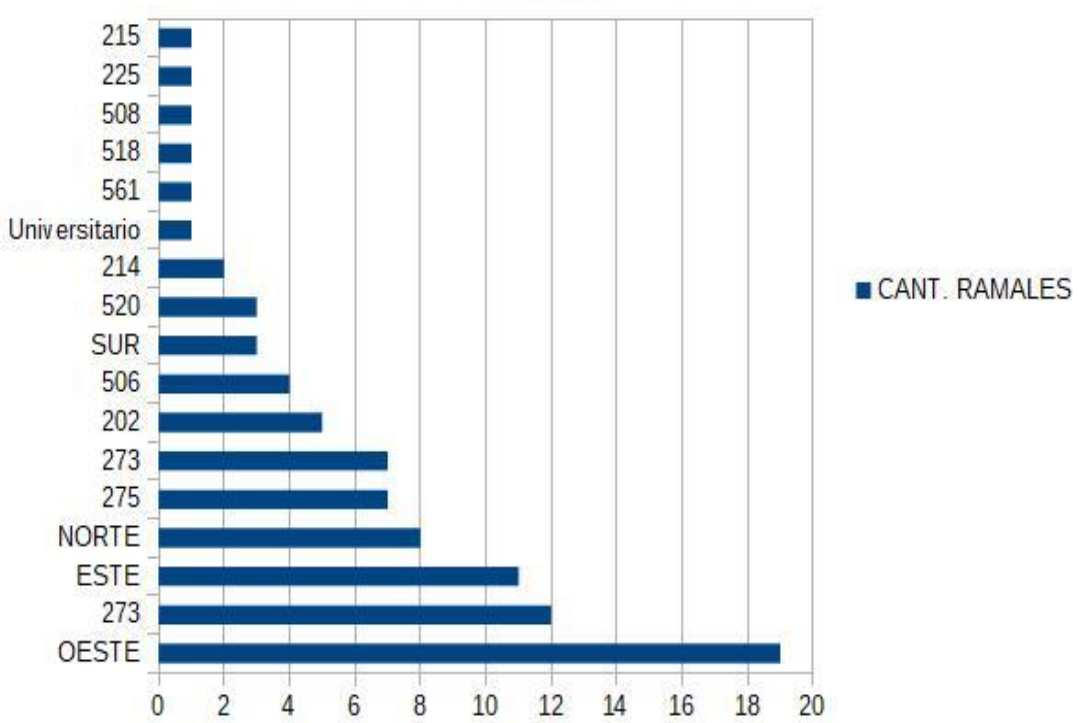

Gráfico 9. Partición de cantidad de ramales por Jurisdicción. Fuente: Elaboración propia, en base a datos de las áreas de Transporte de la Provincia de Buenos Aires y Municipalidad de La Plata

\section{Particion de cantidad de ramales por Jurisdiccion}

$2013 / 2014$

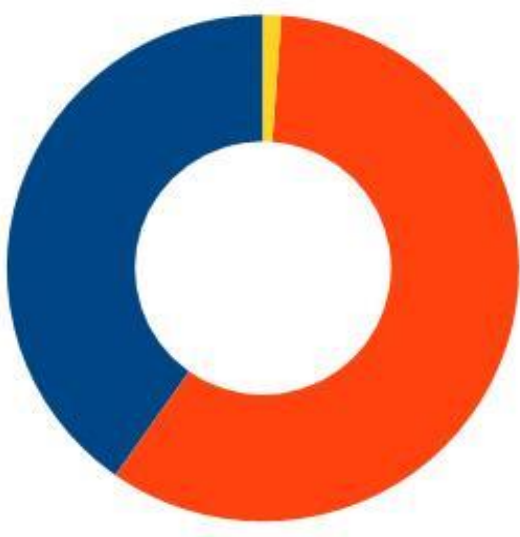

- Provincial

- Municipal

Univ ersitario

Como muestran los Gráfico 8 y 9, la cantidad de líneas provinciales y platenses son similares aunque las de jurisdicción municipal poseen un número mayor de ramales. También se observa que las de mayor cantidad de ramales son las línea Oeste, 273, Este y Norte, mientras que las que menos ramales poseen son las líneas más nuevas ya sean provinciales o municipales como la 215, 225, 508, 518 y 561. Además se puede observar que la espacialización de la cantidad de ramales por línea da como resultado que en las periferias 
Oeste se encuentra la mayor cantidad de recorridos, seguido por zona Norte del partido. Ver Ilustración 23.

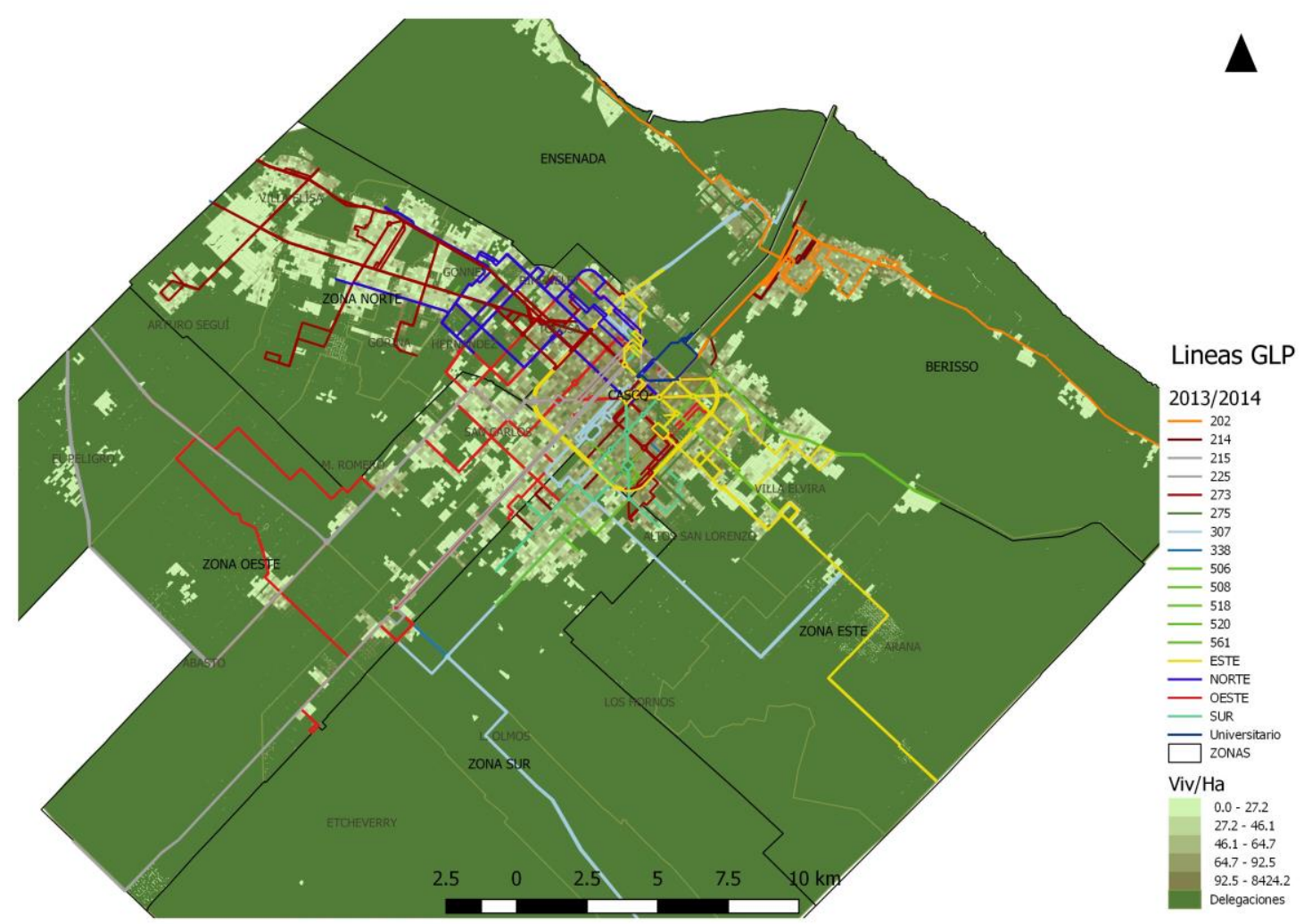

Ilustración 23. Líneas de Transporte Público del Gran La Plata 2013/2014. Fuente: Elaboración propia, en base a datos de las áreas de Transporte de la Provincia de Buenos Aires y Municipalidad de La Plata

La cantidad de ramales encuentra una correlación con la cantidad de kilómetros recorridos y pasajeros transportados por cada línea. Tanto la línea Oeste como la 273 son las que poseen mayor cantidad de pasajeros transportados y kilómetros recorridos anuales. Las líneas con menor cantidad de recorridos como la 215, 225, 508 o 518, son a su vez líneas con menor cantidad de pasajeros transportados y kilómetros recorridos. Ver Gráfico 10, Gráfico 11 y Tabla 16. 
Gráfico 10. Kilómetros recorridos por línea Gran La Plata. Fuente: Elaboración propia, en base a datos de las áreas de Transporte de la Provincia de Buenos Aires y Municipalidad de La Plata

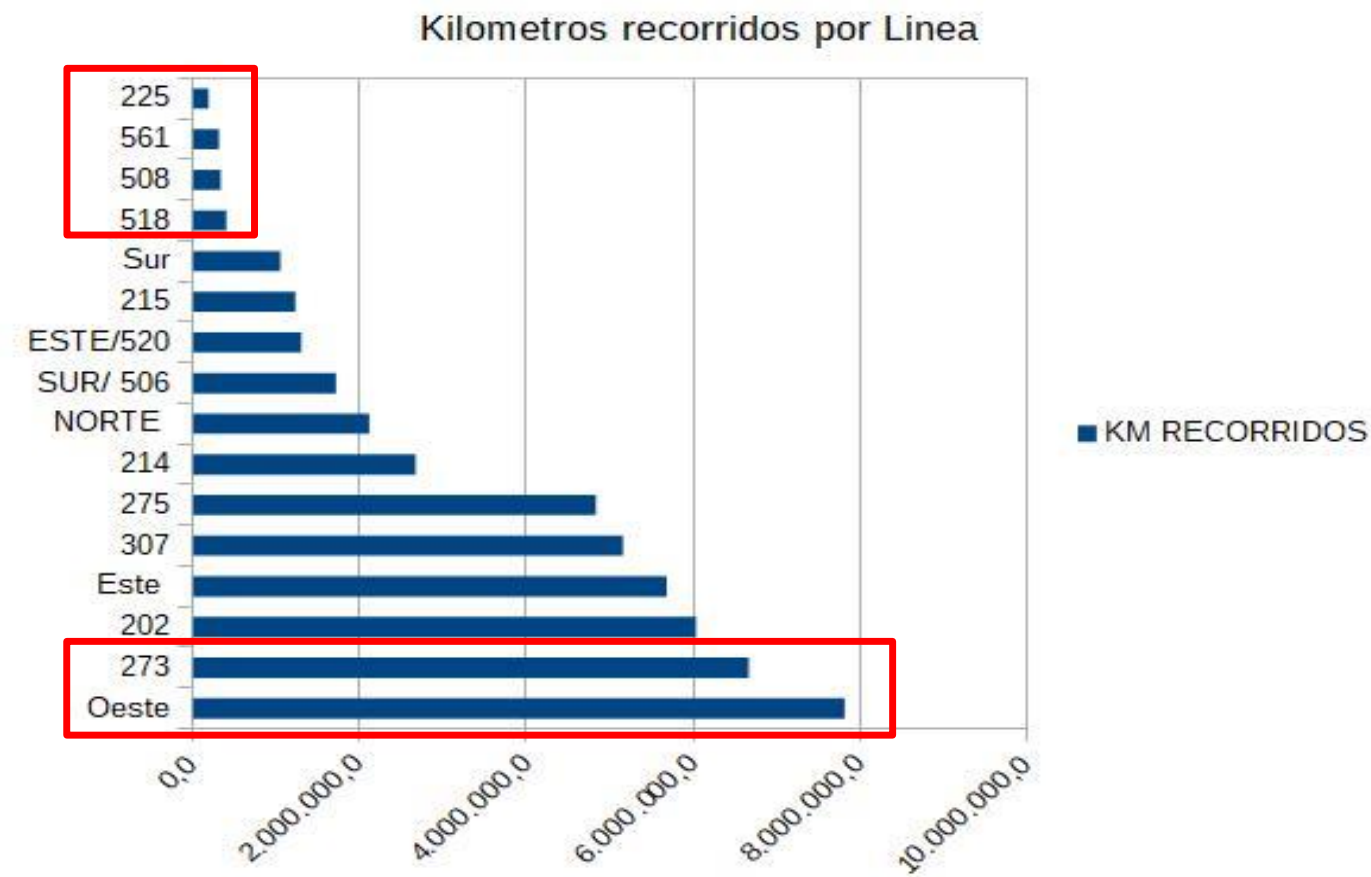

Gráfico 11. Pasajeros transportados por línea. Fuente: Elaboración propia, en base a datos de las áreas de Transporte de la Provincia de Buenos Aires y Municipalidad de La Plata

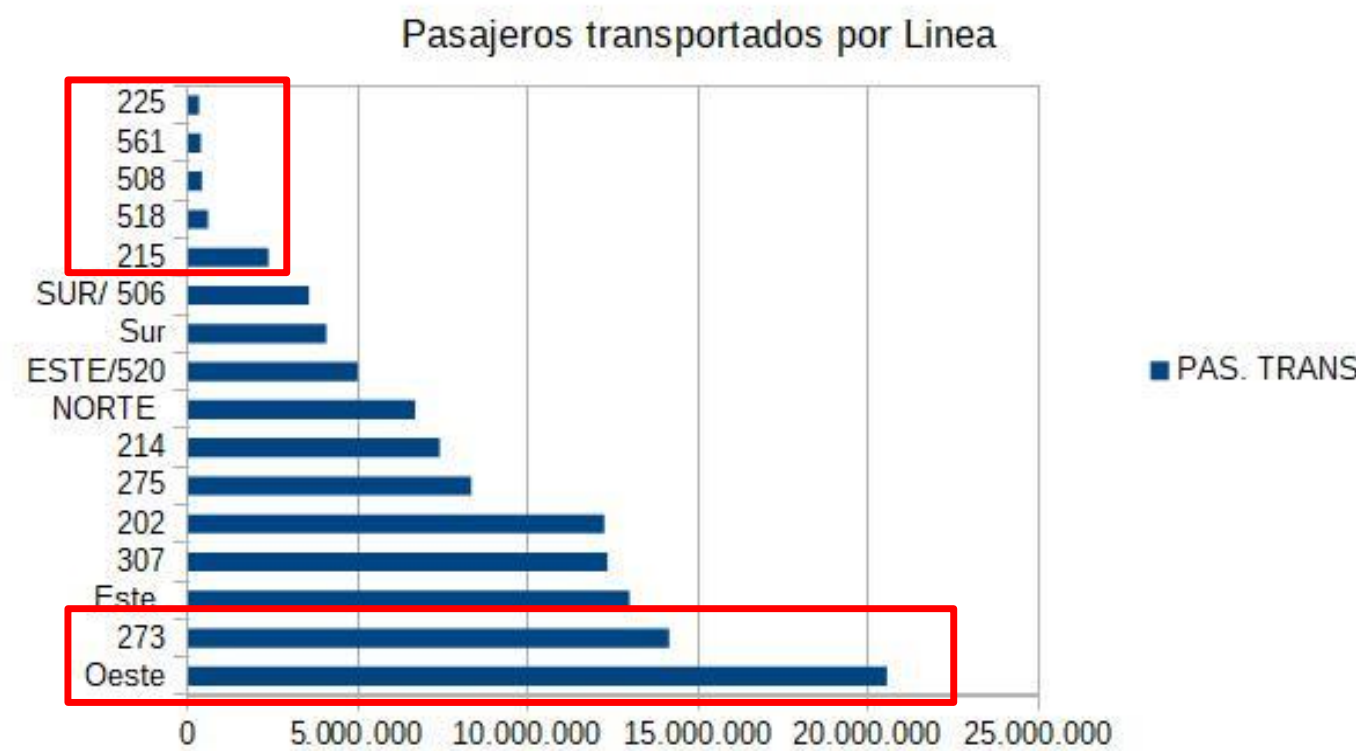


Tabla 16. Kilómetros recorridos y pasajeros transportados por el sistema de transporte público del Gran La Plata. Fuente: Elaboración propia, en base a datos de las áreas de Transporte de la Provincia de Buenos Aires y Municipalidad de La Plata

\begin{tabular}{|c|r|r|c|c|}
\hline LINEA & KM RECORRIDOS & PAS. TRANS. & PAS/KM & KM/PAS \\
\hline Oeste & $7.817 .065,0$ & 20.552 .289 & 2,63 & 0,38 \\
\hline 561 & 310796,0 & 379.090 & 1,22 & 0,82 \\
\hline 508 & 331309,0 & 411.804 & 1,24 & 0,80 \\
\hline Este & 5681369,9 & 12.979 .620 & 2,28 & 0,44 \\
\hline SUR/ 506 & 1717485,7 & 3.558 .040 & 2,07 & 0,48 \\
\hline 518 & 402921,6 & 589.255 & 1,46 & 0,68 \\
\hline ESTE/520 & 1297356,0 & 4.994 .568 & 3,85 & 0,26 \\
\hline NORTE & 2114205,0 & 6.684 .397 & 3,16 & 0,32 \\
\hline Sur & 1050485,0 & 4.070 .814 & 3,88 & 0,26 \\
\hline Sub TOTAL Mun. & $\mathbf{2 2 3 6 4 5 7 8 , 2}$ & $\mathbf{5 4 . 2 1 9 . 8 7 7}$ & $\mathbf{2 , 4 2}$ & $\mathbf{0 , 4 1}$ \\
\hline 202 & 6035009,0 & 12.245 .150 & 2,03 & 0,49 \\
\hline 214 & 2669503,0 & 7.405 .183 & 2,77 & 0,36 \\
\hline 215 & 1227343,0 & 2.373 .307 & 1,93 & 0,52 \\
\hline 225 & 186160,0 & 324.916 & 1,75 & 0,57 \\
\hline 273 & 6666855,0 & 14.152 .365 & 2,12 & 0,47 \\
\hline 275 & 4834287,0 & 8.329 .483 & 1,72 & 0,58 \\
\hline 307 & 5159434,0 & 12.339 .133 & 2,39 & 0,42 \\
\hline Sub TOTAL Prov. & $\mathbf{2 6 7 7 8 5 9 1 , 0}$ & $\mathbf{5 7 . 1 6 9 . 5 3 7}$ & $\mathbf{2 , 1 3}$ & $\mathbf{0 , 4 7}$ \\
\hline TOTAL & $\mathbf{4 9 1 4 3 1 6 9 , 2}$ & $\mathbf{1 1 1 3 8 9 4 1 4}$ & $\mathbf{2 , 2 7}$ & $\mathbf{0 , 4 4}$ \\
\hline & & & & \\
\hline
\end{tabular}

Tanto los kilómetros recorridos como los pasajero transportados expresas el tamaño de la línea. Pero el indicador que ayuda a comprender la racionalidad económica del sistema de transporte es la relación pasajero transportado por kilómetro recorrido (IPK). Los mayores valores de este índice los poseen las líneas Sur y 520 que circulan mayoritariamente por áreas de densidades altas y medias del Partido de La Plata y con mucha dependencia del casco. Esta situación genera que tengan una mayor rentabilidad desde el punto de vista financiero que otras que poseen índices menores, como son la 275 y 225. Por lo general líneas de estas características, con muchos kilómetros y pasajeros pero con un IPK bajo, dan cuenta de que cumplen un rol más de servicio social que de maximización de rentabilidad. Las líneas 561 y 508 son las de menor rentabilidad del sistema, por un lado porque recorren áreas de baja densidad pero también porque compiten con los recorridos de la línea Oeste que posee una mayor frecuencia, y a su vez tanto la 561 como 508 poseen una tarifa mayor por ser semirápidos. Ver Gráfico 12 y Tabla 16. 
Gráfico 12. Pasajeros por kilómetro recorrido por línea Gran La Plata. Fuente: Elaboración propia, en base a datos de las áreas de Transporte de la Provincia de Buenos Aires y Municipalidad de La Plata

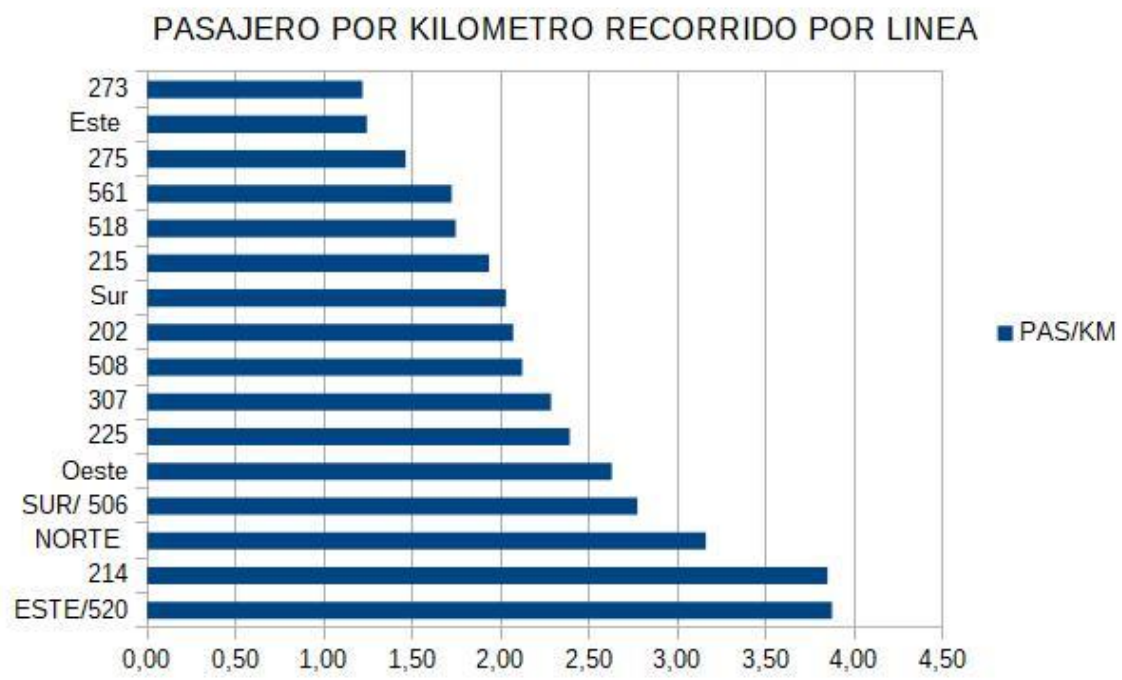

Un caso particular es la línea Oeste ya que posee la mayor cantidad de pasajeros y kilómetros. Es una de las líneas con mayor IPK pero contradictoriamente circula en gran parte por áreas de baja densidad. Esto se explica porque todos sus recorridos parten de la zona del Gran La Plata que más utiliza el transporte público, como se analiza más adelante (ver Tabla 18) a partir de datos de la Encuesta de Movilidad del Gran La Plata ${ }^{66}$

Dicha encuesta muestra que se producen 1.561 .605 viajes en la región, lo que da como resultado una tasa de generación de viaje de 1,69 viajes promedio por persona por día. A su vez el estudio expone que la distribución de los viajes por modo es del 29,08\% en transporte público urbano, el 33,05 en auto particular y el 17,15\%. a pie. Si se agregan los datos según modos, se obtiene que el $42,8 \%$ de los viajes se realizan en medios de transporte masivo como son el transporte público urbano, el interurbano, el transporte escolar y el tren. Los no masivos alcanzan un porcentaje similar con un $34,9 \%$, donde se consideran los viajes de automóvil particular, taxis, remisses, motos y otros. Los viajes no motorizados, es decir los viajes a pie o en bicicleta, representan un $21,2 \%$ del total. Ver Tabla 17 y Gráfico 13.

66 Encuesta realizada por el G2 de Movilidad Ambiente y Territorio del Instituto de Investigaciones y Políticas del Ambiente Construido (IIPAC-FAU UNLP), que hoy impulsa el Observatorio de Movilidad del Gran La Plata. 
Tabla 17. Reparto modal Encuestas movilidad Gran La Plata 2013. Fuente: Elaboración propia, en base a Encuesta de Movilidad del Gran La Plata - GII IIPAC FAU.

\begin{tabular}{|c|c|c|}
\hline \multicolumn{2}{|c|}{ REPARTO MODAL ENCUESTA 2013 GLP } & \multirow{2}{*}{$\begin{array}{r}\text { Viajes totales } \\
\mathbf{4 6 2 0 7 3}\end{array}$} \\
\hline Autos & 33,05 & \\
\hline Taxis & 3,00 & 41940 \\
\hline Remisses & 1,61 & 22466 \\
\hline Motos & 3,02 & 42152 \\
\hline Otros & 1,86 & 25998 \\
\hline Transporte Público & 29,08 & 406473 \\
\hline Transporte Escolar & 3,08 & 43038 \\
\hline Transporte Interurbano & 0,34 & 4782 \\
\hline Tren & 1,71 & 23910 \\
\hline Bicicleta & 6,11 & 85418 \\
\hline A pie & 17,15 & 239758 \\
\hline Total & 100,00 & 1398008 \\
\hline Masivo & 34,21 & 478203 \\
\hline No masivo & 42,53 & 594628 \\
\hline No motorizado & 23,26 & 325177 \\
\hline Población & $826.246,00$ & \\
\hline Tasa De Generación & 1,69 & \\
\hline
\end{tabular}

Gráfico 13. Partición modal por modos de transporte Gran La Plata 2013. Fuente: Elaboración propia, en base a Encuesta de Movilidad del Gran La Plata - GII IIPAC FAU.

REPARTO MODAL AGREGADO - GRAN LA PLATA

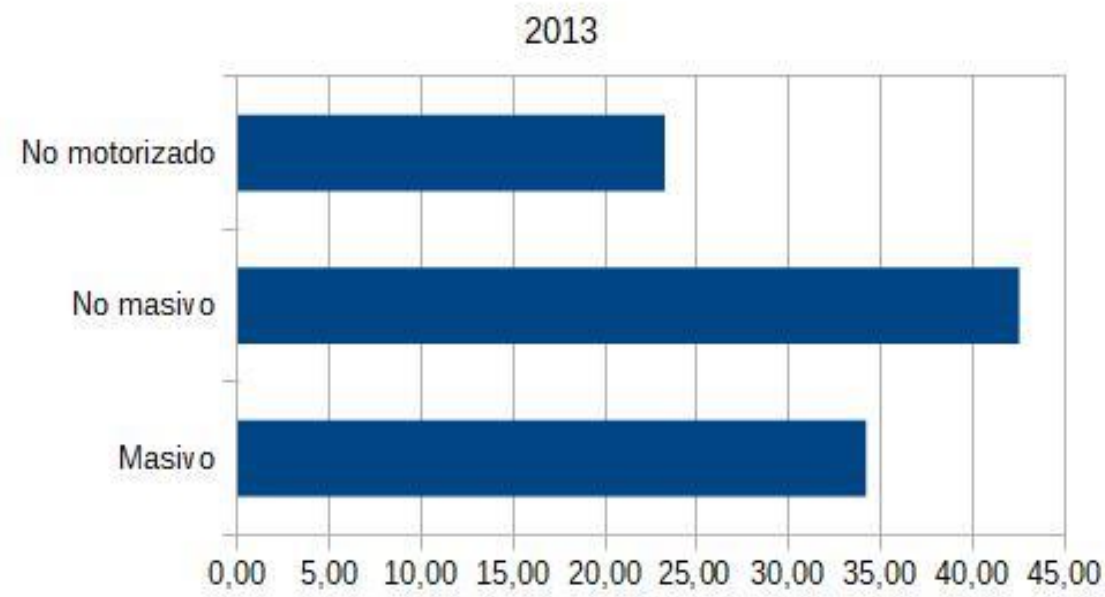




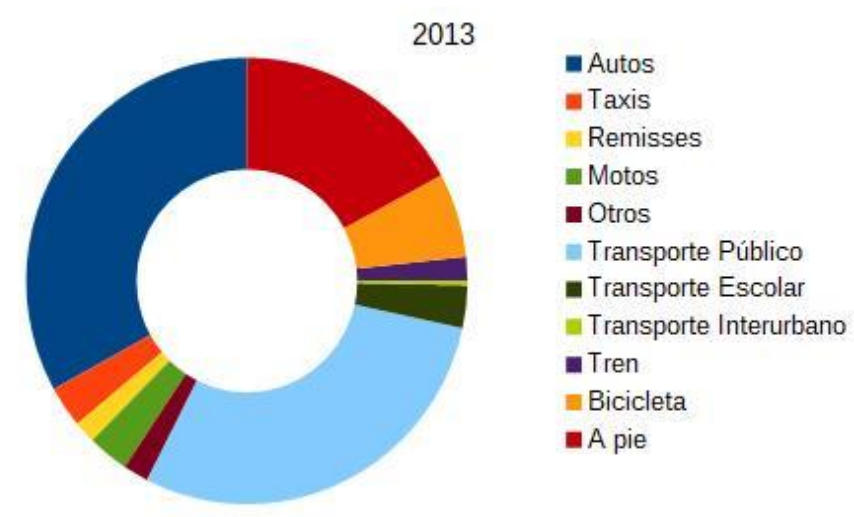

Las particiones modales por zona muestran diferencias al promedio del Gran La Plata. Por ejemplo la zona del casco urbano mantiene una proporción similar entre medios masivos, no masivos y no motorizados. En ese marco se puede identificar como característica principal de la zona en comparación con las otras, un elevado porcentaje de viajes a pie y en bicicleta por sobre los viajes motorizados. Ver Tabla 18.

Tabla 18. Partición modal por zona. Fuente: Elaboración propia, en base a Encuesta de Movilidad del Gran La Plata - GII IIPAC FAU.

\begin{tabular}{|c|c|c|c|}
\hline \multirow{2}{*}{ ZONA } & \multicolumn{3}{|c|}{ PARTICIÓN MODAL (\%) } \\
\cline { 2 - 4 } & MASIVO & NO MASIVO & NO MOTORIZADO \\
\hline CASCO & 30,2 & 33,3 & 36,5 \\
\hline ESTE & 37,6 & 40,6 & 21,8 \\
\hline SUR & 40,4 & 50,4 & 9,1 \\
\hline OESTE & 50,6 & 36,4 & 13 \\
\hline NORTE & 32,8 & 53,6 & 13,6 \\
\hline
\end{tabular}

El resto de las zonas, las periféricas, poseen un porcentaje de viajes No masivos superior al del Casco Urbano. La zona Este es la que muestra mayores similitudes con la partición modal general del Gran La Plata. La Sur con un 9,1\% de viajes no motorizados es la zona donde menos viajes a pie o en bicicleta se producen, mientras que la mitad se realiza en medios no masivos como el auto particular, taxi o remisse. A su vez tiene un porcentaje alto comparado con el resto de viajes en modos masivos como son el transporte público urbano e interurbano. La zona Oeste y la Norte son opuestas en la utilización de modos motorizados. En la Oeste más del $50 \%$ de los viajes se realizan en un medio masivo, mientras que en la Norte ese 
porcentaje se realiza en no masivo, al mismo tiempo que poseen un porcentaje de viajes no motorizados similar.

En términos de cantidad de viajes por modo más utilizado, se observa que el Casco Urbano, la zona Norte y la Oeste son las mayores productoras de viajes, en particular el casco y Norte son las zonas que más viajes generan en todos los modos, el resto varía según el modo de transporte a observar. Ver Ilustración 24, Ilustración 25, Ilustración 26 y Ilustración 27.

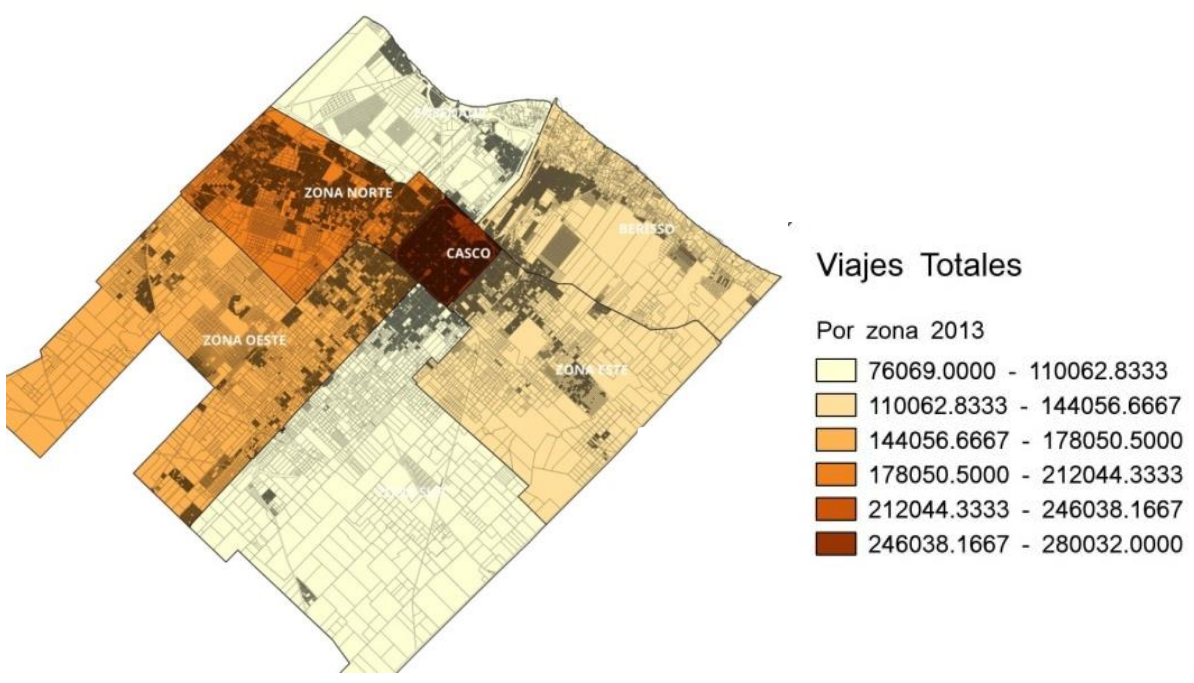

Ilustración 24. Viajes diarios totales por zona en 2013. Fuente: Elaboración propia, en base a Encuesta de Movilidad del Gran La Plata - GII IIPAC FAU.

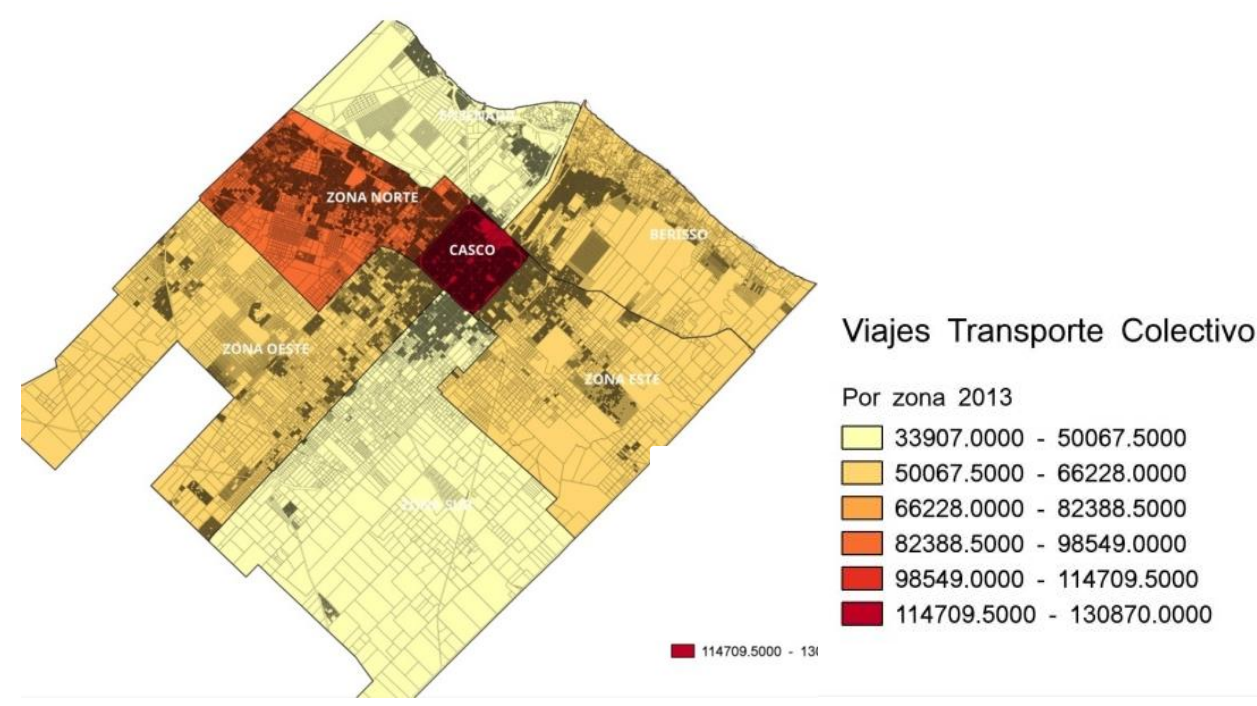

Ilustración 25. Viajes diarios en colectivo por zona en 2013. Fuente: Elaboración propia, en base a Encuesta de Movilidad del Gran La Plata - GII IIPAC FAU. 


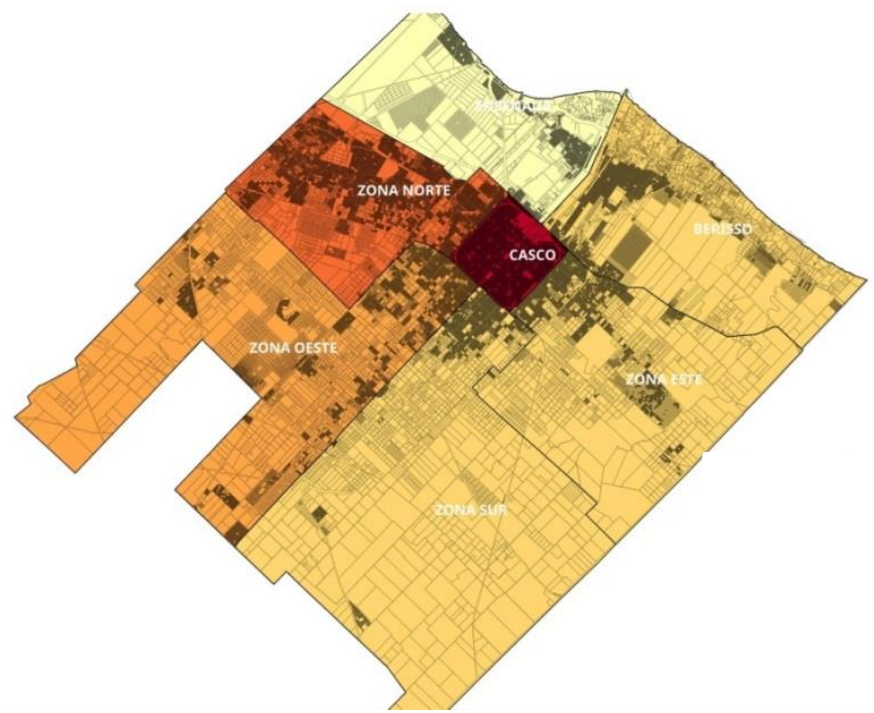

\section{Viajes Automóvil}

Por zona 2013

$37330.0000-53949.5000$

$53949.5000-70569.0000$

$70569.0000-87188.5000$

$87188.5000-103808.0000$

$103808.0000-120427.5000$

$120427.5000-137047.0000$

Ilustración 26. Viajes diarios en automóvil por zona en 2013. Fuente: Elaboración propia, en base a Encuesta de Movilidad del Gran La Plata - GII IIPAC FAU.

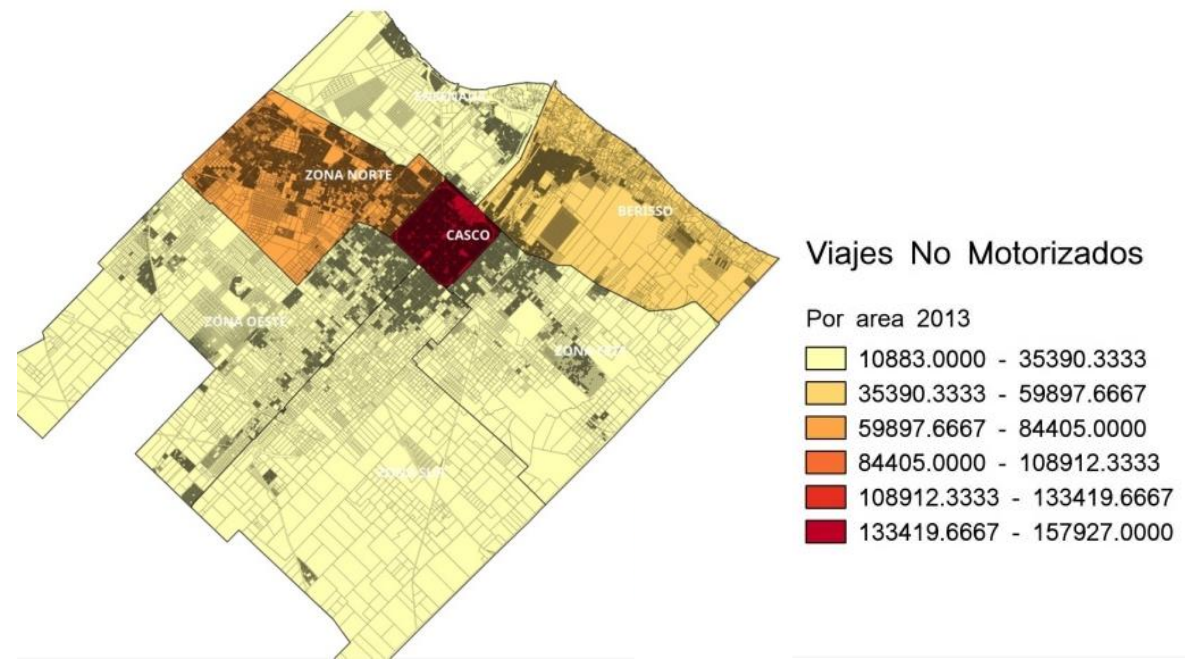

Ilustración 27. Viajes diarios no motorizados por zona en 2013. Fuente: Elaboración propia, en base a Encuesta de Movilidad del Gran La Plata - GII IIPAC FAU.

La cantidad de viajes producidos es importante para analizar la potencia de las zonas atractoras de viaje. Todas las zonas tienen un gran porcentaje de la producción de sus viajes hacia el casco urbano, incluso la mayoría de las zonas periféricas tienen índices similares al propio casco. La excepción es la zona Oeste que posee casi la mitad del porcentaje que el resto, con 45,9\% de los viajes al casco, lo que a su vez muestra que la mayoría de los viajes tienen como destino distintas delegaciones de la misma zona, (ver Tabla 19 y Gráfico 14.) como se analizará más adelante. 
Tabla 19. Porcentajes de viajes al casco urbano por delegación 2013. Fuente: Elaboración propia, en base a Encuesta de Movilidad del Gran La Plata - GII IIPAC FAU.

\begin{tabular}{|c|c|}
\hline Zona & $\begin{array}{c}\text { Viajes al } \\
\text { Casco (\%) }\end{array}$ \\
\hline Casco & 86 \\
\hline Norte & 74,5 \\
\hline Sur & 82,4 \\
\hline Este & 83,4 \\
\hline Oeste & 45,9 \\
\hline
\end{tabular}

Gráfico 14. Viajes al Casco por zona. Fuente: Elaboración propia, en base a Encuesta de Movilidad del Gran La Plata - GII IIPAC FAU.

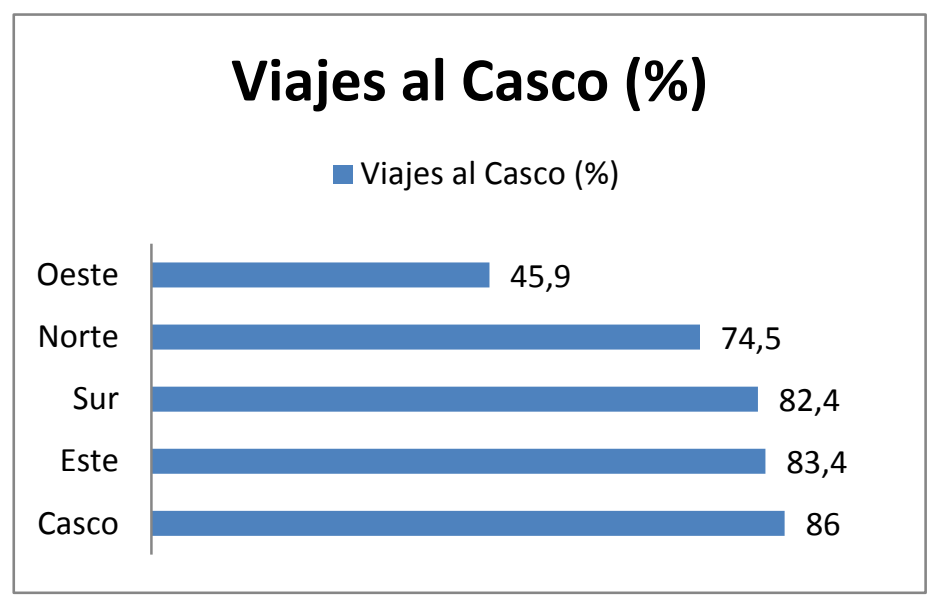

Para ello es que a continuación se realiza un análisis detallado por delegación para la construcción del año base a partir de la variable espacial, profundizando en: a- la partición modal agregada por delegación; b- la cantidad de viajes, tasa de generación de viajes por delegación; c- Análisis de demanda de viajes; d- la cobertura por tiempo de espera y e- las frecuencias y tiempo de viaje en transporte público.

\section{a- Partición modal agregada por delegación}

La partición modal agregada por delegación permite analizar con más detalle las distintas zonas del Gran La Plata y sus comportamientos de movilidad (Gráfico 15 y Tabla 20). Se pueden observar resultados muy disimiles entre delegaciones, en algunos casos diferencias dentro de la misma zona. Por ejemplo en la zona Norte del Gran La Plata en la mayoría de las delegaciones el viaje en auto es mayor que el colectivo y el no motorizado, pero en Villa Elisa los resultados de la encuesta dieron una diferencia de más de 30\% a favor del viaje en 
colectivo por sobre el auto particular; también en Hernández se observa lo mismo aunque allí la diferencia es del 10\%.

Gráfico 15. Partición Modal por Delegación 2013-2014. Fuente: Elaboración propia, en base a Encuesta de Movilidad del Gran La Plata - GII IIPAC FAU.

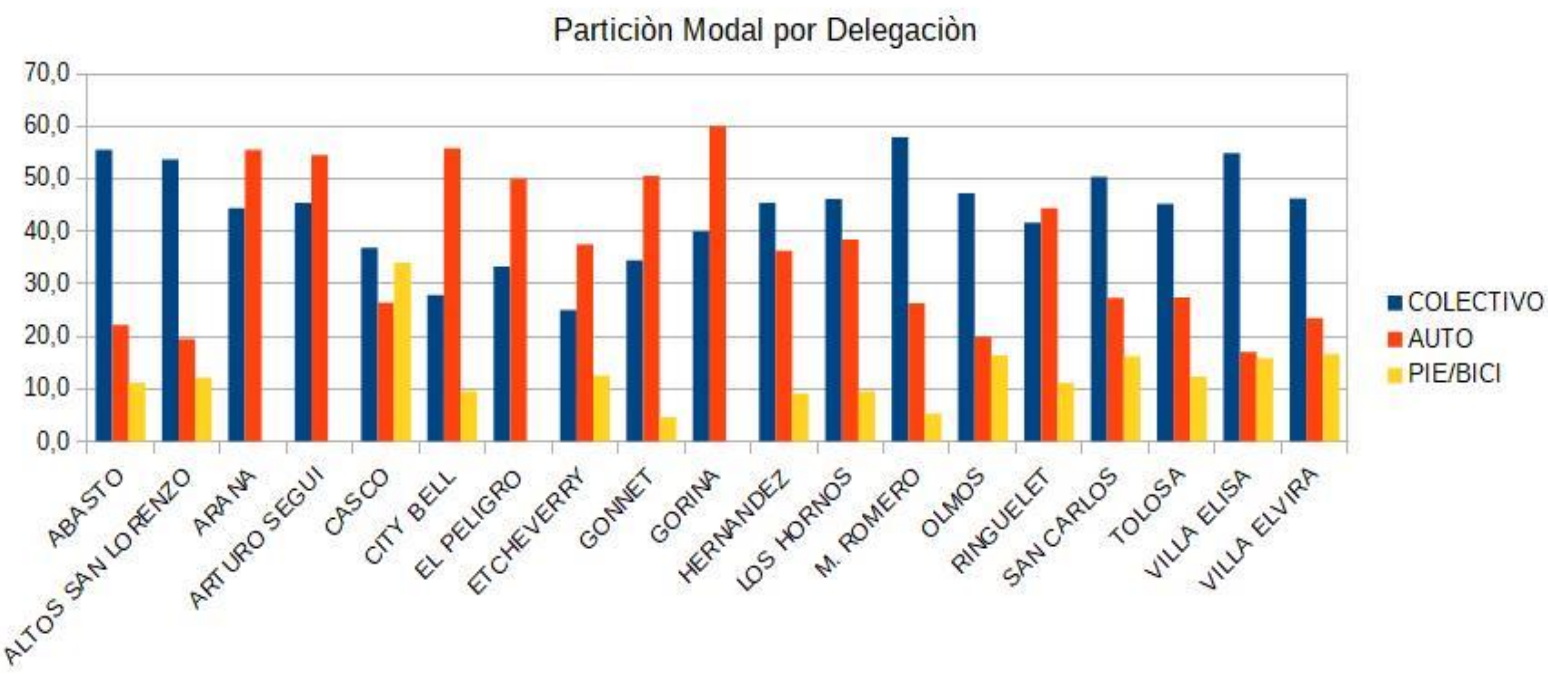

Tabla 20. Partición modal por delegación. Fuente: Elaboración propia, en base a Encuesta de Movilidad del Gran La Plata - GII IIPAC FAU.

\begin{tabular}{|c|c|c|c|c|}
\hline DELEGACIÓN & ZONA & COLECTIVO & AUTO & PIE/BICI \\
\hline CASCO URBANO & CASCO & 36,9 & 26,4 & 34,1 \\
\hline $\begin{array}{c}\text { ALTOS SAN } \\
\text { LORENZO }\end{array}$ & ESTE & 53,7 & 19,5 & 12,2 \\
\hline ARANA & ESTE & 43,4 & 54,6 & 2 \\
\hline VILLA ELVIRA & ESTE & 46,3 & 23,5 & 16,7 \\
\hline ARTURO SEGUI & NORTE & 45 & 54 & 1 \\
\hline CITY BELL & NORTE & 27,9 & 55,8 & 9,6 \\
\hline GONNET & NORTE & 34,5 & 50,6 & 4,6 \\
\hline GORINA & NORTE & 40 & 57 & 3 \\
\hline HERNANDEZ & NORTE & 45,5 & 36,4 & 9,1 \\
\hline RINGUELET & NORTE & 41,7 & 44,4 & 11,1 \\
\hline TOLOSA & NORTE & 45,2 & 27,4 & 12,3 \\
\hline VILLA ELISA & NORTE & 54,9 & 17,1 & 15,9 \\
\hline ABASTO & OESTE & 55,6 & 22,2 & 11,1 \\
\hline EL PELIGRO & OESTE & 33,3 & 49 & 1 \\
\hline M. ROMERO & OESTE & 57,9 & 26,3 & 5,3 \\
\hline SAN CARLOS & OESTE & 50,4 & 27,4 & 16,2 \\
\hline ETCHEVERRY & OESTE & 25 & 37,5 & 12,5 \\
\hline OLMOS & OESTE & 47,3 & 20 & 16,4 \\
\hline LOS HORNOS & SUR & 46,2 & 38,5 & 9,6 \\
\hline
\end{tabular}


En la zona Oeste de la micro región también existen diferencias entre delegaciones. Por ejemplo San Carlos, que es una delegación periférica de desborde del casco, posee un mayor porcentaje de viajes en colectivo que en auto con una diferencia de 23 puntos porcentuales, mientras que en Etcheverry el modo más utilizado es el automóvil con un 37,5\% por sobre el $25 \%$ del colectivo, o El Peligro donde el uso del auto alcanza al 50\% y 33,3\% en colectivo, porcentajes similares a Gonnet que forma parte de la zona Norte. En zona Sur existen diferencias, Los Hornos y Olmos si bien comparten el colectivo como modo más utilizado con porcentajes similares, la diferencia más importante radica en los viajes no motorizados y el uso del automóvil. Olmos con un 16,4 de viajes a pie o en bicicleta, mientras Los Hornos un $9,6 \%$.

Por otro lado, la zona Este del Gran La Plata, Villa Elvira y Altos de San Lorenzo poseen similitudes ya que en ambas delegaciones el principal modo de transporte utilizado es el colectivo, en segundo lugar el auto y por último los modos no motorizados. Esta jerarquía similar se da con porcentajes diferentes en Altos de San Lorenzo el uso del colectivo es mayor y en Villa Elvira el automóvil y los no motorizados, pero muestran diferencias importantes con Arana, donde el uso del automóvil alcanza el 54,6\% de los viajes, similar a City Bell de zona Norte que es la que más utiliza el auto. En cuanto a los viajes no motorizados también se expresan diferencias importantes entre Villa Elvira y Altos de San Lorenzo con Arana, donde el porcentaje de esos viajes llega solo al $2 \%$ mientras que en las otras dos delegaciones están en 16,7\% y 12,2\% respectivamente. Ver Tabla 20.

Los mayores porcentajes de viajes en transporte público se obtuvieron en las delegaciones de la zona Oeste situadas en el corredor de la av. 520 que conecta Abasto, Romero, San Carlos y Hernández por cercanía, después las situadas en el corredor de av. 44 como es Olmos y parte de San Carlos. Como casos puntuales, también se evidencia un importante uso del colectivo urbano en Villa Elisa en zona Norte y en segundo nivel Altos de San Lorenzo en zona Este. En términos de porcentajes, se observa un muy bajo uso del transporte público en Etcheverry, City Bell y el propio Casco Urbano, seguidos por El Peligro, Gorina, Gonnet, Ringuelet y Arana. Los Hornos, Villa Elvira, Tolosa y Arturo Segui son las delegaciones que se ubican en un término medio en el uso del transporte público. Ver Ilustración 28 y Tabla 20. 


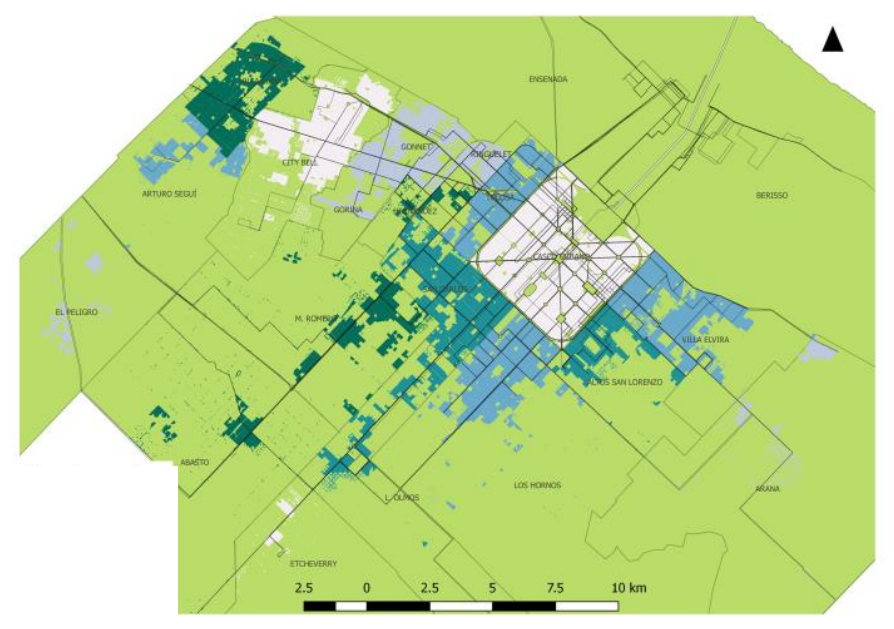

$\%$ modos masivos

- Red T. Publico

$\%$ particion modal

$0.0-30.2$

$30.2-44.4$

$44.4-46.3$

$46.3-53.7$

$53.7-58.6$

Delegaciones

\section{Ilustración 28. Porcentaje de modos masivos por delegación y red de transporte público.}

Fuente: Elaboración propia en base a Encuesta de Movilidad del Gran La Plata 2013/2014.

Por otro lado, la mayor utilización de los modos no masivos (Ilustración 29 y Tabla 20) en términos de porcentaje se obtuvieron en City Bell y Gorina de la zona Norte del partido de La Plata donde se combina la buena oferta de infraestructura vial con el hecho de ser lugar de residencia se sectores de altos recursos económicos en el caso de City Bell, y más heterogéneo en Gorina pero donde los sectores de menores recursos se ubican en áreas con una débil cobertura de transporte público con frecuencias mayores a los 30 minutos. Las delegaciones de El Peligro y Etcheverry que se ubican al extremo Oeste y al extremo Sur de la micro región también presentan un porcentaje alto de uso de modos no masivos. Una las causas de esta situación podría ser la mala cobertura de transporte público, ya que al ser las delegaciones más alejadas del Casco Urbano, mejorar las frecuencias sería inviable económicamente para el empresario que tiene la concesión de las líneas que por allí transitan.

Las delegaciones que presentan un menor uso del automóvil son Villa Elisa en zona Norte, San Carlos y Olmos sobre el corredor de av.44 y Altos de San Lorenzo, donde el uso del transporte público es más extendido. Dentro de las que presentan porcentajes intermedios se pueden considerar el Casco Urbano, Los Hornos, Melchor Romero, Villa Elvira, Hernández y Tolosa. Es decir, delegaciones de todas las zonas del partido. 

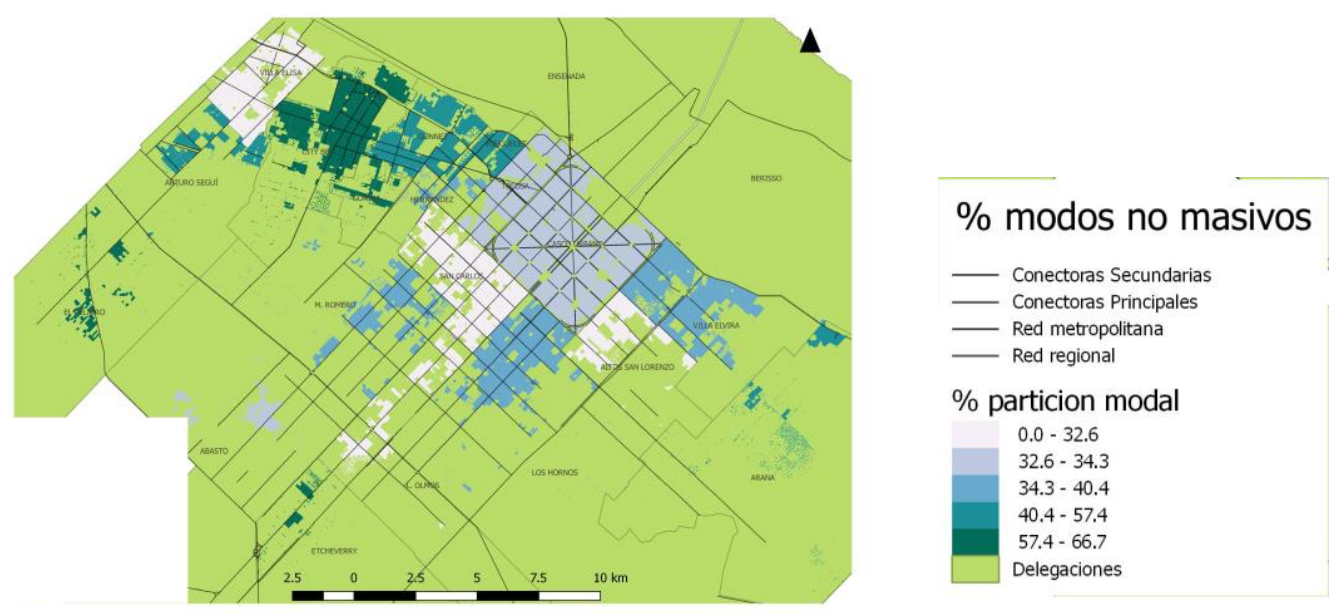

Ilustración 29. Porcentaje de modos no masivos por delegación y red vial. Fuente:

Elaboración propia con datos de Encuesta de Movilidad del Gran La Plata 2013 y vías de López, 2016.

Los mayores porcentajes de viajes no motorizados (Ilustración 30 y Tabla 20) se concentran en el Casco Urbano y en Olmos, de la zona Oeste, con valores del 20,5\% al 36,5\%. En el Casco el uso de los medios no motorizados está muy vinculado a lo que analiza Miralles Guasch (2014) en las áreas centrales de Barcelona sobre la gran mixtura de usos y alta densidad poblacional que permite que gran parte de los tiempos de viaje sean menores a 10 minutos. El caso de Olmos es diferente: si bien el centro de esta delegación se está transformando en la centralidad más importante para la zona Oeste, la densidad poblacional y habitacional es muy baja, además de estar inserta en un área predominantemente rural intensiva con población de recursos medio-bajos y bajos.

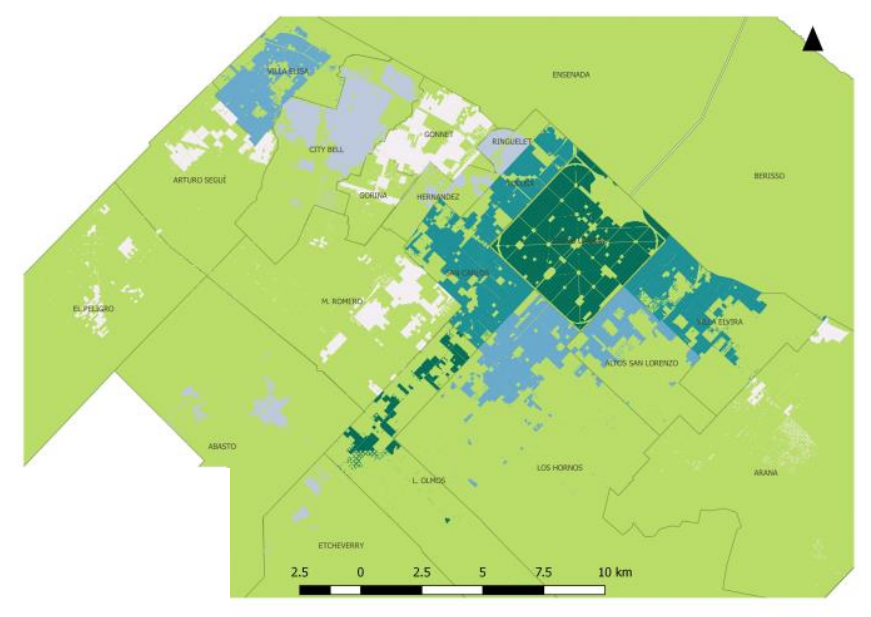

$\%$ modos no motorizados

$\%$ particion modal

$$
\begin{aligned}
& 0.0-8.1 \\
& 8.1-13.3 \\
& 13.3-15.8 \\
& 15.8-20.5 \\
& 20.5-36.5
\end{aligned}
$$

Delegaciones

Ilustración 30. Porcentaje de viajes en modos no motorizados por delegación. Fuente: Elaboración propia en base a Encuesta de Movilidad del Gran La Plata 2013/2014. 
Las delegaciones donde la población realiza menos viajes a pie o en bicicleta son El Peligro y Melchor Romero seguidas por Abasto y Etcheverry de zona Oeste: estas delegaciones se caracterizan por la mala infraestructura urbana, bajas densidades, mucha dependencia de otras delegaciones y sectores sociales de recursos medio-bajos y bajos.

\section{b- Cantidad de viajes, tasa de generación de viajes por delegación}

En general, la cantidad de viajes de cada delegación está relacionado con la cantidad de población de la misma. El Casco Urbano es la delegación que más viajes produce, luego Los Hornos de zona Sur, Villa Elvira zona Este, San Carlos Oeste y Tolosa de Norte, todas ellas delegaciones de desborde del Casco. Las de mayor cantidad de viajes que no cumplen esta característica son Gonnet y City Bell con 64025 y 53292 viajes por día respectivamente, ambas de zona Norte, seguido de Melchor Romero de la zona Oeste. Las que menos viajes generan coinciden con las delegaciones de menor población y ubicadas en los límites del partido, como son El Peligro, Etcheverry, Arana y Hernández. Ver Tabla 21 e Ilustración 31.

Tabla 21. Cantidad de viajes y Tasa de Generación de Viaje por delegación. Fuente: Elaboración propia, en base a Encuesta de Movilidad del Gran La Plata - GII IIPAC FAU.

\begin{tabular}{|c|c|c|c|c|c|c|c|c|c|}
\hline DELEGACION & Población & $\begin{array}{c}\text { Viajes } \\
\text { Expandidos }\end{array}$ & $\begin{array}{c}\mathrm{V} . \\
\text { Colectivo }\end{array}$ & $\begin{array}{c}\text { V. } \\
\text { Auto }\end{array}$ & $\begin{array}{c}\text { V. } \\
\text { Pie/Bici }\end{array}$ & TGVC & TGVA & TGVP/B & TGV \\
\hline CASCO & 205262 & 457836 & 168831 & 120953 & 155934 & 0,82 & 0,59 & 0,76 & 2,23 \\
\hline LOS HORNOS & 63800 & 110753 & 51117 & 42597 & 10649 & 0,80 & 0,67 & 0,17 & 1,74 \\
\hline $\begin{array}{l}\text { VILLA } \\
\text { ELVIRA } \\
\end{array}$ & 66332 & 97114 & 44960 & 22780 & 16186 & 0,68 & 0,34 & 0,24 & 1,46 \\
\hline SAN CARLOS & 52405 & 79123 & 39900 & 21640 & 12849 & 0,76 & 0,41 & 0,25 & 1,51 \\
\hline TOLOSA & 47733 & 69057 & 31218 & 18920 & 8514 & 0,65 & 0,40 & 0,18 & 1,45 \\
\hline GONNET & 29903 & 64025 & 22077 & 32380 & 2944 & 0,74 & 1,08 & 0,10 & 2,14 \\
\hline $\begin{array}{l}\text { ALTOS SAN } \\
\text { LORENZO }\end{array}$ & 44255 & 56040 & 30070 & 10935 & 6834 & 0,68 & 0,25 & 0,15 & 1,27 \\
\hline CITY BELL & 35706 & 53292 & 14860 & 29721 & 5124 & 0,42 & 0,83 & 0,14 & 1,49 \\
\hline M. ROMERO & 488686 & 32338 & 18722 & 8510 & 1702 & 0,38 & 0,17 & 0,03 & 0,66 \\
\hline VILLA ELISA & 24971 & 30918 & 16967 & 5279 & 4902 & 0,68 & 0,21 & 0,20 & 1,24 \\
\hline RINGUELET & 11923 & 26230 & 10929 & 11658 & 2914 & 0,92 & 0,98 & 0,24 & 2,20 \\
\hline OLMOS & 18757 & 16695 & 7892 & 3339 & 2732 & 0,42 & 0,18 & 0,15 & 0,89 \\
\hline $\begin{array}{l}\text { ARTURO } \\
\text { SEGUI } \\
\end{array}$ & 10882 & 14239 & 6472 & 7767 & 0 & 0,59 & 0,71 & 0,00 & 1,31 \\
\hline GORINA & 16451 & 11596 & 4638 & 6958 & 0 & 0,28 & 0,42 & 0,00 & 0,70 \\
\hline ABASTO & 15579 & 11376 & 6320 & 2528 & 1264 & 0,41 & 0,16 & 0,08 & 0,73 \\
\hline HERNANDEZ & 9249 & 7682 & 3492 & 2793 & 698 & 0,38 & 0,30 & 0,08 & 0,83 \\
\hline ARANA & 4897 & 7315 & 3251 & 4064 & 0 & 0,66 & 0,83 & 0,00 & 1,49 \\
\hline ETCHEVERRY & 3929 & 4734 & 1183 & 1775 & 592 & 0,30 & 0,45 & 0,15 & 1,20 \\
\hline EL PELIGRO & 2312 & 4184 & 1395 & 2092 & 0 & 0,60 & 0,90 & 0,00 & 1,81 \\
\hline
\end{tabular}




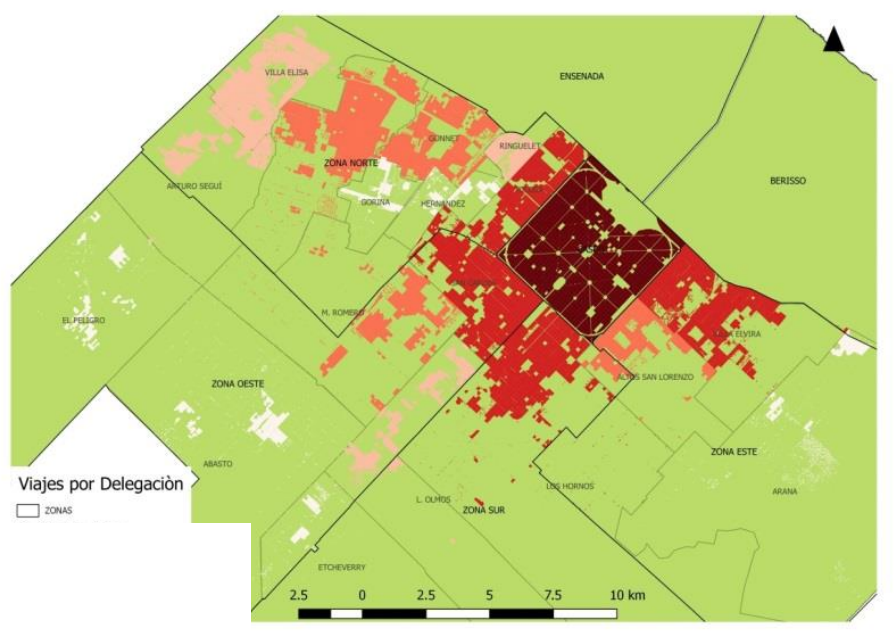

Viajes por Delegaciòn

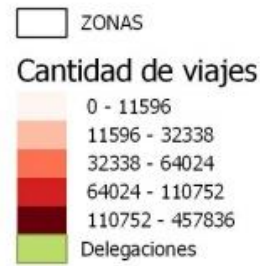

Ilustración 31. Viajes diarios totales por delegación. Fuente: Elaboración propia, en base a Encuesta de Movilidad del Gran La Plata - GII IIPAC FAU.

La mayor cantidad de viajes en automóvil se realizan en el Casco Urbano, Los Hornos y las delegaciones City Bell y Gonnet de zona Norte. En un segundo lugar se encuentran el resto de las delegaciones de desborde del casco, como son Tolosa, San Carlos, Altos de San Lorenzo y Villa Elvira. Olmos resalta dentro de las delegaciones que menos viajes en auto genera porque produce menos de la mitad de los viajes que produce en colectivo. Mientras que otras delegaciones como Hernández, Abasto o El Peligro que también producen pocos viajes en auto, mantienen escasa diferencia con la cantidad de viajes en colectivo cuando se las compara. Ver Ilustración 32.

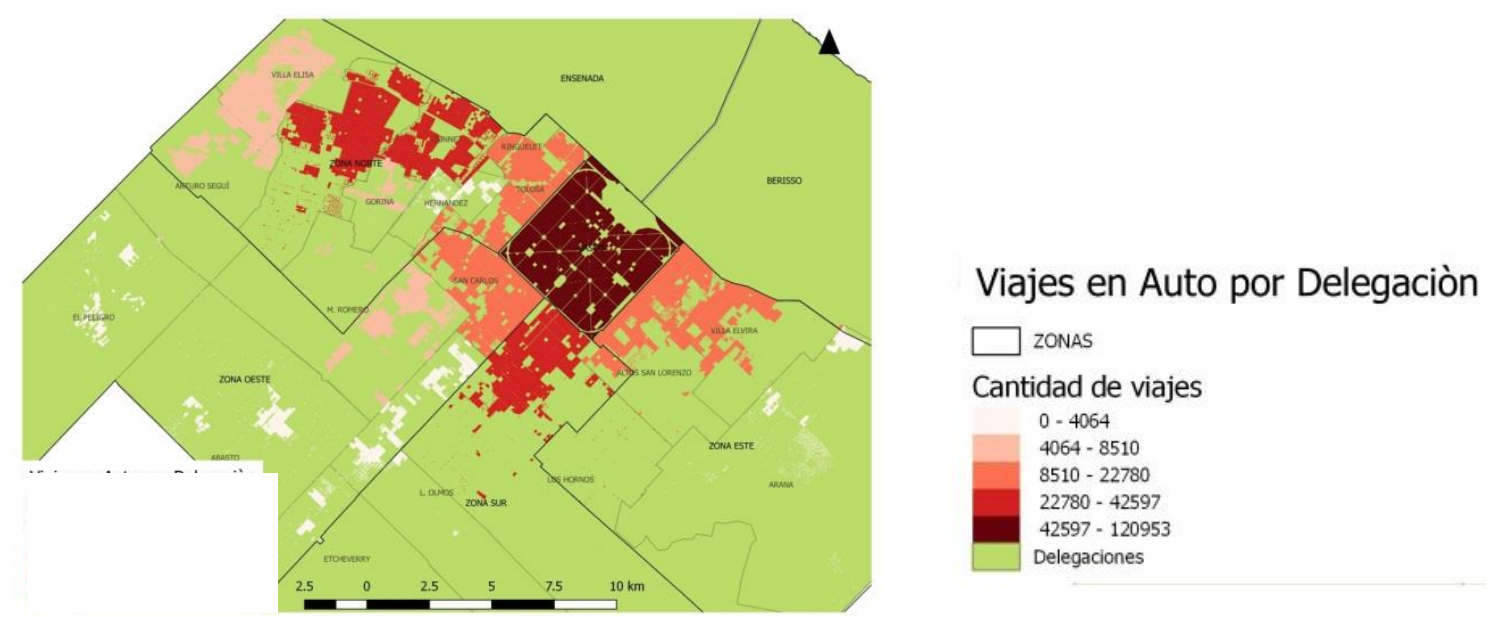

Ilustración 32. Viajes diarios en auto por delegación. Fuente: Elaboración propia, en base a Encuesta de Movilidad del Gran La Plata - GII IIPAC FAU.

En cuanto a los viajes en transporte público, se mantiene la jerarquía de las delegaciones que más viajes generan: Gonnet en la zona Norte, San Carlos en la zona Oeste y Altos de San 
Lorenzo en la zona Este. Las delegaciones que menos viajes en transporte público generan son las mismas que menos viajes generan en general. Ver Ilustración 33.
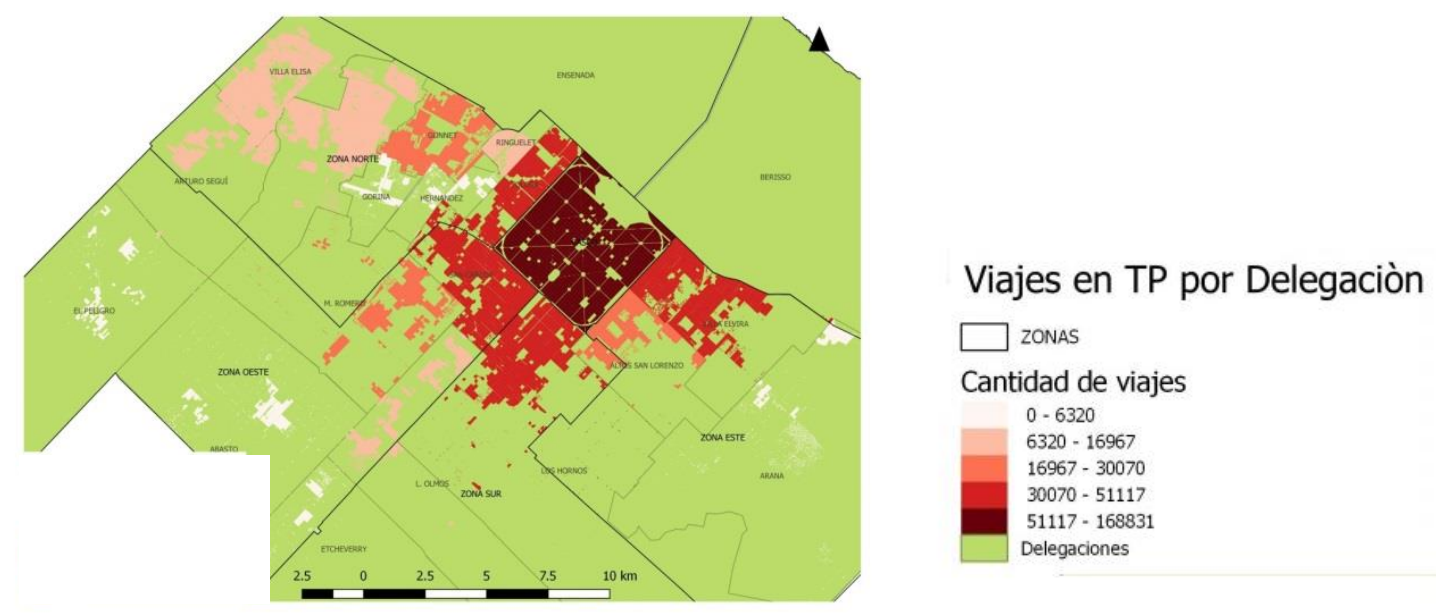

Ilustración 33. Viajes diarios en transporte público por delegación. Fuente: Elaboración propia, en base a Encuesta de Movilidad del Gran La Plata - GII IIPAC FAU.

Los viajes a pie y bicicleta se generan en su mayoría en el casco y las delegaciones de desborde del mismo, así como en las delegaciones de City Bell y Villa Elisa en la zona Norte que poseen un cierto desarrollo de centralidades. Ver Ilustración 34.

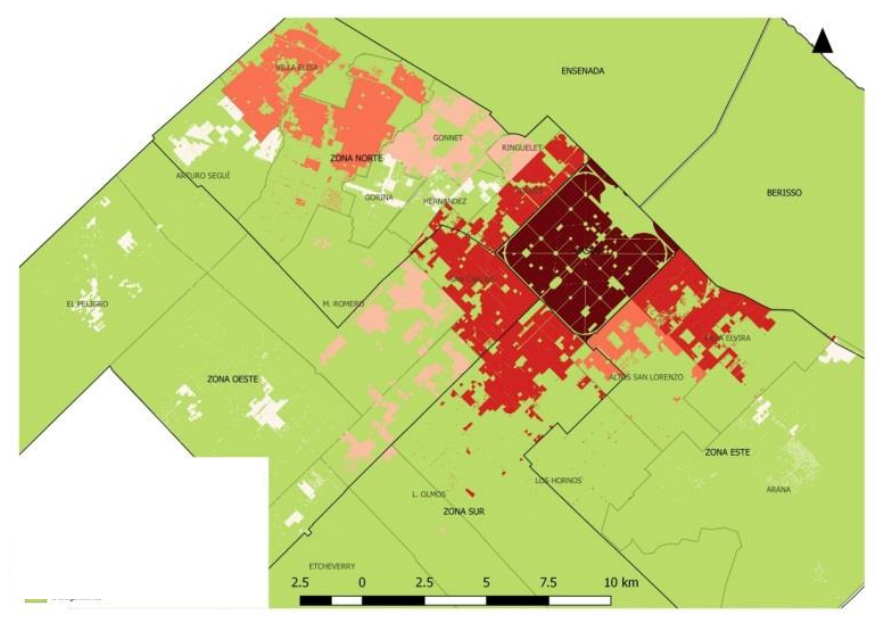

Viajes a pie/bici por Delegaciòn

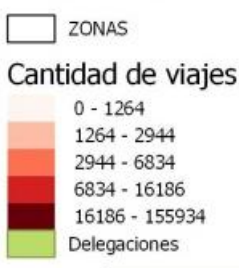

Ilustración 34. Viajes diarios a pie y bicicleta por delegación. Fuente: Elaboración propia, en base a Encuesta de Movilidad del Gran La Plata - GII IIPAC FAU.

La cantidad de viajes por delegación ayuda a comprender el volumen de viajes espacializados que se producen en la región. Para analizarla relación que existe entre éste y la población es necesario calcular la tasa de generación de viajes que se obtiene de la relación entre la cantidad de viajes y la cantidad de personas. 


$$
\begin{gathered}
\text { TGV }=\mathrm{V} / \mathrm{H} \\
\text { TGV: Tasa de generación de viaje } \\
\text { V: Viajes realizados } \\
\text { H: Habitantes / población. }
\end{gathered}
$$

Si bien este valor para la región es de 1,6, no es un valor constante ni representativo para cada delegación. Así, el Casco Urbano tiene una tasa de generación de viajes de 2,23, Ringuelet cuenta con un valor similar de 2,20 y Gonnet cuenta con una tasa de generación de viajes del 2,14 siendo estas las delegaciones que más viajes producen por persona. Ver Ilustración 35.

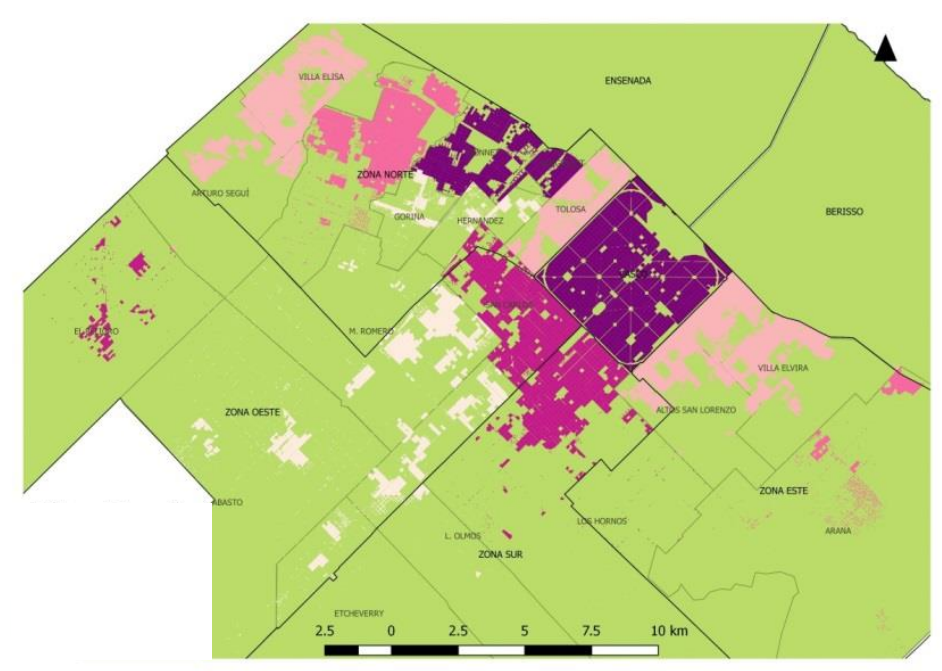

\section{TGV por Delegaciòn}

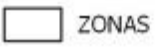

Tasa de generacion de viaje

$0.000-1.205$

$1.205-1.464$

$1.464-1.494$

$1.494-1.810$

$1.810-2.230$

Delegaciones

Ilustración 35. Tasa de Generación de Viaje por delegación. Fuente: Elaboración propia, en base a Encuesta de Movilidad del Gran La Plata - GII IIPAC FAU.

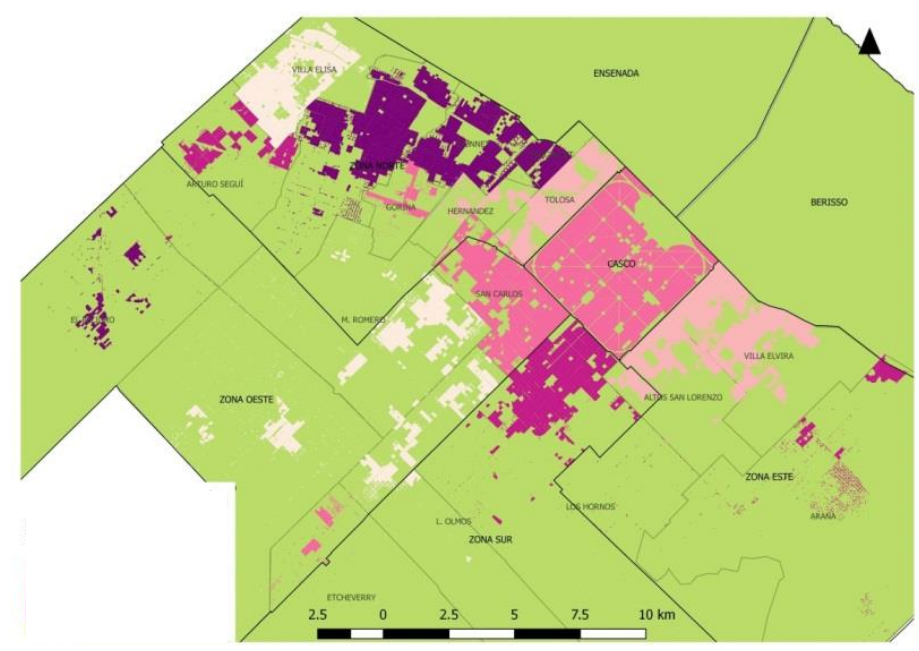

TGV Auto por Delegaciòn

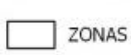

Tasa de generacion de viaje

$0.00-0.21$

$0.21-0.40$

$0.40-0.59$

$0.59-0.83$

$0.83-1.08$

Delegaciones

Ilustración 36. Tasa de Generación de Viaje en auto por delegación. Fuente: Elaboración propia, en base a Encuesta de Movilidad del Gran La Plata - GII IIPAC FAU. 


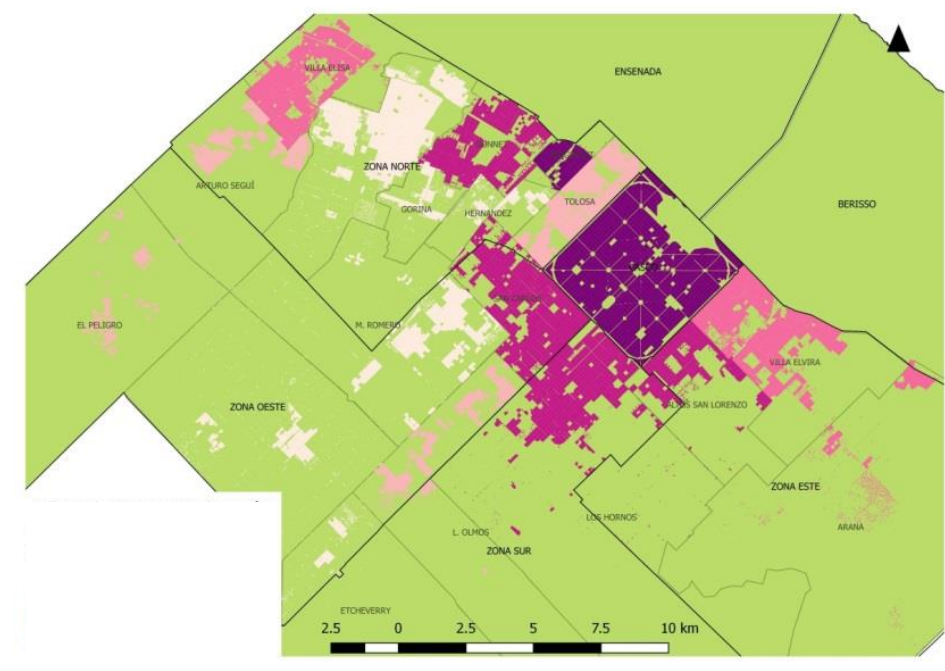

TGV Colectivo por Delegaciòn

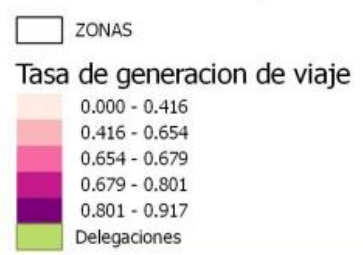

Ilustración 37. Tasa de Generación de Viaje en colectivo por delegación. Fuente: Elaboración propia, en base a Encuesta de Movilidad del Gran La Plata - GII IIPAC FAU.

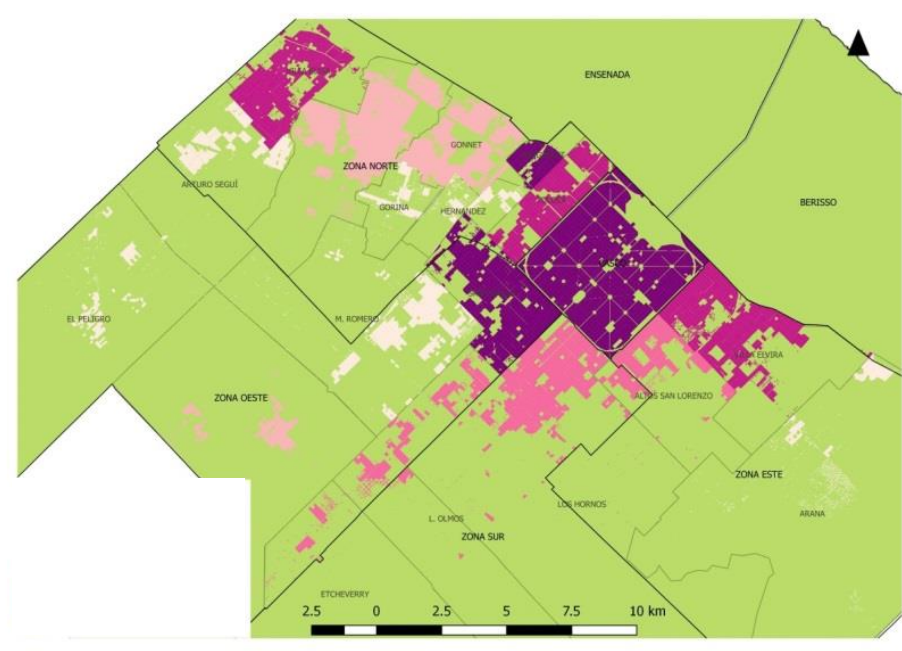

TGV Pie/Bici por Delegaciòn

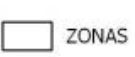

Tasa de generacion de viaje

$0.00-0.08$

$0.08-0.14$

$0.14-0.17$

$0.17-0.24$

$0.24-0.76$

Delegaciones

Ilustración 38. Tasa de Generación de Viaje a pie y bicicleta por delegación. Fuente: Elaboración propia, en base a Encuesta de Movilidad del Gran La Plata - GII IIPAC FAU.

La tasa de generación de viaje en colectivo también muestra el mayor índice en el Casco Urbano y en Ringuelet, seguidos por Gonnet, San Carlos, Los Hornos y Altos de San Lorenzo. En este caso la tasa de generación de viajes en transporte público más baja son las de Gorina, Etcheverry, Hernandez, Melchor Romero, Abasto y City Bell. Las mayores tasas de generación de viaje en auto están se encuentran en las delegaciones Norte de City Bell, Gonnet, Ringuelet y Arturo Segui. La generación de viaje a pie y bicicleta tiene su mayor índice en el Casco con 0,76 y en un segundo nivel entre 0,24 y 0,18, San Carlos, Ringuelet, Villa Elvira, Villa Elisa y Tolosa. En cambio, Melchor Romero, Abasto, Gonnet, City Bell y Olmos se caracterizan por tener una baja tasa que va del 0,03 al 0,15. 


\section{c- Análisis de demanda de viajes}

En este punto se analiza la demanda de viajes de cada delegación la cual nos permite identificar su grado de atractividad de viajes respecto de las otras. Este análisis permitirá contrastar la demanda real de viajes a determinadas zonas con el diseño de la red de transporte.

Las delegaciones periféricas en su conjunto producen altos porcentajes de viajes al Casco Urbano. En la Tabla 22 se puede observar la demanda de viajes al Casco Urbano por zonas, donde se evidencia que dicha demanda es muy alta. A una escala menor, a nivel delegación en la Tabla 22, también se expresa ese alto nivel de atracción que posee el Casco Urbano. En ese marco, Ringuelet es una de las delegaciones más dependientes del Casco urbano con un $81,3 \%$ de viajes, similar al propio Casco Urbano donde el 86,6\% de los viajes son internos, por lo cual se podría considerar un caso especial que se debería estudiar con detenimiento. Exceptuando Ringuelet se podría decir que las delegaciones con mayor atracción al casco son por un lado las delegaciones de desborde en la zona Este y Sur del casco, como son Los Hornos, Altos de San Lorenzo y Villa Elvira. Y por otro lado, delegaciones que se ubican en el límite Norte del partido, El Peligro, Arturo Segui y Villa Elisa, que poseen un crecimiento habitacional mayor al promedio de la ciudad, sobre todo El Peligro y Arturo Segui que están entre las que más crecieron.

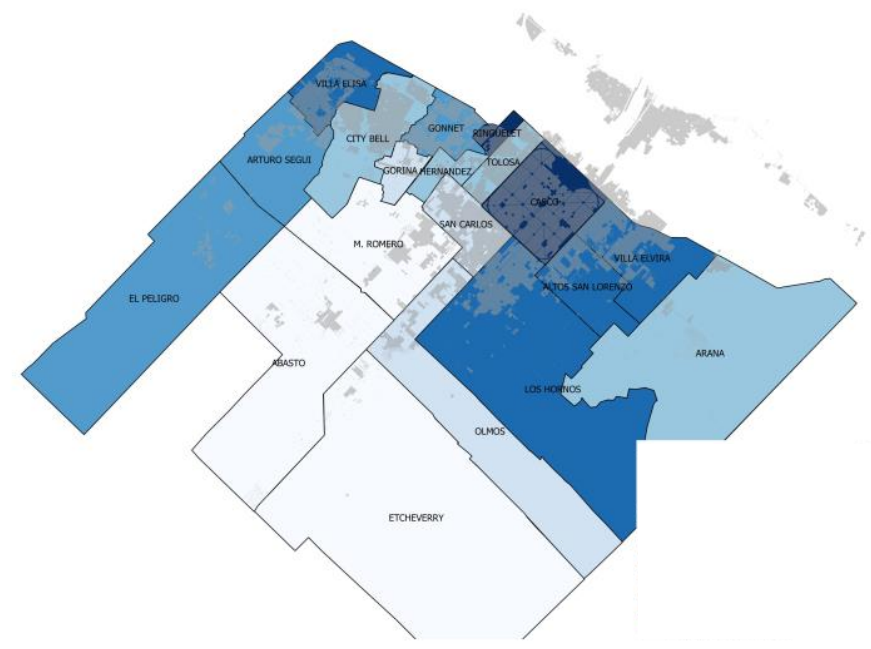

Viajes al casco por delegaciòn Porcentaje

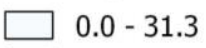

$\square \quad 31.3-50.0$

$\square 50.0-63.2$

$\square 3.2-67.6$

$\square 7.6-75.6$

75.6 - 86.6

mancha censo 2010

Ilustración 39. Porcentaje de viajes de cada delegación al Casco Urbano. Fuente: Elaboración propia, en base a Encuesta de Movilidad del Gran La Plata - GII IIPAC FAU. 
Tabla 22. Porcentaje de viajes de cada delegación hacia el resto de las delegaciones. Fuente: Elaboración propia, en base a Encuesta de Movilidad del Gran La Plata - GII IIPAC FAU.

\begin{tabular}{|c|c|c|c|c|c|c|c|c|c|c|c|c|c|c|c|c|c|c|c|c|c|c|}
\hline DELEGACION & $\begin{array}{c}\text { ABAS } \\
\text { TO }\end{array}$ & $\begin{array}{c}\text { ALTO } \\
\text { S SAN } \\
\text { LORE } \\
\text { NZO }\end{array}$ & $\begin{array}{c}\text { ARA } \\
\text { NA }\end{array}$ & $\begin{array}{c}\text { ARTU } \\
\text { RO } \\
\text { SEGU } \\
\text { I }\end{array}$ & $\begin{array}{c}\text { BERI } \\
\text { SSO }\end{array}$ & $\begin{array}{l}\text { CAS } \\
\mathrm{CO}\end{array}$ & $\begin{array}{c}\text { CIT } \\
\text { Y } \\
\text { BE } \\
\text { LL }\end{array}$ & $\begin{array}{c}\text { ENSEN } \\
\text { ADA }\end{array}$ & $\begin{array}{c}\text { EL } \\
\text { PELIG } \\
\text { RO }\end{array}$ & $\begin{array}{c}\text { GORI } \\
\text { NA }\end{array}$ & $\begin{array}{c}\text { HERNAN } \\
\text { DEZ }\end{array}$ & $\begin{array}{c}\text { OLM } \\
\text { OS }\end{array}$ & $\begin{array}{l}\text { LOS } \\
\text { HOR } \\
\text { NOS }\end{array}$ & $\begin{array}{l}\text { GON } \\
\text { NET }\end{array}$ & $\begin{array}{c}\text { MELC } \\
\text { HOR } \\
\text { ROME } \\
\text { RO }\end{array}$ & $\begin{array}{l}\text { RINGUE } \\
\text { LET }\end{array}$ & $\begin{array}{c}\text { ETCHEV } \\
\text { ERRY }\end{array}$ & $\begin{array}{c}\text { SAN } \\
\text { CARL } \\
\text { OS }\end{array}$ & $\begin{array}{c}\text { TOLO } \\
\text { SA }\end{array}$ & $\begin{array}{c}\text { VIL } \\
\text { LA } \\
\text { ELI } \\
\text { SA }\end{array}$ & $\begin{array}{c}\text { VILL } \\
\text { A } \\
\text { ELVI } \\
\text { RA }\end{array}$ & $\begin{array}{l}\text { EXTE } \\
\text { RNO }\end{array}$ \\
\hline ABASTO & 25 & 0 & 0 & 12,5 & 0 & 25 & 0 & 0 & 0 & 0 & 0 & 25 & 12,5 & 0 & 0 & 0 & 0 & 0 & 0 & 0 & 0 & 0 \\
\hline $\begin{array}{c}\text { ALTOS SAN } \\
\text { LORENZO }\end{array}$ & 0 & 19,4 & 0 & 0 & 0 & 74,2 & 0 & 0 & 0 & 0 & 0 & 0 & 3,2 & 0 & 0 & 0 & 0 & 0 & 0 & 0 & 3,2 & 0 \\
\hline ARANA & 0 & 0 & 12,5 & 0 & 0 & 62,5 & $\begin{array}{c}12, \\
5\end{array}$ & 0 & 0 & 0 & 0 & 0 & 0 & 0 & 0 & 0 & 0 & 0 & 0 & 0 & 12,5 & 0 \\
\hline $\begin{array}{c}\text { ARTURO } \\
\text { SEGUI }\end{array}$ & 0 & 0 & 0 & 11,1 & 0 & 66,7 & $\begin{array}{c}11, \\
1\end{array}$ & 0 & 0 & 0 & 0 & 0 & 0 & 0 & 0 & 0 & 0 & 0 & 11,1 & 0 & 0 & 0 \\
\hline CASCO & 0,2 & 0,2 & 0 & 0 & 0,3 & 86,6 & 0,7 & 1 & 0 & 0 & 0 & 0,7 & 0,7 & 2,1 & 0,3 & 0,3 & 0 & 0,9 & 0,9 & 0,9 & 0,5 & 3,8 \\
\hline CITY BELL & 0 & 0 & 0 & 0 & 2,4 & 57,8 & $\begin{array}{c}28, \\
9\end{array}$ & 0 & 0 & 1,2 & 0 & 0 & 0 & 3,6 & 0 & 0 & 0 & 1,2 & 0 & 1,2 & 0 & 3,6 \\
\hline EL PELIGRO & 0 & 0 & 0 & 0 & 0 & 66,7 & 0 & 0 & 0 & 0 & 0 & 16,7 & 0 & 0 & 0 & 0 & 0 & 0 & 0 & 16,7 & 0 & 0 \\
\hline ETCHEVERRY & 0 & 0 & 0 & 0 & 0 & 25 & 0 & 0 & 0 & 0 & 0 & 37,5 & 0 & 0 & 0 & 0 & 25 & 12,5 & 0 & 0 & 0 & 0 \\
\hline GONNET & 0 & 0 & 0 & 0 & 1,4 & 67,6 & 4,1 & 1,4 & 0 & 0 & 1,4 & 0 & 0 & 14,9 & 0 & 0 & 1,4 & 1,4 & 0 & 2,7 & 0 & 4,1 \\
\hline GORINA & 0 & 0 & 0 & 0 & 0 & 50 & 0 & 0 & 0 & 25 & 0 & 0 & 0 & 0 & 0 & 0 & 0 & 0 & 0 & 25 & 0 & 0 \\
\hline HERNANDEZ & 0 & 0 & 0 & 0 & 0 & 62,5 & 0 & 0 & 0 & 0 & 12,5 & 0 & 0 & 0 & 0 & 0 & 0 & 0 & 0 & 0 & 12,5 & 12,5 \\
\hline LOS HORNOS & 2,3 & 0 & 0 & 0 & 0 & 72,1 & 0 & 0 & 0 & 2,3 & 0 & 2,3 & 11,6 & 2,3 & 0 & 0 & 0 & 4,7 & 0 & 0 & 0 & 2,3 \\
\hline M. ROMERO & 0 & 0 & 0 & 0 & 0 & 31,3 & 6,3 & 0 & 0 & 0 & 0 & 12,5 & 0 & 0 & 18,8 & 0 & 0 & 31,3 & 0 & 0 & 0 & 0 \\
\hline OLMOS & 2,3 & 2,3 & 0 & 0 & 0 & 45,5 & 0 & 0 & 0 & 0 & 0 & 25 & 4,5 & 0 & 4,5 & 4,5 & 4,5 & 6,8 & 0 & 0 & 0 & 0 \\
\hline RINGUELET & 0 & 0 & 0 & 0 & 0 & 81,3 & 0 & 3,1 & 0 & 0 & 0 & 3,1 & 0 & 3,1 & 0 & 6,3 & 0 & 0 & 3,1 & 0 & 0 & 0 \\
\hline SAN CARLOS & 1 & 0 & 0 & 0 & 0 & 42,9 & 0 & 1 & 0 & 0 & 0 & 1 & 3,1 & 1 & 2 & 0 & 0 & 41,8 & 3,1 & 0 & 1 & 2 \\
\hline TOLOSA & 1,8 & 0 & 0 & 0 & 0 & 63,2 & 3,5 & 5,3 & 0 & 0 & 0 & 0 & 0 & 0 & 0 & 1,8 & 0 & 0 & 7 & 10,5 & 1,8 & 5,3 \\
\hline VILLA ELISA & 0 & 0 & 0 & 0 & 0 & 75,4 & 0 & 3,3 & 0 & 0 & 0 & 0 & 3,3 & 0 & 0 & 0 & 0 & 1,6 & 1,6 & 6,6 & 3,3 & 4,9 \\
\hline VILLA ELVIRA & 0 & 0 & 0 & 0 & 0 & 75,6 & 0 & 0,8 & 0 & 0 & 0 & 2,4 & 0 & 2,4 & 0,8 & 1,6 & 0,8 & 1,6 & 1,6 & 0 & 9,8 & 2,4 \\
\hline
\end{tabular}


Las delegaciones con menos de $35 \%$ de atracción de viajes al casco son Melchor Romero, Abasto y Etcheverry. Estas tres delegaciones, las cuales pertenecen a la zona Oeste, se encuentran vinculadas a los corredores de av. 520 y av. 44, y cuando atraviesan zonas urbanas, son comerciales con cierta diversificación de usos, sobre todo Olmos que absorbe el $12 \%$ de los viajes de Melchor Romero, el 25\% de Abasto y el 37\% de Etcheverry.

En la zona Norte el mayor nivel de atracción lo posee City Bell. Cuenta con un porcentaje de viajes internos de casi el 30\% y las delegaciones que tienen mayor porcentaje de viajes a ésta delegación son Arturo Segui, Gonnet, Melchor Romero y Arana. A partir de este análisis se observa un problema en la oferta de transporte público diseñada en su totalidad con destino final al Casco Urbano. Se observa que tanto Melchor Romero como Arana producen entre un $6 \%$ y $12 \%$ de sus viajes, que equivale a 1940 y 878 viajes diarios respectivamente, desde las zonas Oeste y Este con destino a City Bell pero no existen. recorridos de colectivos directos a este destino. De todos esos viajes 1123 se realizan en colectivo desde Melchor Romero y 390 desde Arana hacia la zona Norte del partido, es decir que son viajes con trasbordo, lo que significa un incremento en el precio y en el tiempo de viaje.

Gonnet también posee porcentajes de atracción de delegaciones de otras zonas que no poseen recorridos de transporte público sin transbordo, como son Los Hornos de zona Sur y Villa Elvira con porcentajes que llegan al 2,5\% de los viajes, representando 773 viajes diarios. Lo mismo sucede con Ringuelet, que atrae viajes de Villa Elvira y Olmos. Asimismo, lado Villa Elisa que atrae viajes de El Peligro, que tampoco posee recorrido de transporte publico directo a pesar de ser la tercera delegación más cerca.

Para visualizar los planos atracción de viajes por delegación ir a Anexos: A.4. Planos de conectividad por delegación

\section{d- Cobertura por tiempo de espera}

En cuanto a la cobertura por tiempo de espera, se platea su análisis a partir de la población cubierta por transporte público según frecuencias de los recorridos expresada en cantidad de servicios diarios. Cabe aclarar que las registradas son frecuencias del ramal, no de la línea completa. Los ramales que poseen una mayor cantidad de servicios diarios son el Este 15, 14 y 16, así como el Oeste 16, el $506 \mathrm{n}^{\circ} 80$ y el $520 \mathrm{n}^{\circ} 1$, que alcanzan los 20 servicios lo que equivaldría a una frecuencias de 10 minutos como máximo (Ilustración 40). La población cubierta por esta frecuencia es del $40 \%$ de la población del Gran La Plata, o sea a 337.718 
personas que viven en determinadas áreas de Altos de San Lorenzo, Arana, Berisso, Casco, Ensenada, Los Hornos, Melchor Romero, San Carlos, Tolosa y Villa Elvira. Esa frecuencia es considerada real cuando el destino del viaje en transporte público es el centro del Casco, cualquier otro destino incrementaría el tiempo de espera por la necesidad de un trasbordo.

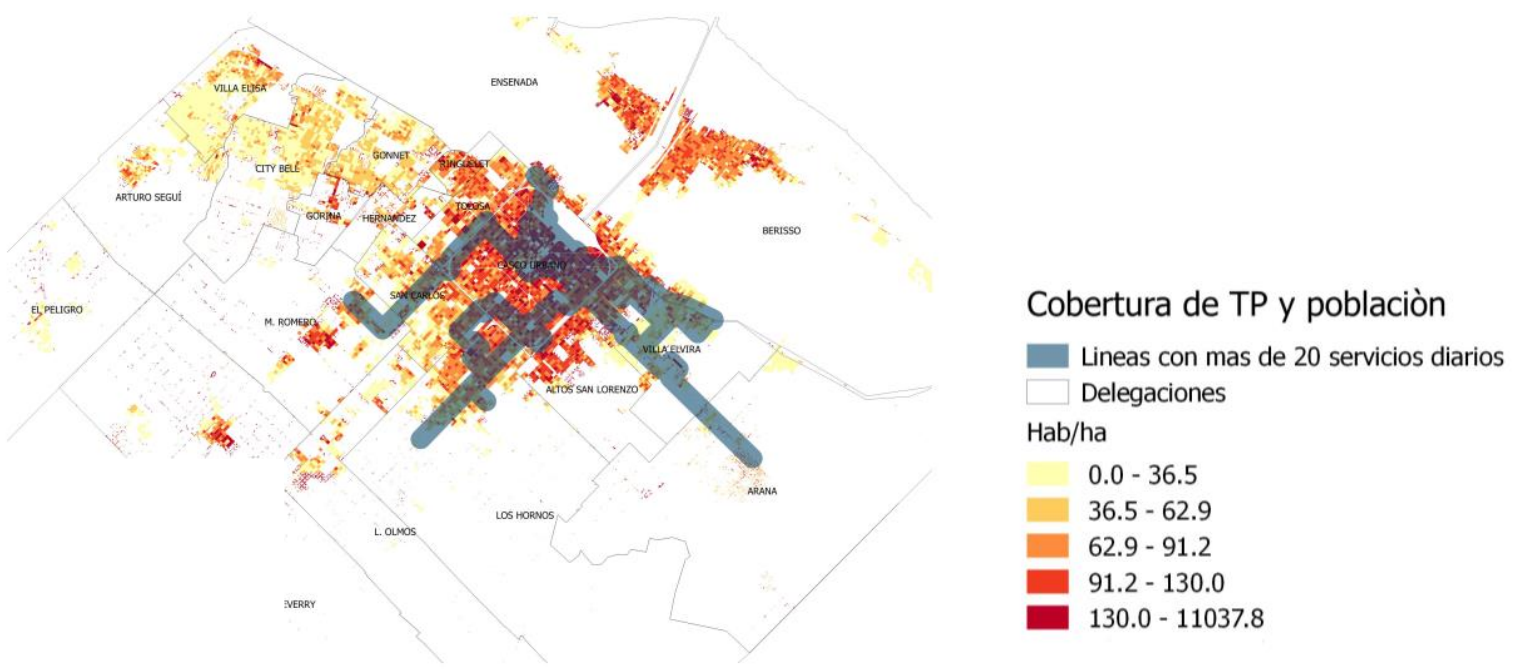

Ilustración 40. Cobertura de TP con más de 20 servicios diarios. Fuente: Elaboración propia, en base a datos de áreas de Transporte de la Provincia de Buenos Aires y Municipalidad de La Plata.

La cobertura para una frecuencia de más de 13 servicios diarios equivaldría a un tiempo de espera menor a 30 minutos (Ilustración 41). En esta situación se encuentran el 84\% de la población del Gran La Plata que viven en determinadas áreas de Altos de San Lorenzo, Arana, Berisso, Casco, City Bell, Ensenada, Etcheverry, Gonnet, Hernández, Los Hornos, Melchor Romero, Olmos, Ringuelet, San Carlos, Tolosa y Villa Elvira, sumando un total de 695.218 personas. Se puede observar que casi la totalidad del Casco Urbano está provisto por una cobertura con este tiempo de espera, así como Villa Elvira, Ensenada, Berisso, Altos de San Lorenzo, Los Hornos y Olmos. 


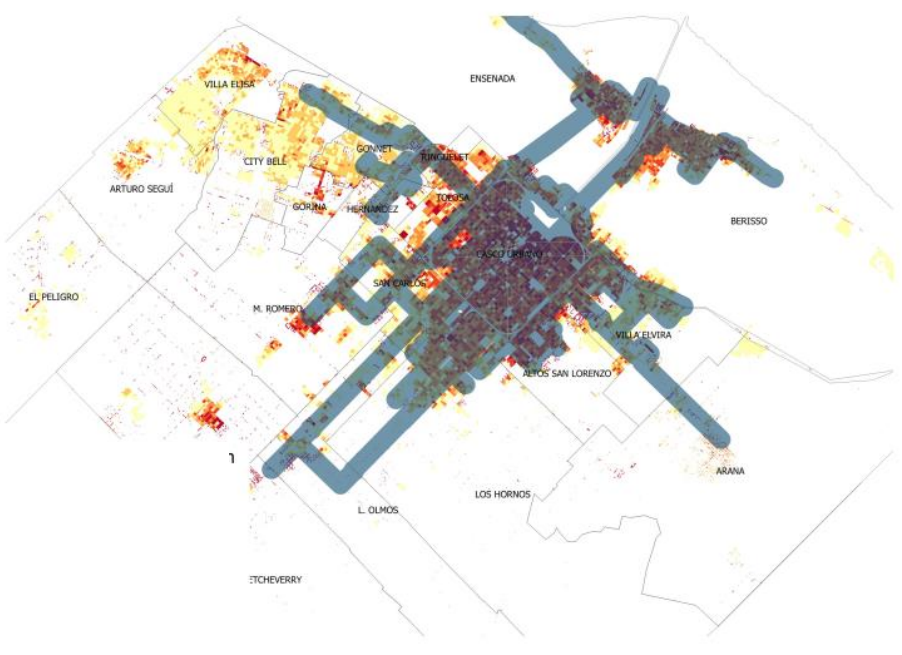

\author{
Cobertura de TP y poblaciòn \\ mas de 13 servicios diarios \\ Delegaciones \\ $\mathrm{Hab} / \mathrm{ha}$ \\ $0.0-36.5$ \\ $36.5-62.9$ \\ $62.9-91.2$ \\ $91.2-130.0$ \\ $130.0-11037.8$
}

Ilustración 41. Cobertura de TP con más 13 servicios diarios. Fuente: Elaboración propia, en base a datos de áreas de Transporte de la Provincia de Buenos Aires y Municipalidad de La Plata.

Los ramales que circulan con 13 a 8 servicios por día equivalen a tiempos de espera entre servicios de 30 a 60 minutos aproximadamente (Ilustración 423). Ramales con este tipo de cobertura se extienden para casi la totalidad de la población del Gran La Plata con un 92,6\% que significan 765.555 personas, alcanzando a todas las delegaciones con excepción de El Peligro.

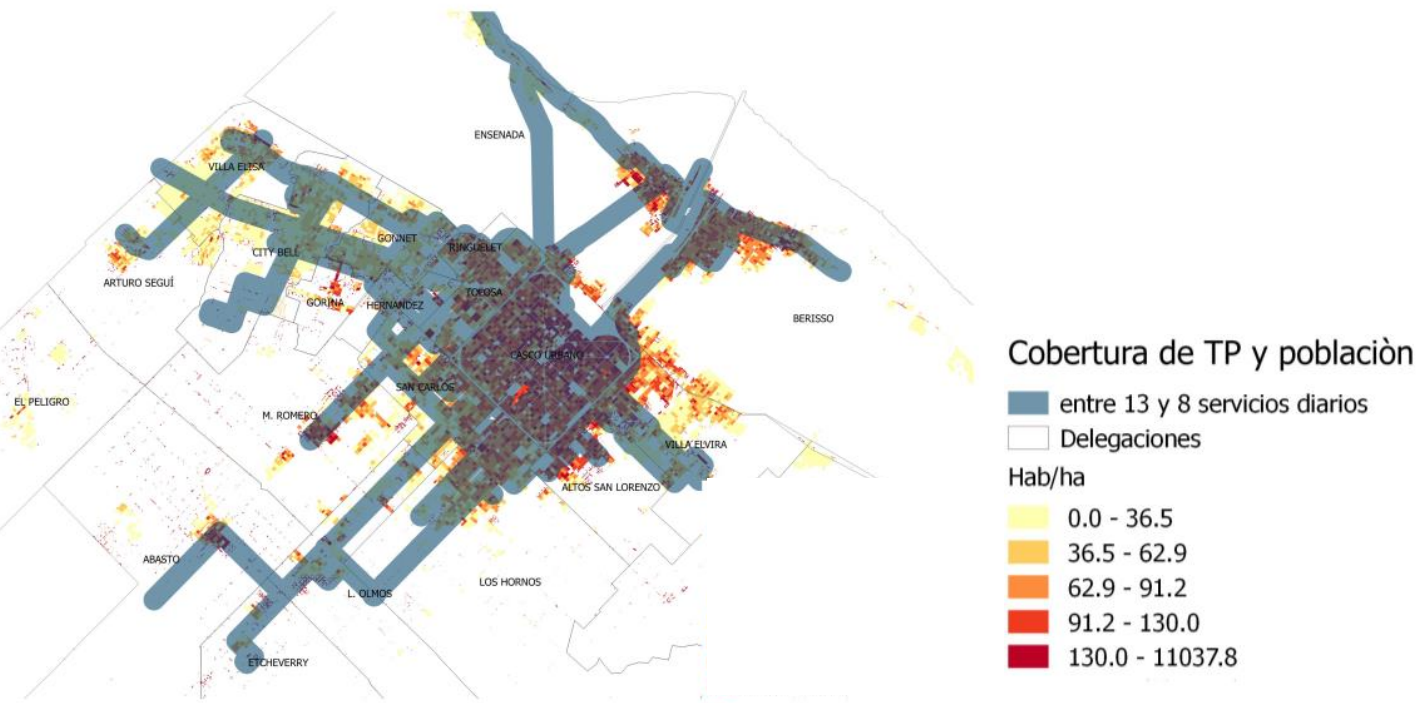

Ilustración 42. Cobertura de TP con 13 a 8 servicios diarios. Fuente: Elaboración propia, en base a datos de áreas de Transporte de la Provincia de Buenos Aires y Municipalidad de La Plata.

Los ramales con 1 a 7 servicios diarios son aquellos que tienen una frecuencia mayor a los 60 minutos (Ilustración 43). Estos ramales se extienden por el conjunto de las delegaciones del partido y alcanzan al $90 \%$ de la población del Gran La Plata. 


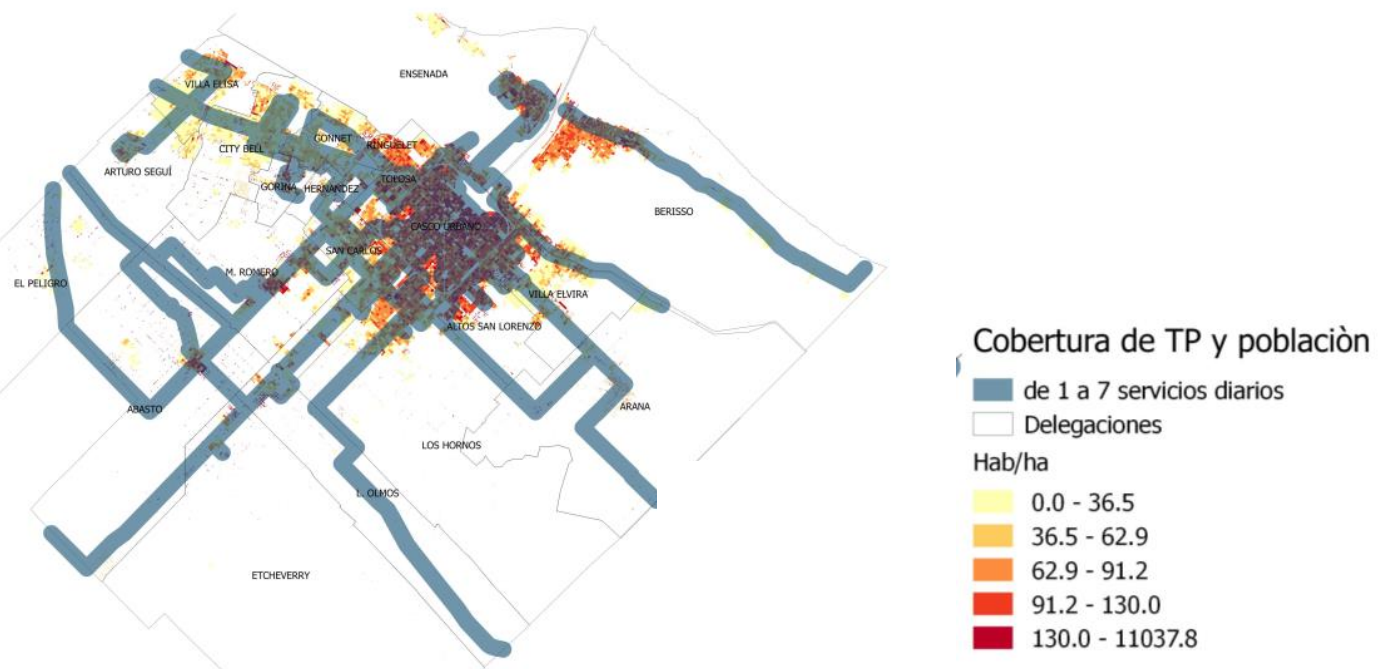

Ilustración 43. Cobertura TP 1 a 7 servicios diarios. Fuente: Elaboración propia, en base a datos de áreas de Transporte de la Provincia de Buenos Aires y Municipalidad de La Plata.

\section{e- Frecuencias y tiempo de viaje en transporte público}

Por último, el tiempo de viaje en transporte público contempla el tiempo que una persona tarda en dirigirse al refugio de micro, el tiempo de espera, de traslado de la parada de origen a la más cercana al destino, y finalmente el tiempo en llegar al destino. El viaje se puede complejizar con la necesidad de trasbordos, pero para sintetizar el análisis en esta instancia se evalúan los tiempos de viaje en transporte público desde todas las delegaciones hacia el Casco Urbano, que es la principal delegación atractora de viajes y donde la totalidad de los recorridos de transporte cambian de sentido, ya sean de ida y o de vuelta.

Según los datos construidos, la población cubierta con ramales que realizan frecuencias de un máximo de 10 minutos, más el tiempo de viaje en el momento del traslado desde las delegaciones que más tardan en llegar a las áreas centrales del casco urbano, estimado en 45 minutos, es de 10.949 y un total de viajes diarios de 5.231 estimados en una duración de entre 45 y 55 minutos. Estas delegaciones son Arana, cubierto con 1.122 viajes, Ensenada con 2.647 viajes y Melchor Romero con 1462 viajes.

Con la misma cobertura de ramales con frecuencias menores a 10 minutos, las delegaciones que demoran en el momento del traslado 40 minutos son un área de Berisso, otra de Los Hornos y San Carlos. En total 57.974 personas que producen 42.391 viajes diarios que tardan entre 40 y 50 minutos en transporte público, 5.299 viajes de Berisso, 25.003 de Ensenada y 12.089 de San Carlos. Las delegaciones con la misma cobertura pero que por su ubicación demoran 30 minutos al llegar al centro del Casco Urbano son Altos de San Lorenzo, Tolosa y 
Villa Elvira, para un total de 59.244 personas que producen 40.065 viajes en transporte público. Ver Tabla 23 e Ilustración 44.

Tabla 23. Personas, tasa de generación de viajes y viajes de la cobertura de ramales con frecuencias menores a 10 minutos por tiempo de traslado por delegaciones cubiertas.

Fuente: Elaboración propia, en base a datos de Encuesta de Movilidad del Gran La Plata.

\begin{tabular}{|c|c|c|c|c|c|}
\hline Min. Traslado & Delegación & Personas & TGV C & $\begin{array}{c}\text { Viajes } \\
\text { (cantidad) }\end{array}$ & $\begin{array}{l}\text { Tiempo Traslado } \\
\text { + espera prom. } \\
\text { (minutos) }\end{array}$ \\
\hline \multirow{3}{*}{45} & Arana & 1700 & 0,66 & 1122 & 50 \\
\hline & Ensenada & 5402 & 0,49 & 2647 & 50 \\
\hline & Melchor Romero & 3847 & 0,38 & 1462 & 50 \\
\hline \multirow{3}{*}{40} & Berisso & 10814 & 0,49 & 5299 & 45 \\
\hline & Los Hornos & 31254 & 0,8 & 25003 & 45 \\
\hline & San Carlos & 15906 & 0,76 & 12089 & 45 \\
\hline \multirow{3}{*}{30} & $\begin{array}{l}\text { Altos de San } \\
\text { Lorenzo }\end{array}$ & 2932 & 0,68 & 1994 & 35 \\
\hline & Tolosa & 7377 & 0,65 & 4795 & 35 \\
\hline & Villa Elvira & 48935 & 0,68 & 33276 & 35 \\
\hline $\begin{array}{c}\text { TOTAL y } \\
\text { PROMEDIO }\end{array}$ & & 350771 & 9,59 & 219190 & 43 \\
\hline
\end{tabular}

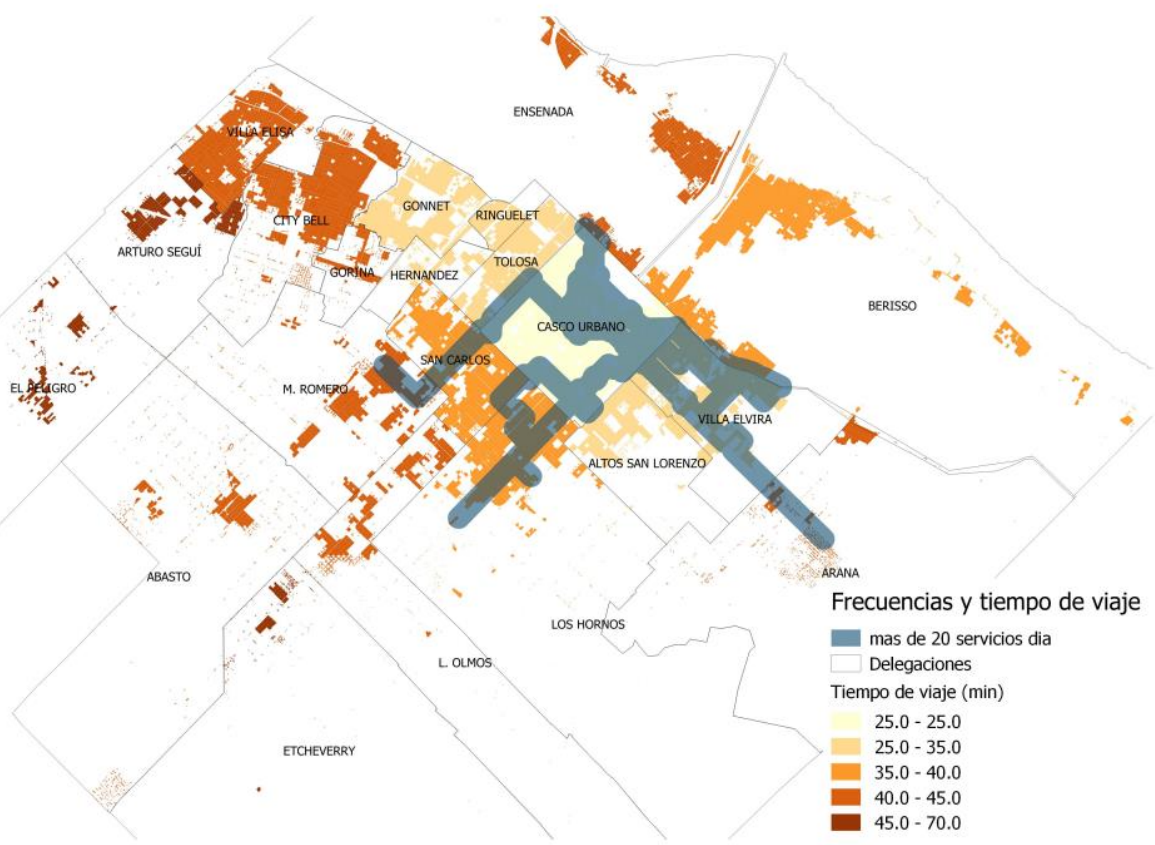

Ilustración 44. Frecuencias y tiempo de viaje de ramales con más de 20 servicios por día.

Fuente: Elaboración propia, en base a datos de áreas de Transporte de la Provincia de Buenos Aires y Municipalidad de La Plata.

Los ramales que realizan más de 13 servicios diarios, lo que serían frecuencias menores a 25 minutos aproximadamente, son 26 de los 90 ramales que posee el conjunto del sistema de transporte público colectivo. Son ramales de las líneas Norte, Este, Oeste, 520, 506 y 518 de las municipales, y 307, 275, 214 y 202 de las provinciales. La mayor cantidad de viajes 
absorbidos por este tipo de cobertura es la delegación de Los Hornos con 40.456 viajes diarios en transporte público. Esta delegación posee un promedio de tiempo de traslado que va entre 40 y 45 minutos a la zona céntrica del casco, lo que da como resultado un tiempo aproximado de 40 a 75 minutos, variable según la frecuencia. En una situación similar se encuentra el municipio de Berisso con 36.964 viajes diarios que usan estos servicios.

De las delegaciones con un tiempo de traslado al área centro del Casco Urbano de 30 a 35 minutos, Villa Elvira es la que posee más viajes cubiertos por estas frecuencias, con 34.068 viajes diarios. La delegación cubierta por esta frecuencia que más demora entre espera y traslado al centro es Etcheverry, con un promedio de 73 minutos. Ver Tabla 24 e Ilustración 45 .

Tabla 24. Personas, tasa de generación de viajes y viajes de la cobertura de ramales con frecuencias menores a 30 minutos por tiempo de traslado por delegaciones cubiertas.

Fuente: Elaboración propia, en base a INDEC y Encuestas de Movilidad del Gran La Plata GII IIPAC-FAU.

\begin{tabular}{|c|l|c|c|c|c|}
\hline $\begin{array}{c}\text { Tiempo de } \\
\text { traslado }\end{array}$ & Delegación & Población & TGV C & $\begin{array}{c}\text { Viajes } \\
\text { (cantidad) }\end{array}$ & $\begin{array}{c}\text { Tiempo } \\
\text { Traslado }+ \\
\text { espera prom. } \\
\text { (minutos) }\end{array}$ \\
\hline $30-35$ & $\begin{array}{l}\text { Altos de San } \\
\text { Lorenzo }\end{array}$ & 26181 & 0,68 & 17803 & 45 \\
\hline & Gonnet & 14888 & 0,74 & 11017 & 45 \\
\hline & Hernandez & 4592 & 0,38 & 1745 & 45 \\
\hline & Ringuelet & 8278 & 0,92 & 7616 & 45 \\
\hline & Tolosa & 19466 & 0,65 & 12653 & 45 \\
\hline & Villa Elvira & 50100 & 0,68 & 34068 & 45 \\
\hline $40-45$ & Arana & 1700 & 0,66 & 1122 & 55 \\
\hline & Berisso & 75436 & 0,49 & 36964 & 55 \\
\hline & City Bell & 4791 & 0,42 & 2012 & 55 \\
\hline & Ensenada & 43008 & 0,49 & 21074 & 55 \\
\hline & Los Hornos & 50570 & 0,8 & 40456 & 55 \\
\hline & Melchor Romero & 7645 & 0,38 & 2905 & 55 \\
\hline & Olmos & 10875 & 0,42 & 4568 & 55 \\
\hline & San Carlos & 33077 & 0,76 & 25139 & 55 \\
\hline 60 & Etcheverry & 164 & 0,3 & 49,2 & 73 \\
\hline TOTAL y & & 350771 & 0,58 & 219190 & 52 \\
\hline
\end{tabular}




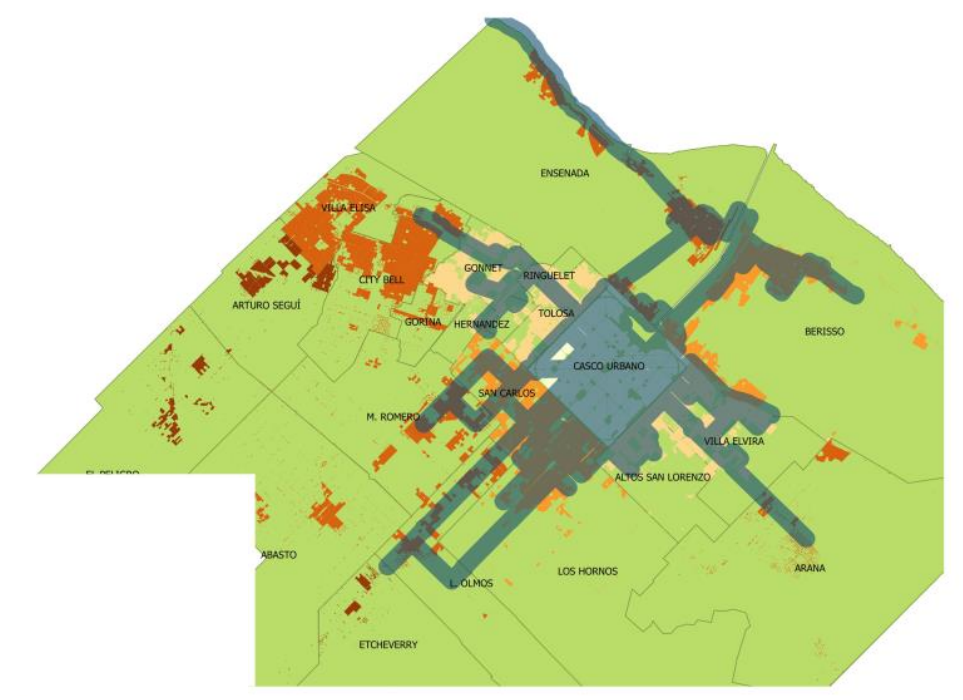

Frecuencias y tiempo de viaje mas de 13 servicios dia Tiempo de viaje ( $\mathrm{min})$ $25.0-25.0$ $25.0-35.0$ $35.0-40.0$ $40.0-45.0$

$45.0-70.0$

Delegaciones

Ilustración 45. Frecuencias y tiempo de viaje de ramales con más de 13 servicios por día. Fuente: Elaboración propia, en base a datos de áreas de Transporte de la Provincia de Buenos Aires y Municipalidad de La Plata.

Los ramales que realizan entre 8 y 13 servicios diarios poseen una frecuencia que varía entre 30 a 60 minutos. Existe un total de 17 ramales con esta característica que corresponden a las líneas Oeste, Norte, 561, 506, 273, 275, y 215. Al igual que la cobertura de ramales de hasta 13 servicios diarios, Los Hornos es la delegación que más cobertura tiene de ramales con estas frecuencias, que poseen tiempos de traslado más espera de 88 minutos promedio para llegar al centro del Casco Urbano. Cabe destacar que los ramales con frecuencias de 30 a 60 minutos tienen una cobertura total de 393.362 personas, 244.153 viajes en transporte público que demoran más de una hora cuando la distancia de las delegaciones más cercanas no supera los 5 kilómetros, es decir a una velocidad más lenta que la caminata humana. Ver Tabla 25 e Ilustración 46. 
Tabla 25. Personas, tasa de generación de viajes y viajes de la cobertura de ramales con frecuencias de 30 a 60 minutos por tiempo de traslado por delegaciones cubiertas. Fuente:

Elaboración propia, en base a Encuesta de Movilidad del Gran La Plata.

\begin{tabular}{|c|c|c|c|c|c|}
\hline $\begin{array}{l}\text { Tiempo de } \\
\text { traslado }\end{array}$ & Delegación & Población & TGV C & $\begin{array}{c}\text { Viajes } \\
\text { (cantidad) }\end{array}$ & $\begin{array}{c}\text { Tiempo } \\
\text { Traslado }+ \\
\text { espera prom. } \\
\text { (minutos) }\end{array}$ \\
\hline \multirow{6}{*}{$30-35$} & $\begin{array}{c}\text { Altos de San } \\
\text { Lorenzo }\end{array}$ & 24719 & 0,68 & 16809 & 78 \\
\hline & Gonnet & 24295 & 0,74 & 17978 & 78 \\
\hline & Hernandez & 8104 & 0,38 & 3080 & 78 \\
\hline & Ringuelet & 11924 & 0,92 & 10970 & 78 \\
\hline & Tolosa & 40515 & 0,65 & 26335 & 78 \\
\hline & Villa Elvira & 35735 & 0,68 & 24300 & 78 \\
\hline \multirow{10}{*}{$40-45$} & Abasto & 3156 & 0,41 & 1294 & 88 \\
\hline & Berisso & 59433 & 0,49 & 29122 & 88 \\
\hline & City Bell & 27431 & 0,42 & 11521 & 88 \\
\hline & Ensenada & 33004 & 0,49 & 16172 & 88 \\
\hline & Gorina & 2204 & 0,28 & 617 & 88 \\
\hline & Los Hornos & 48214 & 0,8 & 38571 & 88 \\
\hline & Melchor Romero & 7618 & 0,38 & 2895 & 88 \\
\hline & Olmos & 11298 & 0,42 & 4745 & 88 \\
\hline & San Carlos & 35980 & 0,76 & 27345 & 88 \\
\hline & Villa Elisa & 15274 & 0,68 & 10386 & 88 \\
\hline \multirow{2}{*}{60} & Arturo Segui & 2327 & 0,59 & 1373 & 105 \\
\hline & Etcheverry & 2131 & 0,3 & 639 & 105 \\
\hline $\begin{array}{c}\text { TOTAL y } \\
\text { PROMEDIO }\end{array}$ & & 393362 & 0,56 & 244153 & 86 \\
\hline
\end{tabular}

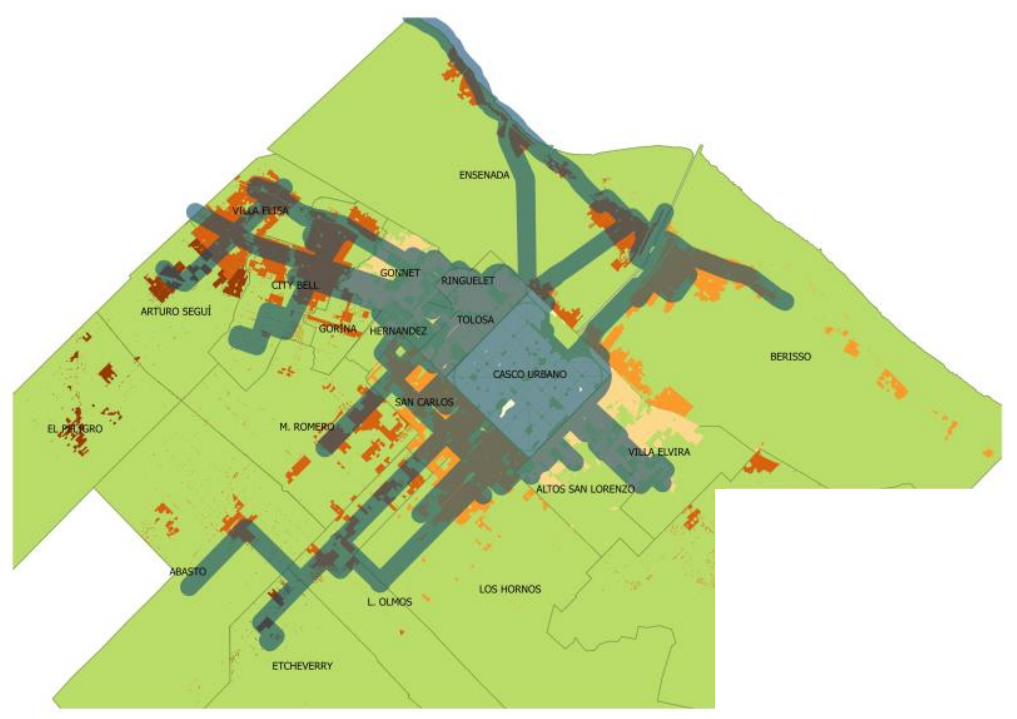

Frecuencias y tiempo de viaje

entre 8 y 13 servicios dia Tiempo de viaje $(\mathrm{min})$

$25.0-25.0$

$25.0-35.0$

$35.0-40.0$

$40.0-45.0$

$45.0-70.0$

Delegaciones

Ilustración 46. Frecuencias y tiempo de viaje de ramales entre 8 y 13 servicios por día.

Fuente: Elaboración propia, en base a datos de áreas de Transporte de la Provincia de Buenos Aires y Municipalidad de La Plata.

Los ramales que tienen menos de 13 servicios diarios son los que menos frecuencias realizan del sistema de transporte del Gran La Plata, entre servicios pueden pasar más de 60 minutos. Estos ramales son 307 "F", 275 Barrio UOM, 225, 215 y los Oeste 62, 84 y 86. Tienen cobertura en todas las delegaciones de la micro región y el tiempo de traslado más el de espera va desde más de 93 minutos a más de 125 minutos. En esta cobertura se ubican los 
únicos dos ramales que llegan a la delegación de El Peligro y el Oeste de Arturo Segui. Ver

Tabla 26 e Ilustración 47.

Tabla 26. Personas, tasa de generación de viajes y viajes de la cobertura de ramales con frecuencias mayores a 60 minutos por tiempo de traslado por delegaciones cubiertas. Fuente: Elaboración propia, en base a datos de Encuesta de Movilidad del Gran La Plata.

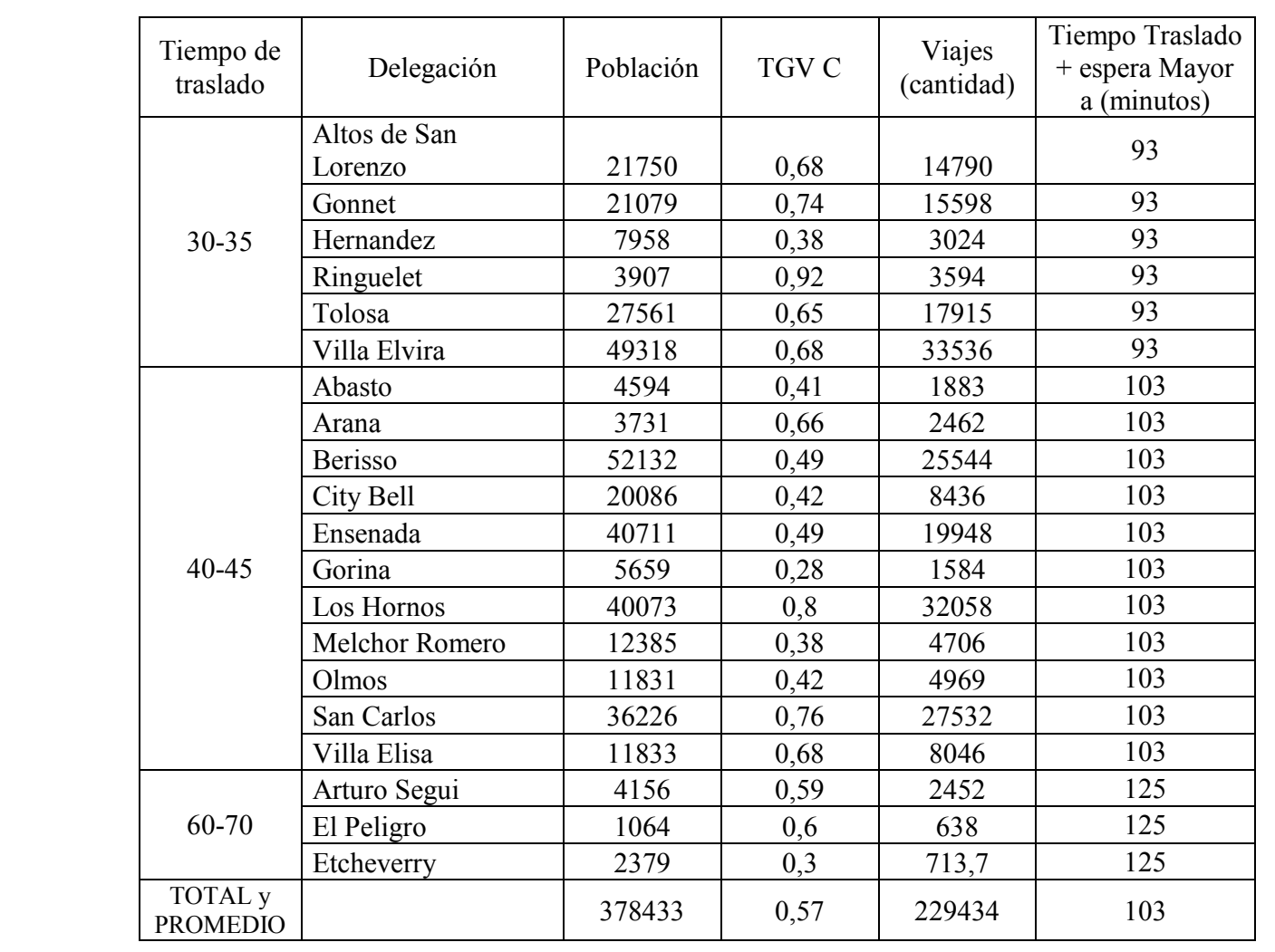

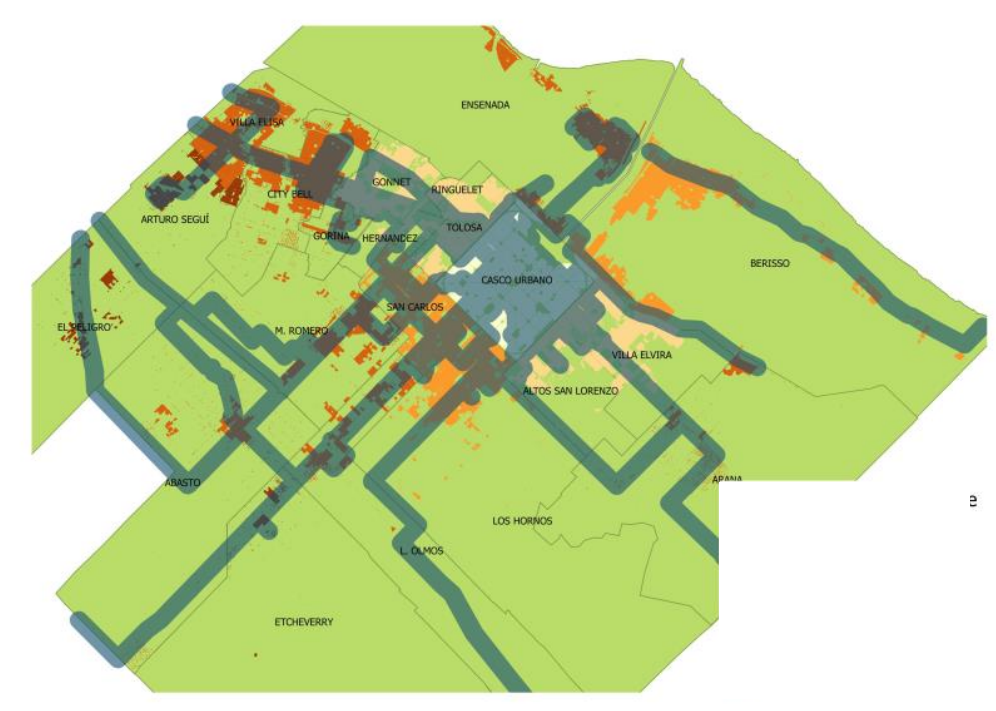

Frecuencias y tiempo de viaje

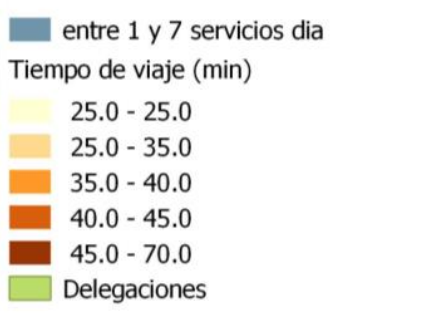

Ilustración 47. Frecuencias y tiempo de viaje de ramales entre 8 y 13 servicios por día.

Fuente: Elaboración propia, en base a datos de áreas de Transporte de la Provincia de Buenos Aires y Municipalidad de La Plata.

A modo de síntesis de este apartado se puede decir que el mayor ritmo de crecimiento tanto habitacional como poblacional del aglomerado se da por expansión y en las áreas del partido 
más alejadas del casco urbano. Esta situación, con infraestructura insuficiente, oferta de transporte con pocas frecuencias y una dependencia de viajes al casco, plantea mayores tiempos de viaje empeorando la accesibilidad a determinados usos y servicios urbanos como salud, educación y trabajo. Esto a su vez genera una mayor tensión a la necesidad de utilizar medios no masivos, motorizados, lo que plantea un escenario verdaderamente conflictivo en el marco de una tendencia al aumento de las tasas de generación de viajes.

\subsubsection{Dimensión Social}

Para el análisis de la dimensión social se plantea el estudio de las características socioeconómicas de la población, utilizando niveles de Necesidades Básicas Insatisfechas ${ }^{67}(\mathrm{NBI})$ del INDEC ${ }^{68}$ del censo 2010.

Se cuantifica la población con NBI de las distintas delegaciones de la micro región según la cantidad de servicios por día, o frecuencias, y tiempo de traslado de los distintos ramales del sistema de transporte público. Según datos censales de 2010, el 15,9\% de la población del Gran La Plata se encuentra con NBI. Esta población, vulnerable desde el punto de vista social y económico, muchas veces utiliza el sistema de transporte público como único medio de movilidad para acceder a determinados servicios esenciales como la salud, el trabajo o la educación.

Las delegaciones con mayor cantidad de personas con NBI son Berisso con 19.249 personas, luego San Carlos de la zona Oeste, Villa Elvira de la zona Este y Los Hornos de la zona Sur. Si bien en términos cuantitativos las delegaciones con NBI no parecen responder a una zona en particular, si observamos porcentajes de población con NBI por delegación, los mayores valores corresponden a la zona Oeste, El Peligro, Melchor Romero, Abasto, Etcheverry,

\footnotetext{
${ }^{67}$ Este indicador fue elaborado por el INDEC en la década de 1980 como un método directo de medición de la pobreza, que consiste en identificar los hogares o personas que no pueden satisfacer alguna necesidad básica. En algunos estudios, para identificar la población en condiciones de pobreza, se utiliza el ingreso, tanto el del jefe de familia o el del grupo familiar. En nuestro trabajo se utilizó el NBI tanto por su utilidad, como por no estar disponible el ingreso, ni personal ni familiar, desagregado por departamento.

El índice NBI del INDEC incluye a hogares que cumplen una o varias de las condiciones que definen los niveles críticos de privación (o personas que viven en los hogares con necesidades básicas insatisfechas). Hacinamiento: hogares que tuvieran más de 3 personas por cuarto o habitaran en una vivienda de tipo inconveniente (pieza de inquilinato, vivienda precaria u otro tipo). Condiciones sanitarias: hogares que no tuvieran ningún tipo de retrete. Asistencia escolar: hogares que tuvieran algún niño en edad escolar que no asista a la escuela. Capacidad de subsistencia: hogares que tuvieran 4 o más personas por miembro ocupado y, además, cuyo jefe tuviera baja educación.

Una de las ventajas del NBI como indicador de pobreza es que se recoge dentro de la información censal (en este trabajo, el Censo 2010), por lo tanto incluye a toda la población y se presenta ampliamente desagregado. El bienestar económico social relativo de cada área se reconoce a través del porcentaje de personas con NBI (cuanto mayor sea el porcentaje de personas con NBI, más alta será la incidencia de pobreza) (Buchbinder, 2008).

${ }^{68}$ Instituto Nacional de Estadísticas y Censo de la República Argentina.
} 
Olmos San Carlos y las delegaciones Sur de la zona Norte como son Arturo Segui y Gorina. Ver Tabla 27 e Ilustración 48.

Tabla 27. Población con NBI por delegación. Fuente: Elaboración propia, en base a datos del INDEC.

\begin{tabular}{|c|c|c|}
\hline Delegación & $\begin{array}{c}\text { Población con } \\
\text { NBI }\end{array}$ & $\begin{array}{c}\text { \% de } \\
\text { población } \\
\text { con NBI }\end{array}$ \\
\hline EI Peligro & 503 & 50,4 \\
\hline Melchor Romero & 10072 & 37,7 \\
\hline Arturo Segui & 2375 & 31,8 \\
\hline Abasto & 2104 & 28,9 \\
\hline Etcheverry & 190 & 27 \\
\hline Gorina & 1045 & 24,7 \\
\hline Arana & 177 & 24 \\
\hline Olmos & 2679 & 23,8 \\
\hline San Carlos & 17940 & 21,2 \\
\hline Altos de San Lorenzo & 8429 & 19,8 \\
\hline Villa Elvira & 15809 & 17,9 \\
\hline Los Hornos & 15262 & 17,6 \\
\hline Berisso & 19249 & 17,1 \\
\hline Ensenada & 10095 & 16,2 \\
\hline Hernandez & 523 & 15,5 \\
\hline Ringuelet & 2141 & 12,2 \\
\hline Villa Elisa & 3128 & 10,9 \\
\hline Tolosa & 6343 & 10,4 \\
\hline City Bell & 3847 & 9,2 \\
\hline Gonnet & 1910 & 6,4 \\
\hline Casco Urbano & 7857 & 3 \\
\hline TOTAL & 131678 & $15,90 \%$ \\
\hline
\end{tabular}

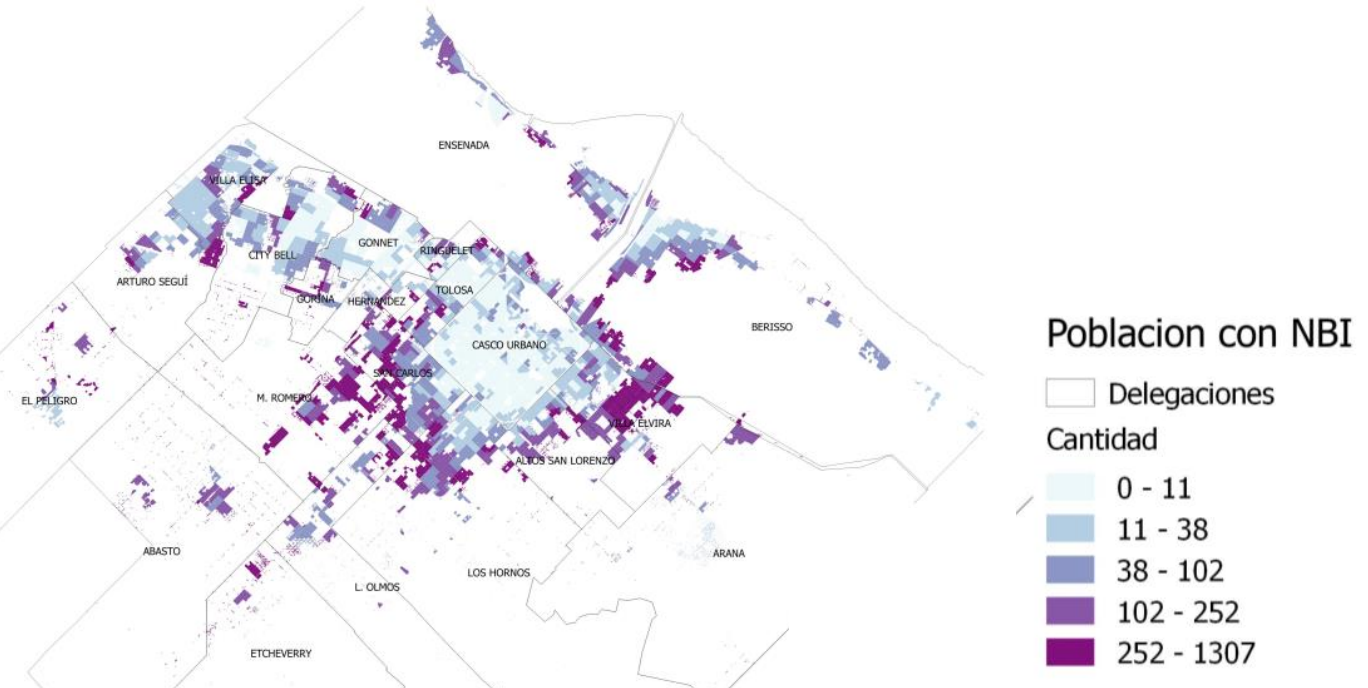

Ilustración 48. Población con NBI Gran La Plata. Fuente: Elaboración propia en base al Censo 2.010, INDEC. 
Desde el punto de vista de la cobertura de transporte público a sectores sociales más vulnerables, el $17 \%$ de la población con NBI no posee cobertura de transporte público, mientras que la población sin NBI, los valores sin cobertura alcanzan al 6,9\% de la población. La cantidad de población con NBI cubierta por los ramales de mayor frecuencia es solo el $24 \%$ de todas las personas en esta situación mientras que las cubiertas por los ramales que poseen una frecuencia mayor a 60 minutos es el 6,7\% del total. Ver Ilustración 49.

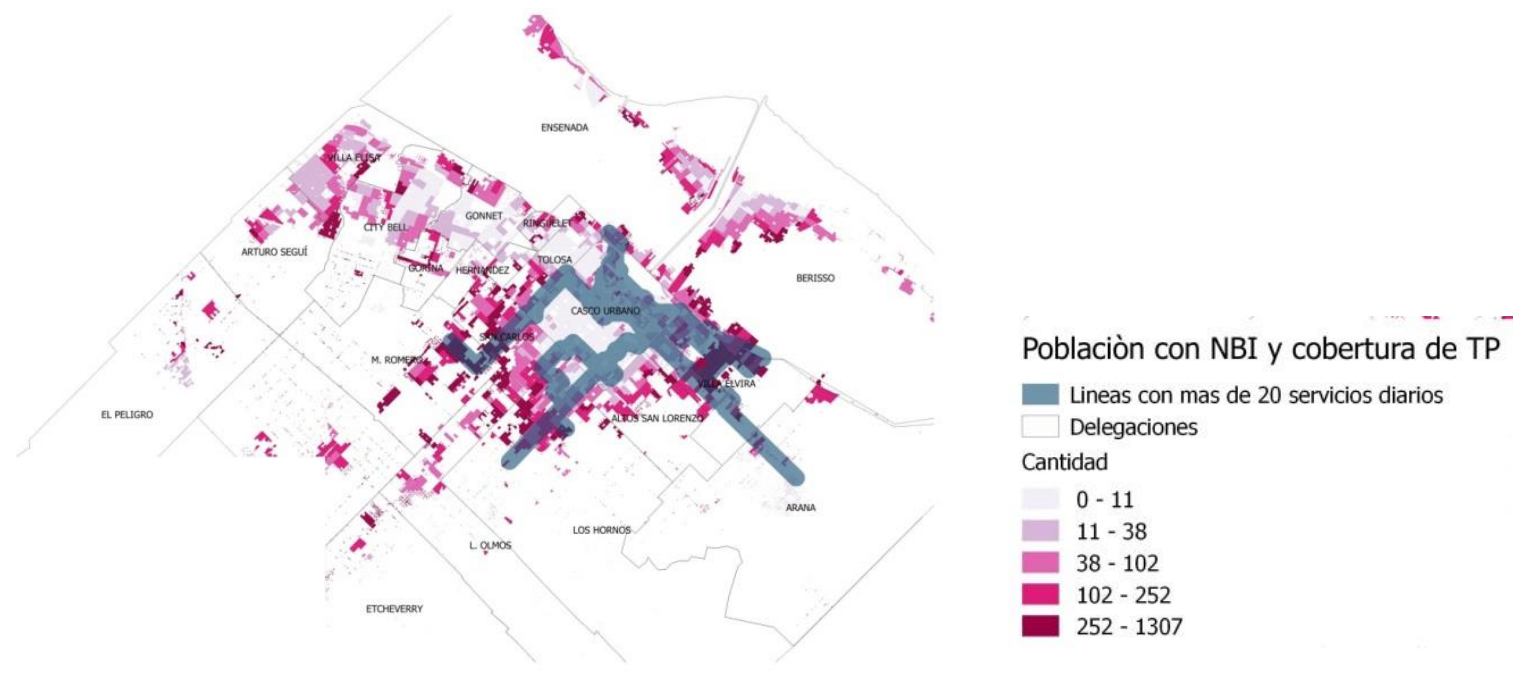

Ilustración 49. Población con NBI cubierta por transporte público con más de 20 servicios diarios. Fuente: Elaboración propia, en base a datos de INDEC y áreas de Transporte PBA y Municipalidad de La Plata.

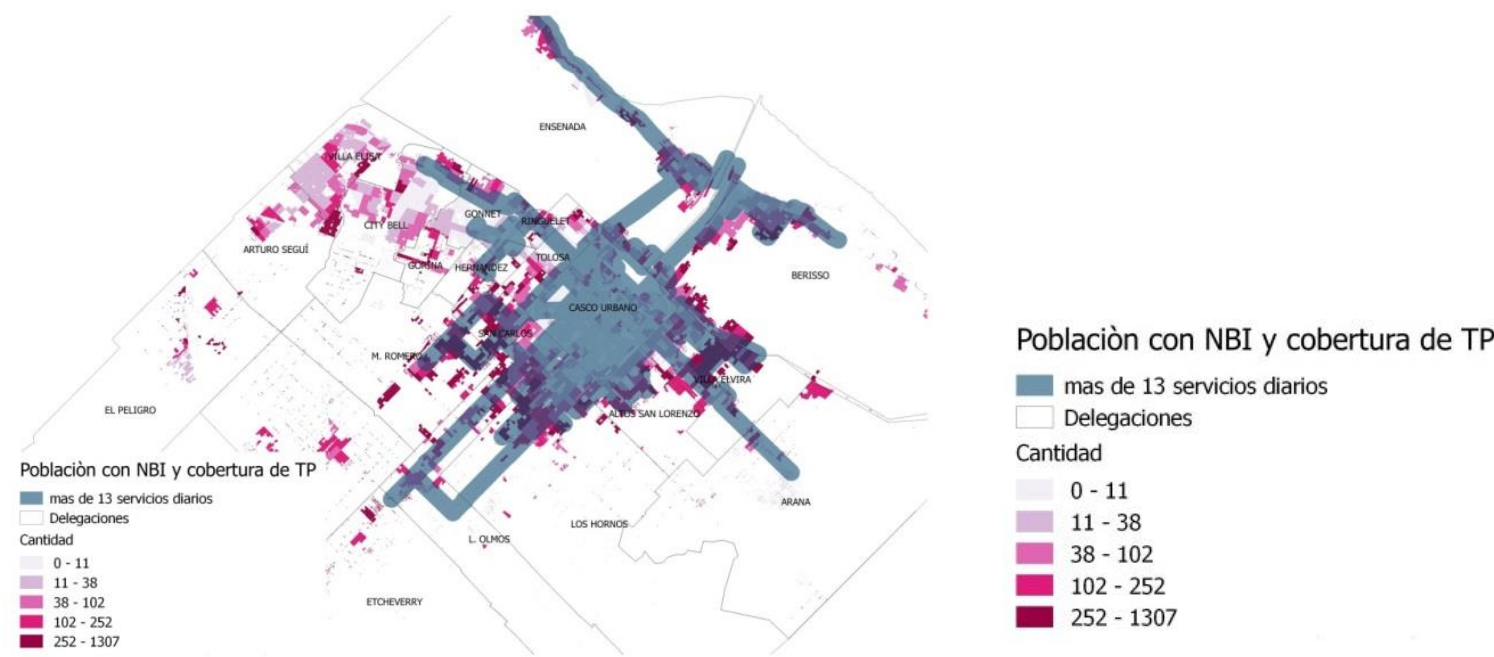

Ilustración 50. Población con NBI cubierta por transporte público con más de 13 servicios diarios. Fuente: Elaboración propia, en base a datos de INDEC y áreas de Transporte PBA y Municipalidad de La Plata. 


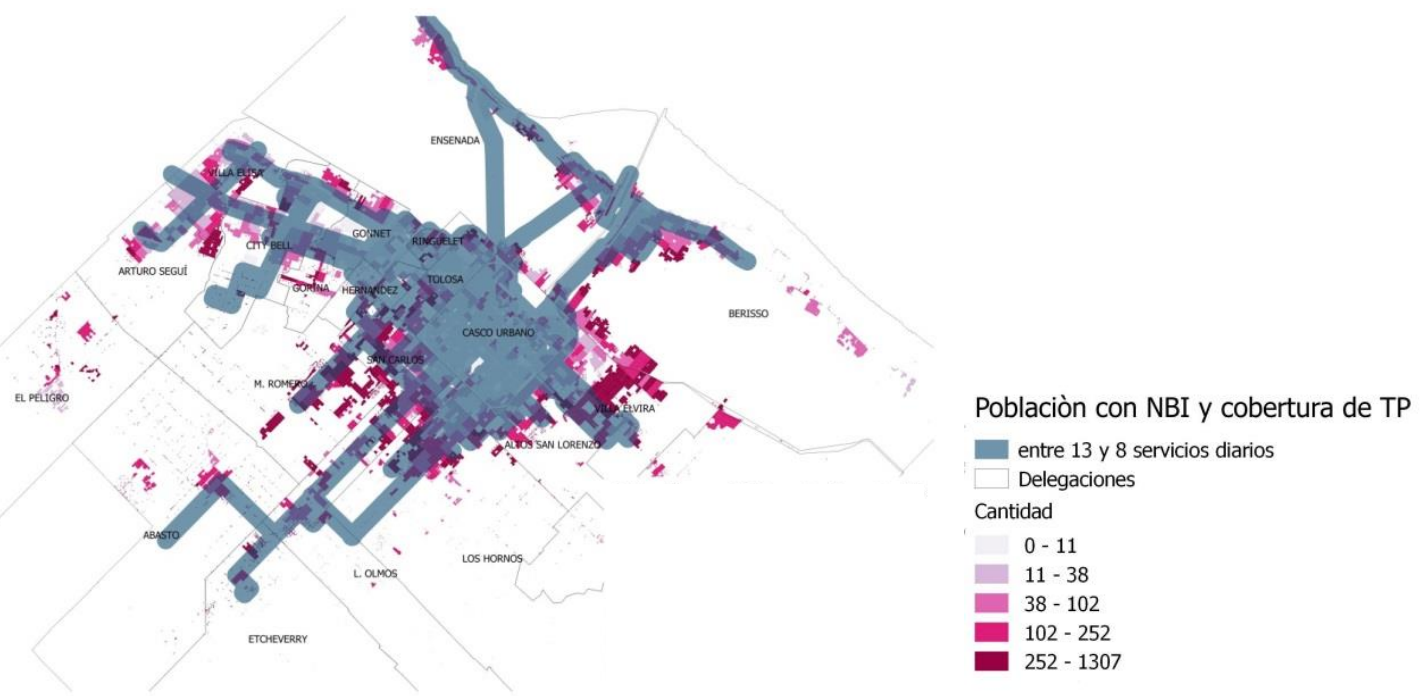

Ilustración 51. Población con NBI cubierta por transporte público con entre 13 a 8 servicios diarios. Fuente: Elaboración propia, en base a datos de INDEC y áreas de Transporte PBA y Municipalidad de La Plata.

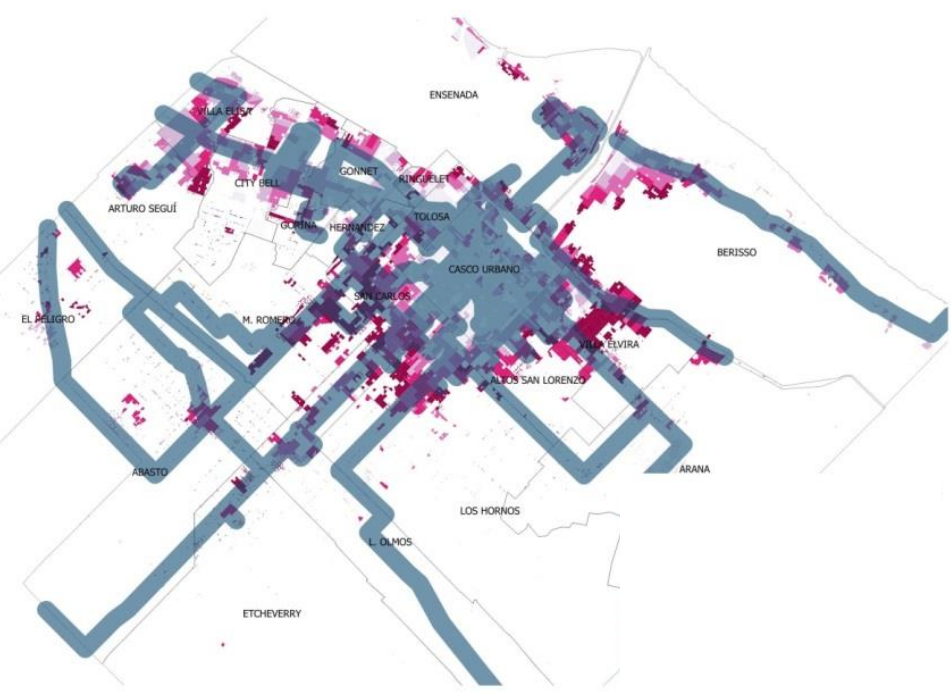

Poblaciòn con NBI y cobertura de TP

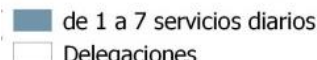
Delegaciones Cantidad $0-11$ - $11-38$ - $38-102$ - $102-252$ - $252-1307$

Ilustración 52. Población con NBI cubierta por transporte público con entre 1 a 7 servicios diarios. Fuente: Elaboración propia, en base a datos de INDEC y áreas de Transporte PBA y Municipalidad de La Plata.

Dentro de la población cubierta por transporte público, algunas de las delegaciones que más NBI poseen son a su vez las que realizan mayor tiempo de viaje en transporte público. Por ejemplo, El Peligro donde el 53\% de su población posee NBI es la delegación que mayor tiempo de viaje registra con un promedio de 103 minutos al Casco Urbano, seguida por Melchor Romero donde el 36\% de la población tiene NBI y el promedio de viaje es de 75 minutos. Por otro lado, las delegaciones con menos NBI como el caso del Casco Urbano, Gonnet, City Bell, Villa Elisa, Tolosa y Ringuelet corresponden a la zona Norte del partido de 
La Plata. En esta zona si bien las frecuencias de los ramales varían entre 25 a 60 minutos, la gran cantidad de ramales que por allí transitan tienen como destino principal el área central del Casco Urbano, por lo que en los hechos el tiempo de espera se reduce en horarios pico a 10 minutos. Ver Tabla 28.

Tabla 28. Población con NBI cubierta por transporte público y tiempos de viaje. Fuente: Elaboración propia, en base a datos de INDEC y áreas de Transporte PBA y Municipalidad de La Plata.

\begin{tabular}{|c|c|c|c|c|c|c|}
\hline Delegación & $\begin{array}{c}\text { Población } \\
\text { cubierta }\end{array}$ & $\begin{array}{c}\text { Población } \\
\text { cubierta con } \\
\text { NBI }\end{array}$ & $\begin{array}{c}\% \text { con } \\
\text { NBI }\end{array}$ & $\begin{array}{c}\text { Promedio } \\
\text { Tiempo de } \\
\text { traslado } \\
\text { (minutos) }\end{array}$ & $\begin{array}{c}\text { Promedio } \\
\text { Tiempo de } \\
\text { espera } \\
\text { (minutos) }\end{array}$ & $\begin{array}{c}\text { Tiempo } \\
\text { de viaje } \\
\text { (minutos) }\end{array}$ \\
\hline El Peligro & 636 & 335 & 53 & 65 & 38 & 103 \\
\hline $\begin{array}{l}\text { Melchor } \\
\text { Romero }\end{array}$ & 21744 & 7884 & 36 & 37 & 38 & 75 \\
\hline Abasto & 6200 & 1784 & 29 & 58 & 39 & 97 \\
\hline Arturo Segui & 5120 & 1432 & 28 & 54 & 40 & 94 \\
\hline Etcheverry & 645 & 163 & 25 & 48 & 40 & 88 \\
\hline Arana & 660 & 163 & 25 & 44 & 37 & 81 \\
\hline Gorina & 3500 & 790 & 23 & 60 & 39 & 99 \\
\hline Olmos & 9102 & 1976 & 22 & 24 & 40 & 64 \\
\hline San Carlos & 75425 & 14982 & 20 & 24 & 39 & 63 \\
\hline $\begin{array}{c}\text { Altos de San } \\
\text { Lorenzo }\end{array}$ & 39940 & 7458 & 19 & 22 & 40 & 62 \\
\hline Villa Elvira & 83358 & 14056 & 17 & 15 & 36 & 51 \\
\hline Los Hornos & 80525 & 13286 & 16 & 17 & 37 & 55 \\
\hline Hernandez & 3277 & 509 & 16 & 30 & 40 & 71 \\
\hline Ensenada & 58248 & 8986 & 15 & 21 & 39 & 60 \\
\hline Berisso & 93124 & 13270 & 14 & 21 & 39 & 60 \\
\hline Ringuelet & 17495 & 2141 & 12 & 28 & 40 & 68 \\
\hline Tolosa & 60724 & 6260 & 10 & 31 & 40 & 71 \\
\hline Villa Elisa & 17860 & 1387 & 8 & 48 & 41 & 89 \\
\hline City Bell & 34627 & 2669 & 8 & 42 & 40 & 83 \\
\hline Gonnet & 25950 & 1292 & 5 & 30 & 40 & 70 \\
\hline Casco Urbano & 258228 & 7852 & 3 & 12 & 37 & 48 \\
\hline
\end{tabular}

Dentro de la población con NBI no cubierta por el sistema de transporte público se encuentran 5.799 familias que viven en villas, asentamientos precarios y barrios degradados del Gran La Plata. Estas familias conforman 38 de los 163 asentamientos que hay en la región, de los cuales 123 no poseen infraestructura vial adecuada para el paso del transporte público. Sin la posesión de algún medio motorizado, estas familias, las más vulnerables, deberán caminar más de 5 cuadras para poder acceder al transporte público. Ver Ilustración 53. 


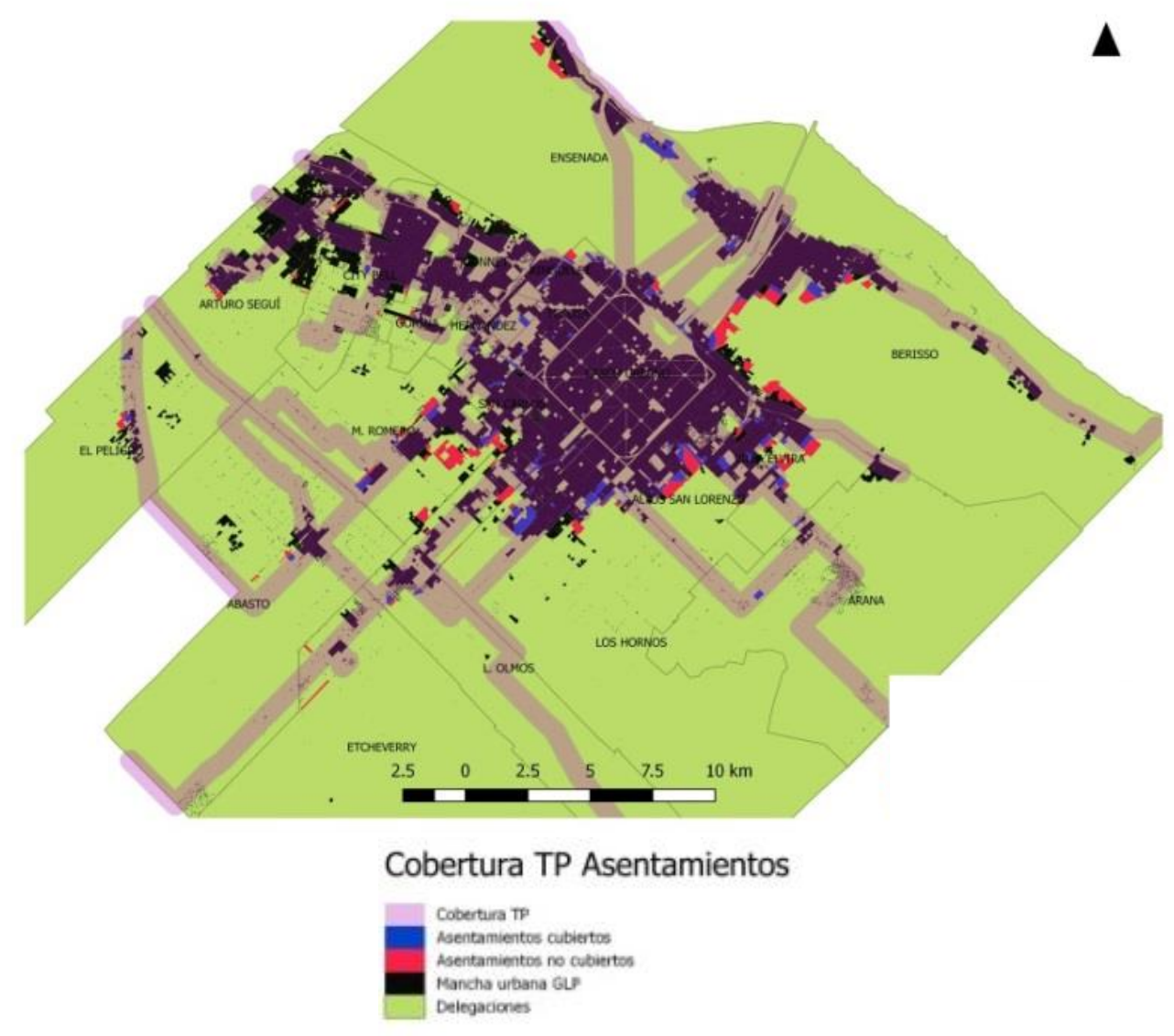

Ilustración 53. Cobertura de transporte público a villas, asentamientos precarios y barrios degradados 2013. Fuente: Elaboración propia. Datos del Registro Público Provincial de Villas y Asentamientos Precarios (RPPVAP) creado en el marco de la Ley 14449. Gobierno de la Provincia de Buenos Aires.

En síntesis, los sectores con mayor índice de NBI se encuentran en las zonas de mayor crecimiento poblacional y habitacional del Gran La Plata. A su vez estas áreas poseen una cobertura de transporte público con pocas frecuencias, a lo cual se suman las familias no cubiertas por transporte que viven en villas o asentamientos precarios.

Estos resultados demuestran que la actual relación entre sectores de menores recursos económicos y el sistema de transporte público no es buena, ya que un gran porcentaje de la población de estas características reside en áreas del Gran La Plata donde la cobertura y frecuencias son deficitarias. Este déficit del sistema de transporte público no es menor ya que al ser el modo motorizado más económico de la región, su rol como servicio público que garantice la accesibilidad social a establecimientos de educación, salud o trabajo es particularmente importante para la población de bajos recursos. 


\subsubsection{Dimensión Económica}

En la variable económica se analizan los costos económicos de la expansión urbana a partir de las distancias medias de viaje según modo de transporte utilizado. En el caso de transporte público, se tiene en cuenta el esquema tarifario según secciones, en comparación con los ingresos de los sectores vulnerables, más dependientes del transporte. Paralelamente se plantea un análisis sobre el grado de impacto de la red de transporte público sobre la variación de los precio del suelo.

\section{i. Costo de la expansión urbana}

En esta apartado se analizaran los costos de traslado de la totalidad de los viajes del Gran La Plata y por delegación municipal, utilizando precios de combustibles y tarifas de transporte público de 2013. Además se realiza una comparación de esos costos acumulados en un mes del miembro del hogar encuestado con el valor de la Canasta Básica Alimentaria (CBA), la Canasta Básica Total (CBT) y el Salario Mínimo (SM) según organismos oficiales.

Según aproximaciones realizadas se puede estimar un gasto del total de los usuarios de colectivo y auto de $\$ 2.614 .913,9$ por día, ${ }^{69}$ teniendo en cuenta solo los viajes de las delegaciones del partido de La Plata hacia el Casco Urbano el cual resulta mayor al 1,7\% del PBG de la ciudad ${ }^{70}$. La partición de este gasto se calcula en un $20,5 \%$ en transporte público y el 79,5\% solo en consumo de combustible del automóvil particular.

A nivel de delegaciones, la distancia al casco es una variable fundamental para la conformación de dicho costo de traslado, ya que en 14 de las 19 delegaciones del Gran La Plata, la producción de viajes con destino al Casco Urbano supera al 50\% de los viajes producidos en cada delegación. En ese marco, las delegaciones más alejadas del centro son las que más gastan en movilizarse, como El Peligro, Arturo Segui, Abasto, Villa Elisa y Etcheverry. Ver Tabla 29.

\footnotetext{
${ }^{69}$ En el procedimiento de cálculo se analizaron los costos económicos de la expansión urbana a partir de las distancias medias de viaje y el consumo de combustible por kilómetro según modo de transporte utilizado. En el caso de transporte público se utilizó el esquema tarifario según secciones basadas en distancias en kilómetros.

${ }^{70}$ El PBG se calculó a partir del PBG per cápita de la Provincia de Buenos Aires, aplicándolo a la población del Gran La Plata en 2013 por día dividiéndolo por los 365 días del año, lo que da como resultado \$153.264.182,7 PBG diario.
} 
Tabla 29. Costos de viaje mensuales por usuario. Fuente: Elaboración propia.

\begin{tabular}{|l|c|c|c|c|}
\hline \multirow{2}{*}{ Delegación } & \multirow{2}{*}{$\begin{array}{c}\text { Distancia } \\
\text { al centro } \\
(\mathrm{Km})\end{array}$} & \multicolumn{3}{|c|}{$\begin{array}{c}\text { Costo viajes mensuales (\$) } \\
\text { (20 días hábiles) }\end{array}$} \\
\cline { 3 - 5 } & & $\begin{array}{c}\text { Auto } \\
\text { Nafta }\end{array}$ & $\begin{array}{c}\text { Auto } \\
\text { Gasoil }\end{array}$ & Colectivo \\
\hline El Peligro & 31,6 & 951,9 & 617,8 & 68 \\
\hline Arturo Segui & 20,4 & 614,5 & 398,9 & 64 \\
\hline Abasto & 18,7 & 563,3 & 365,6 & 64 \\
\hline Villa Elisa & 17,5 & 527,1 & 342,2 & 64 \\
\hline Etcheverry & 16,7 & 503 & 326,5 & 64 \\
\hline $\begin{array}{l}\text { Melchor } \\
\text { Romero }\end{array}$ & 14 & 421,7 & 273,7 & 64 \\
\hline Arana & 13,7 & 412,7 & 267,9 & 64 \\
\hline Olmos & 13,6 & 409,7 & 265,9 & 64 \\
\hline City Bell & 13,5 & 406,7 & 264 & 64 \\
\hline Gorina & 12 & 361,5 & 234,6 & 64 \\
\hline Ensenada & 11,1 & 334,4 & 217 & 64 \\
\hline Berisso & 11 & 331,3 & 215,1 & 64 \\
\hline Gonnet & 9,7 & 292,2 & 189,7 & 64 \\
\hline Hernandez & 8,4 & 253 & 164,2 & 64 \\
\hline San Carlos & 6,7 & 201,8 & 131 & 64 \\
\hline Los Hornos & 5,8 & 174,7 & 113,4 & 64 \\
\hline Ringuelet & 5,7 & 171,7 & 111,4 & 64 \\
\hline Villa Elvira & 5,6 & 168,7 & 109,5 & 64 \\
\hline Tolosa & 5 & 150,6 & 97,8 & 64 \\
\hline $\begin{array}{l}\text { Altos de San } \\
\text { Lorenzo }\end{array}$ & 4,5 & 135,6 & 88 & 64 \\
\hline Casco & 2,5 & 75,3 & 48,9 & 60 \\
\hline
\end{tabular}

Como se observó en el punto anterior, los mayores porcentajes de población con NBI se encuentran en las delegaciones más alejadas, principalmente las de la zona Oeste. Puede deducirse que por los costos de traslado, los sectores más vulnerables de estas delegaciones utilizarían el transporte público por ser el único modo al que pueden acceder. Para los hogares que tienen ingresos equivalentes a la Canasta Básica Alimentaria (calculada en 2013 en $\$ 731,04)$ un viaje ida y vuelta en auto al Casco Urbano todos los días viviendo en El Peligro superarían sus ingresos mensuales si el auto es naftero. En el caso de poseer un auto gasolero, gastarían el 84\% de sus ingresos en trasladarse diariamente al Casco Urbano, mientras que el traslado en colectivo representaría el 9,3\% de la Canasta Básica Alimentaria.

En el caso de Los Hornos, la segunda delegación en cantidad de viajes después del Casco Urbano, posee un porcentaje de población con NBI del 16\%, equivalente a 13.286 personas. Si esas personas tuviesen ingresos similares a la CBA y utilizaran automóvil a nafta gastarían el $23 \%$ de su poder adquisitivo mensual en transportarse una vez por día al Casco Urbano (para esta delegación equivale al 76\% de los viajes), mientras que en transporte público este valor descendería a un $8,8 \%$. 
La población que percibe ingresos similares al salario mínimo (SM), con excepción de los que residen en El Peligro, posiblemente pueda realizar traslados de ida y vuelta al casco en automóvil ya que los porcentajes de ingreso destinados a traslado varían entre 17,8\% a 3,2\% mientras que en colectivo ese porcentaje varía entre $2 \%$ a 1,7\%. Ver Tabla 30.

Tabla 30. Canasta Básica Alimentaria, Canasta Básica Total y Salario Mínimo comparado con el costo de transporte en auto y colectivo, por delegación 2013. Fuente: Elaboración propia, en base a datos del INDEC.

\begin{tabular}{|c|c|c|c|c|c|c|c|c|c|}
\hline \multirow{2}{*}{$\begin{array}{c}\text { Delegaciò } \\
\text { n }\end{array}$} & \multicolumn{3}{|c|}{ \% CBA } & \multicolumn{3}{c|}{ \% CBT } & \multicolumn{3}{c|}{ \% Salario mínimo } \\
\cline { 2 - 10 } & Auto & $\begin{array}{c}\text { Auto } \\
\text { Gasoil }\end{array}$ & $\begin{array}{c}\text { Colectiv } \\
\text { o }\end{array}$ & $\begin{array}{c}\text { Auto } \\
\text { nafta }\end{array}$ & $\begin{array}{c}\text { Auto } \\
\text { Gasoil }\end{array}$ & $\begin{array}{c}\text { Colectiv } \\
\text { o }\end{array}$ & $\begin{array}{c}\text { Auto } \\
\text { nafta }\end{array}$ & $\begin{array}{c}\text { Auto } \\
\text { Gasoil }\end{array}$ & $\begin{array}{c}\text { Colectiv } \\
\text { o }\end{array}$ \\
\hline El Peligro & 130,2 & 84,5 & 9,3 & 56,7 & 36,8 & 4,0 & 27,6 & 17,9 & 2,0 \\
\hline $\begin{array}{c}\text { Arturo } \\
\text { Segui }\end{array}$ & 84,1 & 54,6 & 8,8 & 36,6 & 23,8 & 3,8 & 17,8 & 11,6 & 1,9 \\
\hline Abasto & 77,1 & 50,0 & 8,8 & 33,5 & 21,8 & 3,8 & 16,3 & 10,6 & 1,9 \\
\hline Villa Elisa & 72,1 & 46,8 & 8,8 & 31,4 & 20,4 & 3,8 & 15,3 & 9,9 & 1,9 \\
\hline $\begin{array}{c}\text { Etcheverr } \\
\text { y }\end{array}$ & 68,8 & 44,7 & 8,8 & 30,0 & 19,4 & 3,8 & 14,6 & 9,5 & 1,9 \\
\hline $\begin{array}{c}\text { Melchor } \\
\text { Romero }\end{array}$ & 57,7 & 37,4 & 8,8 & 25,1 & 16,3 & 3,8 & 12,2 & 7,9 & 1,9 \\
\hline Arana & 56,5 & 36,6 & 8,8 & 24,6 & 16,0 & 3,8 & 12,0 & 7,8 & 1,9 \\
\hline Olmos & 56,0 & 36,4 & 8,8 & 24,4 & 15,8 & 3,8 & 11,9 & 7,7 & 1,9 \\
\hline City Bell & 55,6 & 36,1 & 8,8 & 24,2 & 15,7 & 3,8 & 11,8 & 7,7 & 1,9 \\
\hline Gorina & 49,4 & 32,1 & 8,8 & 21,5 & 14,0 & 3,8 & 10,5 & 6,8 & 1,9 \\
\hline Ensenada & 45,7 & 29,7 & 8,8 & 19,9 & 12,9 & 3,8 & 9,7 & 6,3 & 1,9 \\
\hline Berisso & 45,3 & 29,4 & 8,8 & 19,7 & 12,8 & 3,8 & 9,6 & 6,2 & 1,9 \\
\hline Gonnet & 40,0 & 25,9 & 8,8 & 17,4 & 11,3 & 3,8 & 8,5 & 5,5 & 1,9 \\
\hline Hernandez & 34,6 & 22,5 & 8,8 & 15,1 & 9,8 & 3,8 & 7,3 & 4,8 & 1,9 \\
\hline $\begin{array}{c}\text { San } \\
\text { Carlos }\end{array}$ & 27,6 & 17,9 & 8,8 & 12,0 & 7,8 & 3,8 & 5,8 & 3,8 & 1,9 \\
\hline $\begin{array}{c}\text { Los } \\
\text { Hornos }\end{array}$ & 23,9 & 15,5 & 8,8 & 10,4 & 6,8 & 3,8 & 5,1 & 3,3 & 1,9 \\
\hline Ringuelet & 23,5 & 15,2 & 8,8 & 10,2 & 6,6 & 3,8 & 5,0 & 3,2 & 1,9 \\
\hline $\begin{array}{c}\text { Villa } \\
\text { Elvira }\end{array}$ & 23,1 & 15,0 & 8,8 & 10,0 & 6,5 & 3,8 & 4,9 & 3,2 & 1,9 \\
\hline Tolosa & 20,6 & 13,4 & 8,8 & 9,0 & 5,8 & 3,8 & 4,4 & 2,8 & 1,9 \\
\hline $\begin{array}{c}\text { Altos de } \\
\text { San } \\
\text { Lorenzo }\end{array}$ & 18,5 & 12,0 & 8,8 & 8,1 & 5,2 & 3,8 & 3,9 & 2,6 & 1,9 \\
\hline Casco & 10,3 & 6,7 & 8,2 & 4,5 & 2,9 & 3,6 & 2,2 & 1,4 & 1,7 \\
\hline
\end{tabular}

Por otro lado, el alto porcentaje de patentamientos anuales descripto en el punto 3.3.1, según analistas y operadores del sector automotriz ${ }^{71}$, tiene que ver con la disparidad entre el dólar oficial y el dólar blue, que en 2013 alcanzaba una diferencia entre el 86\% al 100\% según se observe en distintos meses del año. En ese marco el crecimiento económico desde 2003 generó una cierta recomposición de los hogares de ingresos medios que en 2013 se volcaron a la compra de automóviles para proteger sus ahorros frente a la alta inflación, el cepo del dólar

\footnotetext{
${ }^{71}$ Nota periodística diario La Nación. https://www.lanacion.com.ar/1765569-no-mejora-la-venta-de-autos-enenero-se-patento-39-

menos?fbclid=IwAR2vEDKfBv2c_UBvydzCVEUa5D4Y1lwq0iy4tmqmrdjr8u8emH6oYiu1DAA
} 
y el alto precio de los inmuebles, cambiando el patrón histórico de ahorro de este sector socioeconómico.

Por otro lado las clases medias que lograron ahorrar en dólares, aprovecharon esta diferencia entre el dólar oficial y el blue para vender dólares en el mercado informal y comprar autos importados que se pagaban en pesos con el tipo de cambio oficial. Es así que 2013 fue record nacional de ventas de autos donde los tipos de vehículos más comprados son los más baratos del mercado, de tipo familiar compacto y monovolumen. Con 56.000 unidades patentadas el WV GOL fabricado en Brasil fue el auto más vendido del año en 2013, seguido por el Chevrolet Classic de fabricación nacional y el Renaut Clio.

\section{ii. Impacto de la cercanía al transporte público sobre la variación en los precios del suelo}

La cercanía a los servicios de transporte público forma parte de la conformación de los precios del suelo urbano. En algunos estudios (Cervero, Kang, 2009) se demuestra que el buen funcionamiento de transporte público, con infraestructura adecuada es un factor que influye notablemente en el precio del suelo ${ }^{72}$.

El esquema de precios del suelo en el partido de La Plata pareciera estar más vinculado a la infraestructura de las vías de comunicación pensadas para el automóvil que para el transporte público ya que no existen inversiones significativas directas para este último. En efecto, estudios sobre la incidencia de la dotación de servicios de infraestructura en el precio del suelo de la zona Sur de la Provincia de Buenos Aires, realizados por Rusconi, L., Casazza, J., Reese, E. (2018), dan cuenta de que la infraestructura que más incrementa el precio de una parcela residencial es la pavimentación de las vías de comunicación. Ante la falta de infraestructura especifica de transporte público colectivo de pasajeros para el caso de estudio, en general se observa una adaptación del sistema de transporte a la infraestructura pensada para el auto.

Los precios de suelo más altos del Gran La Plata, se concentran en las áreas centrales del Casco Urbano; en un segundo nivel, en las delegaciones de la zona Norte que se ubican entre los Caminos Centenario y Belgrano y próximas al casco como Tolosa y en un tercer nivel se encuentran las áreas de expansión de éstas últimas como Los Hornos, Villa Elvira, y delegaciones que muestran ser potenciales centralidades como Melchor Romero, Olmos y

\footnotetext{
${ }^{72}$ En el caso estudiado en Corea, luego de la implementación de un sistema de BRT y el cambio de normativa de uso del suelo en zonas residenciales, se registró un aumento entre un 72,2\% a 88,9\% del precio del suelo.
} 
Abasto vinculadas a los corredores av. 520, av. 44 y Ruta Provincial $\mathrm{N}^{\circ}$ 36. Ver Ilustración 54.

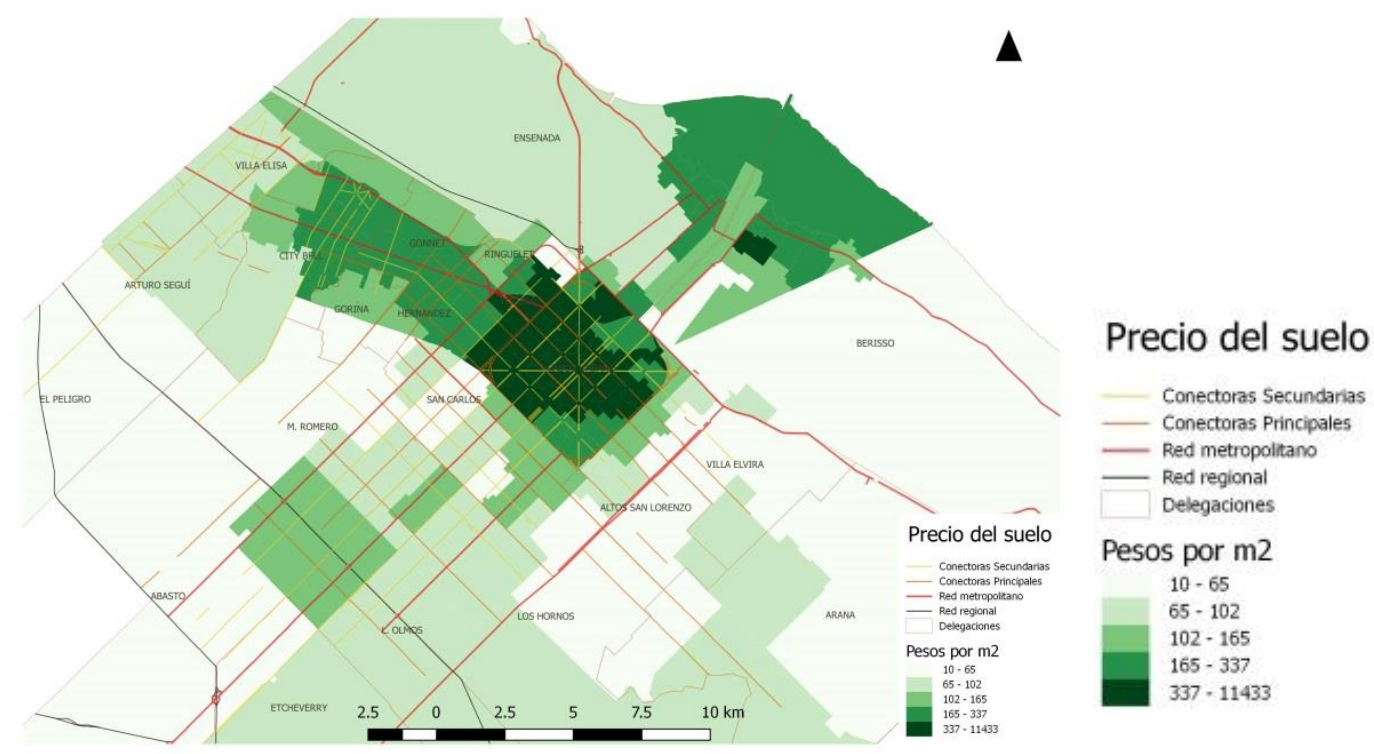

Ilustración 54. Precio de suelo en dólares 2013 y vías jerarquizadas del GLP. Fuente: Elaboración propia, en base a Cola, C., Barbero, D., Martini, I., Aón, L. (2017).

En función de lo expuesto, los recorridos del transporte público en el caso de estudio, parecen no tener una relación directa con el precio del suelo. Por lo general debido a que sus recorridos transitan por vías jerarquizadas construidas para el automóvil, las frecuencias o la cantidad de servicios diarios en una zona determinada no son determinantes sobre la variación de los precios del suelo. Por ejemplo, San Carlos es una de las delegaciones de desborde del casco con menor precio del metro cuadrado (entre US\$10 y US\$ 65), sin embargo posee un ramal que tiene una frecuencia menor a los 10 minutos y es parte de la zona que más servicios diarios realiza, la zona Oeste. Es similar el caso de Villa Elvira y Arana. Ver Ilustración 55. 


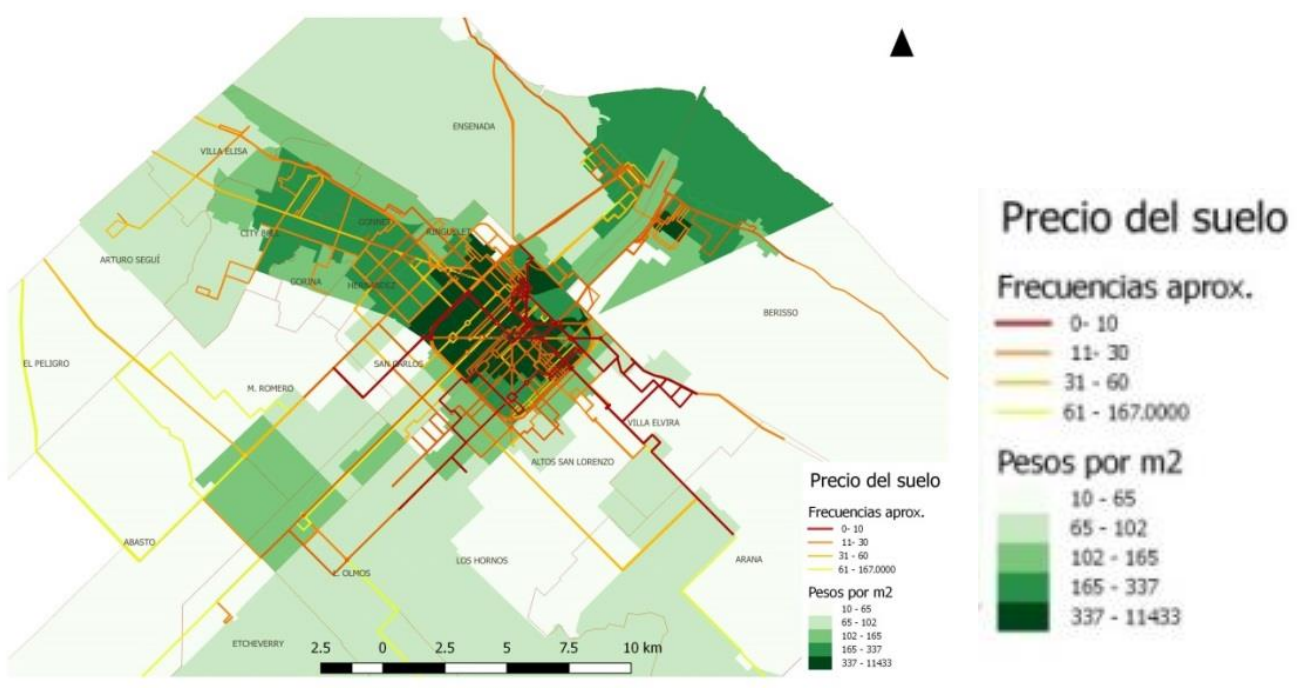

Ilustración 55. Precio del suelo en dólares 2013 y frecuencias de TP GLP. Fuente: Elaboración propia, en base a Cola, C., Barbero, D., Martini, I., Aón, L. (2017).

\subsubsection{Dimensión Ambiental}

Las problemáticas de movilidad, desarrollo urbano, nivel de calidad de vida cotidiana y congestión vehicular tienen además un impacto energético y ambiental sujeto al modelo de desarrollo urbano agravados por la cantidad de personas, viajes y tecnologías aplicadas utilizadas. Efectivamente, este problema es fuertemente cuantitativo y en este caso se analizarán las causas cuya variación depende de la cantidad de personas, la cantidad de viajes, la cantidad de kilómetros recorridos, la cantidad de hogares, la cantidad de sus integrantes y los factores de ocupación de los vehículos. Para dimensionar el problema, se evalúan a continuación de las distintas áreas urbanas mediante indicadores de eficiencia energética y ambiental para los patrones modales observadas para los hogares del Gran La Plata, según NUMEX (2013).

Existe una diferencia del $10 \%$ entre la cantidad de viajes en modos masivos y no masivos a favor de estos último, mientras que para el consumo energético y emisiones de $\mathrm{CO} 2$ esa diferencia es cercana al 60\%. Ver Tabla 31. 
Tabla 31. Viajes, consumo de combustible y emisiones de CO2 GLP 2013. Fuente: Elaboración propia, en base a Encuesta Movilidad del Gran La Plata y NUMEX (2013).

\begin{tabular}{|l|c|c|c|c|c|}
\hline \multicolumn{3}{|c|}{ Emisiones según Modos Masivos/No Masivos - Microrregión La Plata - 2013 } \\
\hline \multirow{2}{*}{ Modo } & \multicolumn{2}{|c|}{ Viajes } & \multicolumn{2}{c|}{ CONSUMO TEP } & Emisiones (Tn) \\
\cline { 2 - 7 } & Cant. & $\%$ & Cant & $\%$ & CO2 \\
\hline Masivos & 478.203 & 44,57 & $35.475,66$ & 18,74 & 99.425 \\
\hline No Masivos & 594.628 & 55,43 & $153.837,93$ & 81,26 & 444.669 \\
\hline Diferencia & 116425 & 10,86 & 118362,27 & 62,52 & 345244 \\
\hline Total & 1.072 .832 & 100 & $189.313,59$ & 100 & 544.094 \\
\hline
\end{tabular}

Desagregado por modo se puede observar que el $61 \%$ del consumo de combustible en TEP (Toneladas Equivalente de Petróleo) de la micro región es producido por los desplazamientos en automóvil particular, el 9\% en taxi, 7\% en remisse, 5\% en transporte público urbano, 4\% transporte público interurbano, $12 \%$ otros y $2 \%$ motos. Ver Gráfico 16.

Gráfico 16. Consumo de combustible en TEP según modo de transporte Gran La Plata 2013. Fuente: Elaboración propia, en base a Encuesta de Movilidad Urbana del Gran La Plata GII IIPAC FAU UNLP

\section{Consumo de combustible en TEP}

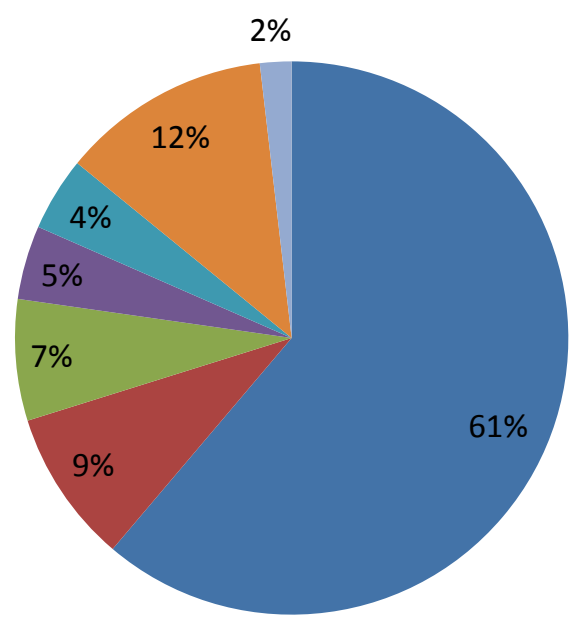

Autos

Taxis

Remisses

- Transporte Público

- Transporte Interurbano

Otros

Motos

- Transporte Escolar

Tren 
Tabla 32. Consumo de combustible y kilómetros recorridos diarios por modo de transporte Gran La Plata año 2013. Fuente: Elaboración propia, en base a Encuesta de Movilidad Urbana del Gran La Plata GII IIPAC FAU UNLP.

\begin{tabular}{|c|c|c|c|c|c|}
\hline \multirow{4}{*}{ Modos de transporte } & Combustible & $\begin{array}{c}\text { Km } \\
\text { Recorridos }\end{array}$ & $\begin{array}{c}\text { Consumo } \\
\text { en m3 }\end{array}$ & $\begin{array}{c}\text { Consumo } \\
\text { en TEP }\end{array}$ & $\begin{array}{c}\text { Consumo } \\
\text { en TJ }\end{array}$ \\
\hline \multirow{4}{*}{ Autos } & Nafta & 854127806 & 81522 & 62014 & 2596,4 \\
\cline { 2 - 6 } & Diesel & 586166141 & 42573 & 37464 & 1568,56 \\
\cline { 2 - 6 } & GNC & 234466457 & 20164 & 16716 & 699,87 \\
\hline \multirow{3}{*}{ Taxis } & Nafta & 36408750 & 3475 & 2643 & 110,68 \\
\cline { 2 - 6 } & Diesel & 41263250 & 2996,95 & 2637 & 110,42 \\
\cline { 2 - 6 } & GNC & 165053000 & 14194,56 & 11767 & 492,67 \\
\hline \multirow{3}{*}{ Memisses } & Nafta & 28743750 & 2743,45 & 2087 & 87,38 \\
\cline { 2 - 6 } & Diesel & 32576250 & 2366,01 & 2082 & 87,17 \\
\cline { 2 - 6 } & GNC & 130305000 & 11206,23 & 9290 & 388,95 \\
\hline \multirow{3}{*}{ Otros } & Nafta & 152777791 & 4583 & 3487 & 145,97 \\
\hline & Nafta & 50270132 & 4798 & 3650 & 152,81 \\
\cline { 2 - 6 } & Gas Oil & 38680204 & 3149 & 2714 & 113,62 \\
\cline { 2 - 6 } & GNC & 5276715 & 454 & 376 & 15,75 \\
\hline Transporte Público & Gas Oil & 46304636 & 23442 & 20204 & 846 \\
\hline Transporte Escolar & Gas Oil & 9125000 & 4620 & 3982 & 167 \\
\hline Transporte Interurbano & Gas Oil & 18781776 & 9508 & 8195 & 343,12 \\
\hline Tren & Gas Oil & 483667 & 5 & 5 & 0,19 \\
\hline
\end{tabular}

La Tabla 33 muestra que la población con mejores índices de eficiencia en el consumo de transporte habita en el área Sur, seguida del área Oeste. Bastante por debajo se ubica el área Este para finalmente llegar a las áreas Norte y Casco Urbano o centro. La curva de estos resultados está más fuertemente relacionada con la extensión urbana que con los niveles de ingreso, los que suelen pautar habitualmente los niveles de consumo. En efecto, los mayores niveles de ingreso del Gran La Plata, se localizan en el casco fundacional y en el área Norte y los menores niveles de ingreso corresponden, de manera predominante, a las demás áreas periféricas.

Si observamos el consumo y las emisiones totales por área, los altos valores en la zona Oeste podría producirse por la gran dispersión urbana de esa zona que incrementa las distancias de viaje. Por otro lado vemos un mayor correlato con los niveles de ingreso especialmente por los altos valores de consumo y emisiones del área Norte. Sin embargo si dividimos estos valores por la cantidad de los hogares que viven en cada área del Gran La Plata, vemos que los consumos más altos corresponden a la población Sur, donde el ingreso es medio o bajo (ver Tabla 32). Asimismo, en la Tabla 33 se observan los valores de eficiencia de consumo (EFI/CONS. $^{73}$ mayores para el casco en primer lugar (2.95) y el área Norte en segundo lugar

\footnotetext{
${ }^{73}$ La eficiencia de consumo se obtiene entre la cantidad de consumo anual por habitante. Es decir de la siguiente
} 
$(2,24)$ mientras que el valor más bajo de eficiencia o, lo que es lo mismo, la mayor ineficiencia, es de 1,03 para el área Sur. En este caso, la eficiencia de las emisiones contaminantes es proporcional al consumo.

Tabla 33. Partición modal, consumo TEP, emisiones CO2 diarios por área para GLP.

Fuente: Elaboración propia en base a la Encuesta de Movilidad Urbana 1993-2013. (Aon, Giglio, Cola, 2016).

\begin{tabular}{|c|c|c|c|c|c|c|c|c|c|c|}
\hline \multirow[b]{2}{*}{ AREA } & \multirow[b]{2}{*}{$\begin{array}{c}\text { Població } \\
\mathrm{n}\end{array}$} & \multirow[b]{2}{*}{$\begin{array}{l}\text { Hogare } \\
\mathrm{s}\end{array}$} & \multicolumn{3}{|c|}{ Partición Modal } & \multicolumn{2}{|c|}{$\begin{array}{c}\text { Consumo TEP } \\
\text { anual }\end{array}$} & \multirow[b]{2}{*}{$\begin{array}{l}\text { Consumo } \\
\text { TEP anual } \\
\text { por hogar }\end{array}$} & \multicolumn{2}{|c|}{ Emisiones $\mathrm{CO} 2$} \\
\hline & & & $\begin{array}{c}\text { Masiv } \\
\text { o }\end{array}$ & $\begin{array}{c}\text { No } \\
\text { masivo }\end{array}$ & $\begin{array}{c}\text { No } \\
\text { motorizado }\end{array}$ & TOTAL & $\begin{array}{l}\text { EFI/C } \\
\text { ONS. }\end{array}$ & & TOTAL & $\begin{array}{l}\mathrm{EFI} / \\
\mathrm{AMB}\end{array}$ \\
\hline CASCO & 203700 & 117409 & 30,2 & 33,3 & 36,5 & 69107,04 & 2,95 & 0,6 & 192544,88 & 1,06 \\
\hline ESTE & 104709 & 42435 & 37,6 & 40,6 & 21,8 & 65262,03 & 1,60 & 1,5 & 180121,10 & 0,58 \\
\hline SUR & 76089 & 30782 & 40,4 & 50,4 & 9,1 & 74003,33 & 1,03 & 2,4 & 204021,49 & 0,37 \\
\hline OESTE & 116421 & 43953 & 50,6 & 36,4 & 13,0 & 84734,36 & 1,37 & 1,9 & 235916,41 & 0,49 \\
\hline NORTE & 180911 & 76300 & 32,8 & 53,6 & 13,6 & 80682,58 & 2,24 & 1,1 & 225713,90 & 0,80 \\
\hline TOTAL & 681830 & 310879 & 35,35 & 41,13 & 23,53 & 373789,34 & 1,82 & 1,2 & 1038317,79 & 0,66 \\
\hline
\end{tabular}

Gráfico 17. Eficiencia de consumo de combustible en TEP a nivel de hogar. Fuentes: Encuesta de movilidad urbana para la micro región del Gran La Plata 1993/2003 y otros. (Aon, Giglio, Cola, 2016).

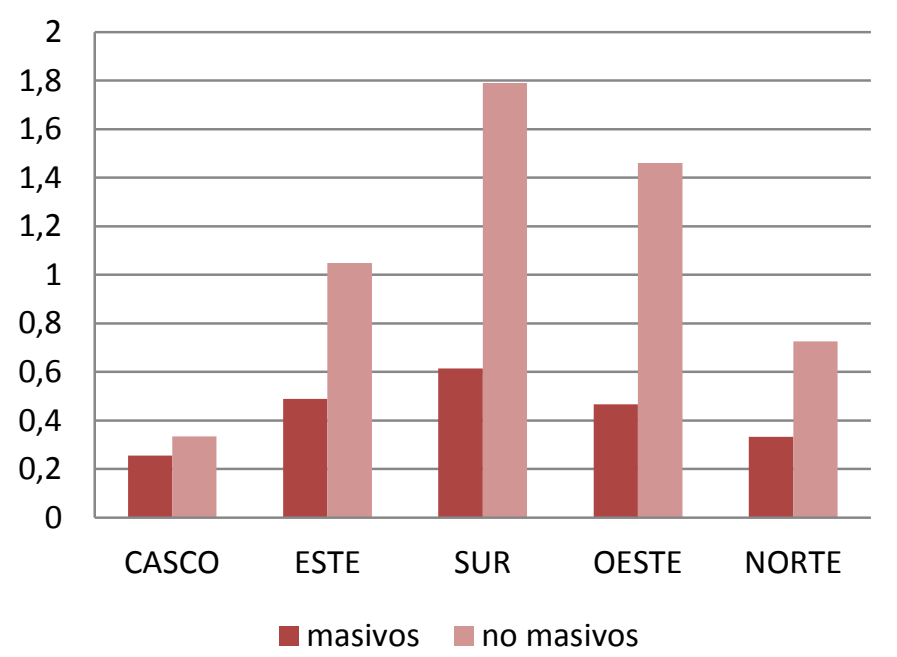

Estos resultados se corresponden con dos dimensiones principales y una subsidiaria: La primera corresponde a las características de usos y actividades de las distintas áreas, donde las más diversas y complejas (en cuanto a usos de suelo e infraestructura de movilidad) de la región (Casco Urbano y Norte) presentan la mayor eficiencia de consumo y emisiones; la

formula:

$\mathrm{EFICONS}=\mathrm{h} / \mathrm{con}$

Donde:

EDCONS: Eficiencia de consumo h: Población con: Consumo energético anual 
segunda es la relación entre la cantidad de población y las distancias al centro de la ciudad, donde las más pobladas y distantes, presentan la mayor ineficiencia.

Analizando cada área en relación al consumo agregado total y a los indicadores respectivos de eficiencia, podemos señalar que, si bien el casco fundacional resulta el área cuya población es más eficiente en términos de consumo y emisiones contaminantes, es a la vez el área más contaminada, por ser el destino del $80 \%$ de los viajes, masivos y no masivos de los casi 850.000 habitantes del Gran La Plata. Esto significa que una proporción muy alta de la producción de emisiones contaminantes calculadas para cada área, se produce en el Casco Urbano fundacional. Esta situación explica la baja calidad ambiental de las áreas centrales, aun cuando los patrones de consumo de su población corresponden a indicadores de eficiencia energética y ambiental buenos (ver Tabla 33). En este contexto se diluyen además las virtudes de la diversidad, proximidad y complejidad de esta área central histórica, con su $37 \%$ de viajes totales no motorizados.

Por su parte es necesario también reconocer que la eficiencia energética para el área Norte, similar a la del Casco (ver Tabla 33), se debe en parte a la densidad de población y a su alta conectividad masiva con el casco fundacional. En efecto el nivel de consolidación de ocupación de las áreas induce mejoras en la oferta de transporte público y su disponibilidad neutraliza en parte los patrones de consumo de la población con niveles de ingreso más alto.

En contraste a lo que sucede en el área Norte, los hogares del área Este y Sur, con niveles de ingreso predominantemente medios y bajos, presentan patrones de consumos energéticos muy altos, En esta ineficiencia incide de manera directa, el alto porcentaje de viajes en modos no masivos (autos y motos) y las distancias promedio de estos viajes, mientras que pesa de manera indirecta el bajo nivel de consolidación urbana de estas áreas, tanto en cantidad de actividades como en cantidad de población, ambas también traccionadas por la falta de infraestructura viaria adecuada para mejorar la oferta de transporte público masivo, promoviendo la dependencia de los medios motorizados de transporte.

Finalmente, el caso del área Oeste al presentar un patrón modal a favor de los modos masivos, posee un factor de eficiencia a nivel de hogar no muy óptimo (casi el doble del área Norte). Esto está relacionado de manera directa con la alta dependencia del área Oeste respecto de las actividades del casco fundacional, visible en las tasas de generación de viajes de la población de estas áreas. En este aspecto pesa también la distancia media de ésta área al centro, y constituye el caso más extremo de la insustentabilidad de la ciudad difusa, ya que su población se mueve predominantemente en modos masivos, pero la cantidad de viajes que 
esta población requiere con destino al centro de la ciudad y las distancias que deben recorrer para llegar a sus actividades, neutralizan los resultados positivos del uso de modos masivos que caracteriza a esta área. La población del área Oeste produce el mayor consumo en TEP de todo GLP (84734,36 TEP) residiendo solo en el área el 19\% de los hogares del partido.

En base a los análisis realizados, podemos afirmar que en todas las áreas estudiadas, el mayor consumo de combustible por movilidad corresponde a los modos no masivos, en consonancia con el crecimiento del parque automotor y la dependencia del auto en las periferias. Sin embargo, la eficiencia energética y de emisiones relativas a la movilidad obedece a distorsiones en la forma del desarrollo urbano, incluyendo como problemas las bajas o heterogéneas consolidaciones de población, de usos y actividades y de infraestructuras. La ineficiencia energética de las áreas Este, Oeste y Sur, se atribuye a una menor consolidación de centralidades urbanas en estas zonas, ya que generan una mayor producción de viajes hacia el centro, la mayoría en modos motorizados de transporte. La población que reside en dichas áreas es, predominantemente, de un nivel socio-económico medio y bajo y corresponde al sector urbano de mayor crecimiento residencial pero con menores densidades habitacionales de los últimos 10 años.

En este contexto de predominancia de viajes a las áreas centrales, en modos masivos y no masivos, con distancias cada vez mayores, la presencia de hogares con mayor cantidad de habitantes en nuevas áreas de baja densidad agrava los indicadores de eficiencia de consumo $\mathrm{y}$ emisiones por efecto de las distancias distorsivas y extremas necesarias de recorrer cotidianamente. De este análisis se desprende la manera en que los procesos de expansión de tan baja densidad, habitados por hogares de varios miembros, en áreas con déficit de infraestructuras y/o de servicios de transporte público masivo, llevan a una mayor ineficiencia energética y ambiental y a un deterior de la calidad de vida urbana.

\section{Síntesis Capítulo III}

En la descripción histórica del desarrollo urbano territorial del Gran La Plata, se dio cuenta de los procesos de apropiación del territorio a partir de una decisión administrativa también ligada al desarrollo productivo y exportador de la región, tanto en actividades agropecuarias como industriales vinculadas al puerto. En este proceso, el transporte ferroviario interurbano fue clave, así como fue importante el tranvía urbano para contener el rápido crecimiento poblacional y ocupacional de La Plata. El transporte público de colectivo surgió como iniciativa privada en competencia con el tranvía cuando la ciudad comenzó a extenderse en 
zonas más alejadas del área fundacional del casco urbano. Los caminos Centenario, Belgrano y finalmente, la Autopista Bs. As. - La Plata, que refuerzan el crecimiento urbano periférico hacia el sector Noreste.

Con el pasar de los años, la región fue perdiendo su capacidad de planificación integral, donde se vinculaba lo productivo (trabajo y producción de mercancías), residencial, el consumo, los servicios sociales como salud y educación a partir del transporte masivo. Los instrumentos de planificación se redujeron a códigos de ordenamiento de los usos de suelo en tensión con la ocupación real y desarticulado de los sistemas de movilidad continuaron rigiéndose por lógicas económicas empresariales propias, incluso luego de la importante modificación en 2002 a partir de la implementación del SUT.

En ese marco, y teniendo en cuenta las tendencias económicas y territoriales nacionales, el aumento del uso del automóvil frente al transporte público ha sido una modificación histórica importante para la región, siendo La Plata la ciudad con más patentamientos anuales en 2013 y con números similares en años anteriores, convergentes a su vez con una intensificación del uso del automóvil de alquiler, a partir de la aparición generalizada del remisse luego de las privatizaciones de empresas estatales en los años '90.

La gran expansión poblacional y habitacional periférica sin planificación integrada, aumentó las distancias de viaje y la utilización de modos no masivos de transporte, aumentando tiempos de viaje por esta situación, por congestión en áreas centrales y en determinados corredores a partir del incremento del uso del auto. En transporte público, esta situación entra en tensión permanente con las frecuencias entre servicios y la forma de financiamiento económico de las empresas a partir de la disposición de subsidios acotados a determinados kilómetros recorridos por empresa, que equivalían aproximadamente al $81 \%$ de sus ingresos en el año 2013.

Esta situación tiene consecuencias en los niveles de accesibilidad de los sectores más vulnerables con y sin cobertura de la red de transporte público. A su vez, la resultante ambiental de este modelo es más crítica, con un incremento del consumo energético y emisiones por un mayor uso del automóvil particular y el aumento de distancias de viaje.

Desde la dirección de transporte dan cuenta de una saturación del sistema de transporte público, limitado por las lógicas empresariales dentro de los marcos legales y económicos que dispone el Estado Nacional a partir de los subsidios, las dificultades de la dirección para un mayor control de los acuerdos con empresarios por falta de presupuesto municipal destinado al área y la presión cotidiana a choferes que son los perjudicados en tener que hacer funcionar un sistema con muchas complicaciones que se derivan de causas diversas. A esta situación se 
le suma la casi nula inversión en infraestructura de transporte público, tanto en centro como en la periferia, ya que se utilizan las que fueron pensadas para el automóvil y que no necesariamente son compatibles con las necesidades del sistema de transporte público masivo. En este contexto, el siguiente capítulo plantea diversos escenarios prospectivos (tendencial a 2030 y alternativos con propuestas de mejora de mejora en distintos plazos) de desarrollo urbano y transporte público. 


\section{CAPITULO IV: ESCENARIOS PROSPECTIVOS DE DESARROLLO URBANO Y TRANSPORTE PÚBLICO EN EL GRAN LA PLATA}

\section{Resumen}

En este capítulo se plantea el ejemplo de aplicación de la construcción de los escenarios tendencial y alternativo, tomando como horizonte temporal el año 2030. Para ello, se utiliza la metodología desarrollada en el Capítulo 2. Asimismo, la simulación de ambos escenarios parte del año base, construido en el capítulo previo, donde se utilizó a la ciudad de La Plata como caso de estudio. 


\subsection{Escenario tendencial}

Una vez elaborado el año base, se plantea la construcción del escenario tendencial, es decir un escenario en el que se proyectan a futuro las tendencias actuales para cada variable analizada con el objetivo de poder visibilizar la criticidad de los distintos indicadores del escenario base en un contexto sin modificaciones que contrarresten dichas tendencias. Este escenario se plantea al año 2030 para el cual el municipio de La Plata fijó sus objetivos con el Plan Estratégico LP.30 desarrollado por la Secretaria de Planeamiento Urbano y Desarrollo Económico. Para ello se analizan los resultados obtenidos para las variables contenidas en las dimensiones espacial, social, económica y ambiental, desarrolladas en el Capítulo III, a partir de datos globales para el Gran La Plata y detallados por delegación municipal.

\subsubsection{Dimensión Espacial}

Así como se planteó en el capítulo III, la dimensión espacial está compuesta por dos variables, una que desarrolla datos poblacionales y de ocupación del territorio por zona y delegación, y otra sobre la situación de la movilidad en general y el transporte público en particular.

\section{i. Población y Ocupación del territorio}

La proyección realizada para el crecimiento poblacional del Gran La Plata para el año 2030 es del $12,5 \%$ con respecto al 2014, equivalente a una población de 929.580 habitantes, es decir un incremento de 90.595 nuevos habitantes. Por otro lado, si se mantiene la relación personas por vivienda obtenida en el año base, se incremetarían 37.796 nuevas viviendas y sumarian un total de 415.751 viviendas en toda la región. La magnitud del crecimiento a 2030 equivale en población y viviendas, por ejemplo, a todo Berisso, o a la suma de City Bell, Gonnet y Villa Elisa, de zona Norte en 2014. Con la misma distribución por partido para el año 2014, en el año 2030 La Plata contaría con 760.660 habitantes, Berisso con 103.130 habitantes y Ensenada con 65.790 habitantes. Ver Tabla 34.

Tabla 34. Proyección variación poblacional 2014-2030. Fuente: Elaboración propia, en base a proyección poblacional INDEC.

\begin{tabular}{|l|c|c|c|}
\hline \multicolumn{1}{|c|}{ Distrito } & Población año base & Población 2030 & $\begin{array}{c}\% \text { de } \\
\text { crecimiento }\end{array}$ \\
\hline La Plata & 676.195 & 760.660 & 12,5 \\
\hline Berisso & 91.466 & 103.130 & 12,8 \\
\hline Ensenada & 58.585 & 65.790 & 12,3 \\
\hline Total GLP & 826.246 & 929.580 & 12,5 \\
\hline
\end{tabular}


Si se proyectan las tendencias de crecimiento poblacional y de viviendas de cada delegación del Gran La Plata, se pueden observar algunos cambios en el orden de delegaciones con mayor población. Los más significativos son Melchor Romero, que pasa a superar en población a Ensenada, Los Hornos y San Carlos, y por otro lado Gorina que supera a Olmos, Villa Elisa y Gonnet. Por otro lado, las tendencias de crecimiento de viviendas no muestran valores que alteren significativamente el orden de las delegaciones con mayor población, es decir que existe una tendencia a una mayor polarización en la relación habitantes por vivienda entre estas delegaciones y las demás. Ver Tabla 35, Gráfico 18, Gráfico 19, Ilustración 56 e Ilustración 57.

Tabla 35. Proyección variación poblacional 2014-2030 por delegación municipal. Fuente: Elaboración propia, en base a proyección poblacional intercensal 2001-2010, INDEC.

\begin{tabular}{|c|c|c|c|}
\hline DELEGACION & Población año base & Población 2030 & $\begin{array}{c}\% \text { de } \\
\text { crecimiento }\end{array}$ \\
\hline CASCO & 205262 & 211194 & 2,9 \\
\hline LOS HORNOS & 63800 & 64125 & 0,5 \\
\hline VILLA ELVIRA & 66332 & 67460 & 1,7 \\
\hline SAN CARLOS & 52405 & 52672 & 0,5 \\
\hline TOLOSA & 47733 & 49437 & 3,6 \\
\hline GONNET & 29903 & 31072 & 3,9 \\
\hline ALTOS SAN LORENZO & 44255 & 46437 & 4,9 \\
\hline CITY BELL & 35706 & 35888 & 0,5 \\
\hline M. ROMERO & 48686 & 64908 & 33,3 \\
\hline VILLA ELISA & 24971 & 25396 & 1,7 \\
\hline RINGUELET & 11923 & 10606 & $-11,0$ \\
\hline OLMOS & 18757 & 21149 & 12,8 \\
\hline ARTURO SEGUI & 10882 & 12214 & 12,2 \\
\hline GORINA & 16451 & 32084 & 95,0 \\
\hline ABASTO & 15579 & 19446 & 24,8 \\
\hline HERNANDEZ & 9249 & 10224 & 10,5 \\
\hline ARANA & 4897 & 5480 & 11,9 \\
\hline ETCHEVERRY & 3929 & 4437 & 12,9 \\
\hline EL PELIGRO & 2312 & 2395 & 3,6 \\
\hline
\end{tabular}


Gráfico 18. Población por delegación municipal 2014-2030. Fuente: Elaboración propia, en base a datos intercensales 2001-2010 de INDEC.

Poblaciòn por delegaciòn 2014-2030

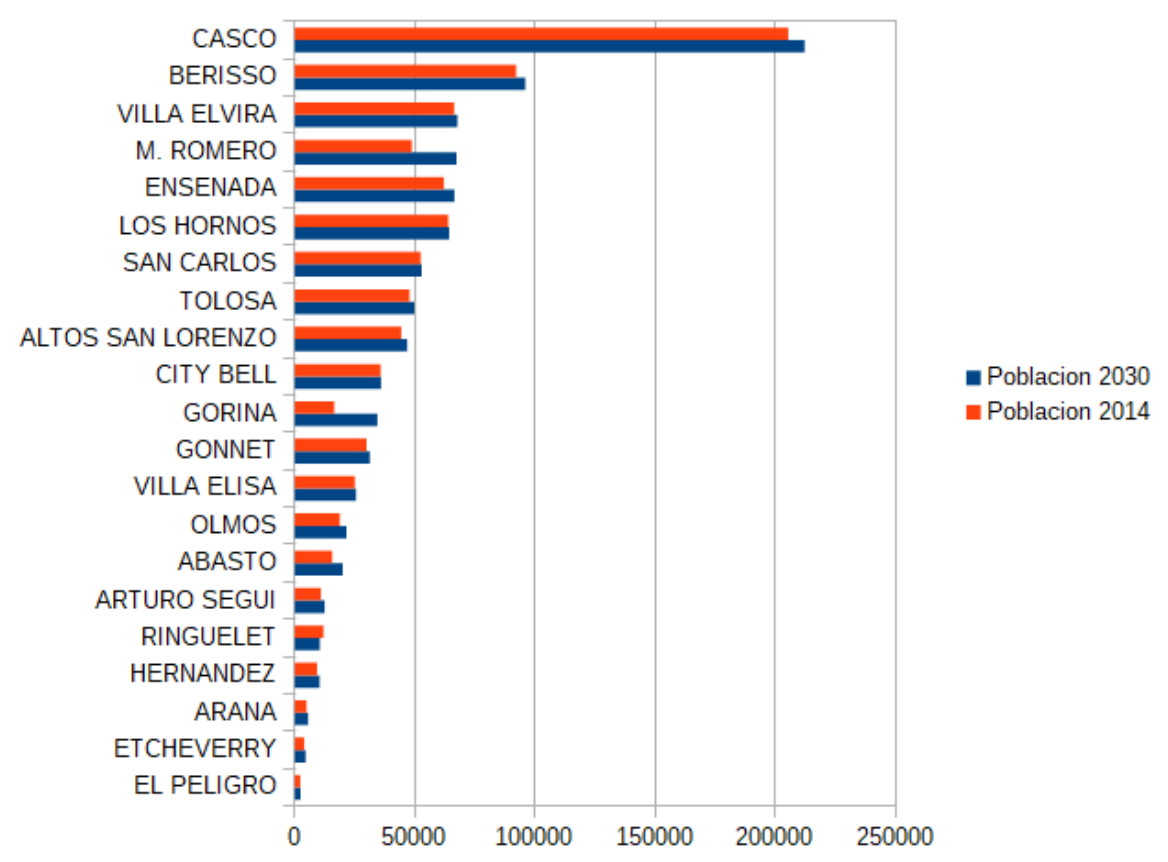

Gráfico 19. Viviendas por delegación municipal 2.014-2.030. Fuente: Elaboración propia, en base a datos de intercensales 2001-2010 de INDEC.

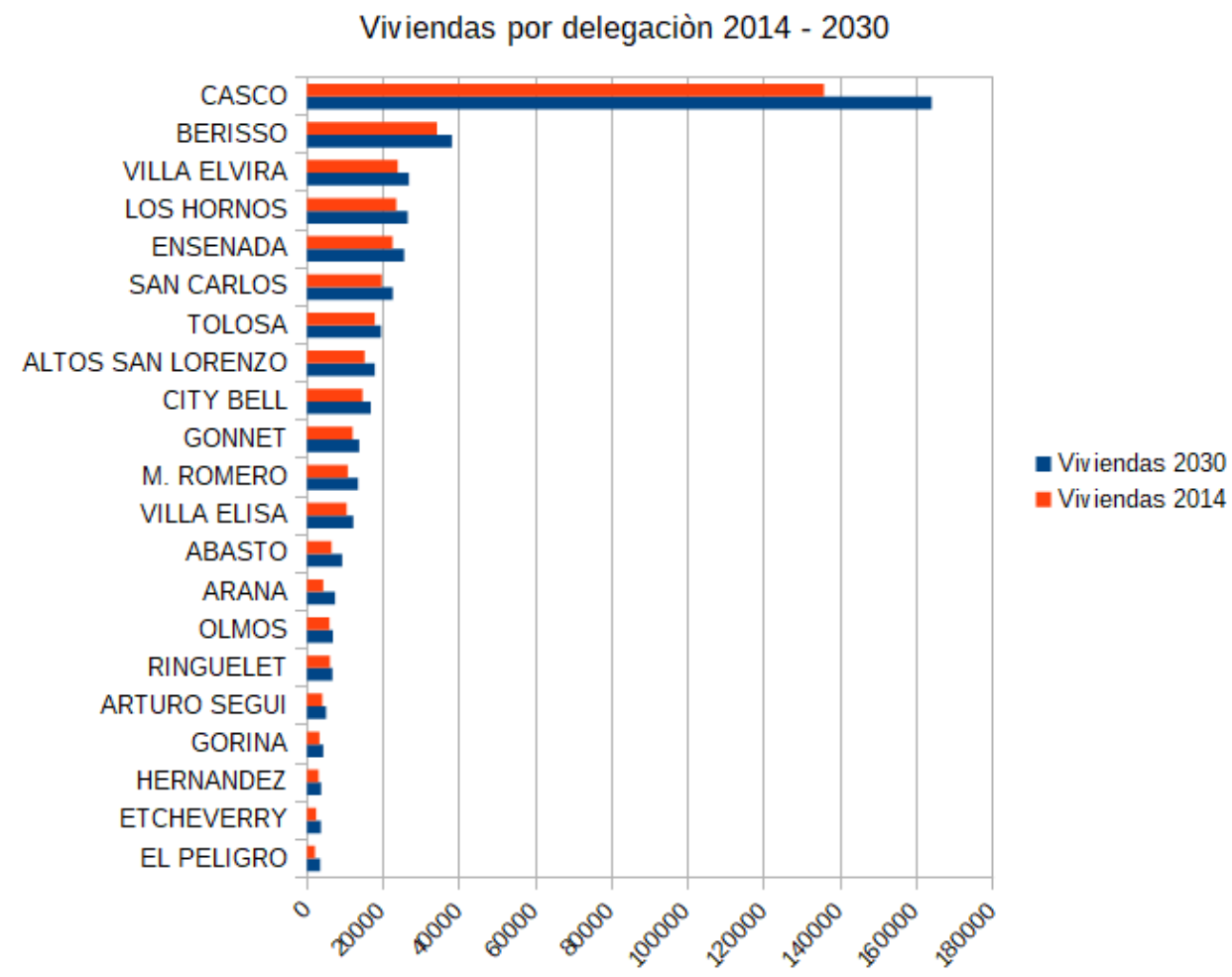




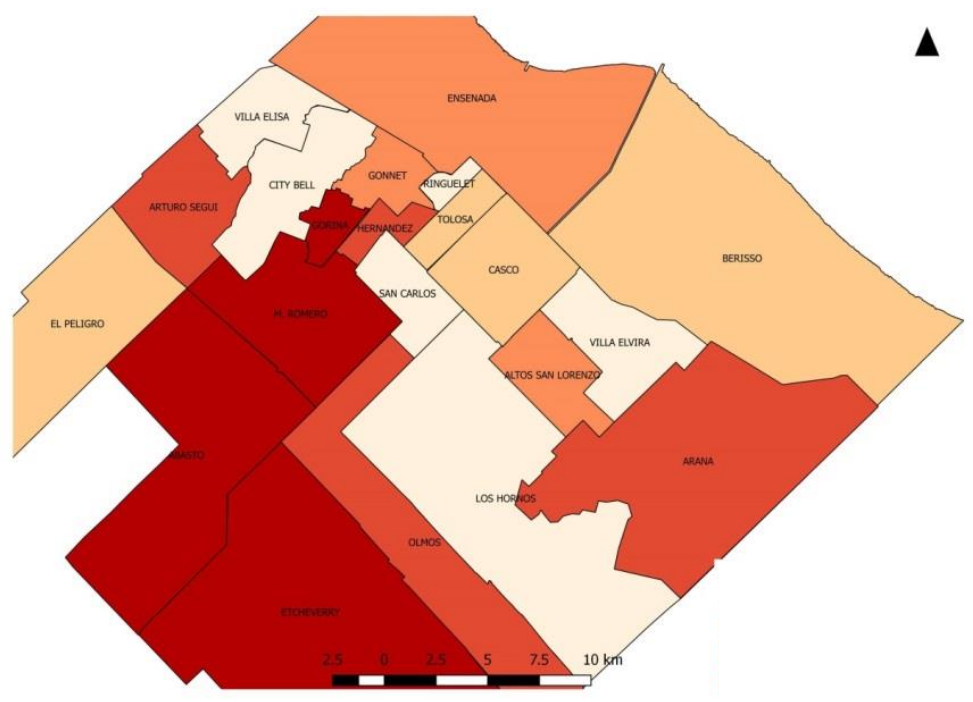

Crecimiento 2014-2030

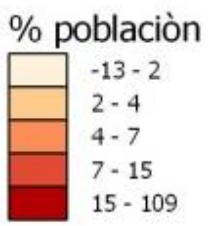

Ilustración 56. Crecimiento poblacional 2014-2030 por delegación municipal del Gran La Plata. Fuente: Elaboración propia, en base a datos intercensales 2001-2010 de INDEC.

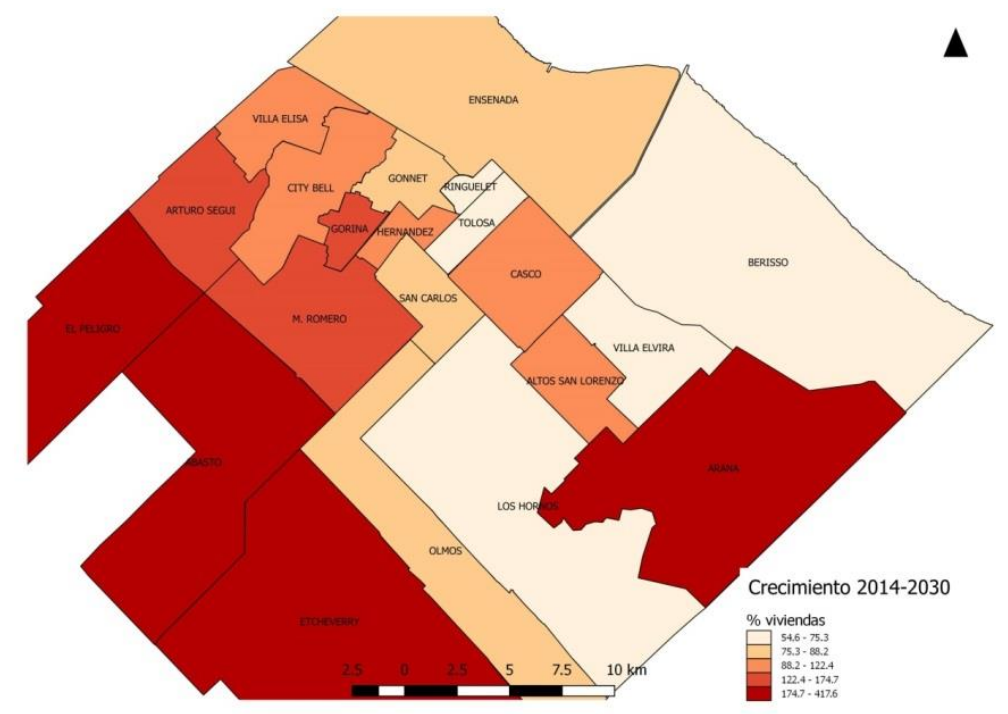

Crecimiento 2014-2030

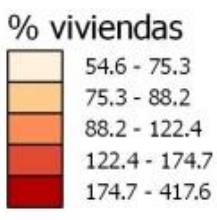

Ilustración 57. Crecimiento viviendas 2014-2030 por delegación del Gran La Plata. Fuente: Elaboración propia, en base a datos intercensales 2001-2010 de INDEC.

Por otro lado, los porcentajes de crecimiento poblacional muestran una tendencia a la intensificación de ocupación en las delegaciones de la zona Oeste como Melchor Romero, Abasto, Etcheverry y Olmos, ligadas a corredores viales provinciales como son la av. 520 y av. 44 y Gorina de zona Norte. En cuanto al crecimiento de viviendas se destacan delegaciones de marcado perfil rural como El Peligro, Abasto y Etcheverry, y Arana que tienen una tendencia de crecimiento importante en el barrio Sicardi, con residencias de sectores de ingresos medios. 
La densidad poblacional para el año 2030 permite reconocer nuevas delegaciones que puedan concentrar mayor cantidad de habitantes. Además de las delegaciones más densas en 2013 como el Casco, San Carlos, Tolosa y Ringuelet, la proyección realizada para 2030 muestra que Gonnet, Gorina, Altos de San Lorenzo y Villa Elvira alcanzan el mismo rango de densificación que las primeras, además se puede observar una tendencia de crecimiento en Hernández, Melchor Romero y también en Olmos. Ver Ilustración 58 y Ilustración 59.

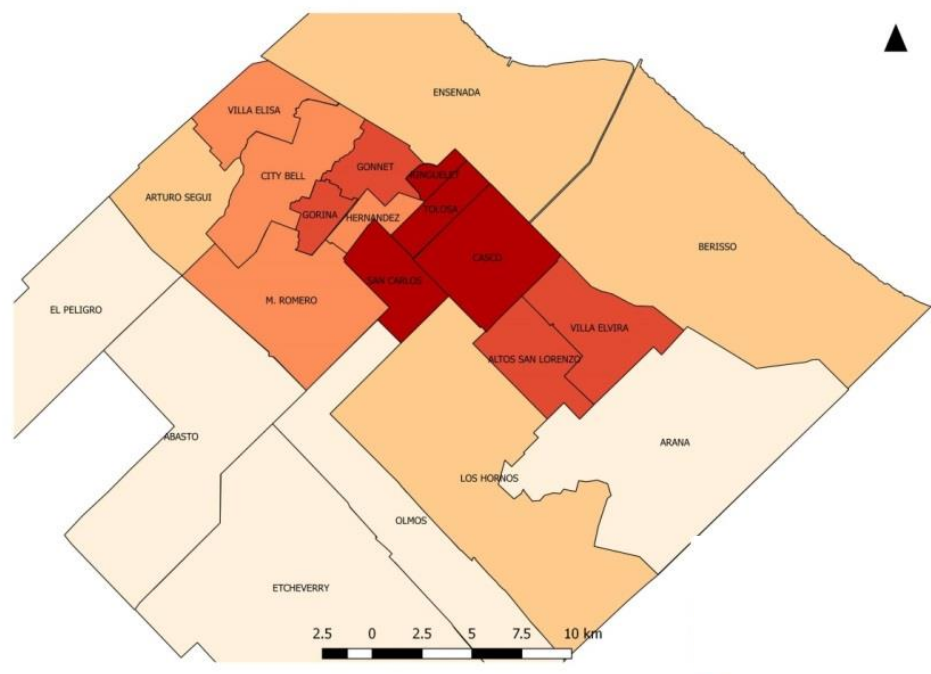

Densidad por delegaciòn 2013 $\mathrm{Hab} / \mathrm{m} 2$

$0.00002-0.00031$

$0.00031-0.00063$

$0.00063-0.00142$

$0.00142-0.0025$

$0.00253-0.00734$

Ilustración 58. Densidad poblacional Gran La Plata 2013. Fuente: Elaboración propia, en base a datos intercensales 2001-2010 de INDEC.

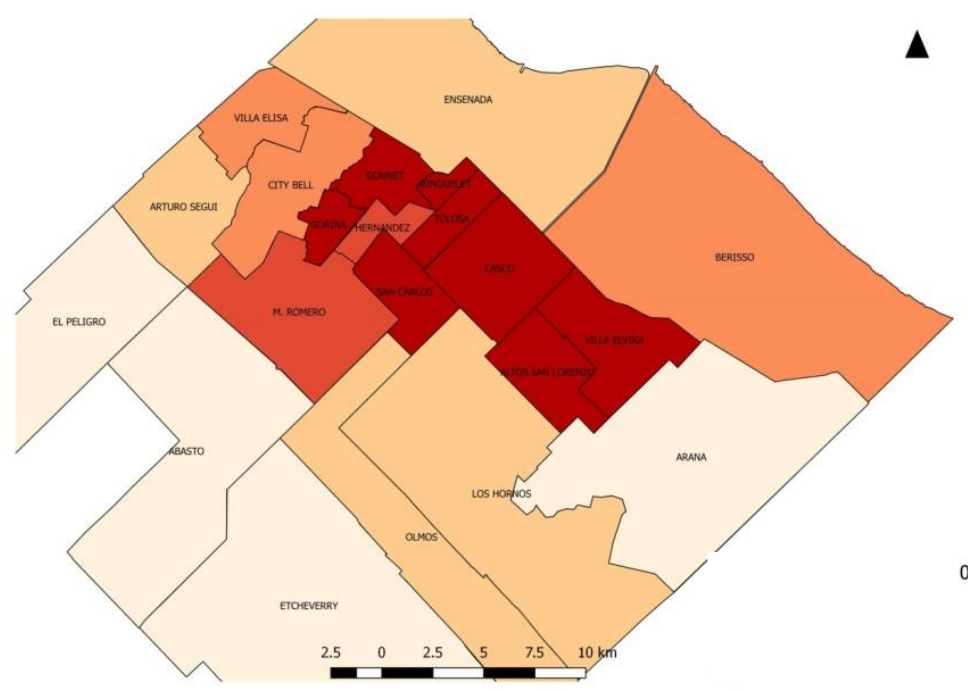

Densidad por delegaciòn 2030 $\mathrm{Hab} / \mathrm{m} 2$

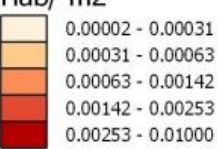

Ilustración 59. Densidad poblacional Gran La Plata proyección 2030. Fuente: Elaboración propia, en base a datos intercensales 2001-2010 de INDEC. 


\section{ii. Análisis de la movilidad y del transporte público}

Siguiendo la estructura de análisis del año base, y las tendencias actuales de crecimiento para el año 2030, se proyecta un parque automotor para el Gran La Plata de 417.791 automóviles, una vez y media más que el parque móvil de 2013 que fue de 281.726. Con una población proyectada de 929.580 habitantes resulta una tasa de motorizacion ${ }^{74}$ de 1,7 personas por auto mientras que en 2013 este índice era 2,7. Ver Gráfico 20

Gráfico 20. Proyección Parque Automotor 1993- 2030. Fuente: Elaboración propia, en base a datos Asociación de Concesionarios de Automotores de la República Argentina.

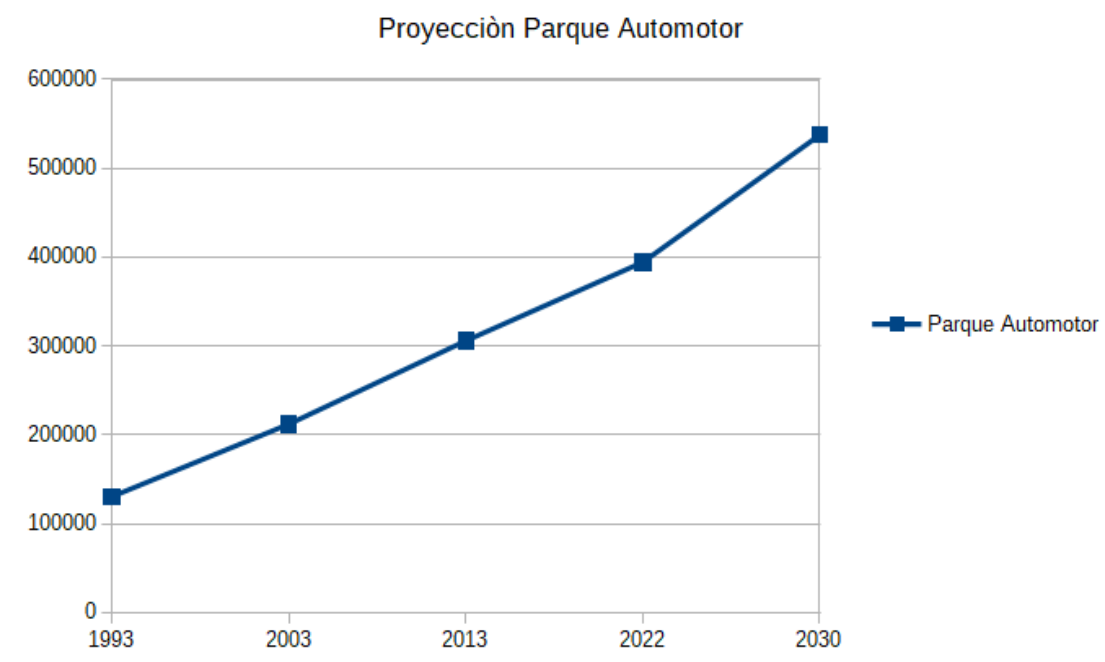

Gráfico 21. Proyección Tasa de Motorización 1993 - 2030. Fuente: Elaboración propia, en base a datos Asociación de Concesionarios de Automotores de la República Argentina.

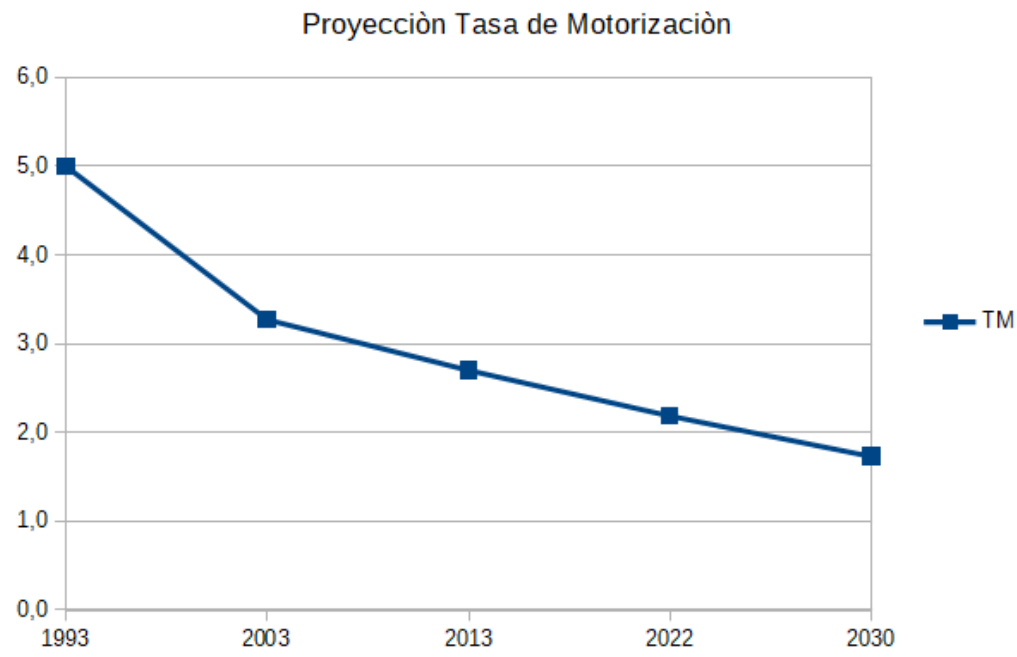

\footnotetext{
${ }^{74}$ Tasa de Motorización: cantidad de personas por auto.
} 
En cuanto a la tasa de generación de viaje, se puede observar un incremento importante en el periodo 1993 a 2003 que aumenta en diez años un punto, de 0,43 a 1,48, equivalente a la proyección desde el año 1999 hasta el año 2.030, de 1,06 a 2,04, donde el incremento de la tasa de generación de viaje es más gradual. Este índice expresa cambios culturales vinculados a los niveles de actividad cotidiana de las personas que requieren un mayor número de viajes diarios para poder realizarlos. Ver Gráfico 22.

Gráfico 22. Proyección Tasa de Generación de Viaje 1993 - 2030. Fuente: Elaboración propia, en base a datos Encuesta OD 1993, Aón, Moro, Ravella (2003) y Encuesta de Movilidad del Gran La Plata GII IIPAC FAU UNLP.

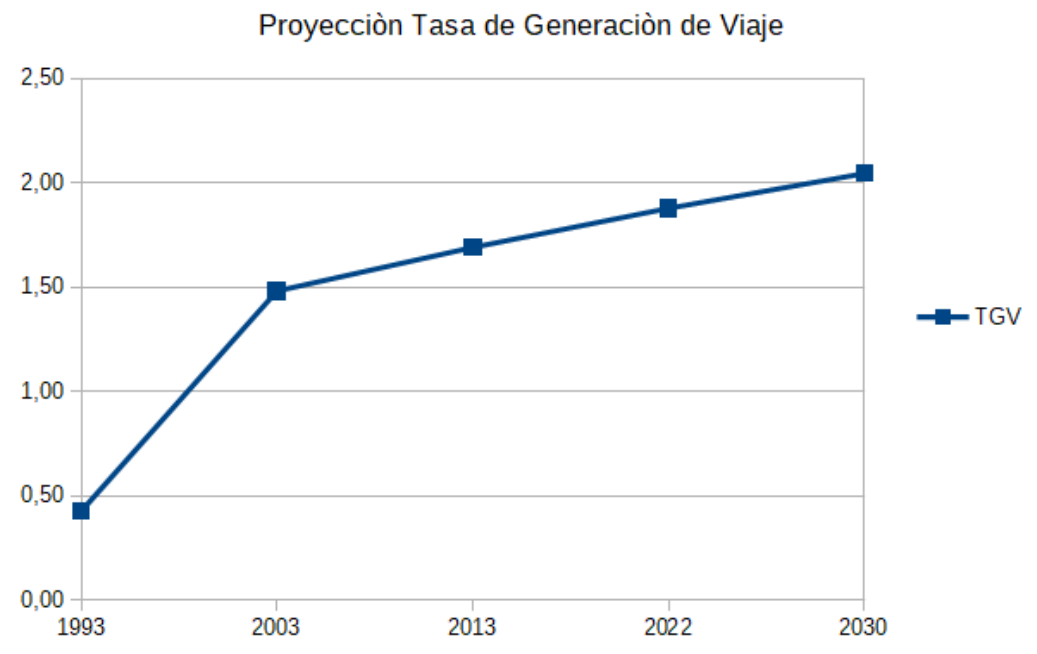

Es decir que para el año 2030 se podría proyectar una cantidad de viajes totales para el Gran La Plata de 1.900.908. Aplicando la misma partición modal de 2013, resulta un total de 808.456 de viajes no masivos, 650.301 masivos y 442.151 no motorizados. Estos resultados muestran un incremento del 35\% con respecto a los viajes de cada modo en 2013. Ver Tabla 36 .

Tabla 36. Reparto modal proyección al año 2030. Fuente: Elaboración propia, en base a Encuesta de Movilidad del Gran La Plata GII IIPAC FAU UNLP.

\begin{tabular}{|c|c|c|c|}
\hline \multicolumn{2}{|l|}{ REPARTO MODAL PROYECCION 2030 } & $\begin{array}{c}\text { Viajes } \\
\text { proyectados } \\
\mathbf{2 0 3 0}\end{array}$ & $\begin{array}{c}\text { Viajes } \\
\mathbf{2 0 1 3}\end{array}$ \\
\hline Autos & $\mathbf{3 3 , 0 5}$ & $\mathbf{6 2 8 2 5 0}$ & $\mathbf{4 6 2 0 7 3}$ \\
\hline Taxis & 3,00 & 57027 & 41940 \\
\hline Remisse & 1,61 & 30605 & 22466 \\
\hline Motos & 3,02 & 57407 & 42152 \\
\hline Otros & 1,86 & 35357 & 25998 \\
\hline Transporte Público & $\mathbf{2 9 , 0 8}$ & $\mathbf{5 5 2 7 8 4}$ & $\mathbf{4 0 6 4 7 3}$ \\
\hline Transporte Escolar & 3,08 & 58548 & 43038 \\
\hline Transporte Interurbano & 0,34 & 6463 & 4782 \\
\hline Tren & 1,71 & 32506 & 23910 \\
\hline Bicicleta & 6,11 & 116145 & 85418 \\
\hline A pie & $\mathbf{1 7 , 1 4}$ & $\mathbf{3 2 5 8 1 6}$ & $\mathbf{2 3 9 7 5 8}$ \\
\hline Total & $\mathbf{1 0 0}$ & $\mathbf{1 9 0 0 9 0 8}$ & $\mathbf{1 3 9 8 0 0 8}$ \\
\hline
\end{tabular}




\begin{tabular}{|c|l|l|l|}
\hline Masivo & 34,21 & 650301 & 478203 \\
\hline No masivo & 42,53 & 808456 & 594628 \\
\hline No motorizado & 23,26 & 442151 & 325177 \\
\hline
\end{tabular}

\begin{tabular}{|l|r|}
\hline Población proyectada & 929580 \\
\hline Tasa De Generación proyectada & 2,04 \\
\hline Población 2013 & 826246 \\
\hline Tasa De Generación 2013 & 1,69 \\
\hline
\end{tabular}

A nivel delegaciones con la proyección realizada, las que más viajes generan se mantiene similar al año 2013, con la misma partición modal. Las modificaciones con mayor impacto en el sistema de transporte son el incremento de la tasa de generación de viaje y el crecimiento poblacional. Ver Tabla 37 y Tabla 37.

Tabla 37. Viajes y por delegación, proyección 2030. Fuente: Elaboración propia, en base a Encuesta de Movilidad del Gran La Plata GII IIPAC FAU UNLP.

\begin{tabular}{|c|c|c|c|c|c|}
\hline DELEGACION & $\begin{array}{c}\text { Población } \\
2030\end{array}$ & Viajes & $\begin{array}{c}\text { Viajes } \\
\text { Colectivo }\end{array}$ & $\begin{array}{c}\text { Viajes } \\
\text { Auto }\end{array}$ & $\begin{array}{c}\text { Viajes } \\
\text { Pie/Bici }\end{array}$ \\
\hline CASCO & 211194 & 569219 & 209309 & 150601 & 193994 \\
\hline LOS HORNOS & 64125 & 134856 & 62003 & 51927 & 13176 \\
\hline VILLA ELVIRA & 67460 & 119040 & 55443 & 27722 & 19568 \\
\hline SAN CARLOS & 52672 & 96128 & 48382 & 26101 & 15915 \\
\hline TOLOSA & 49437 & 86639 & 38838 & 23900 & 10755 \\
\hline GONNET & 31072 & 80367 & 27790 & 40559 & 3755 \\
\hline $\begin{array}{c}\text { ALTOS SAN } \\
\text { LORENZO }\end{array}$ & 46437 & 71279 & 38165 & 14031 & 8419 \\
\hline CITY BELL & 35888 & 64629 & 18218 & 36001 & 6073 \\
\hline M. ROMERO & 64908 & 51777 & 29811 & 13336 & 2353 \\
\hline VILLA ELISA & 25396 & 38061 & 20872 & 6446 & 6139 \\
\hline RINGUELET & 10606 & 28201 & 11793 & 12562 & 3076 \\
\hline OLMOS & 21149 & 22750 & 10736 & 4601 & 3834 \\
\hline $\begin{array}{c}\text { ARTURO } \\
\text { SEGUI }\end{array}$ & 12214 & 19338 & 8710 & 10481 & 0 \\
\hline GORINA & 32084 & 27144 & 10858 & 16287 & 0 \\
\hline ABASTO & 19446 & 17157 & 9636 & 3760 & 1880 \\
\hline HERNANDEZ & 10224 & 10256 & 4696 & 3707 & 989 \\
\hline ARANA & 5480 & 9869 & 4371 & 5497 & 0 \\
\hline ETCHEVERRY & 4437 & 6435 & 1609 & 2413 & 804 \\
\hline EL PELIGRO & 2395 & 5239 & 1737 & 2605 & 0 \\
\hline
\end{tabular}


Tabla 38. Tasa de Generación de Viaje en Colectivo (TGVC), Tasa de Generación de Viaje en Auto (TGVA) y Tasa de Generación de Viaje (TGV) por delegación en 2013 y proyección 2030. Fuente: Elaboración propia, en base a Encuesta de Movilidad del Gran La Plata GII IIPAC FAU UNLP.

\begin{tabular}{|c|c|c|c|c|c|c|}
\hline \multirow{2}{*}{ DELEGACION } & \multicolumn{2}{|c|}{ TGVC } & \multicolumn{2}{c|}{ TGVA } & \multicolumn{2}{c|}{ TGV } \\
\cline { 2 - 7 } & 2030 & 2013 & 2030 & 2013 & 2030 & 2013 \\
\hline CASCO & 0,99 & 0,82 & 0,71 & 0,59 & 2,7 & 2,23 \\
\hline LOS HORNOS & 0,97 & 0,8 & 0,81 & 0,67 & 2,1 & 1,74 \\
\hline $\begin{array}{c}\text { VILLA } \\
\text { ELVIRA }\end{array}$ & 0,82 & 0,68 & 0,41 & 0,34 & 1,76 & 1,46 \\
\hline SAN CARLOS & 0,92 & 0,76 & 0,5 & 0,41 & 1,83 & 1,51 \\
\hline TOLOSA & 0,79 & 0,65 & 0,48 & 0,4 & 1,75 & 1,45 \\
\hline GONNET & 0,89 & 0,74 & 1,31 & 1,08 & 2,59 & 2,14 \\
\hline $\begin{array}{c}\text { ALTOS SAN } \\
\text { LORENZO }\end{array}$ & 0,82 & 0,68 & 0,3 & 0,25 & 1,53 & 1,27 \\
\hline CITY BELL & 0,51 & 0,42 & 1 & 0,83 & 1,8 & 1,49 \\
\hline M. ROMERO & 0,46 & 0,38 & 0,21 & 0,17 & 0,8 & 0,66 \\
\hline VILLA ELISA & 0,82 & 0,68 & 0,25 & 0,21 & 1,5 & 1,24 \\
\hline RINGUELET & 1,11 & 0,92 & 1,18 & 0,98 & 2,66 & 2,2 \\
\hline OLMOS & 0,51 & 0,42 & 0,22 & 0,18 & 1,08 & 0,89 \\
\hline ARTURO & 0,71 & 0,59 & 0,86 & 0,71 & 1,58 & 1,31 \\
\hline SEGUI & 0,34 & 0,28 & 0,51 & 0,42 & 0,85 & 0,7 \\
\hline GORINA & 0,5 & 0,41 & 0,19 & 0,16 & 0,88 & 0,73 \\
\hline ABASTO & 0,46 & 0,38 & 0,36 & 0,3 & 1 & 0,83 \\
\hline HERNANDEZ & 0,8 & 0,66 & 1 & 0,83 & 1,8 & 1,49 \\
\hline ARANA & 0,36 & 0,3 & 0,54 & 0,45 & 1,45 & 1,2 \\
\hline ETCHEVERRY & 0,73 & 0,6 & 1,09 & 0,9 & 2,19 & 1,81 \\
\hline EL PELIGRO & 0,73 & & & & \\
\hline
\end{tabular}

En el punto 3.3.1 se desarrolló la insuficiencia de la red de transporte público para el año 2013 evidenciando la saturación del sistema. Esto se debió principalmente al aumento de la población, de la Tasa de Generación de Viajes, y a una oferta sin modificaciones.

Las proyecciones de cantidad de pasajeros muestran un incremento de 108 pasajeros por coche por día en 2030 con respecto al 2.013 (493 en 2013 y 601 en 2030).Ver Tabla 39. Si se mantiene la misma atracción de pasajeros al Casco Urbano de 2.013, se podría prever una saturación de capacidad promedio de las unidades aun mayor que en 2013. Las normativas vigentes permiten que la cantidad de pasajeros que viajan parados sea el 50\% de la cantidad de asientos de los que dispone cada colectivo, el sistema de transporte de colectivos del Gran La Plata cuenta con unidades que en general poseen 27 asientos por coche, por lo cual se permitiría transportar 14 pasajeros parados dando un límite total de 41 pasajeros por coche. 
Como se ve en la Tabla 39 , el promedio de pasajeros en los coches con destino al Casco Urbano en 2013 es de 51, es decir 10 pasajeros más de los permitidos. Para cubrir esa diferencia debería incorporarse aproximadamente 120 nuevas unidades a las 672 que componen el sistema de transporte público de pasajeros del Gran La Plata, a un costo de $\$ 650.000^{75}$ por colectivo alcanzaría un total de $\$ 78.000 .000$. La proyección a 2030 plantea que la demanda de viajes al Casco Urbano será de 63 pasajeros promedio por coche para ese año, es decir 22 pasajeros más de lo permitido. En este caso la cantidad de unidades necesarias para cubrir esa demanda dentro de la normativa sería de 341 a un costo de $\$ 221.650 .000$.

Tabla 39. Pasajeros por coche 2013-2030. Fuente: Elaboración propia, en base a Encuesta de Movilidad del Gran La Plata GII IIPAC FAU UNLP.

\begin{tabular}{|c|c|c|c|c|c|c|c|c|}
\hline Año & $\begin{array}{c}\text { Cantidad } \\
\text { de Coches }\end{array}$ & Pax & $\begin{array}{c}\text { Pax por } \\
\text { coche }\end{array}$ & $\begin{array}{c}\text { Ser } \mathrm{x} \\
\text { coche }\end{array}$ & $\begin{array}{c}\text { Pax x } \\
\text { coche y } \\
\text { serv. }\end{array}$ & $\begin{array}{c}\text { Pax } \mathrm{x} \\
\text { coche y } \\
\text { serv. } \\
\text { Casco }\end{array}$ & $\begin{array}{c}\text { Coches a } \\
\text { incorporar } \\
\text { para } \\
\text { normativa }\end{array}$ & $\begin{array}{c}\text { Costo coches a } \\
\text { incorporar en } \\
\text { millones de } \$\end{array}$ \\
\hline 2013 & 672 & 315463 & 493 & 6 & 82 & 51 & 120 & 78 \\
\hline 2030 & 672 & 403668 & 601 & 6 & 100 & 63 & 341 & 221,65 \\
\hline
\end{tabular}

La incorporación de estas nuevas unidades también ayudaría a incrementar las frecuencias del sistema, reduciendo tiempos de espera, pero sin una propuesta más integral, podría incrementar la congestión en áreas centrales aumentando los tiempos de viaje.

En cuanto al tiempo de viaje, este se puede incrementar debido a varios factores. Entre ellos se pueden citar:

- Mala frecuencia del servicio, ya que implica extender el tiempo de espera cuando la ocupación de un servicio está completa y el pasajero en la parada tiene que esperar al próximo con menos pasajeros,

- Congestión vehicular

- Mayor tiempo en el ascenso a las unidades producto del incremento del número de pasajeros.

Para cuantificar el tiempo de viaje se calcularon los tiempos de recorrido de dos líneas municipales de La Plata para los años 2012 y 2015 y su proyección al año 2030. Las líneas son la Sur y 520 que en solo tres años tuvieron incrementos en el tiempo que tardan en realizar el recorrido de un promedio de 5,6\% anual. Ver Tabla 40 e Ilustración 60.

\footnotetext{
${ }^{75}$ Costo de colectivo nuevo en 2013. Fuente: La Nación, 04/08/2013. https://www.lanacion.com.ar/1607299colectivos-el-mejor-negocio-de-laargentina?fbclid=IwAR2EaciSeNrtURF545mKbHFU8axIL6I1NKqwY6TwOW9nla7z8JwQo_QTnjg.
} 
Tabla 40. Incremento de tiempo viaje líneas Sur y 520. Fuente: Elaboración propia, en base a datos aportados por la Dirección de Transporte del Municipio de La Plata.

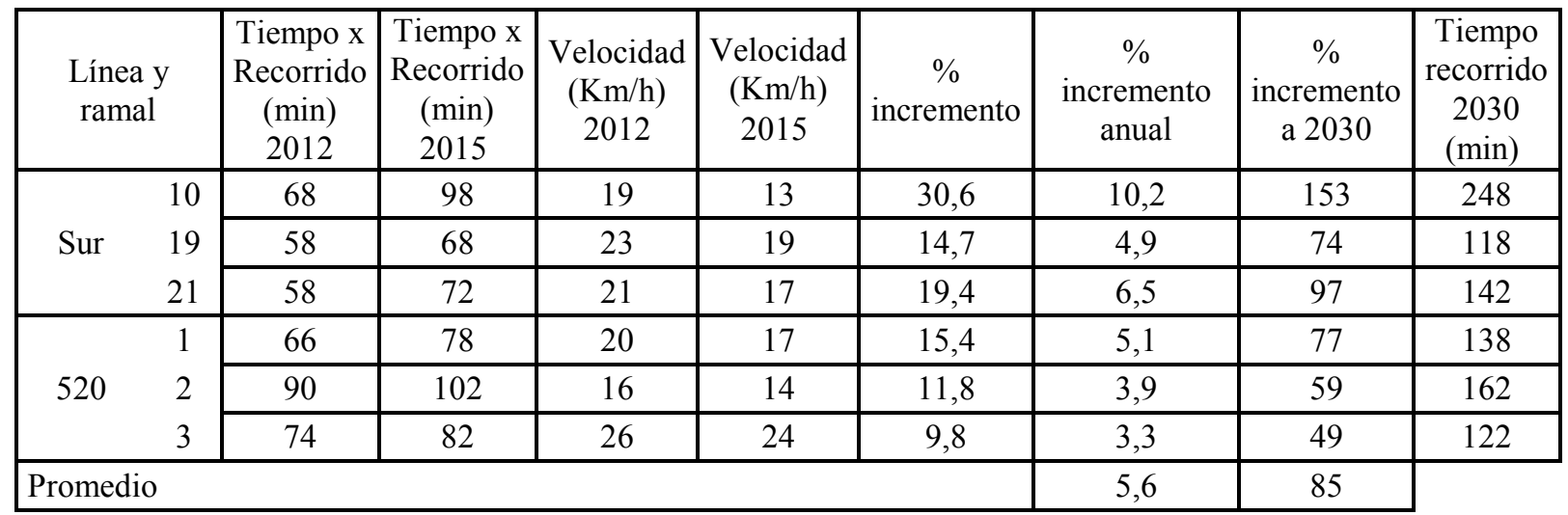

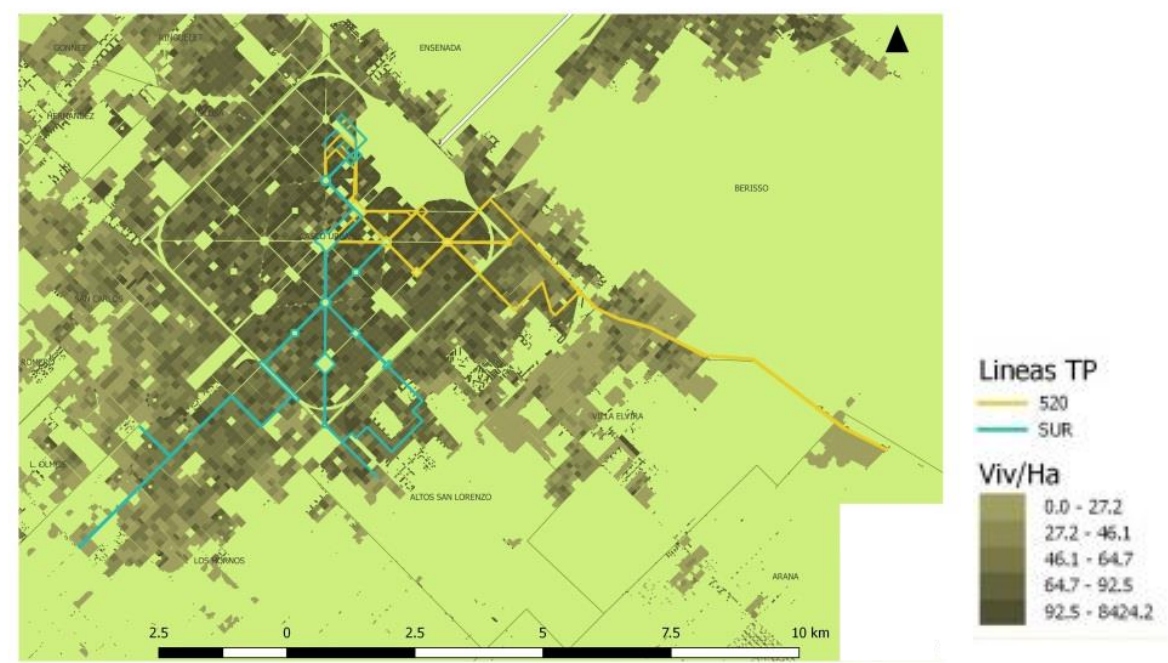

Ilustración 60. Recorridos de líneas Sur y 520. Fuente: Elaboración propia, en base a datos aportados por Dirección de Transporte del Municipio de La Plata.

En ese marco, las proyecciones al año 2030 plantean un incremento promedio del $85 \%$ del tiempo de recorrido. Por ejemplo el ramal 19 de la línea Sur que en 2.015 tenía un tiempo de recorrido de 68 minutos, en 2030 se proyecta que se amplíe a 118 minutos. Para poder mantener las frecuencias en ese ramal se deberían incrementar los servicios en un $74 \%$, es decir que de 87 servicios cubierto por un número aproximado de 14 coches, pasaría a 151 y la necesidad de sumar 11 coches más.

Para identificar qué situaciones incrementan el tiempo de viaje se realizó un análisis de la velocidad de tres ramales en horario pico de mediodía, el 273 BG, 273 D que recorren la zona y el ramal 14 de la línea Este. Las transformaciones en las velocidades se proyectaron a 2030. Ver Ilustración 61, Ilustración 62 y Tabla 41. 


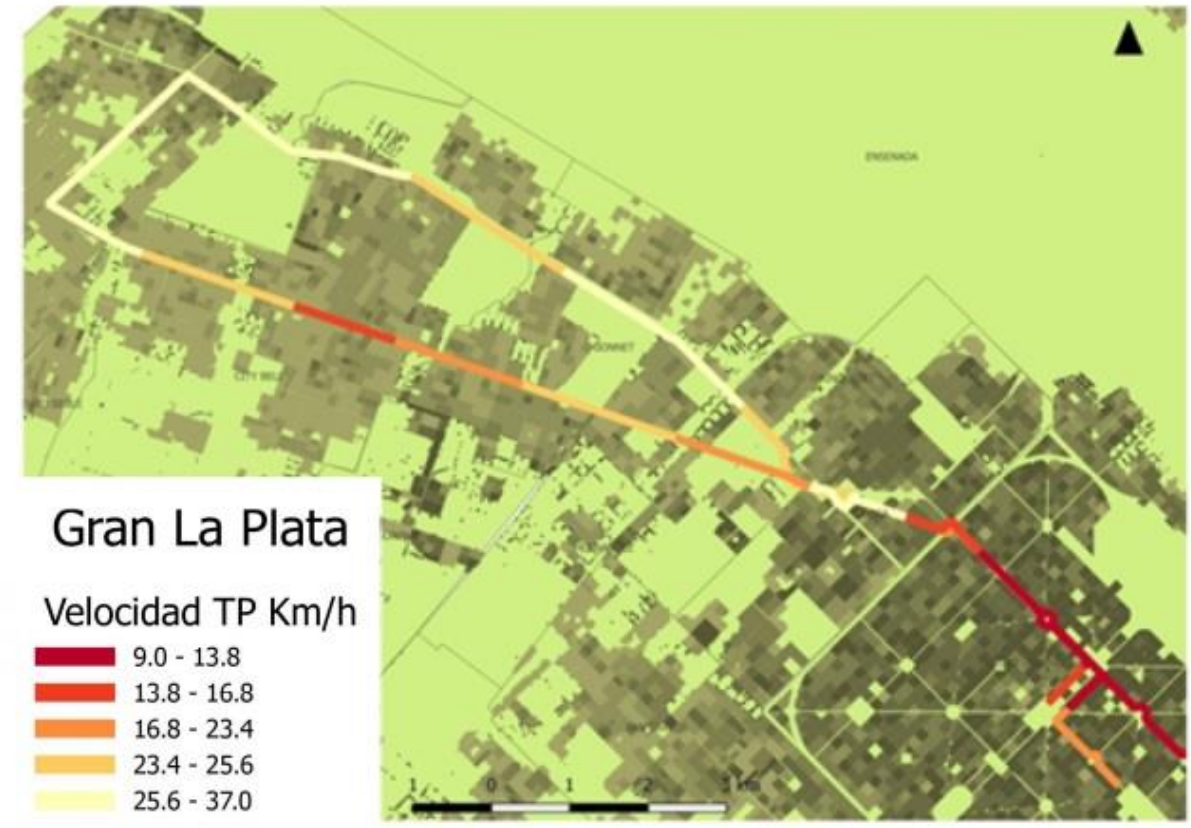

Ilustración 61. Velocidad del Transporte Público en corredores zona norte 2017. Fuente: Elaboración propia.

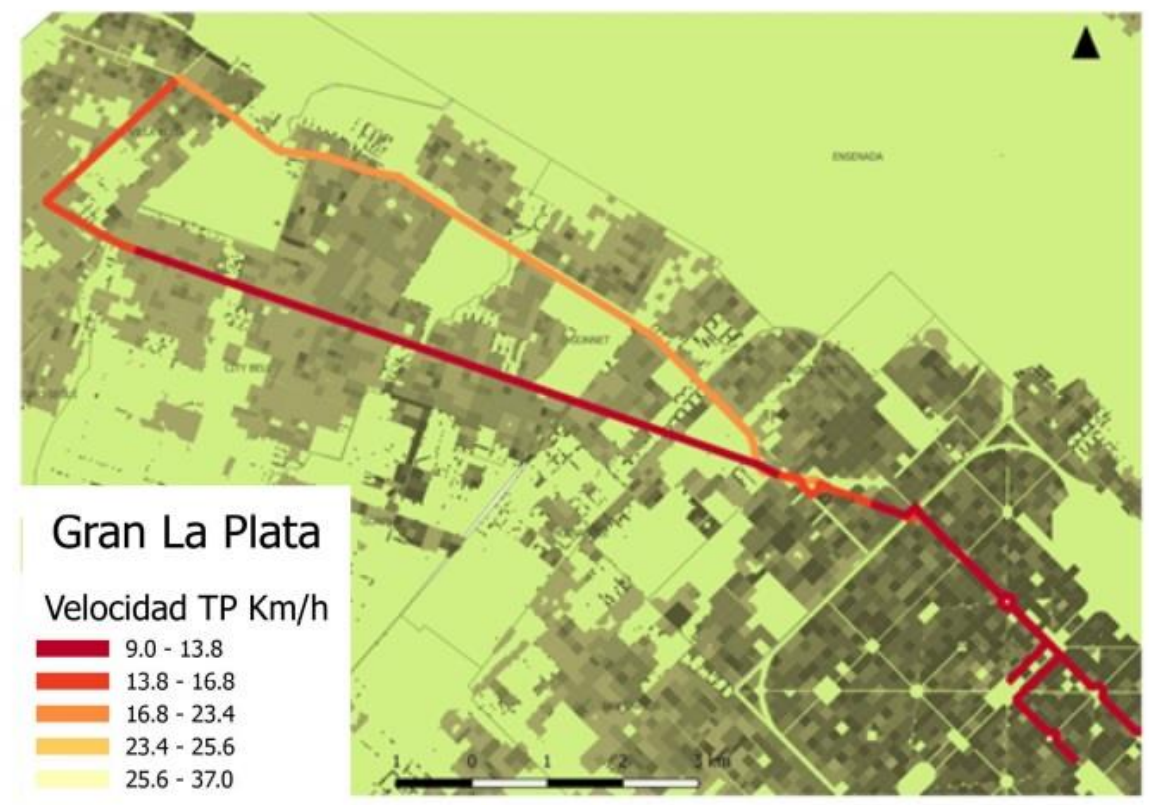

Ilustración 62. Velocidad de Transporte Público en corredores zona norte proyección 2030. Fuente: Elaboración propia. 
Tabla 41. Velocidad de desplazamiento, tiempo de espera y de viaje de los ramales 273 BG, 273 D para el año 2017 y 2030. Fuente: Elaboración propia.

\section{BG Belgrano}

\begin{tabular}{|l|c|c|c|}
\hline Noviembre & 27 & $\begin{array}{c}\text { Tiempo } \\
\text { de espera }\end{array}$ & 17 \\
\hline
\end{tabular}

\begin{tabular}{|c|c|c|c|c|c|c|c|}
\hline REGISTRO & $\begin{array}{c}\text { CALLE } \\
1\end{array}$ & $\begin{array}{c}\text { CALLE } \\
2\end{array}$ & Hora & $\begin{array}{c}\text { Metros } \\
\text { e/registro }\end{array}$ & $\begin{array}{c}\text { Tiempo } \\
\text { e/registro }\end{array}$ & $\begin{array}{c}\text { Velocidad } \\
\text { e/registro }\end{array}$ & $\begin{array}{c}\text { Velocidad } \\
\text { e/registro } \\
2030\end{array}$ \\
\hline 0 & 13 & 63 & $12: 32: 00$ & - & - & - & - \\
\hline 1 & 11 & 54 & $12: 37: 00$ & 1452,15 & 5 & 17,43 & 9,96 \\
\hline 2 & 7 & 51 & $12: 42: 00$ & 784,28 & 5 & 9,41 & 5,38 \\
\hline 3 & 7 & 43 & $12: 47: 00$ & 998,57 & 5 & 11,98 & 6,85 \\
\hline 4 & 7 & 35 & $12: 52: 00$ & 1118,87 & 5 & 13,43 & 7,67 \\
\hline 5 & Belgrano & 528 & $12: 57: 00$ & 1254,79 & 5 & 15,06 & 8,61 \\
\hline 6 & 13 & 520 & $13: 02: 00$ & 2613,54 & 5 & 31,36 & 17,92 \\
\hline 7 & Belgrano & 508 & $13: 07: 00$ & 1948,06 & 5 & 23,38 & 13,36 \\
\hline 8 & Belgrano & 491 & $13: 12: 00$ & 2063,52 & 5 & 24,76 & 14,15 \\
\hline 9 & Belgrano & 476 & $13: 17: 00$ & 1726,12 & 5 & 20,71 & 11,83 \\
\hline 10 & Belgrano & 462 & $13: 22: 00$ & 1374,44 & 5 & 16,49 & 9,42 \\
\hline 11 & Belgrano & 444 & $13: 27: 00$ & 2045,95 & 5 & 24,55 & 14,03 \\
\hline 12 & 419 & 15 & $13: 32: 00$ & 2614,73 & 5 & 31,38 & 17,93 \\
\hline TOTAL & & & & 19995,02 & 60 & 20 & 11,43 \\
\hline
\end{tabular}

\section{D- Centenario}

\begin{tabular}{|c|c|c|c|}
\hline Noviembre & 27 & $\begin{array}{c}\text { Tiempo de } \\
\text { espera }\end{array}$ & 2 \\
\hline
\end{tabular}

\begin{tabular}{|c|c|c|c|c|c|c|c|}
\hline REGISTRO & CALLE 1 & CALLE 2 & Hora & $\begin{array}{l}\text { Metros } \\
\text { e/registro }\end{array}$ & $\begin{array}{c}\text { Tiempo } \\
\text { e/registro }\end{array}$ & $\begin{array}{l}\text { Velocidad } \\
\text { e/registro }\end{array}$ & $\begin{array}{c}\text { Velocidad } \\
\text { e/registro } \\
2030 \\
\end{array}$ \\
\hline 0 & 419 & Centenario & 13:40:00 & - & - & - & - \\
\hline 1 & Centenario & 466 & $13: 45: 00$ & 3052,94 & 5 & 36,64 & 20,94 \\
\hline 2 & Centenario & 492 & 13:50:00 & 2288,8 & 5 & 27,47 & 15,70 \\
\hline 3 & Centenario & 510 & $13: 55: 00$ & 2724,2 & 5 & 32,69 & 18,68 \\
\hline 4 & Belgrano & 526 & 14:00:00 & 2423,23 & 5 & 29,08 & 16,62 \\
\hline 5 & 7 & 36 & 14:05:00 & 1616,37 & 5 & 19,4 & 11,09 \\
\hline 6 & 7 & 45 & $14: 10: 00$ & 1366,84 & 5 & 16,4 & 9,37 \\
\hline 7 & 8 & 51 & $14: 15: 00$ & 767,24 & 5 & 9,21 & 5,26 \\
\hline 8 & 12 & 51 & $14: 18: 00$ & 560,18 & 3 & 11,2 & 6,40 \\
\hline TOTAL & & & & 14799,8 & 38 & 23,37 & 13,35 \\
\hline
\end{tabular}


Para el caso de los ramales que circulan por los corredores Norte se pueden distinguir diferencias de velocidades del transporte público entre los que circulan por el Camino Belgrano y los que circulan por el Centenario. El ramal 273 BG en el Camino Belgrano posee una velocidad promedio menor en todo el recorrido al ramal $273 \mathrm{D}$ en el Centenario y se pueden observar en el primero cambios más bruscos de velocidad cuando atraviesa zonas de mayor densidad poblacional, como por ejemplo City Bell y el límite con Gonnet que pasa de $20,7 \mathrm{~km} / \mathrm{h}$ a $16,4 \mathrm{~km} / \mathrm{h}$ y aumenta hasta $24,5 \mathrm{~km} / \mathrm{h}$, mientras que en el Centenario la velocidad es constante y mayor a $\operatorname{los} 27 \mathrm{~km} / \mathrm{h}$. Los dos ramales dentro del Casco Urbano reducen su velocidad al entrar a $16 \mathrm{~km} / \mathrm{h}$ y se reduce aún más, alrededor de $9 \mathrm{~km} / \mathrm{h}$, al acercarse a la zona más céntrica.

El ramal 14 de la línea Este también reduce su velocidad a $9 \mathrm{~km} / \mathrm{h}$ al llegar a la zona céntrica del Casco Urbano y va aumentando progresivamente hacia la periferia, alcanzando la velocidad de $37 \mathrm{~km} / \mathrm{h}$. Ver Ilustración 63, Ilustración 64 y Tabla 42

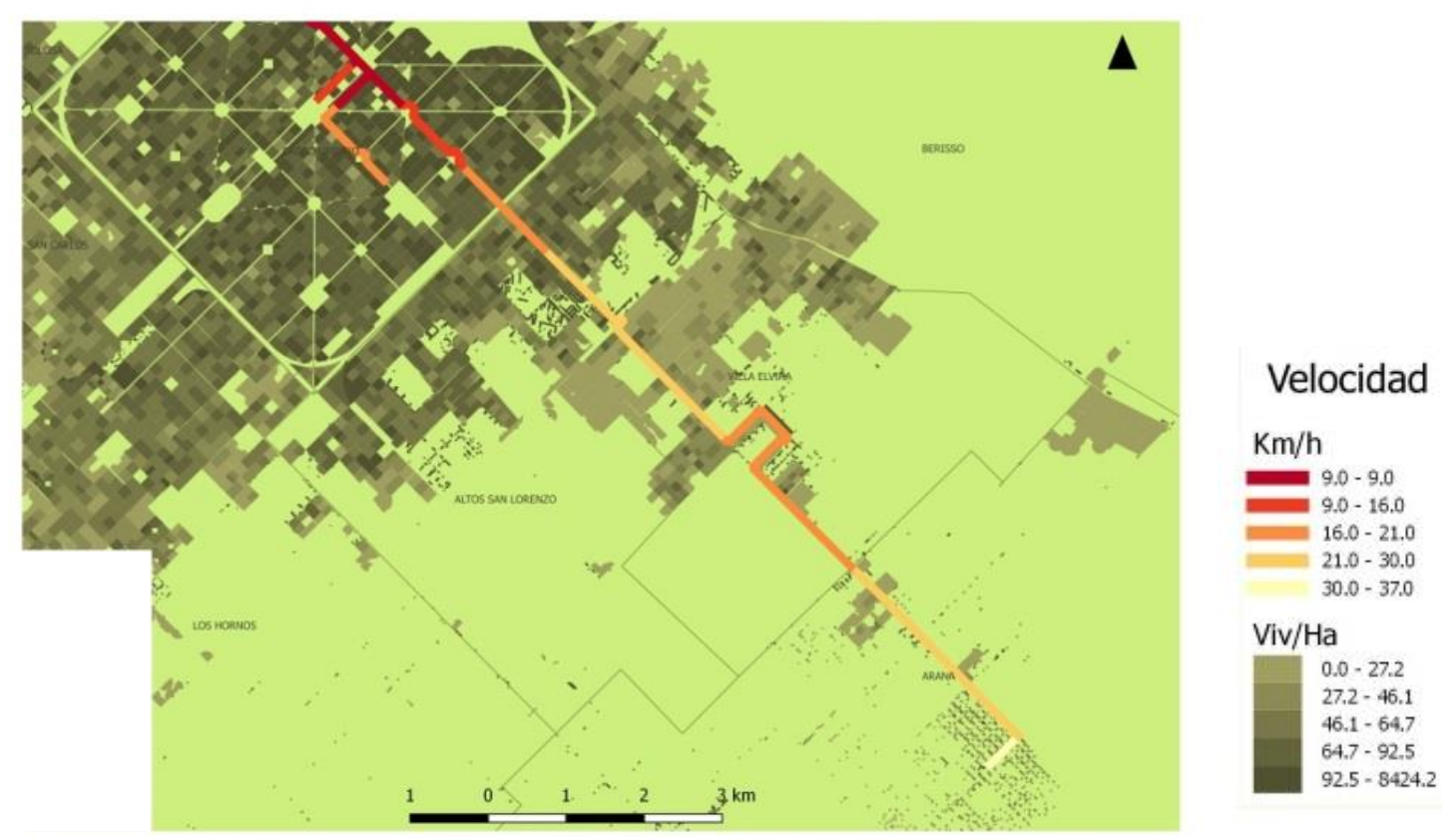

Ilustración 63. Velocidad ramal Este 14 por tramo de 5 minutos en 2017. Fuente: Elaboración propia. 


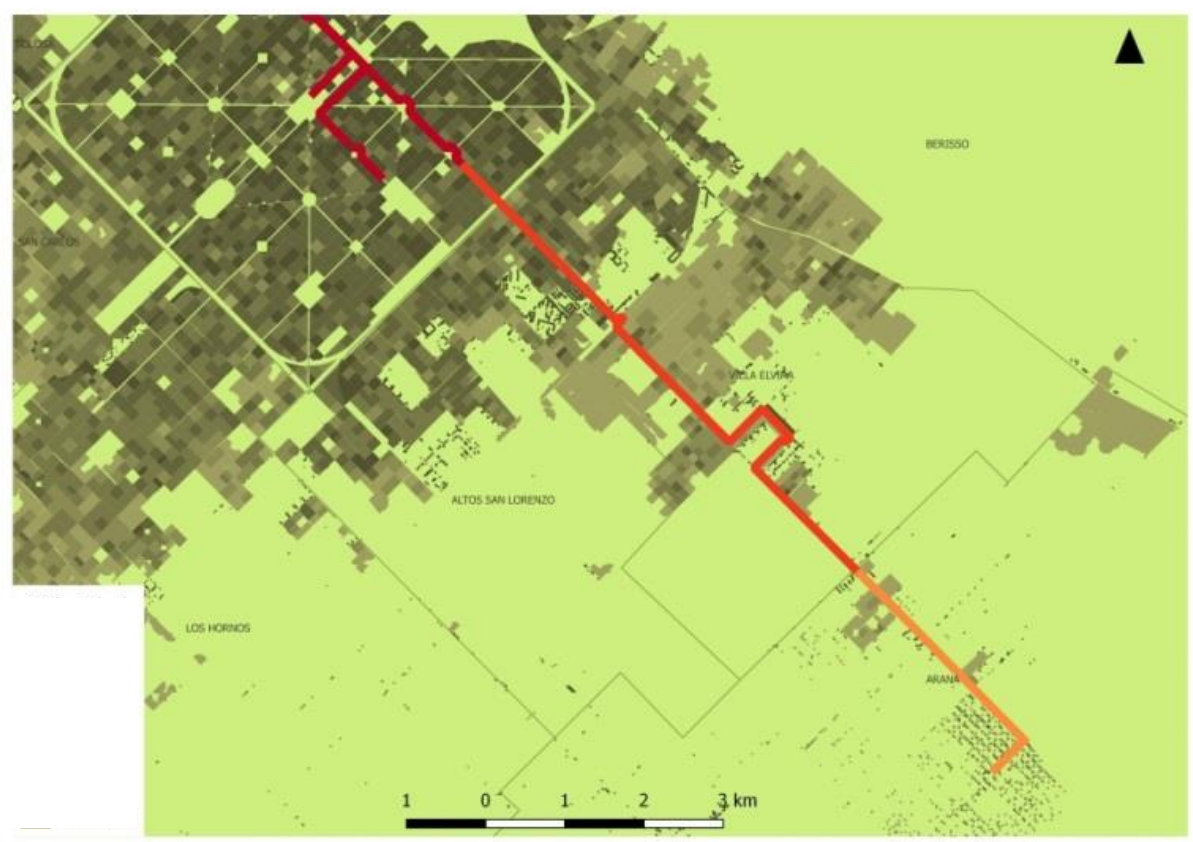

\section{Velocidad}

$\mathrm{Km} / \mathrm{h}$

$4.0-9.0$
$9.0-16,0$

$16.0-21.0$

$\mathrm{Viv} / \mathrm{Ha}$

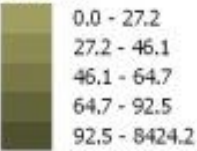

Ilustración 64. Velocidad ramal Este 14 por tramo de 5 minutos proyección a 2030. Fuente: Elaboración propia.

Tabla 42. Velocidad de desplazamiento, tiempo de espera y de viaje de los ramales Este 14 para el año 2017 y 2030. Fuente: Elaboración propia.

\begin{tabular}{|c|c|c|c|c|c|c|c|}
\hline \multicolumn{8}{|c|}{ Este 14} \\
\hline Diciembre & 11 & $\begin{array}{c}\text { Tiempo } \\
\text { de espera }\end{array}$ & 5 & & & & \\
\hline REGISTRO & $\begin{array}{c}\text { CALLE } \\
1\end{array}$ & $\begin{array}{c}\text { CALLE } \\
2\end{array}$ & Hora & $\begin{array}{l}\text { Metros } \\
\text { e/registro }\end{array}$ & $\begin{array}{l}\text { Tiempo } \\
\text { e/registro }\end{array}$ & $\begin{array}{l}\text { Velocidad } \\
\text { e/registro }\end{array}$ & $\begin{array}{c}\text { Velocidad } \\
\text { e/registro } \\
2030 \\
\end{array}$ \\
\hline 0 & 12 & 659 & $12: 13: 00$ & - & - & - & - \\
\hline 1 & 7 & 635 & $12: 18: 00$ & 3101,9 & 5 & 37,22 & 21,27 \\
\hline 2 & 6 & 613 & $12: 23: 00$ & 2486,91 & 5 & 29,84 & 17,05 \\
\hline 3 & 7 & 608 & $12: 28: 00$ & 1770,98 & 5 & 21,25 & 12,14 \\
\hline 4 & 7 & 95 & $12: 33: 00$ & 1989,28 & 5 & 23,87 & 13,64 \\
\hline 5 & 7 & 78 bis & $12: 38: 00$ & 2075,97 & 5 & 24,91 & 14,23 \\
\hline 6 & 7 & 67 & $12: 43: 00$ & 1516,58 & 5 & 18,2 & 10,40 \\
\hline 7 & 7 & 59 & $12: 48: 00$ & 1316,29 & 5 & 15,8 & 9,03 \\
\hline 8 & 7 & 53 & $12: 52: 00$ & 614,82 & 4 & 9,22 & 5,27 \\
\hline TOTAL & & & & 14872,73 & 39 & 22,88 & 13,07 \\
\hline
\end{tabular}


Tanto en el corredor Norte como en el Este, en la mayor parte del recorrido las velocidades del transporte público superan los $20 \mathrm{~km} / \mathrm{h}$. En algunos tramos de menor densidad poblacional, con grandes vacíos urbanos o infraestructuras rápidas, como el distribuidor de zona Norte, las velocidades pueden ser mayores a los $30 \mathrm{~km} / \mathrm{h}$. En ese marco la proyección a 2030 indica que la reducción de la velocidad va a ser entre el 55\% y el $60 \%$ con respecto a 2017 , con un incremento del tiempo de viaje del $75 \%$.

Esta situación sumada a la saturación en la ocupación de las unidades del sistema de transporte en la actualidad, produce un incremento de los tiempos de viaje en transporte público también del 75\%. Por ejemplo un viaje desde el final del recorrido Este 14 en Arana hasta el centro del Casco Urbano, un día de semana en hora pico del medio día en 2017, se tarda aproximadamente 39 minutos. La proyección al año 2030 plantea un tiempo de viaje de 68 minutos, es decir, casi el doble.

Si generalizamos la proyección del incremento del tiempo de traslado al resto del Gran La Plata se observa que delegaciones como Gonnet, Ringuelet, Tolosa, Altos de San Lorenzo o Villa Elvira, que en el año 2013 tenían un tiempo de viaje al área central del Casco Urbano que oscilaba entre los 25 a 35 minutos, en 2030 esos valores ascenderían entre 50 a 70 minutos, es decir un tiempo similar al que una persona residente de El Peligro tardaba en llegar al Casco Urbano en 2013. Ver Ilustración 65 e Ilustración 66.

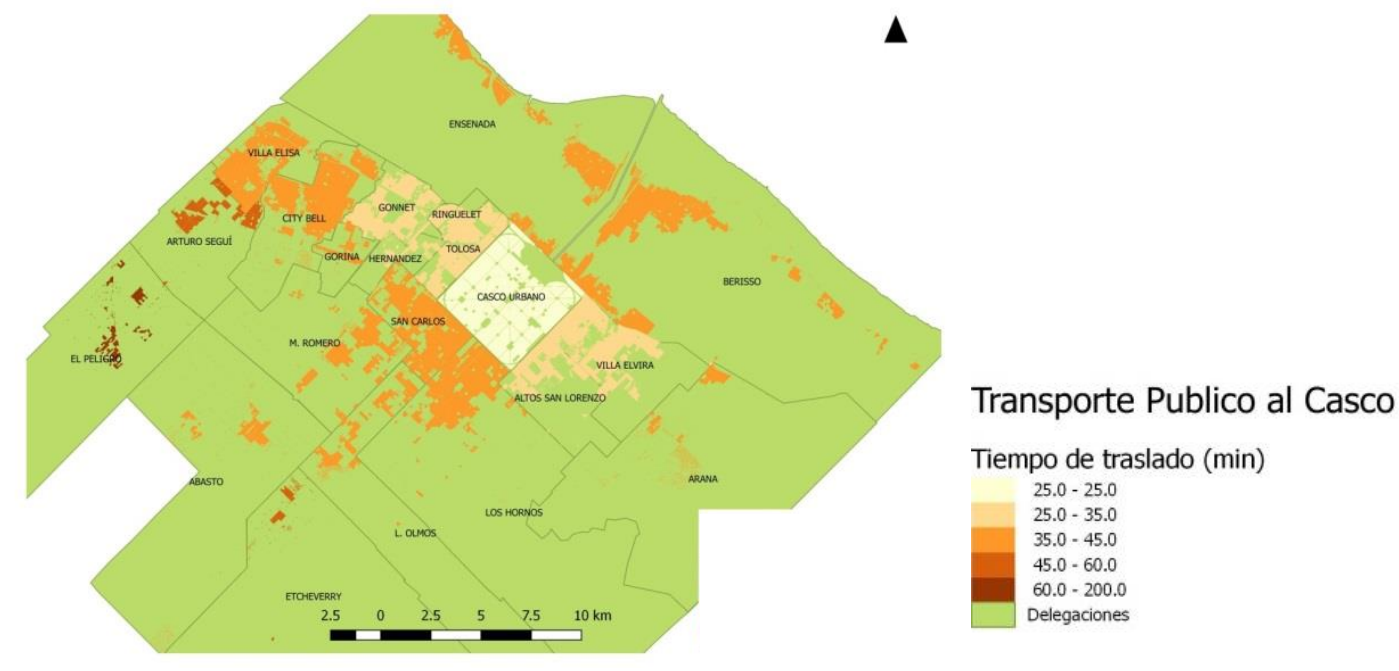

Ilustración 65. Tiempo de traslado en Transporte Público por delegación en 2013. Fuente: Elaboración propia. 


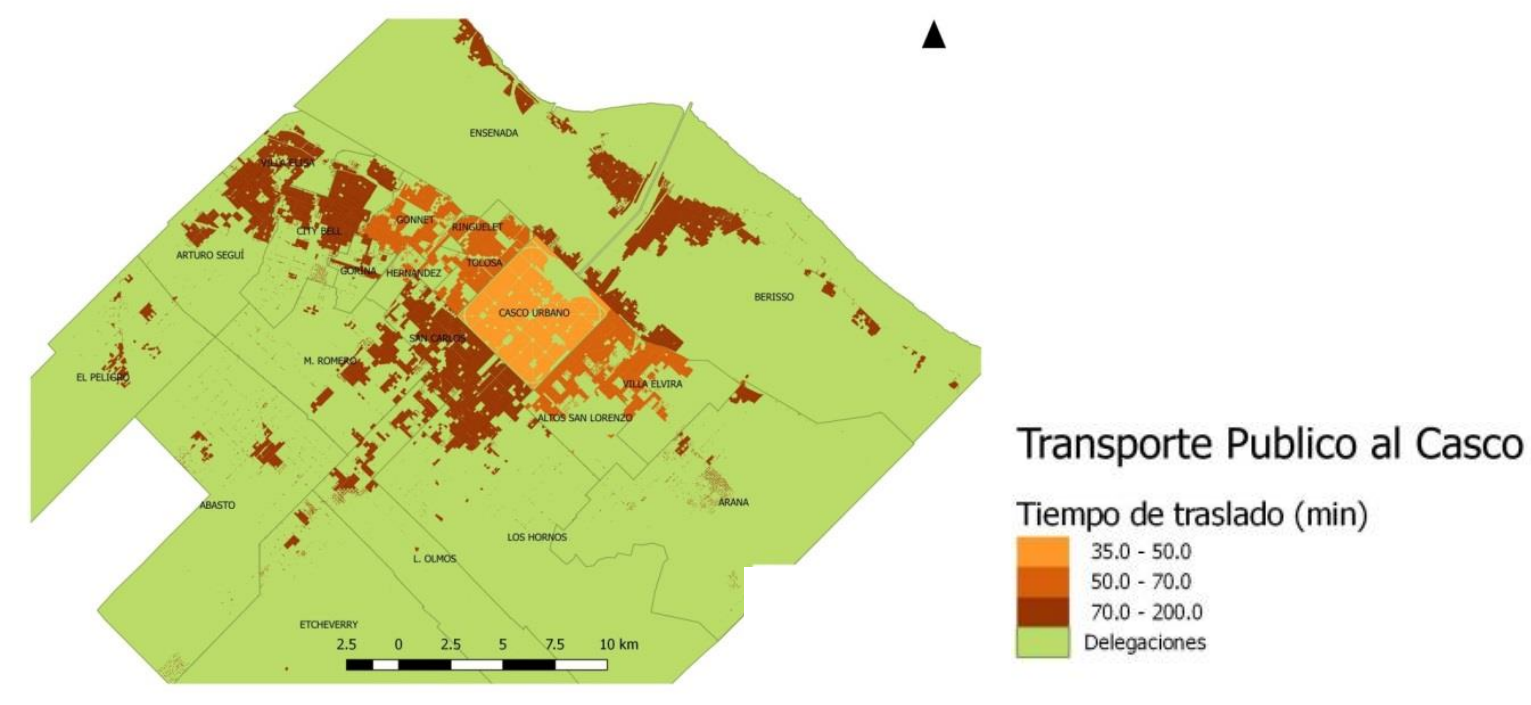

Ilustración 66. Tiempo de traslado en Transporte Público por delegación proyección 2030. Fuente: Elaboración propia.

En cuanto al tiempo de viaje de las zonas cubiertas por transporte público, las proyecciones muestran que áreas que tenían frecuencias entre 8 a 45 minutos en 2013, en el año 2030 pasarán a tener entre 45 y 65 minutos de frecuencia. Así mismo zonas cubiertas con frecuencias de 45 a 65 minutos, según las proyecciones pasaran de 65 a 185 minutos, lo que significaría un tiempo de viaje en transporte público entre 85 a 200 minutos. Por otro lado, las zonas cubiertas con frecuencias entre 8 a 12 minutos en 2013, de no incorporarse unidades, pasaran en 2030 a frecuencias entre 12 y 45 minutos. Ver Ilustración 67 e Ilustración 68.

Estos incrementos de los tiempos de viaje del orden del $75 \%$ plantean un escenario a 2030 muy crítico con respecto a la accesibilidad de la población a servicios urbanos esenciales como son salud y educación, dificultando la igualdad de posibilidades entre los habitantes de las distintas delegaciones del Gran La Plata, sobre todo de los sectores más vulnerables económicamente. 


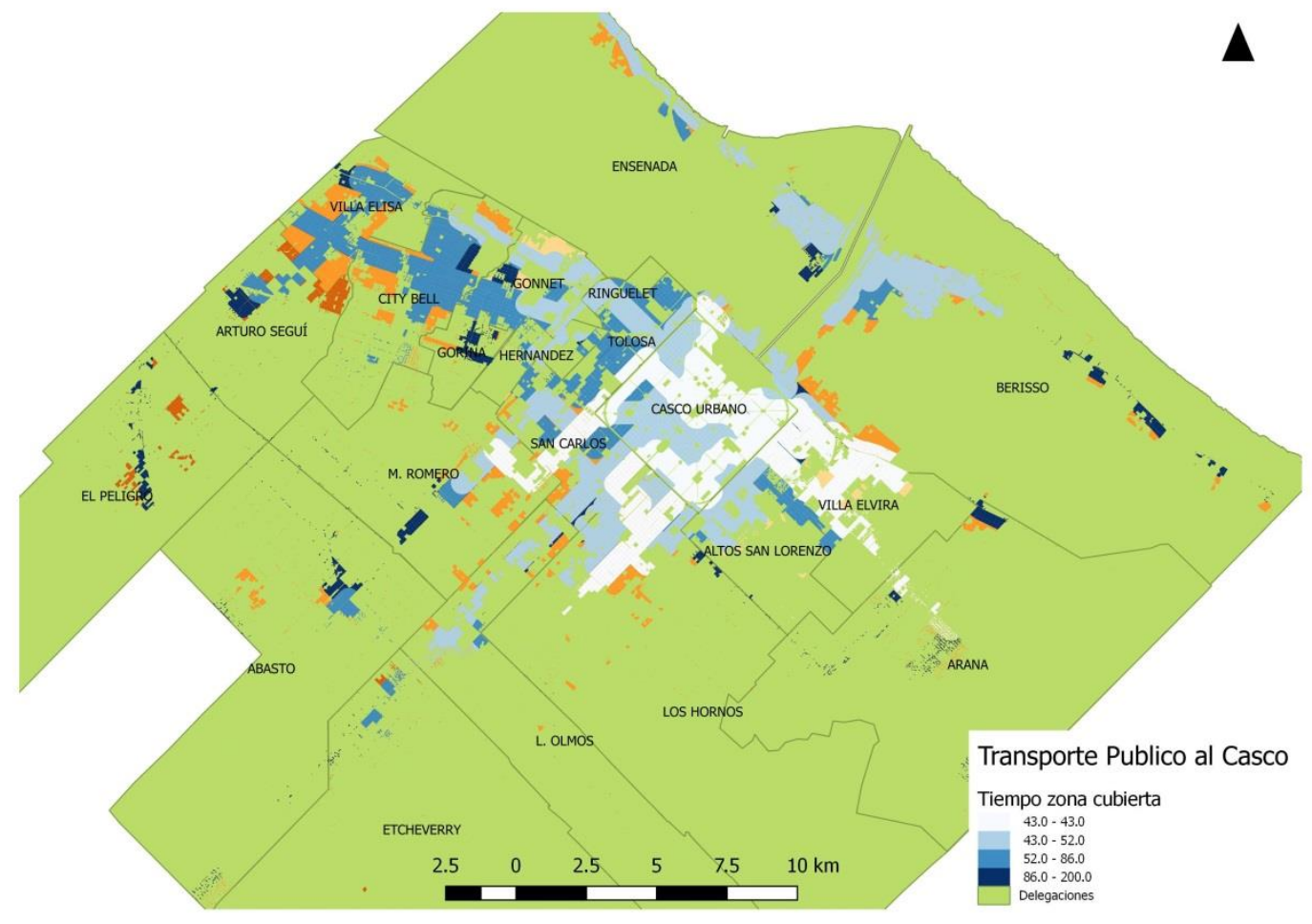

Ilustración 67. Tiempo de viaje en Transporte Público según frecuencias y tiempo de traslado de zonas cubiertas en 2013. Fuente: Elaboración propia.

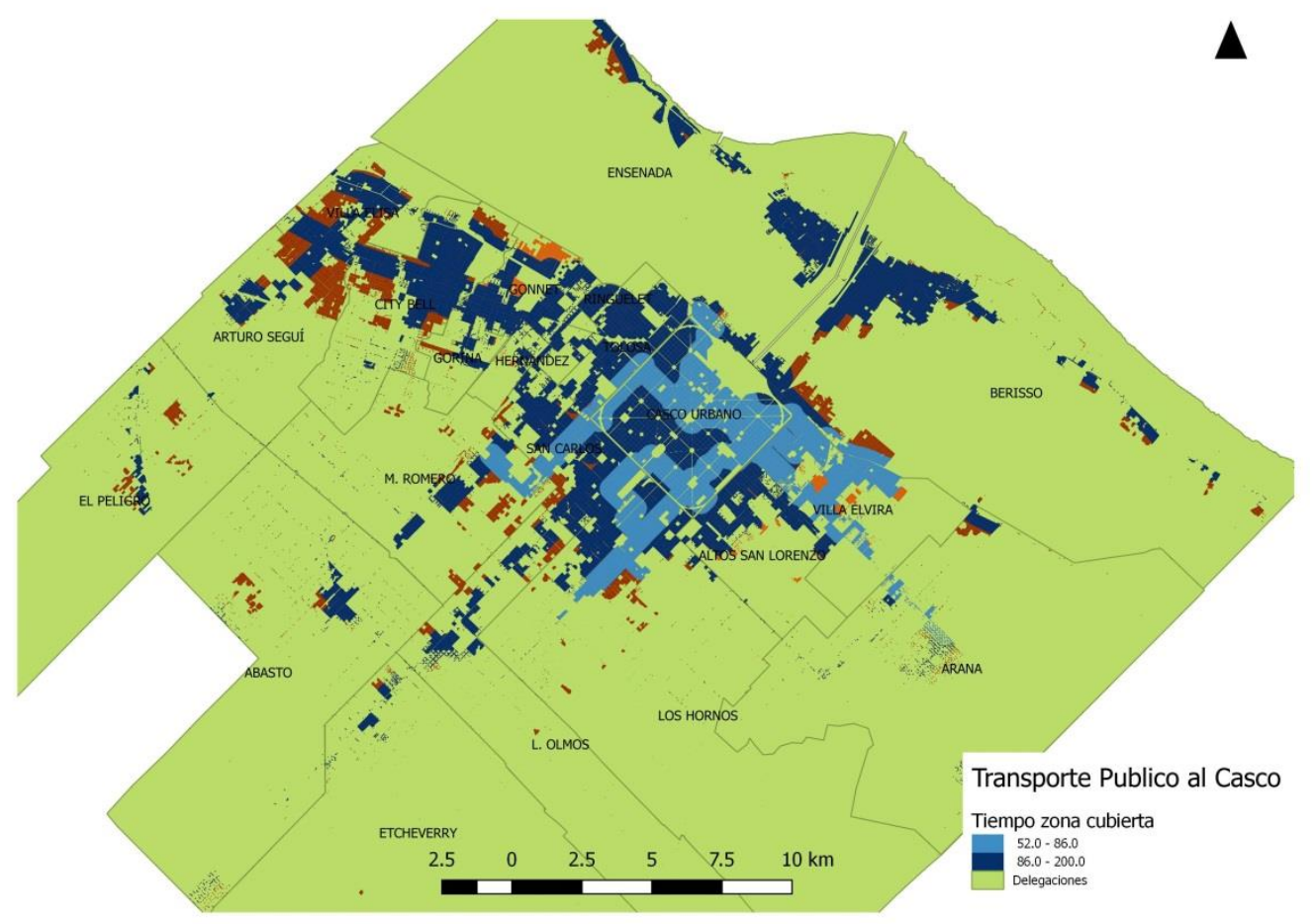

Ilustración 68. Tiempo de viaje en Transporte Público según frecuencias y tiempo de traslado de zonas cubiertas proyección 2030. Fuente: Elaboración propia. 


\subsubsection{Dimensión social}

En la dimensión social se analizan las características socioeconómicas de la población cubierta y no cubierta por redes de transporte público, sobre todo de los sectores más vulnerables, a partir del indicador de NBI, construido en base a datos censales del año 2010 a la proyección poblacional para el año 2.030. Es decir se estima la población con NBI en 2030 aplicando los mismos porcentajes de NBI del censo 2010 a la población por delegación proyectada por el INDEC a 2030.

Los resultados obtenidos muestran un aumento de la población con NBI no cubierta por transporte público, destacándose por sus altos valores el partido de Berisso las delegaciones de Altos de San Lorenzo, Abasto, Melchor Romero y el partido de Ensenada. Ver Gráfico 23 ;Error! No se encuentra el origen de la referencia.,

Tabla 43 e Ilustración 69.

Gráfico 23. Población con NBI por delegación no cubierta por el transporte público, proyección 2030. Fuente: Elaboración propia, en base a datos de INDEC.

\begin{tabular}{|r|r|r|}
\hline Villa Elisa & \\
Ringuelet \\
Etcheverry \\
El Peligro \\
Hernandez \\
Gonnet \\
Arana \\
Villa Elvira \\
Tolosa \\
Olmos
\end{tabular}


Tabla 43. Población con NBI por delegación no cubierta por el transporte público, proyección 2030. Fuente: Elaboración propia, en base a datos de INDEC.

\begin{tabular}{|c|c|c|c|c|}
\hline Delegación & $\begin{array}{c}\text { Población } \\
\mathbf{2 0 3 0}\end{array}$ & $\begin{array}{c}\text { Población } \\
\text { no } \\
\text { cubierta } \\
\text { por TP }\end{array}$ & $\begin{array}{c}\text { \% } \\
\text { Población } \\
\text { con NBI }\end{array}$ & $\begin{array}{c}\text { Población } \\
\text { no } \\
\text { cubierta } \\
\text { con NBI }\end{array}$ \\
\hline Berisso & 95354 & 11483 & 25 & 2871 \\
\hline $\begin{array}{c}\text { Altos de San } \\
\text { Lorenzo }\end{array}$ & 46437 & 6963 & 36 & 2507 \\
\hline Abasto & 19446 & 3481 & 53 & 1845 \\
\hline $\begin{array}{c}\text { Melchor } \\
\text { Romero }\end{array}$ & 64908 & 12955 & 14 & 1814 \\
\hline Ensenada & 65886 & 8285 & 20 & 1657 \\
\hline Casco Urbano & 211194 & 6057 & 25 & 1514 \\
\hline Los Hornos & 64125 & 9036 & 15 & 1355 \\
\hline San Carlos & 52672 & 8684 & 8 & 695 \\
\hline Arturo Segui & 12214 & 2378 & 28 & 666 \\
\hline City Bell & 35888 & 2555 & 23 & 588 \\
\hline Gorina & 32084 & 3029 & 16 & 485 \\
\hline Olmos & 21149 & 3346 & 12 & 401 \\
\hline Tolosa & 49437 & 4461 & 8 & 357 \\
\hline Villa Elvira & 67460 & 9571 & 3 & 287 \\
\hline Arana & 5480 & 970 & 29 & 281 \\
\hline Gonnet & 31072 & 1418 & 17 & 241 \\
\hline Hernandez & 10224 & 1243 & 16 & 199 \\
\hline El Peligro & 2395 & 798 & 22 & 175 \\
\hline Etcheverry & 4437 & 793 & 19 & 151 \\
\hline Ringuelet & 10606 & 1300 & 10 & 130 \\
\hline Villa Elisa & 25396 & 1799 & 5 & 90 \\
\hline
\end{tabular}

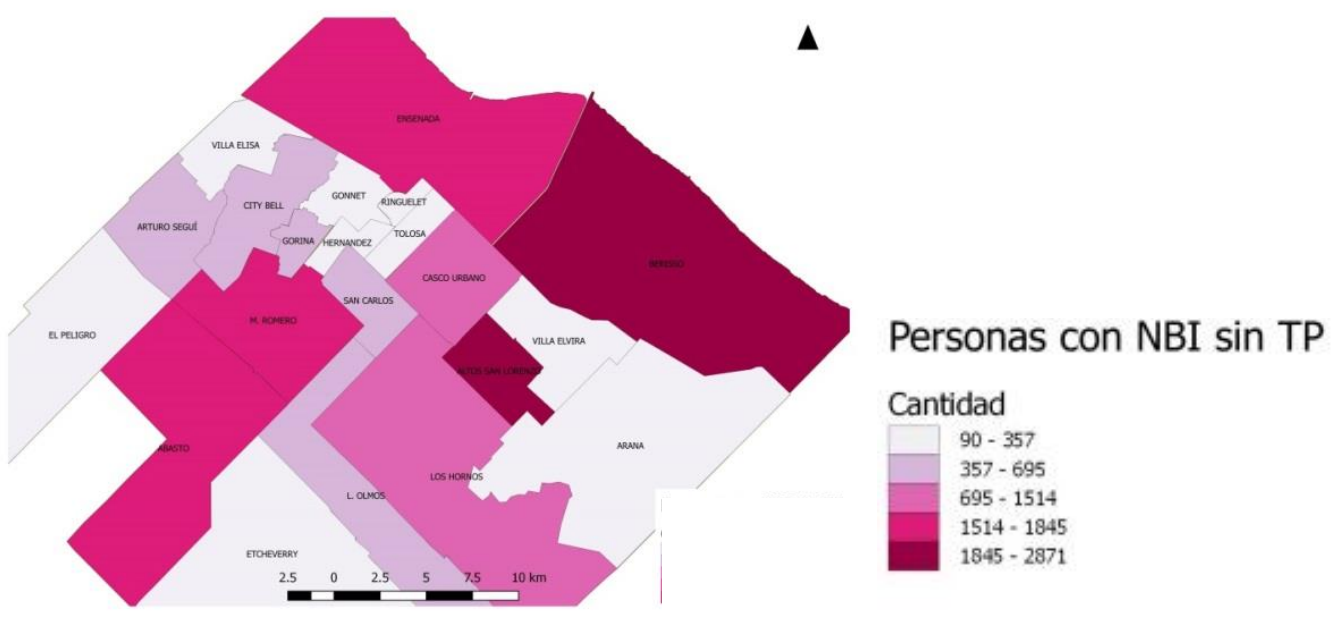

Ilustración 69. Cantidad de personas no cubiertas por TP con NBI. Fuente: Elaboración propia, en base a datos de INDEC. 
Analizando la variable tiempo de viaje, se puede observar que en las delegaciones con mayor cantidad de personas sin cobertura de transporte público y con NBI se proyectan tiempos de viaje mayores a los 86 y hasta los 192 minutos para acceder al Casco Urbano, mientras que en 2013 estaban previstos entre los 45 a 86 minutos. Es decir que los sectores socioeconómicos más vulnerables, se ven perjudicados en el acceso al casco por los mayores tiempos de viajes que se registran actualmente y por los que se proyectan al año 2030.

\subsubsection{Dimensión Económica}

\section{Costos de la expansión urbana a 2030}

En este punto se analizan los costos de traslados globales para el Gran La Plata y detallados por delegación utilizando los precios de combustibles, tarifas de transporte público de 2013 y tasa de generación de viaje proyectada al año 2030.

Según aproximaciones realizadas para el año $2013^{76}$ para el Gran La Plata se estimó un gasto total por usuario de colectivo y auto de \$2.614.913,9 por día. Teniendo en cuenta una partición modal del $20,5 \%$ en colectivo y $79,5 \%$ en auto, equivale a un promedio de $\$ 1,6$ por viaje en transporte público y un promedio de $\$ 8,2$ por viaje en automóvil particular.

A nivel de delegaciones, la distancia al casco y la cantidad de viajes en auto son las variables fundamentales para la conformación de dicho costo de traslado, ya que en 14 de las 19 delegaciones la producción de viajes al Casco Urbano supera al 50\%. En ese marco, los habitantes de las delegaciones más alejadas del centro son las que más gastan en movilizarse, como El Peligro que el viaje puede alcanzar los \$41,5 o Arturo Segui, Abasto, Villa Elisa y Etcheverry entre $\$ 18,4$ a $\$ 26,8$. En transporte público el costo del viaje al Casco Urbano es más parejo, en la mayoría el costo del boleto en 2013 era \$1,6, salvo en el Casco que era de \$1,5 y desde El Peligro que era de \$1,7. Ver Ilustración 70 e Ilustración 71 .

\footnotetext{
${ }^{76}$ Punto 3.3.1.ii. Movilidad y transporte público. Página 132.
} 


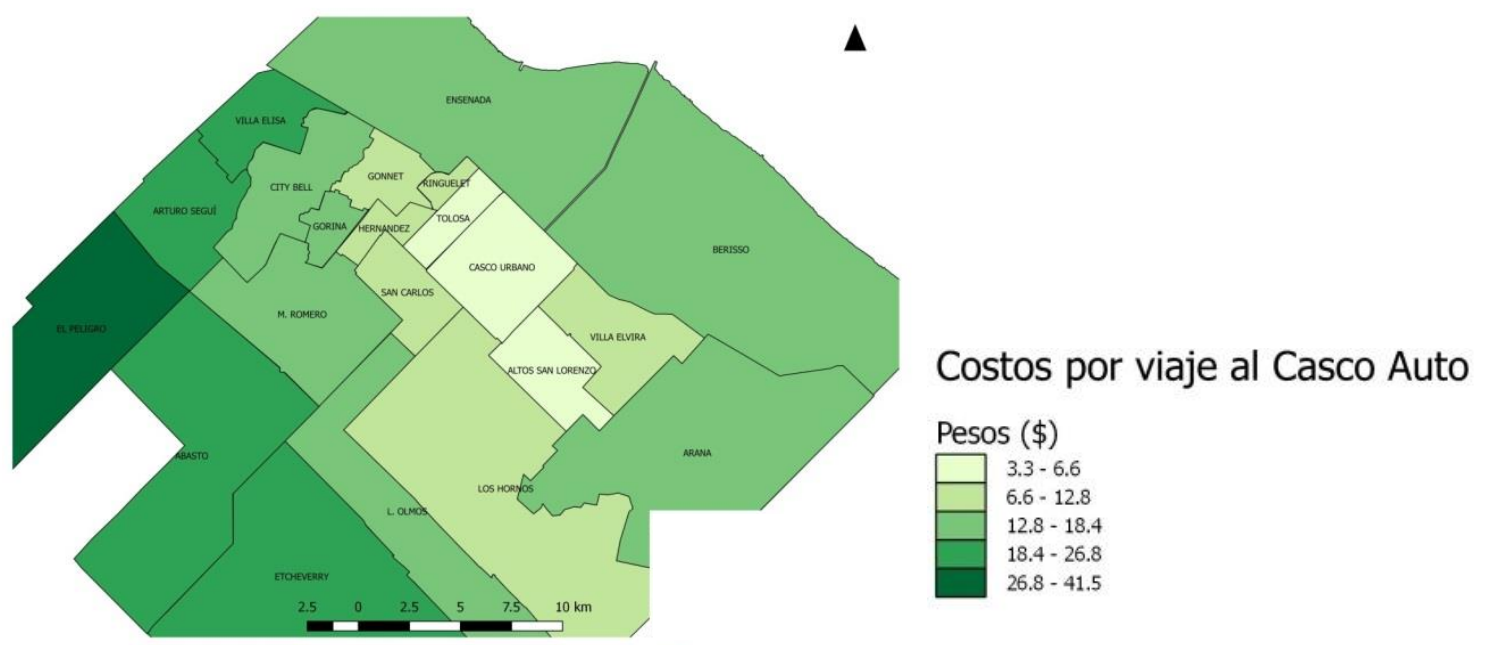

Ilustración 70. Costo por viaje en auto al casco 2013. Fuente: Elaboración propia.

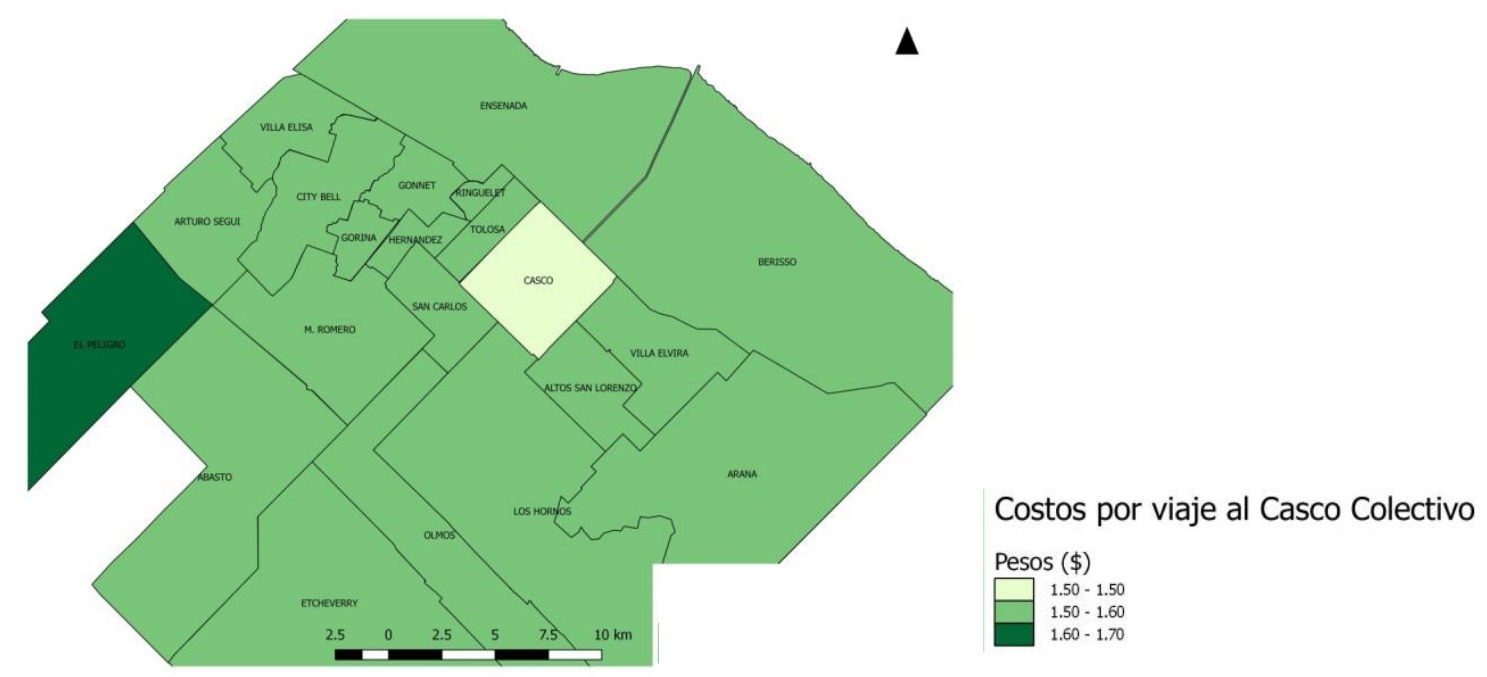

Ilustración 71. Costo por viaje en transporte público al casco 2013. Fuente: Elaboración propia.

En ese marco el viaje en auto es el que define el costo de traslado. En transporte público si bien el costo del boleto es similar en todas las delegaciones del Gran La Plata, la diferencia radica en la calidad el servicio por área como se expuso 4.1.2. En relación a la cantidad de viajes en automóvil y teniendo en cuenta las distancias de cada delegación al casco urbano, las que más gastan en movilidad en la ciudad de La Plata son el Casco Urbano, City Bell, Gonnet y Los Hornos. Las proyecciones a 2030, aunque se incrementan los valores, se mantiene esta jerarquía salvo en Gorina y San Carlos que aumentan sus costos de movilidad relativa con respecto al 2013 debido a sus respectivos aumentos de población proyectada a 2030. Ver Ilustración 72 e Ilustración 73. 


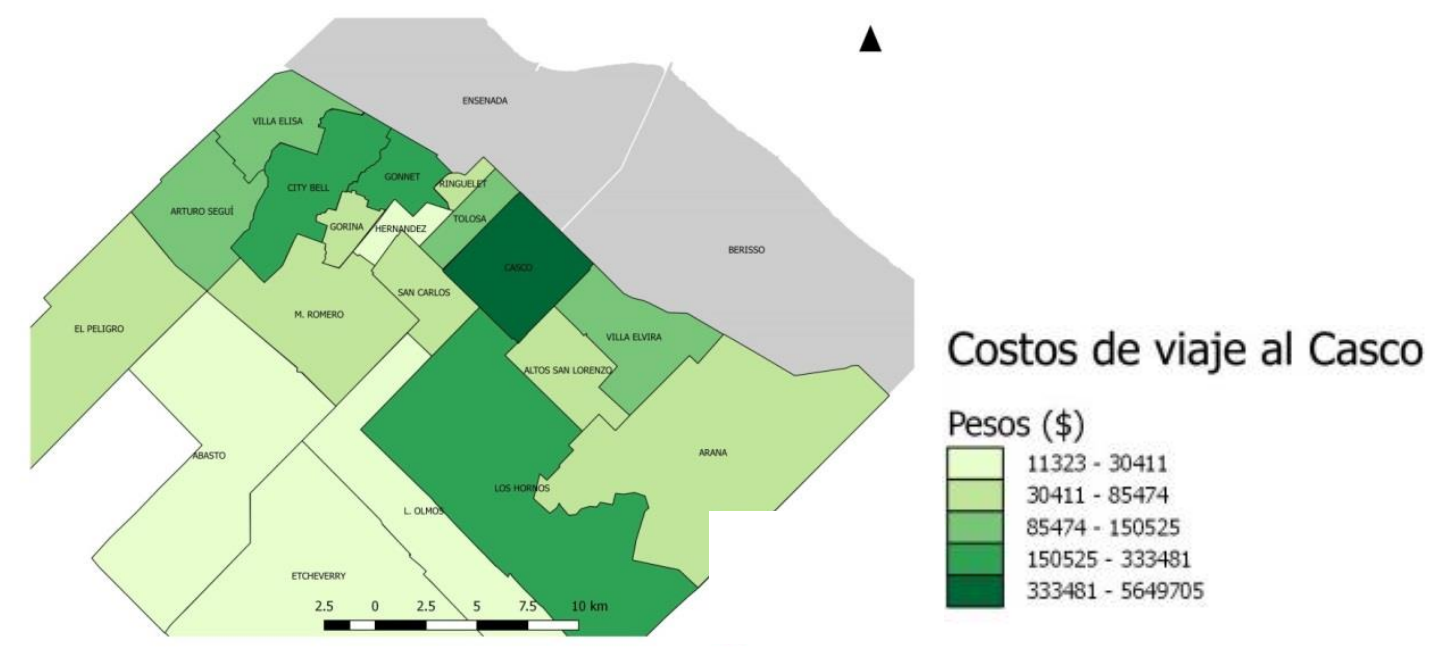

Ilustración 72. Costo por delegación de viajes al Casco Urbano en auto y colectivo en 2013. Fuente: Elaboración propia.

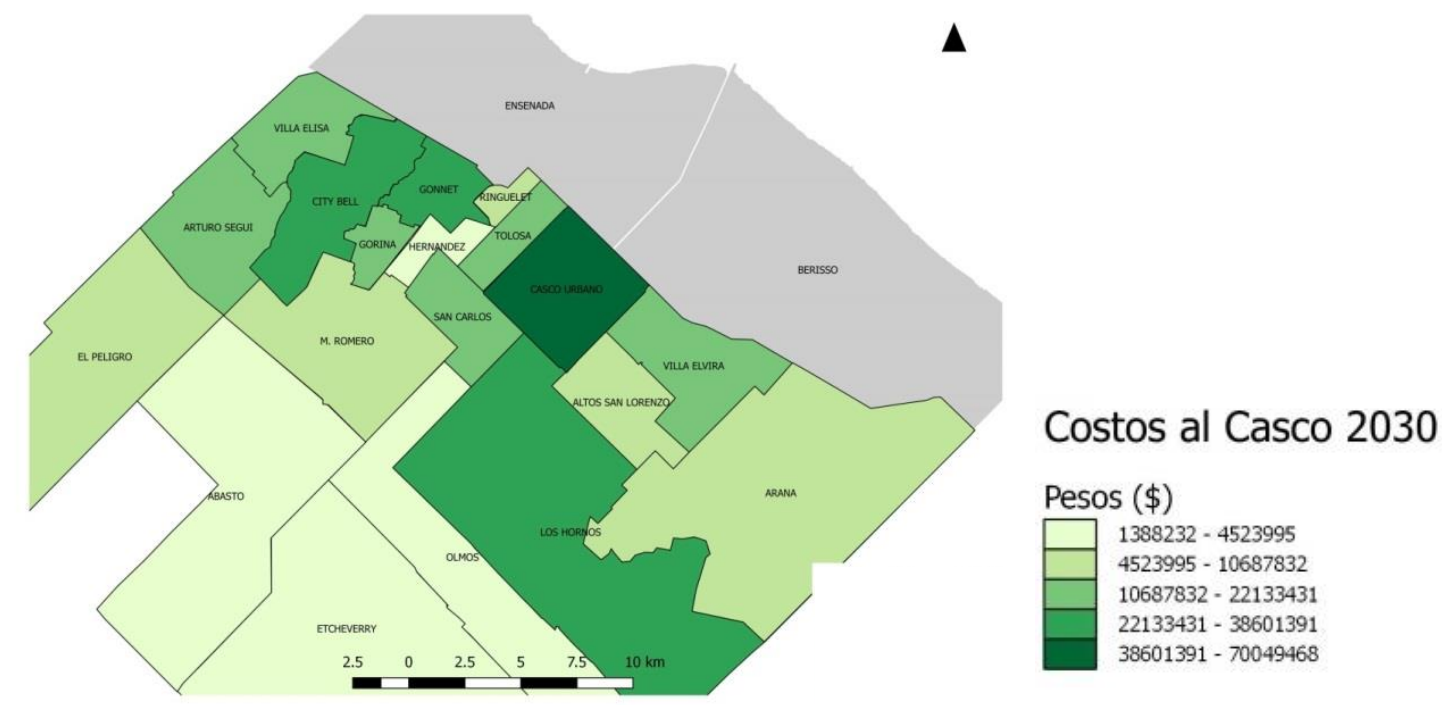

Ilustración 73. Ilustración 6. Costo por delegación de viajes al Casco Urbano en auto y colectivo proyección 2030. Fuente: Elaboración propia.

Los costos por viaje por modo también muestran algunas modificaciones en la proyección a 2030. Los costos por viaje en auto muestran un incremento en sus proporciones en Gonnet, Villa Elvira, Arturo Segui y Gorina, mientras que en transporte público se dan en Olmos, Arturo Segui y Gorina. Estas modificaciones se deben a la variabilidad de las proyecciones de Tasas de Generación de Viaje en automóvil y colectivo (TGVA y TGVC) de cada delegación. Ver Tabla 44 y Tabla 38. 
Tabla 44. Costos de viaje al Casco Urbano por delegación. Fuente: Elaboración propia, se utilizaron datos de Encuesta de Movilidad del Gran La Plata GII IIPAC FAU UNLP.

\begin{tabular}{|c|c|c|c|c|c|c|c|c|}
\hline \multirow{2}{*}{ Delegaciones } & \multirow{2}{*}{$\begin{array}{l}\text { \% viajes } \\
\text { al Casco }\end{array}$} & \multicolumn{2}{|c|}{ Viajes al Casco } & \multicolumn{2}{|c|}{$\begin{array}{c}\text { Costo viajes al } \\
\text { Casco }(\$)\end{array}$} & \multicolumn{3}{|c|}{ Costo total viajes al Casco $(\$)$} \\
\hline & & Colectivo & Auto & Colectivo & Auto & Colectivo & auto & Total \\
\hline ABASTO & 25 & 2409,0 & 940,0 & 1,6 & 24,6 & 3854,4 & 23124 & 26978,4 \\
\hline $\begin{array}{c}\text { ALTOS SAN } \\
\text { LORENZO }\end{array}$ & 74,2 & 28318,4 & 10411,0 & 1,6 & 5,9 & 45309,5 & 61424,9 & 106734,3 \\
\hline ARANA & 62,5 & 2731,9 & 3435,6 & 1,6 & 18 & 4371,0 & 61841,2 & 66212,2 \\
\hline $\begin{array}{c}\text { ARTURO } \\
\text { SEGUI }\end{array}$ & 66,7 & 5809,6 & 6990,8 & 1,6 & 26,8 & 9295,3 & 187354,1 & 196649,4 \\
\hline CASCO & 86,6 & 181261,6 & 130420,5 & 1,5 & 3,3 & 271892,4 & 430387,5 & 702279,9 \\
\hline CITY BELL & 57,8 & 10530,0 & 20808,6 & 1,6 & 17,7 & 16848,0 & 368311,8 & 385159,8 \\
\hline EL PELIGRO & 66,7 & 1158,6 & 1737,5 & 1,7 & 41,5 & 1969,6 & 72107,7 & 74077,2 \\
\hline ETCHEVERRY & 25 & 402,3 & 603,3 & 1,6 & 22 & 643,6 & 13271,5 & 13915,1 \\
\hline GONNET & 67,6 & 18786,0 & 27417,9 & 1,6 & 12,8 & 30057,7 & 350948,9 & 381006,5 \\
\hline GORINA & 50 & 5429,0 & 8143,5 & 1,6 & 15,8 & 8686,4 & 128667,3 & 137353,7 \\
\hline HERNANDEZ & 62,5 & 2935,0 & 2316,9 & 1,6 & 11 & 4696,0 & 25485,6 & 30181,6 \\
\hline LOS HORNOS & 72,1 & 44704,2 & 37439,4 & 1,6 & 7,6 & 71526,7 & 284539,1 & 356065,8 \\
\hline M. ROMERO & 31,3 & 9330,8 & 4174,2 & 1,6 & 18,4 & 14929,3 & 76804,6 & 91734 \\
\hline OLMOS & 45,5 & 4884,9 & 2093,5 & 1,6 & 17,9 & 7815,8 & 37472,8 & 45288,6 \\
\hline RINGUELET & 81,3 & 9587,7 & 10212,9 & 1,6 & 7,5 & 15340,3 & 76596,7 & 91937,1 \\
\hline SAN CARLOS & 42,9 & 20755,9 & 11197,3 & 1,6 & 8,8 & 33209,4 & 98536,4 & 131745,9 \\
\hline TOLOSA & 63,2 & 24545,6 & 15104,8 & 1,6 & 6,6 & 39273,0 & 99691,6 & 138964,6 \\
\hline VILLA ELISA & 75,4 & 15737,5 & 4860,3 & 1,6 & 23 & 25180,0 & 111786,5 & 136966,5 \\
\hline VILLA ELVIRA & 75,6 & 41914,9 & 20957,8 & 1,6 & 7,4 & 67063,9 & 155087,9 & 222151,8 \\
\hline TOTAL & & 431232,8 & 319265,7 & & & 671962,2 & 2663440,9 & 3335403,1 \\
\hline
\end{tabular}

Según las proyecciones los gastos globales en movilidad aumentarían un 27\% en el año 2030 alcanzando \$3.335.403,1 por día solo para los viajes con destino final el Casco Urbano pasando de un equivalente de 1,7\% del PBG en 2013, a 2,9\% en 2030 del PBG de la ciudad de 2013. Si bien en la proyección a 2030 propuesta los valores del precio del viaje se mantienen (el análisis del costo mensual de traslado para una familia con ingresos equivalentes a la CBA, CBT y SM son iguales al desarrollado en el escenario base), el incremento se da en la cantidad de personas en esta situación acompañando las proyecciones de crecimiento poblacional del apartado 4.1.2.i y el incremento de la tasa de generación de viaje por delegación del apartado 4.1.2. 


\subsubsection{Dimensión Ambiental}

El incremento del uso del automóvil junto con el aumento de la tasa de generación de viajes y la tendencia a la dispersión urbana tiene además en la proyección a 2030 un impacto muy negativo en términos de consumo energético y emisiones de contaminantes. En este apartado se exponen resultados de esas proyecciones para el Gran La Plata y sus zonas.

Tanto la cantidad de viajes como el consumo de combustible en TEP, según la partición de 2013 tienen un incremento del 8\%.Asimismo, el impacto en emisiones en toneladas de CO2 también muestra un aumento del 8\%. Ver Tabla 45.

\section{Tabla 45. Emisiones según Modos Masivos/No Masivos del Gran La Plata, proyección}

2030. Fuente: Elaboración propia, en base a Experimentación numérica de politicas y estrategias de desarrollo sustentable. FONCyT-PICT 2011-2013.

\begin{tabular}{|l|c|c|c|c|c|}
\hline \multicolumn{5}{|c|}{ Emisiones según Modos Masivos/No Masivos - Microrregión La Plata - } \\
\hline \multirow{2}{*}{ Modo } & \multicolumn{2}{|c|}{ Viajes } & Consumo en TEP & Emisiones (Tn) \\
\cline { 2 - 7 } & Cant. & $\%$ & Cant & $\%$ & CO2 \\
\hline Masivos & 650.301 & 44,58 & $26.449,40$ & 18,74 & 81.200 \\
\hline No Masivos & 808.456 & 55,42 & $181.849,30$ & 81,26 & 484.362 \\
\hline Total & 1.458 .757 & 100,00 & $189.313,59$ & 100 & 565.562 \\
\hline
\end{tabular}

Desagregada por modo, la proyección a 2030 plantea que el $68 \%$ del consumo de combustibles en TEP de la micro región lo produce el automóvil particular, 7\% más que en 2013. El consumo de combustibles de transporte público proyectado manteniendo la relación pasajero/kilómetro de 2013 , da un $8,8 \%$, el 5,9\% taxi, 5,9 remisse, $4 \%$ motos y 3,5\% transporte interurbano. Ver Gráfico 24 y Tabla 46.

Gráfico 24. Consumo de combustible en TEP por modo con proyección a 2030. Fuente: Elaboración propia, en base a Expe ;Error! La autoreferencia al marcador no es válida.rimentación numérica de politicas y estrategias de desarrollo sustentable. FONCyT-PICT 2011-2013.

Consumo de combustible en TEP por modo

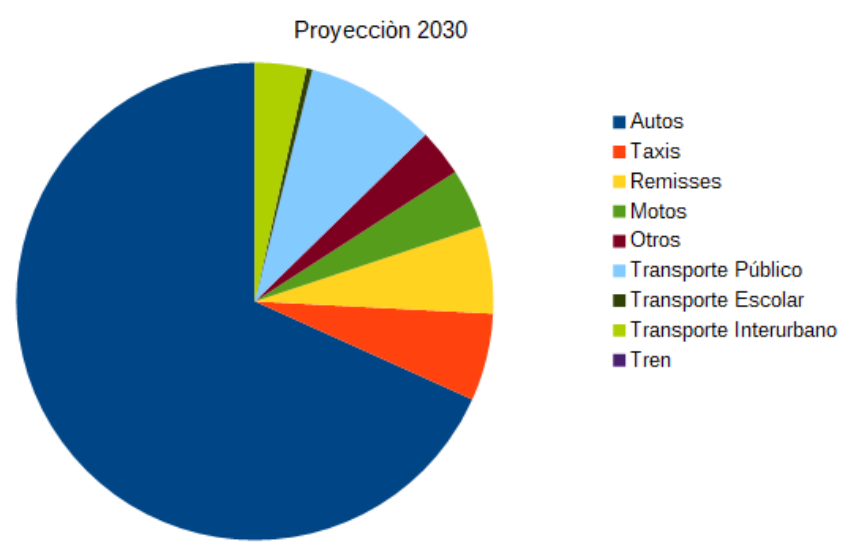


Tabla 46. Consumo en TEP y porcentaje por modo de transporte del Gran La Plata. Fuente: Elaboración propia, en base a Experimentación numérica de políticas y estrategias de desarrollo sustentable. FONCyT-PICT 2011-2013.

\begin{tabular}{|l|c|c|}
\hline \multicolumn{1}{|c|}{ Modos de transporte } & $\begin{array}{c}\text { Consumo } \\
\text { en TEP }\end{array}$ & $\%$ \\
\hline Autos & 142176,4 & 68,3 \\
\hline Taxis & 12330,6 & 5,9 \\
\hline Remisses & 12330,6 & 5,9 \\
\hline Motos & 8378,1 & 4,0 \\
\hline Otros & 6633,6 & 3,2 \\
\hline Transporte Público & 18381,1 & 8,8 \\
\hline Transporte Escolar & 831,4 & 0,4 \\
\hline Transporte Interurbano & 7232,9 & 3,5 \\
\hline Tren & 4 & 0,0 \\
\hline Total & 208298,7 & 100,0 \\
\hline
\end{tabular}

En cuanto al consumo de combustible y emisiones de $\mathrm{CO} 2$ por zona se puede observar que las proyecciones ubican al Casco Urbano en la segunda delegación con valores más alto en emisiones de CO2, cuando en 2013 era la anteúltima por encima de la zona Este. La zona Oeste, a pesar de tener una población menor al Casco, es la primera en emisiones tanto en 2013 como en la proyección a 2030. En cuanto a consumo de combustible en TEP todas las zonas incrementan sus valores con respecto al 2013. El Casco Urbano lo hace en un 48\%, la Oeste en un $27 \%$, la zona Sur en un $11 \%$, Norte $8 \%$ y zona Este 6\%. Ver Tabla 47 y Gráfico 25 .

Tabla 47. Proyección 2030 de consumo en TEP y emisiones de CO2 por zona. Fuente: Elaboración propia, en base a Experimentación numérica de politicas y estrategias de desarrollo sustentable. FONCyT-PICT 2011-2013.

\begin{tabular}{|c|c|c|c|c|c|c|c|c|}
\hline \multirow{2}{*}{ AREA } & \multicolumn{4}{|c|}{ Consumo TEP anual } & \multicolumn{5}{c|}{ Emisiones CO2 } \\
\cline { 2 - 9 } & Masivos & $\begin{array}{c}\text { No } \\
\text { Masivos }\end{array}$ & Total & Total 2013 & Masivos & $\begin{array}{c}\text { No } \\
\text { Masivos }\end{array}$ & $\begin{array}{c}\text { Total } \\
2030\end{array}$ & Total 2013 \\
\hline CASCO & 11254,4 & 91653 & 102907,4 & 69107,04 & 34551 & 240823 & 275374 & 192544,88 \\
\hline ESTE & 20861,7 & 48634 & 69495,7 & 65262,03 & 62512 & 129998 & 192510 & 180121,1 \\
\hline SUR & 18922,2 & 63419,1 & 82341,3 & 74003,33 & 57707 & 170224 & 227931 & 204021,49 \\
\hline OESTE & 20846,8 & 87567,1 & 108413,9 & 84734,36 & 61564 & 242855 & 304419 & 235916,41 \\
\hline NORTE & 25470,46 & 61929,9 & 87400,36 & 80682,58 & 75774 & 169558 & 245332 & 225713,9 \\
\hline TOTAL & 97355,56 & 353203,1 & 450558,66 & 2076635,56 & 292108 & 953458 & 1245566 & 1038317,78 \\
\hline
\end{tabular}


Gráfico 25. Proyección 2030 de consumo en TEP por zona. Fuente: Elaboración propia, en base a Experimentación numérica de políticas y estrategias de desarrollo sustentable. FONCyT-PICT 2011-2013.

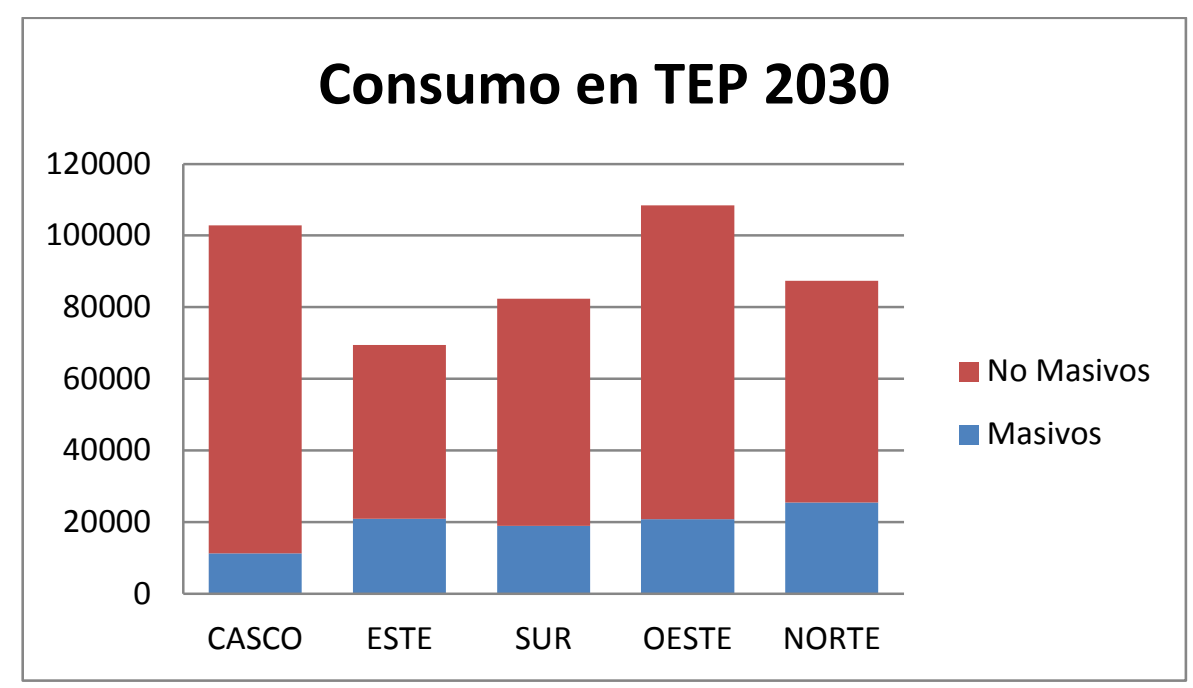

En base a las proyecciones a 2030 realizadas podemos afirmar que en todas las zonas, los mayores consumos de combustible por demanda de movilidad siguen siendo los generados por los modos no masivos, en consonancia con el crecimiento del parque automotor y la dependencia del auto en las periferias. El consumo de combustibles por modos no masivos alcanza los dos tercios del consumo, llegando en el Casco a ser el $89 \%$ y el $81 \%$ en zona Oeste. Es decir que una reducción del uso del automóvil afectaría de forma considerable en el consumo de combustible y de emisiones de contaminantes.

A partir del análisis de los resultados de las variables de las dimensiones del año base y escenario tendencial, se proponen las siguientes propuestas de mejoras de tiempo de viaje en transporte público a partir de la construcción de los siguientes escenarios alternativos.

\subsection{Escenario Alternativo}

En esta sección se presenta la construcción de los escenarios alternativos, los cuales se analizan las posibles medidas de mejoramiento de la movilidad a implementar en el Gran La Plata. Estos escenarios basan su construcción en el relevamiento efectuado en el año base y en aquellos valores obtenidos del escenario tendencial considerados como invariantes. Para su construcción, se clasificaron según los tiempos de implementación: a corto plazo, mediano plazo y largo plazo.

\subsubsection{Análisis de medidas a corto plazo}

Para la implementación de medidas de movilidad a corto plazo se plantea analizar posibles propuestas que reduzcan el tiempo de viaje en transporte público y que permitan aumentar la velocidad de circulación de las unidades. Estas medidas son eficaces al corto plazo porque son 
de rápida implementación, aunque su efecto es limitado si se considera el mediano y el largo plazo.

Dentro de las propuestas se considera: i. la sincronización de semáforos a una velocidad deseable del transporte público entre $20-30 \mathrm{~km} / \mathrm{h}$, ii. la reorganización de las paradas de micro y iii. la implementación de carriles exclusivos para transporte público en áreas centrales sobre corredores principales donde la velocidad operativa disminuye considerablemente por congestión.

Para el análisis de estas medidas se seleccionó el corredor de la Av. 7 en extensión Este sobre el recorrido del ramal Este 14 desde Plaza San Martin a la finalización del recorrido en la delegación de Arana por ser el corredor del que se cuenta con más información de viajes, tiempos de viaje, velocidad de transporte público por tramos y ubicación de paradas. El tramo del corredor seleccionado posee 130 paradas, 65 en cada sentido. La longitud del tramo es de $13,6 \mathrm{~km}$ por lo tanto se obtiene un promedio de distancia entre paradas de 210 metros. Por otro lado, la cantidad de semáforos es de 29 en todo el segmento de corredor seleccionado. Ver Ilustración 74.

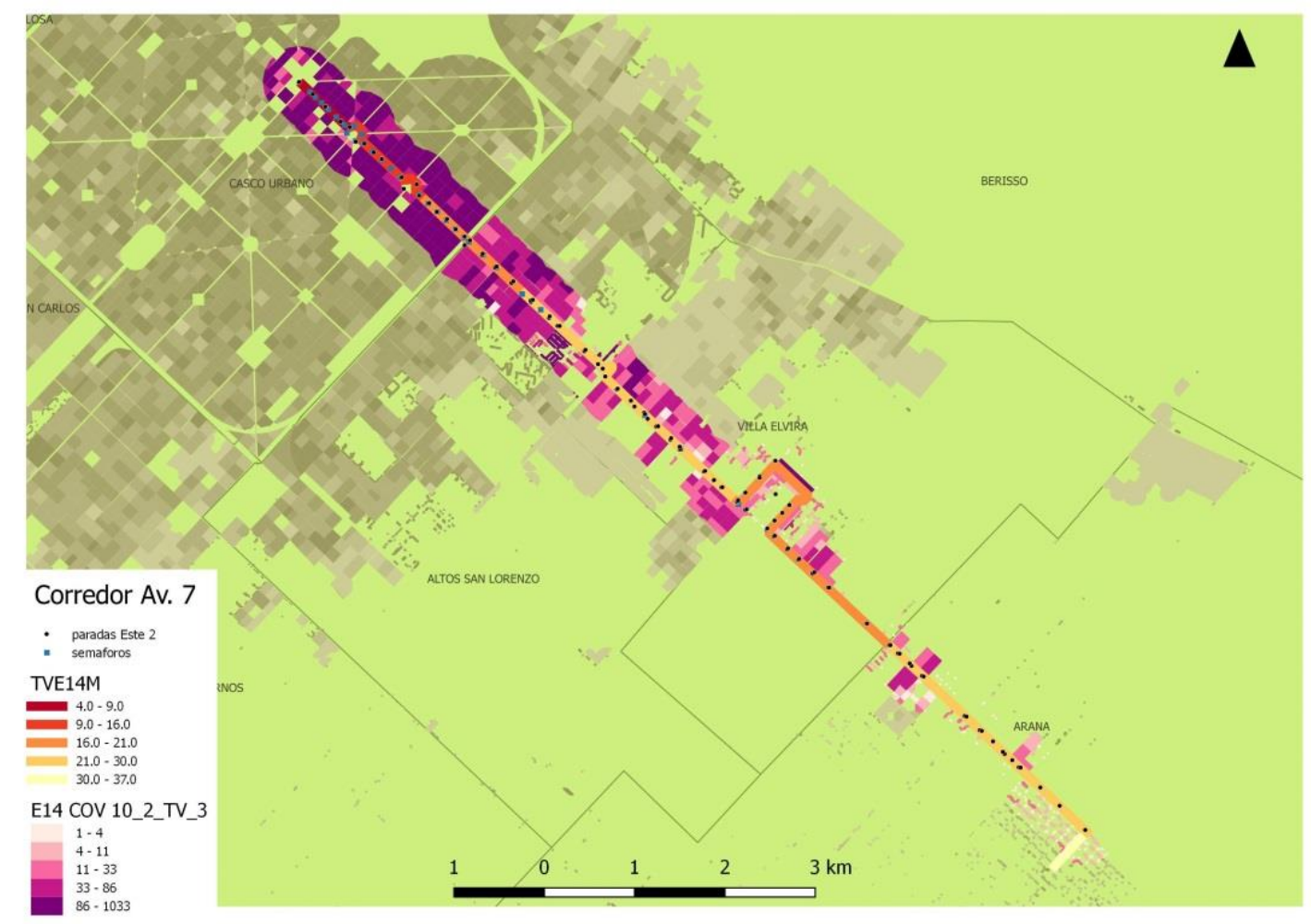

Ilustración 74. Corredor Av. 7: ubicación de paradas, velocidad de TP por tramo y viajes en TP producidos. Fuente: Elaboración propia, se utilizaron datos de densidad obtenidos del INDEC. 
Para analizar el tiempo de traslado y estimar la posible incidencia de las medidas propuestas, es necesario revisar con mayor detalle la composición de ese tiempo, lo que se asocia a la velocidad operativa de cada unidad. Por ejemplo, el tiempo que se destina en cada parada o semáforo. Según estimaciones un colectivo que circula a una velocidad de $25 \mathrm{~km} / \mathrm{h}$ demora 4 segundos en detener la marcha y otros 4 segundos en alcanzar los $25 \mathrm{~km} / \mathrm{h}$ nuevamente, es decir 8 segundos en total.

En el caso que un micro tenga que parar en todas las paradas a levantar pasajeros, siendo un promedio de 82 pasajeros por coche en media vuelta ${ }^{77}$, y además se vea obligado a frenar por luz roja por 20 segundos en al menos la mitad de los semáforos, el tiempo insumido en estas situaciones alcanza un total de 23:30 minutos, equivalente al 60\% del tiempo de recorrido. $\mathrm{Si}$ analizamos por áreas de cobertura al tramo del corredor seleccionado, se pueden encontrar diferencias entre las áreas periféricas, las más consolidadas y las cercanas al centro. Ver Ilustración 75 y Tabla 48.

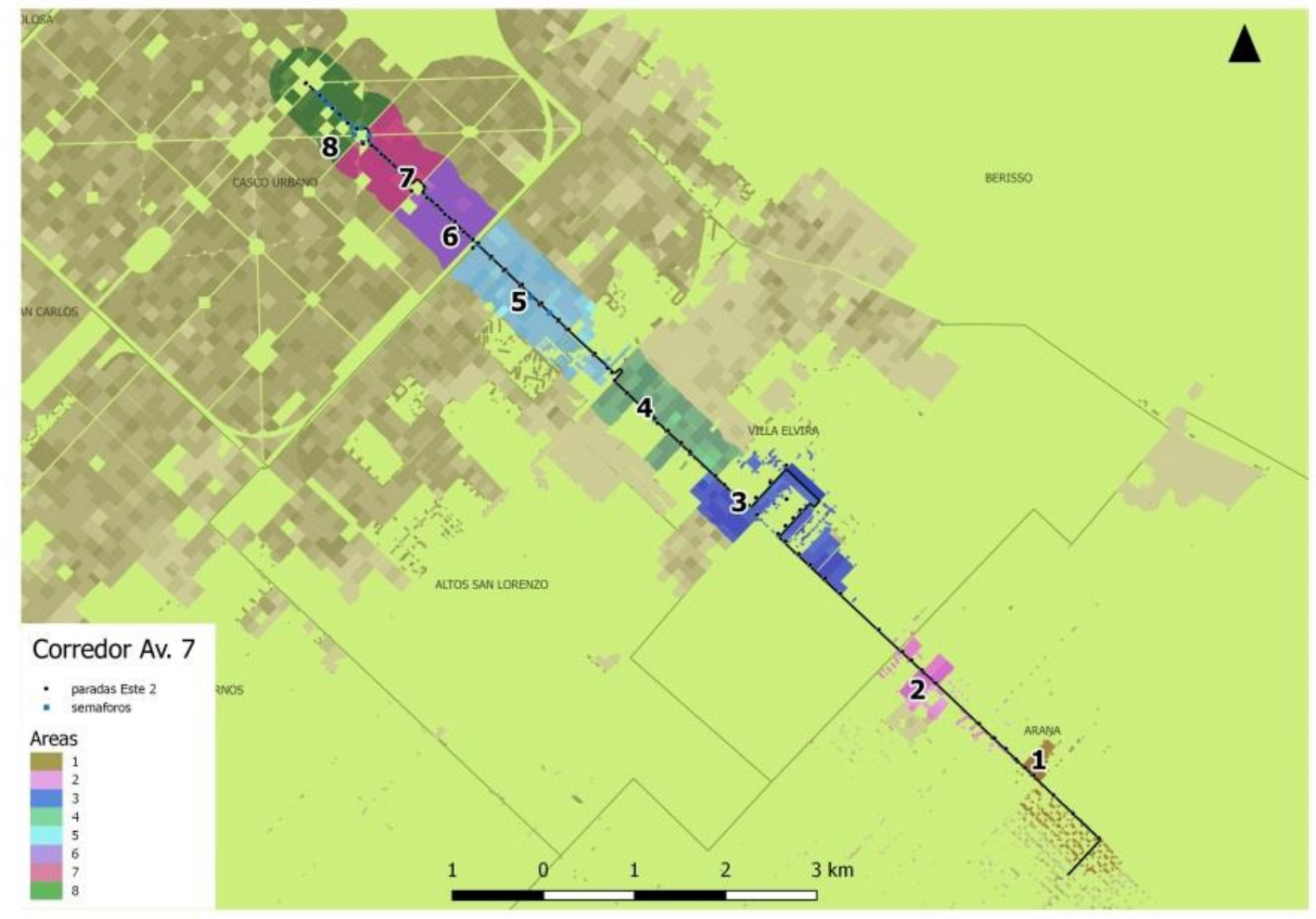

Ilustración 75. Areas del corredor Av. 7. Fuente: Elaboración propia.

\footnotetext{
${ }^{77}$ Estimación realizada en apartado 4.1.2.iii.
} 
Tabla 48. Tiempo utilizado por semáforos y paradas de colectivo por zona del corredor.

Fuente: Elaboración propia.

\begin{tabular}{|c|c|c|c|c|c|c|c|c|c|}
\hline Area & $\begin{array}{c}\text { Semáf } \\
\text { oros }\end{array}$ & $\begin{array}{c}\text { Parada } \\
\mathbf{s} \mathbf{x} \\
\text { sentido }\end{array}$ & $\begin{array}{c}\text { Pasajero } \\
\mathbf{s} \mathbf{x} \\
\mathbf{c o c h e}\end{array}$ & $\begin{array}{c}\text { Personas } \mathbf{x} \\
\text { parada } \mathbf{x} \\
\mathbf{c o c h e}\end{array}$ & $\begin{array}{c}\text { Distancia entre } \\
\text { paradas } \\
\text { (promedio) }\end{array}$ & $\begin{array}{c}\text { Tiempo } \mathbf{x} \\
\mathbf{s e m a f o r o s} \\
\text { (minutos)* }\end{array}$ & $\begin{array}{c}\text { Tiempo } \mathbf{x} \\
\text { pasajeros } \\
\text { (minutos) }\end{array}$ & $\begin{array}{c}\text { Tiempo } \\
\mathbf{x} \\
\text { paradas }\end{array}$ & $\begin{array}{c}\text { Tiempo } \\
\text { semaforo+para } \\
\text { da+pasajeros }\end{array}$ \\
\hline $\mathbf{1}$ & 0 & 5 & 2 & 0,40 & 272 & 0 & 0,10 & 0,67 & 0,77 \\
\hline $\mathbf{2}$ & 0 & 7 & 2 & 0,29 & 334 & 0 & 0,10 & 0,93 & 1,03 \\
\hline $\mathbf{3}$ & 1 & 14 & 6 & 0,43 & 250 & 0,4 & 0,30 & 1,87 & 2,57 \\
\hline $\mathbf{4}$ & 2 & 8 & 5 & 0,63 & 213 & 0,8 & 0,25 & 1,07 & 2,12 \\
\hline $\mathbf{5}$ & 5 & 9 & 20 & 2,22 & 222 & 2 & 1,00 & 1,20 & 4,20 \\
\hline $\mathbf{6}$ & 6 & 4 & 11 & 2,75 & 208 & 2,4 & 0,55 & 0,53 & 3,48 \\
\hline $\mathbf{7}$ & 7 & 5 & 14 & 2,80 & 164 & 2,8 & 0,70 & 0,67 & 4,17 \\
\hline $\mathbf{8}$ & 8 & 5 & 22 & 4,40 & 156 & 3,2 & 1,10 & 0,67 & 4,97 \\
\hline Total & 29 & 57 & 82 & & & 11,6 & 4,10 & 7,60 & 23,30 \\
\hline
\end{tabular}

La Tabla 48 muestra la utilización del tiempo de recorrido según zonas del corredor. En función de estas aproximaciones, el área 8 es la que más tiempo utiliza en semáforos y cargado de pasajeros, seguido por orden descendente a la 7, 6 y el resto de las áreas en cuanto a semáforos siendo el área 5 la que le sigue a la 8 en cuanto a pasajeros.

Estos resultados tienen un correlato con la cercanía al centro, donde la cantidad de semáforos y pasajeros se incrementa, y las cuadras se hacen más cortas. Por ende, la cantidad de paradas y semáforos por kilómetro también aumenta, disminuyendo la distancia entre paradas. En cuanto al tiempo utilizado por cantidad de paradas, el área 3 es la que mayor tiempo utiliza, seguido por el área 5 y la 4 que son más extensas. Ver Gráfico 26 y Tabla 49.

Gráfico 26. Partición de tiempos utilizados en el traslado. Fuente: Elaboración propia

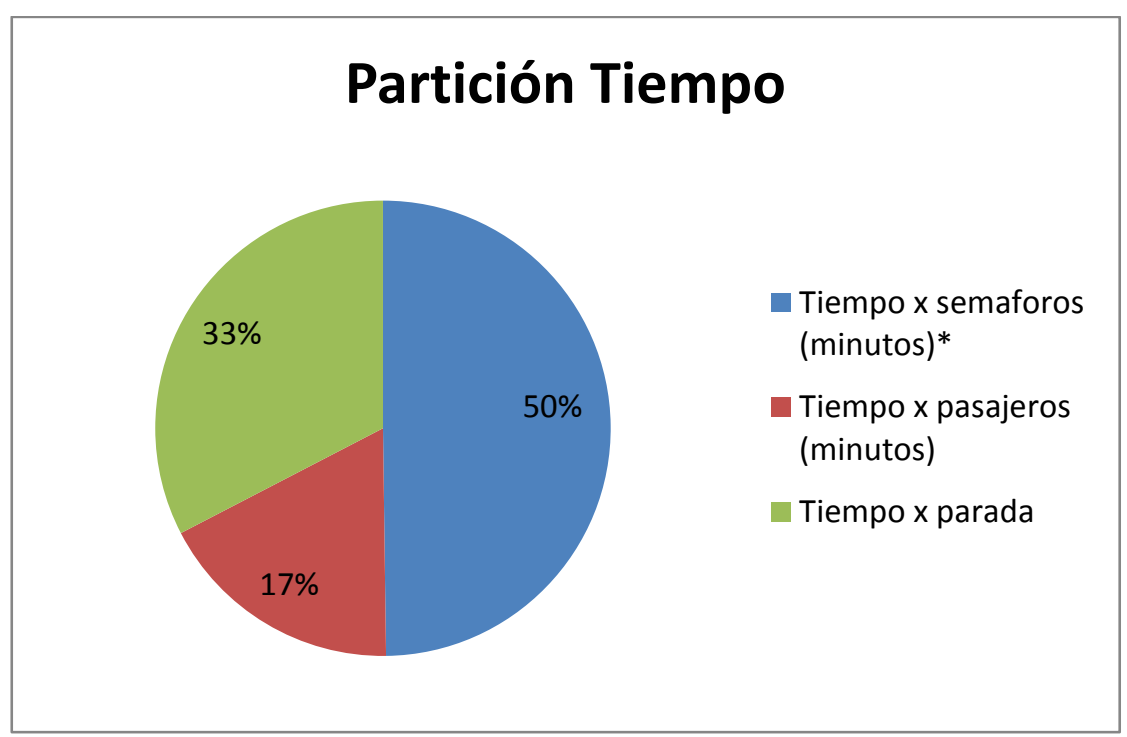


A nivel del corredor, la Tabla 49 muestra que de los 23,3 minutos que utiliza el micro para semáforos y cargar pasajeros, el $50 \%$ es debido a los semáforos, el $33 \%$ por frenar en las pardas y el $17 \%$ restante para cargar pasajeros. Estas aproximaciones coinciden con las problemáticas que detectaron los choferes referidas a la poca distancia entre paradas y a la mala sincronización de semáforos como situaciones que insumen mucho tiempo del viaje. A los efectos de optimizar el tiempo de viaje del transporte público masivo, es que se plantean las siguientes pautas de mejoramiento:

Sincronización de semáforos: se modifica el porcentaje de semáforos en rojo que obligarían al conductor a detener la marcha en el $20 \%$ de los semáforos. El cálculo anterior estimaba el $50 \%$ de los semáforos en rojo, con un promedio de tiempo de espera de 20 segundos. Ver Gráfico 27.

Tabla 49. Tiempo de traslado desagregado y tiempo desagregado optimizado (en minutos) a partir de la sincronización de semáforos para el corredor Av. 7. Fuente: Elaboración propia.

\begin{tabular}{|c|c|c|c|c|c|c|}
\hline Área & $\begin{array}{c}\text { Tiempo x } \\
\text { semáforos }\end{array}$ & $\begin{array}{c}\text { Tiempo x } \\
\text { semáforos } \\
\text { optimizado }\end{array}$ & $\begin{array}{c}\text { Tiempo } \\
\text { carga } \\
\text { pasajeros }\end{array}$ & $\begin{array}{c}\text { Tiempo x } \\
\text { paradas }\end{array}$ & $\begin{array}{c}\text { Tiempo } \\
\text { semaforo+ } \\
\text { parada+pa } \\
\text { sajeros }\end{array}$ & $\begin{array}{c}\text { Escenario } \\
\text { Alternativ } \\
\text { o }\end{array}$ \\
\hline 1 & 0 & 0 & 0,1 & 0,67 & 0,77 & 0,77 \\
\hline 2 & 0 & 0 & 0,1 & 0,93 & 1,03 & 1,03 \\
\hline 3 & 0,4 & 0,4 & 0,3 & 1,87 & 2,57 & 2,57 \\
\hline 4 & 0,8 & $\mathbf{0 , 7}$ & 0,25 & 1,07 & 2,12 & $\mathbf{2 , 0 2}$ \\
\hline 5 & 2 & $\mathbf{1 , 8}$ & 1 & 1,2 & 4,2 & $\mathbf{4 , 0 0}$ \\
\hline 6 & 2,4 & $\mathbf{2 , 2}$ & 0,55 & 0,53 & 3,48 & $\mathbf{3 , 2 8}$ \\
\hline 7 & 2,8 & $\mathbf{2 , 5}$ & 0,7 & 0,67 & 4,17 & $\mathbf{3 , 8 7}$ \\
\hline 8 & 3,2 & $\mathbf{2 , 9}$ & 1,1 & 0,67 & 4,97 & $\mathbf{4 , 6 7}$ \\
\hline Total & 11,6 & $\mathbf{1 0 , 4}$ & 4,1 & 7,6 & 23,3 & $\mathbf{2 2 , 1 0}$ \\
\hline
\end{tabular}


Gráfico 27. Tiempo de desplazamiento desagregado actual y tiempo de desplazamiento en escenario alternativo por área: Sincronización de Semáforos. Fuente: Elaboración propia.

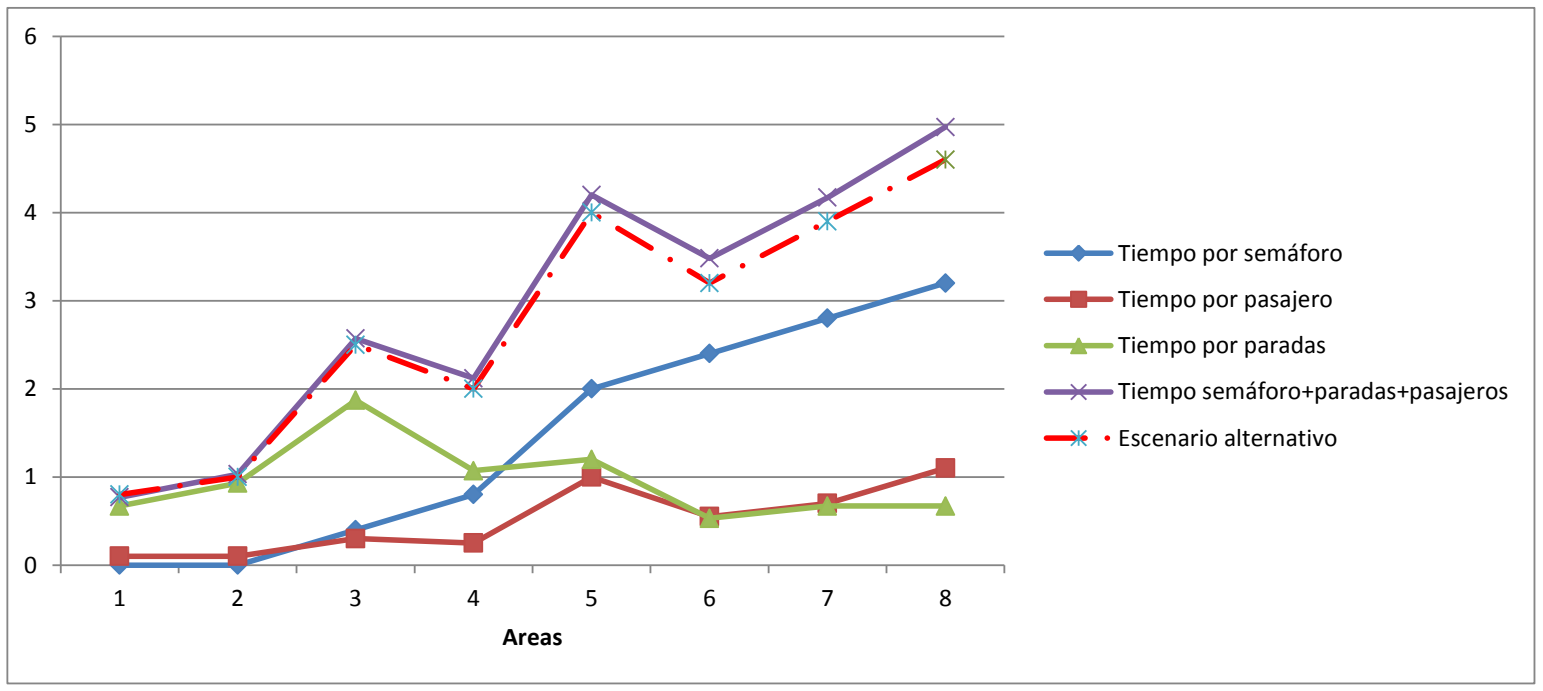

Según la Tabla 49 y Gráfico 27, el tiempo utilizado descendería a 22,1 minutos, es decir un $5 \%$ menos del total del tiempo utilizado en semáforos y carga de pasajeros. En síntesis, teniendo en cuenta el conjunto del tiempo o de traslado, calculado en 39 minutos, la reducción 1,12 minutos significa un 3\% menos.

Esta propuesta podría ser implementada con bajos costos, ya que se requeriría únicamente la coordinación entre la dependencia municipal encargada delos semáforos, el área de Transporte y representantes de los choferes que vayan ajustando los tiempos de cada semáforo en relación a la conveniencia de una circulación más ágil. Por el alto impacto del tiempo utilizado en semáforos en el tiempo de viaje y cuyo costo monetario es despreciable, es una medida importante a tener en cuenta.

Reorganización de paradas: El promedio de distancia entre paradas del corredor seleccionado es de 210 metros, pero varía según el área, disminuyendo desde el área 1 y 2 con una distancia de 272 y 334, hasta las áreas 7 y 8 con una distancia de 164 y 156 metros de distancia promedio entre paradas. Para la construcción del escenario alternativo se plantea normalizar las paradas cada $300 \mathrm{~m}$. La Tabla 50 y el Gráfico 28 presentan los resultados en tiempo si las paradas estuvieran a una distancia de 300 metros. 
Tabla 50. Tiempo utilizado en el traslado por área del corredor Av. 7 con la propuesta de reorganización de paradas. Fuente: Elaboración propia.

\begin{tabular}{|c|c|c|c|c|c|c|c|c|c|c|}
\hline Zona & $\begin{array}{c}\text { Paradas } \\
\mathbf{x} \\
\text { sentido }\end{array}$ & $\begin{array}{c}\text { Paradas } x \\
\text { sentido } \\
\text { (modificado) }\end{array}$ & $\begin{array}{c}\text { Personas } \\
\text { x parada } \\
\text { x coche }\end{array}$ & $\begin{array}{c}\text { Personas } x \\
\text { parada } \\
\text { coche } \\
\text { (modificado) }\end{array}$ & $\begin{array}{c}\text { Distancia } \\
\text { entre } \\
\text { paradas } \\
\text { (m) }\end{array}$ & $\begin{array}{c}\text { Distancia } \\
\text { entre } \\
\text { paradas } \\
\text { (modificado) }\end{array}$ & $\begin{array}{c}\text { Tiempo } \\
\text { x } \\
\text { parada } \\
\text { (min) }\end{array}$ & $\begin{array}{c}\text { Tiempo x } \\
\text { parada (min) } \\
\text { (modificado) }\end{array}$ & $\begin{array}{c}\text { Tiempo } \\
\text { semáforo } \\
\text { +parada } \\
\text { pasajeros }\end{array}$ & $\begin{array}{c}\text { Escenario } \\
\text { Alternativo }\end{array}$ \\
\hline 1 & 5 & 5 & 0 & 0 & 272 & $\mathbf{3 0 0}$ & 0,7 & $\mathbf{0 , 6}$ & 0,77 & $\mathbf{0 , 7}$ \\
\hline 2 & 7 & 8 & 0 & 0 & 334 & $\mathbf{3 0 0}$ & 0,9 & $\mathbf{0 , 8}$ & 1,03 & $\mathbf{1 , 1}$ \\
\hline 3 & 14 & 12 & 0 & 1 & 250 & $\mathbf{3 0 0}$ & 1,9 & $\mathbf{1 , 6}$ & 2,57 & $\mathbf{2 , 3}$ \\
\hline 4 & 8 & 6 & 1 & 1 & 213 & $\mathbf{3 0 0}$ & 1,1 & $\mathbf{0 , 8}$ & 2,12 & $\mathbf{1 , 8}$ \\
\hline 5 & 9 & 7 & 2 & 3 & 222 & $\mathbf{3 0 0}$ & 1,2 & $\mathbf{0 , 9}$ & 4,20 & $\mathbf{3 , 9}$ \\
\hline 6 & 4 & 3 & 3 & 4 & 208 & $\mathbf{3 0 0}$ & 0,5 & $\mathbf{0 , 4}$ & 3,48 & $\mathbf{3 , 3}$ \\
\hline 7 & 5 & 3 & 3 & 5 & 164 & $\mathbf{3 0 0}$ & 0,7 & $\mathbf{0 , 4}$ & 4,17 & $\mathbf{3 , 9}$ \\
\hline 8 & 5 & 3 & 4 & 8 & 156 & $\mathbf{3 0 0}$ & 0,7 & $\mathbf{0 , 3}$ & 4,97 & $\mathbf{4 , 6}$ \\
\hline Total & 57 & 44 & & & & & 7,6 & $\mathbf{5 , 9}$ & 23,30 & $\mathbf{2 1 , 6}$ \\
\hline
\end{tabular}

Gráfico 28. Tiempo de desplazamiento desagregado actual y tiempo de desplazamiento en escenario alternativo por zona: Reorganización de Paradas. Fuente: Elaboración propia.

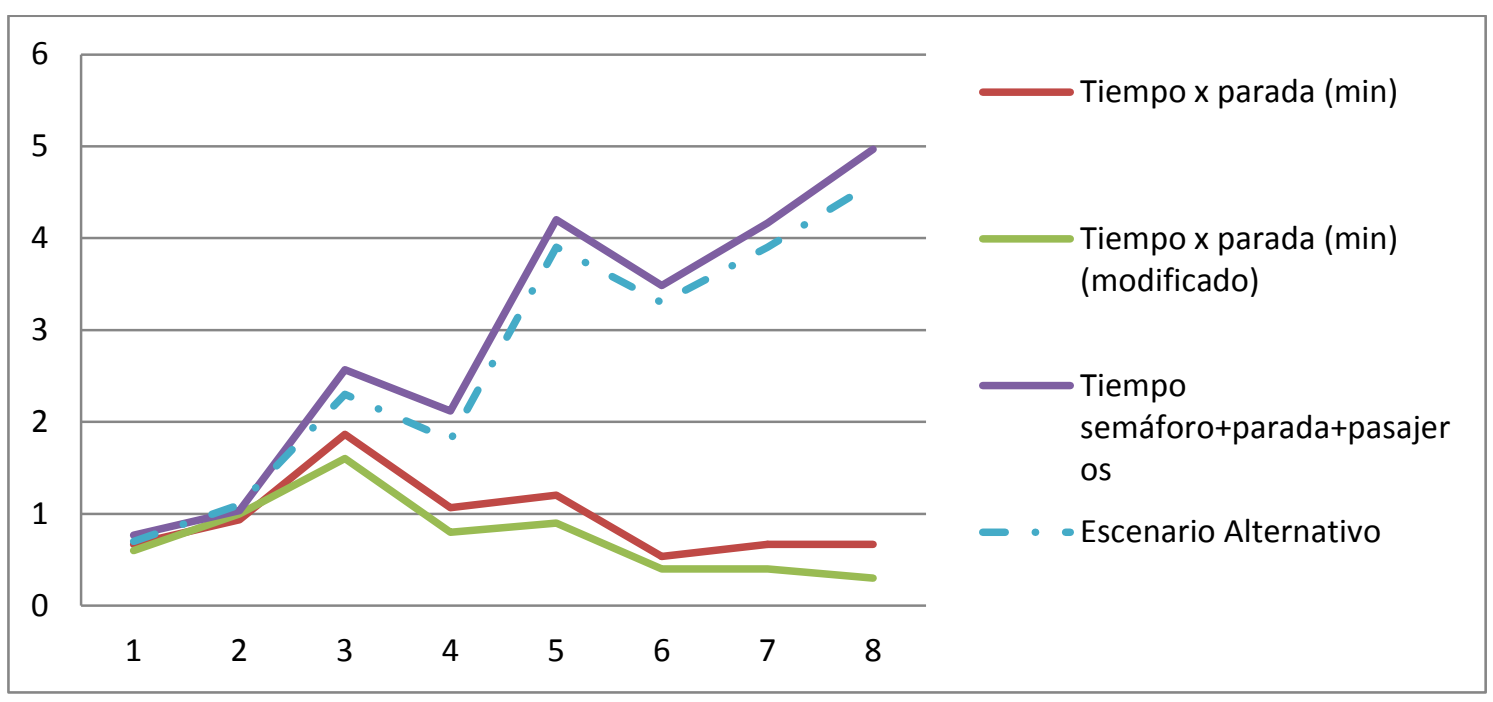

En este caso, el tiempo utilizado descendería de 22,10 minutos a 21,6 minutos, es decir un 7\% menos del total del tiempo utilizado en semáforos y carga de pasajeros. Teniendo en cuenta la totalidad del tiempo de traslado, calculado en 39 minutos, la reducción 1,68 minutos significaría una reducción de un 4\%.

Esta propuesta de reorganización de paradas tendría un costo mínimo de parte de la municipalidad que consistiría en una reubicación y mejoramiento de las paradas existentes ya que la propuesta de reorganización pasaría de 57 paradas a 44 en todo el corredor 
seleccionado. A pesar de la nueva distribución, se mantiene el área de cobertura de las paradas a partir de un radio de 400 metros.

A partir de la aplicación de esta medida, la concentración de paradas implicaría un aumento en la cantidad de pasajeros en cada uno de los refugios. Esta situación puede generar, principalmente en las áreas 7 y 8, la necesidad de agrandar los refugios para contemplar el aumento de pasajeros por parada. Según las estimaciones, el área 7 tendrá un incremento aproximado de 3 a 5 pasajeros y en el caso del área 8 el incremento sería de 4 a 8 pasajeros. Dicho incremento de pasajeros incrementa el tiempo por parada, pero no alcanza a superar la reducción de tiempo del desplazamiento a partir de la reorganización de paradas.

Carril Exclusivo para Transporte Público: Esta propuesta afectaría de forma directa a 35.421 pasajeros en un radio de cobertura de 400 metros. Según algunos estudios (Cervero, 2014), la cercanía a carriles exclusivos de transporte público de alta capacidad incrementa entre 5 a 7 veces su uso con respecto a zonas más alejadas a dichos carriles exclusivos. Si bien la propuesta de carril exclusivo para este corredor no es de alta capacidad (por lo que esas proporciones no serían estrictamente comparables) es posible que la cantidad de pasajeros se incremente. Asimismo, la propuesta de carril exclusivo plantea la posibilidad de elevar la velocidad a $20-30 \mathrm{~km} / \mathrm{h}$. Para la construcción del escenario alternativo se plantea tomar una velocidad mínima de $25 \mathrm{~km} / \mathrm{h}$ en cada área del corredor. Ver Tabla 51.

Tabla 51. Tiempos de traslado y velocidades operativas de transporte público corredor Av. 7 este. Fuente: Elaboración propia

\begin{tabular}{|c|c|c|c|c|c|c|}
\hline \multirow{2}{*}{ REGISTRO } & \multicolumn{2}{|c|}{$\begin{array}{c}\text { Ubicación registro de } \\
\text { tiempo (intersección) }\end{array}$} & \multirow{2}{*}{ Hora } & $\begin{array}{c}\text { Metros } \\
\text { e/registro }\end{array}$ & $\begin{array}{c}\text { Tiempo } \\
\text { entre } \\
\text { registro } \\
\text { (min) }\end{array}$ & $\begin{array}{c}\text { Velocidad } \\
\text { eentr } \\
\text { registro } \\
\text { (km/h) }\end{array}$ \\
\hline & Calle1 & Calle 2 & & & - & - \\
\hline 0 & 12 & 659 & $12: 13: 00$ & - & 5 & 37,22 \\
\hline 1 & 7 & 635 & $12: 18: 00$ & 3101,9 & 5 & 29,84 \\
\hline 2 & 6 & 613 & $12: 23: 00$ & 2486,91 & 5 & 21,25 \\
\hline 3 & 7 & 608 & $12: 28: 00$ & 1770,98 & 5 & 23,87 \\
\hline 4 & 7 & 95 & $12: 33: 00$ & 1989,28 & 5 & 24,91 \\
\hline 5 & 7 & 78 bis & $12: 38: 00$ & 2075,97 & 5 & 18,2 \\
\hline 6 & 7 & 67 & $12: 43: 00$ & 1516,58 & 5 & 15,8 \\
\hline 7 & 7 & 59 & $12: 48: 00$ & 1316,29 & 5 & 9,22 \\
\hline 8 & 7 & 53 & $12: 52: 00$ & 614,82 & 4 & 22,88 \\
\hline TOTAL & & & & 14872,73 & 39 & \\
\hline
\end{tabular}


Según estas estimaciones con la implementación del carril exclusivo para transporte público el tiempo de traslado se reduciría de 39 minutos a 32 minutos, es decir 7 minutos que equivale a una reducción del 18\%. El mayor impacto se dará en las áreas centrales, por ejemplo, en las áreas 7 y 8 , que circulan a velocidades entre $15,8 \mathrm{~km} / \mathrm{h}$ y $9,2 \mathrm{~km} / \mathrm{h}$ en las que la incorporación de carriles exclusivos permitiría reducir tiempos en los trayectos que demandaban entre 5 minutos a 3 y 1 minuto respectivamente. Ver Tabla 52 y Gráfico 29.

Tabla 52. Tiempo y velocidad entre registros y modificaciones según escenario alternativo de Carril Exclusivo. Fuente: Elaboración propia.

\begin{tabular}{|c|c|c|c|c|}
\hline REGISTRO & $\begin{array}{c}\text { Tiempo } \\
\text { entre } \\
\text { registro } \\
(\mathrm{min})\end{array}$ & $\begin{array}{c}\text { Tiempo } \\
\text { entre } \\
\text { registro } \\
(\mathrm{min}) \\
\text { (modificado) }\end{array}$ & $\begin{array}{c}\text { Velocidad } \\
\text { entre } \\
\text { registro } \\
(\mathrm{km} / \mathrm{h})\end{array}$ & $\begin{array}{c}\text { Velocidad } \\
\text { entre } \\
\text { registro } \\
(\mathrm{km} / \mathrm{h}) \\
\text { (modificado) }\end{array}$ \\
\hline 0 & - & - & - & - \\
\hline 1 & 5 & 5 & 37,22 & 37,22 \\
\hline 2 & 5 & 5 & 29,84 & 29,84 \\
\hline 3 & 5 & 4 & 21,25 & 25 \\
\hline 4 & 5 & 5 & 23,87 & 25 \\
\hline 5 & 5 & 5 & 24,91 & 25 \\
\hline 6 & 5 & 4 & 18,2 & 25 \\
\hline 7 & 5 & 3 & 15,8 & 25 \\
\hline 8 & 4 & 1 & 9,22 & 25 \\
\hline TOTAL & 39 & 32 & 22,88 & 28 \\
\hline & & & &
\end{tabular}

Gráfico 29. Tiempo y velocidad entre registro y modificado escenario alternativo Carril Exclusivo por zona. Fuente: Elaboración propia.

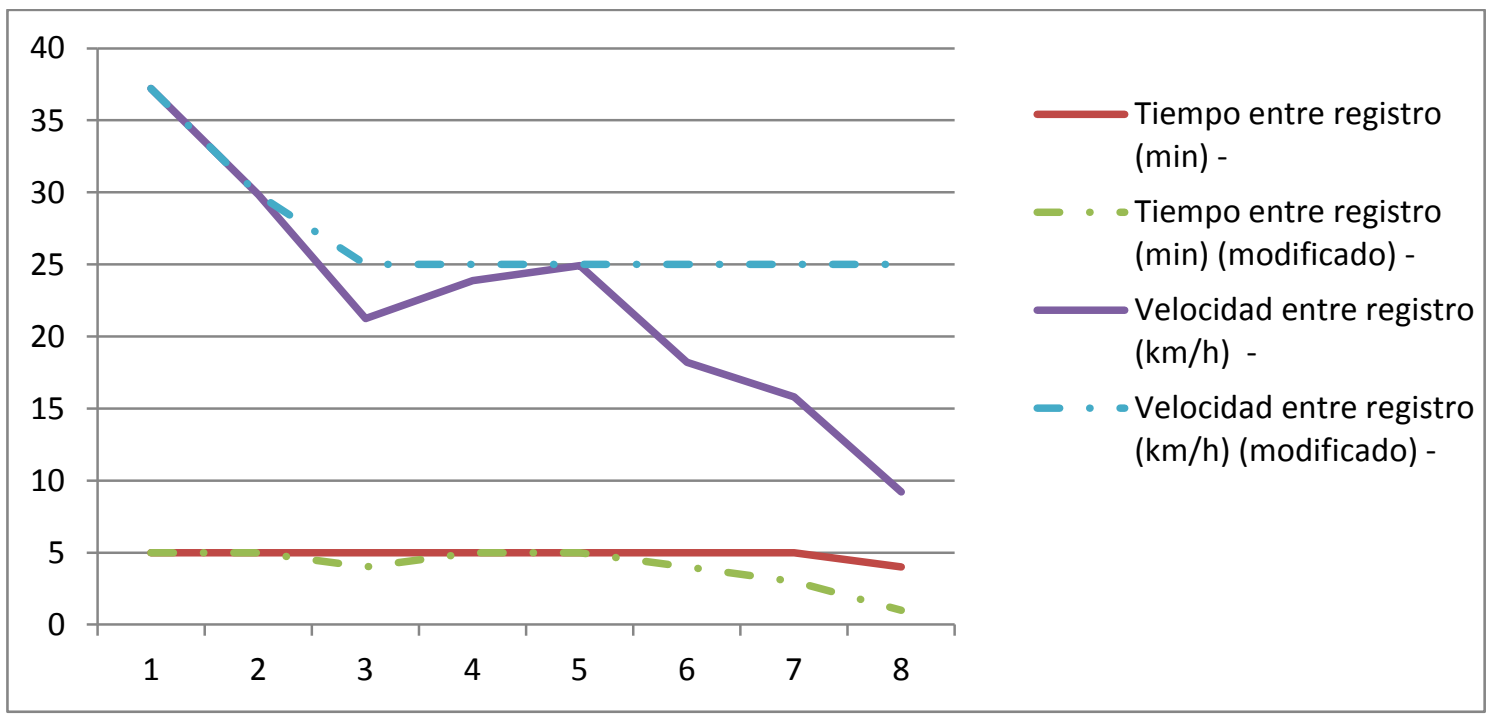

Para estimar los costos de construcción e instalación de los carriles exclusivos, se consideran obras comparables realizadas en el país, como por ejemplo el Metrobus Sur de CABA o el 
realizado en Rosario. Con esa base se estima un costo promedio de $\$ 26.944 .000$ por kilómetro. Teniendo en cuenta las áreas del corredor donde la velocidad de transporte público es menor a $25 \mathrm{~km} / \mathrm{h}$, los kilómetros necesarios de carril exclusivo serían de 9,28 km, es decir, un costo aproximado de \$250.145.940,48. Ver Ilustración 76.

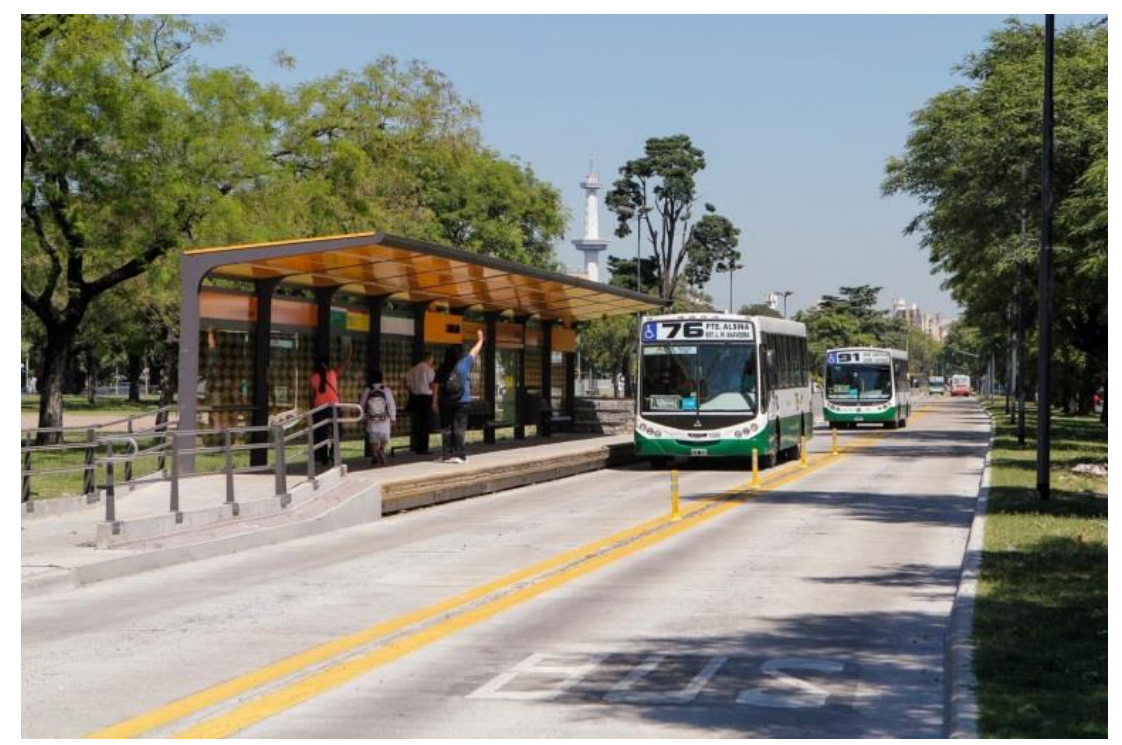

Ilustración 76. Metrobus Sur, C.A.B.A.. Fuente: https://www.cext.es/posts/ciudadania/moverse-porbuenos-aires-sera-mas-caro-a-partir-de-febrero/ (accedido 31-10-2018).

Propuesta conjunta: La implementación de los tres escenarios alternativos planteados permitiría una reducción del 25\% del tiempo de traslado, lo que equivale a reducir 10 minutos del tiempo actual, pasando de 39 minutos a 29 (ver Tabla 53,

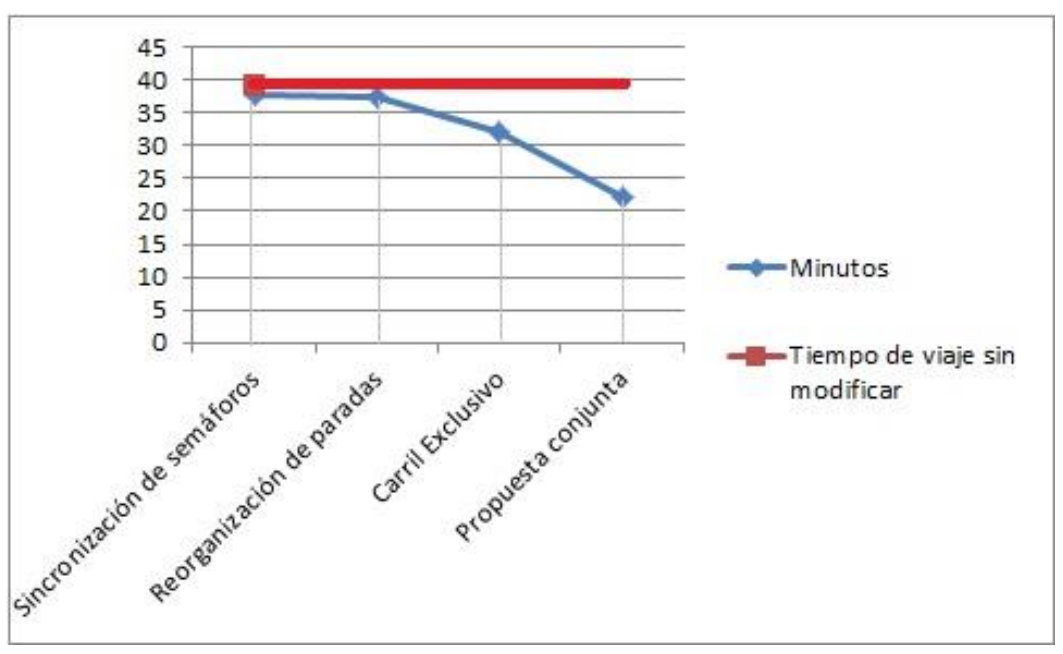

e Ilustración 77) con un costo total similar a la implementación de carriles exclusivos, ya que la sincronización de semáforos y reorganización de paradas, como se analizó, tienen un costo reducido. 
Tabla 53. Síntesis de reducción de tiempo de viaje por propuestas. Fuente: Elaboración propia.

\begin{tabular}{|c|c|c|c|c|c|c|c|c|c|}
\cline { 2 - 10 } \multicolumn{1}{c|}{} & \multirow{2}{*}{$\begin{array}{c}\text { Tiempo de } \\
\text { viaje sin } \\
\text { modificar }\end{array}$} & $\begin{array}{c}\text { Sincronización } \\
\text { de semáforos }\end{array}$ & \multicolumn{2}{c|}{$\begin{array}{c}\text { Reorganización } \\
\text { de paradas }\end{array}$} & \multicolumn{2}{c|}{$\begin{array}{c}\text { Carril } \\
\text { Exclusivo }\end{array}$} & \multicolumn{2}{c|}{$\begin{array}{c}\text { Propuesta } \\
\text { conjunta }\end{array}$} \\
\hline $\begin{array}{c}\text { Reducción de tiempo } \\
\text { por propuesta (min) }\end{array}$ & 0 & 1,12 & 3 & 1,68 & 4 & 7 & 18 & 16,8 & 25 \\
\hline Tiempo de viaje (min) & 39 & \multicolumn{2}{|c|}{37,88} & \multicolumn{2}{|c|}{37,32} & \multicolumn{2}{|c|}{32} & \multicolumn{2}{c|}{22,2} \\
\hline
\end{tabular}

Gráfico 30. Síntesis tiempo de viaje y reducción de tiempo por propuesta. Fuente: Elaboración propia.
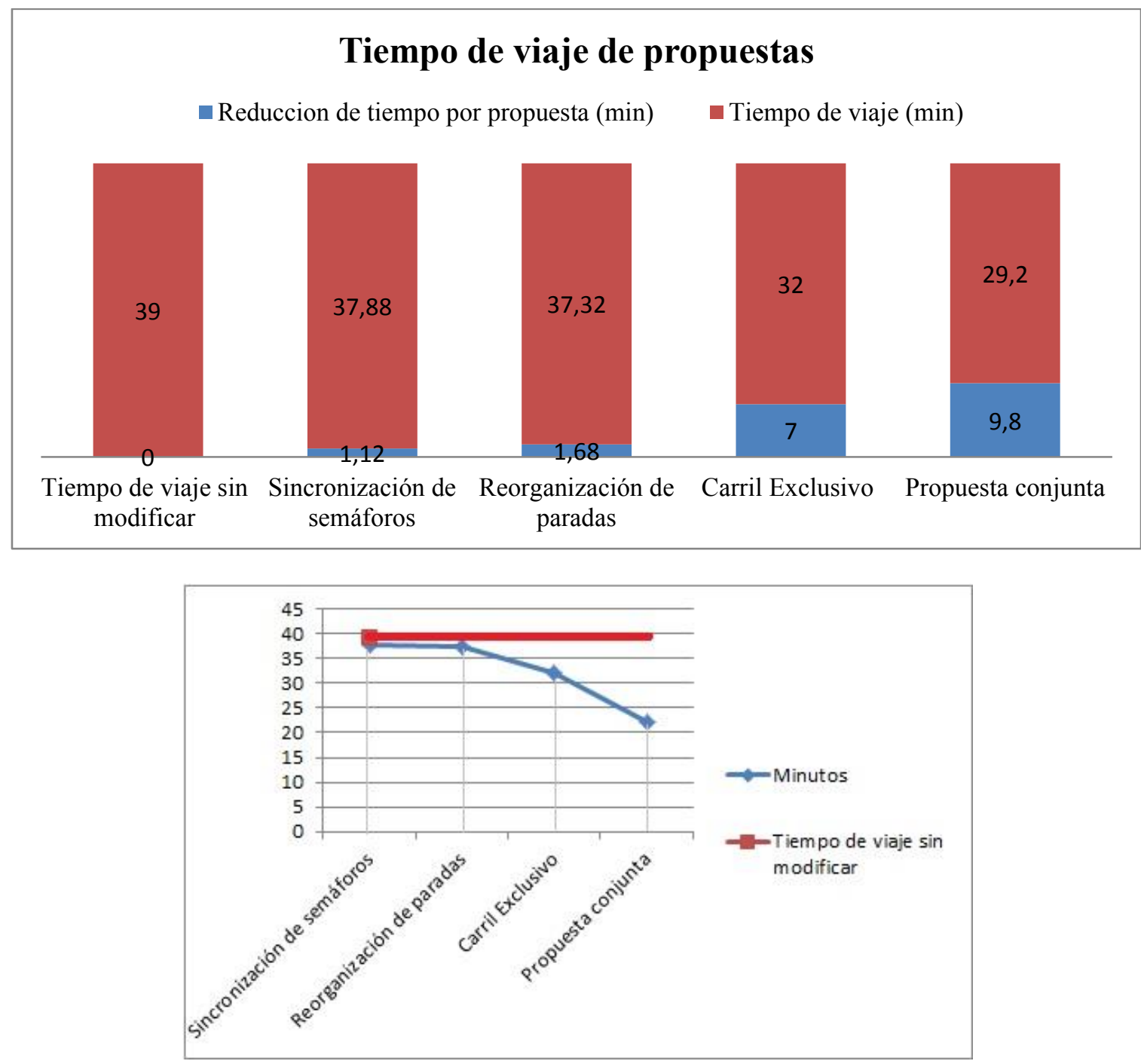


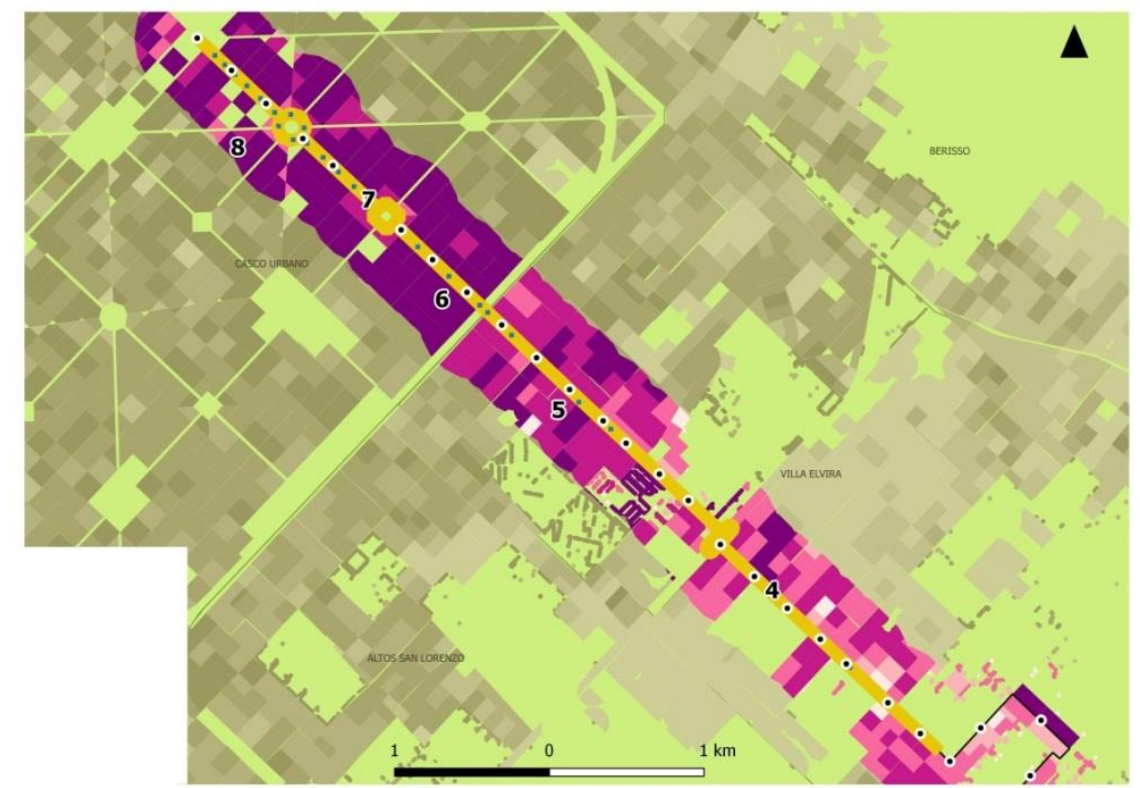

\section{Corredor Av. 7}

- Paradas

- Semaforos

Carril Exclusivo TP - Carril Comun

Viajes en TP

1 - 4

4- 11

$11-33$

$33-86$

$86-1033$

Ilustración 77. Propuesta conjunta, carril exclusivo y distribución de paradas cada 300

metros. Fuente: Elaboración propia.

La concentración de paradas permitiría además, reducir costos de infraestructura de los refugios, mejorar la accesibilidad a la unidad de personas con movilidad reducida ayudando a evitar accidentes y reduciendo el tiempo de ascenso de los pasajeros a la unidad. A su vez reduciría costos de cartelería y señalización de información sobre recorridos de los ramales de cada parada. Estas reducciones serían cercanas al $25 \%$.

\subsubsection{Análisis de medidas a mediano plazo}

En el escenario a mediano plazo, se plantea un incremento de los valores de densidad poblacional en el corredor analizado, incorporando carriles exclusivos para mejorar la racionalidad del transporte público y evaluando la necesidad de modificar el diseño de recorridos del sistema de transporte público.

La normativa de uso de suelo (el Código de Ordenamiento Urbano), plantea zonificaciones diferenciadas para las manzanas frentistas al corredor y reconoce algunas zonas cercanas a arroyos con posibilidad de inundación con la nomenclatura E/AU, pero mantiene las densidades máximas permitidas de las zonas alejadas a los arroyos. Ver Ilustración 78. 


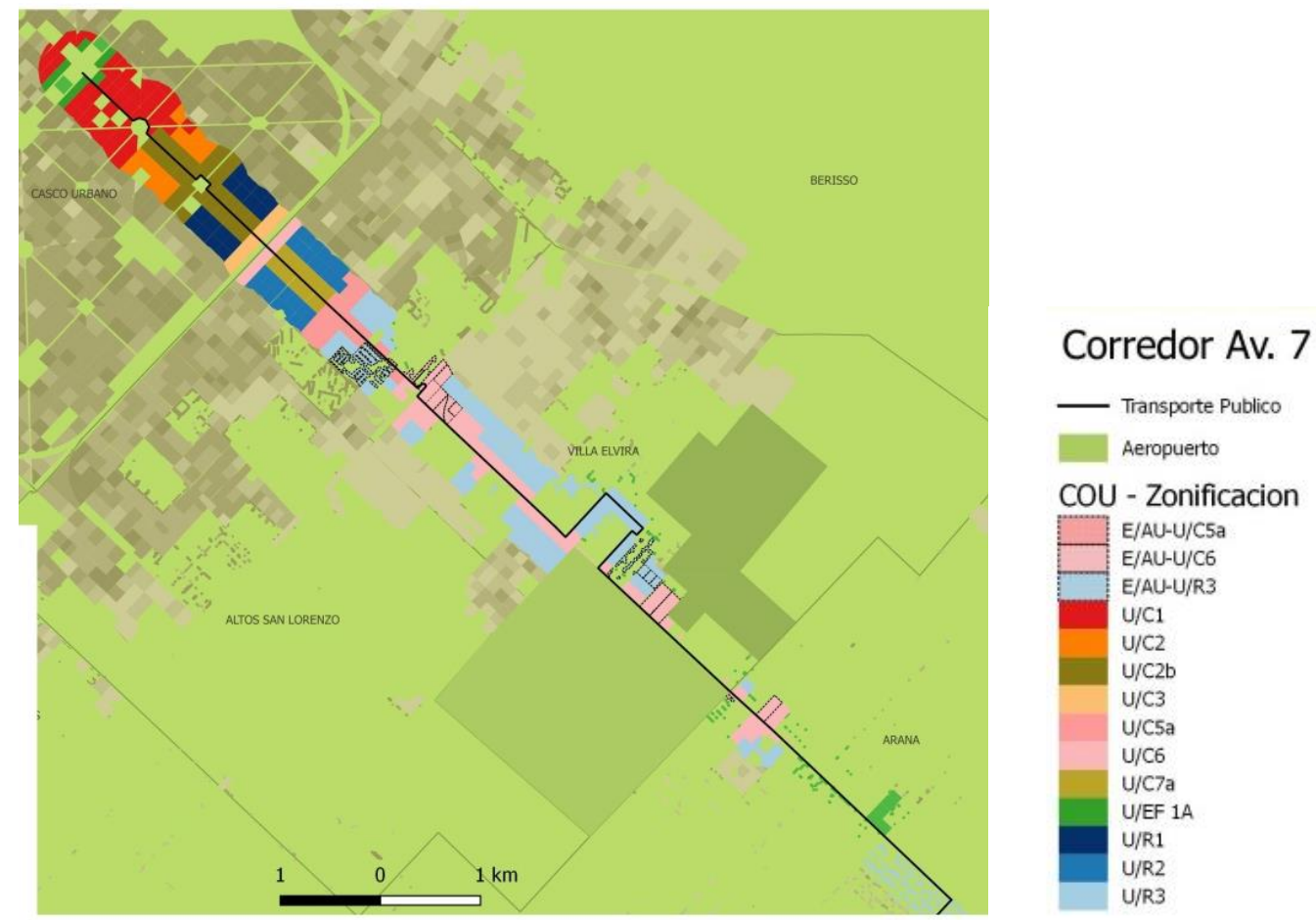

Ilustración 78. Zonificación COU del corredor. Fuente: Elaboración propia, en base al COU de 2010.

Esta zonificación plantea un correlato con las densidades máximas permitidas. En el Casco Urbano las densidades son de 900 y 1000 habitantes por hectárea en las manzanas frentistas al corredor con alturas de 10 niveles en el área céntrica $\mathrm{U} / \mathrm{C} 1$ y 8 niveles en $\mathrm{U} / \mathrm{C} 2 \mathrm{~b}$. Por fuera del casco los índices bajan abruptamente, manteniéndose la densidad sobre el corredor de 300 habitantes por hectárea desde Villa Elvira hasta Arana, de 150 habitantes por hectárea en áreas por fuera del corredor y con una altura máxima de 3 niveles en ambas áreas. Ver Ilustración 79. 


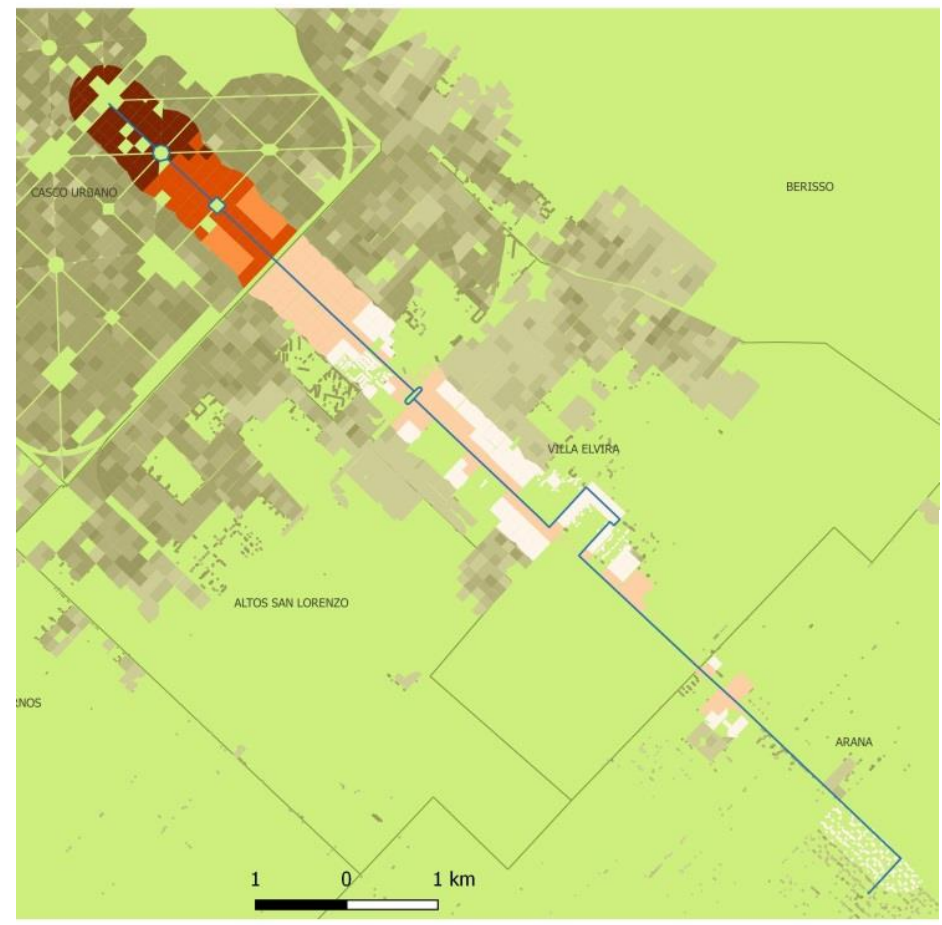

\section{Corredor Av. 7}

- Recorrido TP

Densidad COU

$150-150$

$150-300$

$300-400$

$400-900$

$900-1000$

Ilustración 79. Densidades máximas permitidas por el COU La Plata. Fuente: Elaboración propia, en base al COU de 2010.

Como se observa en la Ilustración 80, a pesar de la propuesta de la normativa para incrementar densidades sobre corredores, resulta insuficiente para lograrlo efectivamente, ya que la tendencia ha sido que las mayores densidades se concentren en las áreas centrales del Casco y no sobre los corredores. Es decir que una propuesta de densificación del corredor debería contemplar otras herramientas de la planificación complementarias. 


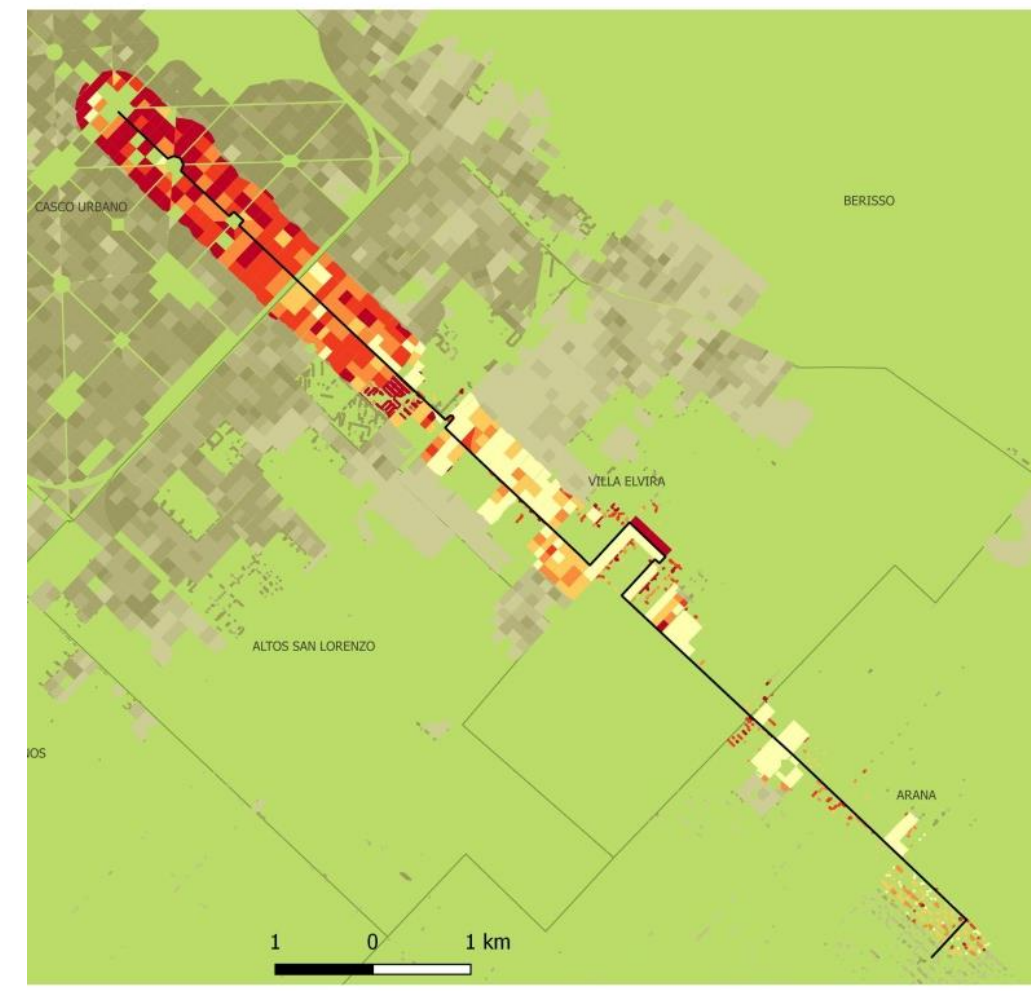

\section{Corredor Av. 7}

- Transporte Publico

Densidad 2014

$2-34$

$34-51$

$51 \cdot 71$

$71-107$

$107-517$

Ilustración 80. Densidad de habitantes por hectárea 2014. Fuente: Elaboración propia, en base a datos de INDEC.

En la periferia, por ejemplo Arana, en el barrio Sicardi donde finaliza el corredor, es el sector del mismo que más crecimiento ha tenido: entre 2001 a 2014 este sector tuvo un $70 \%$ de crecimiento poblacional y un $339,2 \%$ de crecimiento habitacional. Pero este crecimiento se ha dado en una densidad muy baja, con valores que rondan los 10 habitantes por hectárea en las zonas más densas y que a su vez están cubiertas por el transporte público.

En este marco es necesario, por un lado, intervenir desde los instrumentos de gestión y planificación para disipar el proceso de densificación en las áreas centrales del casco hacia los corredores y por otro lado restringir la expansión urbana de baja densidad.

En este contexto, la propuesta del escenario alternativo planteado a mediano plazo es analizar las transformaciones en los tiempos de viaje del transporte público si se lograra incrementar la densificación sobre el corredor seleccionado teniendo en cuenta las proyecciones de crecimiento poblacional en el área para el año 2030. En ese sentido la propuesta consiste en concentrar el crecimiento de la población en las manzanas frentistas a dicho corredor.

Debido a que el corredor está atravesado por el arroyo Maldonado y para evitar que la propuesta de densificación se asiente en zonas con probabilidad de inundación, se decidió no 
incrementar el índice de densificación en un radio de 100 metros de las distintas bifurcaciones del arroyo. Ver Ilustración 81.

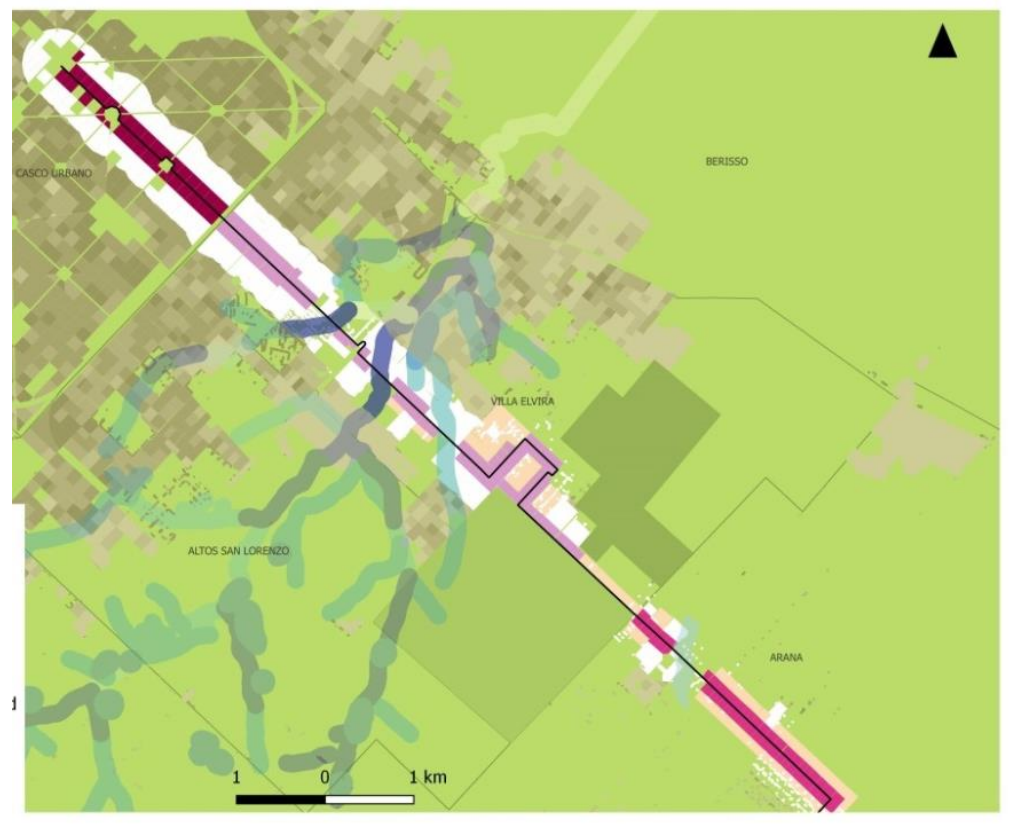

\section{Corredor Av. 7}

- Transporte Publico

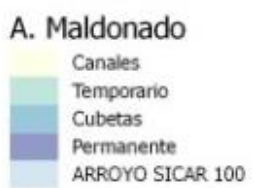
Incremento densidad

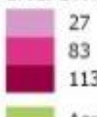

27
83
113

Aeropuerto

Futuro crecimiento

Ilustración 81. Propuesta de densificación del corredor Av. 7. Fuente: Elaboración propia, los cursos de agua provienen de información histórica construida por el IIPAC FAU UNLP.

En este marco, la población estimada que incrementará la densidad poblacional sobre el corredor es de 4.849 en el Casco Urbano que se ubicarán en 43 manzanas, es decir un promedio de 113 personas por manzana. En Villa Elvira, el incremento de la población proyectada con cobertura del corredor para el año 2030 resulta en una suma de 2.283 habitantes que se ubicarían en 86 manzanas sobre el corredor de transporte, lo que resulta en un promedio de 27 habitantes por manzana. Ver Tabla 54.

Tabla 54. Propuesta de densificación del corredor Av. 7. Fuente: Elaboración propia, en base a datos de INDEC.

\begin{tabular}{|l|c|c|c|c|}
\hline \multicolumn{1}{|c|}{ Delegación } & $\begin{array}{c}\text { Población } \\
\text { cubierta 2014 }\end{array}$ & $\begin{array}{c}\text { Población } \\
\text { cubierta 2030 }\end{array}$ & $\begin{array}{c}\text { Incremento } \\
\text { Poblacional }\end{array}$ & $\begin{array}{c}\text { Habitantes a } \\
\text { ubicar x Manzana } \\
\text { en corredor }\end{array}$ \\
\hline Arana & 2041 & 3674 & 1633 & 46 \\
\hline Casco Urbano & 24957 & 29806 & 4849 & 113 \\
\hline Villa Elvira & 19972 & 22255 & 2283 & 27 \\
\hline
\end{tabular}

El barrio de Arana tiene como único acceso el corredor seleccionado, por lo cual se estimó la población como la suma de los habitantes dentro y fuera del área de cobertura aunque con una 
reducción del $50 \%{ }^{78}$, lo que significa un incremento de población para el año 2030 de 1.633 habitantes. El objetivo de la medida propuesta es que se densifiquen 54 manzanas con un promedio de 46 habitantes por manzanas.

El resultado es un incremento de la población sobre el corredor del 112\% para el sector de Arana, del 40\% en el Casco Urbano y del 27\% en Villa Elvira. Ver Tabla 55, Ilustración 82 y Gráfico 31.

Tabla 55. Población 2014, 2030 e incremento del período. Fuente: Elaboración propia, en base a datos de INDEC.

\begin{tabular}{|l|c|c|c|c|}
\hline \multirow{2}{*}{ Delegación } & \multirow{2}{*}{$\begin{array}{c}\text { Población } \\
\text { corredor 2014 }\end{array}$} & \multicolumn{2}{|c|}{ Incremento poblacional } & \multirow{2}{*}{$\begin{array}{c}\text { Población corredor } \\
2030\end{array}$} \\
\cline { 3 - 5 } & 1459 & 1633 & 112 & 3092 \\
\hline Arana & 12136 & 4849 & 40 & 16985 \\
\hline Casco & 8343 & 2283 & 27 & 10626 \\
\hline Villa Elvira & & & & \\
\hline
\end{tabular}

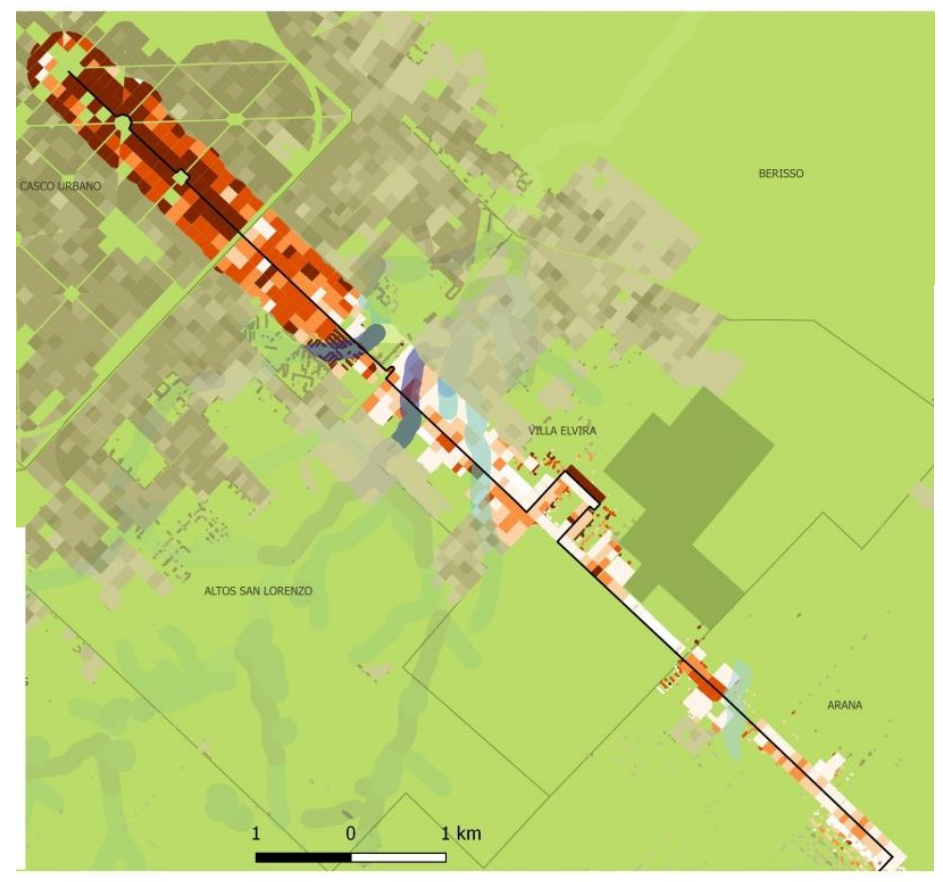

\section{Corredor Av. 7}

\begin{tabular}{l} 
Transporte Pủblico \\
ArroyOS \\
CANALES \\
TEMPORARIO \\
CUBETAS \\
PERMANENTE \\
ARROYO SICAR 100 \\
Densidad \\
$2-35$ \\
$35-54$ \\
$54-74$ \\
$74-112$ \\
$112-600$ \\
Cantera \\
\hline
\end{tabular}

\section{Ilustración 82. Aproximación de implementación de propuesta de densificación del}

corredor Av. 7. Fuente: Elaboración propia, en base a datos de INDEC, y archivo histórico IIPAC FAU.

\footnotetext{
${ }^{78}$ Estimación propia basada en el criterio de que un sector de los habitantes del barrio Sicardi decide instalarse en zonas de muy baja densidad en búsqueda de tranquilidad y vegetación, es decir que no desearía instalarse sobre un corredor de transporte. Ver Vértiz, F. (2016). "La intervención estatal en la producción de la ciudad. Conformación y orientación política en el partido de La Plata (2003-2014). Pag. 186. Tesis doctoral en Ciencias Sociales. FAHCE UNLP.
} 
Gráfico 31. Población sobre el corredor por delegación 2014-2030. Fuente: Elaboración propia, en base a datos de INDEC.

Poblacion sobre corredor 2014-2030

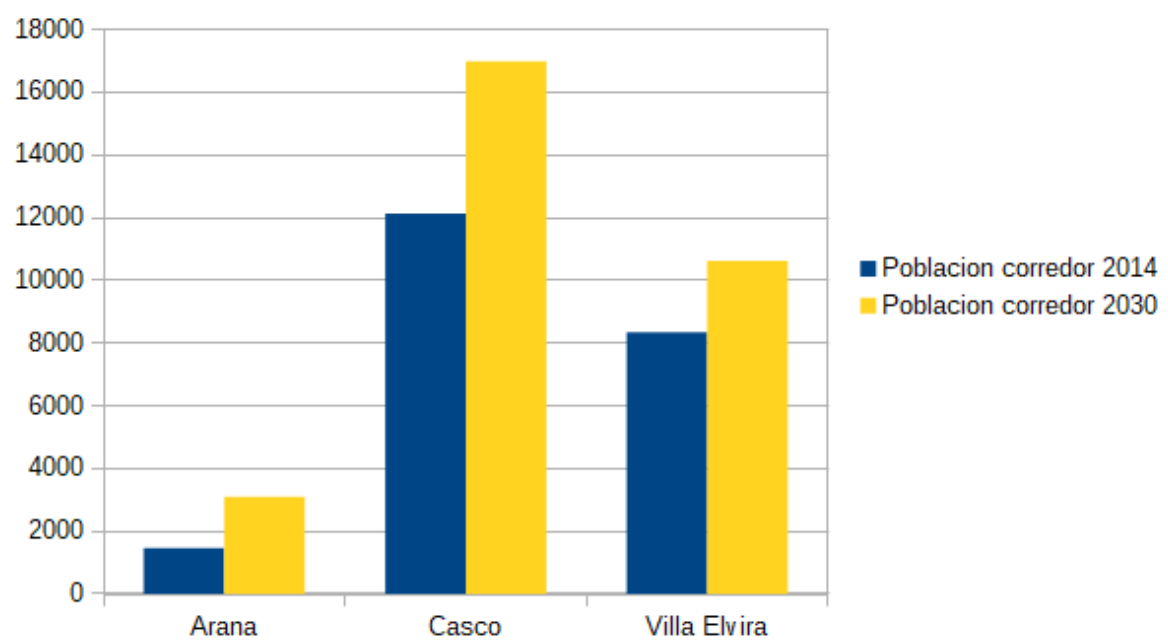

Algunos estudios, como Cervero, R. (2013), donde plantea que la incorporación de infraestructura de segregación de transporte público que permite aumentar la velocidad operativa del servicio (como en el caso del BRT), produce una trasferencia de viajes de los modos no masivos al transporte público que van del $24 \%$ al $33 \%$ en zonas de cobertura. Teniendo en cuenta esos valores, se estimó un promedio de incremento del $28 \%$ de los viajes en transporte público a partir de una reducción de los viajes no masivos producidos en las manzanas que se encuentran sobre el corredor.

Es así que en toda la zona de cobertura a partir de ese incremento la cantidad de viajes en colectivo aumentaría un $21 \%$, suponiendo que el aumento de viajes vendría de un traspaso de viajes provenientes de los modos no masivos (se reducirían en 1.444 viajes) a los masivos, que pasarían al colectivo. Teniendo en cuenta que la relación "Autos por viaje no masivo" para el área es de 1,85, se podría estimar que dejarían de circular cerca de 781 autos diarios de la zona densificada sobre el corredor. Suponiendo que el promedio de superficie que ocupa un auto es aproximadamente $7,5 \mathrm{~m} 2$, se liberarían $5.847,5 \mathrm{~m} 2$ de las calles de la ciudad lo que ayudaría a reducir la congestión y por esa vía los tiempos de viaje de todos los modos motorizados.

Con ese incremento del $21 \%$ en viajes en colectivo la partición modal de las manzanas del Casco que están sobre el corredor sería del $48,6 \%$ para los viajes en colectivo y $16,3 \%$ para autos y motos, en las que están Villa Elvira el 69,3\% en colectivo y 11,6 en no masivos, y en las de Arana el 57,1\% en colectivo y el 42,9\% en no masivos. Ver Tabla 56. 
Tabla 56. Viajes en colectivo y no masivos por delegación a partir de la densificación del corredor Av. 7. Fuente: Elaboración propia, en base a la Encuesta de Movilidad del Gran La Plata GII IIPAC FAU.

\begin{tabular}{|c|c|c|c|c|c|}
\hline \multirow{2}{*}{ Delegación } & \multicolumn{2}{|c|}{ Viajes en colectivo } & \multicolumn{2}{|c|}{ Viajes no masivos } & \multirow{2}{*}{ Total } \\
\cline { 2 - 5 } & Cantidad & $\%$ & Cantidad & $\%$ & \\
\hline Arana & 2830 & 57,1 & 698 & 42,9 & 4285 \\
\hline Casco & 13871 & 48,6 & 2103 & 16,3 & 18129 \\
\hline Villa Elvira & 6797 & 69,3 & 4079 & 11,6 & 9713 \\
\hline
\end{tabular}

\subsubsection{Análisis de medidas a largo plazo}

El escenario alternativo propuesto a largo plazo consiste en analizar la posible reducción de la producción de viajes a otras delegaciones a partir de la descentralización de actividades disminuyendo los tiempos de viaje y la congestión, reduciendo distancias entre origen y destino, favoreciendo los viajes no motorizados.

Para ello se consideró como área testigo la analizada en los escenarios a corto y mediano plazo, es decir un segmento del corredor de Av. 7 hacia la zona Sur del partido de La Plata y su radio de cobertura de transporte público que contempla sectores de Villa Elvira, Arana (más exactamente el barrio Sicardi) y el Casco Urbano. Para ello se analizaron los datos provenientes de la Encuesta de Movilidad realizada por el GII del IIPAC-CONICET-UNLP en el año 2013.

Los resultados muestran, como ya se analizó en el capítulo anterior, una gran dependencia de las delegaciones periféricas a las actividades del Casco. En ese marco los resultados para Arana son elocuentes, el $94 \%$ de los viajes producidos tiene destino a actividades que se producen en otras delegaciones, para Villa Elvira el porcentaje es del 90\%, mientras que en el Casco Urbano solo del 13\%. Ver Gráfico 32. 
Gráfico 32. Porcentajes de destinos de viajes internos y externos de cada delegación del corredor Av. 7. Fuente: Elaboración propia, en base a la Encuesta de Movilidad del Gran La Plata GII IIPAC FAU.

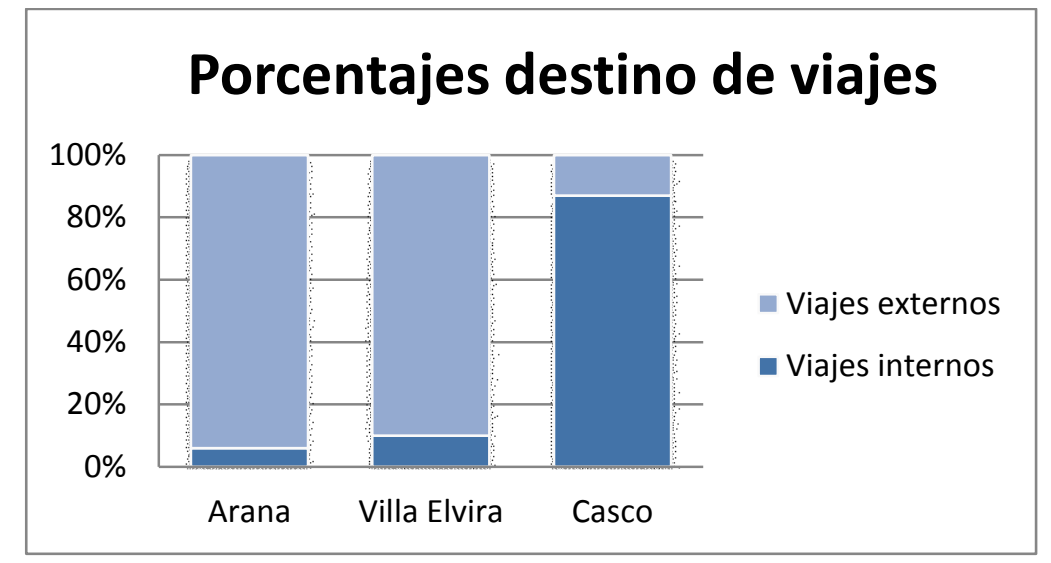

En el caso de Arana, el 59\% de las actividades que se producen en otras delegaciones son por trabajo, el $17 \%$ por estudio, el $12 \%$ compras/tramites, el $6 \%$ viajes por salud y $6 \%$ para llevar y traer niños de la escuela. En Villa Elvira que posee una mayor diversidad de usos, los viajes con destino por fuera de la delegación con el objetivo de llegar al trabajo alcanzan el 83\%, 7\% por estudio, $5 \%$ por salud, 3\% compras/tramites y $2 \%$ llevar y traer niños. En tanto en el Casco Urbano el $95 \%$ de los viajes externos son por trabajo, el $4 \%$ por estudio y solo el $1 \%$ por salud. Ver Gráfico 33 y Tabla 57.

Gráfico 33. Motivos de viaje externo por delegación del corredor Av. 7. Fuente: Elaboración propia, en base a la Encuesta de Movilidad del Gran La Plata GII IIPAC FAU.

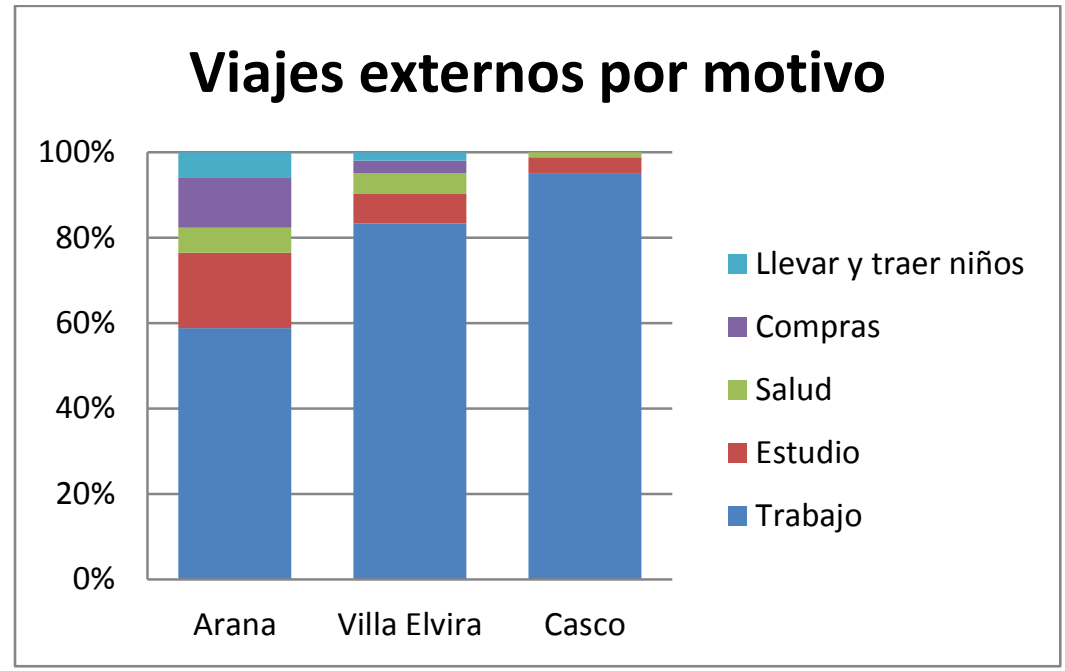


Tabla 57. Porcentaje motivos de viaje por delegación del corredor Av. 7. Fuente: Elaboración propia, en base a la Encuesta de Movilidad del Gran La Plata GII IIPAC FAU.

\begin{tabular}{|c|c|c|c|c|c|}
\hline Delegación & Trabajo & Estudio & Salud & Compras & $\begin{array}{c}\text { Llevar y } \\
\text { traer } \\
\text { niños }\end{array}$ \\
\hline Arana & 59 & 17 & 6 & 12 & 6 \\
\hline Villa Elvira & 83 & 7 & 5 & 3 & 2 \\
\hline Casco & 95 & 4 & 1 & - & - \\
\hline
\end{tabular}

En este contexto se plantea como escenario alternativo a largo plazo, la descentralización de algunas actividades. En esta primera instancia se plantea diversificar los usos en cada delegación relacionados al estudio, salud, compras o llevar y traer hijos de la institución educativa, A partir de esta implementación se podrían reducir las necesidades de desplazamientos a otras delegaciones. Por otro lado, tanto la actividad laboral como el estudio a nivel universitario resultan más difíciles de descentralizar, por lo cual para estos casos se requeriría un mejoramiento de la movilidad urbana. Así, podría decirse que en el largo plazo una política de descentralización a partir de la construcción de nuevas centralidades podrían absorber en Arana el 3,5\% de los viajes por estudio, el $6 \%$ de los viajes por salud, $12 \%$ de compras/tramites y $6 \%$ de llevar y traer niños del colegio. Para el caso de Villa Elvira se podría reducir el 1,4\% de los viajes de estudio, el 5\% de salud, el 3 de compras/tramites y el $2 \%$ de llevar y traer niños al colegio. Es decir que con la descentralización de actividades se podrían reducir el $27 \%$ de los viajes producidos en Arana y el 11,4\% de los viajes producidos en Villa Elvira a otras delegaciones, sobre todo al Casco Urbano. Estos porcentajes equivalen a 694 viajes desde Arana y a 355 autos que podrían dejar de circular en el Casco y otras delegaciones. También equivale a 3.671 viajes producidos en Villa Elvira y un total de 1.984 autos menos desde el área cubierta por el corredor de dicha delegación. Ver Tabla 58.

Tabla 58. Porcentajes de actividades al Casco Urbano que se evitarían con la descentralización de actividades de servicio, viajes totales y autos menos con destino al

Casco Urbano. Fuente: Elaboración propia, en base a la Encuesta de Movilidad del Gran La Plata GII IIPAC FAU.

\begin{tabular}{|c|c|c|c|c|c|c|c|}
\hline \multirow{2}{*}{ Delegación } & \multicolumn{6}{|c|}{ Porcentaje de viajes a actividades al Casco que se evitarían } & \multicolumn{2}{c|}{$\begin{array}{c}\text { Viajes } \\
\text { con la descentralización } \\
\text { Casco al }\end{array}$} & $\begin{array}{c}\text { Autos } \\
\text { menos al } \\
\text { Casco }\end{array}$ \\
\cline { 2 - 8 } & Estudio & Salud & $\begin{array}{c}\text { Compras/ } \\
\text { tramites }\end{array}$ & $\begin{array}{c}\text { Traer/ } \\
\text { llevar niños }\end{array}$ & Total & 694 & 355 \\
\hline Arana & 3,5 & 6 & 12 & 6 & 27,5 & 694 \\
\hline Villa Elvira & 1,4 & 5 & 3 & 2 & 11,4 & 3671 & 1984 \\
\hline TOTAL & 4,9 & 11 & 15 & 8 & 38,9 & 4365 & 2339 \\
\hline
\end{tabular}


Es importante aclarar que existen centros atractores de este tipo de actividades sobre el área de cobertura del corredor de transporte, tales como Escuelas primarias, secundarias, delegaciones municipales, centros de salud, hospitales, bancos y cajeros automáticos.

La Ilustración 83 muestra que la mayoría de las actividades se concentran en el área 8 donde se sitúa el área central del Casco Urbano que cubre el recorrido de transporte que utiliza el corredor seleccionado. En la delegación de Villa Elvira el área 5, la contigua al Casco Urbano, es la que más centros atractores posee, además de ser la que más comercios diarios concentra, cuenta con dos escuelas primarias, una secundaria, un centro de salud, la delegación municipal de Villa Elvira y el único cajero automático de todo el corredor por fuera del Casco Urbano. El área 4 solo cuenta con una escuela primaria, el 3 y 2 un centro de salud cada una y el área 1 no posee ningún centro atractor de estas características.

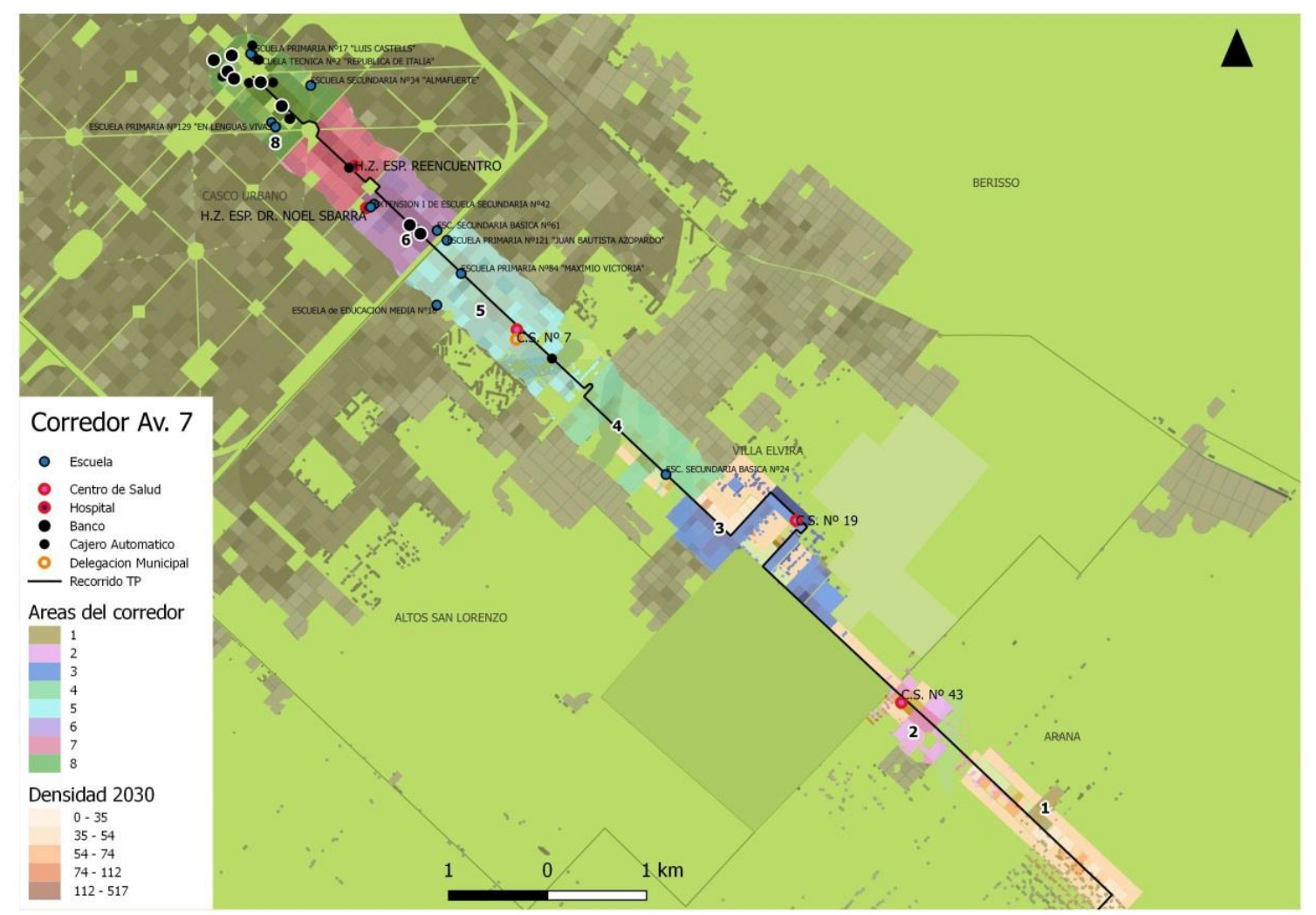

Ilustración 83. Usos atractores de viaje en el corredor Av. 7. Fuente: Elaboración propia, en base a información difundida por el Municipio de La Plata (Datos Abiertos.)

Es decir que podría existir problemas de capacidad operativa de esas instituciones lo que dificultaría cubrir la demanda del área de cobertura del corredor, o problemas de otro tipo que impulsan a los habitantes a cubrir sus actividades en el Casco u otras delegaciones en un $90 \%$ en Villa Elvira, y un 94\% en Arana. 


\section{Síntesis del Capítulo IV}

En este capítulo se avanzó en la construcción de los escenarios tendencial y alternativos. El primer escenario analizado, el tendencial a 2030, demostró que las tendencias analizadas a partir del año base, muestran una consolidación de las formas de crecimiento dispersas en delegaciones con servicios de infraestructura y transporte precarios, con mayor población con NBI y con altos costos por desplazamiento, consumo y emisiones de contaminantes.

En ese marco, las tendencias al incremento de la tasa de generación de viaje que podría alcanzar el 2,04 y una tasa de motorizacion de 2,7 personas por auto en 2030, plantea un escenario de tiempo de viaje de transporte público muy crítico que varían entre un incremento del $49 \%$ al $153 \%$ en las líneas analizadas.

Para prevenir ese escenario se proponen medidas a corto, mediano y largo plazo, expresadas en cada uno de los escenarios alternativos propuestos, donde el alcance temporal de soluciones tiene una relación con el tiempo necesario para implementarlos. Por un lado, con las medidas a corto plazo (como puede ser la sincronización de semáforos o la reorganización de paradas cada 300 metros en las áreas que hoy tienen una distancia menor a ese valor) se llegaría al límite de tener una distancia promedio de 156 metros en el área central del Casco Urbano para las líneas del corredor analizado.

Por otro lado, se evaluó la incidencia de la incorporación de un carril exclusivo para transporte público que permita alcanzar velocidades no menores a los $25 \mathrm{~km} / \mathrm{h}$, cuando en las áreas más congestionadas del Casco Urbano las velocidades son cercanas a los $9 \mathrm{~km} / \mathrm{h}$. De conjunto estas medidas de posible aplicación casi inmediata podrían disminuir el tiempo de viaje en transporte público en un $23 \%$ en el corto plazo.

Como se mencionó este tipo de medidas pueden significar una transformación importante en el corto plazo, pero son insuficientes para contrarrestar las tendencias negativas de la movilidad que está generando el rumbo del desarrollo de la ciudad. En cuanto a la propuesta a mediano plazo, para este caso se planteó la densificación del corredor de transporte con vías segregadas, que permitiría absorber viajes en modos no masivos hacia el transporte público incrementando su uso en aproximadamente un $21 \%$. Este traspaso de viajes en modos no masivos a masivos implicaría una reducción de 781 autos circulando, lo que aportaría a reducir la congestión y a través de éste, los tiempos de viaje de todos los modos. A su vez aportarían a disminuir el consumo energético y emisiones de contaminantes. 
El escenario a largo plazo se basa en promover los viajes cortos en tiempo y distancia, posibles de realizar en modos no motorizados, a partir de la descentralización de actividades en delegaciones periféricas. Esta propuesta permitiría reducir la necesidad de desplazamiento con medios motorizados en un $27 \%$ de los viajes producidos en Arana y en un $11 \%$ de los producidos en Villa Elvira, implicando una reducción de 2.339 autos circulando en la ciudad, con las ventajas antes mencionadas.

Esta descentralización deberá en primera instancia basarse en un diagnostico que permita evaluar si el problema tiene aspectos cuantitativos, cualitativos o una combinación de ambos. Es decir, si el problema radica en que la oferta de actividades de educación, salud o compras/tramites es cuantitativamente insuficiente para la demanda por lo que los habitantes se ven en la necesidad de recurrir a centros atractores de otras delegaciones. Por otro lado, este comportamiento radica en aspectos cualitativos como la calidad de los servicios ofrecidos en el área, el precio o cualquier otro motivo de estas características.

Por último, es necesario remarcar que la posibilidad de densificación sobre el corredor o la de descentralizar actividades, necesitarán una política de usos de suelo más ofensiva que la reglamentación de alturas y densidades permitidas de un código de ordenamiento urbano por parte del municipio. Es decir que requerirán la utilización de herramientas de planificación como la realización de algún Plan Maestro para la zona que contemple las áreas inundables, el reajuste de parcelas o la contribución por mejoras. Es necesario, a su vez, que dichas políticas contemplen mecanismos de financiamiento o recuperación de plusvalías urbanas que provengan de los beneficiarios con mayor poder adquisitivo. En función de los resultados obtenidos, el siguiente capítulo plantea pautas de planificación para el Gran La Plata. 


\section{Resumen}

En este capítulo se expondrán algunas pautas de planificación de la movilidad focalizando en integrar las políticas de transporte público y desarrollo urbano que se desprenden de las problemáticas analizadas en el escenario base y en los escenarios alternativos. Si bien no fue la única variable involucrada en los análisis, la variable tiempo de viaje demostró ser importante a la hora de pensar posibles soluciones a las problemáticas asociadas a la movilidad urbana.

En ese marco las pautas propuestas se pueden agrupar en: a) pautas para la mejora del sistema de transporte público de pasajeros; b) pautas para orientar políticas de uso de suelo con criterios de movilidad; c) ideas de un modelo de gestión del transporte público más eficiente; y, por último, d) algunas pautas para el financiamiento del transporte público de La Plata. 


\subsection{Pautas para la planificación integrada de los usos del suelo y transporte público}

El proceso histórico de conformación del servicio estuvo basado en la competencia entre actores del sector privado empresarial por recorridos rentables. A principios del '00, la Dirección de Transporte de La Plata impulsa el SUT con el objetivo de reducir esta competencia que tenía un impacto negativo en cobertura de áreas periféricas; instrumenta entre cuatro empresas la distribución de las grandes zonas de cobertura de la ciudad ${ }^{79}$, cada una con una línea distinta. Pero esta propuesta, aunque es distinta a la propuesta original, no resolvió el problema de la competencia, solo la concentró en las zonas céntricas del casco urbano donde confluyen todas las líneas y existe una gran sobreoferta.

Como alternativa de diseño del sistema de transporte público, a partir de la investigación realizada, es que se propone la re organización del sistema a partir de corredores de transporte público que atraviesen las zonas periféricas, definidas a través de estudios de demanda por centros atractores de difícil descentralización y factibles de desarrollar.

Los escenarios alternativos mostraron (para el corto plazo) que la sincronización de semáforos sobre los principales corredores de transporte público mejoraría las velocidades de las unidades y aportaría a la dinámica de manejo de los conductores. Como se demostró en el Capítulo IV, a partir del caso de estudio se estimó que la sincronización de semáforos podría reducir entre un 3\% y un 5\% el tiempo de viaje. También la separación de 300 metros entre paradas propuesta por los choferes podría reducir el tiempo de traslado en un 7\% y el carril exclusivo lo podría reducir en un $18 \%$.

Estas propuestas, de implementación y alcance de corto plazo, podrían mejorarse con una distancia entre paradas superior a 300 metros en corredores más extensos, con muchos vacíos urbanos o con infraestructuras de mayor cantidad de carriles como por ejemplo el Camino Centenario de la zona Norte del Partido de La Plata, que se compensaría con tiempos de viaje menores.

El rediseño del sistema de transporte público sobre corredores, con segregación de vías, sincronización de semáforos y ampliación de la separación espacial entre paradas, implicaría a su vez la necesidad de implementar rondines para poder cubrir barrios no alcanzados por los

\footnotetext{
${ }^{79}$ Zona Norte, Sur, Este y Oeste.
} 
corredores principales. La propuesta debería contemplar que las áreas que se sitúen a más de 600 metros de los corredores puedan tener un rondín propio que conecte a la red principal. Los coches a utilizar deberían ser de menor capacidad si son áreas de baja densidad, lo que permitiría un menor consumo energético y una reducción del costo operativo. Esta alternativa podría garantizar la cobertura de las áreas más alejadas donde en muchos casos residen sectores sociales con índices más altos de N.B.I. y que poseen una mayor dependencia del transporte público para acceder a los servicios de salud, educación y trasladarse al trabajo, al mismo tiempo que haría más racional y eficiente al sistema.

Asimismo, es necesario que para la consolidación de los corredores mencionados en el punto anterior se contemple la implementación de políticas de desarrollo urbano que tengan como objetivo densificar las manzanas sobre ellos. A partir de estas políticas es necesario buscar progresivamente una distribución equilibrada del crecimiento poblacional y habitacional (hoy concentrada en las áreas centrales del casco o distribuidas en baja densidad o muy baja densidad en las delegaciones periféricas).

Tales políticas no deben ser sólo normativas de alturas, usos, densidades y parcelamientos. Es necesario la aplicar instrumentos urbanísticos como Planes Maestros que contemplen mecanismos de recuperación de plusvalía para su desarrollo, explorar posibilidades de Cesiones de Suelo, Reajuste de Parcelas o Contribución por Mejoras para crecer sobre los vacíos urbanos que existen en los corredores y gravámenes para inmuebles en desuso que también se encuentren sobre los corredores. También la creación de un Banco de Tierras Municipal que permita ayudar al control del crecimiento urbano y de los valores del suelo, así como otras normativas y regulaciones que puedan intervenir en el mercado inmobiliario en miras de este objetivo.

A su vez, es necesaria una política de descentralización de actividades, comenzando por aquellas en las que tiene injerencia el Estado, como son las instituciones de salud, educación y delegaciones municipales que permitan la descentralización de trámites. Es muy importante que la descentralización no signifique una pérdida de calidad de estos servicios, ya que si esto sucediera, es posible que no cumplan su rol y continúe existiendo demanda de viajes a otras delegaciones que provean un mejor servicio. Esta política permitiría reducir las distancias y tiempos de viaje favoreciendo la utilización de modos no motorizados para el desplazamiento, lo que mejoraría notablemente los niveles de congestión, costos de traslado y consumo de combustible y producción de emisiones contaminantes. Además permitiría a la población disponer de más tiempo (que antes destinaba a la movilidad) para la realización de otras actividades. 


\subsection{Ideas para un modelo de gestión más eficiente}

La problemática de gestión del Transporte Público en el Gran La Plata en 2013 se puede resumir en la confluencia de varias cuestiones. Una de ellas, de carácter histórico, moldeó las características del empresariado local ligado al transporte y la lógica de los gobiernos municipales hacia éstas. Se inició en el marco de la decadencia en la que cayó la ciudad luego del proyecto asociado al puerto que la generación del '80 tenía para la región de La Plata, Berisso y Ensenada y continúa en la actualidad. Este elemento es el histórico rol facilitador del municipio para el funcionamiento del transporte colectivo como iniciativa privada, cuyo desarrollo se fundamenta en la competencia por los recorridos que tuvieran mayor rentabilidad, en primer momento compitiendo con el tranvía y posteriormente entre las distintas líneas de colectivos. Esta situación, aunque detectada por los equipos técnicos que dieron como resultado el SUT a inicios de los años '00, tampoco pudo ser resuelta en ese momento a pesar del esfuerzo realizado, incidiendo incluso en la imposibilidad de la implementación de la propuesta original.

Como se desarrolló en el punto 3.2., la división por zonas de explotación, junto con la diferenciación en subsidios entre líneas provinciales y municipales en los últimos años, favoreció el fortalecimiento de la concentración de líneas en cada vez menos empresas, que pasaron a tener rasgos oligopólicos, incrementando para el municipio las dificultades no sólo para modificar fácilmente aspectos del sistema de transporte, sino también para controlar que se cumplieran los contratos.

Esta situación está relacionada con otra de las cuestiones que hacen a la problemática a la gestión del transporte, y que tiene que ver con las dificultades para construir equipos técnicos en el área de transporte con los recursos necesarios y con la posibilidad de construir una autoridad regional que administre la totalidad del sistema de transporte del Gran La Plata. El último punto está vinculado a la política Nacional sobre los transportes públicos urbanos, en la que (durante el período de estudio) los subsidios del Estado alcanzaron el $81 \%$ de los ingresos de las empresas prestadoras del servicio. Es decir que, estimando un margen de ganancias entre el $15 \%$ y el $17 \%^{80}$, las empresas eran financiadas casi en su totalidad por el Estado Nacional, con la contradicción de que el funcionamiento del sistema de transporte público estaba regido por la racionalidad empresarial desarrollada anteriormente.

\footnotetext{
${ }^{80}$ Información brindada off the record por un actor clave del gobierno municipal de La Plata.
} 
En esta compleja situación, las pautas para mejorar la gestión del transporte público del Gran La Plata deberían partir de jerarquizar la problemática de la movilidad desde los distintos estamentos estatales, nacional, provincial y de los municipios. Sin esto no existe perspectiva alguna de mejora. Dicha jerarquización deberá traducirse en recursos financieros e institucionales para la construcción y formación de equipos técnicos equipados y con incumbencia regional.

Los resultados de la experiencia del proceso de implementación del SUT, en el que existieron equipos técnicos capaces, se contó una encuesta de movilidad y una relación de colaboración mutua entre la Dirección de Transporte municipal y la Universidad Nacional de La Plata, pusieron en evidencia las fuertes dificultades ligadas al diseño y la implementación de un sistema que pueda resolver el conjunto de las problemáticas del transporte público, ya que, además de algunos límites de la propuesta, generó rechazo entre empresarios, gobierno provincial y sindicato.

Para ello es necesario además, jerarquizar la participación tanto de usuarios como de choferes ya que son los que viven cotidianamente los aciertos y debilidades del sistema. Se sugiere la incorporación de instancias participativas, propiciando la conformación de comités de usuarios, choferes y especialistas en los procesos de diagnóstico, formulación, seguimiento y continúa evaluación de los planes.

Para la construcción de ideas para un modelo de gestión más eficiente, resulta necesario contar con información periódica y detallada sobre la movilidad de la región, utilizando herramientas cuantitativas como las encuestas de movilidad, pero también cualitativas como entrevistas o talleres participativos a usuarios y choferes del sistema de transporte. En ese plano, la experiencia de talleres participativos desarrollados en este trabajo y que integra los insumos de esta tesis, como así también el conjunto de actividades que desarrolla el Observatorio de Movilidad del Gran La Plata - IIPAC FAU, son buenos antecedentes.

\subsection{Pautas para el Financiamiento del Transporte Público de La Plata}

Existen varios instrumentos económicos implementados en distintas ciudades en el mundo para desmotivar el uso del automóvil particular a partir de distintos instrumentos impositivos. Por ejemplo, impuestos a la propiedad de vehículos motorizados, impuestos al uso de infraestructura vial a automóviles, al estacionamiento en determinadas áreas, subastas y esquemas de licitación a la patente de nuevos vehículos, o al consumo de combustible. A su 
vez, en algunos casos, la recaudación de estos instrumentos, tiene la intención de financiar el desarrollo del transporte público. Los límites de la aplicación de estos criterios e instrumentos de financiamiento es que no resuelven las características del desarrollo de la ciudad en general (ya reseñadas más arriba y que propician en gran medida el uso del automóvil) por lo que dichas medidas tienden a tener un fin recaudatorio pero no necesariamente la capacidad de modificar las prácticas de movilidad de la ciudad por otras mejores.

Otro criterio utilizado podría ser la distribución de costos de producción de infraestructura para transporte público. Bajo este criterio, los costos de, por ejemplo, la construcción de carriles exclusivos, se distribuyen en primer lugar entre los causantes de la demanda, en segundo lugar entre los beneficiarios restantes y en tercer lugar del presupuesto público.

El objetivo de esta herramienta es poder recuperar de los privados parte de la valorización del suelo generada por las intervenciones (e inversiones) del Estado, en particular a aquellos sectores que puedan especular con el aumento de la renta urbana a partir de dicha valorización. A su vez, es necesario que exista un principio de solidaridad con los beneficiarios o causantes que evidencien reducida capacidad de pago. La identificación de beneficiarios de una infraestructura como los carriles exclusivos de transporte público es más sencilla de identificar, ya que pueden ser los usuarios del transporte público o los residentes cercanos a esa infraestructura que ven valorizada su parcela por un aumento en el nivel de accesibilidad. Por otro lado, la identificación de los causantes de la necesidad de la construcción de carriles exclusivos es más dificultosa ya que reulta más compleja, debido a que es una problemática en la que interviene el conjunto de la ciudad.

Por ello, la identificación de los causantes puede regirse por distintos criterios, como los usuarios de automóvil que aportan mayoritariamente en la congestión y por esa vía a la extensión de los tiempos de viaje. O, por ejemplo, las desarrolladoras, los agentes inmobiliarios o los particulares que promueven urbanizaciones en zonas periféricas sin infraestructura (lo que condiciona la movilidad de los residentes a la utilización del automóvil) o a los actores que valorizan los inmuebles en las áreas centrales a través de la especulación inmobiliaria que expulsa a la población de recursos insuficientes a las periferias escasamente servidas o sin suficientes condiciones adecuadas de urbanización.

Otra propuesta de financiamiento (ya como alternativa más de fondo) sería la creación de empresas estatales que administren las líneas que hoy administran agentes privados. En el marco de finalización de contratos con una inversión inicial se podría conformar una empresa pública con participación de los tres municipios del Gran La Plata (el de La Plata, de Berisso y de Ensenada) y el Gobierno Provincial que funcione en el contexto de una nueva 
distribución de líneas. Esto posibilitaría que las ganancias de la empresa estatal estén destinadas a invertir en la mejora del sistema, imponiendo nuevos standards al resto de las empresas.

Teniendo en cuenta que el Estado Nacional ya subsidia el $81 \%$ a las empresas de los ingresos, y el $19 \%$ restante proviene de la venta de boletos, y por otro lado que entre el 15\% y $17 \%$ del total de ingresos son ganancias, los beneficios para el financiamiento del sistema de transporte en el marco de una estatización serían importantes. Por ejemplo, en el año 2013 la empresa Unión Platense S.R.L. recibió en carácter de subsidio de Nación \$37.190.923,47. La ganancia de la empresa para ese año fue de \$7.081.151,83 aproximadamente, lo que equivale a 300 metros de carril exclusivo con la calidad del MetroBus Sur de la Ciudad de Buenos Aires. En el caso de que el conjunto del sistema fuese administrado por el Estado el margen de ganancia con posibilidad de reinversión, o de reducción de los subsidios, sería para el mismo año un monto de \$36.299.410,2, equivalente 1347,2 metros de carril exclusivo. Es decir que, en un año, casi sin inversión extra, el mismo sistema podría financiar un tramo de carril exclusivo similar a las zonas de mayor congestión del Gran La Plata que es de 1.500 metros aproximadamente, desde Plaza Italia a Plaza Rocha sobre Av. 7. Ver Ilustración 84.
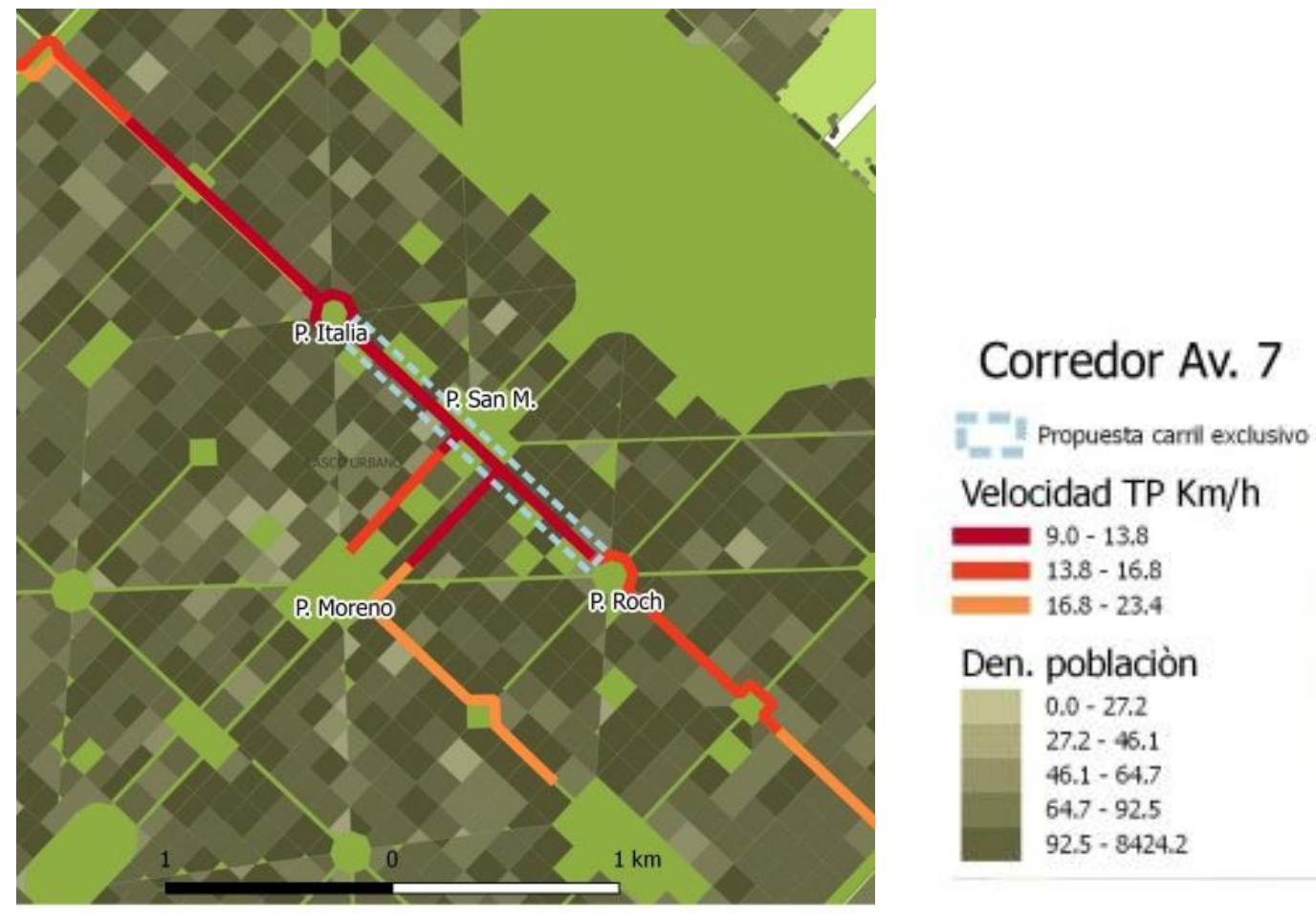

Ilustración 84. Ejemplo: tramo de carril exclusivo posible de construir en 2013, financiable con un monto equivalente a la ganancia de las empresas de transporte durante un año. Fuente: Elaboración propia. 
En este capítulo se formularon pautas para la planificación del transporte público de manera integrada con los usos de suelo para el Gran La Plata como resultado de lo analizado en los distintos escenarios que se desarrollaron en el capítulo IV.

En primer lugar, se plantearon pautas para la mejora del sistema de transporte entre las cuales se encuentra la implementación de carril exclusivo en el tramo del carril más congestionado de la micro región; luego pautas para orientar y desarrollar políticas de suelo desde los criterios de movilidad desarrollados a lo largo de la tesis, tales como la densificación sobre corredores y el control de la expansión urbana. También se plantearon algunas ideas para avanzar en un modelo de gestión más eficiente incorporando actores que cumplen roles importante en el funcionamiento diario del sistema y conocen de primera mano las problemáticas, pero tienen poca o nula participación en la gestión y, por último, algunas pautas propositivas para la financiación del transporte público a partir de un rol más importante del Estado Municipal en la administración de las líneas. 


\section{Resumen}

En este capítulo se exponen los resultados alcanzados a partir de los objetivos del plan de trabajo y la hipótesis. En segundo lugar, se analizan las dificultades y limitaciones del trabajo realizado. Finalmente se plantean nuevos interrogantes para desarrollar futuras investigaciones. 


\subsection{Resultados alcanzados}

A través de la investigación se logró el objetivo planteado el cual consiste en: elaborar pautas de planificación mediante la construcción y ensayo de escenarios de transporte público de pasajeros del Gran La Plata focalizando en el tiempo de viaje como variable crítica en el intento de articular el análisis de la movilidad y el del desarrollo urbano.

En correspondencia, se arriba a las conclusiones finales que se expone en este capítulo también a partir de haber cumplido con los objetivos particulares propuestos: 1) Analizar los aspectos de la variable tiempo de viaje que la vuelven critica en la relación entre el transporte masivo y las modalidades de crecimiento urbano a partir del análisis de las tendencias que configuran la ciudad fragmentada en general y el Gran La Plata, en especial; 2) Caracterizar las lógicas política, económica y social que motorizan las dinámicas de crecimiento y ocupación del suelo y su relación con la movilidad, sus efectos en el transporte público y en el tiempo de viaje; 3) Formular y evaluar escenarios alternativos de transporte público y desarrollo urbano en el mediano plazo, tomando al tiempo de viaje como variable principal; 4) Generar pautas espaciales, temporales, económicas y de gestión para la planificación integrada de transporte y usos de suelo.

De esta manera se lograron analizar los aspectos de la variable "tiempo de viaje en transporte público" que la vuelven crítica en la relación entre el transporte masivo y las modalidades de crecimiento urbano, a partir del análisis de las tendencias que configuran la ciudad fragmentada en general y el Gran La Plata en particular. Entre ellas, las distancias de viaje incrementadas en la última década por el alto crecimiento disperso de la ciudad y la alta dependencia de todas las delegaciones respecto del área central del Casco Urbano, lo que produce aumentos en los índices de congestión vehicular. Esta situación produce extensiones en los tiempos de viaje, dificultando el acceso de vastos sectores de la población a servicios sociales como educación, salud o trabajo, situación en la que, a su vez, los más afectados son los sectores de menores recursos de la región.

Como se analizó en el primer capítulo en el que se abordó el marco teórico sobre el transporte público en la ciudad entendida como sistema complejo, el tiempo es un factor importante muy poco estudiado como instrumento de análisis de los sistemas urbanos y específicamente como una variable destacada para generar propuestas que mejoren la relación entre la movilidad y el desarrollo urbano. En ese marco se analizaron casos interesantes como el municipio de Manizales, Colombia, con el estudio de tiempo de viaje a los Nodos de Actividad Primaria 
(NAP), y los análisis de Accesibilidad según tiempo de viaje a determinadas actividades en Gran Bretaña.

A su vez, la metodología utilizada permitió comprobar que la actual herramienta de planificación territorial que posee el municipio de La Plata (el Código de Ordenamiento Urbano) es claramente insuficiente para desarrollar el crecimiento urbano sobre corredores, a pesar de propiciar usos de suelo diferenciados, con mayor densidad, a las áreas que no se encuentran sobre corredores.

Se logró caracterizar las lógicas política, económica y social que motorizan las dinámicas de crecimiento y ocupación del suelo y relacionarlass a la movilidad, su efecto en el transporte y los tiempos de viaje a partir de un análisis histórico del comportamiento de los actores, una entrevista semiestructurada al director de transporte durante el período de estudio, y el insumo de talleres participativos con choferes de las líneas de transporte público y encuestas a usuarios. No fue posible entrevistar a representantes del sector empresarial debido al rechazo de las empresas, por lo que la caracterización de éstos actores en particular se realizó a partir del análisis de su comportamiento histórico expresado en hechos ejecutados por las mismas, así como su contrastación con la percepción del resto de los actores a los que se tuvo acceso.

Este análisis de actores fue fundamental no sólo para problematizar y generar pautas de planificación integrada de usos de suelo y transporte para el Gran La Plata, sino también para sugerir pautas de gestión que aborden a su vez el factor económico de la política de transporte (asociadas a los subsidios, al presupuesto estatal destinado a políticas y programas relacionados, así como a la conformación de equipos técnicos y, finalmente, las que podrían impactar en las condiciones laborales de los choferes que se reflejan en algunas problemáticas como las frecuencias, accidentalidad e incomodidad del viaje.

Se logró formular cuatro escenarios (uno tendencial al 2030 y tres alternativos) que permitieron dimensionar la degradación de la movilidad en una proyección a 15 años, con aumentos del uso del automóvil particular con casi 200.000 nuevos viajes, mientras que para el transporte público rondan los 150.000 y los no motorizados cercanos a los 100.000 viajes nuevos. Tanto en el escenario base como en el tendencial, los sectores más pobres de la región resultan ser los más perjudicados por las problemáticas de movilidad. Son los sectores de mayor NBI los que, en proporción, tienen menor cobertura de transporte, y los mismos que, en zonas cubiertas, son perjudicados por las peores frecuencias del sistema de transporte público. Como resultado, en proyección a 2030 los tiempos de viaje en transporte público de los casos estudiados se ven incrementados en un promedio del $85 \%$. 
Por otro lado, se evaluaron distintas propuestas de mejora de la movilidad a partir de la integración de políticas de transporte público y desarrollo urbano. Estas propuestas se evaluaron según su factibilidad y los tiempos requeridos para su implementación y alcance temporal en el marco de las tendencias de transformación actuales de la ciudad. Entre ellas, la combinación entre la sincronización de semáforos, la reorganización de paradas y los carriles exclusivos que permitirían reducir el tiempo de viaje en transporte público en un $25 \%$ en el corto plazo. En el mediano plazo, la propuesta de densificación sobre corredores generaría un aumento del $21 \%$ en el traspaso de viajes de los modos no masivos a masivos, lo que reduciría la cantidad de autos circulando y disminuiría la congestión. En el escenario a largo plazo, la descentralización de actividades para reducir tiempos de viaje, plantearía que si se generalizaran los resultados del área testigo, los viajes al Casco Urbano se reducirían alrededor de un 39\%, que para el corredor testigo significarían 2.339 autos menos viajando hacia el Casco.

Por todo esto se puede decir que la hipótesis formulada "La integración de las políticas de desarrollo urbano y movilidad incorporando al tiempo de viaje como variable de ajuste, permitirá a partir de escenarios alternativos del sistema de transporte público masivo y usos de suelo, generar pautas de planificación orientadas a equilibrar la actual situación de sobre oferta en áreas centrales y déficit en áreas periféricas" pudo ser corroborada a partir del trabajo realizado. La incorporación de la variable tiempo de viaje ayudó a sintetizar los efectos del incremento de las distancias de viaje producto del desarrollo urbano disperso y concentrado en las áreas centrales, con los patrones modales tendientes al mayor uso del automóvil que generan la mayor congestión vehicular. En ese marco, la búsqueda y la evalución ex-ante de políticas urbanas que intenten reducir los tiempos de viaje en el corto, el mediano y el largo plazo, permitió formular pautas de planificación integradoras entre el transporte y el desarrollo urbano que tienden a reducir los viajes en auto y fomentan los viajes en transportes masivos y no motorizados a la vez que racionalizan recursos económicos del Estado en relación a los servicios públicos, y de los privados al reducir gastos de traslado y de acceso al suelo urbano.

\subsection{Dificultades y limitaciones del trabajo}

El haber contado con información oficial de movilidad y de transporte público del conjunto de la región habría permitido alcanzar un mayor nivel de precisión en los resultados globales de tiempo de viaje, ya que (debido a esa limitación) los escenarios alternativos se construyeron 
sólo en un tramo de un corredor con el propósito de que sirviera de testigo para aproximar resultados al Gran La Plata.

La información oficial sobre transporte en relación a frecuencias reales, cantidad de unidades en funcionamiento y pasajeros transportados por sección, fue construida a partir de estimaciones propias, aun cuando los organismos oficiales disponen de dicha información a partir de la tarjeta SUBE, aunque no la procesan. El déficit de equipos técnicos municipales en el área transporte y planificación también significó tener menos datos relevados y análisis básicos construidos a lo largo del tiempo, lo que habría permitido dotar de mayor profundidad a los diagnósticos y elaborar pautas con mayor exactitud.

Por otro lado, la información censal espacializada a partir de radios censales resultó insuficiente para el análisis territorial en zonas periféricas, por lo cual se desarrolló un método particular a partir de la localización de medidores residenciales para construir una "mancha urbana" con mayor precisión que permitiera realizar los análisis de cobertura de transporte público.

Un límite del trabajo fue la imposibilidad de entrevistar a las empresas que administran las líneas de transporte, motivada por la constante negativa de parte de los empresarios, por lo que la caracterización de las lógicas empresariales fueron caracterizadas a partir de un análisis histórico de sus hechos, comportamientos efectivos, declaraciones y posicionamientos públicos, en particular en los años coincidentes con el recorte temporal de este trabajo, así como en base a la percepción, registro y evaluación por parte de los demás actores. Estas entrevistas habrían permitido contar con mejores elementos sobre la lógica con la cual intervienen en las problemáticas de movilidad y con el resto de los actores. A su vez, de haber sido posible esta visión de primera mano habría permitido mejorar también la caracterización del resto de los actores.

\subsection{Nuevos interrogantes para futuras investigaciones}

En base al desarrollo del trabajo y de los alcances propuestos originalmente, han surgido nuevos interrogantes que darán continuidad a la presente investigación. El tiempo de viaje ha demostrado ser una variable destacada para generar propuestas que mejoren la relación entre la movilidad y el desarrollo urbano, haciendo a las ciudades más sustentables desde puntos de vista sociales, económicos y ambientales, aunque por otro lado, es innegable que la centralización de determinadas actividades como las industriales, permite mejorar la productividad (y de esta manera a la economía) si es acompañada de avances en la técnica y tecnología. En el mismo sentido puede mencionarse también la centralización de algunas 
actividades al aire libre como los grandes parques o bosques urbanos. Otro ejemplo podrían ser las actividades administrativas del Estado, la centralización de cuyas áreas técnicas de gestión (como la creación de una autoridad regional de transporte y desarrollo urbano) permitiría una base de apoyo importante para decisiones más acertadas desde las gestiones políticas, a partir de las ideas para un modelo más eficiente señaladas en el punto 5.2.

La planificación de la movilidad tiene que poder resolver algún grado de centralidad en las ciudad medianas y grandes que garanticen mejores tiempos de viaje, cobertura espacial de la red, accesibilidades diferenciales y específicas, costos y cuidado del medioambiente de manera coherente con los postulados en esta tesis. Para ello se propone evaluar, en investigaciones futuras, la incorporación de técnicas y las tecnologías en energía no convencional (o renovable) al modelo de análisis urbano y propuestas planteadas. Con esta incorporación se busca conjugar la planificación integrada de los usos del suelo y movilidad, con la aplicación de tecnologías avanzadas en cuanto a consumo de energía y emisiones contaminantes.

Esta continuidad se plasmará en una beca postdoctoral ya aprobada por CONICET para el caso de la ciudad de San Salvador de Jujuy, ciudad con muchas desigualdades urbanoterritoriales y sociales. 
Aón, L., Moro, S., Ravella, O., (2004). Planificación sustentable del transporte: Micro región del Gran La Plata, Argentina- Región Metropolitana de Curitiba, Brasil. En: Revista Rábida, No 24, pp. 81-90.

Aón, L., Cola, C., Giglio, L., Vera Candado, J. (2014). Políticas de transporte y movilidad para la planificación en crecimiento urbano. La Plata, Argentina: XI Simposio de la Asociación Internacional de Planificación Urbana y Ambiente (UPE 11).

Aón, L., Giglio, M. L., Cola, C. (2016). Patrones modales de movilidad y desarrollo urbano no planificado en la ciudad de La Plata. Buenos Aires, Argentina: Revista Transporte y Territorio (17) pp. $117-144$.

Aón, L. (2017). Encuesta web de movilidad y análisis de atractores. Manual sobre metodologías de estudio aplicables a la planificación y gestión del transporte y la movilidad, EUDEBA, pp. 59-68.

Avellaneda, P., Lazo, A. (2011). Aproximación a la movilidad cotidiana en la periferia pobre de dos ciudades latinoamericanas. Los casos de Lima y Santiago de Chile. Revista Transporte y Territorio, Universidad de Buenos Aires, (4) pp. 47-58.

Buchanan, C. (1963). Traffic in Towns. Reino Unido: Report for the UK Ministry of Transport.

Buchbinder, M. (2008). Mortalidad infantil y desigualdad socioeconómica en la Argentina: tendencia temporal. Archivos argentinos de pediatría (Vol. 106, 3), pp. 212-218.

CAF. (2011). Informe anual 2011. CAF, Banco de Desarrollo de América Latina.

Cardoso, F. H., Faletto, E. (1977). Estado y proceso político en América Latina. Revista Mexicana de Sociología, 357-387.

Castro, L., Szenkman, P. (2012). El ABC de los subsidios al transporte. Documento de Políticas Publicas/Análisis nº102. CIPPEC: Buenos Aires, Argentina.

Cely, B. (1999). Metodología de los escenarios para los estudios prospectivos. Revista Ingeniería e Investigación (44). 
Cervero, R. (2001). Integration of urban transport and urban planning. Washington, DC: The World Bank Institute, the Challenge of Urban Government: Policies and Practices 2001 pp 407-427.

Cervero, R. (2002). Transit-Oriented Development and Join Development in the United State: A literature Review. Estados Unidos: Research Results Digest, Transit Cooperative Research Program.

Cervero, R., Kang, C. D. (2009). Bus Rapid Transit Impacts on Land Uses and Land Values in Seoul, Korea. UC Berkeley Center for Future Urban, Transport: A Volvo Center of Excellence.

Cervero, R., Dai, D. (2014). BRT TOD: Leveraging transit oriented development with bus rapid transit investments. Transport Policy, (36) pp. 127-138.

Christaller, W. (1933). Die zentralen Orte in Süddeutschland: eine ökonomisch-geographische Untersuchung über die Gesetzmässigkeit der Verbreitung und Entwicklung der Siedlungen mit städtischen Funktionen. University Microfilms.

Ciccolella, P. (1993). Modelos de integración en América Latina: desafíos y alternativas en la construcción de un nuevo territorio latinoamericano. Los fundamentos de las ciencias del hombre, 91.

Cola, C., Barbero, D., Martini, I., Aón, L. (2017). Estimación del precio del suelo en el Gran La Plata para la construcción de escenarios urbano-energéticos. Revista GeoSig UNLu.

Davis, M. (2007). Planeta de Ciudades Miseria. Madrid, España: FOCA ediciones y distribuciones generales.

Escobar García, D., Cadena, C., Salas, A. (2015). Cobertura geoespacial de nodos de actividad primaria. Análisis de los aportes a la sostenibilidad urbana mediante un estudio de accesibilidad territorial. Envigado, Colombia: Revista EIA (12) pp. 12-27.

Ewing, R. (1997). Is Los Ángeles style sprawl desirable?. Estados Unidos: Journal of American Planning Association Journal (63). 
Feres, J., Mancero, X. (2001). El método de las necesidades básicas insatisfechas (NBI) y sus aplicaciones en América Latina. División de la Estadística y Proyecciones Económicas, CEPAL.

Fernández Duran, R., Castro, I. (1980). Transporte, espacio y capital. Madrid, España: Nuestra Cultura.

Fernández, C. A. (2015). Los subsidios al transporte público de pasajeros por automotor en el AMBA. Ciudad Autónoma de Buenos Aires: Tesis de Maestría en Economía Urbana, Universidad Torcuato Di Tella.

Figueroa, O. (2005). Transporte urbano y globalización. Políticas y efectos en América Latina. Santiago de Chile: Revista EURE (94), pp. 41-53.

Freaza, N., Aón, L. (2013). Una ciudad, dos modelos: Fractura del tejido urbano y social en la ciudad de La Plata. Ponencia presentada en Congreso ICO - UNGS.

Frediani, J., Elizalde, M.E. (2003). La reestructuración del sistema de transporte publico automotor de pasajeros en el partido de La Plata, en el marco de los cambios en la movilidad. Pensar La Plata, políticas públicas, sociedad y territorio en la década de los noventa. La Plata, Argentina: Ediciones Al Margen. pp. 115-138.

Gakemheimer, R. (2006). Transporte y uso del suelo en los países en vías de desarrollo: planificar en medio de la controversia. Madrid, España: I Congreso Internacional sobre Desarrollo Humano 2006.

García, R. (2006). Sistemas complejos. Barcelona, España: Editorial Gedisa.

García, R. (2010). Interdisciplinaridad y sistemas complejos. Revista Latinoamericana de Metodología de las Ciencias Sociales, (1), pp. 66-101.

Geertz, C. (1973). La interpretación de las culturas. Barcelona, España: Gedisa Editorial.

Gordon, P., Kumar A., Richardson, H. (1989). Congestion, Changing Metropolitan Structure, and City Size in the United State. International Regional Science Review, 12 (1) pp. $45-56$.

GTZ. (2006). Planificación del Uso de Suelo y Transporte Urbano" República Federal de Alemania: Proyecto sectorial Servicio de Asesoría en política de Transporte para el Ministerio Federal de Cooperación Económica y Desarrollo. 
Gutiérrez, A. (2005). Políticas de transporte público en la ciudad de los '90: Reglamentación y concentración empresarial en el autotransporte metropolitano de Buenos Aires. Tesis doctoral Facultad de Filosofía y Letras, Universidad Nacional de Buenos Aires.

Gutiérrez, A. (2009). La movilidad de la metrópolis desigual: el viaje a la salud pública y gratuita en la periferia de Buenos Aires. Montevideo, Uruguay: Congreso XII Encuentro de Geógrafos de América Latina

Gutiérrez, A. (2017). Manual sobre metodologías de estudio aplicables a la planificación del transporte y la movilidad. Recomendaciones sobre el uso de herramientas cualicuantitativas de base territorial. EUDEBA, Editorial Universitaria de Buenos Aires.

Haedicar, P., Curtis, C. (1998). The location of new residential development: Its influence on car-based travel. Londres: Banister D., Transport Policy and the Environment, pp. 427-444.

Hanson, S. (1982). The determinants of daily travel activity patterns: relative location and sociodemographic factors. Urban Geography, 3:3,pp. 179-202.

Hansz, M. (2016). Análisis de la distribución espacial de la provisión de transporte público y las necesidades de transporte en Montevideo. Montevideo, Uruguay: XIX Congreso Latinoamericano de Transporte Público y Urbano (CLATPU 2016).

Hall, P. (1996). Ciudades del mañana. Historia del urbanismo en el siglo XX. Ediciones del Serbal, Barcelona.

Jacobs, J. (1961). Muerte y vida de las grandes ciudades. Madrid, España: Capitán Swing Libros, SL.

Jaramillo, C., Lizarraga, C., Grindlay, A. (2012). Spatial disparity in transport social needs and public transport provision in Santiago de Cali (Colombia). Journal of Transport Geography (24) pp. 340-357.

Karol, J., Fernández, L. (2008). Sustentabilidad urbana: del desarrollo del concepto a la propuesta de indicadores. DT proyecto PICT 03/14422, ANPCyT, UI 6B, IDEHAB, FAU, UNLP. 
Kitamura, R.; Mokhtarian, P. Laidet, L. (1997). A micro-analysis of land use and travel in five neighbourhoods in the San Francisco Bay area. Transportation, Vol. 24, pp. 125 158.

Lattes, A. (2000). Población urbana y urbanización en América Latina. Quito, Ecuador: Jornadas Iberoamericanas de Urbanismo sobre las Nuevas Tendencias de la Urbanización en América Latina.

Liffmann, R., Huntsinger, L., Forero, L. (2000). To ranch or not to ranch: Home on the urban range?. California, Estados Unidos: Department of Environmental Science Policy and Management, University of California.

López, M. J. (2015). Red viaria, ciudad y paisaje. Aproximación teórica metodológica para su diseño. Tesis doctoral, Doctorado en Arquitectura y Urbanismo FAU- UNLP.

Lösch, A. (1940). Teoría económica especial, Buenos Aires, El Ateneo Ediciones. Edición original en alemán.

Lösch, A. (1957). Teoría económica especial (No. 330.19 L8).

Marquet Sardà, O., Miralles-Guasch, C. (2014) La proximidad en Barcelona, Un análisis desde los tiempos de desplazamiento cotidiano. Revista Ciudades 1 (17).

Marx, C. Engels, F. (1848). Manifiesto del Partido Comunista. Edición México 2011: Centro de Estudios Socialistas Carlos Marx.

Marx, K. (1867). El Capital. Critica de la economía política. Tomo I. (Vol. 1, 2).

Merle, N. (2013). Los planes de movilidad sostenible (PDU) en Francia. Department Deplacement Durables, CERTU, Ministerio Francés de la Ecología.

Miralles- Guasch, C., Cebollada, A., Requena, R. (2010). Estrategias de participación ciudadana en la gestión de la movilidad y el transporte. La Universidad Autónoma de Barcelona como ejemplo. Barcelona, España: Scripta Nova 14.

Miralles-Guasch, C. (2011). Dinámicas metropolitanas y tiempos de la movilidad. La región metropolitana de Barcelona, como ejemplo. Universidad Complutense de Madrid, España: Anales de geografía de la Universidad Complutense (Vol. 31, N. ${ }^{\circ}$ 1) pp.124. 
Municipalidad de La Plata. (1996). El transporte en La Plata. Equipo técnico coordinado por Cichino, $\mathrm{C}$.

Municipalidad de La Plata. (2016). Plan estratégico LP.30. Municipalidad de La Plata.

Naciones Unidas. (2015). Objetivos del Desarrollo del Milenio, Informe 2015. Naciones Unidas, Nueva York.

Naess, P. (1993). Can urban development be made environmentally sound?. Journal of Environmental Planning and Management, 36:3, pp. 209-333.

Newman, P., Kenworthy, J. (1989). Cities and Automobile Dependence an International Sourcebook. UK: Gower Publishing Ltd.

Novick, A. (2003). El urbanismo en las historias de la ciudad. Buenos Aires, Argentina: Revista Registros (1) pp. 5-26.

NUMEX. (2013). Experimentación numérica de políticas y estrategias de desarrollo sustentable. FONCyT-PICT 2011-2013.

Moovit. (2018) Datos obtenidos de la web, cuyo link es: https://moovitapp.com/insights/es419/Moovit_Insights_\%C3\%8Dndice_de_Transporte_P\%C3\%BAblico_Brasil_Curitiba-942. Accedido 07/05/2018.

Park, R.E., Burgess, W.W., MeKenzie. (1925). The City, Chicago. Estados Unidos.

Petersen, R. (2006). Planificación del uso del suelo y transporte urbano. Alemania: Wuppertal Institute.

PIM Rosario. (2011). Plan Integral de Movilidad de Rosario. Ente del Transporte de Rosario Municipalidad de Rosario.

Portal UE. (2003) Transporte y Uso del Suelo. Unión Europea: Portal material didáctico de transporte.

Prebisch, R. (1949). El desarrollo económico de la América Latina y sus principales problemas (No. 330.13/P92d).

PTUMA. (2009). Proyecto de Transporte Urbano para Áreas Metropolitanas. Estado Nacional con apoyo crediticio del Banco Mundial para su aplicación en Buenos Aires, Mendoza, Tucuman, Posadas, Cordoba y Rosario. 
Ravella, O., Carriquiriborde, H., Gershanik, G. (1994). El transporte urbano de pasajeros en la micro-región del Gran La Plata. La Plata, Argentina: Facultad de Arquitectura y Urbanismo UNLP, Instituto de Estudios del Hábitat.

Ravella, O. (2000). La modelización integrada Transporte-Uso del suelo como herramienta de planificación urbana. Proyecto PIP/CONICET 4716, UI N. ${ }^{\circ}$ 6B, IDEHAB, FAU UNLP.

Rojo, A., Luzuriaga, J., Moretti, W., Lotito, D. (2016). Cien años de historia obrera en la Argentina 1870-1969. Ciudad Autónoma de Buenos Aires: Ediciones IPS.

Rueda, S. (1997). La ciudad compacta y diversa frente a la conurbación difusa. Fuente: https://alojamientos.uva.es/guia_docente/uploads/2013/474/46059/1/Documento38.pdf

Rusconi, L., Casazza, J., Reese, E. (2018). La incidencia de la dotación de infraestructura para los servicios públicos en red en el precio del suelo: evidencia del Gran Buenos Aires. Revista EURE, 44.

Sánchez, J. (2011). Estudio de la mejora de datos en subsidio al Transporte Público de Pasajeros Urbanos. Región Metropolitana de Buenos Aires. Buenos Aires, Argentina.

Sanderson, S. (2013). Land Reform in Mexico: 1910-1980. Pennsylvania, Estados Unidos: School of Urban and Public Affairs, Carnegie Mellon University.

Scholl, L., Bouillon, C., Oviedo, D., Corsetto, L., Jansson, M. (2016). Los Efectos de Sistemas de BRT en Accesibilidad y Movilidad para los Pobres de Cali y Lima. Montevideo, Uruguay: XIX Congreso Latinoamericano de Transporte Público y Urbano (CLATPU 2016).

Segovia, M., Vallejos, V.H., Ciafardo, R., Lagos, S. (2003). La Plata y la crisis del transporte colectivo regional. Pensar La Plata, políticas públicas, sociedad y territorio en la década de los noventa. La Plata, Argentina: Ediciones Al Margen. pp. 139-172.

Soria, A. (1895). Ciudad Lineal, Compañía Madrileña de Urbanización.

Stead, D. (2001). Relationships between Land Use, Socioeconomic Factors and Travel Patterns in Britain. Inglaterra: The Bartlett School of Planning University College. 
TECHO (2016). Relevamiento de Asentamientos Informales 2016. Link de acceso: http://relevamiento.techo.org.ar, accedido el 24/02/2018.

Torns, T., Borràs, V., Carrasquer, P. (2004). La conciliación de la vida laboral y familiar:¿un horizonte posible?. Sociología del Trabajo: Revista Cuatrimestral de Empleo, Trabajo y Sociedad, (50) pp. 111-137.

Ventura I Teixidor, F., Nunes da Silva, F., Castro, W. (2016). Reflexiones sobre la evolución del concepto sistemas BRT en los últimos años, en especial América Latina. Rosario, Argentina: XVII Congreso Latinoamericano de Transporte Público y Urbano (CLATPU 2014).

Vértiz, F. (2016). "La intervención estatal en la producción de la ciudad. Conformación y orientación política en el partido de La Plata (2003-2014). Pag. 186. Tesis doctoral en Ciencias Sociales. FAHCE UNLP.

Von Bertalanffy, L. (1976). Teoría general de los sistemas. Fondo de Cultura Económica Mexico.

Von Thünen, J. H. (1820). El estado aislado. Alemania.

Weber, A. (1909). Teoría de la localización industrial. Alemania.

Zamora, U., Campos, H., Calderón, J. (2013). Bus Rapid Transit (BRT) en ciudades de América Latina, los casos de Bogotá (Colombia) y Curitiba (Brasil). Toluca, México: Quivera (15) pp. 101-118. 
En anexos se complementa con la Entrevista al ex director de transporte y una matriz construida a partir de los talleres participativos con choferes de de las distintas líneas de transporte del Gran La Plata. 


\section{A.1. Entrevista a ex director de transporte}

Para abordar este punto se realizó una entrevista semiestructurada al el ex Director de Transporte de la Municipalidad de La Plata, donde se desarrollaron las problemáticas en el transcurso de su gestión relacionadas a los problemas de transporte de la región, problemas de gestión por parte del Estado Municipal, la relación con los empresarios a cargo de las concesiones de los servicios, los choferes, usuarios y algunas propuestas que no pudo implementar.

En cuanto a los problemas del transporte en la región, el ex Director plantea que la baja densidad poblacional por fuera del Casco Urbano genera una mala relación pasajero/kilometro desde el punto de vista económico para las empresas prestadoras, por lo cual el Estado se ven en la necesidad de incrementar los subsidios. Además plantea que la baja densidad genera que las unidades sean insuficientes para la demanda de la periferia, poniendo como ejemplo la zona este donde en determinados horarios, un servicio que va desde Arana al Casco Urbano completa su capacidad en 7 y 96, es decir a tres kilómetros del casco.

Otro de los problemas que el ex Director visualiza es la poca infraestructura en corredores de transporte público en zonas de mucho crecimiento tanto habitacional como poblacional, haciendo hincapié en la zona oeste y la este. De la zona oeste pone en crisis las avenidas perpendiculares a la av.44 y av.520, como son av. 143. 149, 155, 173 y 179. Los mismo sucede en la zona este donde los únicos corredores son av. 7, av. 122 y un tramo de av. 1, y perpendiculares solo av. 609 y av. 635, es decir un corredor con cierta infraestructura cada tres kilómetros aproximadamente. Ademas plantea que la infraestructura de corredores existente esta pensada para el automóvil y que no necesariamente debe ser la que el sistema de transporte público necesita para cubrir: "Y después hay otra cosa que también. Vos diagramas recorridos, das frecuencia en función de la infraestructura (vial) que tenés... ¿No? Eso o sea eso te determina, eso no quiere decir que este bien que por donde pueden pasar los micros sea el mejor lugar por donde pasen los micros."

A nivel general plantea que se daban muchas situaciones conflictivas en lo cotidiano que tenían que ver con falta de inversión en infraestructura, deterioro de los corredores, con pozos y con calles cortadas. Por otro lado afirma que la política del tránsito no acompañaba a la de 
transporte público. Cuestiona la cantidad de estacionamiento disponible en áreas centrales de la ciudad, la necesidad de zonas de prohibición de estacionamiento para que la velocidad comercial pueda ser mayor.

\section{A.1.1. Relación con las empresas}

Desde el punto de vista de la relación con las Empresas prestatarias plantea que no era una relación mala pero que el sistema en su conjunto los favorece y que desde la dirección de transporte trataban de intervenir en los problemas más críticos que afectaban a los usuarios. En ese sentido, destaca dos situaciones muy propicias para el criterio económico de las empresas pero no tanto para los usuarios, como son la sobreoferta de recorridos en el centro y la división de las concesiones de los ramales entre la provincia y el municipio. Destaca “...al empresario le conviene andar entre Plaza Italia y Plaza Rocha es como pescar en una pecera" en el sentido de ser los recorridos más rentables que ayudan a equilibrar el IPK, continua “...Si vos al tipo (empresario) le decís -mira hay gente de Arana que está en 4to año de medicina o de derecho, que sale a las 10 de la noche de cursar y necesitamos cubrir ese recorrido, el tipo te dice "Eh hasta Arana a las 10 de la noche con 5 tipos! no me conviene..." y agrega " el estatus quo actual en la medida que vos no le cambies las cosas, al empresario le viene bárbaro ¿Por qué? Porque los centros atractores, llamémosle, antes era considerado el Hospital de Niño, Plaza Moreno y el sistema está pensado en función de eso, entonces cuando vos tenes que incorporar a la UTN, el empresario te dice "Ah por la UTN pasa la linea $214 \mathrm{y}$ la 202” ¿Pero solo porque pasa el 214 y la 202 históricamente? ¿Por qué un chico que estudia en la UTN y vive en Ringuelet no puede llegar con un ramal de la linea Norte?".

También hace mucho hincapié en la variación de la demanda según horarios, días de la semana y meses del año. Plantea como ejemplo la demanda de transporte que crece desde los dos ultimo días hábiles del mes a los cinco primeros días hábiles del mes por la gran actividad bancaria que después te desaparece. Otro ejemplo de esta situacion lo observa en junio, julio y agosto de 5.45 de la mañana a 10 de la mañana, donde crece la demanda de transporte hacia hospitales por enfermedades respiratorias en los menores que tambien desaparece a partir de septiembre u octubre.

Plantea que "algo que las empresas nunca quisieron analizar cómo cambian los centros atractores en banda horaria, en día y en mes. Porque vos, por ejemplo con el Estadio Único, con la feria de los fines de semana, como con el régimen carcelario y el régimen de visitas, a 
vos te aparecen situaciones distintas que no podes atender con la misma frecuencia estática." El ex Director plantea que muchas veces les exigía a los empresarios mayor frecuencia de determinados ramales los fines de semana, pero que eso implicaba para las empresas incrementar los kilómetros recorridos mensuales lo que podía provocar penalidades a los subsidios otorgados por el Estado Nacional, por eso encontraba resistencia. Además debido a la insuficiente capacidad del sistema en horas pico, muchas veces los empresarios incrementan frecuencias en esos horarios, quitándole servicios al sistema en los fines de semana o en horarios valle.

Entendiendo esta situación, el ex Director plantea que hacía "hincapié que en los fines de semana, aun cuando se reducía la frecuencia, se cumpliese con los acuerdos que se publicaba en la página de la municipalidad, eso se controlaba mucho. Después controlábamos a la mañana, estábamos muy presentes en los puntos donde también se satura la carga de pasajeros, como era 7 y 80, 117 y 96, 32 y 149, bueno íbamos alternando y siempre buscábamos reforzar en esa franja crítica de horario. Cuando digo franja crítica, me refiero a horario y me refiero a una porción de la traza, porque el micro cuando arranca subiendo pasajeros en un punto y satura su carga, después en otro punto descomprime, entonces le proponíamos al empresario que cubra con un coche más ese tramo en determinado horario".

En ese sentido, situaciones de ese tipo ocurrían muchas veces entorno a la salida y entrada de los colegios. Plantea que sobre todo en "los colegios más críticos, hay otros que son menos críticos porque asisten mucho en auto o con transporte escolar, pero hay colegios donde el modo más usado es el transporte público y más cuando van acompañados de la mamá, o la mamá lo está esperando, si, se daban situaciones también que hacían que estuviesen alguno de los colegios monitoreados" con el objetivo de que se cumplan frecuencias y no queden chicos varados.

En ese marco afirma que incumplimientos con frecuencias, servicios y recorridos "son infinitas, pero se tiene que dar dentro de una lógica del derecho administrativo para que yo te pueda sancionar. En la primer semana yo que hago, apercibimiento. En la segunda semana, apercibimiento. La tercer semana ¿Qué te hago? Mil pesos. La tercer semana dos mil pesos. La cuarta semana cinco mil, llega un momento en que, que le tengo que sacar el ramal. Te saco el ramal, ¿Cómo hago con la licitación? ¿O te saco la línea? Esto es un sistema que está en algún punto cerrado ¿Cómo hago después para licitar esa línea? ¿Quién viene a reemplazar?". 


\section{A.1.2. Relación con los usuarios}

Según el ex Director de Transporte de La Plata, la relación con los usuarios se da sobre todo a través de llamados telefónicos y de conversaciones con los inspectores de calle, después se corroboraba lo que los vecinos planteaban, ya que como el servicio no es lo bueno que debería ser, hay problemas que escapaban de lo solucionable dentro de ese marco. "Una vez detectado eso en seguida tomas contacto con la empresa, en seguida el inspector de la empresa, al otro día con el inspector nuestro y a partir de ahí te hacen un seguimiento hasta que se lo registra”.

Para corroborar las situaciones problemáticas trasmitidas por las llamadas de los usuarios, el ex funcionario manifiesta que han realizado encuestas y sobre todo reuniones con vecinos por casos particulares, y comenta algunos casos. Por ejemplo existía un reclamo de los vecinos por un ramal que cubriese la calle 38 de 131 a 155 "ahí lo que se hizo, y que lo prevé la ordenanza también, es una encuesta a los comerciantes, a las personas, a quien están afectados por ese corredor, que en definitiva siempre termina siendo por el manifiesto la necesidad que pase el micro". De todas formas manifiesta que la metodología más utilizada era reunirse con los vecinos, y pone como ejemplo “cuando se creó el ramal de Gorina para que el 273 pudiese llegar a la puerta del Colegio Nacional. Una vez el 273 y otra vez (la línea) Norte, hicimos como una frecuencia alternada ahí teníamos provincia y municipio bueno ahí también se hizo un trabajo de relevamiento con los vecinos. Cuando se trabajó Puente de Fierro para que también convivan 275 y el SUR también. Pero después otras situaciones se iban resolviendo de hecho y sobre la marcha, y sobre todo con las mamás de los nenes en edad escolar, ósea la demanda que uno priorizaba era esa, sobre todo en invierno con los horarios la nocturnidad que tenés cuando el nene va a tomar el micro y los episodios de inseguridad que se daban, le robaban la mochila, que se pegaban, bueno ahí tratábamos de ponerle un micro con espera. Eso también es una cosa que da resultado, entonces vos pones un micro que está en espera en 122 y 604, todas las mamas de cinco cuadras a la redonda saben que 6.50hs sale ese micro. Entonces ahí la utilización de los recursos es eficiente por que vos los esperas, el nene llega seguro y el micro sale lleno, y es un micro que no está afectado a la frecuencia del ramal ese micro termina con el último nene y se vuelve. A veces esas situaciones hay que propiciar. Y siempre en la medida de que pueda, porque esto es como una frazada corta, vos sacas dos o tres micros para cubrir esas situaciones, pero los sacaban de los ramales que van a Sicardi (Arana), no es que se agregaba un servicio más". 


\section{A.1.3. Relación con los choferes}

En cuanto a la situación de los choferes, el ex Director reconoce que están en una situación de vulnerabilidad por tener que sostener un sistema de transporte con muchas dificultades. Pone el acento en el tiempo de viaje, ya que si logra reducir el tiempo de recorrido por vuelta ayuda a disminuir el índice de accidentes, enfermedades profesionales en cervicales, dorsales. Según el ex Director, esta situación además genera un problema para el sistema de transporte ya que los choferes deben sacar carpeta médica de 15 a 20 días que la empresa muchas veces no reemplaza.

En esa situación donde el chofer esta en tensión permanente, el ex director plantea "otra cosa que se da con el chofer es que vos lo podes entrenar una vez, dos, a la tercera vez que su condición de profesional y no recupera nunca más su carnet. Es una cosa que también es un poco arbitraria, porque cualquier otro profesional se equivoca, aún un médico y recupera su condición de médico. El chofer tiene un accidente, por una circunstancia que le toco participar en el siniestro, y el chofer nunca más vuelve a recuperar su condición de chofer. Entonces siempre trataba de ser flexible o siempre estar charlando y tratando de corregir las cosas pero no en el plano de la sanción a veces".

\section{A.1.4. Problemas de gestión estatal}

Los problemas de la gestión estatal del transporte en la región, el ex Director plantea que de fondo tienen que ver con la poca inversión estatal en el área de transporte en términos de personal técnico constante en el tiempo, división del sistema entre líneas provinciales y municipales y poca inversión en infraestructura para transporte público. En ese sentido afirma que es necesario incluso para controlar mejor a las empresas: "ahora cuando vos queres discutir eso (incumplimientos de la empresa), eso implica más diagramación, más gente laburando, llamémosle en laboratorio de la Dirección de Transporte". Según el ex funcionario las correciones del servicio que se le puede imponer a la empresa son las que la dirección puede fundamentar con datos irrefutables que den cuenta del problema, y para hacer eso en necesario un buen equipo. "Y el estado no forma cuadros, los concejales viste te mandan pedido de informe pero en ningún momento nadie se le cae una idea por ver qué presupuesto tiene el área de transporte entonces vos después tenes chicos (trabajadores de la dirección) que si le pagan a la niñera para cuidarle a los hijos no pueden venir" y continua "además 
tampoco porque no se agotan recolectarse, después tenes que procesar, después ¿Cómo haces? Y tenes que tener toner, tenes que tener impresora".

Otro de los problemas importantes que resalta es el poco compromiso del área de transporte de la provincia, que se encarga de controlar las líneas provinciales que funcionan en la ciudad: "Para mí, aparte otra cosa que también es el tema, es que provincia nunca se compromete, quedas en una situación de desventaja al momento de instalar estos temas y que se genere un poco de consenso de todos los que se tienen que involucrar" (...) "toda esta fragmentación, es desorden, es falta de controles que terminan favoreciendo a la empresa", plantea como ejemplo "Y otra cosa que a los tipos (empresarios) le favorece también es la confusión en el marco de la jurisdicción de las líneas. Agarra un tipo común y te nos putea nosotros, vos atendés el teléfono y te putea "No paso el 202, 40 min estuve esperando" y capaz que a provincia llamaban tipos por la línea Norte”.

\section{A.1.5. Ideas de mejoras}

Uno de los puntos que el ex Director plantea necesario es que exista un organismo conjunto entre los municipios del Gran La Plata y la Provincia, para la planificación del transporte público de la región con una perspectiva de mediano y largo plazo, la cual contemple a su vez subsistemas de cada municipio: "el tema de que esto no sea una región, en términos de que este concebido el transporte como sistema regional. Y con subsistemas, por que debería tener subsistemas en término municipio para entender situaciones específicas de cada municipio. Esto, hace que todo sea una gran confusión y nadie toma el tema, nadie hace, nadie hace planeamiento en término de mediano o y largo plazo, por que la solución tampoco viene acá en el corto plazo" y continua "Vos fíjate por ejemplo ahora si vos te sentás con la 273 terminaron, lo manda a La Plata-Constitución, que necesidad tiene de venir un 273 de Villa Elisa a Plaza San Martin ya el 273 debería reformularse e integrarlo y que la conectividad este dada... tiene que aumentar la conectividad con el ferrocarril, tiene que haber subsistemas o rondines que a vos te lleven a la terminal de Ringuelet, de Tolosa, de City Bell”

Otro de las propuestas que señala el ex Director de Transporte es la implementacion del boleto combinado para cubrir la monocentralidad de recorridos al centro del Casco Urbano: "Otras cosas que se podría trabajar con todo el avance (teconologico) que hay hoy por ejemplo con la gente de la facultad de informática, ¿Por qué no se va una sube con tiempo? Si vos tenes, una conectividad que se va a dar en el mundo real, porque el tipo se va a bajar en 
Plaza Rocha y si tiene un lapso de tiempo de 20 minutos automáticamente va a tomar otro micro. Al costo que pago su boleto y después las empresas dicen es un quilombo, no es un quilombo, hoy ya es un tema de plata. Si yo mi tarjeta a las 9.10 de la mañana la pase por la 275 y por la 506, bueno habrá que determinar que coeficiente se lleva cada grupo empresario de su boleto, pero no es imposible".

Además plantea la necesidad de apoyarse más en la tecnología para poder tener un mayor control por parte del Estado del cumplimiento de las empresas prestadoras del servicio y con participación de la universidad u ONG preocupadas por el sistema de transporte de pasajeros: “después se dejó de aplicar, pero en su momento estaba el GPS por micro, después se daban situaciones que el GPS no se reportaba porque no había antena, porque era dificultoso por que los choferes tardaban mucho programando cuando se desprogramaba. Bueno, era un sistema que tenía críticas por parte de los empresarios y crítica por parte de los propio choferes y se dejó de utilizar. Pero bueno en otras partes del mundo, funciona, en todo caso habrá, hablar con las telefónicas o con quien trasmite datos y aumentar la cantidad de antenas que haya más conectividad y poder hacer que ese micro sea relevado, que sea controlado pero desde el estado, porque eso estaba previsto pero está en manos de los operadores" y agrega "inclusive, para evitar cualquier tipo de cosa, debería tener presencia de una ONG o de pasantes de la Universidad".

Desde el punto de vista de la infraestructura plantea la necesidad de incorporar un carril exclusivo para transporte público y mejores refugios en las paradas: "Esta todo, pero por eso hay que hacer un carril exclusivo de transporte publico pronto y que tengan mayor frecuencia y que tengan mayor velocidad comercial, ya con eso los tipos van a mejorar, digamos, que tengan mayor velocidad que el auto, porque el auto hoy llegas tarde pero llegas más rápido que el colectivo" y agrega "condiciones que tienen que ver también con, con la infraestructura en las paradas, con más iluminación, con dársenas para que sea más seguro el acceso y el descenso de pasajeros, y que el chofer este en mejores condiciones de seguridad."

\section{A.1.6. Transcripción entrevista a Ex Director de Transporte de La Plata}

Archivo: Gabriel Perez 2-8_10am

Duración: $53 \mathrm{~m} 56 \mathrm{~s}$

Día: $02-08$

Hora inicio: 10 am 
Lugar:

Entrevistador: Laura Aón, Cristian Cola

Entrevistado: Gabriel Pérez

\section{Referencias transcripción}

$\mathrm{I}=$ Entrevistador

$\mathrm{R}=$ Informante entrevistado

$\mathrm{n}=$ Número de intervención entrevistador / entrevistado

[] = Aclaraciones transcripción

Cursiva $=$ Dato contextual

$\mathrm{R}_{1}$ : Si la cantidad de kilómetros que tienen que recurrir... en la baja densidad poblacional hacen que el IPK que ellos le llaman

$\mathrm{I}_{1}: \mathrm{Si}$

$\mathrm{R}_{2}$ : El Índice de Pasajeros Kilómetros sea bajo entonces ahí si no aparece el estado subsidiando esa diferencia

$\mathrm{I}_{2}: \mathrm{Si}$, si bueno

$\mathrm{R}_{3}$ : No la van a corregir nunca, al tipo le conviene andar entre Plaza Italia y Plaza Rocha es como capaz en una pecera es así...

$\mathrm{I}_{3}$ : claro 
$\mathrm{I}_{4}$ : -risas-

$\mathrm{R}_{4}$ : -risas- Si vos al tipo le decís no mira hay gente de Arana que está en 4to año de medicina o de derecho, y sale a las 10 de la noche y el tipo te dice "Eh hasta Arana a las 10 de la noche con 5 tipos"

$\mathrm{I}_{5}$ : Claro, ja ni loco

$\mathrm{R}_{5}$ : Ahí tiene que aparecer el estado

$\mathrm{I}_{6}$ : Claro, bueno por eso pero el estado... no si por eso bueno, a eso apunta todo esto también pero hay que ver

$\mathrm{R}_{6}$ : $\mathrm{Y}$ otra cosa que a los tipos le favorece también y al sector es la confusión en el marco de jurisdicción. Agarra un tipo común y te putea nosotros, vos atendés el teléfono y te putea "No paso el 21240 min" y capaz que a provincia llamaban tipos por el NORTE

$\mathrm{I}_{7}$ : Claro

$(01: 04)$

$\mathrm{R}_{7}$ : El tema de, de. El tema de que esto no sea una región, en términos de que este concebido el transporte como sistema regional

I 8 : Claro y haya una oficina de transporte que regule la región...

$\mathrm{R}_{8}$ : $\mathrm{Y}$ con subsistemas, por que debería tener subsistemas en término municipio para entender situaciones específicas de cada municipio. Hace esto, hace que todo sea una gran confusión y nadie toma el tema, nadie hace, nadie hace planeamiento en término de mediano o y largo plazo, por que la solución tampoco viene acá en el corto plazo. Y después esta la otra cosa que también. Vos diagramas recorridos das frecuencia en función de la infraestructura que tenés... ¿ ¿No? Eso o sea eso te determina, eso no quiere decir que este bien el sistema de transporte por donde pueden pasar los micros que nada tiene que ver con cuál sería el mejor lugar que pasen los micros. No sé si me entedes 
$\mathrm{I}_{9}$ : Y sí, hay otra realidad también .Si si. Es notable eso. La otra cuestión que a mí me sorprendió es en el último grupo mencionaban que ellos en la época anterior al SUD los 90, salían cada $5 \mathrm{~min}$ los colectivos y en todos dijeron, en todos los grupos como se redujo la flota de unidades. Y como todos señalaban como creció la demanda, y a la cantidad de población a la que no le pueden dar respuesta, como que si pusieran los coches de aquella época y la frecuencia de aquella época habría viajes acorde. Está bien que el parque automotor residencial y mayor quilombo que tienen

$\mathrm{R}_{9}$ : Mira lo primero pensar que la ciudad de La Plata está pensada para el sistema ferroviario

$\mathrm{I}_{10}$ : No pero unos buenos colectivos con carril exclusivos también

$\mathrm{R}_{10}$ : Si por supuesto

$\mathrm{I}_{11}:$ ¿Por qué decís ferroviario solo?

$\mathrm{R}_{11}$ : Acá no hay nada, acá se lo abandono de a poco una ciudad que estuvo en, en, en, en los años 40 en el inicio del micro infinidad de líneas de micros. Esto fue un proceso que se dio en el transporte público y ¿Qué pasa? El estatus quo este al empresario en la medida que vos no le cambies cosas, al tipo le viene bárbaro ¿Por qué? Porque los centros a tractores, llamémosle, antes era considerado el Hospital de Niño, Plaza Moreno y esta mucho está pensado en función de eso, entonces cuando vos tenés que incorporar la UTN, "Ah por la UTN para 214 y la 202” ¿Por qué pasa el 214 y la 202 históricamente? ¿Por qué un chico que estudia en la UTN y vive en Ringuelet no puede llegar con un ramal del NORTE?

$\mathrm{I}_{12}$ : Claro

$\mathrm{R}_{12}$ : ¿Entendes? Y otra cosa que ellos nunca quisieron analizar es el tema de cómo cambian los centros a tractores en banda horaria, en día y en mes. Porque vos, por ejemplo con el Estadio Único, con la feria de los fines de semana, como el régimen carcelario y el régimen de visitas, a vos te aparecen situaciones distintas que no podes atender con la misma frecuencia estática

$\mathrm{I}_{13}$ : Que en la semana 
$\mathrm{R}_{13}$ : Que en la semana

$\mathrm{I}_{14}$ : Claro

$(04: 19)$

$\mathrm{R}_{14}$ : ¿Entendes? Ahora cuando vos queres discutir eso, eso implica más diagramación, más gente laburando, llamémosle en laboratorio, de lo que tendría que tener la empresa que o sea, en el laboratorio de la empresa cuando vos lo empezas a putear en la parada de 1 y 60 y ponen un coche más ese es el factor de corrección que utiliza

$\mathrm{I}_{15}$ : Claro, pero esto lo sacan de otro lado. Porque ese es el tema

$\mathrm{R}_{15}$ : Después lo empiezan a putear en...

$\mathrm{I}_{16}$ : Que no aprecian ellos

$\mathrm{R}_{16}$ : en 7 y 96 por que se llenó de 122 a 7, se llenó cuando paso por la feria paraguaya entonces el que está en 7 y 96 y viene lleno, 20 llamadas puteando po po po. Un coche más pero lo sacan del ramal 15 que, entendes como funciona

$\mathrm{I}_{17}$ : Claro, claro si, si, si no mueven...

$\mathrm{R}_{17}$ : Y el estadio no forma cuadro, los concejales viste te mandan previo informe pero cuando vos tenes presupuesto en ningún momento nadie se le cae una idea por ver qué presupuesto tiene el área de...

$\mathrm{I}_{18}$ : Claro

$\mathrm{R}_{18}$ : De transporte entonces vos después tenes chicos que si le pagan a la niñera

$\mathrm{I}_{19}$ : -risas- después no pueden venir a trabajar 
$\mathrm{R}_{19}$ : No pueden venir... Entendes

$\mathrm{I}_{20}$ : Claro

$\mathrm{I}_{21}$ : O le pagan y no pueden vivir o si vinieron pueden ir a trabajar

$\mathrm{R}_{20}$ ¿ ¿Entendes?

$\mathrm{I}_{22}$ : Escuchame hay una cosa entre bueno

$\mathrm{R}_{21}$ : Si es todo muy loco

$\mathrm{I}_{23}$ : Lo que yo veo, también que el, la actual intendente le destina más recursos al transporte a la gestión de transporte en cargos, que Bruera o que el equipo de ustedes, era más chico pero los pibes que están no tienen la menor idea, con lo cual...

$\mathrm{R}_{22}$ : El nombramiento no tiene que ser político, el nombramiento tiene que ser técnico político

$\mathrm{I}_{24}$ : Bueno

$\mathrm{R}_{23}$ : Vos tenes que llevar un a un tipo con capacidad de análisis

$\mathrm{I}_{25}$ : Lo que pasa es que el pro en todas las áreas metió gente que fuera de su partido no que fuera que tenga expertiz técnica o sea esos tipos están aprendiendo, están como... y la vez

$(06: 11)$

pasada yo charlaba con Oscar, y le decía "Che..." bueno no, che no le decía "Oscar no sé si te parece que por ahí podamos encontrarnos cuando terminemos esta, este trabajo, hacer un 
encuentro en donde pueda venir Gabriel y traigamos al director de transporte para que empiece entender..."

$\mathrm{R}_{24}$ : A eso no les gusta mucho eso

$\mathrm{I}_{26}$ : Con Cristobal no quiero hablar más me dijo, yo por...

$\mathrm{I}_{27}:$ ¿Con quién?

$\mathrm{I}_{28}$ : Con Emiliano, este que...

$\mathrm{R}_{25}$ : Pero mira estaba allá y miraba los diarios de todos los días ¿No? Y por ejemplo veo el punto a punto, anunciaron en Plaza Moreno un coche. Bueno ahora, ese los semi rápidos de la 520 y la 44 tenían 4 coches cada uno, ahora eso punto a punto ¿Son coches que se dieron de alta en el sistema? ¿Tenemos más coches en el parque móvil? ¿O son coches que le sacaron a la OESTE? Y es una picardía para tener una tarifa diferencial. Ni pregunte para no comprometer a los chicos, pero estoy segurísimo que lo que hicieron fue sacar coches del parque móvil de la OESTE de tarifa común y mandarlo en un servicio semi rápido donde la tarifa es más cara

$\mathrm{I}_{28}$ : Claro

$\mathrm{R}_{26}$ : Entonces con esas cosas...

$\mathrm{I}_{30}$ : No hay $\mathrm{xxx}$ de dos unidades

$\mathrm{R}_{27}$ : Con esas cosas no se juega

$\mathrm{I}_{31}$ : Bueno, eh... así que lo que tenemos por delante son unos tres encuentros más para terminar con todos los ramales y después surgió de ellos mismos hacer en un encuentro final que vengan dos de cada... de cada línea a consensuar un plano general... 
$\mathrm{R}_{28}$ : Una conclusión

$\mathrm{I}_{32}$ : Con propuestas, con problemas como un diagnóstico del sistema para consensuar con ellos, bueno y después hacer un encuentro también invitando a que venga la UTA con ustedes...

$\mathrm{R}_{29}$ : Que se yo, hay pila de cosas...

I $_{33}$ : Y la gente de la muni no sé si los vamos a convencer a Oscar de que venga

$\mathrm{R}_{30}$ : Para mí, aparte otra cosa que también es el tema, es que provincia nunca se compromete, fue... quedas en una situación de desventaja al momento de instalar estos temas y que se genere un poco de consenso de todos los que se tienen que involucrar

$\mathrm{I}_{34}$ : Bueno, es que provincia nunca se metió en el tema de transporte, ¿Cuándo se metió?

$\mathrm{R}_{31}$ : No

$(08: 42)$

$I_{35}$ : Nunca jamás

$\mathrm{R}_{32}$ : Yo sabes lo que discutía...

$\mathrm{I}_{36}$ : Con el tema de la plata, no se

$\mathrm{R}_{33}$ : Discutía en el buen sentido, no por la terminal de micro y la terminal de trenes, lo único que me repetía el pibe ¿Te acordás que estaba?

$\mathrm{I}_{37}$ : -risas- 
$\mathrm{R}_{34}$ : Si bien, es importante como centro... de carga, de la estación, la terminal de micros, terminal de trenes, no es la situación que se previó cuando el tren tenia muchísima carga cuando la gente lo tenía muy asociado a ir Buenos Aires el tren tuvo períodos que fue un desastre en término de servicio, la demanda se trasladó al micro, al Plaza, al Costera.

Entonces ya no es un centro de a tracción tan importante, y si, así lo fuese tendrían que llegar todas las líneas ¿O no?

I $_{38}$ : Y no llegan, y lo que pasa es que

$\mathrm{R}_{35}$ : Y si la terminal de micros...

$\mathrm{I}_{39}:$ Claro, si

$\mathrm{R}_{36}$ : Fuese tan importante no debería estar en donde está y también deberían llegar todas las líneas, debería ser casi un nodo o de transporte urbano

$\mathrm{I}_{40}$ : Y si de transferencia, sí, pero el tema es... tiene que haber troncales y otras más barriales. Para que eso funcione mejor, pero bueno eso es un cambio...

$\mathrm{R}_{37}$ : Vos fíjate por ejemplo ahora si vos te sentás con la 273 terminaron, lo manda a La PlataConstitución, que necesidad tiene de venir un 273 de Villa Elisa a Plaza San Martin ya el 273 debería reformularse e integrarlo y que la conectividad este dada...

$\mathrm{I}_{41}$ : Directo en Plaza Moreno

$\mathrm{R}_{38}$ : No, tiene que aumentar la conectividad con el ferrocarril, tiene que haber subsistemas o rondines que a vos te lleven a la terminal de Ringuelet, de Tolosa, de City Bell...

$\mathrm{I}_{42}$ : Bueno, si 
$\mathrm{R}_{39}:$ ¿Me explico?

$\mathrm{I}_{1}$ : Pasa que el tren, mira el tren...

$\mathrm{R}_{40}$ : Bueno pero ahora va a ser eléctrico en algún momento

$\mathrm{I}_{43}:$ ¿Cuándo haya electricidad? -risas-

$\mathrm{R}_{41}$ : Bueno, cuando haya

$(10: 44)$

I44: -risas-

$\mathrm{R}_{42}$ : Pero cuando vos plantees esto ¿Qué haces? O le estas quitando un montón de kilómetros a la 273 y le estas quitando secciones donde más rentabilidad tiene por que el subsidio es mayor que son la cuarta y la quinta, ¿Entendés?

$\mathrm{I}_{45}: ¿ Y$ por qué el subsidio es mayor ahí?

$\mathrm{R}_{43}$ : Porque ahí te dan más pesos por kilómetros, que en lo que es primera

I46: ¿Por qué es así?

$\mathrm{R}_{44}$ : Hay una estudio de costo que lo justifique

$\mathrm{I}_{47}$ : Lo justifican ellos, lo elaboran ellos. Es como medio secreto el tema de los subsidios todavía 
$\mathrm{R}_{45}:$ ¿Medio?

I48: -risas-

$\mathrm{R}_{46}$ : Otras cosas que se podría trabajar con todo el avance que hay hoy por ejemplo si, que se yo, la gente de la facultad de informática, ¿Por qué no se va una sube con tiempo? Si vos tenes, una conectividad que se va a dar en el mundo real, porque el tipo se va a bajar en Plaza Rocha y si tiene un lapso de tiempo de 20 minutos automáticamente va a tomar otro micro. Al costo que pago su boleto y después las empresas dicen es un quilombo, no es un quilombo, hoy ya es un tema de xxxx. Si yo mi tarjeta a las 9.10 de la mañana la pase por la 275 y por la 506 , bueno habrá que determinar que coeficiente se lleva cada grupo empresario de su boleto, pero no es imposible

$\mathrm{I}_{49}$ : No lo que pasa que informatizar tanto todo transparenta un montón de situaciones

$\mathrm{R}_{47}:$ Claro

$\mathrm{I}_{50}:$ Y ahí...

$\mathrm{R}_{48}:$ Se espantan ellos

$\mathrm{I}_{51}$ : No quieren, claro. Prefieren seguir cobrando... si fuera por ellos seguirían cobrando con el boleto viejo

$\mathrm{R}_{49}$ : Ellos quieren que a vos te dejen en Plaza Italia y después otros 25 minutos de Plaza Italia y de ahí te tomas el otro bondi

$\mathrm{I}_{52}$ : Si, pero bueno también hay un interés en modificar las cosas, porque si no la UTA no nos estaría respaldando para hacer esto, ellos quieren, lo que pasa que no quieren hacer algo que modifique tanto...

$\mathrm{R}_{50}: \mathrm{Si}$ 
$\mathrm{I}_{53}$ : No modifique sus números para peor

$\mathrm{R}_{51}$ : La UTA, si, la UTA en esto la verdad que tuvo un gesto noble, acompaña, en definitiva lo que hacen hoy es tener información para que si algún día viene algo muy drástico tener como ir articulándolo y tabicandolo para que sea todo mucho más gradual

$\mathrm{I}_{54}$ : Claro, con esto no se sabe

$\mathrm{R}_{52}$ : Bueno, yo te digo la verdad vos me decís y ustedes estuvieron cuatro años ¿Qué haces? Lo que podes sin recursos...

$\mathrm{I}_{55}$ : Claro

$\mathrm{R}_{53}$ : Entonces hacelo...

$\mathrm{I}_{53}$ : Claro lo que te digo

$\mathrm{R}_{54}$ : Que están haciendo estos chicos no se

$\mathrm{I}_{54}$ : Si Bruera hubiera destinado la proporción de guita que tiene este tipo, a transporte con el equipo de que tenía hubiera hecho más cosas, hubiera podido tener más gente, mas inspectores controlando a los empresarios, ¿Me entendes? Pero ¿Cuántos inspectores tenían ustedes? Eduardo igual muchos inspectores no tiene, tiene todos caciques -risas- Tampoco tiene muchos inspectores, no sé, hoy nos vamos a enterar bien cuanta gente está operando ahí, bueno, bueno así que como que la perspectiva es esa y como lo que queremos hacer ahora a fines, a principios de septiembre hacer un encuentro con los directores de escuelas presentado los resultados y a fin, principios de octubre con hospitales, no, ¿O al revés? Perdón, al revés, perdón, primero con hospitales dijimos, ahora $1^{\circ}$ de septiembre y $1^{\circ}$ de octubre con escuelas, como para empezar a... a tener como una periodicidad en los relevamientos, en un año medimos otro año presentamos resultados... 
$\mathrm{R}_{55}$ : Y por ahí 2018 devuelta hacer trabajo de campo y recolectas dato

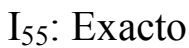

$\mathrm{R}_{56}$ : Está bien

$\mathrm{I}_{56}$ : Como para empezar a... por que, sin datos... no queda nada, ni vos, ni los empresarios, ni la pública

$\mathrm{R}_{57}$ : Y que pasa, la foto de un año en definitiva si vos no la repetís después...

$\mathrm{I}_{57}$ : Es una cosa aislada

$\mathrm{R}_{58}$ : Y si, es una cosa aislada por eso te digo que acá tienen que pensar por lo menos en mediano plazo

$\mathrm{I}_{58}$ : Exacto

$\mathrm{R}_{59}$ : Tiene que pensar, bueno a ver ¿Qué hacemos? Acompañado de un plan de obra con infraestructura a... lo primero que tenes que pensar por lo menos es a cinco años

$\mathrm{I}_{59}:$ Claro, y si

$(14: 59)$

$\mathrm{R}_{60}$ : Mínimo, vos fíjate todo lo que es la zona oeste por ejemplo, vienen por la 44, por la 32, por la 520, no hay nada todavía hecho en términos de corredores así, vos no tenés, está la $137 \ldots$

$\mathrm{I}_{60}:$ A si, si 
$\mathrm{R}_{61}$ : Un poquito la 143 , después son cada vez más cortitas...

$\mathrm{I}_{61}: \mathrm{Si}, \mathrm{si}$

$\mathrm{R}_{62}: 149,155$ olvídate, ya $173,179 \ldots$

$\mathrm{I}_{62}: \mathrm{Y}$ no

$\mathrm{R}_{63}$ : Llegas a Echeverri y no tenes nada

$\mathrm{I}_{63}: \mathrm{Si}, \mathrm{si}, \mathrm{si}$

$\mathrm{R}_{64}$ : O sea eso es requerir un plan de obra, de no sé...

I64: Muy importante de vialidad, si, si, hay una carencia. Y en el Plan Estratégico estan...

$\mathrm{R}_{65}$ : Tenés la 122 acá...

$\mathrm{I}_{65}$ : Están hablando de eso pero no de esos barrios

$\mathrm{I}_{66}:$ La ciento...

$\mathrm{R}_{66}:$ Vos manejas el...

$\mathrm{I}_{67}$ : El GIS 
$\mathrm{R}_{67}$ : Bueno, vos tenes la 122 acá y la 7 acá... ¿No? Acá hay 1, pero 1 se corta. Para cruzar de acá hasta acá, tenes la 609 y después te vas al camping que es de tierra de xxxx, como 635 ¿Entendes? Y acá está lleno de gente, gente

$\mathrm{I}_{68}: \mathrm{Si}, \mathrm{si}$

$\mathrm{I}_{69}$ : Si por eso ahora las, incluso la 51, también viste que por la universidad esta, colapsada o ahí tiene mucha, mucha demanda de, de autos sobre todo

$\mathrm{I}_{70}: \mathrm{Y}$ la 51

$\mathrm{I}_{71}$ : Atravesando de la 152 a 1 ¿Viste?

$\mathrm{R}_{68}:$ Ah si

$\mathrm{I}_{72}$ : Esa esta, porque es la única que cruza, el bosque

$\mathrm{R}_{69}$ : Claro, porque después te vas hasta 60

I73: Claro

$\mathrm{I}_{74}$ : Esta todo, pero por eso hay que hacer un carril exclusivo de transporte publico pronto y que tengan mayor frecuencia y que tengan mayor velocidad comercial, ya con eso los tipos van a mejorar, digamos, que tengan mayor velocidad que el auto, porque el auto hoy llegas tarde pero llegas más rápido que el colectivo

$\mathrm{R}_{70}$ : Es menos tiempo de viaje, es menos índice de siniestro, es menos índice de enfermedades profesionales, porque acá es todo una cosa oculta, el chofer termina... 
$\mathrm{I}_{75}$ : Están todos con tratamientos psicológicos

$\mathrm{R}_{71}$ : ¿Qué psicológico? Después todos terminan con tratamientos cervicales, de dorsales, de, ese tipo es carpeta, es carpeta de 20 días, de 15 días, la empresa no lo reemplaza, entonces...

$\mathrm{I}_{76}$ ¿ ¿Cómo que no lo reemplaza?

$\mathrm{R}_{72}$ : ¿Y cómo tomas un chofer por 15 días? El chofer tiene su condición de ser un profesional, no podes decir al tipo, che vos tenes un carnet de...

$\mathrm{I}_{77}:$ ¿Pero no tienen suplentes?

$\mathrm{R}_{73}: \mathrm{Si}$, pero...

$\mathrm{I}_{78}$ : Bueno ahí es parte del negocio de la empresa

$\mathrm{R}_{74}$ : Yo te diría que no ¿Quién puede tener suplente un tipo que te sale 40 mil pesos por mes? Es un coche menos un día que tenés varias carpetas

$\mathrm{I}_{79}$ : Ellos dicen que ojala cobraran 40 mil pesos por mes, por ahí le sale eso con los aporte

$\mathrm{R}_{75}$ : A la empresa le debe salir eso

$\mathrm{I}_{80}$ : Claro, porque ellos no cobran eso, deben cobrar $28 \mathrm{mil}, 30 \mathrm{mil}$

$\mathrm{R}_{76}$ : Igual son de los tipos con un salario de los más...

$\mathrm{I}_{81}$ : Claro, si bueno... bueno te voy a hacer la entrevista porque si no te vas a tener que ir 
$\mathrm{R}_{77}: \mathrm{Si}, \mathrm{si}$

$\mathrm{I}_{82}$ : Este es para el proyecto de...

$\mathrm{R}_{78}$ : Si pero hacémela anónima en lo posible, yo diría una idea que te resulte... si te sirve la tomas y si hay alguna idea que te parece que es un desastre... decía que la escuchaste en...

$\mathrm{I}_{83}$ : No, yo te, yo te la mando la síntesis escrita para que vos después la veas y si te parece que algo... no sé qué lo chequees... fijate que las preguntas tiene que ver con tu etapa de gestión... no sé si vos te acordás de estos datos pero aproximado por lo menos, en tu etapa ¿Cuántas líneas de transporte público había en la ciudad? ¿Cuántas empresas operando en el servicio? Si tiene autorización, bueno hay cosas que yo sé pero igual te las voy a preguntar, como, por

rigor ¿No? ¿Quién otorga esos permisos? ¿Cuántas líneas maneja o regula la jurisdicción municipal donde estabas vos?

$\mathrm{R}_{79}$ : Para esto tengo que hacer memoria

I $_{84}$ : Por eso, por eso te digo, vamos viendo y vamos aproximando y después de ultima corregimos los datos pero lo armamos y después te lo mando y lo corregimos... y los permisos que están vigentes este, cuando vos estabas ¿Cuándo vencían aproximadamente? ¿Cuáles requisitos para obtener esos permisos había? ¿Hay una copia? Yo creo, yo tengo los permisos de los noventa, pero...

$\mathrm{R}_{80}$ : Vos tenés que pedir copia del

$\mathrm{I}_{85}$ : Del pliego

$\mathrm{R}_{81}$ : Copia del pliego y copia del decreto que adjudicó y copia de la ordenanza que convalido la adjudicación por que en definitiva... 
$\mathrm{I}_{86}$ : Claro

$\mathrm{R}_{82}$ : Todo el proceso, todo, digo, el consejo deliberante es el que tiene la facultad

$\mathrm{I}_{87}$ : Claro

I88: ¿Estas grabando ahí? Uno, dos, ahí está, listo bueno. Vamos de nuevo entonces ¿Vos te acordás en tu gestión cuantas líneas de transporte público había en La Plata?

$\mathrm{R}_{83}$ : Municipales

$\mathrm{I}_{89}$ : Municipales

$\mathrm{R}_{84}$ : Al principio ESTE, OESTE, SUR Y NORTE, 508, 506, 518, 520... el SUR era la 506 y la SUR... NORTE, 518, 520, 530, si básicamente si se me puede estar yendo alguna pero básicamente era, era eso

$\mathrm{I}_{90}$ : Y las empresas ¿Cuántas eran?

$\mathrm{R}_{85}: \mathrm{Y}$ en ese momento eran tres operadores

$\mathrm{I}_{91}$ : Tres ¿Cuáles eran?

$\mathrm{R}_{86}$ : Y cuatro con Unión, en su momento la SUR lo operaba Unión Plate... la operaba La Unión

$\mathrm{I}_{92}:$ ¿La Unión es una distinta que Unión Platense? 
$\mathrm{R}_{87}: \mathrm{Si}$, bueno pero en definitiva después quedó todo eso quedó en manos de Unión Platense

$\mathrm{I}_{93}:$ ¿Unión y Unión Platense ahora son lo mismo?

$\mathrm{R}_{88}$ : No, La Unión era una cosa. La unión es la 202, la operadora de la 202 y Unión Platense la operadora de la 273 ... después estaba línea 7 que operaba la 307 y la ESTE y la 506, y después

estaba Fuerte Barragán que operaba la 275, que era la provincial, después estaba la 9 de Julio que operaba la OESTE y la 508, y después estaba... estos tres... si en definitiva eso era el grupo, los grupos empresarios que estaban...

I94: Y después se hicieron dos

$\mathrm{R}_{89}$ : No, después quedó, tengo entendido, porque nosotros ya estamos en la etapa final que línea 7 se quedó con la 275, no con la 307, perdón, y que la 506 paso a ser operada por Fuerte Barragán que era la 275 y como la ESTE se volvió a licitar parte de la ESTE, el ramal 12 y 13 lo tomo el grupo empresario, que era la de la 9 de Julio con otra empresa y los otros ramales de la ESTE lo tomo el grupo de Unión Platense pero con otra empresa que me parece que se llama Expreso...

$\mathrm{I}_{95}:$ Expreso

$\mathrm{R}_{90}$ : Expreso La Plata Buenos Aires o Expreso City Bell, eso es un poco el cuadro de los grupos empresarios que están detrás de cada línea

$\mathrm{I}_{96}: \mathrm{Y}$ operaban con una autorización

$\mathrm{R}_{91}$ : No, operaban en el marco de la licitación, en el marco de un pliego de base y condiciones, donde se... se terminaban adjudicando y se terminaba convalidando vía consejo deliberante con un plazo de 10 años 
$\mathrm{I}_{97}$ : Ah, 10 años ¿Y cuando habían empezado cuando estaba vos? ¿Te acordás?

$\mathrm{R}_{92}$ : Y nosotros ahí agarrábamos muchas que estaban vencidas, así que y la mayoría tienen que remontarse al 2012, 2013 así que tenÉs 10 años con un opción con un opción creo que la ordenanza prevé una opción de prórroga por 2 años mas

I98: Ajá ¿Vos en qué año me habías llevado?

$\mathrm{R}_{93}: 2011$

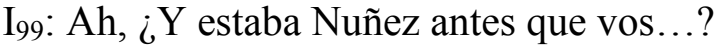

$\mathrm{R}_{94}$ : No, estaba Gabriel Sinieti, ya se había ido...

$\mathrm{I}_{100}$ : Ah, hubo un recambio de gente importante, bueno, ¿Los permisos que tenían eran todos iguales para todas las empresas o eran distintos para las provinciales, para las municipales?

$\mathrm{R}_{95}$ : No, de las provinciales desconozco

$\mathrm{I}_{101}$ : No pasaban nunca por la muni, ellos responden a Provincia

$\mathrm{R}_{96}$ : No

$\mathrm{I}_{102}$ : Eso no está bien -risas-

$\mathrm{R}_{97}$ : En definitiva la ley de transporte provincial lo que prevé es que cuando vos creas un ramal o línea en términos que estén en juego dos jurisdicciones, se les da traslado a los municipios 
que están involucrados para que genere suposición... por si entendes que se está afectado alguna de las líneas municipales, o ahora en algún punto acordar todo lo que sería la política de tránsito, por dónde pasan y eso que es facultad del municipio salvo que el corredor sea provincial. Pero después vos no tenes acceso al pliego, no participas en la confección del pliego de una línea provincial, vos como se soluciona el pliego de la línea municipal previendo recorrido, previendo paradas, previendo personal, previendo cantidad de parque móvil, previendo requisitos en término fiscales, en término contable, el precio justificas con presentación de balance, eso es básicamente el sustento jurídico donde después se mueve la... la concesión digamos

\section{$\mathrm{I}_{103}$ : Claro}

$\mathrm{R}_{98}$ : O con un régimen de sanciones, bueno, pero eso, eso es público o sea podrías ir vos o cualquiera pedir copia del pliego, pedir copia del decreto que adjudicó, pedir copia de la ordenanza que convalidó todo, no...

$\mathrm{I}_{104}:$ ¿Al consejo deliberante o a la municipalidad?

$\mathrm{R}_{99}$ : No sé por dónde, yo creo que una nota del consejo, te lo deberían dar o un nota presentada en la dirección de transporte, también te la deberían dar

$\mathrm{I}_{105}$ : Bueno, cuantas líneas no sabemos el, la cantidad de líneas en la jurisdicción que regulan la jurisdicción

$\mathrm{R}_{100}$ : Municipal

$\mathrm{I}_{106}:$ Ajá

$\mathrm{R}_{101}$ : Y para vamos a hacer un ejercicio para no equivocarnos, vos tenés SUR... OESTE, ESTE, 520, 506, 508, hay otro semi rápido por la que la OESTE tiene dos semi rápidos, no porque 520,561 ¿No hay una? 
$\mathrm{I}_{107}:$ Si y 518

$\mathrm{R}_{102}: 581,518$, creo que esto es todo el marco municipal

$\mathrm{I}_{108}$ : Bueno la 581 mucho no... no funcional pero...

$\mathrm{R}_{103}:$ Uno, dos, tres

$\mathrm{I}_{109}: \mathrm{No}$, funciona

$\mathrm{R}_{104}$ : Nueve

$\mathrm{I}_{110}$ : Son nueve

$\mathrm{R}_{105}$ : No me acuerdo de otra

$\mathrm{I}_{111}:$ ¿Y las provinciales sumarian en total...? Son cuatro más, no

$\mathrm{R}_{106}$ : No, hay más ahora

$(27: 36)$

$\mathrm{I}_{112}$ : Cinco mas

$\mathrm{R}_{107}$ : Lo que pasa es que ahora tenés la $502 \ldots$

$\mathrm{I}_{113}: 214$ 
$\mathrm{R}_{108}: 214,273,307 \ldots$

$\mathrm{I}_{114}: 275$

$\mathrm{R}_{109}: 275$, después esta la $414,418 \ldots$

$\mathrm{I}_{115}: 414,215$

$\mathrm{R}_{110}: 414,215$ que va a Gómez, después hay otra que es la 418, no me acuerdo ahora...

$\mathrm{I}_{116}$ : Son ocho provinciales y 9 municipales

$\mathrm{R}_{111}$ : Pero seguramente acá nos esté faltando alguna mira, sobre todo en estas nuevas que crearon a lo último, no sé si hay una que es 218 también...

$\mathrm{I}_{117}: 228$ una cosa así

$\mathrm{R}_{112}$ : Que va a Varela o a....

$\mathrm{I}_{118}$ : Bueno, son el orden de...

$\mathrm{I}_{119}$ : Después la 338 que no sé como

$\mathrm{I}_{120}$ : No, pero esa ya es... del conurbano, el TALP, no

$\mathrm{R}_{113}$ : Pero vos fijate por ejemplo, acá tenés, esto lo único que provoca... toda esta fragmentación, es desorden, es falta de controles 
$\mathrm{I}_{121}$ : Son los negocios de cada uno -risas- es lo que pasa con los negocios, no te dignifica, es así. Bueno los permisos estarían vigentes, estaban vigentes todos, no, se te habían vencido decías

$\mathrm{R}_{114}$ : No, no, ahora están vigentes

$\mathrm{I}_{122}$ : Pero en el momento que estabas vos como director de transporte

$\mathrm{R}_{115}$ : Algunos estaban vencidos, estaban vencidos por que en realidad la licitación se había suspendido y no se habían adjudicado por que en ese momento había muchos problemas con el precio del gasoil y fue una etapa crítica con el régimen de, del combustible

$\mathrm{I}_{123}$ : ¿Más que crítica que ahora?

$\mathrm{R}_{116}$ : Le asignaban cuotas, no alcanzaba era un quilombo, que se yo

$\mathrm{I}_{124}$ : Bueno, y cuando, y vencían cada 10 años ósea que cuando vos estabas en gestión...

$(29: 30)$

$\mathrm{R}_{117}$ : Y deberían estar venciendo en el 2022 por ahí

$\mathrm{I}_{125}$ : Bueno, los requisitos para obtener los permisos por parte de las empresas ¿Te acordas?

$\mathrm{R}_{118}$ : $\mathrm{Y}$ eso depende de cómo vos gestiones el pliego

$\mathrm{I}_{126}: \mathrm{Y}$ en aquellos pliegos... 
$\mathrm{R}_{119}$ : $\mathrm{Y}$ básicamente era tener antecedente de la actividad, tener un patrimonio neto importante, bueno que los socios no tengan condición de... son casi requisitos típicos en ese aspecto los pliegos, que no esté quebrado, que no esté inhabilitado, después básicamente todo lo que era la parte fiscal, no tener deuda fiscales, no tener deuda con los aportes y carga sociales

$\mathrm{I}_{127}$ : De los choferes

$\mathrm{R}_{120}$ : Exactamente, bueno tener una proyección de lo que iba a ser la línea de inversión, los años de antigüedad del parque móvil, un piso de frecuencia que después bueno, ahí por lo general los pliegos tienen un artículo abierto que es el que te autoriza a vos como estado a poder requerir el aumento de frecuencia, el aumento de parque móvil, la misma ordenanza lo prevé, los cambios de los recorridos, nuevos ramales, bueno, ósea el marco jurídico es amplio, para que desde el estado pueda intervenir

$\mathrm{I}_{128}$ : Claro, bueno, respecto a las copias ya hablamos, tendríamos que gestionarlas en la muni o en el consejo. Bueno ¿Medían? ¿Qué median? Ustedes median varias cosas en la época que estabas vos de director ¿Median la calidad del servicio del transporte público de alguna forma?

$\mathrm{R}_{121}$ : $\mathrm{Si}$, nosotros mediamos mucho el tiempo de espera, en definitiva indirectamente era consultar un poco con la frecuencia y para situaciones estacionalidad lo mediamos mucho en hospitales, hacíamos mucho en San Martin, le dábamos mucha importancia al Hospital de Niños, hacíamos relevamiento los fines de semana de la frecuencia que por ahí empieza a ser menor o se disparaba de 20 min a 40 en algunas situaciones, bueno lo controlábamos

$\mathrm{I}_{129}$ : De hecho es mucho más que lo que piden los pliegos ¿No?

$\mathrm{R}_{122}$ : No porque en definitiva uno tenía la potestad de decirle al o exigirle al empresario que sea menor pero por ahí la carga de fines de semana en determinados ramales es muy baja, entonces tampoco se justificaba aumentar mucho la oferta cuando en definitiva por ahí, en este esquema que como empresario tiene reconocido determinada cantidad de kilómetros por el Organismo Nacional que le subsidia, bueno entonces esos kilómetros vos tratas de guardártelo, en el buen sentido, para cuando en definitiva tenes muchísima más actividad, donde necesitas mucha más oferta. Pero bueno hacíamos hincapié que en los fines de semana aun cuando se reducía la frecuencia se cumpliese en los parámetros que se establecía o que se publicaba en la página de la muni, eso se controlaba mucho y después controlábamos a la mañana, estábamos muy presente en los puntos donde también se satura la carga, como era 7 y 80, 117 y 96, 32 y 149, bueno íbamos alternando y siempre buscábamos reforzar en esa franja crítica de horario y de... cuando digo franja crítica, me refiero a horario y me refiero a 
una porción de la traza, porque el micro cuando, esto como se da, el micro cuando no eligen destino el micro arranca subiendo pasajeros en un punto satura su carga y después en otro punto descomprime porque. Bueno entonces en ese tramo siempre con coche le decíamos "Bueno vos cubrime aunque sea en esta franja horaria con dos coches este tramo porque si

no" Bueno y tratábamos de mejorar la condición así. Bueno y después muy presente también en el tema colegios, los colegios más críticos, hay otros que son menos críticos porque asisten mucho en coche o con transporte escolar, y hay colegios donde bueno el transporte público y sobre todo que va acompañado de la mamá, la mamá lo está esperando, si, se daban situaciones también que hacían que estuviesen alguno de los chicos monitoreando

$\mathrm{I}_{130}$ : Bueno, claro. El tema de la, de la información que les da la empresa, que les daba la empresa a ustedes antes de que este la sube, ahí ¿No les daban información?

$\mathrm{R}_{123}$ : $\mathrm{Si}$, ahí te daban información en concepto declaración jurada pero la verdad que la capacidad de corroborar lo fehaciente que podían ser los datos, no teníamos los recursos humanos, ni técnicos, ni...

$\mathrm{I}_{131}$ : Bueno, entonces ¿Tenían inspectores propios no?

$\mathrm{R}_{124}: \mathrm{Si}$

$\mathrm{I}_{132}:$ ¿Cuantos tenían?

$\mathrm{R}_{125}$ : Y mira estaban Martin, Diego, Blanca, Federico... seis

$\mathrm{I}_{133}:$ ¿Y que controlaban?

$\mathrm{R}_{126}$ : Un poco lo que te...

$\mathrm{I}_{134}$ : Si, la espera. Horarios y frecuencia del servicio, cumplimiento de paradas, pago e boleto 
$\mathrm{R}_{127}$ : No

$\mathrm{I}_{135}$ : Condiciones del vehículo

$\mathrm{R}_{128}$ : La condiciones del vehículo, esto por lo general es también por que el propio seguro, la propia empresa que le cubre los siniestros le exige que el vehículo está bien y aparte esta la VTV en definitiva también es un reconocimiento del estado la condición de que el vehículo circule, si se veía una situación así muy grosera, o faltaban pasamanos, te afectaban un poco, pero básicamente el parque móvil estaba...

$\mathrm{I}_{136}$ : Estaba bien

$\mathrm{R}_{129}$ : Estaba bien

$\mathrm{I}_{137}: \mathrm{Si}$, mira es nuevo. La licencia de los choferes y el seguro ¿No?

$\mathrm{R}_{130}$ : Hay un legajo en la dirección donde todos los meses las empresas te acompañan, te acompañan la copia de la póliza y te acompaña... la licencia de los choferes en realidad no contaba en los legajos pero también ahí se da una situación donde la propia empresa es la que más prioriza que el chofer esté en condiciones de manejar porque si no pone en riesgo la cobertura de cualquier siniestro que tenga

$\mathrm{I}_{138}$ : Claro, eso le conviene cuidarlo a la empresa, bueno...

$(36: 26)$

$\mathrm{R}_{131}$ : Y nosotros en algún punto no hacíamos porque teníamos una persona que era Mariana pobre para atender los trecientos y pico de legajos parque móvil era imposible

$\mathrm{I}_{139}$ : Que tema este 
$\mathrm{R}_{132}$ : No terminas de armar uno que ya empieza otro mes, otro mes y otro mes...

$\mathrm{I}_{140}$ : Claro, necesitaban más equipo. Bueno, como trabajan estos inspectores o trabajaban en ese momento ¿Solo en la calle? ¿Solo en las cabeceras de las empresas? Cuantos son ya te los pregunte ¿Trabajan en la calle?

$\mathrm{R}_{133}$ : Básicamente

$\mathrm{I}_{141}$ : Básicamente

$\mathrm{R}_{134}$ : Y si queres controlar frecuencia una situación es trabajar en las cabeceras que después con todo el tema de la velocidad comercial se te distorsiona, entonces vos decís tiene que estar en Plaza Rocha 7.15 y son las 7.30 y ni apareció el micro pero por ahí se comió...Casa de Gobierno, pero el mejor control es en la calle

$\mathrm{I}_{142}$ : Claro

$\mathrm{R}_{135}$ : En la calle en paradas críticas

$\mathrm{I}_{143}$ : Bueno ustedes realizaron algunas encuestasen ¿Verdad? De opinión de los usuarios, de algún tipo de...

$\mathrm{R}_{136}$ : No tanto mira, cuando se, no había ningún ramal que cubriese la calle 38 de 131 a 155 , ahí lo que se hizo es... porque lo prevé la ordenanza también, se hace un se hace una encuesta a los comerciantes, a las personas, bueno a quien están afectados por ese corredor, que en definitiva siempre termina siendo por el manifiesto la necesitad que pase el micro. Así que hicimos eso, después en otra situación no se daban en términos formales así, sino se daba mucho porque usábamos mucho el método de reunirnos con los vecinos viste y que venían a la oficina y bueno también por ejemplo cuando se creó el ramal de Gorina para que el 273 pudiese llegar a la puerta del Colegio Nacional. Una vez el 273 y otra vez el NORTE, hicimos como una frecuencia alternada ahí teníamos provincia y municipio bueno ahí también se hizo un trabajo de relevamiento con los vecinos. Cuando se trabajó Puente de Fierro para que también convivan 275 y el SUR también. Pero después otras situaciones se iban resolviendo de hecho y sobre la marcha, y sobre todo con las mamás de los nenes en edad escolar, ósea la demanda que uno priorizaba era esa, sobre todo en invierno con los horarios la nocturnidad que tenés cuando el nene va a tomar el micro y los episodios de inseguridad que se daban, le 
robaban la mochila, que se pegaban, bueno ahí tratábamos de ponerle un micro con espera. Eso también es una cosa que da resultado, entonces vos pones un micro que está en espera en 122 y 604, todas las mamas de cinco cuadras a la redonda saben que 6.50hs sale ese micro, entonces ahí también...

$\mathrm{I}_{144}$ : Esta bueno

$\mathrm{R}_{137}$ : La utilización de los recursos es eficiente por que vos los esperas, el nene llega seguro y el micro sale lleno

$\mathrm{I}_{145}$ : Claro, está bueno

$\mathrm{R}_{138}$ : $\mathrm{Y}$ es un micro que no está afectado a la frecuencia del ramal ese micro termina con el último nene y se vuelve

$\mathrm{I}_{146}:$ Claro

$\mathrm{R}_{139}$ : A veces esas situaciones hay que propiciar. $\mathrm{Y}$ siempre en la medida de, porque esto es como una brazada corta vos donde sacas dos o tres micros para cubrir esas situaciones pero me los sacaban de Sicardi, no es que me lo...

$\mathrm{I}_{147}$ : Bueno, tenían algún tipo de formulario con el que organizaban los estudios, las preguntas, trabajo... hay algo de eso, que supongo vos lo trabajas con Jaqueline, ahí en el barrio para ver con los vecinos, armaban algún tipo de cuestionario

$\mathrm{R}_{140}$ : Eso se hacía mucho porque cuando la gente por ahí pedía, venir nosotros recibíamos a todos y por lo general hacíamos,, la política era que participen los inspectores, yo no hacia reuniones cerradas con los tipo, entonces venían, poníamos sillas, estaban los inspectores, más los cinco seis vecinos que entre ellos se elegían que venga a, a representar la situación. Y no bueno básicamente con lo que el vecino decía nosotros teníamos elementos para confrontar por que por lo general cuando medís en cualquier situación es así, vos medís. Vos tomás un lugar y hora, siempre. Son las dos cosas que... que tenés que descubrir cuando pensas en transporte. A qué lugar y a qué hora, porque ligar y a qué hora tengo que pasar. Esa es el gran trasfondo de todo esto. Entonces vos tomabas si iba vacío, si iba medio o si iba lleno. 
Entonces, si se te daba lleno, se te daba lleno, se te daba lleno entonces por qué un tramo origen destino, hay u tramo que se torna crítico y ahí aparecía la figura del refuerzo.

Obviamente que esta situación se tenía que repetir en más de una oportunidad porque por ahí había situaciones excepcionales

$\mathrm{I}_{148}$ : Como parte de la regularidad de la semana

$\mathrm{R}_{141}$ : Que pasa, hay situaciones por ejemplo de los dos ultimo días hábiles del mes, a los cinco primeros días hábiles del mes que vos tenés en la franja bancaria un montón de movilidad, que después te desaparece

$\mathrm{I}_{149}$ : Claro, claro

$\mathrm{R}_{142}$ : O tenés junio, julio y agosto de 5.45 de la mañana a 10 de la mañana toda una movilidad que se da por enfermedades respiratorias en los nenes que después desaparece, el nene en septiembre, octubre...

$\mathrm{I}_{150}$ : Ya está

$\mathrm{R}_{143}$ : Ya está, atendías así situaciones particulares

$\mathrm{I}_{151}$ : Claro. Bueno. Registraban ustedes los reclamos de los usuarios ¿No?

$\mathrm{R}_{144}: \mathrm{Si}$

$\mathrm{I}_{152}:$ ¿Como lo hacían? ¿Con números, teléfonos?

$\mathrm{R}_{145}$ : Se registran, se lo... y sobre todo después, en la medida de lo posible, porque a veces no estábamos en condiciones... porque no teníamos factor humano para controlar todo, pero por 
ahí lo que entendíamos que es lo más crítico, iba y se lo controlaba y se le buscaba a ver como se lo podía corregir

$\mathrm{I}_{153}$ : ¿Era a través del 0800 y la página web? ¿También tenían?

$\mathrm{R}_{146}$ : $\mathrm{Si}$, pero básicamente la gente llamaba por teléfono o mucho partía por ahí de la situación de que los chicos estén en la parada entonces el propio vecino por ahí le trasladaba alguna situación...

$\mathrm{I}_{154}:$ Claro

$\mathrm{R}_{147}$ : Que escapaba del horario de la presencia de los chicos, que hacíamos nosotros, nosotros controlábamos de 6.30 a 8.30 de la mañana, que es lo más crítico, llevar todos los chicos a la escuela

$\mathrm{I}_{155}: \mathrm{Y}$ después traerlos

$\mathrm{R}_{148}$ : $\mathrm{Y}$ después lo más crítico era de 4.45 a 6.30 era sacar toda esa masa de chicos del centro para...

$\mathrm{I}_{156}$ : Los barrios

$\mathrm{R}_{149}$ : Para la periferia

$\mathrm{I}_{157}$ : Claro

$\mathrm{R}_{150}$ : Y qué otra cosa que había entender a la gente del consejo escolar o los que piensan, cuando decían que tiene que ser interdisciplinario, es que vos si no pones... tenes que hacer escuelas en la periferia, por que vos a la mañana la carga el $80 \%$ se te repite básicamente. Si vos vas una parada y sacas una foto durante un mes el $80 \%$ de la gente es la misma, pero aparte hay nenitos acompañados por sus padres que la mamá tiene que venir dejarlo en la 
escuela y volver a tomar el micro para volver a su casa y después tiene que tomar otro micro para venir a buscar al nene ¿Entendes?

$\mathrm{I}_{158}: \mathrm{Si}, \mathrm{si}, \mathrm{si}, \mathrm{si}$. Son viajes doble

$\mathrm{R}_{151}$ : Entendes cuando un... si vos pensas establecimiento en el periférico, todo eso lo evitas

$\mathrm{I}_{159}$ : Bueno, ¿Cómo trataban esa información de los reclamos? Vos me decías que priorizaban con los que parecían prioritarios

$\mathrm{R}_{152}: \mathrm{Si}$, las situaciones más criticas

$\mathrm{I}_{160}:$ ¿Cuáles serían esas? ¿Cómo lo priorizaban?

$\mathrm{R}_{153}$ : Mira, en principio corroborando lo que nos planteaban, porque también a veces te plantean cosas que no con tan graves como te las plantean, pero bueno a veces la gente está cansada, de que el servicio no es lo bueno que debería ser y cuando te traslada el reclamo te lo magnifica un poquito. Una vez detectado eso en seguida tomas contacto con la empresa, en

seguida el inspector de la empresa, al otro día con el inspector nuestro y a partir de ahí te hacen un seguimiento hasta que se lo registra

$\mathrm{I}_{161}$ : Claro ¿Pero había sanciones para la empresa o era solo a través del diálogo, del acuerdo?

$\mathrm{R}_{154}$ : No, mira yo particularmente en lo que en lo que es transporte urbano vos pensa que son 10 años de concesión, vos pensa que son casi 50 millones de tickets al año con 20 y pico de millones de kilómetros al año. Las situaciones de incumplimiento que debería ser en el pliego son infinitas, esta parte después cortala...

$\mathrm{I}_{162}$ :-risas- 
$\mathrm{R}_{155}$ : Son infinitas, entonces yo a la primer semana porque esto se tiene que dar dentro de una lógica del derecho administrativo para que yo te pueda sancionar. En la primer semana yo que hago, apercibimiento. En la segunda semana, apercibimiento. La tercer semana ¿Qué te hago? Mil pesos. La tercer semana dos mil pesos. La cuarta semana cinco mil, llega un momento en que, que tengo que ir... te saco el ramal. Te saco el ramal, como lici... o te saco la línea. Esto es un sistema que está en algún punto cerrado ¿Cómo hago después para licitar esa línea? ¿Quién viene?

$\mathrm{I}_{163}$ : Claro, ósea que no

$\mathrm{R}_{156}$ : La lógica era trabajar siempre muy encima, muy encima de ellos. $\mathrm{Y}$ bueno vos lo has visto, yo trabajaba muy encima de ellos y muy encima del gremio. También otra cosa que se da con la sanción...

$\mathrm{I}_{164}$ : Decile a las chicas que hablen bajo que estamos grabando

$\mathrm{R}_{157}$ : Otra cosa que se da con el chofer es que vos lo podes entrenar una vez, dos, a la tercera vez que su condición de profesional y no recupera nunca más su carnet... Es una cosa que también es un poco arbitraria, porque cualquier otro profesional se equivoca, aún un médico y recupera su condición de médico. El chofer tiene un accidente, un accidente de que se yo, donde hay lesiones culposas o un homicidio culposo por una situación con su, con la circunstancia que le toco participar en el siniestro, y el tipo nunca más vuelve a recuperar su condición de chofer. Entonces siempre trababa de ser...

$\mathrm{I}_{165}:$ Flexible, tolerante

$\mathrm{R}_{158}$ : Flexible o siempre estar charlando y tratando de corregir las cosas pero no... en el plano de la sanción a veces. Se nos ve una situación muy particular con línea 7, por que en línea 7 se entre pasa de acciones y no lo denuncio al municipio como lo debería entones ahí por ahí hubo una situación mucho más... tirante porque en definitiva la gente de empresa de línea 7 era gente de bien ¿Entendés? No es que, pero bueno se había dado esa situación que generó todo un poco de conflicto

$\mathrm{I}_{166}:$ Claro

$\mathrm{R}_{159}$ : Pero sino básicamente no... 
$\mathrm{I}_{167}$ : Bueno, y premios en las empresas ustedes no...

$(48: 53)$

$\mathrm{R}_{160}:$ No

$\mathrm{I}_{168}$ : No le pueden dar tampoco. Bueno, ¿Registran otra información dada por los usuarios o registraban en su momento algún otro tipo de información...

$\mathrm{R}_{161}:$ No

$\mathrm{I}_{169}: \ldots$ aparte de los reclamos?

$\mathrm{R}_{162}$ : No teníamos recursos para...

$\mathrm{I}_{170}$ : Claro

$\mathrm{R}_{163}$ : Porque no se agotan recolectarse, después tenes que procesar, después ¿Cómo haces?

$\mathrm{I}_{171}$ : Claro. Y generar propuesta de proyecto y presentarlo

$\mathrm{R}_{164}$ : $\mathrm{Y}$ tenes que tener toner, tenes que tener impresora, tenes que tener...

$\mathrm{I}_{172}$ : Claro

$\mathrm{I}_{173}:$ Y no tenían 
$\mathrm{R}_{165}$ : Vos tenés que tener gente que vaya en condiciones saludables a laburar, y que se yo por ahí esta una hora contándose todos los problemas de la casa, después te comes una galletita tomando un mate. Cuando queres acordar a las 2 te vas porque es un régimen de 6 horas

$\mathrm{I}_{174}$ : Bueno... en tu opinión, que mejoras en aquel momento te parecía que había que hacer, sobre los datos que miden, para promover una mejor calidad de transporte público colectivo automotor. Hay cosas que me parece se tendrían que medir, tendrían que haber podido medir...

$\mathrm{R}_{166}$ : Claro, para decirte que cosa hubiesen calificado al sistema y le hubiese mejorado, debería haber tenido un trabajo interdisciplinario con recolección de datos trabajo de campo y ahí... si no la visión que puedo dar es un muy, muy...

$\mathrm{I}_{175}$ : No pero...

$\mathrm{R}_{167}$ : Muy limitada

$\mathrm{I}_{176}$ : No pero desde tu punto de vista, para que mejore la calidad del sistema con todas las falencias que vos contás que tiene...

$\mathrm{R}_{168}:$ No...

$\mathrm{I}_{177}: \mathrm{O}$ los reclamos de la gente

$\mathrm{R}_{169}$ : En acción se da muchas situaciones que tenían que ver con falta de inversión en infraestructura, deterioro de los corredores, con pozos con calles cortadas, la política del tránsito no acompañaba a lo que corresponde con el transporte urbano

$(50: 55)$

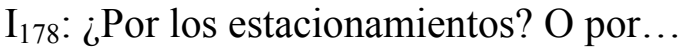


$\mathrm{R}_{170}$ : Y muchísimos estacionamiento, faltaban zonas de prohibición de estacionamiento para que la velocidad comercial del micro sea otro. Condiciones que tienen que ver también con, con la infraestructura en las paradas, con más iluminación, con dársenas para que sea más seguro el acceso y el descenso de pasajeros, y que el chofer este en mejores condiciones de seguridad. Acá en La Plata hay cosas que [ruido de fondo que no permite escuchar] De un plan a mediano plazo, porque no lo haces ni en seis meses

$\mathrm{I}_{179}$ : Claro. Bueno. Hay una norma nueva, pero igual me parece que no estaba vigente cuando vos estabas en función, que es la norma IRAM 3810

$\mathrm{R}_{171}:$ No

$\mathrm{I}_{180}$ : No, no estaba vigente. Bueno. Y en los permisos te parece que se podría exigir algo más específico para que mejore la calidad del servicio que no está presente por lo menos en los permisos que estaba, que tenían las empresas cuando estabas vos como...

$\mathrm{R}_{172}$ : Lo más importante, de cara al futuro, es utilizar información

$\mathrm{I}_{181}:$ ¿Qué información?

$\mathrm{R}_{173}$ : Porque eso genera el control social

$\mathrm{I}_{182}$ : Claro. De lo de los subsidios por ejemplo

$\mathrm{R}_{174}$ : No sobre todo en su momento, después se dejó de aplicar, pero en su momento estaba el GPS por micro, después se daban situaciones que el GPS no se reportaba porque no había antena, porque era dificultoso por que los choferes tardaban mucho en micro programando cuando se desprogramaba. Bueno, era un sistema que tenía crítica por parte de los empresarios y crítica por parte de los propio choferes y se dejó de utilizar. Pero bueno en otras partes del mundo, funciona, en todo caso habrá que poner, hablar con las telefónicas o con quien trasmite datos y aumentar la cantidad de antenas que haya más conectividad y poder hacer que ese micro sea... sea relevado, que sea controlado pero desde el estado, porque eso estaba previsto pero está en manos de los operadores 
$\mathrm{I}_{183}:$ Se controlan a sí mismos

$\mathrm{R}_{175}$ : Eso debería, inclusive, para evitar cualquier tipo de cosa, debería tener presencia de una ONG o de pasantes de la Universidad

$\mathrm{I}_{184}:$ Claro

$\mathrm{R}_{176}$ : Porque hoy vos, para controlar frecuencia, tenes seis tipos en la calle, siete tipos en la calle con cámaras que te transmiten en términos inalámbricos, los tenían acá, los podes mirar acá como está la parada de...

$\mathrm{I}_{185}:$ Claro

$\mathrm{R}_{177}$ : Del Hospital San Martin. Y para ver si ese micro te dice que tiene que estar circulando a partir de las $10.15 \ldots$

\section{A.2. Talleres con Choferes de líneas de Transporte}

Ahondar en la situación de los choferes de las diferentes líneas de transporte del Gran La Plata a partir de talleres participativos ayudo a identificar situaciones problemáticas del sistema de transporte difíciles de reconocer a través de metodologías cuantitativas, incluso cualitativas pero a actores responsables de gestionar o controlar el sistema, ya que en este caso los choferes son los responsables de hacer funcionar el sistema.

\section{A.2.1. Problemáticas de transporte detectada por los choferes}

Entre las problemáticas detectadas por los choferes se encuentra el crecimiento del parque automotor que ellos lo perciben de una manera exponencial en los últimos 10 años, sumada a un crecimiento de la expansión urbana que produce mayor demanda de transporte público en las periferias y hacinamiento en los coches. Encuentran como problemático una situación vinculada a la gestión del tránsito que fue agudizándose junto con el crecimiento del parque automotor como es el estacionamiento en doble fila y en las paradas de colectivo. Esta 
situación, como así también los recorridos que usan vías secundarias, que incrementan las posibilidades de accidente y retrasos en los tiempos de viaje. Lo mismo plantean de la sincronización de semáforos que califican como mala, ya que también dificulta que puedan cumplir con los tiempos de viaje y genera una tensión tendiente a no respetar algunas normas de tránsito por el hecho de cumplir esos objetivos de tiempo.

Otras situaciones que resaltaron que repercuten en la movilidad son los recorridos diseñados que pasan por zonas industriales tienen complicaciones de tránsito y demoras por circulación de transporte de carga. Por otro lado también problematizaron la inseguridad que sufren en horarios nocturnos en zonas periféricas, muchas veces con amenazas y armas de fuego.

\section{A.2.2. Relación con la empresa y el gobierno}

En cuanto a la relación de las empresas de las cuales son empleados y el gobierno, plantearon que la manera en la que hoy funciona el sistema de subsidios impide que puedan sumarse más unidades y mejorar el servicio. Esta situación según ellos se da porque las empresas obtienen rentabilidad gracias a que el Estado subsidia la mayor parte de su funcionamiento. Gran parte de ese subsidio mensual se otorga a un límite de kilómetros recorridos fijados por el Estado según el área de cobertura y la flota de cada empresa al momento de realizar el convenio y hoy desactualizados. En ese marco denuncian que son presionados por la empresa a cumplir tiempos de recorrido desactualizados, lo que muchas veces les dificulta cumplir con los reglamentos y son sancionados por la empresa o el estado. A su vez plantean una mayor responsabilidad del gobierno por sobre de la empresa a la hora de abordar la problemática del transporte público y la gestión del tránsito, además fundamentan que no son escuchadas su preocupaciones a pesar de hacer peticiones.

\section{A.2.3. Calidad de las infraestructuras}

En los cinco talleres participativos los choferes describieron que la infraestructura vial es inadecuada en el casco en los tramos que recorren sobre calles secundarias y en mal estado en algunas zonas periféricas, sobre todo en la periferia sureste. También alertaron sobre la falta de información sobre recorridos en las paradas y de señalización, dársenas y refugios en las periferias. A su vez, plantearon que en algunas zonas de la periferia de la ciudad la falta de veredas genera competencia en el uso de la calle entre peatones y transporte público, lo que 
puede provocar accidentes o en el mejor de los casos demoras en el recorrido. Otra situación conflictiva en torno a la mala calidad de la infraestructura vial por donde circulan algunos ramales en la periferia este, es que vecinos le presentan quejas a los choferes que el tránsito de colectivos daña las conexiones de los servicios de gas, agua y cloacas.

\section{A.2.4. Características/problemáticas de los usuarios}

Dentro de las problemáticas que o situaciones conflictivas con los usuarios plantean centralmente dos situaciones. Por un lado cuando los pasajeros van hacinados en los coches e instigan al chofer que no suba a más pasajeros y por otro lado con los usuarios que esperan en las paradas cuando los servicios vienen con retraso o directamente tiene que pasar de largo por el nivel de hacinamiento o porque no llegan a cumplir el tiempo de recorrido. Además

plantean situaciones estresantes cuando tienen que responder a las preguntas del pasajero sobre el recorrido propio o de otros ramales, ya que no existe información de este tipo en cartelería en las paradas.

\section{A.2.5. Situación laboral y condiciones de trabajo}

La descripción de la situación laboral por parte de los choferes es de mucho estrés, condiciones alienantes, enfermedades en la espalda y riñones. Los problemas de estrés lo manifiestan por la cantidad de situaciones a las que tienen que prestar atención al manejar vinculado a la congestión del tránsito, aumento de peatones, del parque automotor tanto de automóviles como de motos, camiones que no respetan los horarios de carga y descarga en zonas céntricas.

A esta situación le suman el poco tiempo de descanso por los tiempos de recorrido que tienen que cumplir plantean que los tiempos que tarda una vuelta de cada recorrido son los mismos de hace 30 años, las largas jornadas de trabajo para el tipo de trabajo aun cuando está declarado insalubre muchas veces sobrepasan las 8 hs frente al volante.

También afirman que debido al poco tiempo que les dan para cumplir los horarios, sin descansos, muchas veces los choferes comenten infracciones de tránsito o son parte de accidentes de los cuales son los únicos responsables, mientras la legislación que los protege es vulnerada. 


\section{A.2.6. Sistema actual y el anterior}

Un punto que les generó rechazo a los choferes fue la manera de implementación del sistema de transporte SUT, porque se reducía la cantidad de líneas y corrían riesgo sus puestos de trabajo. Por otro lado plantean que recibieron muchos reclamos de incomodidad por parte de los usuarios por implementarse de manera abrupta. También argumentan que la sincronización lograda durante muchos años antes del SUT con el nuevo sistema se des sincronizó hasta la actualidad, lo que les perjudica para cumplir con los tiempos por vuelta y mayor trabajo.

Plantean que cuando el ingreso de la empresa estaba asociado a la cantidad de pasajeros transportados, las empresas bajaban las frecuencias de los ramales con menor cantidad de pasajeros y se concentraba en los más rentables, controlando que no se dejen pasajeros varados, si los choferes lo hacían podían quedar suspendidos por 3 o 4 días. Hoy, si bien se diseña el servicio en función de las horas pico, a la empresa le preocupan los kilómetros recorridos por sobre los pasajeros ya que es el parámetro que utiliza el Estado para entregar subsidios que rondan en un $80 \%$ de los ingresos totales de las empresas.

Por otro lado reconocen que antes del SUT había recorridos inútiles que se superponían pero que con el nuevo sistema algunas líneas provinciales modificaron sus servicios para tomar pasajeros que cubrían las antiguas líneas municipales.

Además los choferes con mayor antigüedad dan cuenta que a lo largo del tiempo, a pesar de incrementarse la población, se fueron reduciendo la cantidad de unidades por línea, lo que sumado a la congestión en algunos casos hubieron frecuencias que pasaron de 3 minutos a 20 .

Ven como algo positivo la implementación de la tarjeta SUBE porque les ahorra tiempo trabajo a la hora del cobro del boleto y también cuando funcionó el carril exclusivo sobre av. 7 desde calle 54 a plaza Italia por unos meses, pero lamentan que fue por un periodo muy corto de corto de tiempo.

\section{A.2.7. Matriz Síntesis Talleres con Choferes de líneas de Transporte}




\begin{tabular}{|c|c|c|c|c|c|c|c|}
\hline $\begin{array}{l}\text { Lineas } \\
\text { p/GF }\end{array}$ & $\begin{array}{l}\text { Problematicas de } \\
\text { transporte detectada } \\
\text { por los choferes. }\end{array}$ & $\begin{array}{l}\text { Relacion con la } \\
\text { empresa y el } \\
\text { gobierno }\end{array}$ & $\begin{array}{l}\text { Calidad de las } \\
\text { infraestructuras }\end{array}$ & $\begin{array}{l}\text { Caracteristicas de } \\
\text { los usuarios }\end{array}$ & $\begin{array}{c}\text { Situación laboral } \\
\text { y condiciones de } \\
\text { trabajo }\end{array}$ & $\begin{array}{l}\text { Sistema actual y el } \\
\text { anterior }\end{array}$ & $\begin{array}{l}\text { Propuestas de } \\
\text { mejoras del sistema } \\
\text { de transporte }\end{array}$ \\
\hline \multirow{7}{*}{273} & $\begin{array}{l}\text { a) el gran crecimiento } \\
\text { de la ciudad, en } \\
\text { expansión en la } \\
\text { periferia y por } \\
\text { densificación en el } \\
\text { centro de la ciudad. }\end{array}$ & $\begin{array}{l}\text { a) Responsabilidad } \\
\text { del Estado por sobre } \\
\text { a empresa sobre los } \\
\text { problemas del } \\
\text { ransporte publico. }\end{array}$ & $\begin{array}{l}\text { a) infraestructura } \\
\text { inadecuada en el } \\
\text { camino Gral. Belgrano } \\
\text { y algunas calles } \\
\text { secundarias del casco } \\
\text { urbano; }\end{array}$ & $\begin{array}{l}\text { l) Algunos } \\
\text { conflictos con los } \\
\text { Jsuarios por } \\
\text { hacinamiento en } \\
\text { as unidades, por } \\
\text { fo poder parar a } \\
\text { yeces en todas las } \\
\text { paradas por este } \\
\text { motivo. }\end{array}$ & $\begin{array}{l}\text { a) estrés por la } \\
\text { cantidad de } \\
\text { situaciones a las } \\
\text { que tienen que } \\
\text { prestar atención al } \\
\text { manejar; }\end{array}$ & $\begin{array}{l}\text { Se expreso que se } \\
\text { produjo un traspaso } \\
\text { de pasajeros de } \\
\text { algunas lineas } \\
\text { municipales a la } 273 . \\
\text { Este traspaso se } \\
\text { debe a que existen } \\
\text { ramos de recorridos } \\
\text { que el sistema } \\
\text { municipal anterior } \\
\text { ealizaba y el actual } \\
\text { ho. Por ejemplo los } \\
\text { choferes } \\
\text { mencionaron que los } \\
\text { amales que } \\
\text { anteriormente } \\
\text { legaban al } \\
\text { cementerio o al } \\
\text { hospital de niños y } \\
\text { ehora solo a Plaza } \\
\text { San Martín, en esos } \\
\text { fasos los ramales de } \\
\text { a línea } 273 \text { son } \\
\text { utilizados por los } \\
\text { Hsuarios para } \\
\text { fompletar el viaje } \\
\text { haciendo trasbordo } \\
\text { en Plaza San Martin. }\end{array}$ & $\begin{array}{l}\text { a) Medidas para } \\
\text { disminuir el acceso del } \\
\text { auto particular al } \\
\text { centro, como por } \\
\text { ejemplo: centros de } \\
\text { disuasión en las } \\
\text { periferias vinculado al } \\
\text { sistema de transporte, } \\
\text { estacionamiento } \\
\text { medido, mayor control } \\
\text { desde la oficina de } \\
\text { transito municipal, } \\
\text { campañas de } \\
\text { concientizacion al } \\
\text { conductor de auto } \\
\text { particular; }\end{array}$ \\
\hline & $\begin{array}{l}\text { b) crecimiento del } \\
\text { parque automotor }\end{array}$ & $\begin{array}{l}\text { b) El transporte } \\
\text { público requiere mas } \\
\text { ondos. El subsidios } \\
\text { al transporte } \\
\text { nsuficientes o los } \\
\text { poletos muy baratos. }\end{array}$ & $\begin{array}{l}\text { b) falta de darsenas } \\
\text { en paradas; }\end{array}$ & $\begin{array}{l}\text { b) Roces con los } \\
\text { isuarios por que la } \\
\text { demora por } \\
\text { congestion dificulta } \\
\text { a puntualidad del } \\
\text { servicio. }\end{array}$ & $\begin{array}{l}\text { b) poco tiempo de } \\
\text { descanso por los } \\
\text { tiempos de } \\
\text { recorridos que } \\
\text { tiene que cumplir; }\end{array}$ & $\begin{array}{l}\text { a) Traspaso de } \\
\text { pasajeros de lineas } \\
\text { municipales a } \\
\text { provinciales. }\end{array}$ & $\begin{array}{l}\text { b) Sincronización de } \\
\text { semáforos }\end{array}$ \\
\hline & $\begin{array}{l}\text { c) la practica del } \\
\text { estacionamiento en } \\
\text { doble fila, y desde el } \\
\text { punto de vista de la } \\
\text { oferta de transporte se } \\
\text { planteo; }\end{array}$ & $\begin{array}{l}\text { f) Los choferes se } \\
\text { ven presionados por } \\
\text { parte de la empresa } \\
\text { fumplir horarios de } \\
\text { ecorridos } \\
\text { desactualizados. }\end{array}$ & $\begin{array}{l}\text { c) Situación crítica en } \\
\text { el cruce de } 7 \text { y } 54\end{array}$ & $\begin{array}{l}\text { c) Mala calidad del } \\
\text { jiaje para los } \\
\text { usuarios. "Muchas } \\
\text { veces viajan como } \\
\text { ganando". }\end{array}$ & $\begin{array}{l}\text { c) largas jornadas } \\
\text { de trabajo }\end{array}$ & & $\begin{array}{l}\text { c) Carriles exclusivos } \\
\text { para transporte } \\
\text { público de } 7 \text { y } 32 \text { a } \\
\text { plaza san martin, en } \\
\text { calle } 54 \text {, y también en } \\
\text { calle } 13 \text {, }\end{array}$ \\
\hline & $\begin{array}{l}\text { d) cantidad de } \\
\text { unidades circulando de } \\
\text { la línea insuficientes; }\end{array}$ & & & & $\begin{array}{l}\text { d) conflictos } \\
\text { producidos al tener } \\
\text { lidiar con el cobro } \\
\text { del boleto; }\end{array}$ & & $\begin{array}{l}\text { d) Aumento de la } \\
\text { cantidad de unidades } \\
\text { circulando (mayor } \\
\text { subsidio o aumento } \\
\text { del boleto) y separar al } \\
\text { chofer del contacto } \\
\text { con los pasajero. }\end{array}$ \\
\hline & $\begin{array}{l}\text { e) paradas de } \\
\text { colectivos } \\
\text { inadecuadas, y/o a } \\
\text { poca distancia. }\end{array}$ & & & & $\begin{array}{l}\text { e) situación de } \\
\text { inseguridad en } \\
\text { determinadas } \\
\text { zonas. }\end{array}$ & & $\begin{array}{l}\text { f) Reducción de la } \\
\text { jornada laboral a } 6 \text { hs. }\end{array}$ \\
\hline & $\begin{array}{l}\text { f) falta de } \\
\text { sincronización de } \\
\text { semaforos; }\end{array}$ & & & & & & $\begin{array}{l}\text { g) Reorganizar las } \\
\text { paradas con una } \\
\text { distancia no menor a } 2 \\
\text { cuadras evitando la } \\
\text { superposición, }\end{array}$ \\
\hline & $\begin{array}{l}\text { g) hacinamiento en las } \\
\text { unidades en hora pico }\end{array}$ & & & & & & $\begin{array}{l}\text { h) sumar informacion } \\
\text { de frecuencias y } \\
\text { recorridos a las } \\
\text { paradas de colectivo }\end{array}$ \\
\hline \multirow{3}{*}{$\begin{array}{c}\text { 202-214 } \\
\text { ver }\end{array}$} & $\begin{array}{l}\text { a) falta de } \\
\text { sincronización de } \\
\text { semaforos; }\end{array}$ & $\begin{array}{l}\text { a) Resposabilidad } \\
\text { del gobierno a la } \\
\text { hora de responder a } \\
\text { as recomendaciones } \\
\text { de los choferes. }\end{array}$ & $\begin{array}{l}\text { a) Malas reparaciones } \\
\text { del asfalto, "parecen } \\
\text { lomos de burro". }\end{array}$ & $\begin{array}{l}\text { a) Cada vez mas } \\
\text { pasajeros. Segun } \\
\text { os chofres uno de } \\
\text { as razones es el } \\
\text { aumento del precio } \\
\text { del combustible y } \\
\text { pajo precio del } \\
\text { poleto. "Despues } \\
\text { del } 15 \text { aumentan } \\
\text { os pasajeros, } \\
\text { antes del } 15 \text { tienen } \\
\text { plata para usar el } \\
\text { auto y te complican } \\
\text { el transito." }\end{array}$ & $\begin{array}{l}\text { a) Estrés por la } \\
\text { cantidad de } \\
\text { situaciones a las } \\
\text { que tienen que } \\
\text { prestar atención al } \\
\text { manejar; }\end{array}$ & $\begin{array}{l}\text { a) Se explicó que en } \\
\text { a implementacion del } \\
\text { SUT generó rechazo } \\
\text { entre los choferes ya } \\
\text { que se proponia } \\
\text { cerrar una linea } \\
\text { entera de colectivos } \\
\text { municipales, de } 5 \\
\text { pasaron a } 4 \text {. Al } \\
\text { quedar menos } \\
\text { folectivos circulando } \\
\text { fo sabian si iban a } \\
\text { quedarse sin trabajo. }\end{array}$ & $\begin{array}{l}\text { a) Carril exclusivo } \\
\text { transporte público y } \\
\text { taxis en av. } 7 \text { entre av. } \\
32 \text { y Plaza Rocha; }\end{array}$ \\
\hline & $\begin{array}{l}\text { b) paradas mal } \\
\text { ubicadas y muy cerca } \\
\text { una de otras; }\end{array}$ & $\begin{array}{l}\text { ) Mala gestion del } \\
\text { ransito por parte del } \\
\text { municipio }\end{array}$ & $\begin{array}{l}\text { b) Falta de } \\
\text { información en las } \\
\text { paradas. }\end{array}$ & & $\begin{array}{l}\text { b) poco tiempo de } \\
\text { descanso por los } \\
\text { tiempos de } \\
\text { recorridos que } \\
\text { tiene que cumplir } \\
\text { (la } 202 \text { tien el } \\
\text { mismo horario a } \\
\text { cumplir que hace } \\
80 \text { años); }\end{array}$ & $\begin{array}{l}\text { p) Ademas } \\
\text { llantearon que fue un } \\
\text { rastorno para el } \\
\text { pasajero que de un } \\
\text { dia para el otro se } \\
\text { quedo sin las lineas } \\
\text { que usaba. }\end{array}$ & $\begin{array}{l}\text { b) Recorridos de } \\
\text { contingencia } \\
\text { establecidos ante } \\
\text { cortes de calle } \\
\text { (basurero, arbolado, } \\
\text { manifestaciones, } \\
\text { UOCRA) }\end{array}$ \\
\hline & $\begin{array}{l}\text { c) crecimiento del } \\
\text { parque automotor y } \\
\text { congestion; }\end{array}$ & $\begin{array}{l}\text { No actualizacion } \\
\text { de los tiempos de } \\
\text { ecorrido }\end{array}$ & & & $\begin{array}{l}\text { c) largas jornadas } \\
\text { de trabajo; }\end{array}$ & $\begin{array}{l}\text { Tambien se } \\
\text { mencionó que se } \\
\text { camabiaba la }\end{array}$ & $\begin{array}{l}\text { c) Reorganizacion de } \\
\text { las paradas cada } 3 \\
\text { cuadras, sacarlas de }\end{array}$ \\
\hline
\end{tabular}




\begin{tabular}{|c|c|c|c|c|c|c|c|}
\hline \multirow{6}{*}{ 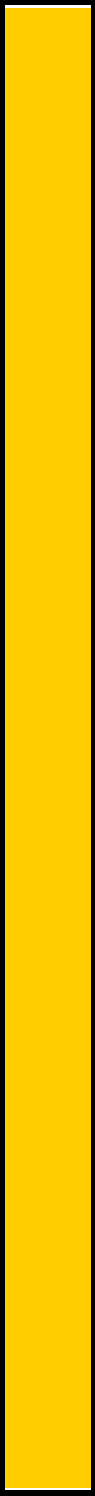 } & 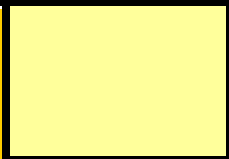 & & & & & $\begin{array}{l}\text { sincronizacion de los } \\
\text { semaforos que se } \\
\text { venia luchando hacia } \\
\text { ato para conseguir y } \\
\text { se cambio todo de } \\
\text { golpe. }\end{array}$ & $\begin{array}{l}\text { las plazas y que no } \\
\text { queden concetradas; }\end{array}$ \\
\hline & $\begin{array}{l}\text { d) doble fila en } \\
\text { colegios e instituciones } \\
\text { estatales, carga y } \\
\text { descarga comercios; }\end{array}$ & $\begin{array}{l}\text { d) Problemas en el } \\
\text { ipo de subsidio por } \\
\text { kilometro. Las } \\
\text { empresas no se } \\
\text { preocupan por dejar } \\
\text { parados a pasajeros. }\end{array}$ & & & $\begin{array}{l}\text { d) conflictos } \\
\text { producidos al tener } \\
\text { lidiar con el cobro } \\
\text { del boleto; }\end{array}$ & & $\begin{array}{l}\text { d) Implementar } \\
\text { información del } \\
\text { servicio en los refugios } \\
\text { y tambien en los } \\
\text { carteles de las } \\
\text { unidades; }\end{array}$ \\
\hline & $\begin{array}{l}\text { e) falta de informacion } \\
\text { en paradas y } \\
\text { colectivos. }\end{array}$ & & & & $\begin{array}{l}\text { e) situación de } \\
\text { inseguridad en } \\
\text { determinadas } \\
\text { zonas. }\end{array}$ & $\begin{array}{l}\text { d) Plantean que: El } \\
\text { sut queria poner } \\
\text { servicios troncales } \\
\text { que vayan por la } \\
\text { periferia, pero la } \\
\text { mayoria de la gente } \\
\text { ra al centro, entonces } \\
\text { si habia una que iba } \\
\text { de } 122 \text { y } 71 \text { y llegaba } \\
\text { a la } 520 \text { y } 32 \text {, al otro } \\
\text { dia tenes el mico } \\
\text { facio y el empresario } \\
\text { e lo saca. Donde } \\
\text { staba el negocio, } \\
\text { que de } 122 \text { agarre } \\
\text { diagonal } 74 \text { y vaya } \\
\text { hasta plaza moreno y } \\
\text { pase por plaza italia } \\
\text { por plaza san martin, } \\
\text { en ese entonces no } \\
\text { uncionaba el } \\
\text { subsidio por } \\
\text { kilometro, entonces } \\
\text { subir pasajeros y con } \\
\text { eso a nosotros nos } \\
\text { pagaban" }\end{array}$ & $\begin{array}{l}\text { e) Mayor control del } \\
\text { transito por parte del } \\
\text { municipio. Doble fila. }\end{array}$ \\
\hline & $\begin{array}{l}\text { f) Mucha congestion } \\
\text { en } 2 \text { y diagonal } 80 \text { por } \\
\text { el transito que genera } \\
\text { la baja de la autopista. }\end{array}$ & & & & & $\begin{array}{l}\text { P) Subsidio por } \\
\text { Kilometro o por } \\
\text { Pasajero: }\end{array}$ & $\begin{array}{l}\text { f) Unificación de } \\
\text { paradas. }\end{array}$ \\
\hline & $\begin{array}{l}\text { g) Plantean no } \\
\text { incrementar unidades } \\
\text { porque uaumentaria la } \\
\text { congestion. Afirmarn } \\
\text { que el problema es } \\
\text { agilizar el transito. }\end{array}$ & & & & & $\begin{array}{l}\text { Cuando era por } \\
\text { pasajero la empresa } \\
\text { extendia las } \\
\text { recuencias de los } \\
\text { amales que bajaban } \\
\text { a cantidad de } \\
\text { pasajeros, ahora } \\
\text { omo es por km } \\
\text { nantienen la } \\
\text { recuencias. }\end{array}$ & $\begin{array}{l}\text { g) Habilitar calle } 1 \\
\text { entre } 42 \text { y } 45 \text { para } \\
\text { descongestionar } \\
\text { diagonal } 80 \text { por la baja } \\
\text { de la autopista. }\end{array}$ \\
\hline & & & & & & $\begin{array}{l}\text { Ademas la empresa } \\
\text { controlaba que no se } \\
\text { dejen pasajeros } \\
\text { parados, si lo hacian } \\
\text { podian quedar } \\
\text { suspendidos por } 3 \text { o } \\
4 \text { dias. }\end{array}$ & $\begin{array}{l}\text { h) 202: planos con } \\
\text { rediseño de recorridos } \\
\text { y ubicación de } \\
\text { paradas. }\end{array}$ \\
\hline \multirow{4}{*}{$307-506$} & $\begin{array}{l}\text { a) Principal problema } \\
\text { es el incremento del } \\
\text { transporte privado, por } \\
\text { congestion. En av. } 54 \\
\text { de } 12 \text { a av. } 7 \text {. En hora } \\
\text { pico tardan } 20 \text { minutos } \\
\text { para hacer } 5 \text { cuadras. }\end{array}$ & $\begin{array}{l}\text { a) El gobierno } \\
\text { municipal por } \\
\text { mantener la } \\
\text { ecaudacion del } \\
\text { estacionamiento } \\
\text { medido no quiere } \\
\text { iberar de autos la } \\
\text { calle } 54 \text { de } 12 \text { a } 7 . \\
\text { Tambien plantean } \\
\text { que hubo una } \\
\text { concentracion de } \\
\text { paradas para liberar } \\
\text { mas espacio para } \\
\text { estacionamiento } \\
\text { medido, lo que } \\
\text { genera mas } \\
\text { congestion y alarga } \\
\text { el tiempo de viaje. }\end{array}$ & $\begin{array}{l}\text { a) Mala infraestructura } \\
\text { de la calle } 72 \text { por } \\
\text { pozos }\end{array}$ & $\begin{array}{l}\text { 9) En hora pico la } \\
\text { alta de frencuencia } \\
\text { el hacinamiento } \\
\text { de los coches } \\
\text { genera que } \\
\text { muchas veces los } \\
\text { pasajeros lleguen } \\
\text { arde a los trabajos } \\
\text { porque los } \\
\text { colectivos no parar } \\
\text { por estar } \\
\text { paturados. }\end{array}$ & $\begin{array}{l}\text { a) La congestion } \\
\text { en el centro les } \\
\text { genera mucho } \\
\text { estres. }\end{array}$ & $\begin{array}{l}\text { ) Antes habia } \\
\text { ecorridos inutiles que } \\
\text { se superponian }\end{array}$ & $\begin{array}{l}\text { a) No deberia haber } \\
\text { estacionamiento en la } \\
\text { calle } 54 \text { de } 12 \text { a } 7\end{array}$ \\
\hline & $\begin{array}{l}\text { b) Paradas } \\
\text { superpuestas. } \\
\text { Problema particular en } \\
\text { plaza italia. }\end{array}$ & $\begin{array}{l}\text { p) La empresa no } \\
\text { mejora las } \\
\text { recuencias porque } \\
\text { iene subsidio solo } \\
\text { para los coches en } \\
\text { uncionamiento. }\end{array}$ & $\begin{array}{l}\text { b) Mala infraestructura } \\
\text { vial en calle } 96 \text { en El } \\
\text { Carmen por pozos. }\end{array}$ & $\begin{array}{l}\text { p) Se generan } \\
\text { conflictos con los } \\
\text { pasajeros que van } \\
\text { enla unidad } \\
\text { hacinados y el } \\
\text { colectivero carga } \\
\text { mas pasajeros. }\end{array}$ & $\begin{array}{l}\text { b) Los coches son } \\
\text { comodos y el cobro } \\
\text { con sube agilizo el } \\
\text { ingreso de } \\
\text { pasajeros al } \\
\text { colectivo. }\end{array}$ & $\begin{array}{l}\text { ) Era mejor en } \\
\text { ransito cuando } \\
\text { unciono el carril } \\
\text { exclusivo de } 54 \text { hasta } \\
\text { plaza italia }\end{array}$ & $\begin{array}{l}\text { b) Liberar las paradas } \\
\text { de colectivos de } \\
\text { estacionamiento } \\
\text { particular en avenidas } \\
\text { principales. }\end{array}$ \\
\hline & $\begin{array}{l}\text { c) Mucha congestion, } \\
\text { autos estacionados en } \\
\text { doble fila, en calle } 7 \text { de } \\
\text { plaza rocha a plaza } \\
\text { italia, la calle } 32 \text { de } 15 \\
\text { a } 13 \text {, de } 5 \text { a } 7 \text {. En } 60 \text { y } \\
66 \text { desde } 135 \text { a } 137, \\
\text { distintas zonas donde } \\
\text { hay semaforos y } \\
\text { estacionamieto de } \\
\text { autos. }\end{array}$ & $\begin{array}{l}\text { c) Los fines de } \\
\text { emana bajan mucho } \\
\text { as frecuencias, } \\
\text { ambien porque la } \\
\text { empresa no quiere } \\
\text { ncorporar mas } \\
\text { choferes. }\end{array}$ & & $\begin{array}{l}\text { E) Aseguran que el } \\
\text { pasajero viaja mal } \\
\text { en hora pico y en } \\
\text { fora valle, tiene } \\
\text { que esperar mucho } \\
\text { iempo el micro. }\end{array}$ & \begin{tabular}{|l|} 
c) Por el poco \\
tiempo para \\
cumplir los \\
horarios, sin \\
descansosm, \\
muchas veces los \\
choferes se ven \\
presionados a \\
cometer \\
infracciones de \\
transito o son parte \\
de accidentes y se \\
tienen que hacer \\
responsables. \\
\end{tabular} & $\begin{array}{l}\text { E) El sistema sube es } \\
\text { mejor, mas rapido. }\end{array}$ & $\begin{array}{l}\text { c) Sacar paradas de } \\
\text { las plazas. }\end{array}$ \\
\hline & d) Mala sincronizacion & d) Cuando se rompe & & d) Maryor carga de & & d) Antes teniamos & d) Dividir el los \\
\hline
\end{tabular}




\begin{tabular}{|c|c|c|c|c|c|c|c|}
\hline & de semaforos. & $\begin{array}{l}\text { In coche se pierde } \\
\text { un servicio porque no } \\
\text { hay unidades } \\
\text { disponibles por } \\
\text { contingencias. }\end{array}$ & & $\begin{array}{l}170 \text { a } 137 \text { mayor } \\
\text { afluencia de } \\
\text { pasajeros a la hora } \\
\text { pico a la mañana. }\end{array}$ & & $\begin{array}{l}\text { Ina frecuencias cada } \\
3 \text { minutos y ahora } \\
\text { fada } 20\end{array}$ & $\begin{array}{l}\text { ramales que van por } \\
54 \text { para que una parte } \\
\text { pueda ir por } 49 \text {, como } \\
\text { funcionaba } \\
\text { anteriormente, antes } \\
\text { de la propuesta de } \\
\text { peatonalización de } \\
\text { calle } 8 \text {. }\end{array}$ \\
\hline & $\begin{array}{l}\text { e) Muchas veces por } \\
\text { los estacionamientos } \\
\text { tiene que parar lejos } \\
\text { del cordon. }\end{array}$ & $\begin{array}{l}\text { c) Las empresas no } \\
\text { cumplen los pliegos } \\
\text { icitatorios, en } \\
\text { espaldo de choferes } \\
\text { colectivos, tampoco } \\
\text { en calidad de las } \\
\text { unidades (caja } \\
\text { automatica, } \\
\text { suspension } \\
\text { iidraulica). }\end{array}$ & & $\begin{array}{l}\text { ) Hay carga a la } \\
\text { madrugada de los } \\
\text { pasajeros que van } \\
\text { a trabajar fuera de } \\
\text { a plata que van a } \\
\text { a estacion de } \\
\text { renes o de } \\
\text { pmnibus. }\end{array}$ & & $\begin{array}{l}\text { ) Con el sistema } \\
\text { anterior } 307 \\
\text { funcionaba con } 94 \\
\text { foches y hoy tiene } 83 \\
\text { se redujeron al } \\
\text { momento del cambio. }\end{array}$ & $\begin{array}{l}\text { e) Aumentar el tiempo } \\
\text { del semaforo en verde } \\
\text { de } 7 \text { y } 54 \text {. }\end{array}$ \\
\hline & $\begin{array}{l}\text { f) Hacinamiento en las } \\
\text { unidades en hora pico } \\
\text { "de plaza moreno } \\
\text { hasta los hornos no } \\
\text { tenes mas lugar, el } \\
\text { colectivo cargará } \\
\text { minimo } 60 \text { personas". }\end{array}$ & $\begin{array}{l}\text { La cantidad de } \\
\text { coches por linea fue } \\
\text { decreciendo a lo } \\
\text { argo del tiempo. "la } \\
\text { inea sur se licito con } \\
51 \text { coches, hoy } \\
\text { declaran } 26, \text { y } \\
\text { funcionan } 24 \text { ". }\end{array}$ & & & & & $\begin{array}{l}\text { d) Carriles exclusivos } \\
\text { en av } 7 \text { entre } 32 \text { y } 54\end{array}$ \\
\hline & $\begin{array}{l}\text { g) cantidad de } \\
\text { unidades insuficientes }\end{array}$ & $\begin{array}{l}\text { 9) "lo que declarar } \\
\text { as empresas sobre } \\
\text { as frecuencias no es } \\
\text { lerdad". }\end{array}$ & & & & & \\
\hline & $\begin{array}{l}\text { h) Complicacion de } \\
\text { transito con camiones } \\
\text { de carga en zonas } \\
\text { industriales de } \\
\text { Ensenada. }\end{array}$ & $\begin{array}{l}\text { p) La empresa los } \\
\text { sanciona con el } \\
\text { equivalente a un dia } \\
\text { de trabajo menos si } \\
\text { po cumplen con lo } \\
\text { eglamentado. } \\
\text { Tambien si se les } \\
\text { acumulan las } \\
\text { panciones los } \\
\text { combian de servicio, } \\
\text { de horario. }\end{array}$ & & & & & \\
\hline & $\begin{array}{l}\text { i) Problemas de } \\
\text { inseguridad en El } \\
\text { Carmen y por los } \\
\text { asentamientos que } \\
\text { estan atrás de la carcel } \\
\text { de mujeres. }\end{array}$ & $\begin{array}{l}\text { ) Crecimiento } \\
\text { poblacional en las } \\
\text { periferias, antes se } \\
\text { estudiaban que } \\
\text { empresa lo tiene que } \\
\text { cubrir, ahora no "el } \\
\text { ransporte siempre } \\
\text { quedo relegado al } \\
\text { istema de } \\
\text { reciemiento de la } \\
\text { ciudad", "el pasajero } \\
\text { del transporte publico } \\
\text { es de las periferias". }\end{array}$ & & & & & \\
\hline & $\begin{array}{l}\text { a) Plantean como } \\
\text { problema la situacion } \\
\text { de cercania entre sí de } \\
\text { las paradas, ya que les } \\
\text { hace perder mucho } \\
\text { tiempo de vuelta. }\end{array}$ & $\begin{array}{l}\text { a) La poblacion } \\
\text { crecio pero es la } \\
\text { misma cantidad de } \\
\text { ficros, las mismas } \\
\text { frecuencias, nos } \\
\text { aumento la cantidad } \\
\text { de semaforos, los } \\
\text { omos de burro, es el } \\
\text { nismo sitema de } \\
\text { tace } 30 \text { años. Por } \\
\text { jemplo la av. } 13 \\
\text { desde } 90 \text { para el } \\
\text { sureste "antes era } \\
\text { campo y ahora es } \\
\text { odo casas". }\end{array}$ & $\begin{array}{l}\text { a) Mala infraestructura } \\
\text { desde } 7 \text { y } 85 \text { al } \\
\text { sureste. Muchos } \\
\text { pozos, calles } \\
\text { angostas lo que hace } \\
\text { dificultoso doblar. Los } \\
\text { choferes lo reflejan } \\
\text { diciendo "cruzamos } 7 \\
\text { y } 85 \text { y parece que } \\
\text { entramos a las } \\
\text { canteras", " hasta } \\
\text { barrio jardin vamos } \\
\text { bien, despues } \\
\text { entramos en otro } \\
\text { mundo". "si, a partir } \\
\text { de ahi, ponete la } 4 \times 4 \\
\text { y dale". }\end{array}$ & $\begin{array}{l}\text { ) Padecen mucho } \\
\text { iempo de espera } \\
\text { por colectivos } \\
\text { lenos y frecuencias } \\
\text { nsuficientes }\end{array}$ & $\begin{array}{l}\text { a) Presionados por } \\
\text { el tiempo que tiene } \\
\text { que cumplir y por } \\
\text { no dejar a la gente } \\
\text { esperando (chicos } \\
\text { que salen de la } \\
\text { escuela) muchas } \\
\text { veces no se toman } \\
\text { la espera, ir al } \\
\text { baño. }\end{array}$ & & $\begin{array}{l}\text { a) Sincronizacion de } \\
\text { semaforos y mas } \\
\text { inspectores para } \\
\text { ordenar el transito. }\end{array}$ \\
\hline $\begin{array}{l}\text { Norte- } \\
\text { Este- } \\
520\end{array}$ & $\begin{array}{l}\text { b) Mala sincronizacion } \\
\text { de semaforos. }\end{array}$ & $\begin{array}{l}\text { e) El subsidio que } \\
\text { eciben las empresas } \\
\text { es por una cantidad } \\
\text { de coches } \\
\text { nsuficiente y el } \\
\text { empresario no esta } \\
\text { dispuesto a } \\
\text { ncorporar coches sin } \\
\text { subsidio. Por ejemplo } \\
\text { ray ramales que } \\
\text { fecesitan } 2 \text { coches, } \\
3 \text { coches mas por } \\
\text { servicio. Cuando se } \\
\text { facer refuerzos en } \\
\text { tora pico, salida de } \\
\text { colegios, se saca de } \\
\text { un servicio. }\end{array}$ & $\begin{array}{l}\text { b) No hay veredas } \\
\text { entonces la calle se } \\
\text { utiliza tambien para } \\
\text { hacer viajes a pie, lo } \\
\text { que dificulta el transito } \\
\text { de colectivos y reduce } \\
\text { la velocidad operativa. }\end{array}$ & $\begin{array}{l}\text { b) Los choferes } \\
\text { culpan a los } \\
\text { usuarios por la } \\
\text { distancia actual } \\
\text { entre paradas, Si } \\
\text { pien las establece } \\
\text { el municipio, } \\
\text { comentan que } \\
\text { esponde a } \\
\text { planteos de los } \\
\text { Isuarios. }\end{array}$ & $\begin{array}{l}\text { b) Muchas veces la } \\
\text { empresa para } \\
\text { reducir frecuencias } \\
\text { sin incorporar } \\
\text { servicios achica las } \\
\text { esperas de los } \\
\text { chofers que por ley } \\
\text { corresponde } 15 \\
\text { minutos. A veces } \\
\text { son de } 15 \text {, otras de } \\
8 \text {, otra de } 10 \text {. } \\
\text { Algunos recorridos } \\
\text { de varias horas } \\
\text { que estan mucho } \\
\text { tiempo sin ir al } \\
\text { baño y le dan } \\
\text { espera de } 8 \\
\text { minutos y tiene que } \\
\text { volver a salir. }\end{array}$ & & $\begin{array}{l}\text { b) Dividir los ramales } \\
\text { que van por } 54 \text { y que } \\
\text { algunos vayan por } 53 .\end{array}$ \\
\hline & $\begin{array}{l}\text { c) Carga y descarga } \\
\text { de camiones de } \\
\text { abastecimiento en } \\
\text { horarios no aptos, a } \\
\text { veces en doble fila. } \\
\text { Doble fila a la entrada } \\
\text { y salidad de los } \\
\text { colegios, instituciones } \\
\text { estatales, bancos, } \\
\text { comercios. }\end{array}$ & $\begin{array}{l}\text { d) La empresa } \\
\text { diagrama la } \\
\text { distribución del } \\
\text { servicio según la } \\
\text { pora pico. }\end{array}$ & $\begin{array}{l}\text { c) Debido a la mala } \\
\text { calidad de la } \\
\text { infraestructura de la } \\
\text { red vial, de las } \\
\text { cañerias de agua y } \\
\text { cloacas, los vecinos } \\
\text { sufren rotura de caños } \\
\text { en determinados } \\
\text { lugares donde } \\
\text { eventualmente pasan }\end{array}$ & $\begin{array}{l}\text { c) Plantean que } \\
\text { pay muchos } \\
\text { pasajes } \\
\text { subsidiados de } \\
\text { distinto tipo donde } \\
\text { pagan } 2,93,2,80 \text {, } \\
\text { 2,82. Los fines de } \\
\text { semana que no hay } \\
\text { subsidios muchos } \\
\text { to pagan. }\end{array}$ & $\begin{array}{l}\text { c) Plantean } \\
\text { problemas con la } \\
\text { ubicación de la } \\
\text { maquina cobradora } \\
\text { cuando esta frente } \\
\text { el parabrisas, ya } \\
\text { que les reduce la } \\
\text { vision. }\end{array}$ & & $\begin{array}{l}\text { c) Sacar paradas en } \\
\text { las plazas }\end{array}$ \\
\hline
\end{tabular}




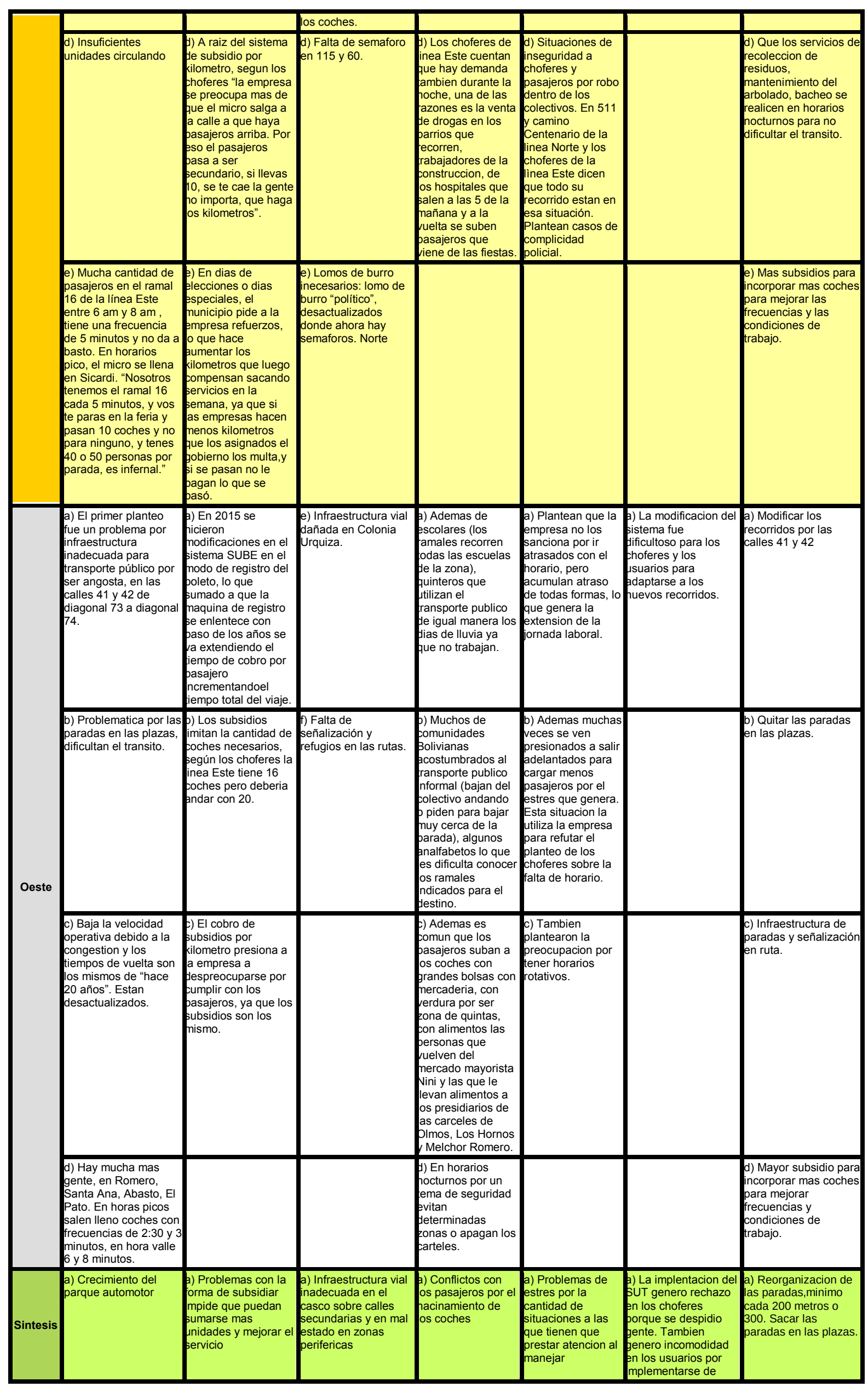




\begin{tabular}{|c|c|c|c|c|c|c|}
\hline & & & & & manera abrupta. & \\
\hline $\begin{array}{l}\text { b) Estacionamiento en } \\
\text { doble fila o en las } \\
\text { paradas de micro }\end{array}$ & $\begin{array}{l}\text { P) Son presionados } \\
\text { por la empresa a } \\
\text { cumplir tiempos de } \\
\text { ecorrido } \\
\text { desactualizados, lo } \\
\text { que muchas veces } \\
\text { es dificulta cumplir } \\
\text { con los reglamentos } \\
\text { son sancionados } \\
\text { por la empresa o el } \\
\text { estado. }\end{array}$ & \begin{tabular}{|l|} 
b) Falta de \\
información en las \\
paradas del sistema. \\
Falta de señalizacion, \\
darsenas y refugios \\
en las periferias
\end{tabular} & $\begin{array}{l}\text { b) Conflictos con } \\
\text { os pasajeros por el } \\
\text { ho cumplimiento de } \\
\text { os horarios. Los } \\
\text { coches no paran } \\
\text { por que van llenos } \\
\text { el servicio pierde } \\
\text { puntualidad. }\end{array}$ & $\begin{array}{l}\text { b) Estres por } \\
\text { congestion del } \\
\text { transito }\end{array}$ & $\begin{array}{l}\text { p) La sincronizacion } \\
\text { ograda durante } \\
\text { muchos años antes } \\
\text { del sut con la } \\
\text { mplementacion del } \\
\text { sut se desincronizó } \\
\text { hasta la actualidad }\end{array}$ & $\begin{array}{l}\text { b) Sincrionización de } \\
\text { semaforos. }\end{array}$ \\
\hline $\begin{array}{l}\text { c) Mala distribucion de } \\
\text { paradas en el centro, } \\
\text { concetradas, muy } \\
\text { frecuentes y en } \\
\text { lugares que dificultan } \\
\text { el transito (en las } \\
\text { plaszas) }\end{array}$ & $\begin{array}{l}\text { R) Responsabilidad } \\
\text { del gobierno sobre la } \\
\text { problemática del } \\
\text { ransporte publico y } \\
\text { a gestion del } \\
\text { ransito. No son } \\
\text { escuchadas su } \\
\text { preocupaciones }\end{array}$ & $\begin{array}{l}\text { c) En la periferia este } \\
\text { la falta de } \\
\text { infraestructura de } \\
\text { veredas genera } \\
\text { competencia en el uso } \\
\text { de la calle entre } \\
\text { peatones y transporte } \\
\text { público. }\end{array}$ & & $\begin{array}{l}\text { c) Poco tiempo de } \\
\text { descanso por los } \\
\text { tiempos de } \\
\text { recorrido que } \\
\text { tienen que cumplir } \\
\text { (plantean que los } \\
\text { horarios son los } \\
\text { mismos hace } 30 \\
\text { años) }\end{array}$ & $\begin{array}{l}\text { C) Cuando el subsidio } \\
\text { era por pasajero la } \\
\text { empresa extendia las } \\
\text { recuencias de los } \\
\text { amales que bajaban } \\
\text { a cantidad de } \\
\text { pasajeros, ahora } \\
\text { como es por km } \\
\text { nantienen la } \\
\text { recuencias. Ademas } \\
\text { a empresa } \\
\text { controlaba que no se } \\
\text { dejen pasajeros } \\
\text { parados, si lo hacian } \\
\text { podian quedar } \\
\text { suspendidos por } 3 \text { o } \\
4 \text { dias. }\end{array}$ & $\begin{array}{l}\text { c) Carriles exclusivos } \\
\text { en av } 7 \text { de } 32 \text { a plaza } \\
\text { rocha }\end{array}$ \\
\hline $\begin{array}{l}\text { d) Mala sincronización } \\
\text { de los semaforos }\end{array}$ & & $\begin{array}{l}\text { d) la mala } \\
\text { infraestructura de } \\
\text { servicios en la } \\
\text { periferia este produce } \\
\text { rotura de cañerias con } \\
\text { el transito de los } \\
\text { colectivos }\end{array}$ & & $\begin{array}{l}\text { d) Largas jornadas } \\
\text { de trabajo para el } \\
\text { tipo de trabajo } \\
\text { (esta declarado } \\
\text { insalubre) }\end{array}$ & $\begin{array}{l}\text { d) Antes habia } \\
\text { ecorridos inutiles que } \\
\text { se superponian }\end{array}$ & $\begin{array}{l}\text { d) Medidas para } \\
\text { disminuir el acceso del } \\
\text { auto particular al } \\
\text { centro, como por } \\
\text { ejemplo: centros de } \\
\text { disuasión en las } \\
\text { periferias vinculado al } \\
\text { sistema de transporte, } \\
\text { estacionamiento } \\
\text { medido, mayor control } \\
\text { desde la oficina de } \\
\text { transito municipal, } \\
\text { campañas de } \\
\text { concientizacion al } \\
\text { conductor de auto } \\
\text { particular; Liberar de } \\
\text { estacionamiento sobre } \\
\text { las paradas de } \\
\text { colectivo. }\end{array}$ \\
\hline $\begin{array}{l}\text { e) Crecimiento abrupto } \\
\text { de la expansion } \\
\text { urbana }\end{array}$ & & & & $\begin{array}{l}\text { e) Por el poco } \\
\text { tiempo para } \\
\text { cumplir los } \\
\text { horarios, sin } \\
\text { descansosm, } \\
\text { muchas veces los } \\
\text { choferes se ven } \\
\text { presionados a } \\
\text { cometer } \\
\text { infracciones de } \\
\text { transito o son parte } \\
\text { de accidentes y se } \\
\text { tienen que hacer } \\
\text { responsables. }\end{array}$ & $\begin{array}{l}\text { 2) A lo largo del } \\
\text { iempo se fueron } \\
\text { educiendo la } \\
\text { cantidad de unidades } \\
\text { por linea. Sumado a } \\
\text { a congestion en } \\
\text { algunos casos } \\
\text { hubieron frecuencias } \\
\text { que pasaron de } 3 \\
\text { minutos a } 20 .\end{array}$ & $\begin{array}{l}\text { e) Incorporar mas } \\
\text { unidades para que } \\
\text { mejoren las } \\
\text { frecuencias }\end{array}$ \\
\hline $\begin{array}{l}\text { f) Hacinamiento de } \\
\text { pasajeros en las } \\
\text { unidades }\end{array}$ & & & & & $\begin{array}{l}\text { ) El sistema sube } \\
\text { ggilizo el cobro del } \\
\text { poleto }\end{array}$ & $\begin{array}{l}\text { f) Rediseño de } \\
\text { algunos tramos de los } \\
\text { recorridos por } \\
\text { infraestructura vial } \\
\text { inadecuada y por } \\
\text { congestion. }\end{array}$ \\
\hline $\begin{array}{l}\text { g) Problemas en } \\
\text { recorridos que circulan } \\
\text { por calles secundarias } \\
\text { (linea oeste) }\end{array}$ & & & & & $\begin{array}{l}\text { g) El carril exclusivo } \\
\text { pobre } 7 \text { de } 54 \text { a plaza } \\
\text { tualia ayudaba a } \\
\text { educir losproblemas } \\
\text { que se generan por la } \\
\text { congestion. }\end{array}$ & $\begin{array}{l}\text { g) Sumar informacion } \\
\text { del servicio en las } \\
\text { paradas. Mejora de } \\
\text { infraestructura de } \\
\text { paradas en ruta. }\end{array}$ \\
\hline $\begin{array}{l}\text { h) Inseguridad en } \\
\text { determinadas zonas } \\
\text { de las periferias en } \\
\text { horarios nocturnos }\end{array}$ & & & & & & $\begin{array}{l}\text { h) Reduccion de la } \\
\text { jornada laboral a } 6 \\
\text { horas. }\end{array}$ \\
\hline $\begin{array}{l}\text { i) Complicaciones de } \\
\text { transito por circulacion } \\
\text { de transporte de carga } \\
\text { en zonas industriales } \\
\text { (ramales a Ensenada) }\end{array}$ & & & & & & $\begin{array}{l}\text { i) Que los servicios de } \\
\text { recoleccion de } \\
\text { residuos, } \\
\text { mantenimiento del } \\
\text { arbolado, bacheo se } \\
\text { realicen en horarios } \\
\text { nocturnos para no } \\
\text { dificultar el transito. }\end{array}$ \\
\hline & & & & & & $\begin{array}{l}\text { j) Rocrridos de } \\
\text { continjencia ante } \\
\text { cortes. Horio de poda, } \\
\text { bacheo, carga y } \\
\text { descarga en horarios } \\
\text { nocturnos. }\end{array}$ \\
\hline
\end{tabular}




\section{A.3. Tablas de cálculo consumo energético y emisiones de $\mathrm{CO2}$}

A continuación se muestra un ejemplo de las tablas utilizadas para la obtención de resultados de la dimensión ambiental.

\section{A.3.1. Tablas de kilómetros recorridos y partición modal.}

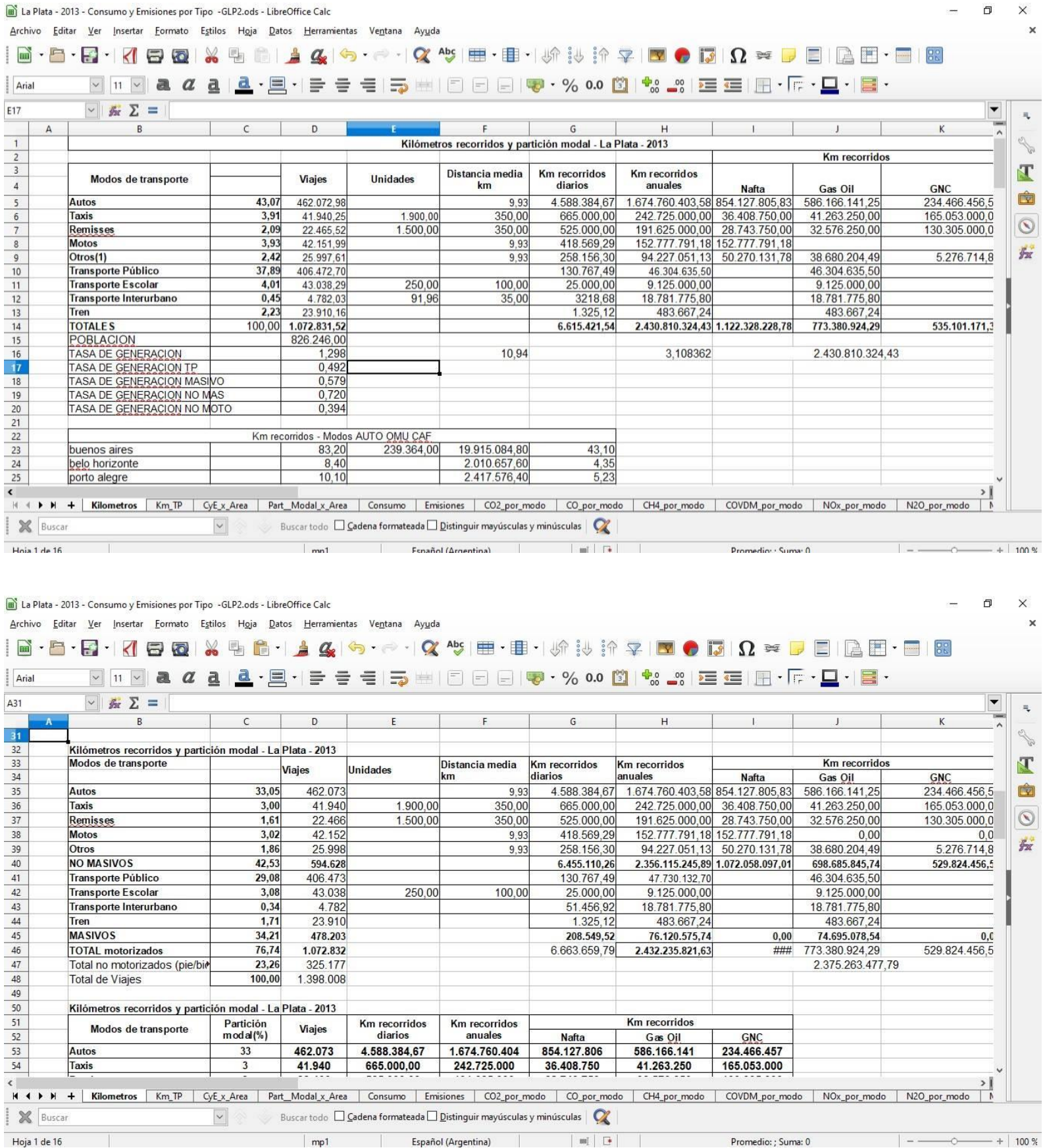




\section{A.3.2. Tabla de consumo de combustible}

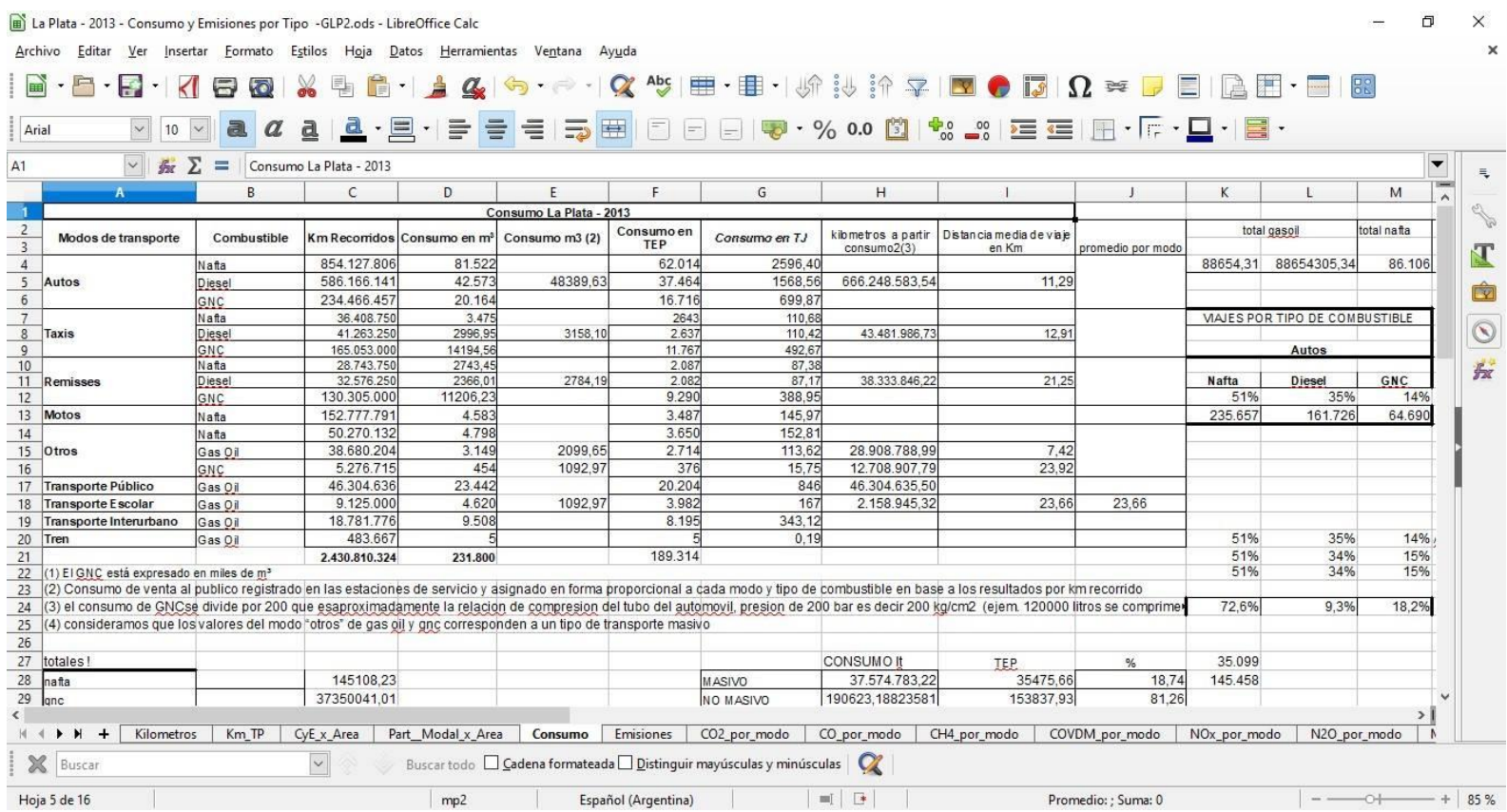

\section{A.3.3. Tabla de emisiones de gases contaminantes}

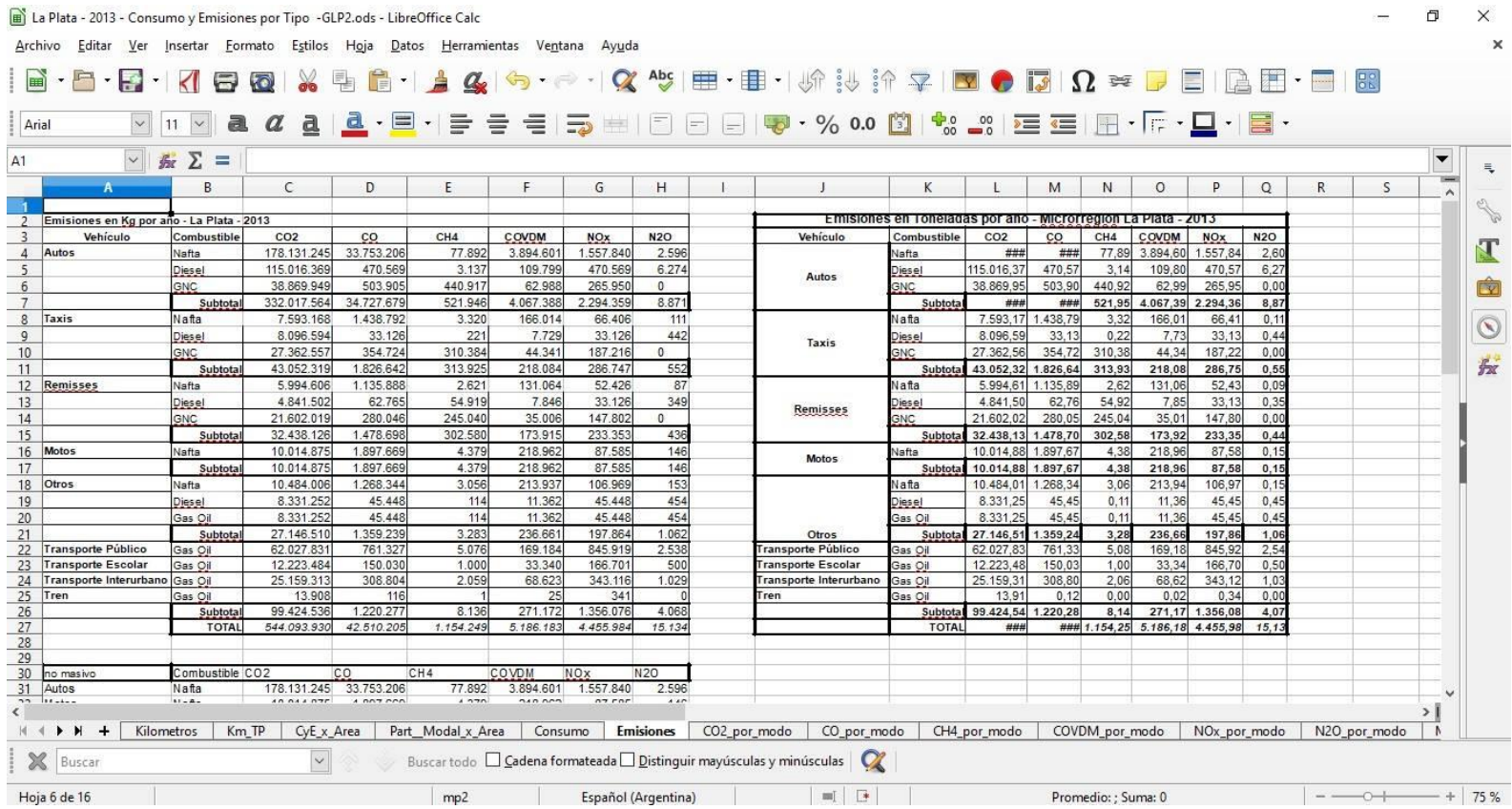




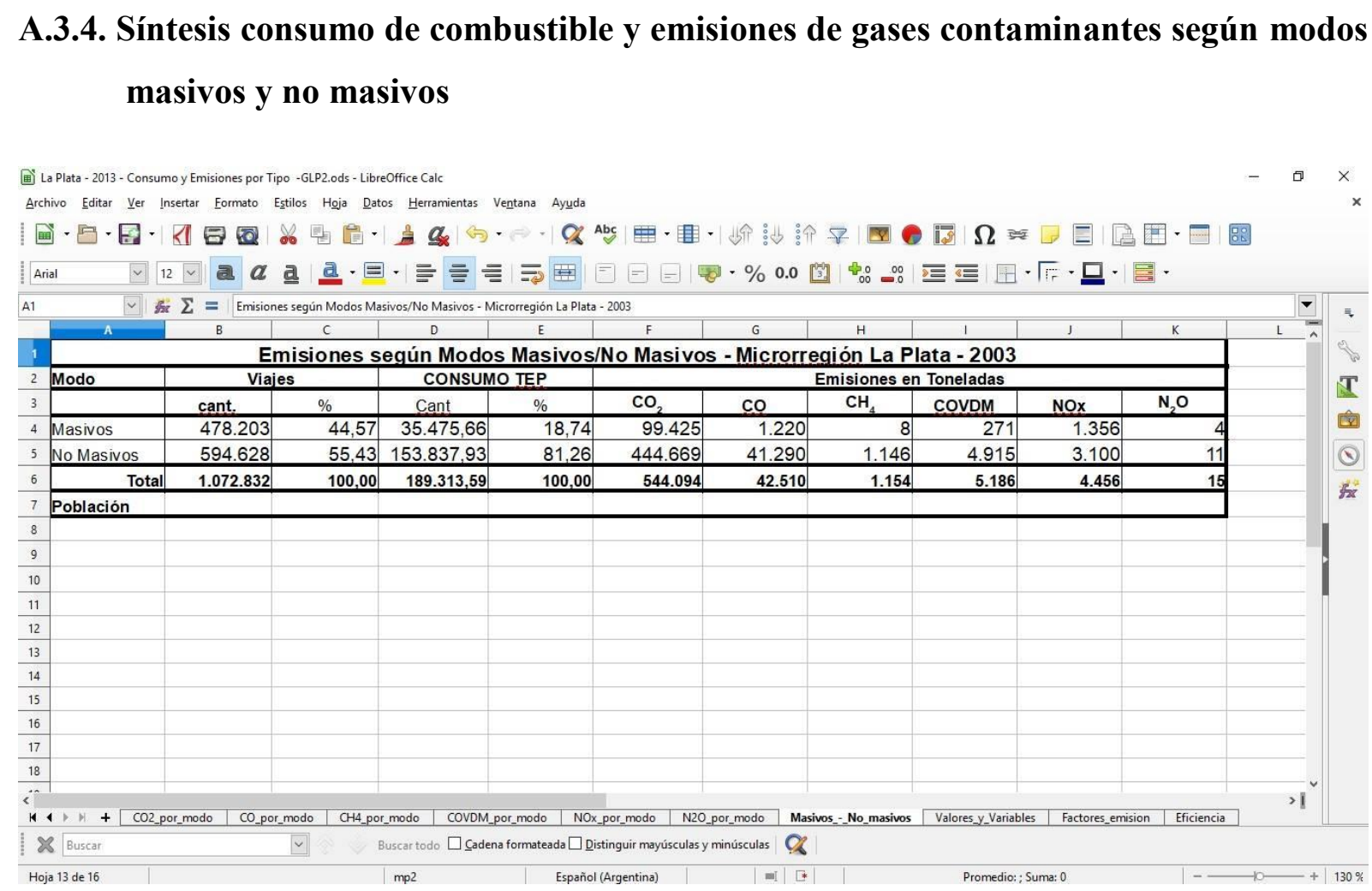

A.3.5. Tablas de valores y variables utilizadas para los cálculos

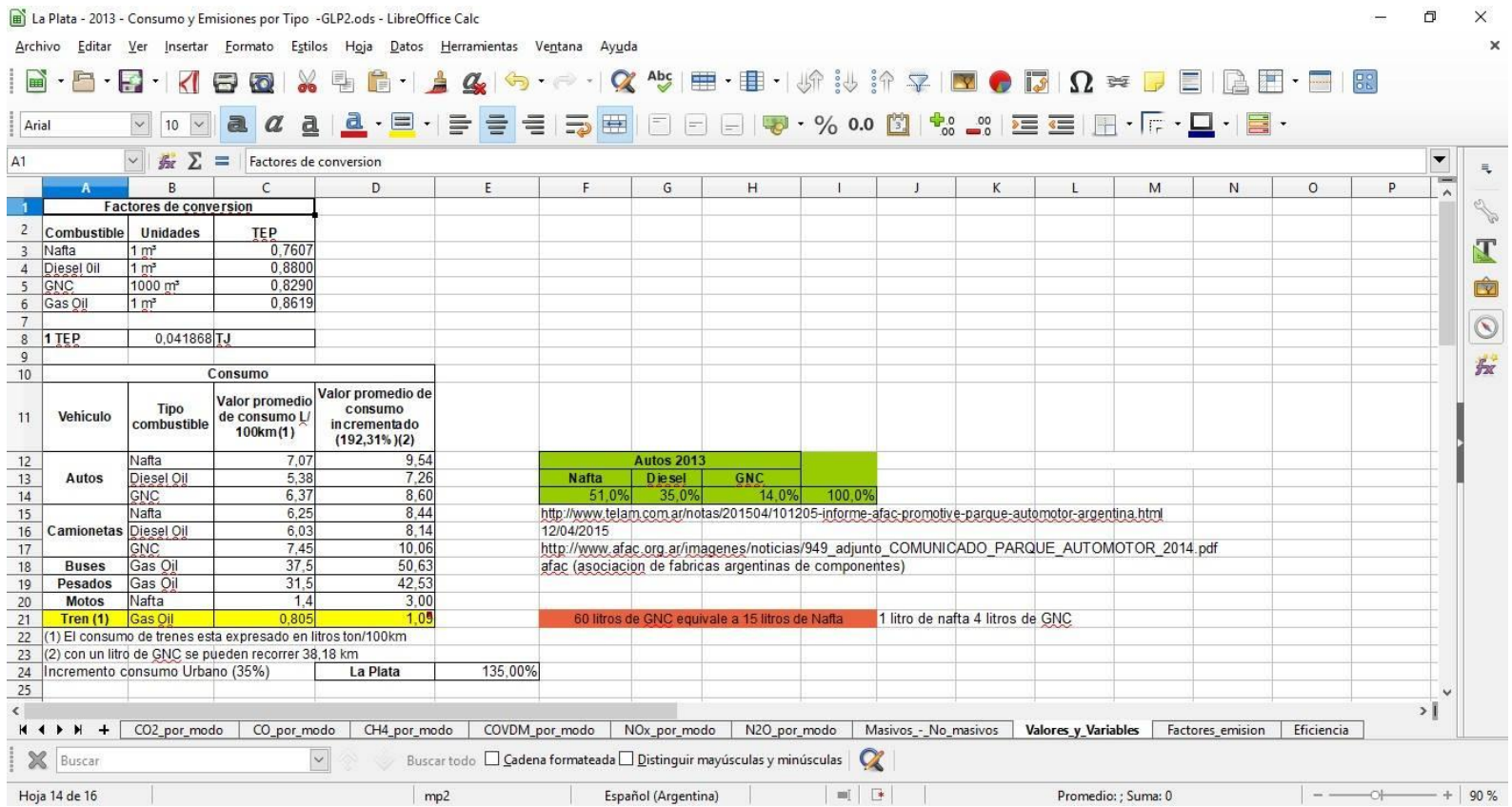




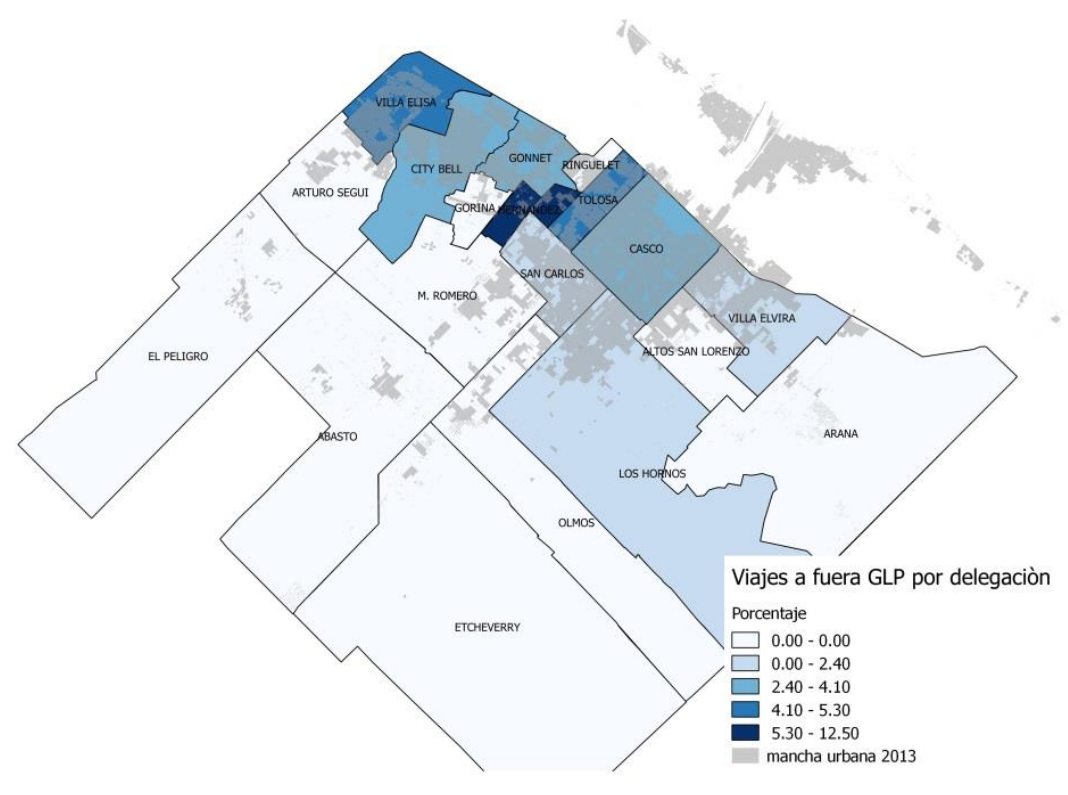

Ilustración 85. Viajes a lugares externos al GLP por delegación municipal. Fuente:

Elaboración propia, en base a datos de la Encuesta de Movilidad del Gran La Plata GII- IIPAC FAU UNLP.

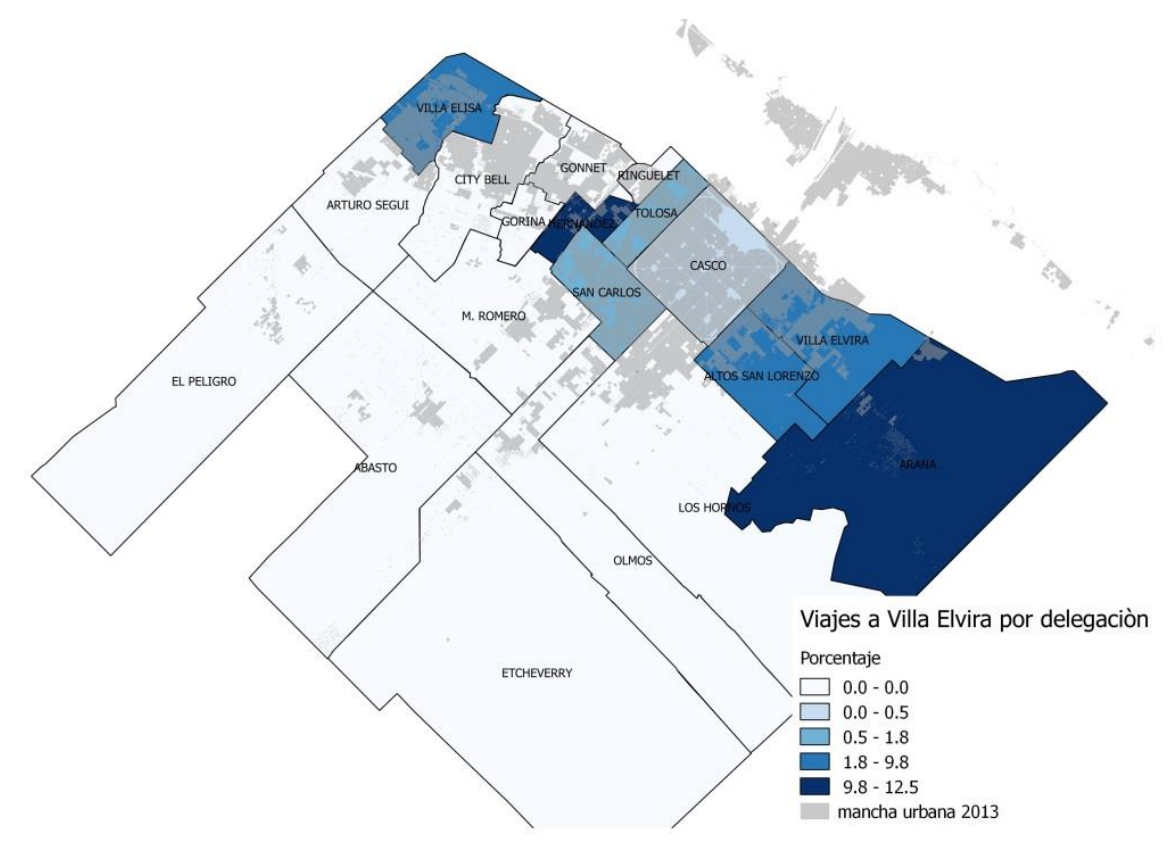

Ilustración 86. Viajes a Villa Elvira por delegación municipal. Fuente: Elaboración propia, en base a datos de la Encuesta de Movilidad del Gran La Plata GII- IIPAC FAU UNLP 


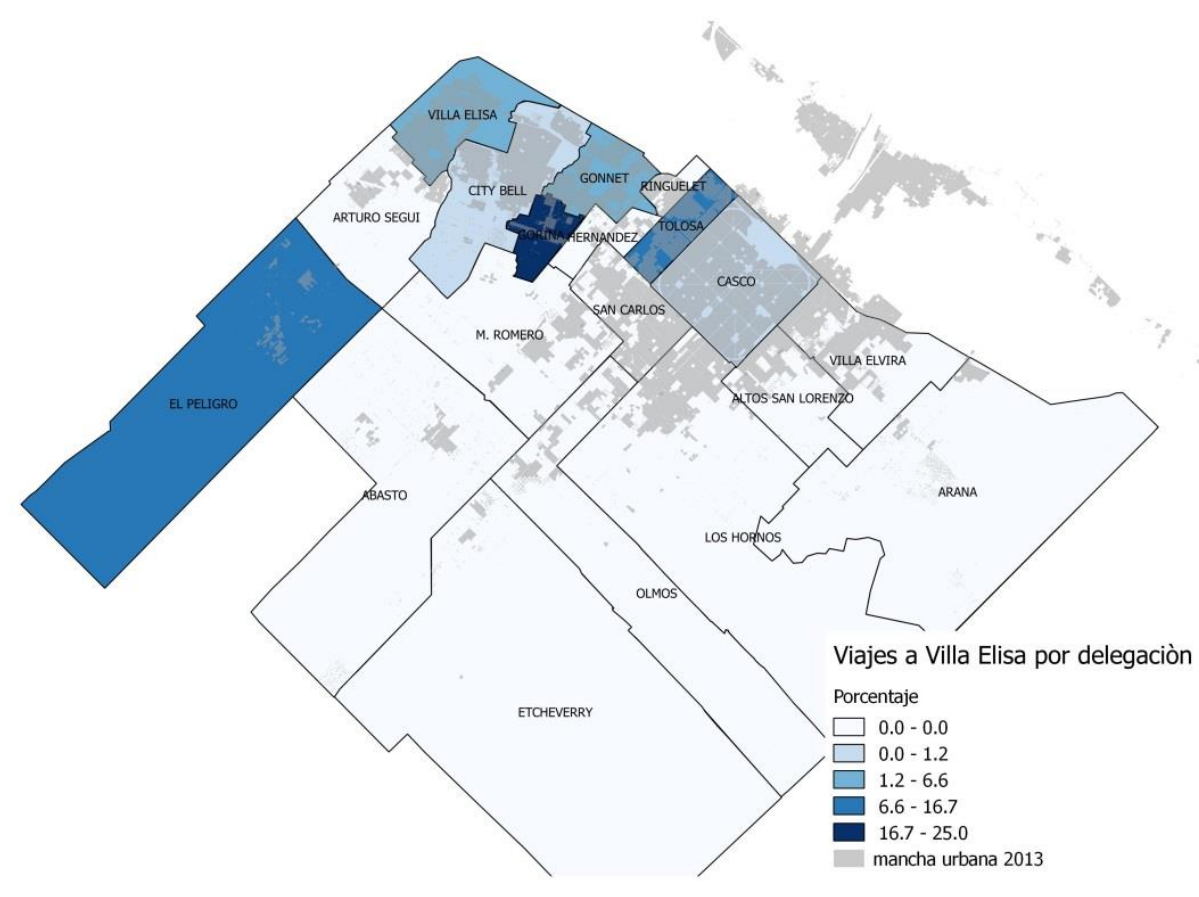

Ilustración 87. Viajes a Villa Elisa por delegación municipal. Fuente: Elaboración propia, en base a datos de la Encuesta de Movilidad del Gran La Plata GII- IIPAC FAU UNL.P

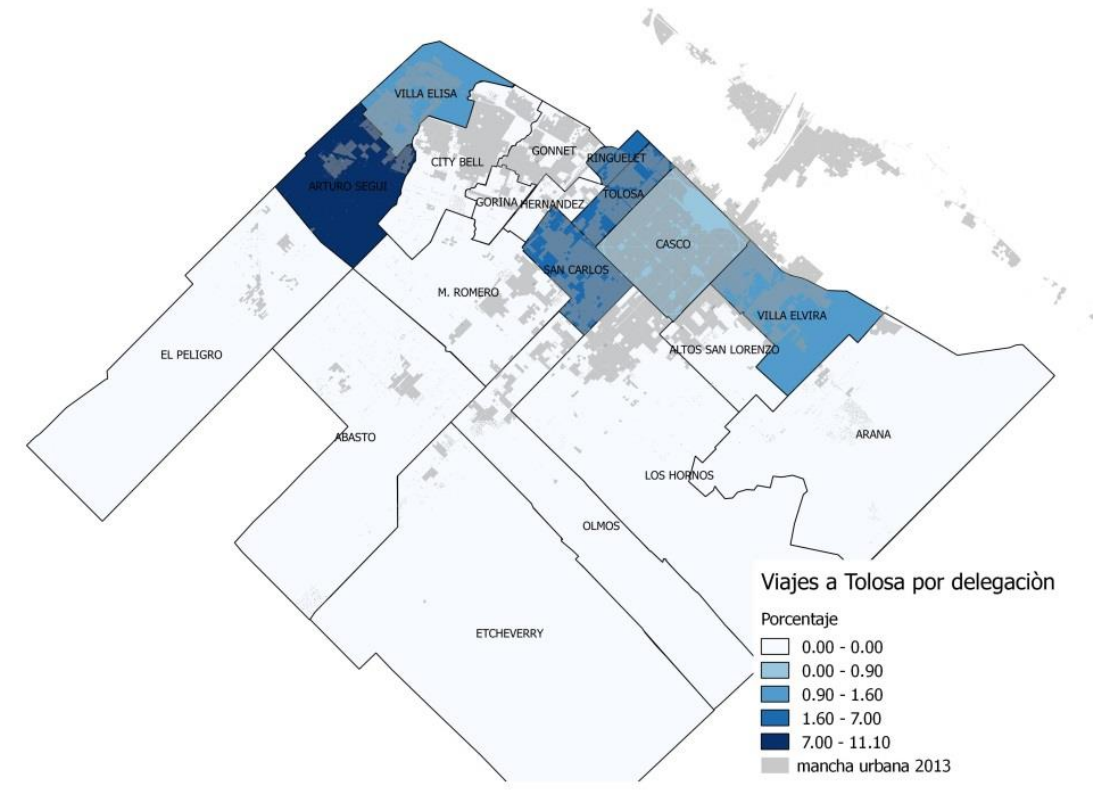

Ilustración 88. Viajes a Tolosa por delegación municipal. Fuente: Elaboración propia, en base a datos de la Encuesta de Movilidad del Gran La Plata GII- IIPAC FAU UNLP 


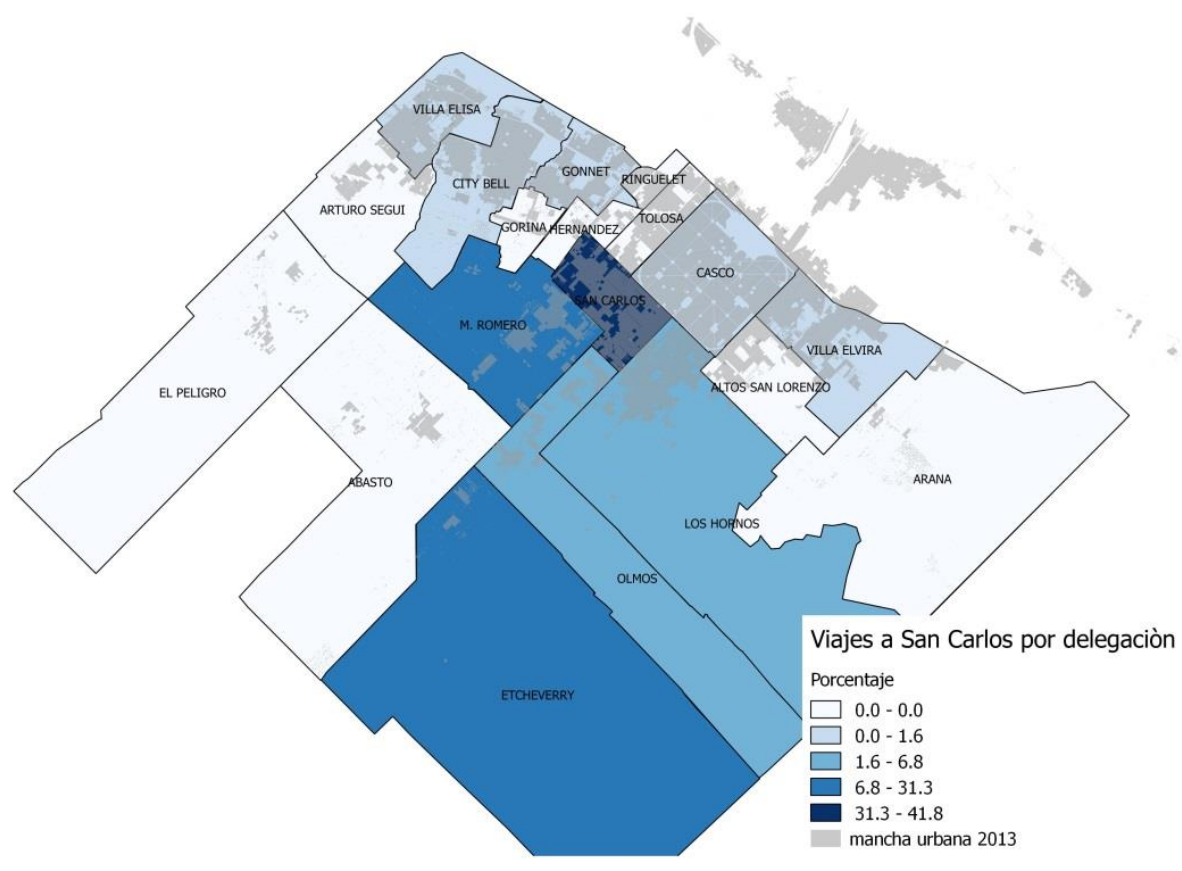

Ilustración 89. Viajes a San Carlos por delegación municipal. Fuente: Elaboración propia, en base a datos de la Encuesta de Movilidad del Gran La Plata GII- IIPAC FAU UNLP.

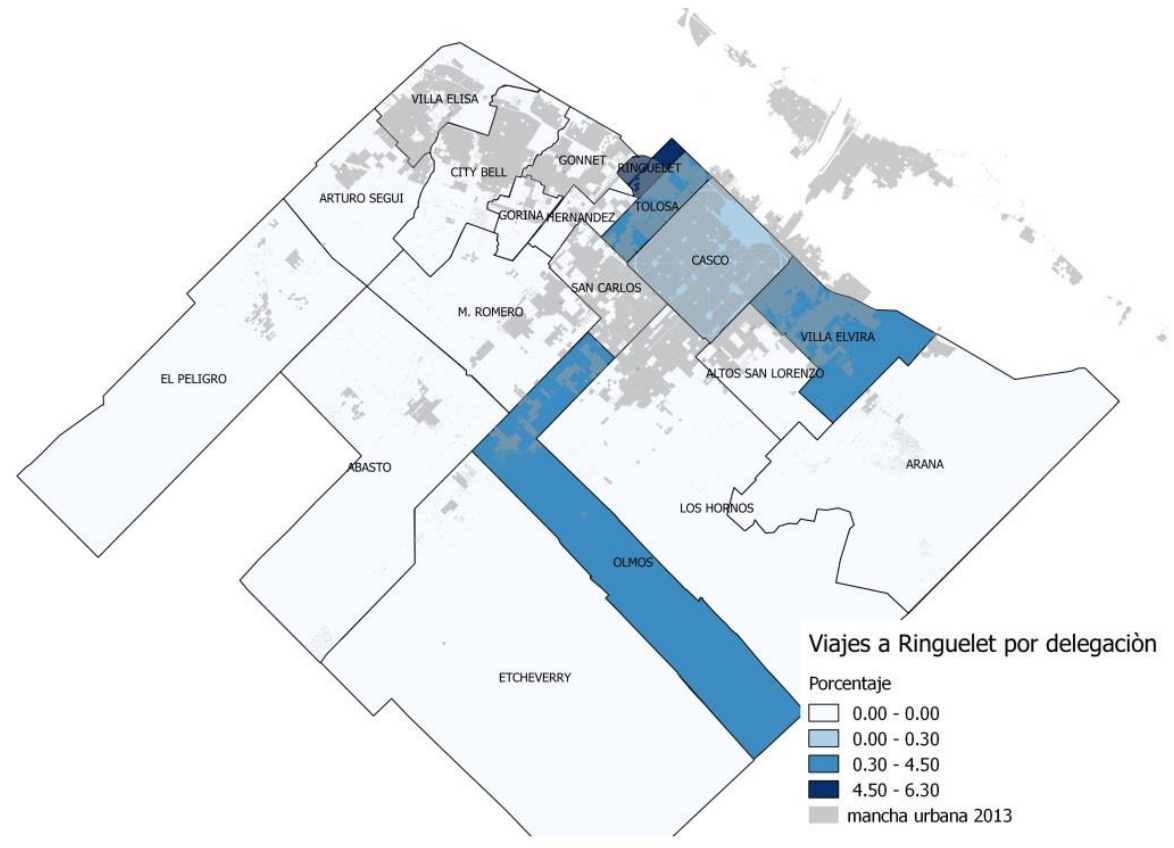

Ilustración 90. Viajes a Ringuelet por delegación municipal. Fuente: Elaboración propia, en base a datos de la Encuesta de Movilidad del Gran La Plata GII- IIPAC FAU UNLP 


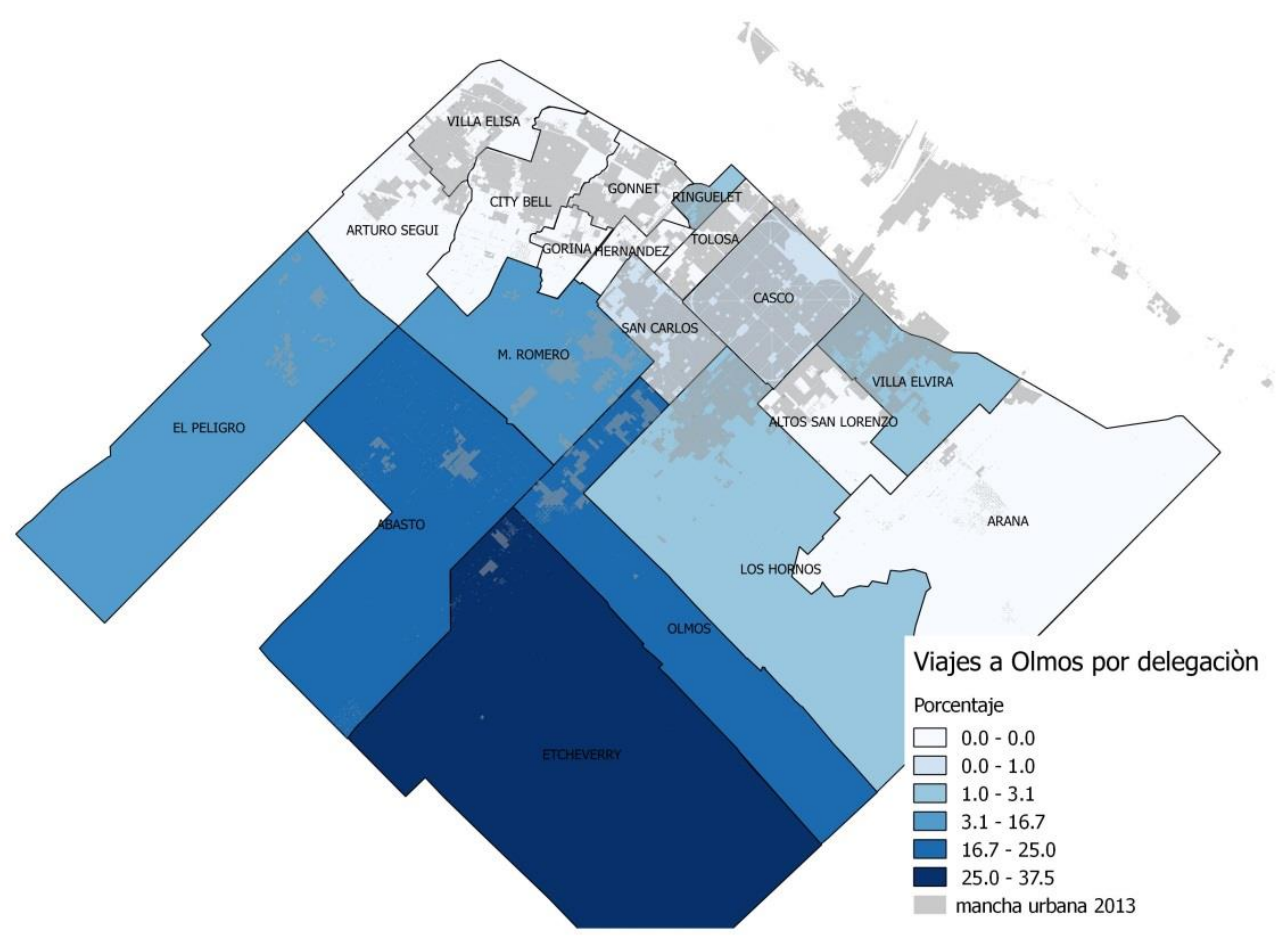

Ilustración 91. Viajes a Olmos por delegación municipal. Fuente: Elaboración propia, en base a datos de la Encuesta de Movilidad del Gran La Plata GII- IIPAC FAU UNLP.

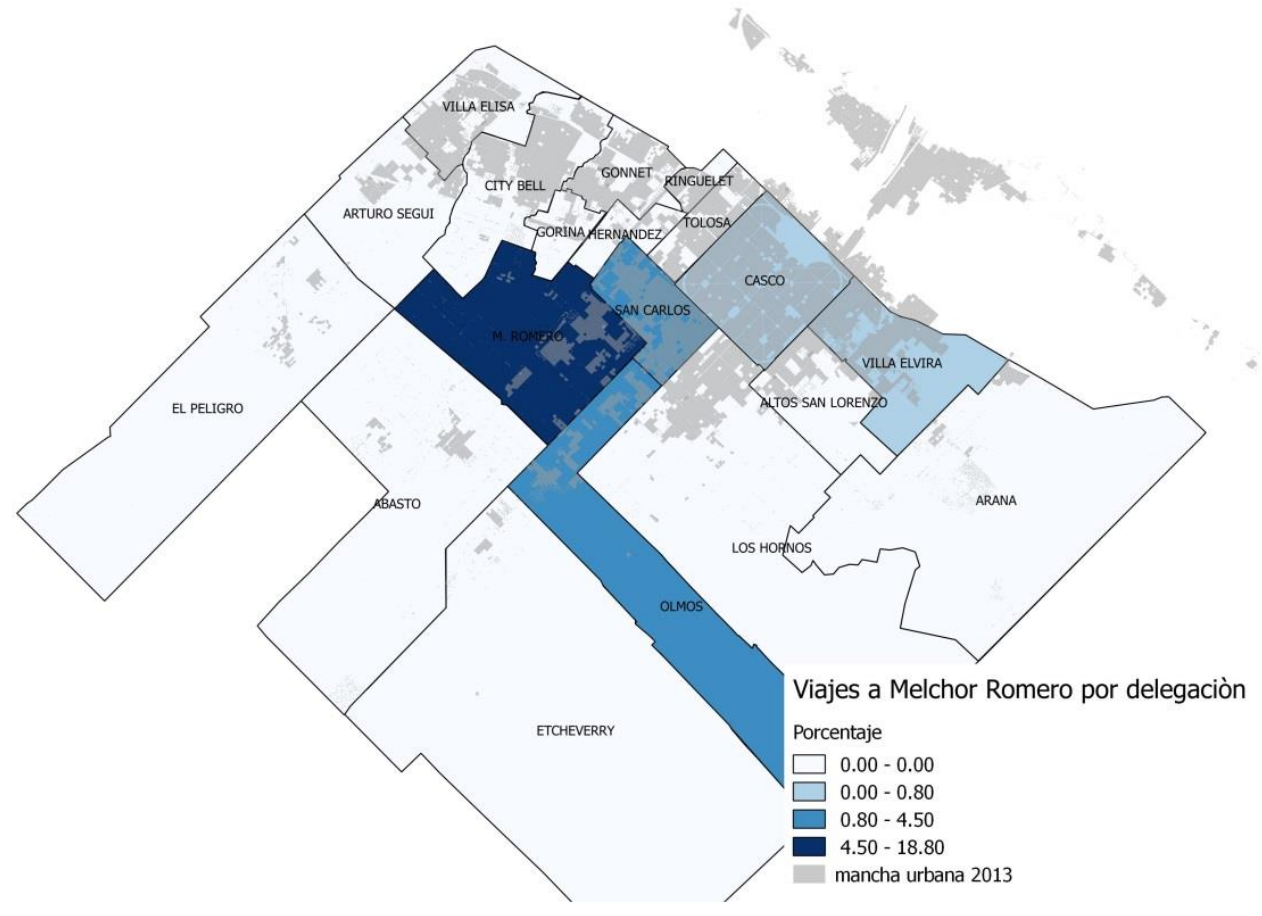

Ilustración 92. Viajes a Melchor Romero por delegación. Fuente: Elaboración propia, en base a datos de la Encuesta de Movilidad del Gran La Plata GII- IIPAC FAU UNLP 


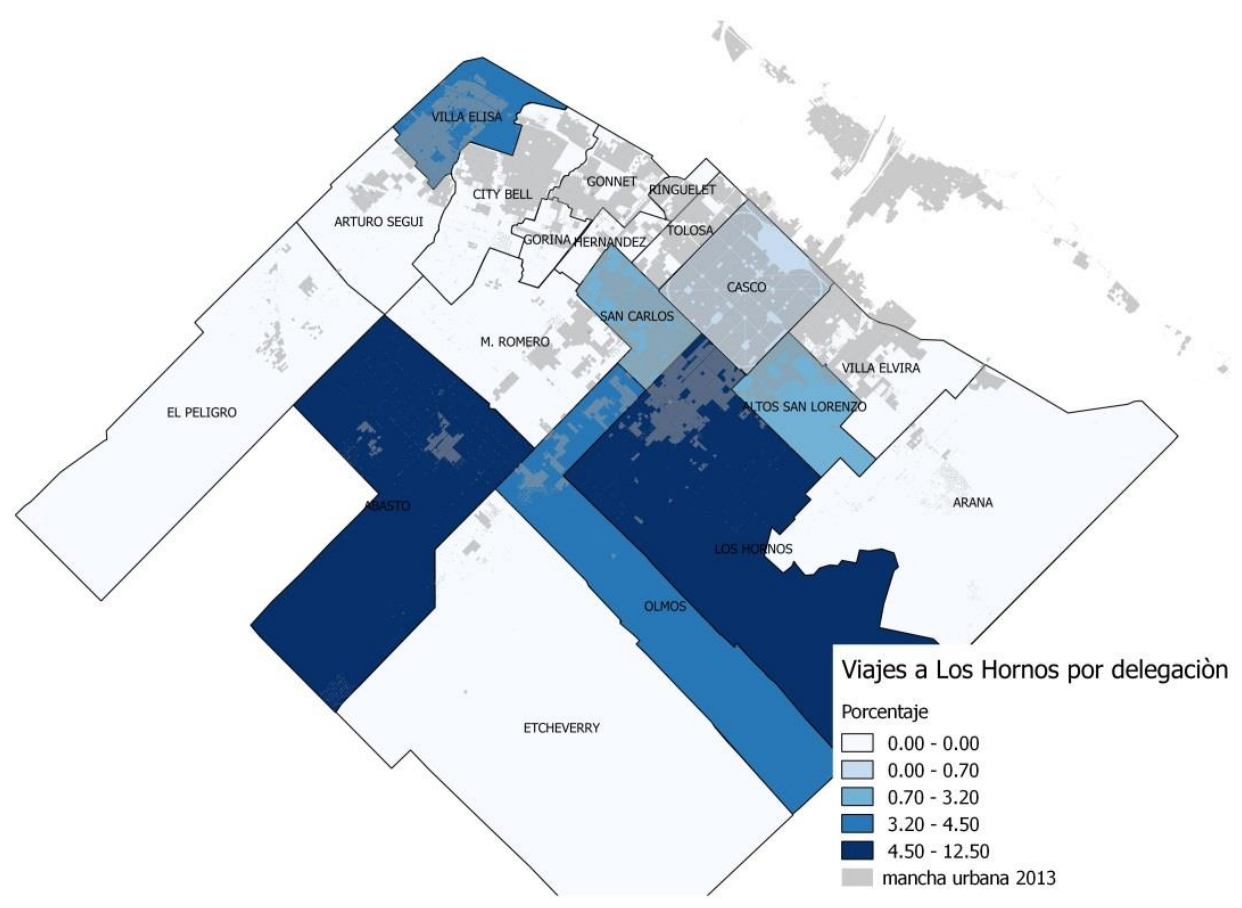

Ilustración 93. Viajes a Los Hornos por delegación municipal. Fuente: Elaboración propia, en base a datos de la Encuesta de Movilidad del Gran La Plata GII- IIPAC FAU UNLP.

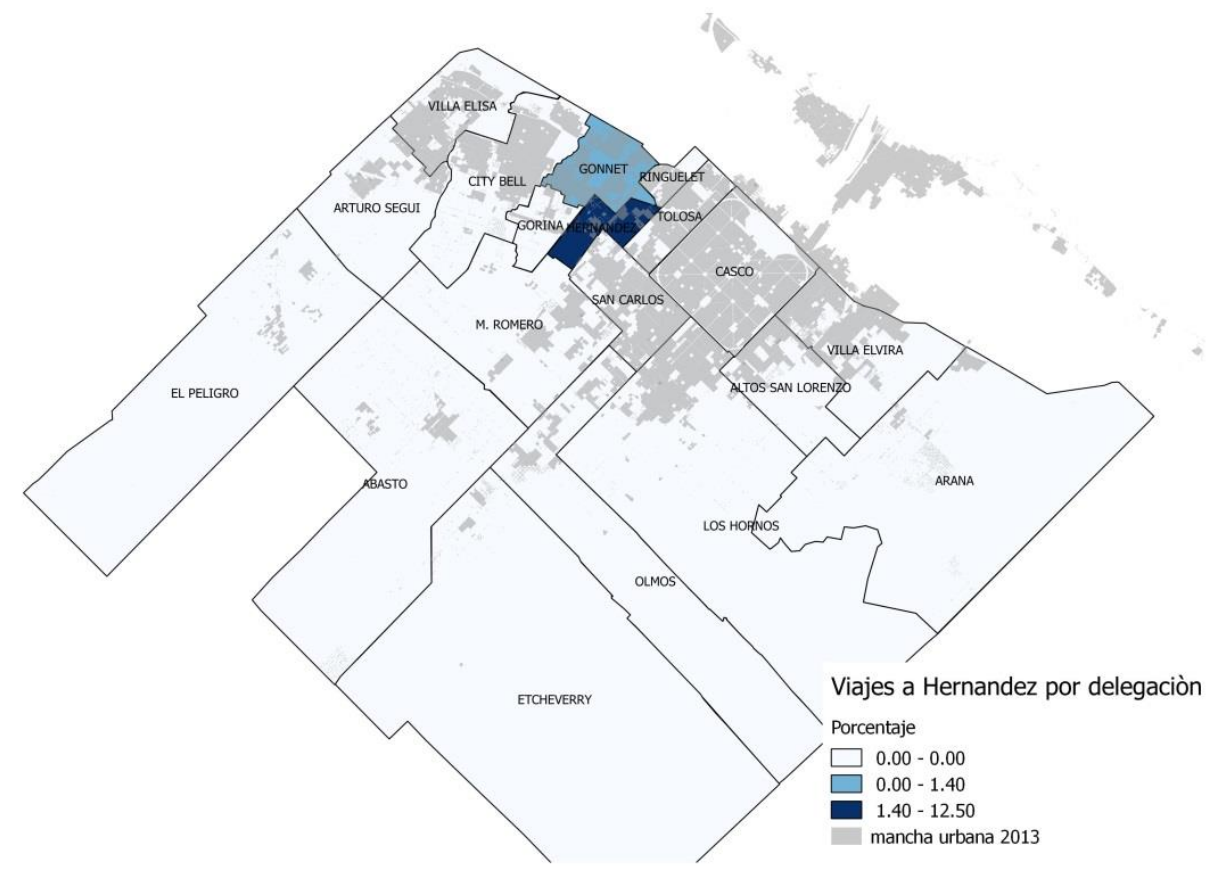

Ilustración 94. Viajes a Hernández por delegación municipal. Fuente: Elaboración propia, en base a datos de la Encuesta de Movilidad del Gran La Plata GII- IIPAC FAU UNLP. 


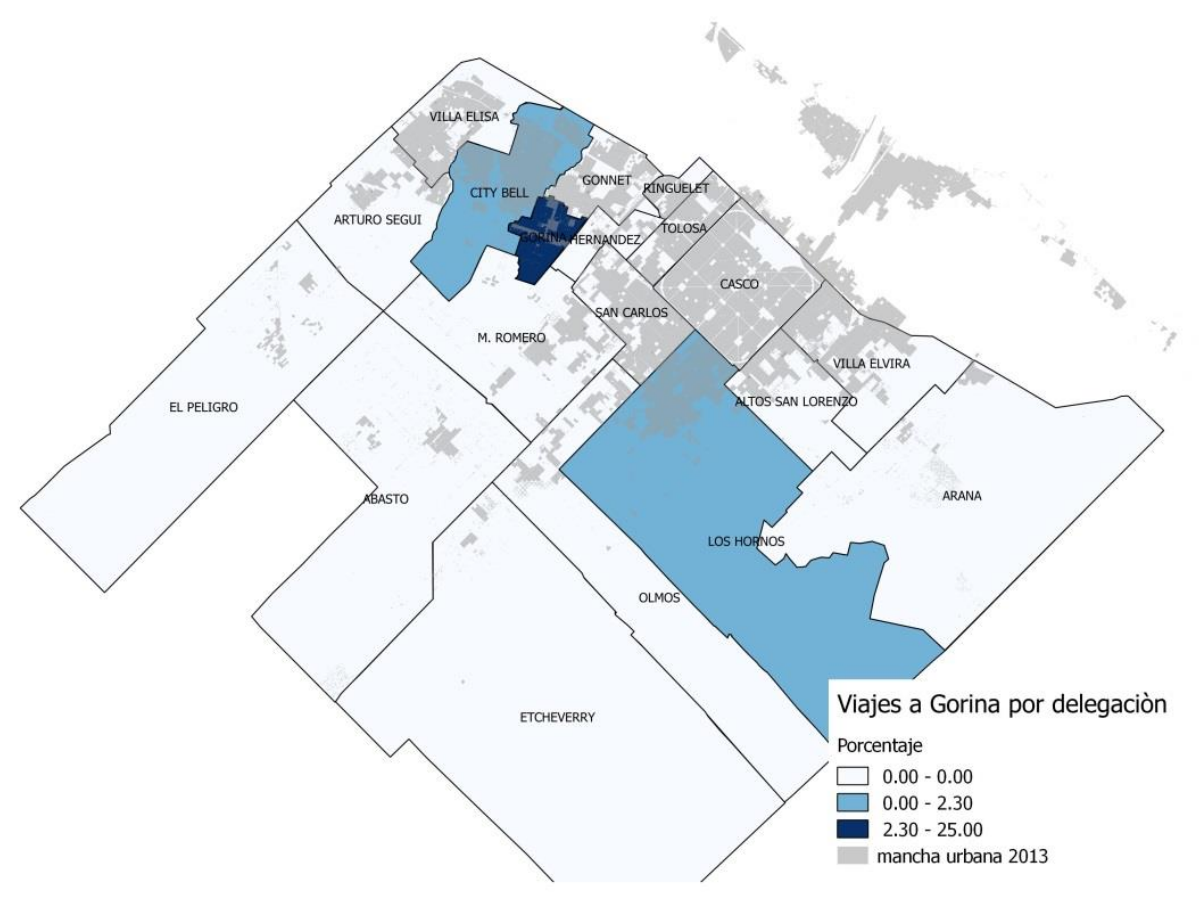

Ilustración 95. Viajes a Gorina por delegación municipal. Fuente: Elaboración propia, en base a datos de la Encuesta de Movilidad del Gran La Plata GII- IIPAC FAU UNLP.

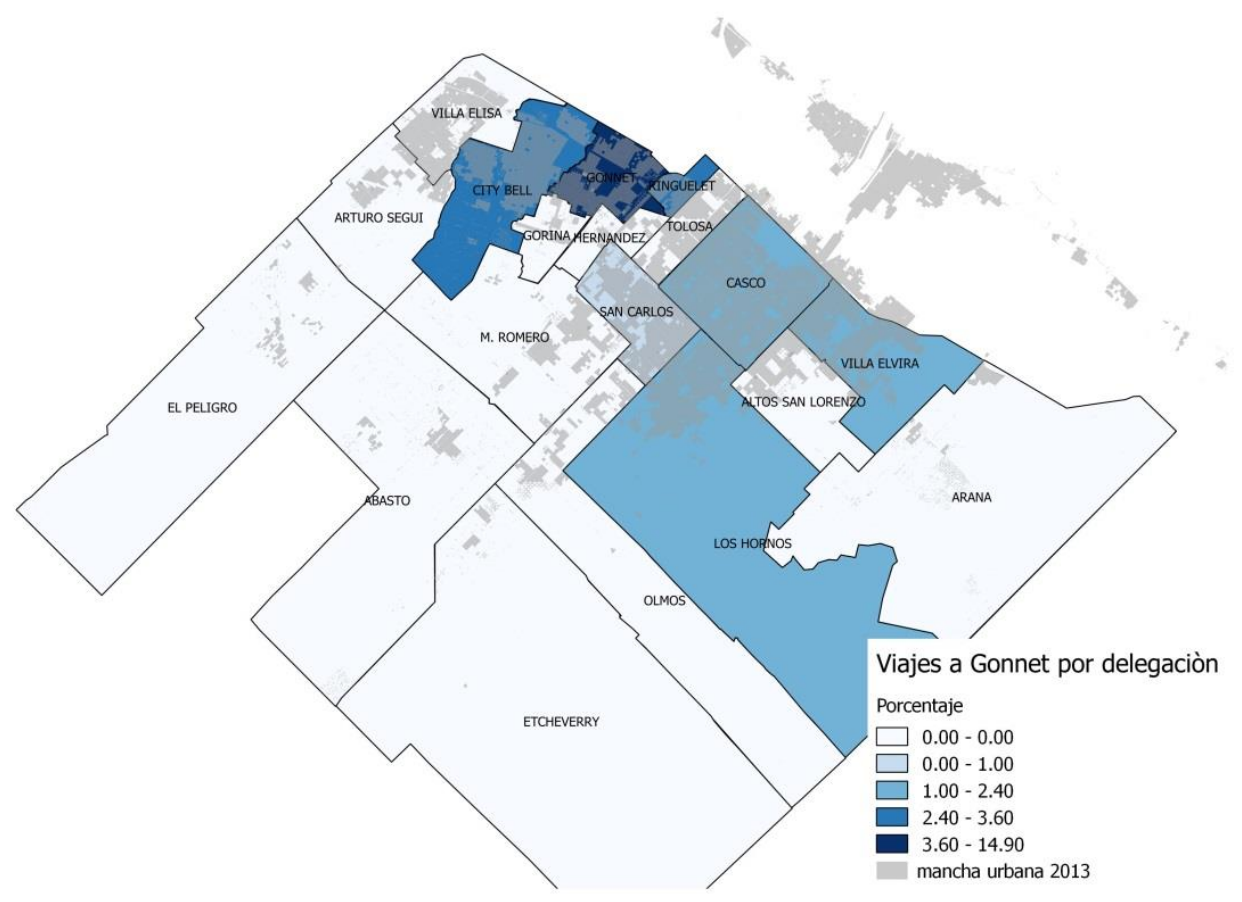

Ilustración 96. Viajes a Gonnet por delegación municipal. Fuente: Elaboración propia, en base a datos de la Encuesta de Movilidad del Gran La Plata GII- IIPAC FAU UNLP 


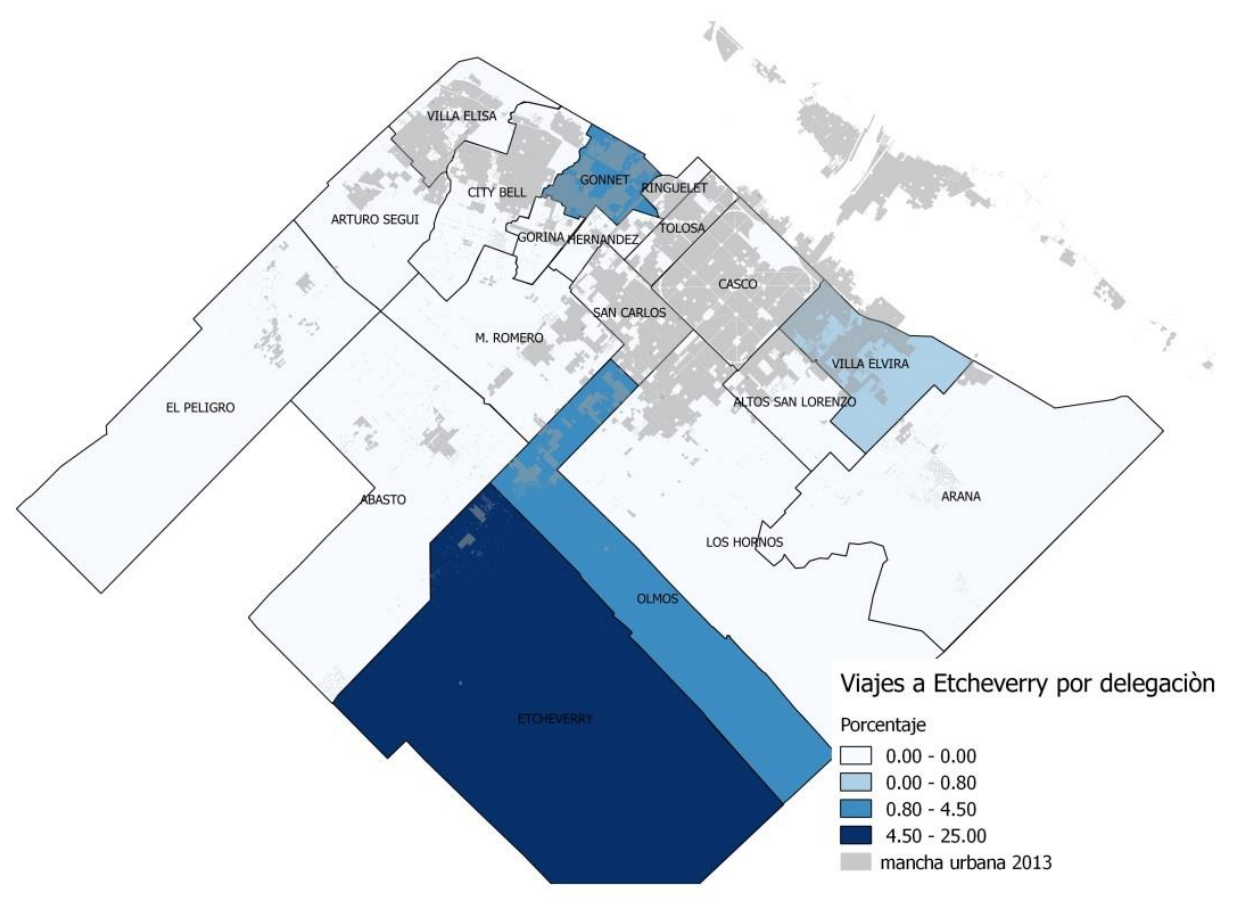

Ilustración 97. Viajes a Etcheverry por delegación municipal. Fuente: Elaboración propia, en base a datos de la Encuesta de Movilidad del Gran La Plata GII- IIPAC FAU UNLP.

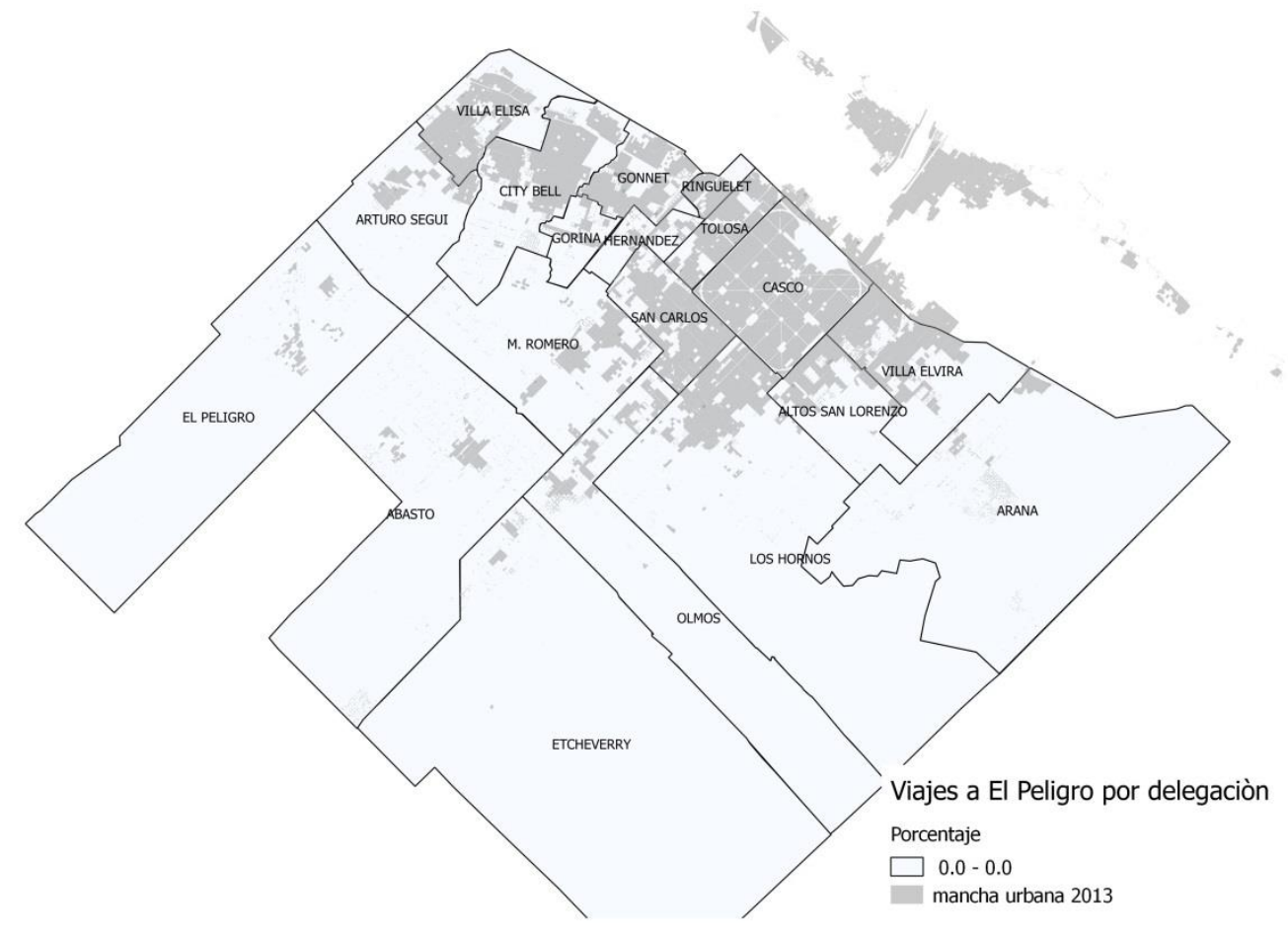

Ilustración 98. Viajes a El Peligro por delegación municipal. Fuente: Elaboración propia, en base a datos de la Encuesta de Movilidad del Gran La Plata GII- IIPAC FAU UNLP 


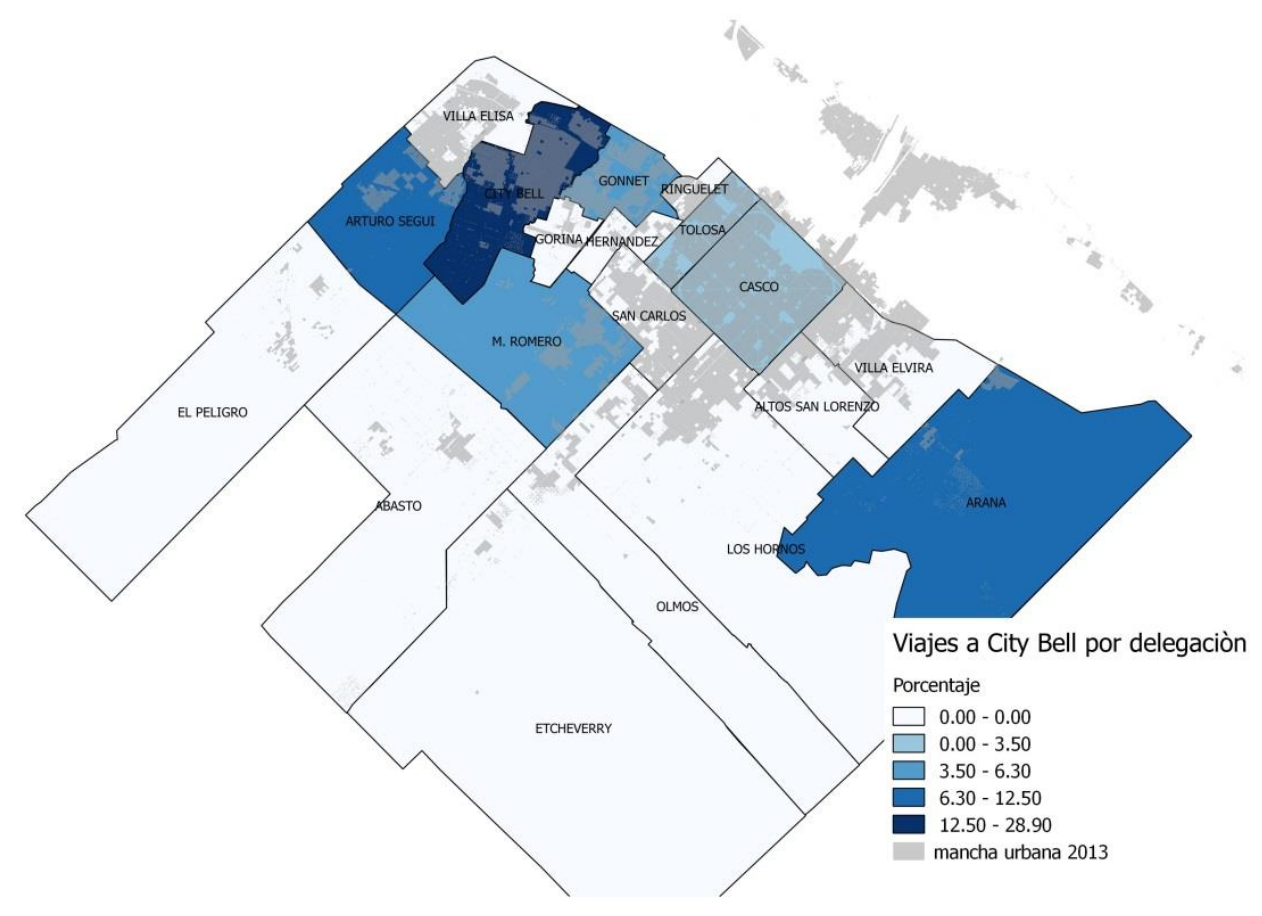

Ilustración 99. Viajes a City Bell por delegación municipal. Fuente: Elaboración propia, en base a datos de la Encuesta de Movilidad del Gran La Plata GII- IIPAC FAU UNLP.

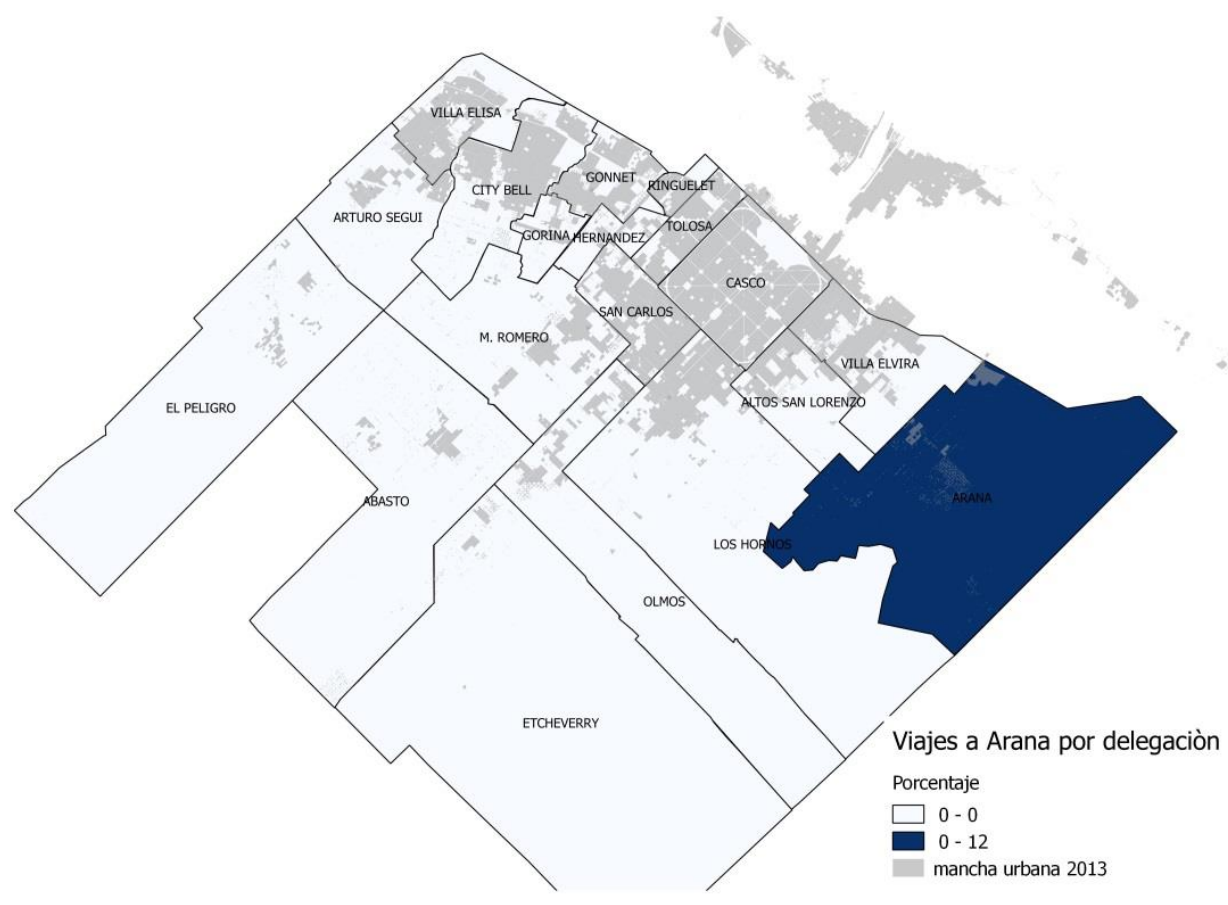

Ilustración 100. Viajes a Arana por delegación municipal. Fuente: Elaboración propia, en base a datos de la Encuesta de Movilidad del Gran La Plata GII- IIPAC FAU UNLP 


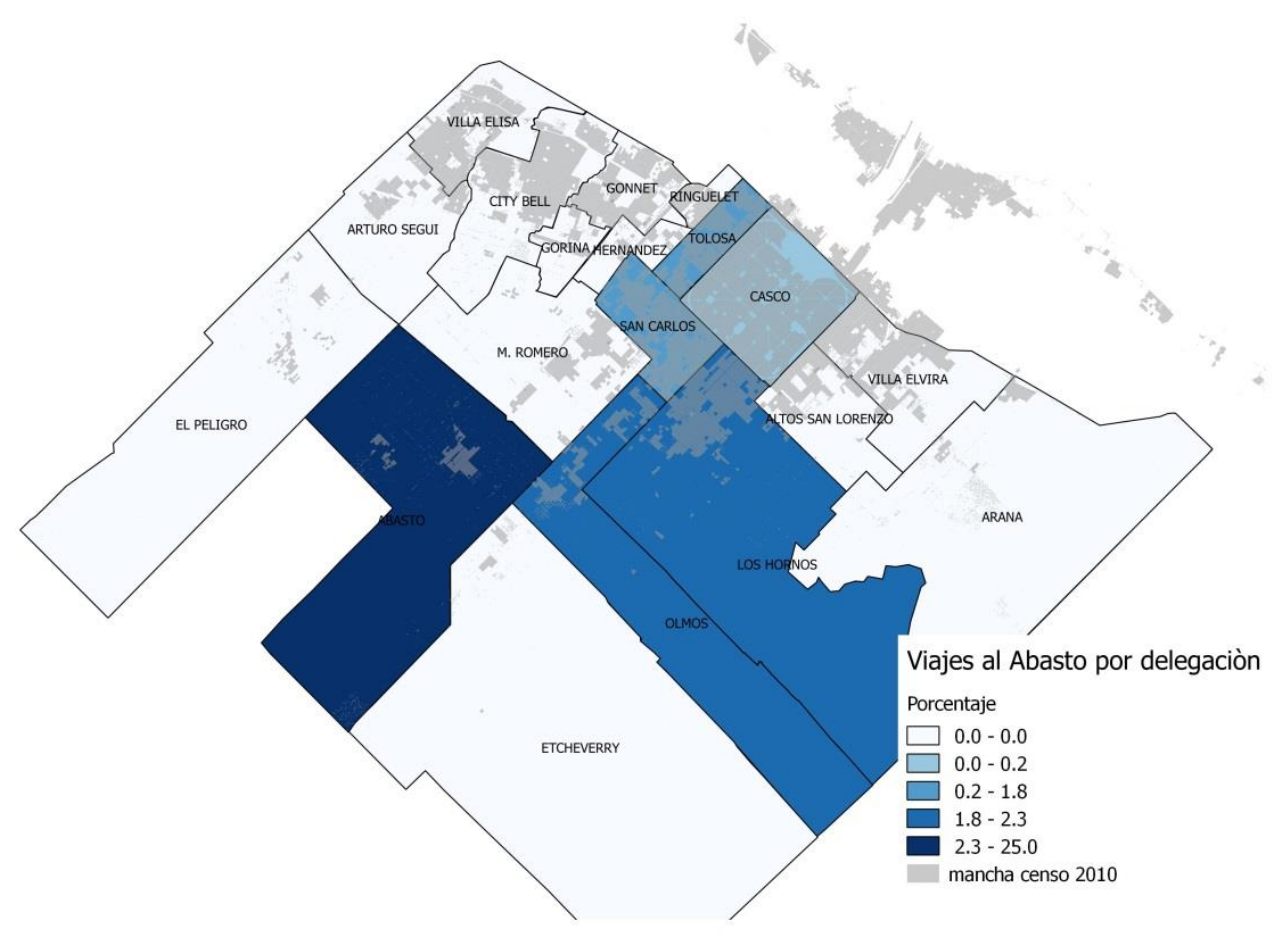

Ilustración 101. Viajes a Abasto por delegación municipal. Fuente: Elaboración propia, en base a datos de la Encuesta de Movilidad del Gran La Plata GII- IIPAC FAU UNLP

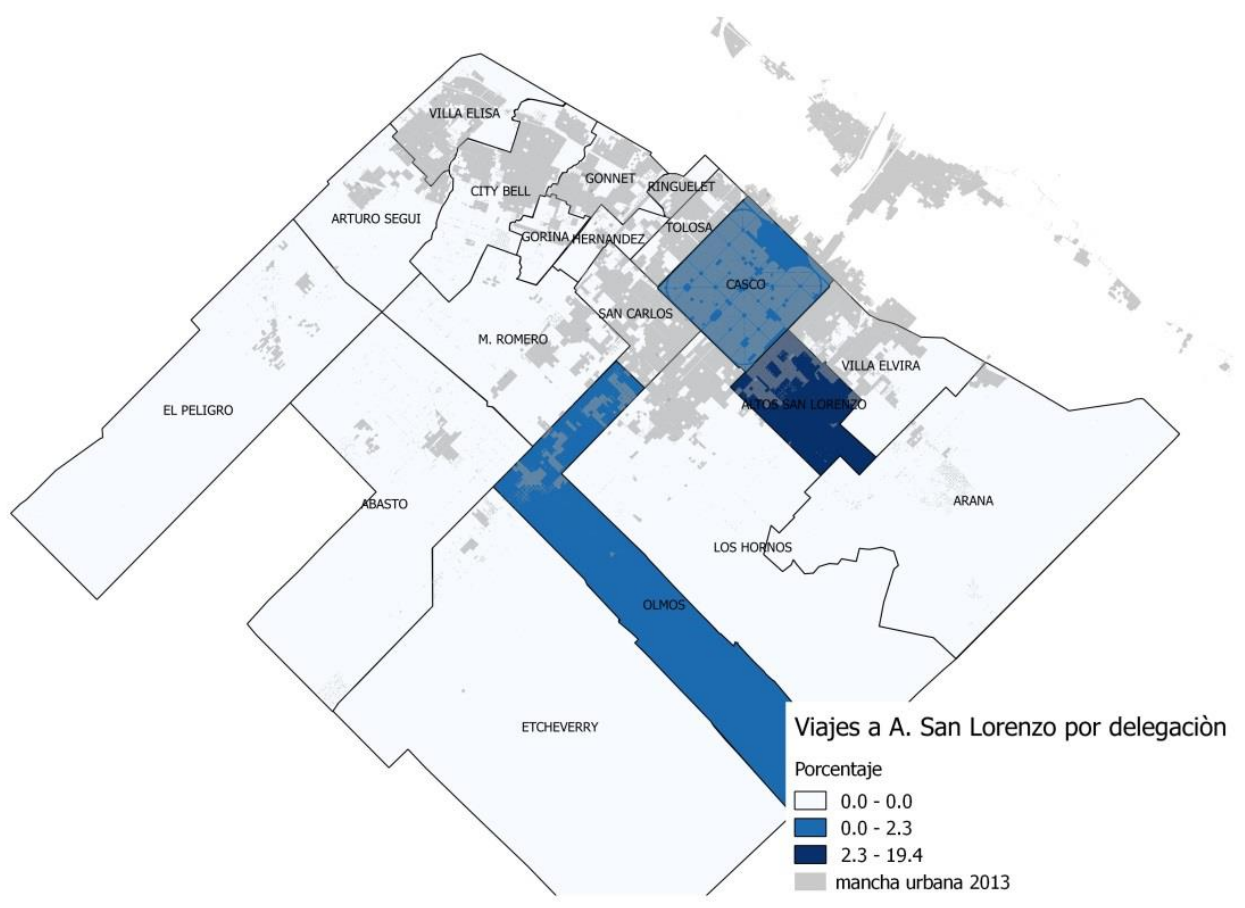

Ilustración 102. Viajes a Altos de San Lorenzo por delegación municipal. Fuente: Elaboración propia, en base a datos de la Encuesta de Movilidad del Gran La Plata GII- IIPAC FAU UNLP 